\title{
DEFORMACIONES PERMANENTES EN MEZCLAS ASFÁLTICAS
}

Efecto de la reología de los asfaltos, la temperatura y las condiciones de carga

\author{
Francisco Morea \\ Tesis presentada para el grado de \\ DOCTOR EN INGENIERÍA
}

Departamento de Construcciones, Facultad de Ingeniería, Universidad Nacional de La Plata, 6 de septiembre de 2011

Director: Jorge O. Agnusdei Co-Director: Raúl L. Zerbino 

Dedicada a Natalia, Gracias por todo 



\section{Agradecimientos}

En primer lugar quisiera agradecer al Dr. Raúl Zerbino por su invalorable ayuda, apoyo y confianza en todos estos años. Él fue en gran parte promotor de que haya logrado alcanzar el doctorado.

Al Dr. Jorge Agnusdei por su experiencia y guía a lo largo del desarrollo de mí doctorado.

A la Ing. Rosana Marcozzi por brindarme su experiencia y ayuda durante estos años.

A la Ing. Graciela Giaccio por su ayuda.

A mis compañeros por sus consejos y aportes en la realización de estos trabajos.

A las autoridades del LEMIT por brindarme sus instalaciones y en especial al personal del área Tecnología Vial, donde se llevaron a cabo los diferentes ensayos y estudios de esta tesis por su ayuda en el desarrollo de los mismos.

Agradecer a mi mujer Natalia por todo el apoyo y comprensión que me ofreció en estos años que lograron que me mantenga firme en alcanzar el objetivo y no decaiga.

Agradecer a mi familia: papá (Pancho), mamá (Lili) y mis hermanos Soledad y Federico por estar siempre ahí. Un cariño especial a mis sobrinos Franco, Santino y Matías y Adelia, Adrián, Carolina, Celina y Javier. 



\section{Resumen}

Las deformaciones permanentes o ahuellamientos son un modo de falla característico de los pavimentos asfálticos. Históricamente la contribución del asfalto en el proceso de deformaciones permanentes de un concreto asfáltico se ha considerado a partir de propiedades de carácter empírico de los ligantes asfálticos. En la actualidad se han impuesto la medición de propiedades reológicas de los asfaltos para caracterizar este comportamiento en las mezclas asfálticas. Por otra parte la temperatura y las cargas a la que está expuesto el pavimento son variables que sin duda afectan el desempeño en las mezclas asfálticas.

El estudio y la caracterización de las deformaciones permanentes en forma racional han llevado al desarrollo de ensayos de laboratorio que tratan de reproducir el problema. Así surgen los ensayos de rueda cargada que brindan un parámetro de la resistencia al ahuellamiento de una mezcla asfáltica. Este ensayo simula el efecto del tránsito sobre el pavimento midiendo las deformaciones que sufre la mezcla asfáltica a través del tiempo bajo condiciones extremas de tránsito y temperatura.

El estudio de las deformaciones permanentes a través de las propiedades reológicas de los asfaltos es reciente y no existen metodología que se valga de ellas a la hora de diseñar las mezclas y predecir su desempeño. Por su parte la utilización del ensayo de rueda cargada no es generalizada a la hora de diseñar una mezcla asfáltica al igual que no se consideran las condiciones de carga y temperaturas a las que se verá expuesta la mezcla en el pavimento.

En esta tesis se analizó y caracterizó las deformaciones permanentes en mezclas asfálticas a partir de las propiedades reológicas de los asfaltos y su relación con el desempeño en la mezcla asfáltica a partir de ensayos de rueda cargada. Las propiedades reológicas de los asfaltos, que se asocian con el comportamiento a las deformaciones permanentes, se compararon con medidas en mezclas asfálticas por medio del ensayo de rueda cargada definiendo cual representa mejor la contribución del asfalto en la resistencia al ahuellamiento.

Por otra parte se estudió el efecto de la temperatura y del aumento de la carga sobre las medidas de deformaciones permanentes, investigando las diferencias de comportamiento de distintos tipos de mezclas.

Se desarrolló una metodología para predecir el desempeño al ahuellamiento de las mezclas asfálticas a partir de conocer las características del ligante utilizado, más concretamente su propiedad reológica Low Shear Viscosity (LSV). Esta metodología original de predicción permite considerar las condiciones de temperatura a las cuales será expuesta la mezcla en el pavimento dentro del diseño. 
La profundización en el estudio de los mecanismos y variables que inciden sobre las deformaciones permanentes permitió proponer criterios límites de la LSV para una posible especificación relacionada con la resistencia frente a las deformaciones permanentes en mezclas asfálticas, debida al ligante.

Los estudios de desempeño a diferentes temperaturas y niveles de cargas sobre diferentes tipos de mezcla proveen una base de análisis para tener en cuenta, dentro del diseño, mayores volúmenes de tránsito y posibles sobrecargas que pueda sufrir el pavimento.

Finalmente se relacionaron las diferentes variables (LSV, temperatura y carga) en conjunto con las medidas de deformaciones permanentes en mezclas. De esta manera se obtuvo un modelo para caracterizar el desempeño al ahuellamiento que tiene en cuenta las características del ligante así como la sensibilidad frente a cambios de temperatura y carga de cada tipo de mezcla. 


\section{Abstract}

Permanent deformations or rutting are a common failure in asphalt pavements. The asphalt contribution to permanent deformation process has traditionally been handled by looking at empirical asphalt properties. Nowadays the asphalt rheological properties are used instead of those to characterize this behaviour in asphalt mixtures. In the same way temperature and loads at which pavement is submitted are factors that significantly affect the asphalt mixture performance.

The study and characterization of permanent deformations in a rational way have led to the development of laboratory test procedures that tried to reproduce the problem. The wheel tracking tests give an indication of the asphalt mixture rutting resistance. This test simulates the traffic load on a pavement, measuring the variation of permanent deformations of an asphalt concrete along a period of time under extreme temperature and traffic load conditions.

The study of permanent deformation through asphalt binder rheological properties is recent and there is no methodology that employs it in the design process of asphalt mixture to predict the mixture performance. On the other hand the use of wheel tracking test is not generalized in the design of a mixture; likewise, the temperature and load conditions at which pavement will be exposed are not taken into account.

In this thesis the asphalt mixture permanent deformations are analysed and characterized through asphalt binder rheological properties and its relation with the asphalt mixture performance in the wheel tracking tests. The asphalt rheological properties, associated with the rutting behaviour, were related to measurements in asphalt mixtures by means of the wheel tracking test, defining which one represents better the asphalt contribution in the rutting resistance of mixture.

The effect on the permanent deformation performance of increasing temperature and load applied were studied. The behaviour differences of different asphalt mixtures were investigated.

A methodology to predict the asphalt mixture rutting performance only knowing a binder rheological characteristic, specifically the rheological property Low Shear Viscosity (LSV), was developed. This original methodology of mixture performance prediction allows to consider the temperature conditions at which the mixture will be exposed in the design process.

The study of the mechanisms and variables that affect the permanent deformation allowed to propose criteria of LSV limits, for possible specification about rutting resistance in asphalt mixtures granted by the asphalt binder. 
The performance studies at different temperatures and load levels on different types of mixtures provide a base of analysis to consider, within the mixture design, the possibility of greater traffic volumes and overloads on the pavement.

Finally the different variables (LSV, temperature and load) were related to the permanent deformation in mixtures. In this way, it was found a model to characterize the rutting performance taking into account the binder characteristics and the temperature and load sensibilities of each kind of mixture. 


\section{Índice}

Agradecimientos _. iii

Resumen

Abstract

Índice

Índice de figuras

Índice de tablas $\quad$ xvii

Nomenclatura $\ldots$ xix

Capítulo 1. Introducción

1.1 Deformaciones permanentes en mezclas asfálticas $\ldots$

1.2 Objetivos 3

1.3 Estructura de la tesis 3

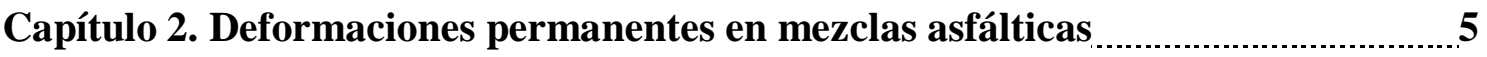

2.1 Introducción

2.2 Fisuración

2.3 Deformaciones permanentes 7

2.3.1 El rol del asfalto

2.3.2 Las cargas de tránsito

2.3.3 Factores que intervienen en desarrollo de deformaciones permanentes _......... 12

2.3.3.1 Propiedades volumétricas de la mezcla

2.3.3.1.a Porcentaje de vacíos

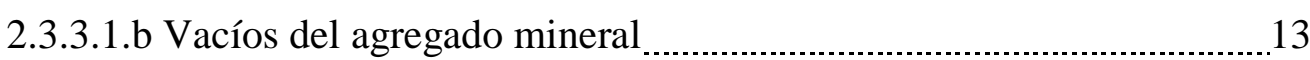

2.3.3.1.c Porcentaje de asfalto ............................................................................. 13

2.3.3.2 Granulometría de la mezcla

2.3.3.3 Efecto del agua, daño por humedad 16 
2.3.3.4 Efecto del agregado

2.3.3.4.a Angularidad del agregado grueso.

2.3.3.4.b Angularidad del agregado fino 18

2.3.3.4.c Partículas planas y alargadas 19

2.3.3.4.d Contenido de arcilla 19

2.3.3.4.e Resistencia 19

2.3.3.5 Efecto del polvo mineral o filler...... 20

2.3.3.6 Efecto del asfalto 21

2.3.4 Uso de la reología para el estudio de las deformaciones permanentes 22

2.3.4.1 La especificación de ligantes asfálticos SHRP. 23

2.3.4.2 El concepto de la Viscosidad de Corte Cero (ZSV). 32

2.3.4.2.a Ensayo de barrido de frecuencias y el ensayo de barrido de velocidades de corte 33

2.3.4.2.b ensayo de fluencia (creep) 37

2.3.4.2.c Ensayo de creep repetitivo 40

2.3.4.3 Relación entre el G*/sen $\delta$ y la ZSV $\ldots . \ldots . \ldots \ldots$

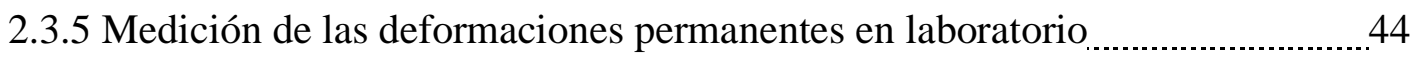

2.4 Comentarios y consideraciones finales

Capítulo 3. Programa experimental

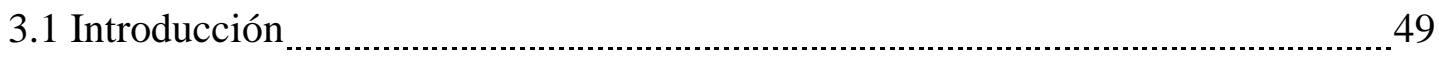

3.2 Materiales 50

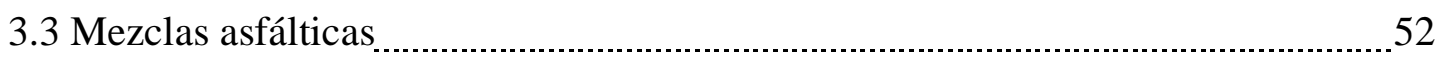

3.3.1 Agregados

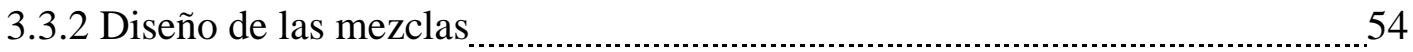

3.3.2.1 Mezcla densa (D-20) 54

3.3.2.2 Microaglomerado discontinuo (M-10)

3.3.2.3 Stone mastic asphalt (SMA-10)

3.4 Metodologías de ensayo

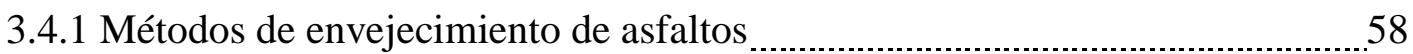

3.4.1.1 Envejecimiento en horno de película delgada rotativa (RTFOT) _............ 59

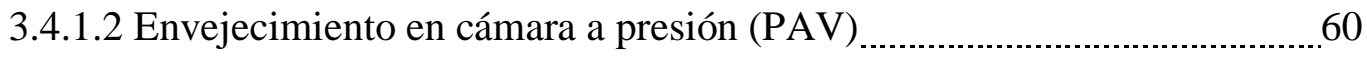

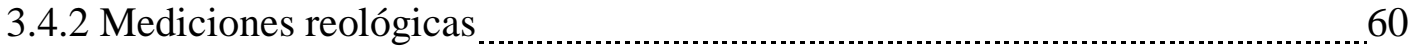

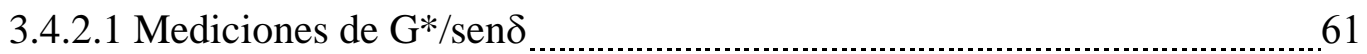


3.4.2.2 Medición de ZSV - Ensayo de Creep

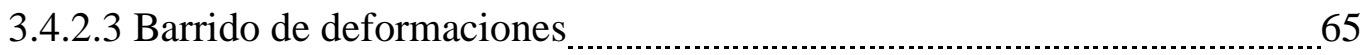

3.4.2.4 Medición de la LSV - Ensayo de barrido de frecuencias _......................65

3.4.3 Medición de deformaciones permanentes sobre mezclas asfálticas _..............68

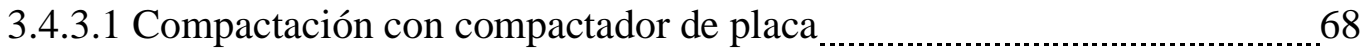

3.4.3.2 Ensayo de rueda cargada

3.5 Otras propiedades físicas y mecánicas de los asfaltos y de las mezclas ..................74

Capítulo 4. Estudio en los asfaltos de las propiedades reológicas vinculadas a las deformaciones permanentes _...........................

4.1 Introducción

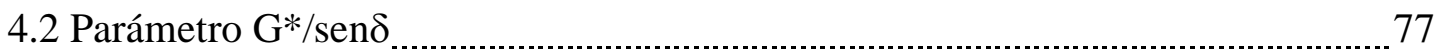

4.3 Medición de la ZSV y la LSV

4.4 Parámetro LSV

4.5 Comparación entre G*/sen $\delta$ y la LSV

4.6 Conclusiones y comentarios sobre las propiedades reológicas de los asfaltos

vinculadas a las deformaciones permanentes _............................................. 94

Capítulo 5. Mediciones de ahuellamientos en el ensayo de rueda cargada. Caracterización mediante propiedades reológicas _.................................97

5.1 Introducción

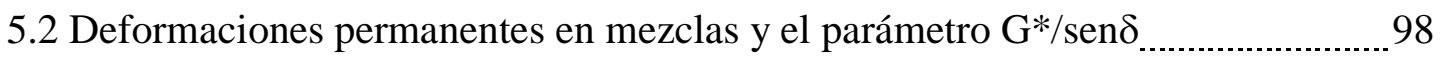

5.3 Deformaciones permanentes en mezclas y la medida de la LSV _....................... 101

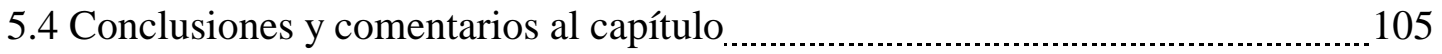

Capítulo 6. Efecto de la temperatura y el nivel de carga sobre el desarrollo

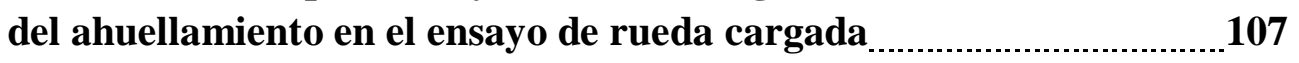

6.1 Introducción

6.2 Efecto de la temperatura

6.2.1 Análisis de los resultados 108

6.2.2 Predicción del desempeño a partir de la LSV

6.2.3 Validación experimental

6.2.4 Conclusiones sobre el efecto de la temperatura

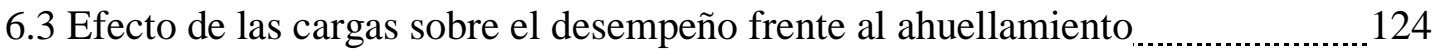

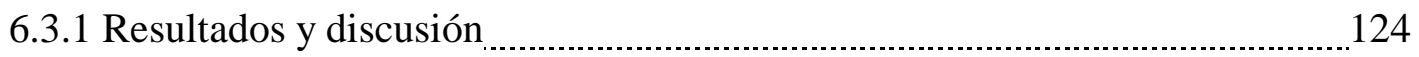

6.3.2. Consideración de las sobrecargas dentro del diseño $\ldots \ldots \ldots$ 
6.3.3. Consideración de mayores volúmenes de tránsito dentro del diseño 130

6.3.4 Conclusiones sobre la influencia del nivel de carga 131

6.4. Relación entre propiedades reológicas, temperatura y cargas 132

6.4.1. Análisis de resultados 132

6.4.2. Consideraciones a la relación LSV-T-Carga

Capítulo 7. Conclusiones 139

7.1 Conclusiones de la tesis 139

7.2 Recomendaciones de estudios futuros 143

Capítulo 8. Referencias 145

Anexo I. Ensayos de barrido de frecuencias 151

Anexo II. Curvas de deformación-tiempo. Ensayos de rueda cargada 201 


\section{Índice de figuras}

Figura 2.1. Tipos de fisuración en pavimentos asfálticos _.................................................. 6

Figura 2.2. Deformaciones permanentes 7

Figura 2.3. Tipos de ahuellamientos

Figura 2.4. Cambio en el comportamiento del asfalto en función de la temperatura .........9

Figura 2.5. Acumulación de deformaciones permanentes en sucesivos veranos _........... 10

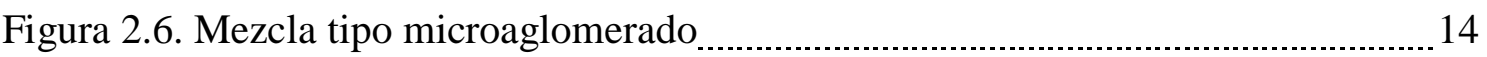

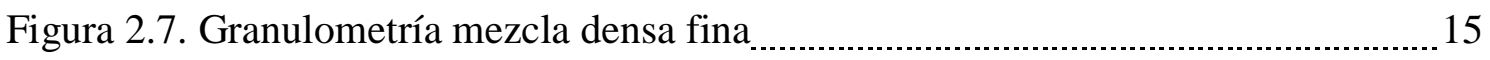

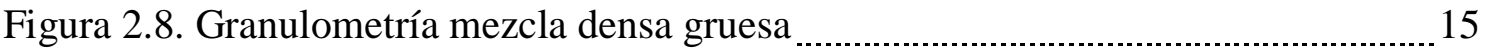

Figura 2.9. Huso granulométrico Superpave con zona restringida

Figura 2.10. Desprendimiento del ligante del agregado por efecto de la humedad ......... 17

Figura 2.11. Efecto de la forma de agregado en el VAM

Figura 2.12. Equipo de ensayo para angularidad según norma AASTHO T304 ...............19

Figura 2.13. Susceptibilidad térmica de tres asfaltos de igual grado. A y C: igual grado de penetración; B y C: igual grado por viscosidad a $60{ }^{\circ} \mathrm{C} \ldots \ldots \ldots \ldots$

Figura 2.14. Mapa de temperaturas viales de Argentina para un $98 \%$ de confiabilidad.

Figura 2.15. Reómetro de corte (DSR) y comportamiento esfuerzo-deformación en un ensayo oscilatorio

Figura 2.16. Módulo dinámico $\left(\mathrm{G}^{*}\right)$ y ángulo de fase $(\delta)$ en función de la frecuencia de carga (izquierda) y en función de la temperatura (derecha) _................. 27

Figura 2.17. Importancia del $\delta$ en el trabajo disipado

Figura 2.18. Esquema de deformaciones en el tiempo durante un proceso de carga y descarga.

Figura 2.19. Diagramas típicos de creep para asfaltos convencionales y modificados.

Figura 2.20. Curva de viscosidad en función de la velocidad de carga _......................... 34

Figura 2.21. Viscosidad en función de la frecuencia

Figura 2.22. Viscosidad en función de la velocidad de corte para asfaltos convencionales y modificados 
Figura 2.23. Modulo complejo G* versus deformaciones

Figura 2.24. Modelo de Burger 38

Figura 2.25. Ensayo de creep incompleto

Figura 2.26. Comparación entre un ciclo de carga y descarga sobre un asfalto en el DSR y la acción del tránsito sobre la mezcla asfáltica. 40

Figura 2.27. Deformaciones en el tiempo en ensayo de multicreep de varios asfaltos para el primer ciclo de carga

Figura 2.28. Deformaciones en el tiempo en ensayo de multicreep de varios asfaltos para el ciclo de carga $\mathrm{N}^{\circ} 100$

Figura 2.29. Deformaciones en el tiempo medidas en el MSCRT

Figura 2.30. Relación de la ZSV con G*/sen $\delta$ de diferentes ligantes a diferentes temperaturas

Figura 2.31. Resultados de velocidad de deformación de testigos de pavimentos ensayados en el equipo de rueda cargada.

Figura 3.1. Agregados utilizados 53

Figura 3.2. Fibras utilizadas en la SMA 53

Figura 3.3. Gradación de la mezcla densa (D-20). 54

Figura 3.4. Gráficos del diseño Marshall de mezcla densa (D-20) 55

Figura 3.5. Gradación del microaglomerado (M-10) 56

Figura 3.6. Gradación de la SMA (SMA-10) 58

Figura 3.7. Ensayo RTFOT. Recipientes de ensayo (Izquierda), Vista interior (Derecha) 59

Figura 3.8. Equipo PAV. Vista general (Izquierda). Bandejas y bastidor (Derecha) _...... 60

Figura 3.9.Reómetro de Corte Dinámico (DSR). 61

Figura 3.10.Vista del plato de carga con cabezales de calentamiento (izquierda). Diferentes accesorios del equipo (derecha) 61

Figura 3.11. Detalle del plato de carga 62

Figura 3.12. Respuesta esfuerzo deformación 62

Figura 3.13. Modulo complejo $\left(\mathrm{G}^{*}\right)$ versus deformaciones 65

Figura 3.14. Resultado de un barrido de frecuencias en el DSR 66

Figura 3.15. Curva maestra generada por corrimientos de los barridos de frecuencias ... 67

Figura 3.16. Equipo compactador de placa 68

Figura 3.17. Molde para probetas de ensayo de rueda cargada 68

Figura 3.18. Detalle de la placa compactando 69 
Figura 3.19. Equipo de rueda cargada. Vista general (izquierda); Detalle LVDT (derecha) 70

Figura 3.20. Curva típica de deformaciones permanentes en función del tiempo obtenida en un ensayo de rueda cargada 71

Figura 3.21. Pesos de las diferentes configuraciones de carga 73

Figura 3.22. Detalle de las diferentes configuraciones de carga 73

Figura 4.1. G*/sen $\delta$ vs T $-\omega 1=10 \mathrm{rad} / \mathrm{s}$. Asfaltos en estado original 80

Figura 4.2. $\mathrm{G}^{*} / \mathrm{sen} \delta$ vs $\mathrm{T}-\omega 1=10 \mathrm{rad} / \mathrm{s}$. Asfaltos envejecidos en RTFOT 80

Figura 4.3. $\mathrm{G}^{*} / \mathrm{sen} \delta$ vs $\mathrm{T}-\omega_{2}=0,61 / \mathrm{s}$. Asfaltos en estado original 81

Figura 4.4. G*/sen $\delta$ vs T $-\omega_{2}=0,61 /$ s. Asfaltos envejecidos en RTFOT 82

Figura 4.5. G* versus deformaciones. $f=10 \mathrm{~Hz}$ (arriba); $f=1 \mathrm{~Hz}$ (abajo) 83

Figura 4.6. Análisis comparativo de los resultados de los ensayos de Creep y Barrido de frecuencias (BF). Izquierda: asfaltos convencionales; derecha: asfaltos modificados

Figura 4.7. Viscosidad en función de la frecuencia para las muestras del asfalto MP2

Figura 4.8. Viscosidad en función de la frecuencia para las muestras del asfalto C2

Figura 4.9. Viscosidad en función de la frecuencia para las muestras del asfalto C3

Figura 4.10. Detalle de dos muestras de asfalto MP2 luego de estar sometidas a diferentes tiempos en el ensayo de creep

Figura 4.11. LSV versus $\mathrm{G}^{*} / \mathrm{sen} \delta(\omega=10 \mathrm{rad} / \mathrm{s})$. Asfaltos en estado original 91

Figura 4.12. LSV versus $\mathrm{G}^{*} / \mathrm{sen} \delta(\omega=10 \mathrm{rad} / \mathrm{s})$. Asfaltos envejecidos 91

Figura 4.13. LSV versus $\mathrm{G}^{*} / \mathrm{sen} \delta(\omega=0,6 \mathrm{rad} / \mathrm{s})$. Asfaltos en estado original 93

Figura 4.14. LSV versus $\mathrm{G}^{*} / \mathrm{sen} \delta(\omega=0,6 \mathrm{rad} / \mathrm{s})$. Asfaltos envejecidos en RTFOT 94

Figura 5.1. Vd en función del $\mathrm{G} * / \operatorname{sen} \delta(\omega=10 \mathrm{rad} / \mathrm{s})$ en asfalto original 99

Figura 5.2. Vd en función del G*/sen $\delta(\omega=10 \mathrm{rad} / \mathrm{s})$ en asfalto envejecido 100

Figura 5.3. Vd en función del $\mathrm{G} * / \mathrm{sen} \delta(\omega=0,6 \mathrm{rad} / \mathrm{s})$ en asfalto original 100

Figura 5.4. Vd en función del $\mathrm{G}^{*} / \mathrm{sen} \delta(\omega=0,6 \mathrm{rad} / \mathrm{s})$ en asfalto envejecido 101

Figura 5.5. Vd en función de la LSV en asfalto original 102

Figura 5.6. Vd en función de la LSV en asfalto envejecido. 103

Figura 5.7. Relaciones Vd-LSV de los asfaltos en estado original 104

Figura 5.8. Relaciones Vd-LSV de los Asfaltos envejecidos en RTFOT 105

Figura 6.1. Varilla helicoidal dentro del recipiente de vidrio del RTFOT 110 
Figura 6.2. Relación Vd-Temperatura con los distintos asfaltos de la mezcla D-20 _....111

Figura 6.3. Relación Vd-Temperatura con los distintos asfaltos de la mezcla M-10 _...111

Figura 6.4. Relación Vd-Temperatura con los distintos asfaltos de la mezcla SM A-10

Figura 6.5. Aspecto de diferentes muestras después del ensayo de rueda cargada. Mezcla M-10 C3 (Arriba), mezcla SMA-10 MP3 (Abajo)

Figura 6.6. Vd de las mezclas D-20 en función de la LSV de los asfaltos 113

Figura 6.7. Vd de las mezclas M-10 en función de la LSV de los asfaltos 114

Figura 6.8. Vd de las mezclas SMA-10 en función de la LSV de los asfaltos 114

Figura 6.9. Vd versus LSV del asfalto para las diferentes mezclas 115

Figura 6.10. Vd versus LSV del asfalto envejecido 116

Figura 6.11. Variación de la LSV de los asfaltos en estado original en función de la temperatura

Figura 6.12. Variación de la LSV de los asfaltos envejecidos en función de la temperatura

Figura 6.13. Vd medidas en el ensayo de rueda cargada versus Vd estimadas para la mezcla D-20.

Figura 6.14. Vd medidas en el ensayo de rueda cargada versus Vd estimadas, con la ecuación de ajuste para todas las mezclas

Figura 6.15: Comparación de curvas de deformación-tiempo de probetas ensayadas bajo diferentes niveles de carga

Figura 6.16. Fotos de probetas ensayadas bajo diferentes niveles de carga 125

Figura 6.17. Vd en función de la presión de contacto de las diferentes mezclas 126

Figura 6.18. Vd en función en la LSV para diferentes niveles de carga. Mezcla D-20

Figura 6.19. Vd en función en la LSV para diferentes niveles de carga. Mezcla M-10

Figura 6.20. Vd en función en la LSV para diferentes niveles de carga. Mezcla SMA-10 128

Figura 6.21. Vd del ensayo mezcla D-20 versus Vd estimadas. Izquierda: con la ecuación 6.2, derecha: con la ecuación 6.3

Figura 6.22. Vd del ensayo versus Vd estimadas (Izquierda: con la ecuación 6.2, derecha: con la ecuación 6.3). Arriba: mezcla M-10, abajo: mezcla SMA-10

Figura 6.23. $\mathrm{LSV}_{\mathrm{i}}$ versus parámetro $\mathrm{LSV}_{60}{ }^{\circ} \mathrm{C} /\left(\mathrm{T} / \mathrm{T}_{0}\right)^{\mathrm{CT}}$. 


\section{Índice de tablas}

Tabla 2.1. Temperaturas de los grados de performance $\ldots$

Tabla 2.2. ZSV correspondientes a G*/sen $\delta$ de 1 y 2,2 $\mathrm{kPa} \ldots \ldots \ldots \ldots$

Tabla 2.3. Diferentes equipos de rueda cargada

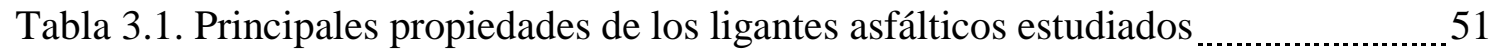

Tabla 3.1 (continuación). Principales propiedades de los ligantes asfálticos estudiados

Tabla 3.2. Principales propiedades de los agregados _...

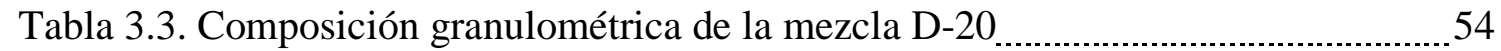

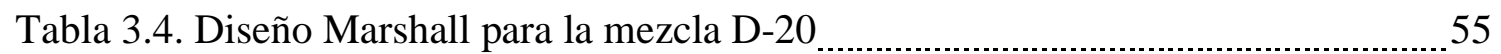

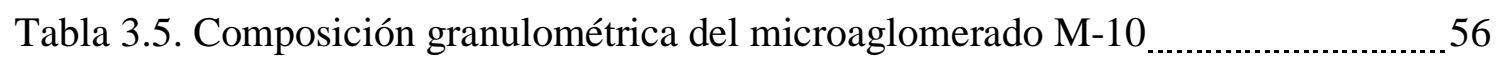

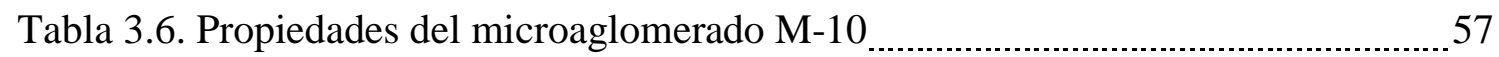

Tabla 3.7. Composición granulométrica de la SMA-10 57

Tabla 3.8. Propiedades de la SMA-10 58

Tabla 3.9. Restantes ensayos realizados sobre asfaltos, agregados y mezclas asfálticas

Tabla 3.9 (continuación). Restantes ensayos realizados sobre asfaltos, agregados y mezclas asfálticas 75

Tabla 4.1. Resultados de $\mathrm{G}^{*} / \mathrm{sen} \oint[\mathrm{Pa}]$ a $\omega=10 \mathrm{rad} / \mathrm{s} \ldots$

Tabla 4.2. Resultados de $\mathrm{G} * / \mathrm{sen} \delta[\mathrm{Pa}]$ a $\omega=0,6 \mathrm{rad} / \mathrm{s} \ldots \ldots \ldots$

Tabla 4.3. Límites de deformación máxima

Tabla 4.4. Resultados de ensayo y análisis de varianza (ANOVA) _................................ 84

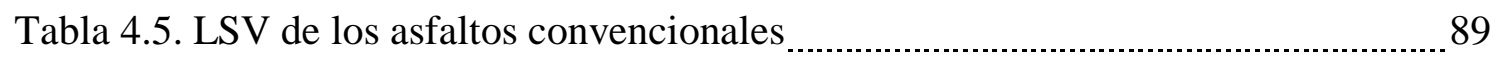

Tabla 4.6. LSV de los asfaltos modificados _ 89

Tabla 4.7. Temperaturas de alta asociadas a la LSV y el G*/sen $\delta \ldots$

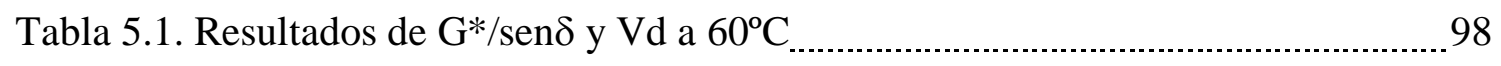

Tabla 5.2. Resultados de LSV y Vd a $60^{\circ} \mathrm{C} \ldots 102$

Tabla 5.3. Parámetros de ajuste por regresión no lineal - relación Vd-LSV _................... 104

Tabla 6.1. Resultados de LSV de los asfaltos y Vd de las diferentes mezclas _............... 109 
Tabla 6.2. LSV del asfalto MP3 de diferentes procesos de envejecimiento en RTFOT y recuperado de mezcla 110

Tabla 6.3. Temperaturas de alta relacionadas a los conceptos de $\mathrm{T}_{500} \mathrm{y} \mathrm{T}_{2000}$ 117

Tabla 6.4. Coeficientes de ajuste de las mezclas estudiadas 119

Tabla 6.5. Resultados de ensayos y valores calculados (etapa de validación) 121

Tabla 6.6. Vd $[\mu \mathrm{m} / \mathrm{min}]$ de diferentes mezclas elaboradas con los asfaltos C3, M y MP3 bajo diferentes presiones de contacto

Tabla 6.7. Resultados de Vd de todas las mezclas estudiadas bajo diferentes temperaturas y presiones de contacto

Tabla 6.8. Aumentos en la $\mathrm{T}_{\text {alta }}$ del asfalto por mayores volúmenes de tránsito 131

Tabla 6.9. Resultados de Vd a diferentes temperaturas y cargas de las mezclas 133

Tabla 6.10. Coeficientes de ajuste a la ecuación 6.2 para las mezclas estudiadas 134

Tabla 6.11. Coeficientes de ajuste a la ecuación 6.3 para las mezclas 134 


\title{
Nomenclatura
}

\begin{abstract}
Abs: absorción [\%].
$\mathrm{D}_{105}$ : deformación permanente en mezcla para 105 minutos $[\mu \mathrm{m}]$.

$\mathrm{D}_{120}$ : deformación permanente en mezcla para 120 minutos [ $\left.\mu \mathrm{m}\right]$.

DSR: Dinamic Shear Rheometer, reómetro de corte dinámico.

E: estabilidad Marshall [kN].
\end{abstract}

ESAL: equivalent single axle load, ejes equivalentes de carga simple.

$e$ : altura del molde de rueda cargada [mm].

F: fluencia Marshall [mm].

$f:$ frecuencia angular $[\mathrm{Hz}]$.

$\mathrm{G}^{*},\left|\mathrm{G}^{*}\right|$ : Modulo dinámico complejo del asfalto [kPa].

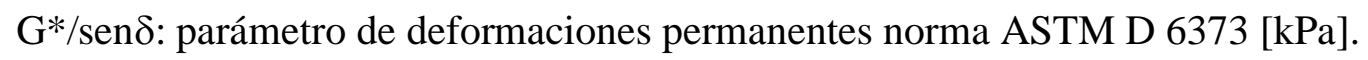

$h$ : espesor $[\mathrm{mm}]$.

$\mathrm{H}$ : profundidad en el pavimento desde la superficie [mm].

IP: índice de penetración.

$J_{d} \Psi(t)$ : Compliance viscoelastico [1/Pa, $\left.1 / \mathrm{kPa}\right]$.

$\mathrm{J}_{\text {final }}$ : compliance al final del ensayo[1/kPa].

$\mathrm{J}_{\text {final-15 }}$ : compliance 15 minutos previos al fin del ensayo $[1 / \mathrm{kPa}]$.

$J_{o}$ : Compliance elastico $[1 / \mathrm{Pa}, 1 / \mathrm{kPa}]$.

$J_{v}$ : compliance viscoso $[1 / \mathrm{Pa}, 1 / \mathrm{kPa}]$.

$J_{v}$ : creep compliance $[1 / \mathrm{Pa}, 1 / \mathrm{kPa}]$.

LA: Desgaste Los Angeles [\%].

Lat: Latitud geográfica $\left[^{\circ}\right]$.

$L$ : largo del molde de rueda cargada [mm].

l: ancho del molde de rueda cargada [mm].

LSV: Low Shear Viscosity, viscosidad a baja velocidad de corte [Pa.s].

M: masa de mezcla [kg].

P: presión de inflado del neumático $\left[\mathrm{Kg} / \mathrm{cm}^{2}\right]$. 
PAV: Pressure Aging Vessel, ensayo de envejecimiento en vasija a presión.

Pe: peso específico $\left[\mathrm{gr} / \mathrm{cm}^{3}\right]$.

PG: Performance Grade. Grado de desempeño del ligante asfaltico.

r: factor de destrucción.

$\mathrm{R}$ : radio del área de contacto del neumático con el pavimento [cm].

$r$ : radio del plato de ensayo del DSR [mm].

RTFOT: Rolling Thin Film Oven Test, ensayo de envejecimiento de película fina rotativa.

RTI: resistencia a tracción indirecta [kPa].

SMA: Stone mastic asphalt.

t: tiempo [s, min].

$\mathrm{T}_{\text {alta }}$ : temperatura del pavimento a altas temperaturas del aire $\left[{ }^{\circ} \mathrm{C}\right]$.

$\mathrm{T}_{\text {baja }}$ : temperatura del pavimento a bajas temperaturas del aire $\left[{ }^{\circ} \mathrm{C}\right]$.

$t_{\text {creep }}$ : tiempo de aplicación de carga en el ensayo de creep [s].

$T_{\text {max }}$ : torque máximo aplicado.

$\mathrm{v}, v$ : porcentaje de vacíos [\%].

VAM: vacíos del agregado mineral [\%].

Vd: velocidad de deformación, ensayo rueda cargada [ $\mu \mathrm{m} / \mathrm{min}, \mathrm{mm} / \mathrm{min}]$.

$\mathrm{Vd}_{60}$ : velocidad de deformación a $60 \mathrm{~min}$. de ensayo[ $\left.\mu \mathrm{m} / \mathrm{min}, \mathrm{mm} / \mathrm{min}\right]$.

$\mathrm{Vd}_{120}$ : velocidad de deformación para $120 \mathrm{~min}$. de ensayo [ $\mu \mathrm{m} / \mathrm{min}, \mathrm{mm} / \mathrm{min}$ ].

W: carga de referencia aplicada al pavimento [kg].

$\mathrm{W}_{\text {disp. }}$ : trabajo disipado en el pavimento por ciclo de carga.

$\mathrm{W}_{\mathrm{i}}$ : carga cualquiera aplicada [kg].

ZSV: zero shear viscosity (Viscosidad de corte cero) [Pa.s].

$\Psi(t)$ : función de memoria del asfalto.

$\theta$ : ángulo de rotación [rad].

$\rho_{\text {max }}$ : densidad máxima rice de la mezcla $\left[\mathrm{kg} / \mathrm{m}^{3}\right]$.

$\delta$ : ángulo de fase $\left[{ }^{\circ}\right]$.

$\varepsilon_{\mathrm{p}}$ : deformación permanente en la mezcla asfáltica [mm].

$\gamma$ : deformación específica [-].

Y: velocidad de corte $[\mathrm{rad} / \mathrm{s}]$.

$\gamma_{\max }$ : Deformación específica máxima [-].

$\eta^{*}$ : viscosidad compleja [Pa.s]. 
$\eta$ ': componente viscosa de la viscosidad compleja (también denominada real) [Pa.s]. $\eta$ '’: componente elástica de la viscosidad compleja [Pa.s].

$\eta_{\infty}$ : viscosidad a velocidad de corte infinita [Pa.s].

$\eta_{\mathrm{o}}$ : viscosidad de corte cero [Pa.s].

$\sigma:$ desviación estándar.

$\sigma_{\text {aire}}$ : desviación estándar de las mediciones de temperatura del aire.

$\tau$ : tensión de corte aplicada $[\mathrm{Pa}]$.

$\tau_{\max }$ : tensión de corte máxima $[\mathrm{Pa}]$.

$\tau_{0}$ : tensión de corte constante $[\mathrm{Pa}]$.

$\omega$ : frecuencia angular $[\mathrm{rad} / \mathrm{s}]$. 



\section{Capítulo 1}

\section{Introducción}

\subsection{Deformaciones permanentes en mezclas asfálticas}

Las deformaciones permanentes son uno de los tipos de falla que se presentan en los pavimentos asfálticos cuando son expuestos ya sea por separado o en forma combinada a altas temperaturas, tránsito pesado y bajas velocidades de carga.

Las deformaciones permanentes son causadas por la acumulación de pequeñas deformaciones ocasionadas por las cargas del tránsito. El tránsito da lugar a cargas cíclicas. En cada ciclo de carga se realiza cierto trabajo para deformar la superficie del pavimento. Ese trabajo supone una energía cedida al pavimento; una fracción de esa energía se usa en recuperar parte de la deformación y otra es disipada en forma de calor y flujo. Esto genera que en cada ciclo de carga quede una deformación residual.

Históricamente la resistencia de una mezcla a las deformaciones permanentes se considera en función de la consistencia del asfalto utilizado. Dicha consistencia se evaluaba con los ensayos de penetración (IRAM 6576, ASTM D 5) y punto de ablandamiento (IRAM 6841, ASTM D 36) del asfalto. Sin embargo estos ensayos presentan el inconveniente de no representar ninguna propiedad física del material. Así, diferentes asfaltos pueden tener la misma penetración pero no igual comportamiento frente a las deformaciones permanentes para un mismo tipo de mezcla.

En la actualidad se considera que las especificaciones por penetración o viscosidad no son suficientes para garantizar un buen desempeño del asfalto (Kim 2009, Lesueur 2009). Estas especificaciones dieron buenos resultados antiguamente, cuando sólo existían asfaltos convencionales y eran otras las cargas de tránsito. Hoy en día con la aparición de los asfaltos modificados y de mayores cargas, dichas especificaciones ya no alcanzan a representar las características de los asfaltos por lo que se necesita un enfoque más racional del problema.

En nuestro país, al igual que a nivel mundial, se han visto los mismos problemas en cuanto a la caracterización del comportamiento de la mezcla asfáltica frente a las deformaciones permanentes, sobre todo con la aparición de los asfaltos modificados. El 
problema de las deformaciones permanentes o ahuellamiento es un problema serio en nuestros caminos que necesita ser resuelto.

La reología es la ciencia que estudia el flujo y la deformación de los materiales en el tiempo. Las deformaciones permanentes de las capas asfálticas son básicamente un problema de flujo por tanto es coherente realizar la elección del asfalto en función de propiedades reológicas del mismo.

En Argentina y Latinoamérica el estudio de las propiedades reológicas asociadas a los diferentes modos de falla que suceden en un concreto asfáltico es un campo de muy reciente desarrollo sin ningún tipo de especificaciones asociadas. Así mismo a nivel mundial es muy reciente el desarrollo de estas propiedades y su incorporación como parámetros de especificación de asfaltos.

Entre las variables que sin duda afectan las deformaciones permanentes se destacan la temperatura y las cargas a la que está expuesto el pavimento (Perraton et al. 2010, Wang y Machemehl 2006). A altas temperaturas el asfalto se comporta más como un fluido viscoso que como un sólido elástico por lo que aumenta la componente plástica de deformación del mismo y aumentan en consecuencia las deformaciones remanentes. Este comportamiento del ligante se traslada a la mezcla. Si la rigidez del ligante no es suficiente, no es capaz de sujetar las partículas de agregado en su sitio y éstas pueden moverse compactando el esqueleto hacia una configuración más densa, pudiendo ocurrir exudaciones y deformaciones excesivas en la superficie.

Las cargas pesadas tienen un papel preponderante en el ahuellamiento ya que aumentan la magnitud de las deformaciones y por lo tanto aumentan la tasa de deformación de la mezcla. Existe legislación respecto a las cargas máximas permitidas pero muchas veces las mismas no son respetadas. Un mínimo aumento de las cargas acarrea un severo deterioro del pavimento (Salem 2008).

El estudio y caracterización de las deformaciones permanentes en forma racional han llevado al desarrollo de ensayos de laboratorio que tratan de reproducir el problema. Así surgen los ensayos de rueda cargada que brindan un parámetro de la resistencia a las deformaciones permanentes o ahuellamiento de una mezcla asfáltica. Estos ensayos simulan el efecto del tránsito sobre el pavimento midiendo las deformaciones que sufre la mezcla asfáltica a través del tiempo bajo condiciones extremas de tránsito y temperatura.

Por otra parte existen a nivel mundial tendencias diferentes que basan el estudio de la mezcla asfáltica tomando en cuenta el desempeño de éstas relacionadas a los modos de falla del pavimento. Allí el estudio de los ligantes asfálticos se realiza midiendo propiedades reológicas que se relacionan al desempeño en el concreto asfáltico.

El estudio de las deformaciones permanentes constituye un tema de interés debido a que ocasiona una pérdida de prestaciones del pavimento asfáltico desde el punto de vista del confort del usuario y de seguridad al tránsito de los vehículos; esto se traduce en una disminución del desempeño y de la vida útil del pavimento. Las deformaciones permanentes en las carpetas asfálticas se presentan dentro de los primeros 8 a $10 \mathrm{~cm}$ de espesor. Es por esto que la superficie de rodamiento es la capa asfáltica más importante 
a cuidar en cuanto a la presencia de deformaciones permanentes. La valoración del desempeño debe ser parte primordial del diseño de una mezcla asfáltica.

\subsection{Objetivos}

El objetivo general de esta tesis es el estudio y caracterización de las deformaciones permanentes en mezclas asfálticas para uso vial considerando tanto los materiales componentes, en particular las propiedades reológicas de los asfaltos, como el desempeño de las mezclas. Para esto último se utilizan métodos de laboratorio como es el ensayo de rueda cargada que permiten a su vez el estudio de dos variables de gran influencia en el comportamiento frente a las deformaciones permanentes como son la temperatura y las cargas de circulación que soporta el pavimento.

Se estudia las propiedades reológicas de los asfaltos que se asocian con el comportamiento y desempeño de las mezclas asfálticas, especialmente aquellas relacionadas a las deformaciones permanentes. Más específicamente se pretende comparar estas propiedades reológicas con medidas de deformaciones permanentes en mezclas asfálticas definiendo cual representa mejor la contribución del asfalto en la resistencia al ahuellamiento.

La profundización en el estudio de los mecanismos y variables que inciden sobre las deformaciones permanentes dará lugar a resultados de aplicación específica como la selección de los asfaltos teniendo en cuenta las condiciones climáticas y de carga a las que será expuesto el pavimento en base a las propiedades reológicas.

Por otra parte se estudia el efecto de la temperatura y del aumento de la carga aplicada sobre las medidas de deformaciones permanentes. De esta manera se pretende analizar las diferencias en el comportamiento de diferentes mezclas asfálticas para lo cual se usa el equipo de rueda cargada. Como objetivo específico se busca poder predecir las deformaciones permanentes a partir de las características del ligante utilizado, más concretamente sus propiedades reológicas, teniendo en consideración las condiciones de temperatura a las cuales será expuesto en el pavimento.

Se pretende, a partir de los estudios realizados, proponer criterios límites de las propiedades reológicas estudiadas que caractericen el problema en estudio para una posible especificación.

El escaso desarrollo del estudio del tema de las propiedades reológicas y el poco uso del equipo de rueda cargada como herramienta de diseño de una mezcla asfáltica en Argentina y Latino América fueron también promotores del enfoque dado en esta tesis.

\subsection{Estructura de la tesis}

Una síntesis del estado actual del conocimiento y antecedentes sobre el tema se incluyen en el capítulo 2, donde se describen las principales fallas que ocurren en un pavimento asfáltico y específicamente la problemática de las deformaciones permanentes que se producen en una mezcla asfáltica. Se definen los mecanismos de falla y las causas que las generan tomando en cuenta a los materiales, el clima y el tránsito. Se hace énfasis en la relación de las deformaciones permanentes en la mezcla 
asfáltica en relación a las propiedades reológicas, la temperatura y las cargas del tránsito.

En el capítulo 3 se describe la estructura general y aspectos vinculados con el desarrollo del programa experimental. Se detallan las principales propiedades de diferentes asfaltos de producción comercial de Argentina sobre los que se estudiaron las diferentes propiedades reológicas y las mezclas asfálticas elaboradas para la evaluación de las deformaciones permanentes. A la vez se describe las diferentes metodologías utilizadas en la medición de las propiedades reológicas sobre los ligantes asfálticos y para la evaluación de las deformaciones permanentes en las mezclas asfálticas.

En el capítulo 4 se estudia la problemática planteada desde el punto de vista del ligante, considerando diferentes propiedades reológicas asociadas al problema de las deformaciones permanentes. Se caracterizan y analizan una serie de asfaltos, convencionales y modificados, representativos de las distintas alternativas de que se dispone en la actualidad. Se analizan y discuten los resultados obtenidos desde el punto de vista de la contribución a la resistencia de los ligantes asfálticos frente al ahuellamiento.

Ya abordando el estudio de las deformaciones permanentes a nivel de las mezclas asfálticas, en el capítulo 5 se estudia la respuesta en el ensayo de pista de un tipo de mezcla elaborada con los diferentes ligantes. De este modo se plantea y analiza la vinculación entre las propiedades reológicas de los asfaltos y las deformaciones permanentes y la incidencia de las primeras respecto a la caracterización de los asfaltos en el proceso de ahuellamiento. Se definirá aquí cuál de las propiedades es más conveniente desde el punto de vista de la caracterización al problema abordado.

Siendo las temperaturas del pavimento y las cargas variables importantes en el desarrollo de los ahuellamientos y para brindar mayor amplitud al estudio realizado, en el capítulo 6 se estudia el desempeño frente a las deformaciones permanentes de mezclas expuestas a distintas temperaturas y diferentes configuraciones o niveles de carga respecto a las previstas en el ensayo de rueda cargada. De este modo se busca extender las conclusiones y obtener criterios para el mejor diseño y prevención del ahuellamiento de pavimentos asfálticos expuestos a diversas condiciones de uso.

Finalmente el capítulo 7 integra la discusión general de todo lo observado y presenta las conclusiones obtenidas. Además del análisis de la influencia que tienen las propiedades reológicas de los asfaltos y las variables externas consideradas (temperatura y cargas) en el comportamiento frente a las deformaciones permanentes, se ofrecen soluciones a este tipo de deterioro y se presentan las recomendaciones para futuros estudios.

En el capítulo 8 se muestran todas las referencias citadas en esta tesis. 


\section{Capítulo 2}

\section{Deformaciones permanentes en mezclas asfálticas}

\subsection{Introducción}

Las mezclas asfálticas son una combinación de agregados pétreos y cemento asfáltico que forman parte de un sistema multicapas denominado pavimento. Estas, están destinadas a ser la capa de rodamiento así como a proteger a las capas granulares de base subyacente de las inclemencias climáticas y de la circulación de los vehículos. Por otro lado son las que reciben la incidencia directa de las cargas debiendo absorber la mayor parte de esa energía. Por tanto el desempeño (performance) de una mezcla asfáltica es de gran importancia para asegurar:

$>$ Confort y resistencia al tránsito.

$>$ Resistencia a las condiciones climáticas.

$>$ Reducir las tensiones provocadas por el tránsito a valores admisible para la base granular por debajo de ella.

Varios factores afectan el desempeño de un pavimento incluyendo la temperatura, la tensión de carga, el envejecimiento y la humedad. La valoración del desempeño de una mezcla asfáltica debe ser parte primordial del diseño de manera de obtener un pavimento resistente y durable a lo largo de su vida útil.

Actualmente los pavimentos son sometidos a mayores volúmenes de tránsito, mayores cargas y condiciones climáticas extremas. El diseño, caracterización y evaluación del pavimento en laboratorio se hace estudiando su comportamiento teniendo en cuenta los diferentes modos de falla. Las fallas que presenta un pavimento pueden dividirse en fisuraciones (térmica o por fatiga) y deformaciones permanentes. Una breve descripción de cada una de ellas se realiza a continuación.

\subsection{Fisuración}

La fisuración es un fenómeno complejo que puede ser causado por varios factores. Se asocia con tensiones inducidas en el pavimento producto de las cargas de tránsito, variaciones de temperatura o una combinación de ambas. Una mezcla asfáltica, a partir 
de contener un ligante asfáltico, tiene un comportamiento visco elástico. Si una mezcla asfáltica es sometida a una deformación que se mantiene constante en el tiempo una tensión se induce en la misma. Dependiendo de la temperatura, esa tensión se disipará más o menos rápido. Esto se conoce como relajación. A altas temperaturas la relajación se produce en pocos minutos mientras que puede llevar horas, o incluso días, a bajas temperaturas del pavimento.

La fisuración ocurre cuando la tensión inducida por las cargas de tránsito y/o variaciones térmicas excede la resistencia a tracción de la mezcla. Este punto no se alcanza inmediatamente sino que se produce en sucesivos ciclos de carga y descarga que van consumiendo la capacidad de la mezcla de resistir las tensiones inducidas.

Es conocido que el asfalto en la mezcla va sufriendo a lo largo del tiempo un proceso de oxidación y envejecimiento. Esto genera un endurecimiento del ligante y una disminución en su capacidad de relajación. Este hecho reduce la resistencia a la fisuración de una mezcla asfáltica.

La fisuración presenta diferentes formas, las más frecuentes son fisuras longitudinales, fisuras transversales y fisuración refleja, figura 2.1. Las fisuras longitudinales se ubican principalmente en la huella de circulación del tránsito, las transversales pueden indistintamente presentarse en la huella o fuera de ella. A medida que el daño aumenta las fisuras se empiezan a interconectar formando una red que es la que se conoce como piel de cocodrilo, figura 1. Las fisuras reflejas se deben a la reflexión de fisuras subyacentes en una capa inferior y no a causas propias de la mezcla.
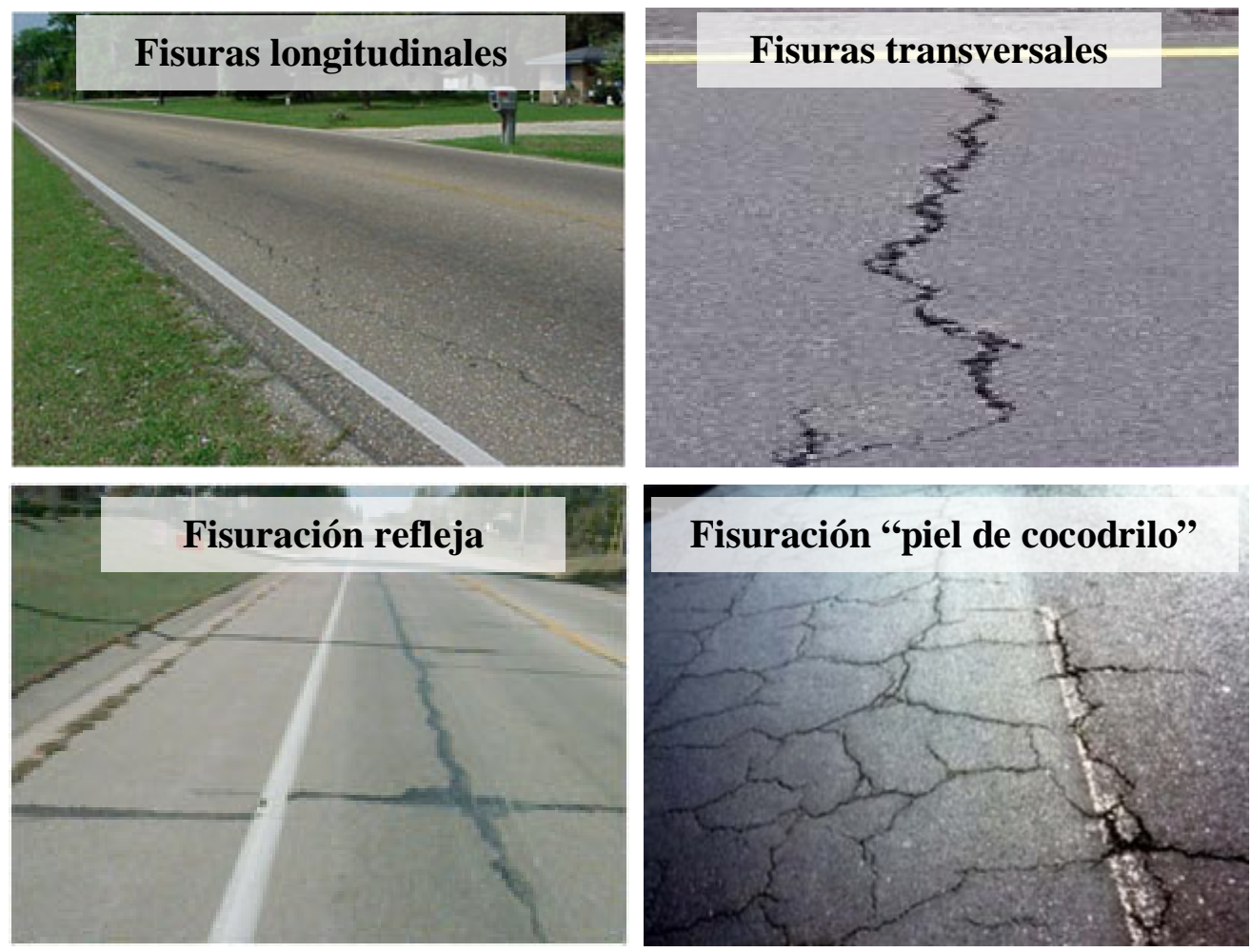

Figura 2.1. Tipos de fisuración en pavimentos asfálticos. 
En forma más general se habla de fisuración por fatiga y fisuración térmica. La fisuración pon fatiga se asocia a temperaturas medias del pavimento entre 10 a $30{ }^{\circ} \mathrm{C}$ y es producto de la acción sucesiva de las cargas o de ciclos térmicos. Por su parte la fisuración térmica se produce en un solo ciclo de enfriamiento. La mezcla se enfría y, al impedir las capas inferiores la libre contracción, se generan tensiones que de superar la resistencia a tracción provocarán la fisuración. Este tipo de fisuración se da a temperaturas muy por debajo de los $0{ }^{\circ} \mathrm{C}$.

\subsection{Deformaciones permanentes}

Las deformaciones permanentes o ahuellamientos son el deterioro caracterizado por la existencia de una sección transversal de la superficie que ya no ocupa su posición original. Se llama deformación "permanente" pues representa la acumulación de pequeñas deformaciones producidas con cada aplicación de carga que son irrecuperables. En las mezclas asfálticas son uno de los modos de falla más frecuentes que se producen sobre los pavimentos y consisten en una depresión canalizada en la huella de circulación de los vehículos, figura 2.2. Este proceso se ve favorecido por la acción combinada de elevados niveles de tránsito, tránsito pesado y/o lento y altas temperaturas. Los pavimentos asfálticos ahuellados tienen una seguridad deficiente porque los surcos que se forman retienen suficiente agua para provocar hidroplaneo o acumulación de hielo.
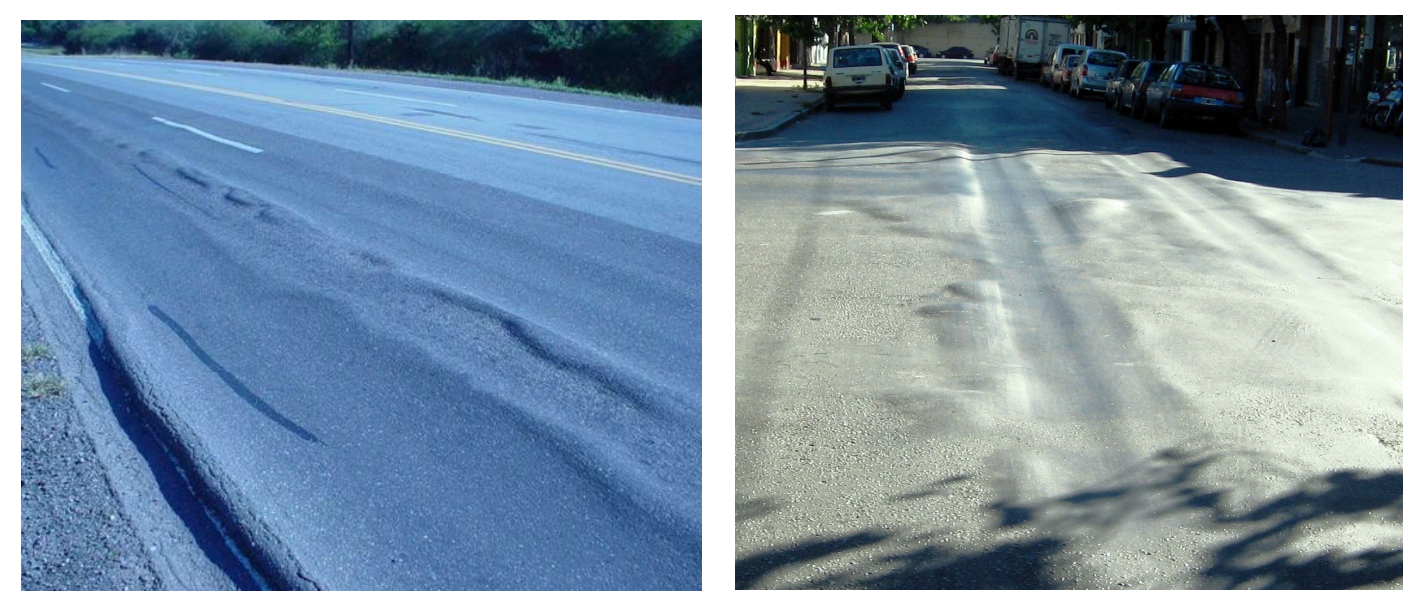

Figura 2.2. Deformaciones permanentes.

Si bien el ahuellamiento puede tener varias causas hay dos principales, la falla estructural de la subrasante y la falla de la carpeta asfáltica.

El ahuellamiento por falla de la subrasante se genera por la aplicación repetida de carga al suelo natural; subbase o base por debajo de la capa asfáltica, figura 2.3a; la cual cede y se deforma. Frecuentemente este ahuellamiento es el resultado de una sección de pavimento demasiado delgada sin la suficiente profundidad para reducir, a niveles tolerables, las tensiones sobre la subrasante cuando las cargas son aplicadas. También se puede deber a una escasa compactación de las capas de suelo o podría ser el resultado de una subrasante debilitada por el ingreso inesperado de agua. En este caso la acumulación de la deformación permanente ocurre más en la subrasante que en las 
capas asfálticas. Aunque la utilización de materiales viales más rígidos reduce parcialmente este tipo de ahuellamiento, el fenómeno es normalmente considerado más un problema estructural que un problema de los materiales.

El otro tipo principal de ahuellamiento se debe a la acumulación de deformaciones en las capas asfálticas. Este tipo de ahuellamiento es causado por una mezcla asfáltica cuya resistencia al corte es demasiado baja para soportar las cargas pesadas repetidas a las cuales está sometida, figura 2.3b. A veces el ahuellamiento ocurre en una capa superficial débil. En otros casos, la capa superficial no es en si misma propensa al ahuellamiento, pero acompaña la deformación de una capa asfáltica inferior más débil. Las deformaciones permanentes se producen primero con un cambio de volumen debido a la compactación por el paso del tránsito; luego se producen deformaciones a volumen constante por flujo de la mezcla. Finalmente, se produce un tercer estado denominado tercer flujo en el cual la mezcla pierde la capacidad de tomar carga y se deforma rápidamente, este proceso está asociado con cambios de volumen en la mezcla asfáltica.
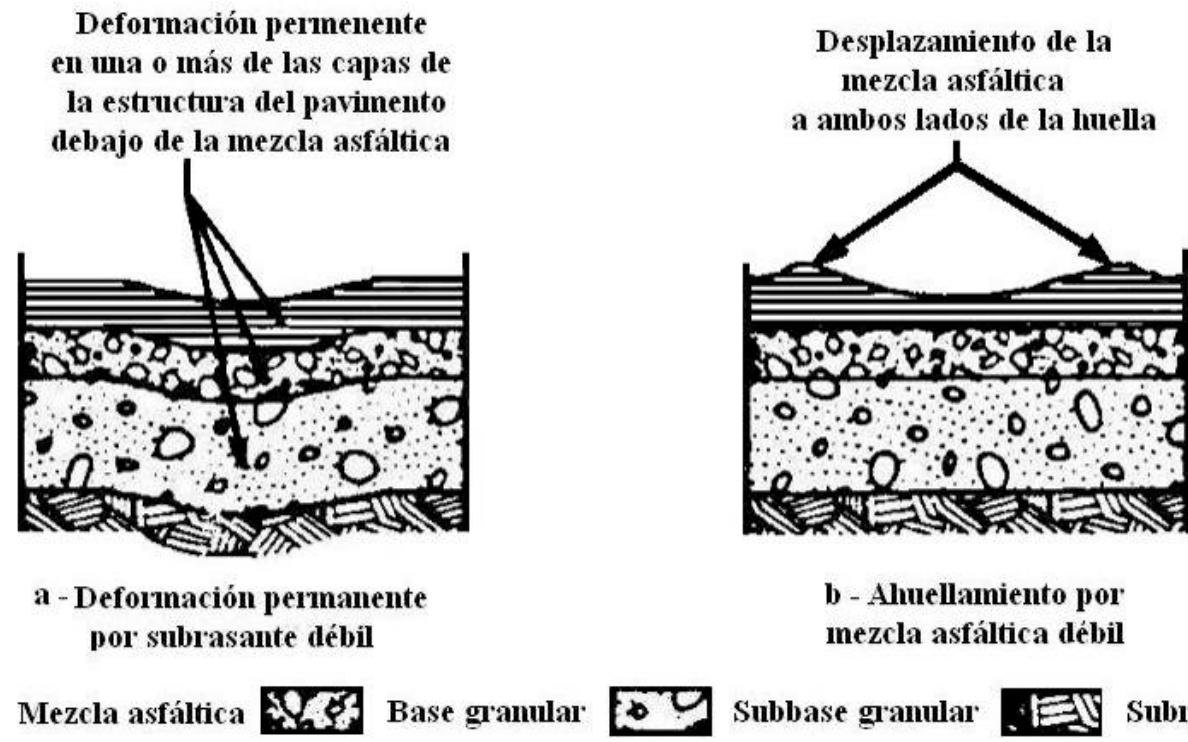

Figura 2.3. Tipos de ahuellamientos. ${ }^{1}$

El perfil transversal de la deformación es diferente en cada caso (ahuellamiento de la mezcla o de capas de suelo interiores), y es relativamente fácil de distinguir cuando se produce uno u otro. Cuando la deformación proviene de la subrasante debilitada la mezcla asfáltica acompañará dicha deformación observándose un descenso del nivel de la mezcla coincidente con la huella de circulación. Por su parte cuando la deformación es debida a la mezcla asfáltica se produce, además del descenso de la mezcla en coincidencia con la huella, un ascenso de la misma en los laterales de la huella de circulación. Este tipo de movimiento no es ni más ni menos que una típica falla de corte.

Por lo general será conveniente adoptar la palabra ahuellamiento (rutting en inglés) para referirse a la deformación permanente de la mezcla asfáltica, y utilizar la palabra deformación para referirse a las deformaciones de las capas subyacentes. El que nos

\footnotetext{
${ }^{1}$ Figura adaptada del Nchrp report $N^{\circ} 468$
} 
ocupa aquí es el ahuellamiento de la capa asfáltica que ocurre por la acumulación de pequeñas deformaciones plásticas de la mezcla que ocurren cada vez que se aplica una carga sobre el pavimento.

\subsubsection{El rol del asfalto}

El asfalto tiene una interesante propiedad con la variación de temperatura, su susceptibilidad térmica. A bajas temperaturas el ligante tiene el comportamiento de un sólido elástico mientras que a altas temperaturas el mismo es el de un fluido viscoso puro. En el medio se produce una transición entre los dos estados presentando un comportamiento visco-elástico, figura 2.4. Debido a esto es importante tener en cuenta las condiciones de temperatura a las que será expuesto el pavimento, a bajas temperaturas se tendrá una mezcla que puede sufrir fisuración y a altas temperaturas ahuellamientos.

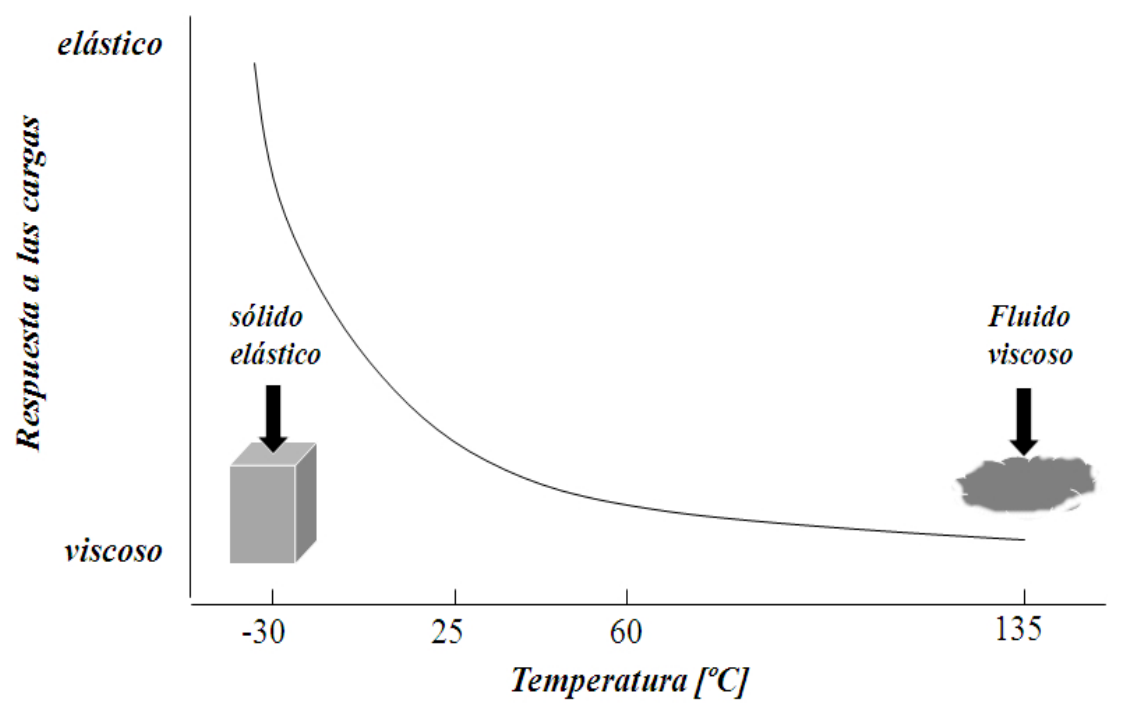

Figura 2.4. Cambio en el comportamiento del asfalto en función de la temperatura.

El ahuellamiento de las mezclas asfálticas débiles es, por tanto, un fenómeno asociado a las altas temperaturas para el pavimento, y es más probable que ocurra en verano (en ocasiones el ahuellamiento se puede producir en forma parcial en dos o tres veranos consecutivos), figura 2.5. A estas temperaturas el asfalto se comporta más como un fluido viscoso que como un sólido elástico, por lo que aumenta la componente plástica de deformación del mismo y aumentan en consecuencia las deformaciones remanentes. Este comportamiento del ligante se traslada a la mezcla. Si la rigidez del ligante no es suficiente, no es capaz de sujetar las partículas de agregado en su sitio y éstas pueden moverse compactando el esqueleto hacia una configuración más densa, pudiendo ocurrir exudaciones y deformaciones excesivas en la superficie. 


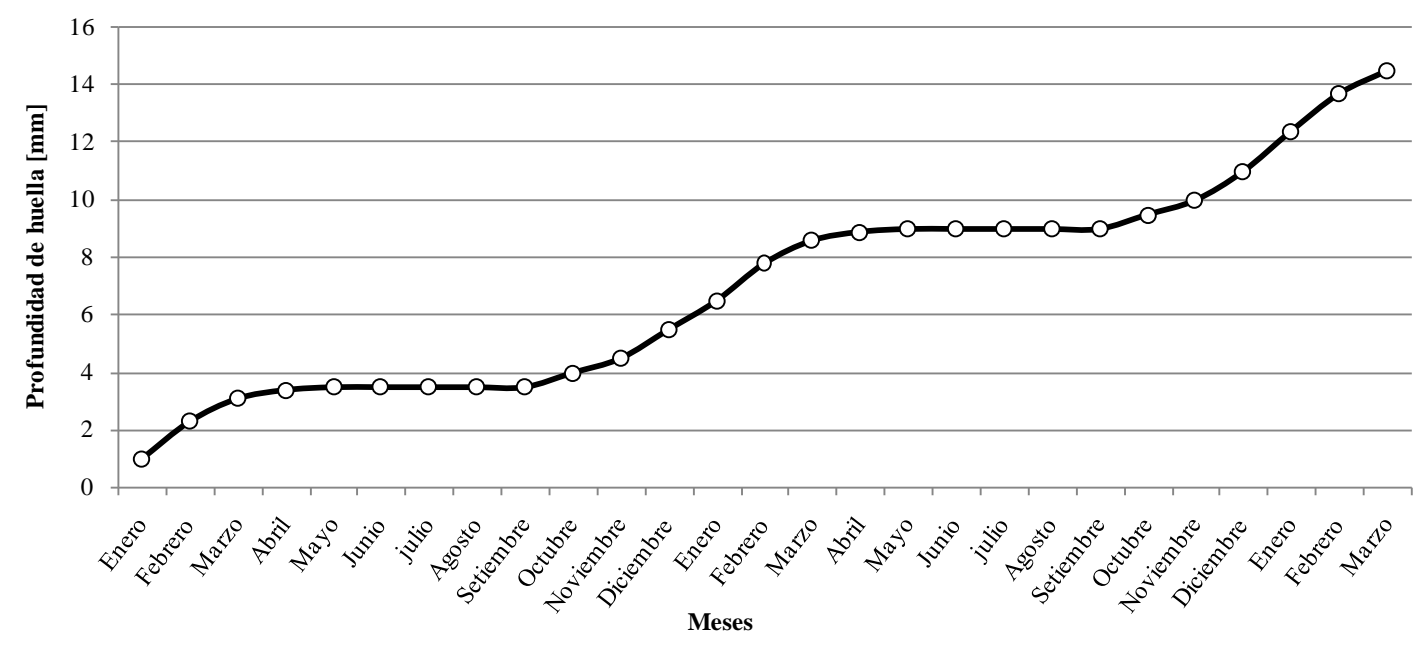

Figura 2.5. Acumulación de deformaciones permanentes en sucesivos veranos.

\subsubsection{Las cargas de tránsito}

Las cargas pesadas tienen un papel preponderante en el ahuellamiento ya que aumentan la magnitud de las deformaciones y por lo tanto aumentan la tasa de deformación de la mezcla. Las cargas pesadas las producen los camiones, que se ve acrecentado si los mismos circulan a bajas velocidades. Este es otro factor que también aporta al problema del ahuellamiento. A bajas velocidades la respuesta del ligante asfáltico se da con una menor rigidez, producto de que tiene tiempo para relajar las tensiones, y así se aumenta la componente plástica e irrecuperable de las deformaciones. Este es un efecto equivalente a un aumento de la temperatura de servicio.

En el análisis de las cargas actuantes se debe tener en cuenta el peso y el número de vehículos que van a circular durante la vida útil del pavimento. No es posible llegar al conocimiento exacto de estos números, pudiéndose hacer solamente inferencias estadísticas en base a hipótesis. La carga de un conjunto de ruedas se expresa en función del peso que soporta cada rueda, la presión de contacto interviniente en la interface rueda-pavimento y el número de ruedas.

La carga máxima por eje permitida es distinta dependiendo del país. En Argentina (ley No 2449 1994) los vehículos y su carga no deben transmitir a la calzada un peso mayor al siguiente:

Por eje simple con ruedas individuales: 6 tn; y con rodado doble: 10,5 tn.

Por conjunto (tándem) doble de ejes con ruedas individuales: 10 tn y ambos con rodado doble: 18 tn.

Por conjunto (tándem) triple de ejes con rodado doble: 25,5 tn.

En total para una formación normal de vehículos se permite un peso bruto de 45 tn y para camión acoplado o acoplado considerados individualmente el peso es de 30 tn.

En la comunidad Europea la carga máxima permitida es de 11,5 tn por eje simple. En USA la carga máxima para un eje simple es de 9 tn mientras que para un eje tándem es 15 tn. 
La carga de una rueda es la carga en el área de contacto del neumático con el pavimento. La mayoría de los análisis asumen que la carga de la rueda es uniformemente distribuida sobre un área circular (Wang y Machemehl 2006). Generalmente se asume también que la presión de inflado de los neumáticos y la presión de contacto con el pavimento son aproximadamente iguales. La ecuación 2.1 relaciona el radio del área de contacto de la rueda $(\mathrm{R})$ con la presión de inflado $(\mathrm{P})$ y la carga total (W).

$$
R=\sqrt{\frac{W}{P . \pi}}
$$

La presión de inflado de la rueda tiene un significativo efecto en la tensión impuesta al pavimento, sobre todo en la capa de rodamiento (Morton et al 2004). Con el correr de los años la presión de inflado en los camiones se ha incrementado notoriamente. La principal razón para ello se debe a las mejoras en la industria de los neumáticos que resultan en presiones de operación seguras más grandes y en incrementos de la capacidad de carga. Los métodos de diseño de pavimentos actuales se basan generalmente en presiones de inflado de diseño de $520 \mathrm{kPa}$, si bien ciertos métodos de diseño empírico mecanicistas han sido subsecuentemente verificados para la aplicabilidad utilizando presiones de inflado de $700 \mathrm{kPa}$.

La legislación respecto a las cargas máximas permitidas normalmente no es respetada. Un mínimo aumento de las cargas acarrea un severo deterioro del pavimento (Salem 2008). El daño en el pavimento se incrementa rápidamente con mayores cargas por eje y con una tasa mayor que la del crecimiento del exceso de carga. Un eje de 9 tn de peso genera un daño diez veces mayor que uno de 5 tn. La relación antes mencionada surge de los estudios en los caminos experimentales WASHO y AASHO (AASHO 1962), ecuación 2.2.

$$
r=\left(\frac{W_{i}}{W}\right)^{4}
$$

donde $\mathrm{r}$ es el factor de destrucción que produce el incremento de la carga, $\mathrm{W}_{\mathrm{i}}$ es la nueva carga y $\mathrm{W}$ la carga de referencia.

El factor r se utiliza para calcular el número equivalente de ejes que son necesarios para alcanzar la ruptura del pavimento con la carga $\mathrm{W}_{\mathrm{i}}$ respecto a los que son necesarios con la carga W para alcanzar ese mismo deterioro.

El número de ejes cambia en forma significativa el daño ocasionado al pavimento (Massachusetts Highway Department 1995). Un eje tándem puede soportar más peso de carga con un pequeño incremento del daño al pavimento. Los ejes tridem son aún mejores para reducir el daño.

Por otra parte el número de ruedas es también importante. El cambio de ruedas duales a simples ocasiona un aumento de la tensión impuesta al pavimento del $20 \%$ 
aproximadamente, debido a que la carga pasa de estar aplicada sobre un punto en lugar de dos. El efecto de las ruedas duales depende en parte de la altura de la capa asfáltica.

El diseño de mezclas que resistan mayores cargas es un desafío. Bahia y coautores (2009) en su investigación estudiaron la sensibilidad de asfaltos y mezclas frente al incremento de tensiones bajo ciclos de carga repetidas. Ellos afirman que son necesarios imponer límites a las cargas máximas y que estos límites deben basarse en análisis de la sensibilidad de las mezclas a los incrementos en los niveles de tensión impuestas al pavimento.

\subsubsection{Factores que intervienen en el desarrollo de deformaciones permanentes}

Producto de las mayores tensiones impuestas por las cargas de tránsito y las mayores temperaturas en la superficie del pavimento las deformaciones permanentes de la capa asfáltica se producen en los 8 a $10 \mathrm{~cm}$ superiores del paquete del pavimento. Por debajo las tensiones y la temperatura son mucho menores.

El diseño de la mezcla altera en gran medida la respuesta de la misma frente al ahuellamiento. Las propiedades volumétricas de la mezcla así como la elección adecuada de los materiales, agregados y asfalto, en función de las condiciones de tránsito y el clima pueden influir para que esta sea más o menos resistente a las deformaciones permanentes. A continuación se hace una reseña de los diferentes factores que intervienen en el desarrollo de las deformaciones permanentes en las mezclas asfálticas.

\subsubsection{Propiedades volumétricas de la mezcla}

Para tener un buen comportamiento de la mezcla asfáltica se necesita no sólo que esté realizada con buenos materiales, además éstos deben estar combinados de manera que el comportamiento sea óptimo. De allí que numerosas propiedades de la mezcla deben ser tenidas en cuenta. Entre ellas aparecen el porcentaje de vacíos, los vacíos del agregado mineral y el porcentaje de asfalto.

\subsubsection{1.a. Porcentaje de vacíos}

El porcentaje de vacíos óptimo de diseño de una mezcla asfáltica densa debe estar entre 3 y 5 \% según la metodología Marshall y en un 4 \% según el programa Superior Performance Pavement (Superpave) de Estados Unidos (manual Asphalt Institute, 1996).

Con contenidos de vacíos menores de 3\%, para el porcentaje óptimo de ligante, la mezcla asfáltica puede exudar y/o ahuellarse sobre todo con altas temperaturas. Esto es debido a que las cargas del tránsito deforman la estructura del pavimento y el mastico de asfalto-finos es movido entre la estructura de agregados pétreos hacia la zonas de vacíos. Si estos vacíos son escasos, el escape de este mastico se produce hacia la superficie en forma de exudación. El mismo no reingresa posteriormente en la estructura de la mezcla y la falta del mastico produce deformaciones permanentes bajo el tránsito debido al acomodamiento de la estructura pétrea de agregados gruesos sin contención por parte de aquel. 
Generalmente se especifica que las mezclas deben presentar un 8 \% de vacíos inmediatamente después de compactadas en el camino. Se asume que la mezcla con la circulación de vehículos densificará normalmente hasta alcanzar su porcentaje final de vacíos después de algunos años de servicio liberada al tránsito. Contenidos de vacíos superiores al 8 \% hacen que la mezcla se compacte bajo la circulación del tránsito rápidamente y en forma localizada en la huella de circulación generando problemas de seguridad y falta de confort.

Las mezclas especiales como la Stone Mastic Asphalt (SMA) que tiene de 2 a $4 \%$ de vacíos o el microaglomerado con aproximadamente un 4 a 7 \% son casos particulares. Estos tipos de mezclas se realizan con asfaltos modificados y presentan una estructura granular discontinua, similar en ambas, pero con un contenido mayor de asfalto (más del 6 \%) en las SMA. En esta mezcla esa mayor incorporación de asfalto se logra con la adición de fibras. La resistencia en estas mezclas radica en la trabazón piedra-piedra y en la cohesión otorgada por el ligante. En cuanto a los vacíos, no deben ser menores al $2 \%$, de lo contrario pueden provocarse exudaciones y por tanto pérdida de material. De igual forma que en las mezclas densas, si el porcentaje de vacíos es excesivo habrá deformaciones prematuras por efecto del tránsito en la zona de la huella.

\subsubsection{1.b. Vacíos del agregado mineral}

Otros parámetros volumétricos relacionados con el ahuellamiento y la exudación, que están relacionados al contenido de vacíos, son los vacíos del agregado mineral (VAM). El VAM es una propiedad que depende de propiedades del agregado, de la granulometría y del contenido asfáltico. El VAM define los vacíos entre los agregados pétreos de la mezcla asfáltica compactada.

En un diseño de mezcla asfáltica, para porcentajes de asfalto crecientes el VAM disminuye hasta un mínimo para luego aumentar progresivamente. Es preferible que el porcentaje de asfalto seleccionado en el diseño sea tal que se alcance el mínimo valor de VAM posible y del lado "seco" de la curva. Si el porcentaje de asfalto ideal se encuentra del lado "húmedo" de la curva VAM - \% asfalto, es preferible rediseñar la distribución granulométrica. Existen dos demandas a satisfacer en el diseño de la mezcla: debe haber suficiente espacio entre partículas para poder colocar la cantidad de asfalto necesaria y mantener los vacíos de diseño y, al mismo tiempo, se debe asegurar un esqueleto granular capaz de soportar las cargas de tránsito.

Valores de VAM muy bajos pueden indicar que en terreno el asfalto no tendrá suficiente espacio y que por lo tanto podría ahuellarse y/o exudar. Valores de VAM muy altos también se han asociado con el ahuellamiento, ya que se requerirá un mayor contenido asfáltico para cumplir las especificaciones de diseño. Este exceso de asfalto hace necesario un mayor porcentaje de ligante entre los agregados, el esqueleto granular se debilita, por lo que la mezcla es más deformable pudiendo llegar a tener ahuellamientos excesivos.

\subsubsection{1.c. Porcentaje de asfalto}

El contenido de asfalto está relacionado con el contenido de vacíos. La estabilidad Marshall, a pesar de no ser un parámetro relevante en el comportamiento de las mezclas 
frente al ahuellamiento, muestra cómo afecta el contenido de ligante al comportamiento mecánico de las mezclas. Hasta cierto valor la estabilidad aumenta con incrementos en el contenido asfáltico; a partir de dicho valor, la estabilidad de la mezcla disminuye con nuevos incrementos de asfalto. Esto se debe al efecto lubricante que produce el exceso de asfalto sobre las partículas de agregado reduciendo el contacto entre las partículas de agregado y por lo tanto disminuyendo la fricción interna de la mezcla. Por tanto se tendrá una mezcla más deformable y con riesgo de exudación.

\subsubsection{Granulometría de la mezcla}

Las mezclas tradicionales se producen en base a granulometrías densas. Estas mezclas, en condiciones extremas de servicio, pueden ser susceptibles de ahuellarse. Para que una mezcla sea resistente al ahuellamiento debe existir un contacto íntimo entre las partículas gruesas, más resistentes y de mayor fricción interna. El mismo concepto es aplicado en las mezclas SMA (Stone Mastic Asphalt o Stone Matrix Asphalt) o microaglomerados (figura 2.6). La cantidad de agregado de menor tamaño debe ser tal que pueda ser colocado en el espacio que dejan los agregados más gruesos, sin interferir en su contacto entre partículas, y así sucesivamente con los tamaños más finos.

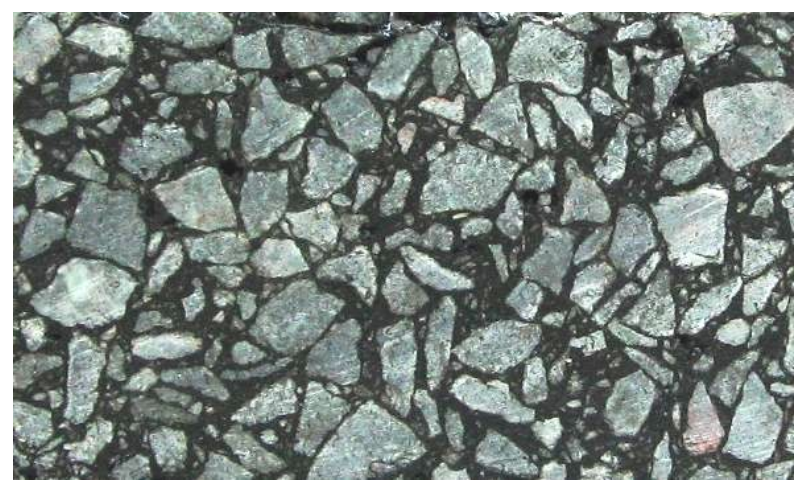

Figura 2.6. Mezcla tipo microaglomerado.

Para una banda granulométrica y un tamaño máximo la granulometría puede estar más cerca del límite superior (mezcla fina, figura 2.7) o del límite inferior (Mezcla gruesa, figura 2.8). La mezcla será menos susceptible al ahuellamiento cuanto la granulometría se aproxime al límite inferior del huso en los tamaños medios. En el estudio del proyecto Superpave se recomienda que a medida que el nivel de tránsito aumenta, la granulometría se acerque al límite inferior de la banda en los tamaños finos (a partir del tamiz $\mathrm{N}^{0} 4$ [4,75 mm] o el $\mathrm{N}^{0} 8$ [2,36 mm]) (manual Asphalt Institute, 1995).

Cuando hay un exceso de arenas de tamaño medio, la mezcla puede ser inestable en condiciones extremas de servicio. Esto produce una deformación paulatina de la mezcla, y un reacomodamiento interno de las partículas, acercándose unas a otras hasta que las partículas gruesas quedan en contacto, de modo que proveen suficiente fricción interna, y la deformación se detiene. 


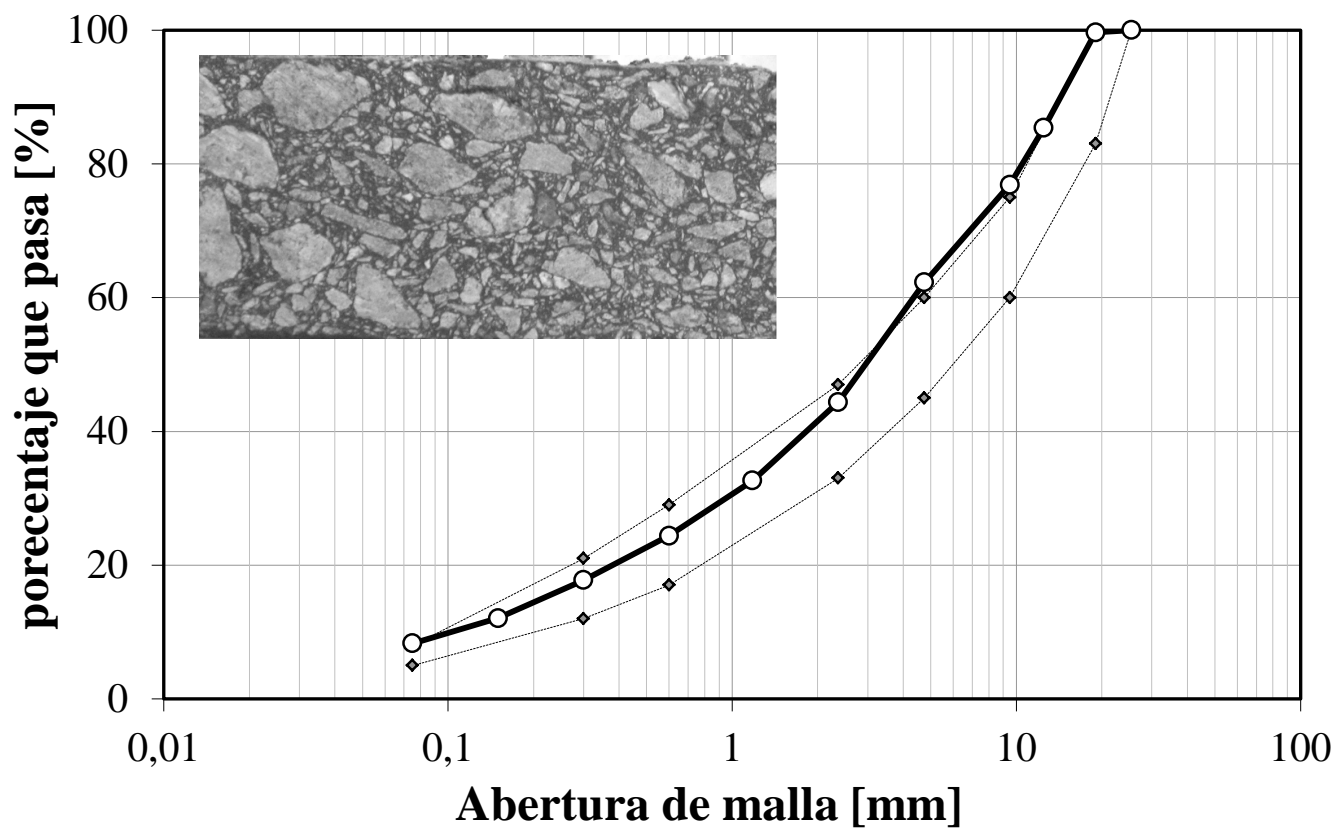

Figura 2.7. Granulometría mezcla densa fina.

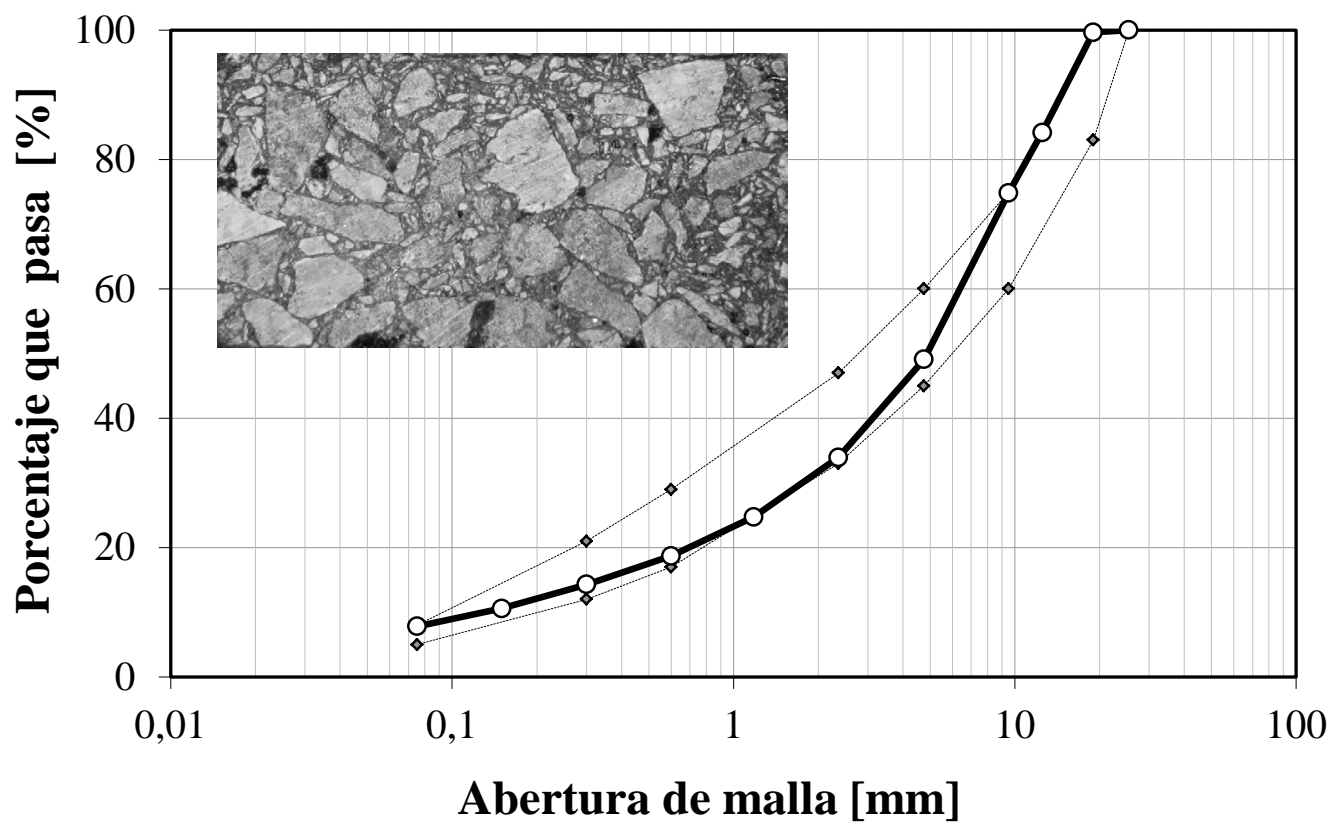

Figura 2.8. Granulometría mezcla densa gruesa.

Superpave para el diseño de mezclas asfáltica define dentro del huso granulométrico una zona restringida por donde no debe pasar la gradación granulométrica, figura 2.9. La misma se localizada entre los tamaños 0,3 mm y 4,75 mm o 2,36 mm (dependiendo del tamaño máximo nominal del agregado). Actualmente se puede pasar la granulometría por esta zona no siendo una restricción dentro de la especificación. El fin de esta zona restringida era limitar la cantidad de arena natural redondeada que puede contribuir a la inestabilidad de la mezcla asfáltica (NCHRP report 557, 2006). 


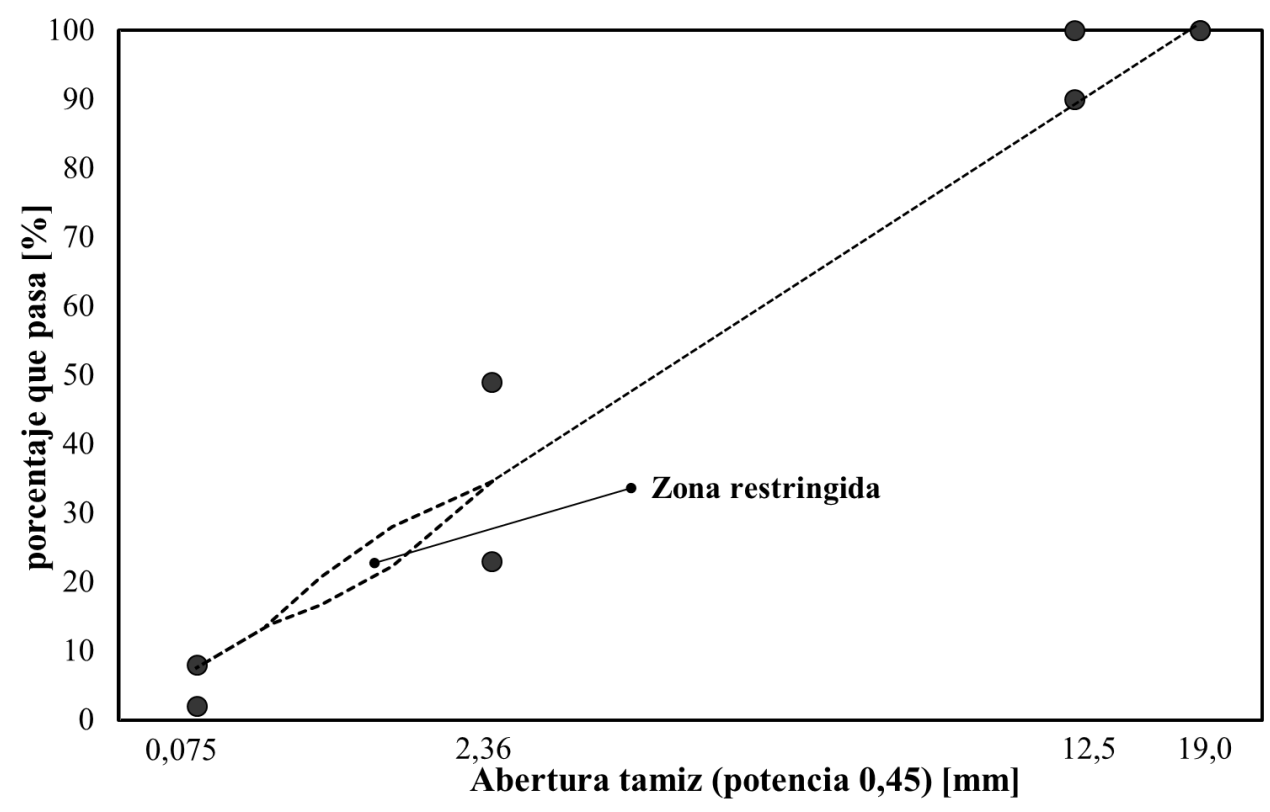

Figura 2.9. Huso granulométrico Superpave con zona restringida.

El desempeño de la mezcla asfáltica también es influenciado por el tamaño máximo del agregado. Romero et al. (1998) y Brown et al. (1990) indican que mezclas elaboradas con tamaños máximos más grandes exhiben mejor desempeño frente al ahuellamiento que las elaboradas con tamaños máximos menores. Por su parte Khedaywi y Tons (1998) encontraron que partículas de agregado grueso más pequeñas proveen mayor trabazón entre agregados resultando en un incremento de la resistencia al corte de la mezcla.

\subsubsection{Efecto del agua, daño por humedad}

El daño por humedad se genera por la presencia de agua en contacto con el pavimento. El agua genera una pérdida de resistencia y durabilidad de la mezcla asfáltica debido a que favorece el desprendimiento de la película de asfalto de la superficie del agregado pétreo. El efecto deletéreo del agua se ve incrementado además por las temperaturas elevadas y la acción del tránsito.

El daño por humedad genera una pérdida de resistencia al romper la adhesión de la película de asfalto de la superficie del agregado pétreo, figura 2.10. Esa adhesión trata de explicarse a partir de diferentes teorías que involucran diversos procesos o fenómenos como: I) reacciones químicas, II) energía superficial, III) orientación molecular, IV) adhesión mecánica. Lo más probable es que el fenómeno de adhesión esté regido por una combinación de los anteriores.

El desprendimiento de la película de ligante asfáltico de la superficie del agregado pétreo se conoce como "stripping”. El stripping es un fenómeno que comienza en la parte inferior de la mezcla asfáltica y evoluciona hacia la superficie del pavimento. La situación progresa gradualmente con pérdidas de resistencia, aparición de ahuellamientos, desprendimiento de agregados y fisuración. 


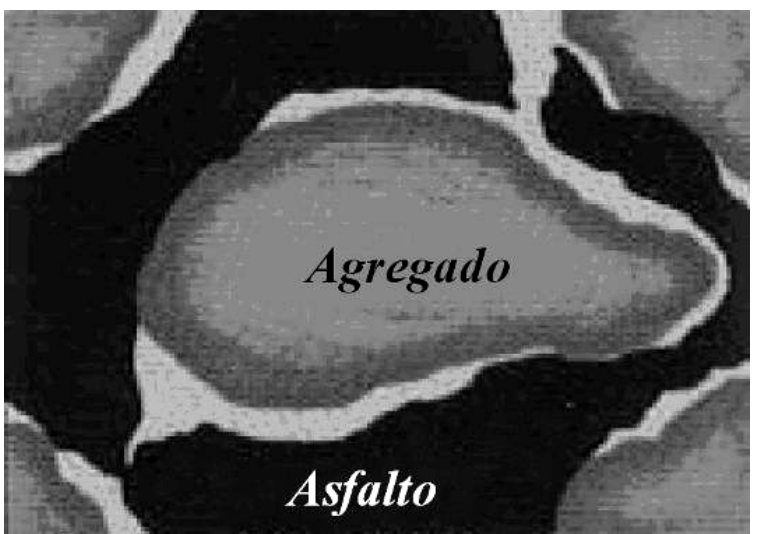

Figura 2.10. Desprendimiento del ligante del agregado por efecto de la humedad. $^{2}$

\subsubsection{Efecto del agregado}

Los agregados de una mezcla asfáltica deben ser de buena calidad y cumplir determinadas características para asegurar un buen comportamiento frente al ahuellamiento. Entre las propiedades de los agregados las más importantes relacionadas a un mejor desempeño del pavimento son la angularidad del agregado grueso, la angularidad del agregado fino, la presencia de partículas planas y alargadas y el contenido de arcillas. Estas propiedades son denominadas en el programa Strategic Highways Research Program (SHRP) de Estados Unidos como propiedades de consenso ya que son consideradas críticas e imprescindibles para alcanzar un buen desempeño. Además propiedades de la roca de origen como la resistencia y la presencia de materiales deletéreos son también importantes.

\subsubsection{4.a. Angularidad del agregado grueso}

Los agregados que se obtienen por procesos de trituración tienen forma angular, filos y textura rugosa. Las mezclas con este tipo de agregados tienen mayor resistencia al corte y por tanto mayor resistencia al ahuellamiento (Prowell et al. 2005). Los agregados triturados generan mayores valores de VAM en la mezcla que los agregados con partículas redondeadas, figura 2.11. Esta angularidad se mide habitualmente por el porcentaje en peso del agregado que presenta dos o más caras de fractura (IRAM 1851, ASTM D 5821).

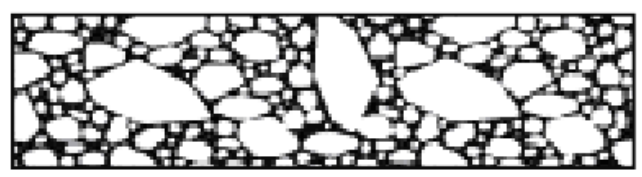

Agregado Angular

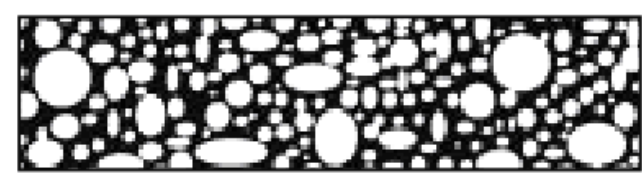

Agregado redondondeado

Figura 2.11. Efecto de la forma de agregado en el VAM.

\footnotetext{
2 Tomada del libro Chemical and Mechanical Processes of moisture damage in hot mix asphalt pavement. Moisture Sensitive of Asphalt Pavement: a national seminary.
} 
En Argentina el pliego de especificaciones técnicas para mezclas asfálticas en caliente (Comisión Permanente del Asfalto, 2006) estipula para el diseño de carpetas de rodamiento, comunes o de bajo espesor que el $75 \%$ del agregado debe presentar dos o más caras fracturadas mientras que el porcentaje restante debe tener al menos una cara fracturada, mientras que para bases y subbases asfálticas se permite hasta un $25 \%$ de agregados naturales. En Estados Unidos Superpave especifica porcentajes mínimos de las caras fracturadas en función del nivel de tránsito de diseño del pavimento que son mayores a medida que se incrementa el mismo (Guía de diseño de mezclas Superpave, 2001). De esta manera se incrementa la resistencia al corte de la mezcla frente a posibles deformaciones permanentes.

\subsubsection{4.b. Angularidad del agregado fino}

Similar a lo que pasa con los gruesos es conveniente que los agregados finos sean productos de trituración ya que éstos presentan mayor resistencia al corte. El uso de arenas de trituración aumenta la fricción interna en la mezcla asfáltica ya que presentan más caras de fractura aumentando el VAM de la mezclas de diseño con respecto a las de una arena de río.

Topal y Sengoz (2005) encontraron a mayor angularidad del agregado fino una mejora en el desempeño frente al ahuellamiento de las mezclas asfálticas, ya que la mayor angularidad genera mayor trabazón entre los agregados.

En SHRP la angularidad se evalúa en el ensayo de la norma ASTM C 1252 (1993), figura 2.12. En él se evalúa el contenido de vacíos de una porción de agregados finos. Este porcentaje de vacíos se relaciona con la angularidad y la textura superficial del agregado. SHRP especifica en función del tránsito diferentes porcentajes mínimos para asegurar un alto grado de fricción interna del agregado fino y de resistencia al ahuellamiento.

La angularidad del agregado fino influencia significativamente el VAM. Debe tenerse especial cuidado ya que agregados con mayor angularidad pueden resultar en mezclas con mayores VAM, lo cual conlleva a un porcentaje excesivo de asfalto de diseño para lograr porcentajes óptimos de vacíos.

En Argentina, dentro del pliego de especificaciones técnicas de mezclas asfálticas en caliente de bajo espesor para carpetas de rodamiento redactado por la Comisión Permanente del Asfalto (pliego CPA, 2006), no admite la utilización de agregados finos no triturados. 


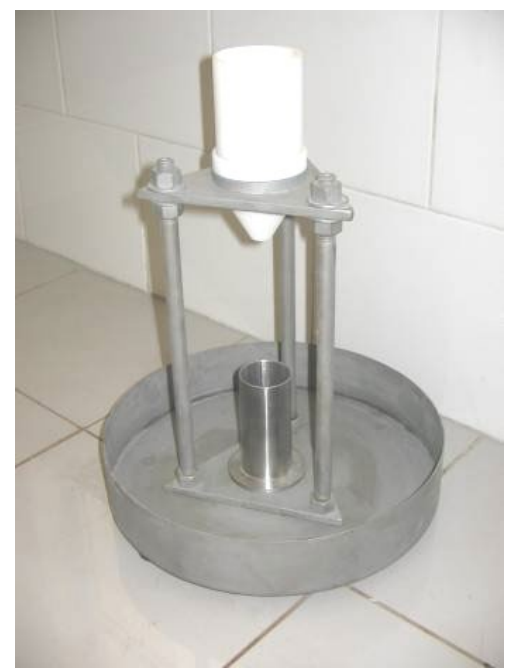

Figura 2.12. Equipo de ensayo para angularidad según norma ASTM C 1252.

\subsubsection{4.c. Partículas planas y alargadas}

El porcentaje de partículas planas y alargadas es un parámetro muy importante. Este tipo de partículas se quiebran durante el proceso de construcción, cambiando la granulometría de la mezcla y por tanto sus propiedades. Las partículas planas tienden a colocarse en el pavimento sobre su cara plana, creando planos preferenciales de deslizamiento y reduciendo la trabazón entre agregados. Un pequeño porcentaje de partículas planas y alargadas en la mezcla pueden aumentar el VAM durante el diseño en laboratorio de la misma. Sin embargo en producción en planta el VAM puede decrecer debido a la trituración de estos agregados durante el mezclado.

SHRP especifica en función del tránsito porcentajes mínimos de partículas planas y alargadas que deben cumplir los agregados gruesos según la norma ASTM D 4791 "Flat Particles, Elongated Particles, or Flat and Elongated Particles in Coarse Aggregate.”. Este porcentaje nunca debe ser mayor al $10 \%$ de partículas planas y alargadas de relación 5:1. Sin embargo este nivel es demasiado riguroso (Nchrp report 539, 2005). Actualmente se ha cambiado la relación de 5:1 por la de 3:1 o 4:1. Investigaciones recientes han demostrado que porcentajes entre 20 y $40 \%$ de partículas planas y alargadas de relación mayor a 3:1 va en detrimento del desempeño de la mezcla.

\subsubsection{4.d. Contenido de arcilla}

La presencia de arcillas da lugar a mezclas propensas a sufrir daños por humedad que en combinación con agua puede causar que una mezcla actúe como "blanda” (pérdida de densidad con la compactación continua en el campo). Los contenidos de arcilla se controlan a través del ensayo de equivalente arena (IRAM 1682, ASTM D 2419).

\subsubsection{4.e. Resistencia}

Un agregado resistente no se tritura o degrada fácilmente durante la compactación en laboratorio o durante la producción en la planta asfáltica. Agregados débiles generalmente se trituran levemente en la etapa de diseño y en mayor grado en la etapa de producción. Esto hace difícil el diseño ya que la mezcla producida en planta diferirá 
de la diseñada con mayor presencia de finos, producto de la trituración de los agregados gruesos en el tambor secador-mezclador, y una reducción del VAM.

Además, los agregados deben ser capaces de resistir las tensiones generadas por la aplicación de las cargas de tránsito sin romperse, de lo contrario con el paso del tiempo se estaría modificando la granulométrica de diseño y pueden generarse ahuellamientos debido a este hecho.

\subsubsection{Efecto del polvo mineral o filler}

El polvo mineral junto con el ligante forman una masa asfáltica o mastico cuya calidad tiene una importancia fundamental en el comportamiento reológico, impermeabilidad, y durabilidad de la mezcla. Los factores a considerar para conseguir un buen mastico son la relación filler/betún y la finura del filler y afinidad con el agua.

Cuanta más alta sea la relación filler/betún más elevada es la viscosidad de masa y más rígida es la mezcla. Esto disminuye la magnitud de las deformaciones permanentes, sobre todo a altas temperaturas ya que se aumenta la rigidez del asfalto.

Cuando el polvo mineral tiene afinidad por el agua puede producirse una degradación en el tiempo, de la estructura íntima de la mezcla, que se traducirá en una menor estabilidad de la misma con riesgo de deformaciones inesperadas. El riesgo de sensibilidad al agua del mortero puede deberse no solamente a la naturaleza del polvo mineral sino también a la composición química de algunos asfaltos.

El polvo mineral tiene un papel fundamental en el comportamiento de las mezclas asfálticas por su elevada superficie específica, en función de su naturaleza, finura, actividad y proporción en la que forma parte de la mezcla. Los polvos minerales pueden ser el contenido en los áridos procedente de la trituración de los mismos; un producto comercial de naturaleza pulverulenta como el cemento o la ceniza volante procedente de central térmica o un polvo, en general calizo, especialmente preparado para este fin.

El Polvo Mineral o Filler forma parte del esqueleto mineral y por lo tanto soporta las tensiones por rozamiento interno o por contacto entre las partículas, además cumple con las siguientes funciones:

$>$ Rellena los vacíos del esqueleto de agregados gruesos y finos, por lo tanto impermeabiliza y densifica el esqueleto. Sustituye parte del asfalto o betún que de otra manera sería necesario para conseguir unos huecos en mezcla suficientemente bajos.

$>$ Proporciona puntos de contacto entre agregados de mayor tamaño y los encaja limitando sus movimientos, aumentando así la estabilidad del conjunto.

$>$ Facilita la compactación, actuando a modo de rodamiento entre los áridos más gruesos.

$>$ Hace la mezcla más trabajable al envolver los áridos gruesos y evitar su segregación. 


\subsubsection{Efecto del asfalto}

La selección del asfalto debe hacerse principalmente en base al clima. Sin embargo también deben incluirse factores de proyecto tales como el nivel de tránsito y las velocidades de circulación. Históricamente, al diseñar un pavimento la resistencia al ahuellamiento se considera a partir de tener una adecuada consistencia del asfalto para soportar las condiciones climáticas y de cargas del tránsito. En un clima caluroso o con excesiva carga se utiliza un asfalto más “duro” y si el clima es frío uno más "blando”. Esta consistencia se relacionó siempre a los valores obtenidos de los ensayos de penetración (IRAM 6576, ASTM D 5) y punto de ablandamiento (IRAM 6841, ASTM D 36), sin embargo en la actualidad estos valores no sirven por sí solos para definir la elección del ligante adecuado.

Sybilski (1996) encontró una pobre relación entre el ahuellamiento de mezclas asfálticas, elaboradas con asfaltos convencionales y modificados, con propiedades del ligante como la penetración a $25^{\circ} \mathrm{C}$ ó el punto de ablandamiento.

A modo de ejemplo en la figura 2.13 se observan tres asfaltos (A, B y C). Los asfaltos B y C se clasifican con el mismo grado de viscosidad a $60{ }^{\circ} \mathrm{C}$ y los asfaltos A y C se clasifican con el mismo grado de penetración. Los asfaltos A y C tienen la misma consistencia a $25^{\circ} \mathrm{C}$, igual penetración, pero su susceptibilidad térmica es marcadamente diferente para las demás temperaturas. Por su parte los asfaltos B y C además de tener la misma consistencia a $60{ }^{\circ} \mathrm{C}$ no muestran ninguna otra similitud. Se observa de este análisis como a pesar de que estos tres asfaltos son clasificados bajo el mismo grado, ya sea por penetración o por viscosidad, son diferentes uno de otro. Por tanto no es posible esperar características similares durante la construcción y menos aun un desempeño equivalente en una mezcla asfáltica (Manual Asphalt Institute, 1996).

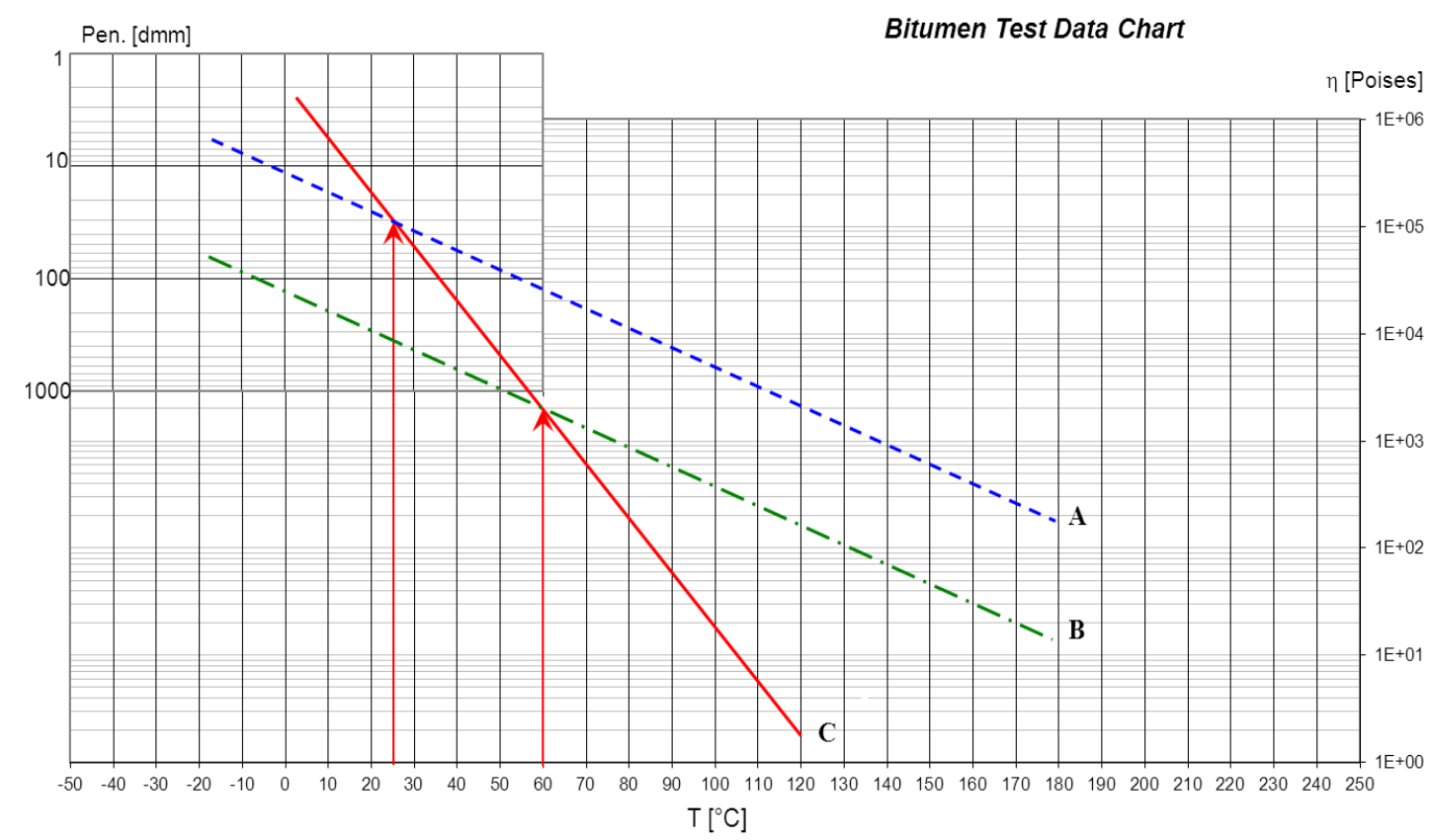

Figura 2.13. Susceptibilidad térmica de tres asfaltos de igual grado. A y $\mathrm{C}$ : igual grado de penetración; B y C: igual grado por viscosidad a $60^{\circ} \mathrm{C}$. 
Kim (2009) indica que el problema de las determinaciones tradicionales como la penetración o el punto de ablandamiento, además de tratarse de un valor obtenido para una sola condición, es su carácter empírico. Otras propiedades como la viscosidad posee un sentido físico y pueden expresarse en unidades absolutas, sin embargo sólo representan una medida fundamental para los fluidos newtonianos, ya que sus propiedades son independientes de la velocidad de corte o el nivel de tensión aplicado. Los asfaltos sólo exhiben un comportamiento newtoniano a muy altas temperaturas o a muy bajas velocidades de corte (Lesueur 2009). A las temperaturas de trabajo o para las velocidades de carga que sufren los pavimentos los asfaltos son fluidos no newtonianos. Por lo tanto un valor absoluto de viscosidad no describe en su totalidad el aporte de un determinado ligante en el desempeño de la mezcla asfáltica.

Por lo dicho en la actualidad se considera que las especificaciones por penetración o viscosidad no son suficientes para garantizar un buen desempeño del asfalto. Estas especificaciones dieron buenos resultados antiguamente, cuando sólo existían asfaltos convencionales y eran otras las cargas de tránsito. Hoy en día con la aparición de los asfaltos modificados y la aplicación de mayores cargas de tránsito, estas especificaciones ya no alcanzan a representar las características de los asfaltos para prevenir deformaciones permanentes en los concretos asfálticos. Es necesario un enfoque más racional del problema.

\subsubsection{Uso de la reología para el estudio de las deformaciones permanentes}

Las deformaciones permanentes de las capas asfálticas son básicamente un problema de flujo por tanto es coherente realizar la elección del asfalto en función de propiedades reológicas del mismo. Shenoy (2000) afirma es que esencial obtener un parámetro reológico que cubra un amplio rango de velocidades de corte y de temperaturas bajo condiciones ambientales simuladas.

La reología es la ciencia que estudia el flujo y la deformación de los materiales en el tiempo. Los asfaltos son materiales cuyo comportamiento reológico depende principalmente de la temperatura y la velocidad de carga.

Como se mencionara anteriormente una propiedad particular del asfalto es su sensibilidad a la temperatura en el rango de variación que puede sufrir en un pavimento. El módulo de rigidez del asfalto puede variar tanto como ocho órdenes de magnitud entre bajas y altas temperaturas. La distribución relativa entre las componentes elástica y viscosa puede variar radicalmente entre verano e invierno. Algo similar ocurre en relación con la respuesta frente a la velocidad de carga entre estacionaria o a alta velocidad (Anderson et al. 1994), por tal motivo la valoración de las propiedades reológicas adquiere una significativa importancia práctica.

En Estados Unidos, con el programa SHRP, y en Europa surgen dos tendencias diferentes que basan el estudio de la mezcla asfáltica tomando en cuenta el desempeño de estas relacionadas a los modos de falla del pavimento. Allí el estudio de los ligantes asfálticos se realiza midiendo propiedades reológicas.

SHRP genera una nueva clasificación de ligantes asfálticos (ASTM D 6373) basándose en la medición de propiedades reológicas que se relacionan con el 
desempeño de la mezcla asfáltica. Por su parte en Europa numerosas investigaciones a lo largo de los últimos 15 años han estudiado el desempeño de mezclas asfálticas relacionándolo con las propiedades reológicas de los ligantes. En lo referente a las deformaciones permanentes se ha desarrollado el concepto de Viscosidad de Corte Cero, Zero Shear Viscosity (ZSV) en inglés, para calificar el aporte del asfalto frente a las deformaciones permanentes.

\subsubsection{La especificación de ligantes asfálticos SHRP}

El Programa de investigaciones SHRP, desarrollado en Estados Unidos en la década del 90, crea una nueva especificación para clasificar los asfaltos para pavimentación en base a sus propiedades reológicas. Esta especificación está diseñada para proveer parámetros que se relacionen con el desempeño de la mezcla asfáltica.

La especificación por grados de desempeño (ASTM D 6373) clasifica al asfalto en una serie de grados que designan el rango de temperaturas máxima y mínima de buen desempeño del asfalto para resistir los modos de falla típicos de un pavimento. El grado de desempeño, en ingles performance grade (PG), se define con dos números, por ejemplo 64-22, y representa el rango de temperaturas en el cual el asfalto brinda buenas prestaciones en lo que respecta a resistir ahuellamientos, fisuración por fatiga y fisuración por bajas temperaturas. En el ejemplo el 64 representa la temperatura de alta y se relaciona con las máximas temperaturas en las que el ligante tendría buenas prestaciones frente a las deformaciones permanentes y fatiga. Por su parte el -22, temperatura de baja, es la mínima temperatura a la cual el ligante ofrece resistencia a la fisuración térmica. Es importante recalcar que estas temperaturas límites se obtienen a partir de mediciones reológicas sobre los ligantes a las cuales el asfalto alcanza valores críticos de estas propiedades. Los grados PG están delineados en incrementos de $6{ }^{\circ} \mathrm{C}$. La tabla 2.1 muestra las temperaturas de los diferentes grados de performance tanto de alta como de baja, luego dependiendo de cada ligante, el grado de desempeño es la combinación de la temperatura de alta y la temperatura de baja.

Tabla 2.1. Temperaturas de los grados de performance.

\begin{tabular}{ccccccc}
\hline \multicolumn{7}{c}{ Temperatura de alta $\left[{ }^{\circ} \mathrm{C}\right]$} \\
\hline 46 & 52 & 58 & 64 & 70 & 76 & 82 \\
\hline \multicolumn{7}{c}{ Temperatura de baja $\left[{ }^{\circ} \mathrm{C}\right]$} \\
\hline-4 & -10 & -16 & -22 & -28 & -34 & -40 \\
\hline
\end{tabular}

A partir de conocer el grado PG de un asfalto se conoce dentro de que temperaturas cumple con buenas prestaciones, ahora también es necesario conocer las condiciones de temperaturas extremas del pavimento en su ubicación geográfica para poder definir que ligante asfáltico será el que mejor se adapta a las necesidades climáticas y asegurar cumplir un buen desempeño de la mezcla asfáltica. Las temperaturas extremas del pavimento en una determinada zona geográfica se obtienen a partir de convertir datos 
históricos de temperatura del aire obtenidos de estaciones meteorológicas en temperaturas del pavimento. Dentro del programa SHRP la temperatura de alta se define como el valor promedio de temperaturas durante siete días consecutivos que resulta el mayor promedio respecto a los demás conjuntos promedios de siete días dentro de un año de mediciones. De cada año de registro histórico se toma el promedio más alto y se calcula el promedio y la desviación estándar de la muestra. Para la temperatura de baja se toma las temperaturas mínimas absolutas de cada año y se calcula el promedio y la deviación estándar de la muestra.

Con los valores previamente descriptos las temperaturas del pavimento se calculan a partir de las ecuaciones 2.3 y 2.4. La ecuación 2.3 es la utilizada para la conversión a temperaturas del pavimento con altas temperaturas del aire mientras que la ecuación 2.4 es para la conversión a temperaturas del pavimento con bajas temperaturas del aire. En estas ecuaciones se incorporan además de la temperatura del aire datos de profundidad dentro del pavimento donde se quiere conocer la temperatura, latitud de ubicación del pavimento, la desviación estándar de temperaturas y un factor de confiabilidad de los datos estadísticos de las temperaturas ambientales. En lo que respecta a la confiabilidad esta se define como la probabilidad que en el curso de un año la temperatura real exceda la temperatura promedio histórica calculada a partir de los datos meteorológicos. Para una mayor seguridad es conveniente adoptar una confiabilidad del $98 \%$. Por ejemplo, si consideramos que la temperatura media de alta de una zona es de $32{ }^{\circ} \mathrm{C}$, con una desviación estándar $(\sigma)$ de $2{ }^{\circ} \mathrm{C}$. La probabilidad de que esos $32{ }^{\circ} \mathrm{C}$ sean superados es de $50 \%$, por tanto la confiabilidad es de $50 \%$. Sin embargo solo hay un $2 \%$ de probabilidad de que la temperatura sobrepase los $36{ }^{\circ} \mathrm{C}\left(32{ }^{\circ} \mathrm{C}+2 \sigma\right)$, por tanto los 36 ${ }^{\circ} \mathrm{C}$ ofrecen una confiabilidad del $98 \%$.

$$
\begin{gathered}
T_{\text {alta }}=54,32+0,78 \cdot T_{\text {aire }}-0,0025 \cdot \operatorname{Lat}^{2}-15,14 \cdot \log _{10}(H+25)+z\left(9+0,61 \cdot \sigma_{\text {aire }}\right)^{1 / 2} \\
T_{\text {baja }}=-1,56+0,72 \cdot T_{\text {aire }}-0,004 \cdot \text { Lat }^{2}+6,26 \cdot \log _{10}(H+25)-z\left(4,4+0,52 . \sigma_{\text {aire }}\right)^{1 / 2}
\end{gathered}
$$

donde:

$\boldsymbol{T}_{\text {alta }}$ : temperatura del pavimento para altas temperaturas.

$\boldsymbol{T}_{\boldsymbol{b a j a}}$ : temperatura del pavimento para bajas temperaturas.

$\boldsymbol{T}_{\text {aire }}$ : temperatura del aire en la superficie del pavimento.

Lat: latitud geográfica en la que se ubica el pavimento.

$H$ : profundidad en mm desde la superficie a la que se quiere conocer la temperatura del pavimento.

z: coeficiente estadístico a obtener de tabla para distribución normal en función de la confiabilidad ( $\mathrm{z}=2,055$ para $98 \%$ de confiabilidad).

$\sigma_{a i r e}$ : desviación estándar de las mediciones de temperatura del aire.

En argentina Iosco y Agnusdei (1997) desarrollaron el mapa de temperaturas para nuestro país que se observa en la figura 2.14. Las temperaturas extremas del pavimento 
se calcularon en base a datos suministrados por estaciones meteorológicas de todo el país para un periodo de datos de 25 años de acuerdo la metodología SRHP antes mencionada. Este mapa de temperaturas se puede utilizar para conocer los rangos de temperaturas extremas que se pueden esperar en un pavimento dependiendo de la zona geográfica de ubicación del mismo. Ofrece la posibilidad de seleccionar el tipo de ligante adecuado por grados de performance o por medio de otro tipo de consideración similar basada en temperaturas extremas del asfalto.

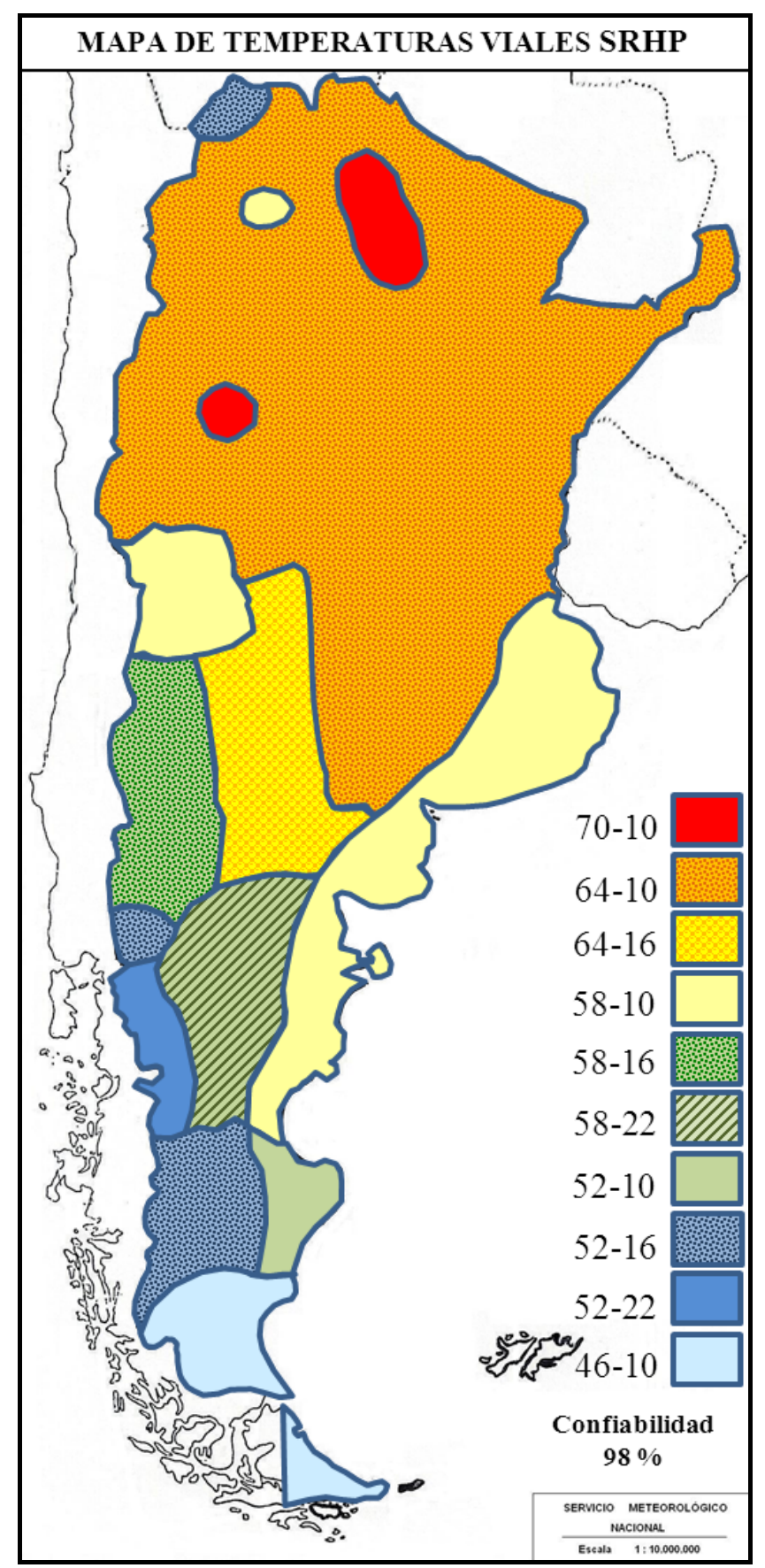

Figura 2.14. Mapa de temperaturas viales de Argentina para un $98 \%$ de confiabilidad. ${ }^{3}$

\footnotetext{
${ }^{3}$ Mapa adaptado del presentado en el trabajo “Mapa de temperaturas viales” Iosco y Agnusdei (1997)
} 
Mayor volumen de tránsito (mayores cargas) y bajas velocidades de carga son factores que aumentan significativamente el riesgo de deformaciones permanentes. Las bajas velocidades de carga son equivalentes a mayores temperaturas del pavimento, según el principio de superposición tiempo-temperatura (Ferry 1980), mientras que mayores cargas son más repeticiones de vehículos circulando sobre el camino. Respecto al incremento del tránsito cuando el mismo excede de 10 millones de ejes equivalentes (ESAL), SHRP sugiere considerar aumentar un grado de desempeño el valor de alta temperatura, es decir de 58 a 64 por ejemplo. En caso de exceder los 30 millones de ESALs SHRP impone el aumento en un grado de desempeño el valor de alta temperatura. De similar forma recomienda elevar el valor de alta temperatura en un grado de desempeño cuando la velocidad esperada del tránsito es entre 20 a $70 \mathrm{Km} / \mathrm{h}$ y en dos grados si la velocidad es menor de $20 \mathrm{Km} / \mathrm{h}$. La especificación aclara que se debe incrementar el grado de desempeño ya sea por mayor tránsito o por bajas velocidades, pero no por los dos al mismo tiempo.

En lo referente al ahuellamiento, dentro de la especificación ASTM D 6373, el comportamiento del asfalto es caracterizado por dos propiedades, la resistencia total a la deformación bajo carga y la distribución relativa de la deformación entre las componentes elástica y viscosa. La resistencia a la deformación es representada por el módulo dinámico $\left(\left|\mathrm{G}^{*}\right|\right.$ en adelante $\left.\mathrm{G}^{*}\right)$ mientras que la distribución relativa de componente elástica y viscosa es representada por el ángulo de fase $\delta$.

El Módulo complejo ( $\mathrm{G}^{*}$ ) se define como el cociente entre el torque máximo aplicado y la deformación máxima experimentada obtenidos por medio de un ensayo en un reómetro de corte dinámico, como el que se observa en la figura 2.15, conocido como DSR (Dinamic Shear Reomether). El tipo de carga aplicada durante el ensayo es del tipo sinusoidal a una frecuencia fija, figura 2.15, por lo que este tipo de ensayo se conoce como oscilatorio. Las deformaciones que ocurren producto de la aplicación de cargas también siguen una ley sinusoidal y en particular por ser el asfalto un material viscoelástico se presentan con un cierto desfasaje $\delta$ respecto a la aplicación de la carga como se observa en la figura 2.15. La distribución relativa de estos componentes depende de la composición del material, la velocidad de carga y la temperatura, figura 2.16 . 

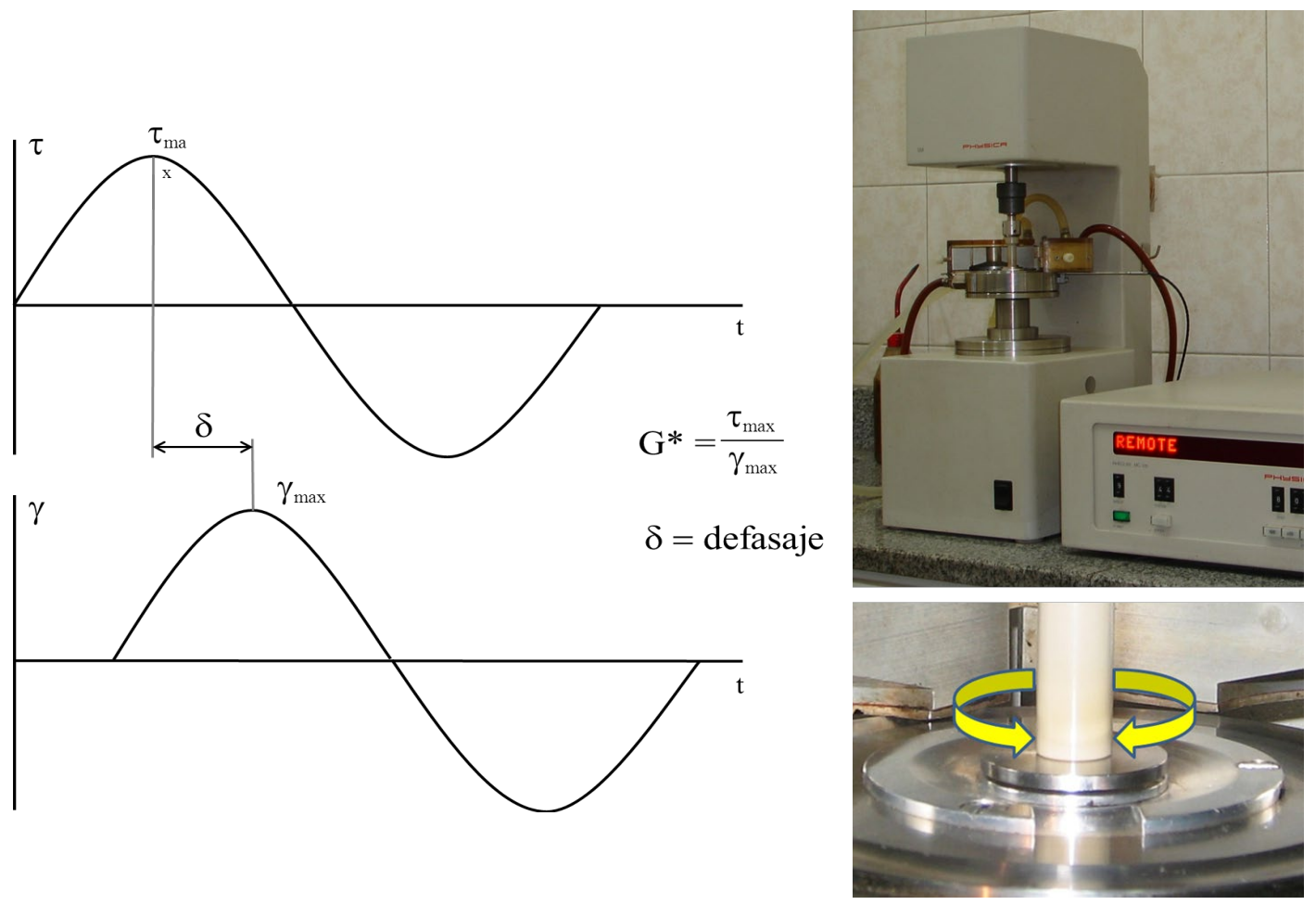

Figura 2.15. Reómetro de corte (DSR) y comportamiento esfuerzo-deformación en un ensayo oscilatorio.
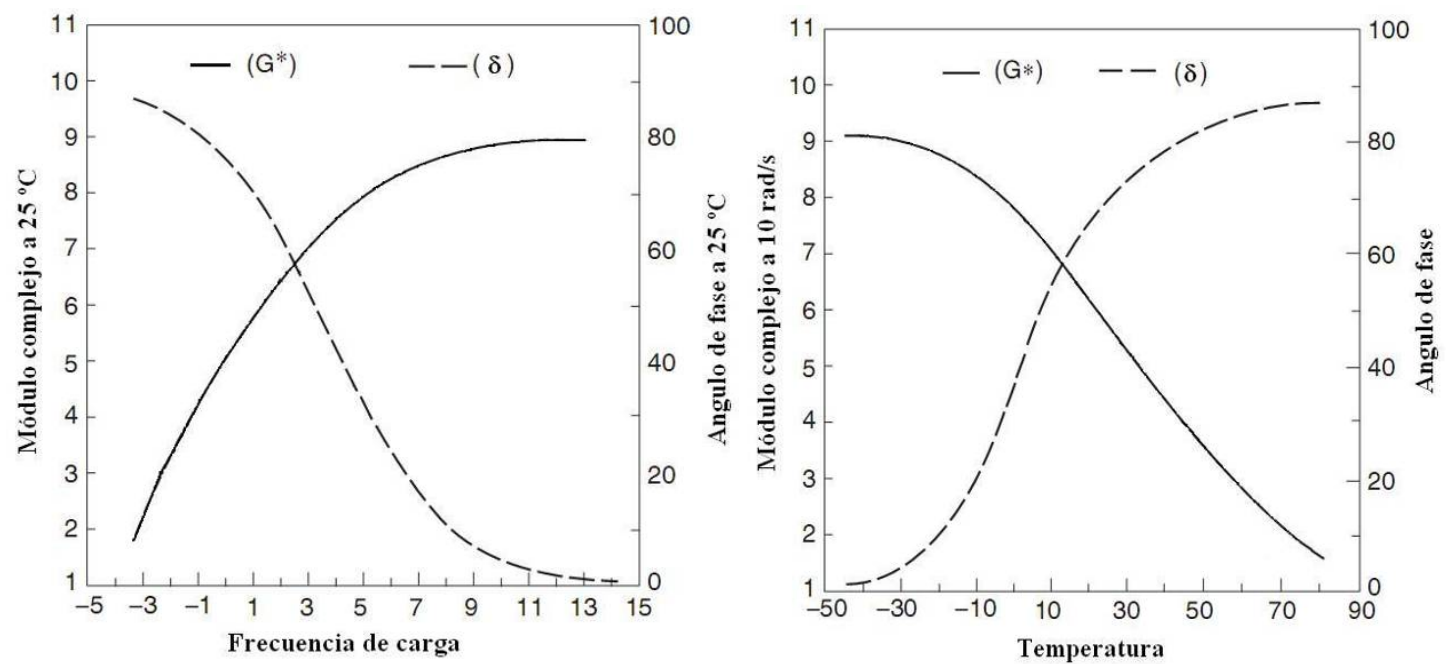

Figura 2.16. Módulo dinámico $\left(\mathrm{G}^{*}\right)$ y ángulo de fase $(\delta)$ en función de la frecuencia de carga (izquierda) y en función de la temperatura (derecha).

En el pavimento, el asfalto, y por ende la mezcla, tiene un comportamiento viscoelástico a temperaturas de servicio y las deformaciones resultan una combinación de deformaciones elásticas y plásticas (o viscosas) producto del tránsito. Cada vez que se aplica una carga tiene lugar, aunque sea en una mínima medida, una deformación permanente. Las cargas cíclicas entregan energía deformando la superficie del pavimento. Una fracción de esa energía se recupera en forma elástica y la otra se disipada en forma de calor y flujo. Para reducir las deformaciones permanentes debe minimizarse la energía disipada en cada ciclo. Para el ligante asfáltico se puede 
demostrar (Stuart et al., 2000) que la energía o el trabajo disipado por la componente viscosa por ciclo de carga se calcula como:

$$
W_{\text {disipado }}=\int \tau d \gamma
$$

Integrando la ecuación (2.5) a lo largo de un ciclo de carga entre 0 y $2 \pi$ para una onda de carga sinusoidal se obtiene la ecuación (2.6).

$$
W_{\text {disipado }}=\pi \cdot \tau_{\text {máx }} \cdot \gamma_{\text {máx }} \cdot \operatorname{sen} \delta
$$

Donde $\tau_{\text {máx }}$ es la tensión máxima aplicada, $\gamma_{\text {máx }}$ es la deformación máxima y $\delta$ es el ángulo de fase que muestra la respuesta del material a partir de la diferencia en el tiempo que aparecen las deformaciones en el material respecto a la aplicación de la tensión. Este parámetro da una idea del comportamiento visco elástico del material, es decir, la relación de deformación que es recuperable o elástica y la no recuperable o viscosa. Las deformaciones permanentes pueden considerarse un fenómeno producido por cargas cíclicas donde se somete al pavimento a la misma tensión máxima. De esta manera la tensión máxima se vuelve una constante $\left(\tau_{0}\right)$. De esta forma la $W_{\text {disipado }}$ se vuelve proporcional a la deformación y el ángulo de fase, ecuación 2.7.

$$
W_{\text {disipado }} \propto \gamma_{\text {máx }} . \operatorname{sen} \delta
$$

La deformación máxima se define como $\gamma_{\text {máx }}=\tau_{0} / G^{*}$ y a su vez $G^{*}=\tau_{\text {máx. }} / \gamma_{\text {máx }}$. Reemplazando estos valores en la ecuación 2.6 y reordenando los parámetros la misma se puede reescribir como se observa en la ecuación 2.8.

$$
W_{\text {disipado }}=\pi \cdot \frac{\tau_{0}^{2}}{G * / \operatorname{sen} \delta}
$$

SHRP usa la ecuación 2.8 en lugar de la 2.6 debido a que G* es constante en el rango visco-elástico lineal, de esta forma diferentes asfaltos no tienen que ser ensayados a la misma tensión máxima de corte. Además el hecho de que esta fórmula se relacione con el módulo del ligante la hace más familiar para los tecnólogos viales.

Puede observarse en la ecuación 2.8 que el trabajo disipado es inversamente proporcional al parámetro $\mathrm{G}^{*} / \mathrm{sen} \delta$; a mayores valores de $\mathrm{G}^{*} / \mathrm{sen} \delta$ el trabajo disipado y, consecuentemente, la susceptibilidad al ahuellamiento deberían disminuir. Esto puede lograrse o bien incrementando el valor de $\mathrm{G}^{*}$, disminuyendo sen $\delta$ o una combinación de ambas. G* es una medida de la resistencia a la deformación, cuanto más grande sea el valor de $G^{*}$ para una determinada temperatura y/o velocidad de carga, mayor resistencia presentará ese ligante. Por su parte sen $\delta$ representa la componente viscosa, no 
recuperable, de la deformación. Por tanto si se tiene un menor $\delta$, menor será el seno y menor la energía disipada, figura 2.17.

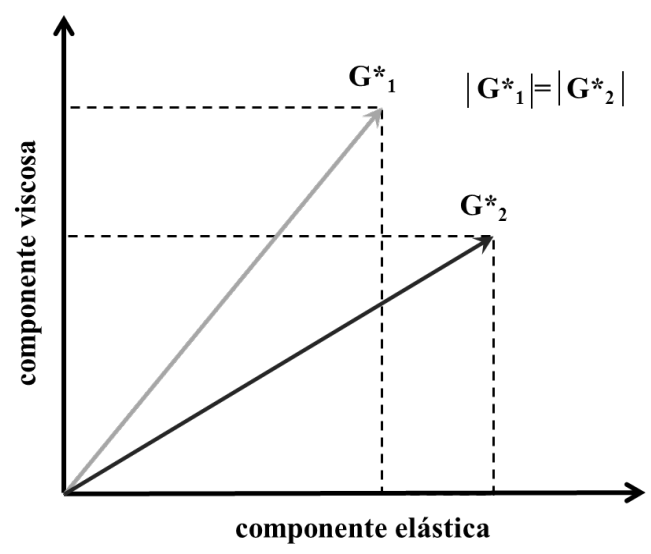

Figura 2.17. Importancia del $\delta$ en el trabajo disipado.

El G*/sen $\delta$ es el parámetro propuesto por SHRP para determinar el desempeño de los asfaltos convencionales o modificados frente a las deformaciones permanentes en el rango de las temperaturas medias y altas, el ligante debe cumplir con tener un valor de $\mathrm{G}^{*} / \mathrm{sen} \delta$ de $1 \mathrm{kPa}$ para el asfalto en estado original y 2,2 kPa para el asfalto envejecido en el ensayo de película delgada rotativo, Rolling Thin Film Oven Test (RTFOT) en inglés. Los requerimientos son siempre iguales para cualquier asfalto, variando de uno a otro la temperatura a la cual se obtiene ese requerimiento.

Numerosos investigadores han analizado la relación entre el parámetro G*/sen $\oint$ y las deformaciones permanentes de las mezclas asfálticas. Al respecto Stuart et al (2000) midieron ahuellamiento con el Accelerated Loading Facility (ALF) sobre dos mezclas asfálticas elaboradas con diferentes ligantes asfálticos para validar el parámetro de altas temperaturas de la especificación SHRP y encontraron una pobre relación entre dicho parámetro y los ahuellamientos.

Se ha comprobado que el $\mathrm{G}^{*} / \mathrm{sen} \delta$ clasifica eficientemente el desempeño de asfaltos vírgenes sin embargo no define satisfactoriamente el comportamiento de asfaltos modificados con polímeros; asfaltos modificados que presentaron menores $\mathrm{G}^{*} / \mathrm{sen} \delta$ mostraron mejores resultados frente al ahuellamiento que otros con mayor valor de G*/sen $\delta$.

Oliver y Tredrea (1998) estudiaron una mezcla asfáltica con diferentes ligantes (convencionales, multigrados y modificados con polímeros) obteniendo medidas de ahuellamiento en laboratorio por medio de un equipo de pista. Concluyen que el parámetro $\mathrm{G}^{*} / \mathrm{sen} \delta$ no tiene una aceptable correlación con los resultados de ahuellamiento cuando se consideran en conjunto, sin embargo el parámetro representa bien el comportamiento de los asfaltos convencionales y los multigrados.

Bahia et al. (2001) realizaron mediciones de ahuellamientos en laboratorio con el Repeated Shear Constant Height sobre diferentes mezclas preparadas con asfaltos modificados. La relación entre las deformaciones permanentes medidas y el G*/sen $\delta$ de los ligantes fue muy pobre. Los autores sugieren que el $G^{*} / s e n \oint \underline{\text { subestima el }}$ 
comportamiento de algunos asfaltos, sobre todo aquellos con elasticidad retardada elevada como, por ejemplo, asfaltos modificados con polímero del tipo SBS.

Le Hir et al. (2003) concluyen que el criterio de especificación SHRP no da una aceptable caracterización de los ligantes modificados con polímero. Más recientemente Dressen et al. (2009) mostraron resultados de deformaciones permanentes en mezclas con diferentes asfaltos modificados, medidas con un equipo de rueda cargada, en relación a valores de $\mathrm{G}^{*} / \mathrm{sen} \delta$ de los mismos ligantes con una muy pobre correlación entre ellos.

Bahia (2007) explica el problema con el concepto desarrollado por SHRP con el $\mathrm{G}^{*} / \operatorname{sen} \delta$ a partir de la energía involucrada en el proceso de deformación. Las deformaciones del ligante pueden dividirse en tres componentes: una deformación elástica, una deformación viscoelástica retardada y una deformación viscosa pura (figura 2.18). A cada una de estas deformaciones se les puede asociar una energía. Por tanto la energía involucrada en el proceso de deformación $\left(W_{i}\right)$ tendrá una componente elástica, una viscoelástica retardada y una viscosa pura (ecuación 2.9). La magnitud de la energía viscoelástica retardada depende del tiempo de aplicación de la carga y de relajación que disponga el material para recuperar la deformación, mientras que la parte viscosa es la energía que contribuye a las deformaciones permanentes de la mezcla, la cual se disipada y es irrecuperable.

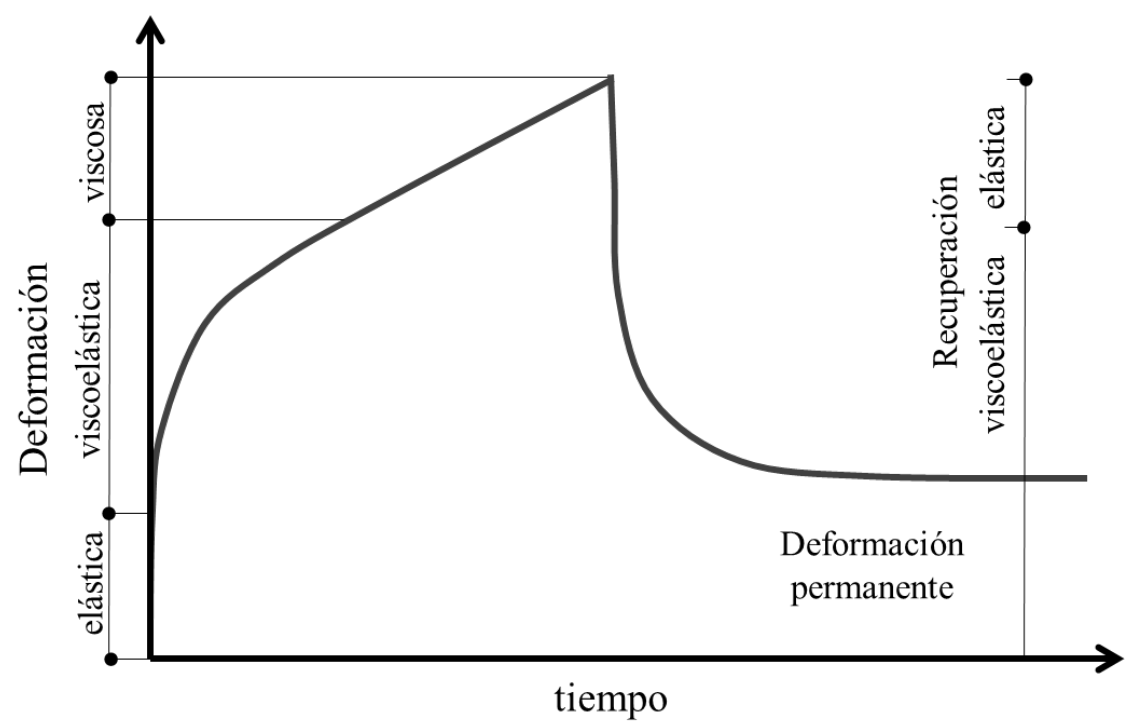

Figura 2.18. Esquema de deformaciones en el tiempo durante un proceso de carga y descarga..

$$
W_{i}=W_{\text {elástica }}+W_{\text {viscoelásticaretardada }}+W_{\text {vis } \cos a}
$$

En los ligantes convencionales las componentes elástica y viscoelástica retardada a altas temperaturas del pavimento son prácticamente despreciables (figura 2.18-b) pudiendo considerarse que la componente viscosa es muy cercana a la energía $W_{i}$. En 
consecuencia la energía disipada, y por tanto el $\mathrm{G}^{*} / \mathrm{sen} \delta$, es un buen indicador de las deformaciones permanentes en asfaltos convencionales. Por su parte los asfaltos modificados presentan una importante componente elástica retardada a altas temperaturas (figura2.18-abajo); y por lo tanto $W_{i}$ no se relaciona directamente con la energía disipada en el flujo viscoso, la cual se relaciona con las deformaciones permanentes. Por el contrario parte de la energía viscoelástica recuperable que aportaría a la resistencia a las deformaciones permanentes se toma como parte de la energía disipada. De esta forma se subestima el real potencial de ese ligante en la contribución frente a las deformaciones permanentes.

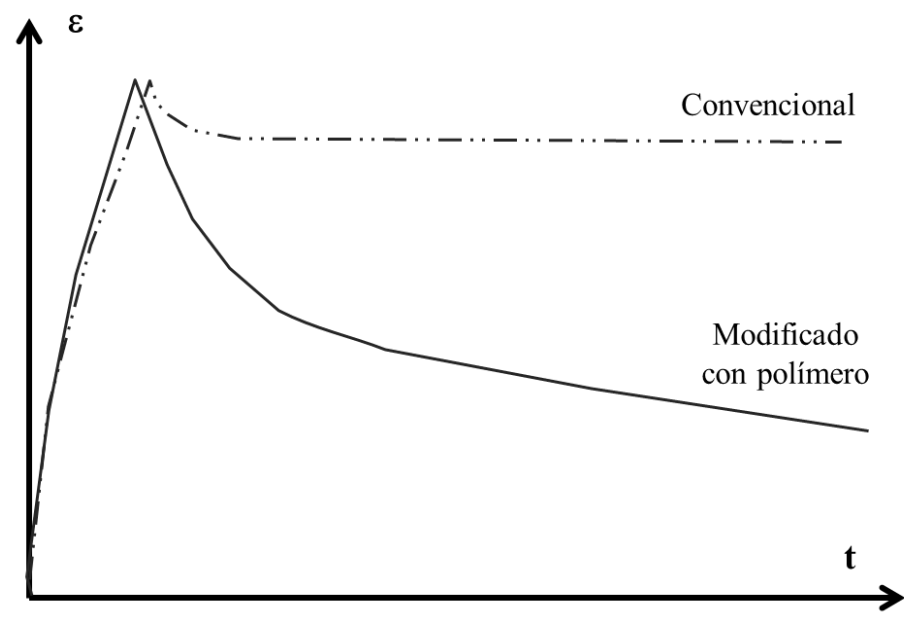

Figura 2.19. Diagramas típicos de creep para asfaltos convencionales y modificados.

La frecuencia a la cual se realiza el ensayo para la determinación del G*/sen $\delta$ es de $10 \mathrm{rad} / \mathrm{s}$, lo que equivale a un vehículo circulando sobre el pavimento a una velocidad de entre 80 y $90 \mathrm{~km} / \mathrm{h}$. A estas velocidades de tránsito, lo más probable, es que el pavimento no sufra excesivas deformaciones por los bajos tiempos de aplicación de las cargas. Una velocidad/frecuencia de $10 \mathrm{rad} / \mathrm{s}$ es equivalente a velocidades de aplicación de la carga rápida, con las cuales no se toma en cuenta la recuperación elástica retardada que el ligante pueda aportar en el proceso de deformaciones permanentes.

Oliver y Tredrea (1998) realizaron mediciones del parámetro G*/sen $\delta$ a una frecuencia de 0,6 rad/s, que era la menor frecuencia posible desde el punto de vista experimental que se asemejaba a la velocidad del equipo de pista con el cual obtuvieron ahuellamiento en laboratorio sobre mezclas con asfaltos convencionales y modificados. Al utilizar la contribución de los ligantes frente a las deformaciones permanentes a una velocidad de carga menor, comparable a la de los ensayos de rueda cargada, obtuvieron una mejor relación entre los ahuellamientos de las mezclas asfálticas y los valores de $\mathrm{G} * / \operatorname{sen} \delta$.

Shenoy (2001) propone una modificación al parámetro G*/sen $\delta$ para hacerlo más sensible a las variaciones del ángulo de fase $\delta$, tomando en cuenta la mayor elasticidad que pueda presentar el ligante. El nuevo parámetro se basa también en el módulo de 
corte complejo y el ángulo de fase (ver ecuación 2.10). Con este parámetro el aporte elástico del ligante es enfatizado; sin embargo no se ha implementado como sustituto del actual parámetro $\mathrm{G}^{*} / \operatorname{sen} \delta$.

$$
\frac{G^{*}}{1-\frac{1}{\operatorname{tg}(\delta) \cdot \operatorname{sen}(\delta)}}
$$

\subsubsection{El concepto de la Viscosidad de Corte Cero (ZSV)}

El avance de la tecnología de los asfaltos ha sido propiciado y acompañado por un importante desarrollo en los ligantes disponibles y, en particular el desarrollo de los asfaltos modificados. Como fuera indicado en el apartado anterior una limitación importante del parámetro $\mathrm{G}^{*} / \mathrm{sen} \delta$ es que no clasifica eficientemente a los asfaltos modificados con polímero. Es evidente que las propiedades seleccionadas para vincular propiedades reológicas de los asfaltos con el desempeño de las mezclas asfálticas deben caracterizar tanto a asfaltos convencionales como modificados.

Los asfaltos son materiales termoplásticos, lo que significa que su consistencia y propiedades reológicas cambian con la temperatura. A ciertas temperaturas se comportan como fluidos newtonianos y en otras no. El cambio se produce a las denominadas temperaturas de transición. Existe una primera transición a bajas temperaturas (bajo cero) donde el asfalto pasa de un régimen elástico a uno visco elástico a medida que aumenta la temperatura. Esta temperatura es próxima a $-20{ }^{\circ} \mathrm{C}$ para los asfaltos convencionales (Stastna et al 2003). La otra transición se da para altas temperaturas donde se pasa del comportamiento visco elástico a uno viscoso puro. Los asfaltos convencionales presentan esta transición a temperaturas de $60{ }^{\circ} \mathrm{C}$ aproximadamente, en cambio los asfaltos modificados con polímeros pueden presentan esta transición a mayores temperaturas. Son necesarias temperaturas superiores a $95{ }^{\circ} \mathrm{C}$ para generar la transición vítrea del poliestireno en el SBS (Stastna et al 2003) y romper la red de polímero dentro del asfalto. Por lo antes dicho, para las altas temperaturas del pavimento los asfaltos convencionales tienen una respuesta del tipo newtoniano frente a esfuerzos de corte. Su comportamiento reológico es simple y su viscosidad es independiente de la velocidad de fluir. En los asfaltos modificados no sucede lo mismo sino que se comportan como un fluido pseudo plástico, en el que la respuesta reológica es fuertemente dependiente de la velocidad de flujo. Sin embargo a muy bajas velocidades de flujo el comportamiento se torna menos complejo y se asemeja al de un fluido newtoniano. Para velocidades muy bajas la energía se va disipando hasta que la resistencia al flujo que ofrece la estructura del material alcanza un valor constante. En este punto la viscosidad se hace independiente de la velocidad de corte (Groupement Professionnel des Bitumes, 2001). Esta viscosidad se conoce como viscosidad de corte cero (ZSV por su nombre en inglés) y es una propiedad intrínseca del ligante. Mediante el uso de la ZSV es posible poner en un mismo plano de comparación asfaltos convencionales y modificados. 
Sybilski (1994) en un estudio realizado sobre varios asfaltos de uso vial, sobre todo modificados con polímeros, sugiere el uso del concepto de ZSV relacionado con las deformaciones permanentes en concretos asfálticos. En otro de sus trabajos (Sybilski, 1996) encontró una buena relación entre la ZSV y las medidas de deformaciones permanentes de diferentes asfaltos incluidos ligantes modificados con polímero.

A la vez Phillips and Robertus (1996) concluyen que la ZSV es una propiedad clave que determina la contribución del ligante asfáltico en el proceso de deformaciones permanentes del pavimento.

Asimismo De Visscher y Vanelstraete (2004) consideran que este parámetro es un indicador de dos características del ligante relacionadas con las deformaciones permanentes: a) la rigidez del asfalto y b) su resistencia a la aparición de deformaciones permanentes por efecto de cargas sostenidas de larga duración.

La medición del valor de ZSV del ligante asfáltico de manera confiable y reproducible es uno de los temas de estudio de muchas investigaciones recientes (De Visscher 2004, Robertus 1996). Existen diversos procedimientos experimentales para medir la ZSV (Morea et al 2010, Biro et al 2009) entre ellos merecen citarse:

$>$ El ensayo de barrido de frecuencias (frequency sweep test).

$>$ El ensayo de barrido de velocidades de corte (shear rate sweep test).

$>$ El ensayo de fluencia a tensión constante y posterior relajación hasta alcanzar un estado estable de fluir (creep test).

$>$ El ensayo de fluencia/cargas repetitivo (multi creep test).

Una somera descripción de cada uno de ellos se realiza a continuación.

2.3.4.2.a. Ensayo de barrido de frecuencias y el ensayo de barrido de velocidades de corte

El barrido de frecuencia es un ensayo donde la muestra de asfalto es sometida a diferentes frecuencias de oscilación utilizando un DSR a una dada temperatura. Durante el ensayo se mantiene la amplitud de oscilación constante. Para cada frecuencia se evalúa la viscosidad del asfalto. Esta viscosidad es denominada compleja ya que se calcula a partir del módulo complejo $\left(\mathrm{G}^{*}\right)$ según indica la ecuación 2.11 , donde $\omega$ es la velocidad angular.

$$
\eta^{*}=\frac{G^{*}}{\omega}[\text { Pa.s }]
$$

El módulo complejo $\left(\mathrm{G}^{*}\right)$ como ya se dijera anteriormente se puede descomponer en una componente elástica y una viscosa. La viscosidad compleja también puede presentar una componente elástica y una viscosa, denominadas $\eta^{\prime \prime}$ y $\eta^{\prime}$ respectivamente. Usualmente en la literatura sólo la componente viscosa, llamada también real, es tomada en cuenta en los barridos de frecuencia, ya que es la relacionada con la energía disipada en el proceso de deformación (Rowe et al 2002). Sin embargo es importante 
indicar que el concepto de "componente viscosa" de la viscosidad no tiene un significado físico real, y sólo se desprende del concepto de componentes del módulo complejo y su relación con el trabajo de deformación. Si se desea conocer la resistencia al flujo de un asfalto en un ensayo oscilatorio se debe considerar la viscosidad compleja como un todo.

El ensayo de barrido de velocidades de corte es similar al de frecuencias. La muestra se somete a diferentes velocidades de corte y se evalúa la viscosidad cinemática del asfalto. La viscosidad compleja y la viscosidad cinemática son completamente análogas entre sí (Stastna et al 2003). Esto se ve claramente en la figura 2.20 donde, para un mismo asfalto, se volcaron los valores de viscosidad compleja obtenidos en un barrido de frecuencias $(\omega)$ y los de viscosidad resultantes de un barrido de velocidades de corte $(\bar{Y})$.

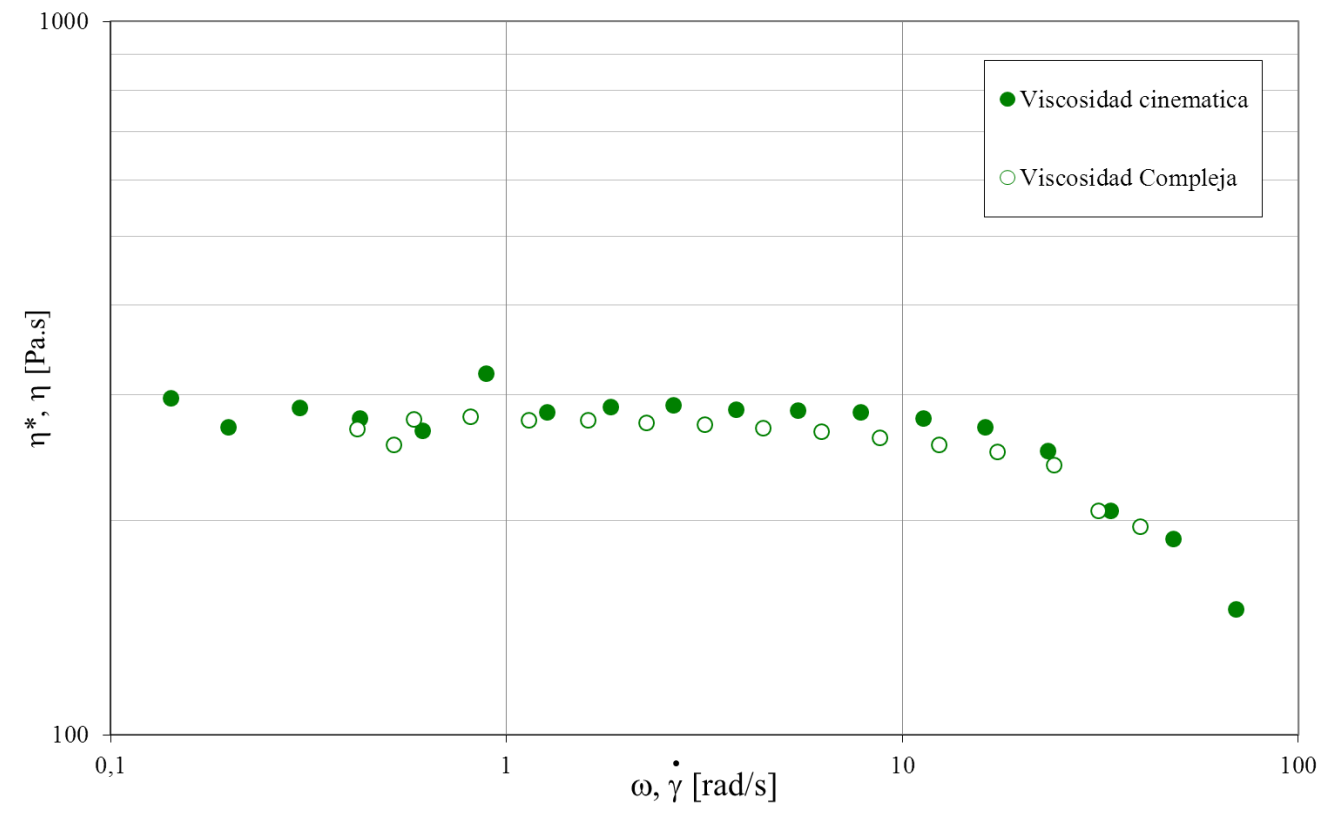

Figura 2.20. Curva de viscosidad en función de la velocidad de carga.

El comportamiento en función de la velocidad de carga (frecuencia o velocidad de corte) es característico de los asfaltos. La viscosidad decrece con el incremento de la velocidad de carga entre dos valores de viscosidad bien definidos, una superior $\left(\eta_{\mathrm{o}}\right.$, la ZSV) tendiendo a velocidades de carga cero y la viscosidad limite $\left(\eta_{\infty}\right)$ para velocidades tendiendo a infinito, figura 2.21. En ambas regiones, superior e inferior, la viscosidad es constante y se verifica un comportamiento newtoniano. Los términos superior e inferior se refieren a las bajas y a las altas velocidades de carga, y no al valor de la viscosidad. Para los asfaltos convencionales en el rango de bajas frecuencias los valores de viscosidad tienden claramente al valor de la ZSV, pero no sucede lo mismo para los asfaltos modificados como se observa en la figura 2.22. A veces esta platea es difícil de obtener producto de la imposibilidad de materializar bajas frecuencias en el DSR debido a la resolución del equipo, incluso en algunos asfaltos modificados con polímero esta región de comportamiento newtoniano a bajas frecuencias no existe. 


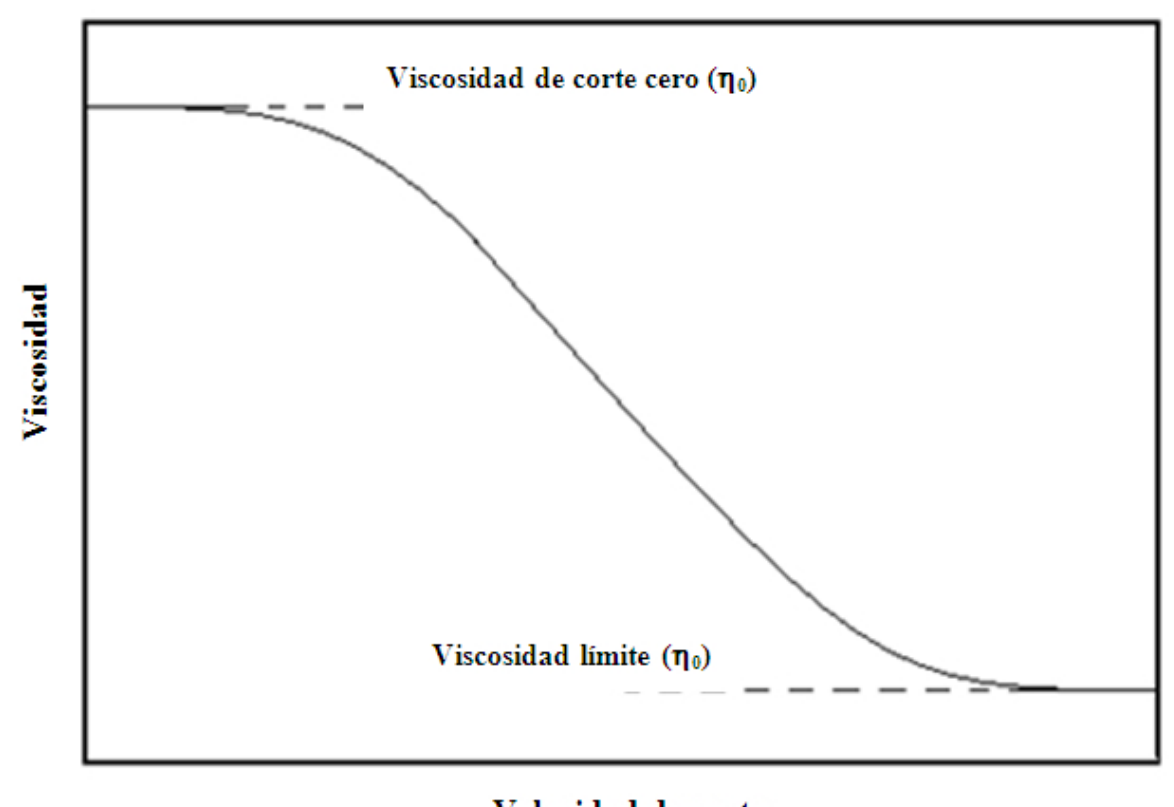

Figura 2.21. Viscosidad en función de la frecuencia.

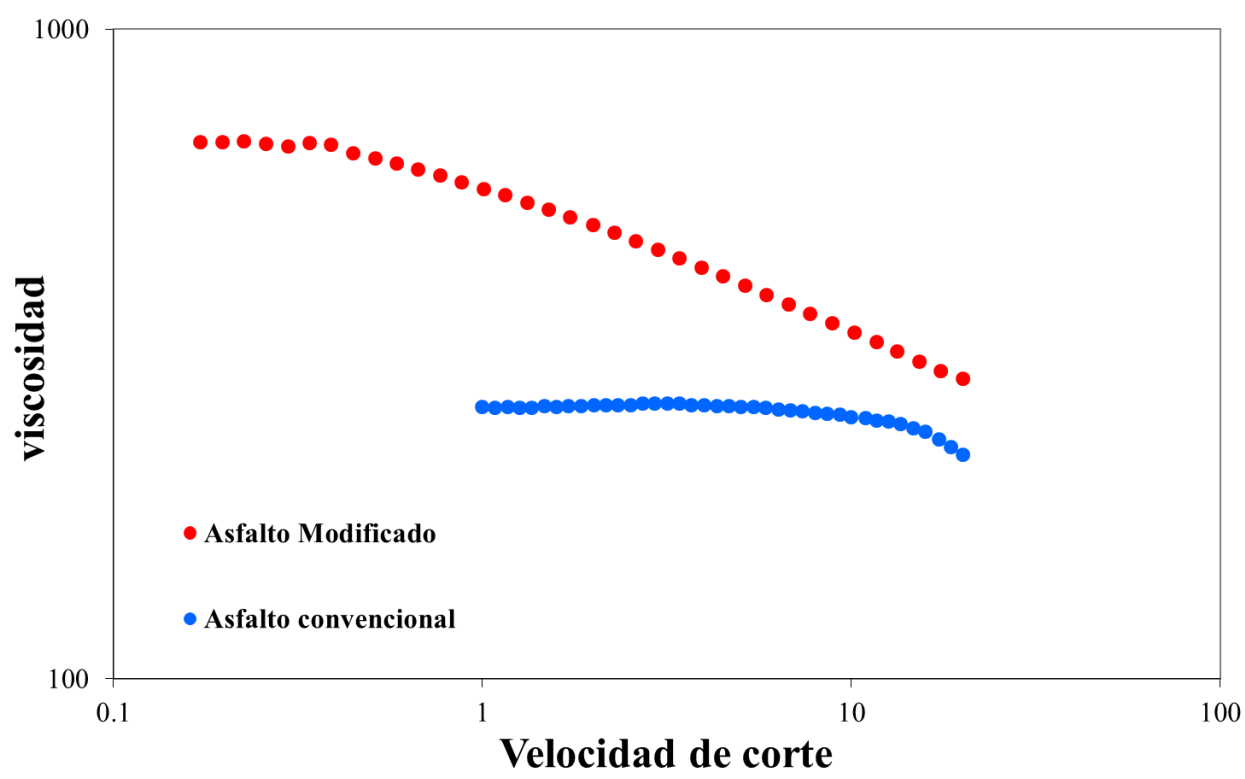

Figura 2.22. Viscosidad en función de la velocidad de corte para asfaltos convencionales y modificados.

El ensayo de barrido de frecuencias se debe realizar asegurando que los datos sean obtenidos dentro del dominio lineal visco-elástico del asfalto. El dominio lineal viscoelástico de un material se basa en el principio de linealidad, por el cual la deformación por el efecto acumulado de diferentes tensiones es igual a la suma de las deformaciones para cada tensión, principio de Boltzmann (Tschoegl, 1989). Desde un punto de vista práctico esto se observa en que el valor de $G^{*}$, por ejemplo, se mantiene constante independientemente del nivel de tensión aplicado.

El límite del rango linear visco-elástico se define a través del ensayo de barrido de deformaciones. En este ensayo se mide el modulo $\mathrm{G}^{*}$ a diferentes deformaciones. Si se 
representa $G^{*}$ en función de las deformaciones impuestas, figura 2.23, puede verse como $\mathrm{G}^{*}$ se mantiene constante a bajas deformaciones hasta que empieza a disminuir a altos valores. Airey (2002) define el límite linear visco-elástico como aquella deformación para la cual el valor de G* disminuye a un 95 \% del máximo valor medido.

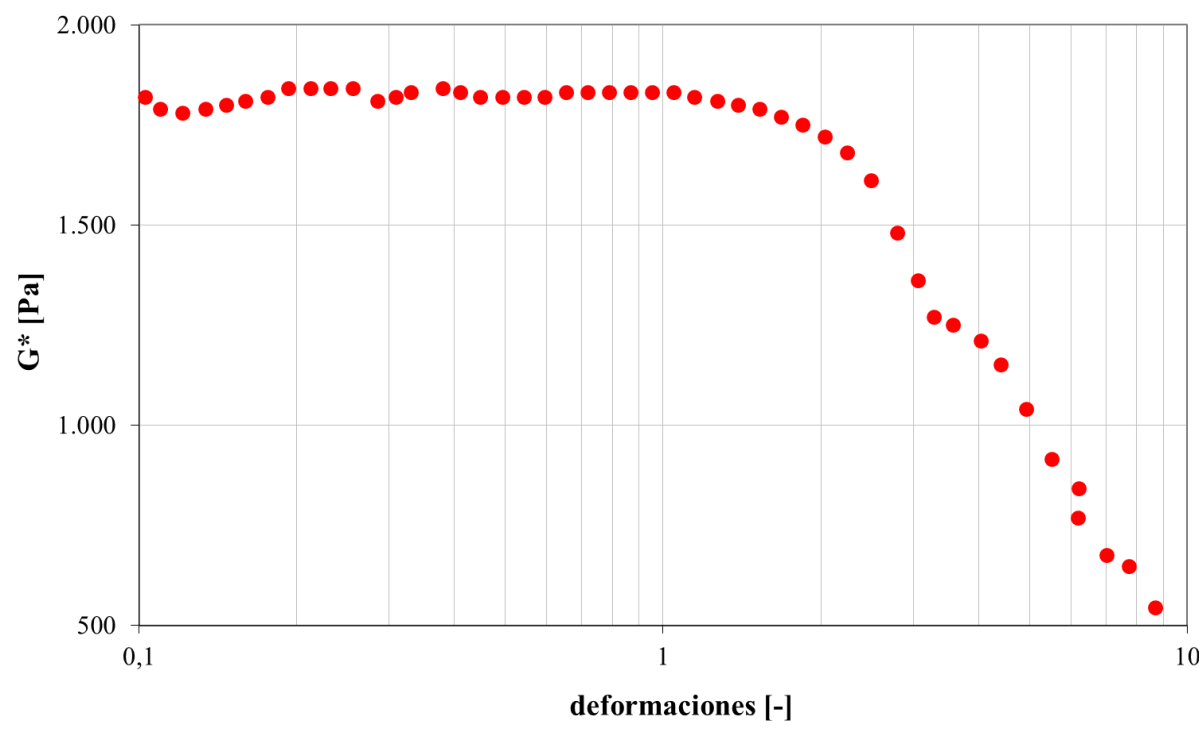

Figura 2.23. Modulo complejo $\mathrm{G}^{*}$ versus deformaciones.

El modelo de Cross es usado para ajustar los datos de viscosidad compleja en función de la frecuencia, ecuación 2.12. En el caso del barrido de velocidades de corte los datos son viscosidades cinemáticas y el modelo se expresa en función de las velocidades de corte en lugar de las frecuencias.

$$
\eta^{\prime}=\eta_{\infty}^{\prime}+\frac{\eta_{0}^{\prime}-\eta_{\infty}^{\prime}}{1+(k . \omega)^{n}}
$$

donde:

$\eta^{\prime}$ : viscosidad compleja medida.

$\eta_{0}^{\prime}$ : viscosidad a corte cero (ZSV).

$\eta_{\infty}^{\prime}$ : viscosidad a frecuencia infinita.

K y n: constantes del modelo.

El modelo da el valor de ZSV como resultado del ajuste. Sin embargo para las bajas frecuencias de ensayo algunos asfaltos modificados aún presentan una variación importante de la viscosidad en función de la frecuencia. Esto provoca valores irreales (altos) de ZSV en el ajuste a través del modelo de Cross. Para evitar esto es conveniente ajustar los datos y calcular una viscosidad a una baja frecuencia. Este concepto es usado en la normativa CEN prEN 15324 (2006) donde la viscosidad se calcula para una frecuencia de 0,0001 Hz luego de un ajuste lineal de los datos de viscosidad compleja obtenidos en un barrido de frecuencias. Esta viscosidad se denomina Low Shear Viscosity (LSV). 
De Visscher y Vanelstraete (2009) calcularon la LSV de una serie de asfaltos convencionales y modificados a las frecuencias de 0,0001; 0,001 y 0,01 Hz y compararon los valores con los resultados de ensayos de deformaciones permanentes en una mezcla asfáltica elaborada con los mismos materiales. Concluyeron que la LSV a las frecuencias de 0,001 y 0,01 Hz presenta mejor relación con los ahuellamientos medidos y encontraron que la LSV a $0,0001 \mathrm{~Hz}$ sobreestima el potencial de los asfaltos modificados con polímero en lo que se refiere a su contribución frente a las deformaciones permanentes.

A través de la norma CEN prEN 15324 también se calcula una temperatura para la cual el ligante presenta una viscosidad igual a 2000 Pa.s. Esta temperatura de equiviscosidad, como la define la norma, es un indicador de un límite para la contribución parcial del asfalto en la resistencia frente a las deformaciones permanentes de mezclas asfálticas a temperaturas elevadas del pavimento. De esta forma se define la temperatura máxima del pavimento en la que el ligante puede utilizarse en una mezcla asfáltica sin que sufra deformaciones permanentes excesivas.

Este límite de viscosidad se obtuvo al estudiar mezclas asfálticas elaboradas con asfaltos modificados en el ensayo de pista. Allí se observó que los ahuellamientos aumentaban drásticamente cuando los ligantes presentaban viscosidades menores de 2000 Pa.s (Fabb, 2000).

\subsubsection{2.b. ensayo de fluencia (creep)}

En un ensayo de fluencia, la muestra de asfalto es sometida a una tensión constante y se mide la evolución de las deformaciones en el tiempo. En estas condiciones el asfalto presenta primero una deformación elástica instantánea, seguida de una deformación visco-elástica para, finalmente, si el tiempo de ensayo es suficientemente largo, presentar una deformación viscosa pura (figura 2.18).

La fluencia (creep) se puede modelar a través de un simple sistema de resortes y amortiguadores hidráulicos colocados en configuraciones de serie y paralelo, figura 2.24, que se conoce como modelo de Burger. Usualmente este modelo se escribe en términos de lo que se conoce como "compliance” en lugar de las deformaciones (ver la ecuación 2.13). El creep compliance se define como la deformación medida dividida la tensión aplicada, y es proporcional a la deformación e independiente del nivel de tensión aplicado si se está dentro del rango lineal visco-elástico del ligante. En el modelo de Burger las deformaciones viscosas puras están representadas por el término $t / \eta_{o}$. Durante el ensayo es necesario alcanzar el estado de deformación viscosa puro que se denomina estado estable de fluir, en estas condiciones la tasa de deformación en función del tiempo se vuelve constante y la $\eta_{\text {o }}$ obtenida de aplicar el modelo de Burger es la ZSV del asfalto. El tiempo requerido para alcanzar el estado estable de fluir depende del tipo de asfalto y puede tomar desde unos minutos para los asfaltos convencionales hasta horas para los ligantes modificados con polímeros; inclusive en algunos casos este estado estable no se puede alcanzar. 


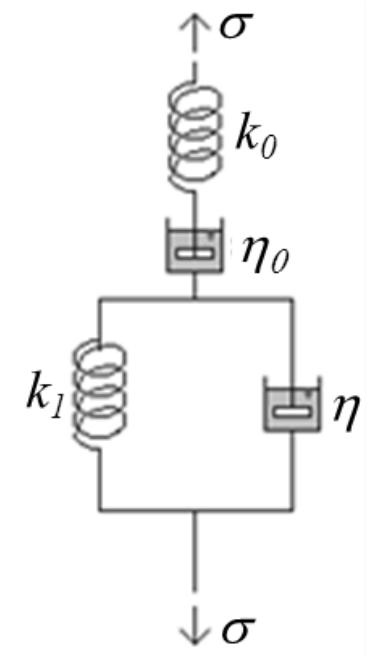

Figura 2.24. Modelo de Burger.

$$
J(t)=\frac{\gamma(t)}{\tau_{0}}=J_{0}+J_{d} \psi(t)+\frac{t}{\eta_{o}}
$$

donde:

$\gamma(t)$ : deformación.

$\tau_{0}$ : tensión de corte constante aplicada.

$J_{0}$ : compliance elástico (deformación elástica).

$J_{d} \Psi(t)$ : compliance visco-elástico retardado (deformación visco-elástica).

$t / \eta_{0}$ : compliance viscoso puro (deformación viscosa).

$\Psi(t)$ : función de memoria.

$\eta_{0}$ : viscosidad de corte cero (ZSV).

La tensión aplicada durante el ensayo de fluencia debe ser lo suficientemente baja como para mantener las mediciones dentro del rango lineal visco-elástico del asfalto. Para asfaltos convencionales se está dentro de este rango con tensiones de corte menores a 5000 Pa (Groupement Professionnel des Bitumes, 2001), pero para asegurar el régimen lineal con asfaltos modificados con polímeros es necesario aplicar tensiones entre 10 y 50 Pa (Dezmanes et al., 2002). En ciertas ocasiones esta tensión se puede llevar hasta 100 Pa para los asfaltos modificados (Morea et al. 2010).

Una vez retirada la carga comienza la etapa de recuperación. Las deformaciones que se producen en esta etapa son primeramente una recuperación elástica instantánea seguida de una recuperación visco-elástica retardada quedando finalmente, para suficiente tiempo de relajación, una deformación permanente, figura 2.19. Con esta deformación permanente irrecuperable es posible calcular también la ZSV, ecuación 2.14; donde $J_{v}$ es el compliance viscoso resultante de dividir esta deformación irrecuperable por la tensión de corte aplicada en la etapa de carga y $t_{\text {creep }}$ es el tiempo durante el cual se aplicó dicha tensión de corte. Este valor de ZSV debería ser similar al obtenido con el modelo de Burger. 


$$
\eta_{0}=\frac{J_{v}}{t_{\text {creep }}}
$$

En la comunidad europea el ensayo creep está especificado en la norma CEN prEN 15325 del 2006. Sin embargo en esta normativa los ensayos de creep para los asfaltos modificados conllevan largos tiempo de ensayo, pudiendo no arrojar resultados confiables (Morea et al. 2010).

Existe una variante al ensayo de creep para reducir los tiempos de ensayo denominada creep incompleto. En la misma se realiza un ensayo de creep sin relajación en el cual no se alcanza el estado establece de fluir.

Para el ensayo se aplica una tensión $\sigma_{0}$ durante un tiempo determinado y se miden las deformaciones. Luego, a partir de esas deformaciones se puede construir un periodo de relajación ficticio. Como es claro, durante el periodo de relajación la tensión aplicada es igual a cero. Esta tensión cero puede ser asumida como la suma de dos tensiones de igual módulo pero sentido contrario $\left(\sigma_{0}+-\sigma_{0}\right)$. Tomando en cuenta el principio de Boltzman de superposición de efectos, la deformación para una suma de tensiones será la resultante de sumar la deformación $\gamma_{1}$ para la tensión $\sigma_{1}$ y $\gamma_{2}$ para la tensión $\sigma_{2}$. En primer lugar se elige un tiempo $t=t$ ' donde se define cesa la acción de la tensión $\sigma_{0}$, figura 2.25. A partir de t' se simula la tensión cero donde las deformaciones de este periodo resultan de la suma de deformaciones para $\sigma_{0}$ y $-\sigma_{0}$. En la figura 2.24 se muestra gráficamente la metodología antes descripta. Para t $>$ t' las deformaciones resultantes salen de la suma de $\gamma_{1}+\gamma_{2}$, donde $\gamma_{1}$ son las deformaciones para $\sigma_{0}$ y $\gamma_{2}$ las deformaciones para $-\sigma_{0}$ (que actúa cuanto $t>t^{\prime}$ ).

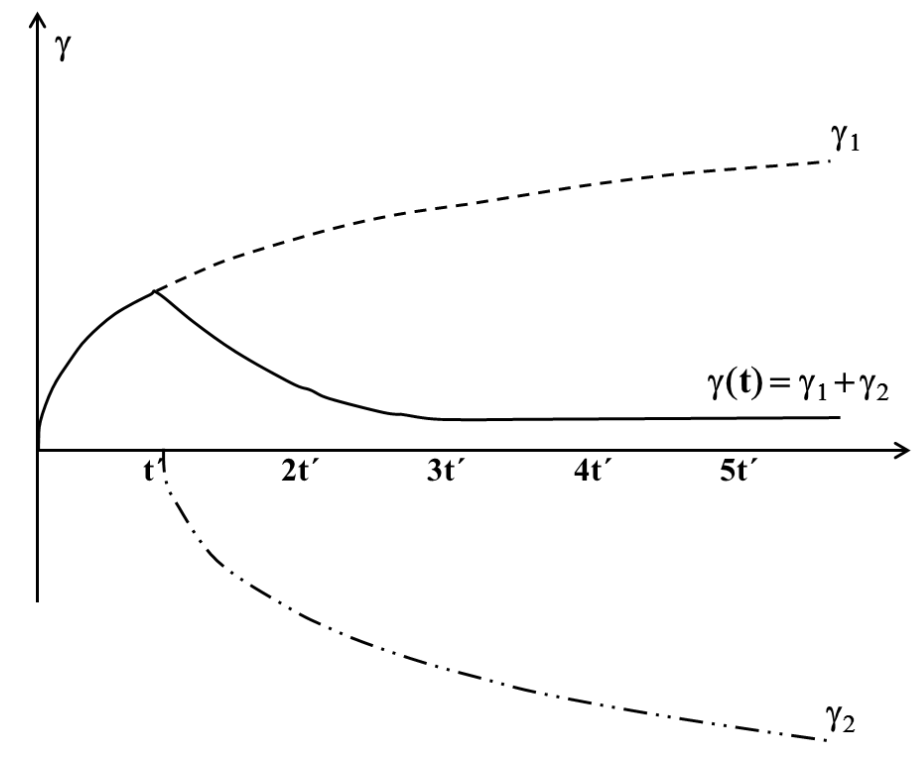

Figura 2.25. Ensayo de creep incompleto.

De esta forma se obtiene una curva de creep completa sin la necesidad de alcanzar el estado estable de fluir. Aquí la ZSV se calcula a partir de la ecuación 2.14 donde el $J_{v}$ es igual de la deformación permanente final dividida por $\sigma_{\mathrm{o}} \mathrm{y}_{\mathrm{creep}}=\mathrm{t}$ '. La única 
precaución a tomar en cuenta en este método es que la curva de relajación presente un valor asintótico al eje del tiempo, es decir una deformación permanente irrecuperable.

\subsubsection{2.c Ensayo de creep repetitivo}

En el ensayo de creep repetitivo una muestra de asfalto es sujeta a múltiples ciclos de carga y descarga en un DSR. El ensayo fue diseñado por Bahia et al (2001) como parte del proyecto NCHRP 9-10. Ellos proponen este ensayo basándose en que los ciclos de carga con recuperación completa de la deformación, como son los del G*/sen $\delta$, no son apropiados para diferenciar la contribución del asfalto frente al ahuellamiento de la mezcla. El ensayo de creep repetido se basa en el comportamiento de las cargas cíclicas que ejerce el tránsito sobre el pavimento. En la figura 2.26 se observa comparativamente como en un ciclo de carga y descarga sobre el asfalto en el ensayo es similar a la acción del tránsito en la mezcla asfáltica. Este ensayo permite medir la respuesta del ligante frente a la acumulación de deformaciones permanentes a la vez que evalúa la respuesta elástica del material mismo.
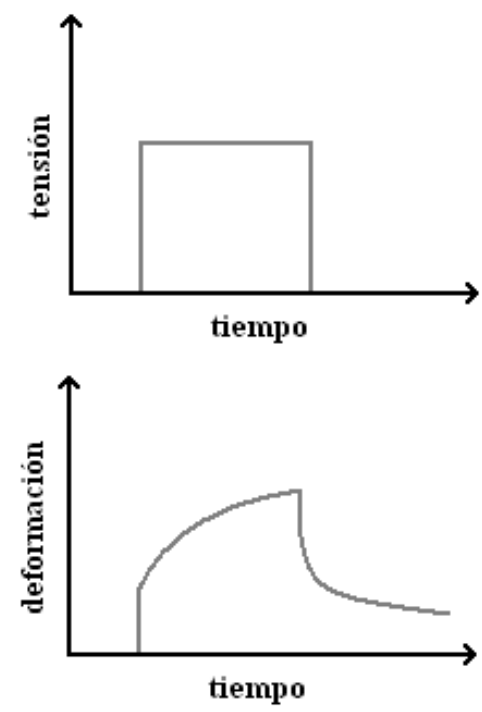

En el asfalto (en el DSR)
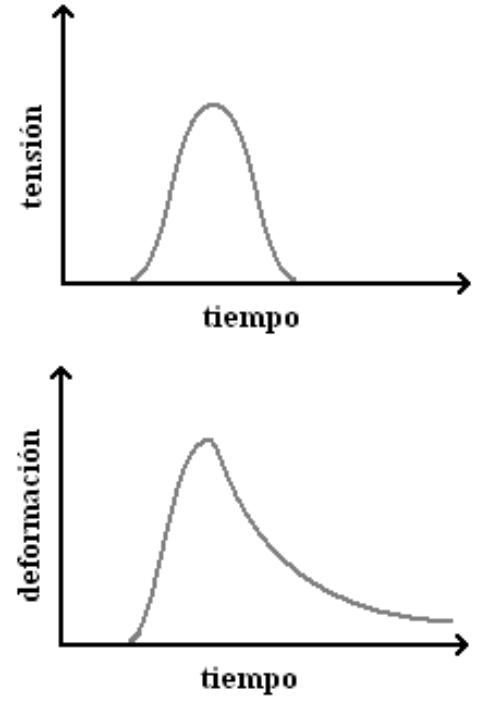

En el pavimento (bajo tránsito)

Figura 2.26. Comparación entre un ciclo de carga y descarga sobre un asfalto en el DSR y la acción del tránsito sobre la mezcla asfáltica.

En el ensayo de creep repetitivo los tiempos de carga y descarga así como la tensión aplicada son seleccionados tratando de simular la posible velocidad y carga del tránsito. En el proyecto se definieron tiempos de carga y descarga de 1 y 9 s respectivamente. Se pueden usar tiempos de 2 y 3 s de carga, con sus respectivos tiempos de relajación de 18 y 27 s, en los casos de problemas de resolución del DSR para la adquisición de datos. Asimismo la tensión aplicada debe estar entre 25 y 300 Pa. El criterio usado la selección de la tensión va en conjunción con los tiempos de carga y descarga seleccionados de manera que las deformaciones permanentes excedan en 20 veces la resolución de medición de deformaciones mínima del reómetro. Durante el ensayo un total de 100 ciclos son aplicados a la muestra. Luego los datos para el ciclo 50 y 51 son ajustados con el modelo de Burger obteniendo del mismo el resultado de la ZSV. No es claro por 
qué es necesario aplicar 100 ciclos durante el ensayo si sólo los datos de los ciclos 50 y 51 serán tenidos en cuenta para el ajuste (De Visscher y Vanelstraete, 2004).

El calcular la ZSV con los datos de los ciclos 50 y 51 se debe al efecto que los repetidos ciclos de carga ocasionan en las deformaciones recuperadas. Dependiendo de la resistencia del ligante a medida que se acumulan los ciclos de carga las deformaciones recuperadas aumentan.

Bahia et al desarrollaron esta metodología para el reemplazo del parámetro G*/sen $\delta$ a partir de estudios sobre diferentes ligantes asfálticos convencionales y modificados. La principal hipótesis del ensayo se basa en medir la respuesta del ligante frente a los ciclos de carga en forma similar a lo que ocurre en una mezcla asfáltica frente al paso del tránsito. Observaron las diferentes respuestas de asfaltos convencionales (PG82 SD) y modificados con polímeros (PG82 Pes y PG82 SBSr) en este tipo de ensayo. Las figuras 2.27 y 2.28 muestran comparativamente las deformaciones recuperadas en el tiempo para los ciclos 1 y 100 respectivamente. Se observa como para el asfalto PG82 SD las deformaciones recuperadas al final de los ciclos 1 y 100 son iguales mientras que para los asfaltos PG82 Pes y PG82 SBSr en el ciclo 100 se tiene mayores recuperaciones respecto al ciclo 1. Este efecto de mayores recuperaciones con los ciclos de carga explica las menores deformaciones permanentes acumuladas y la mejor respuesta frente a las deformaciones permanentes de los asfaltos modificados.

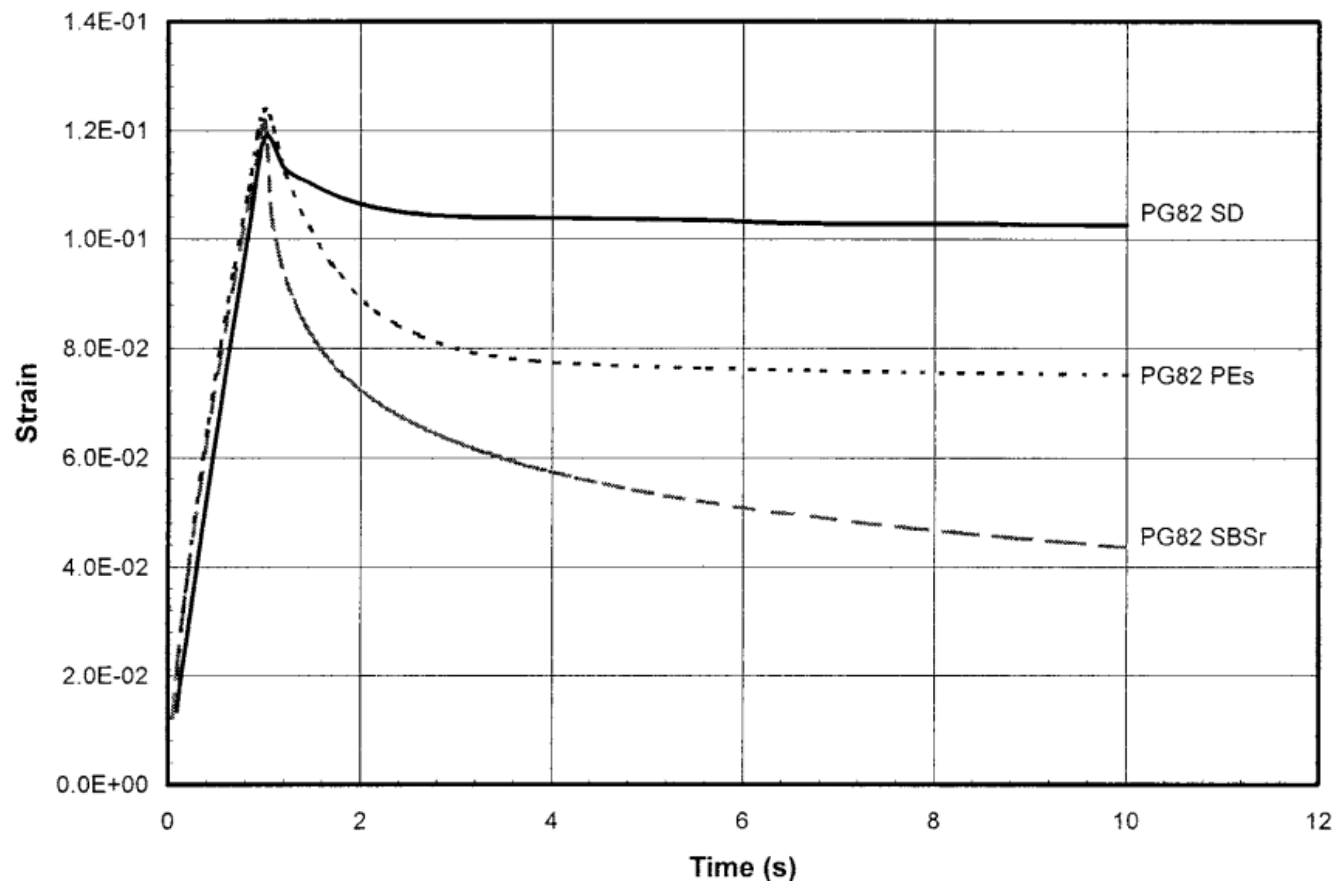

Figura 2.27. Deformaciones en el tiempo en ensayo de multicreep de varios asfaltos para el primer ciclo de carga. ${ }^{4}$

\footnotetext{
${ }^{4}$ Figura tomada del reporte Nchrp 459.
} 


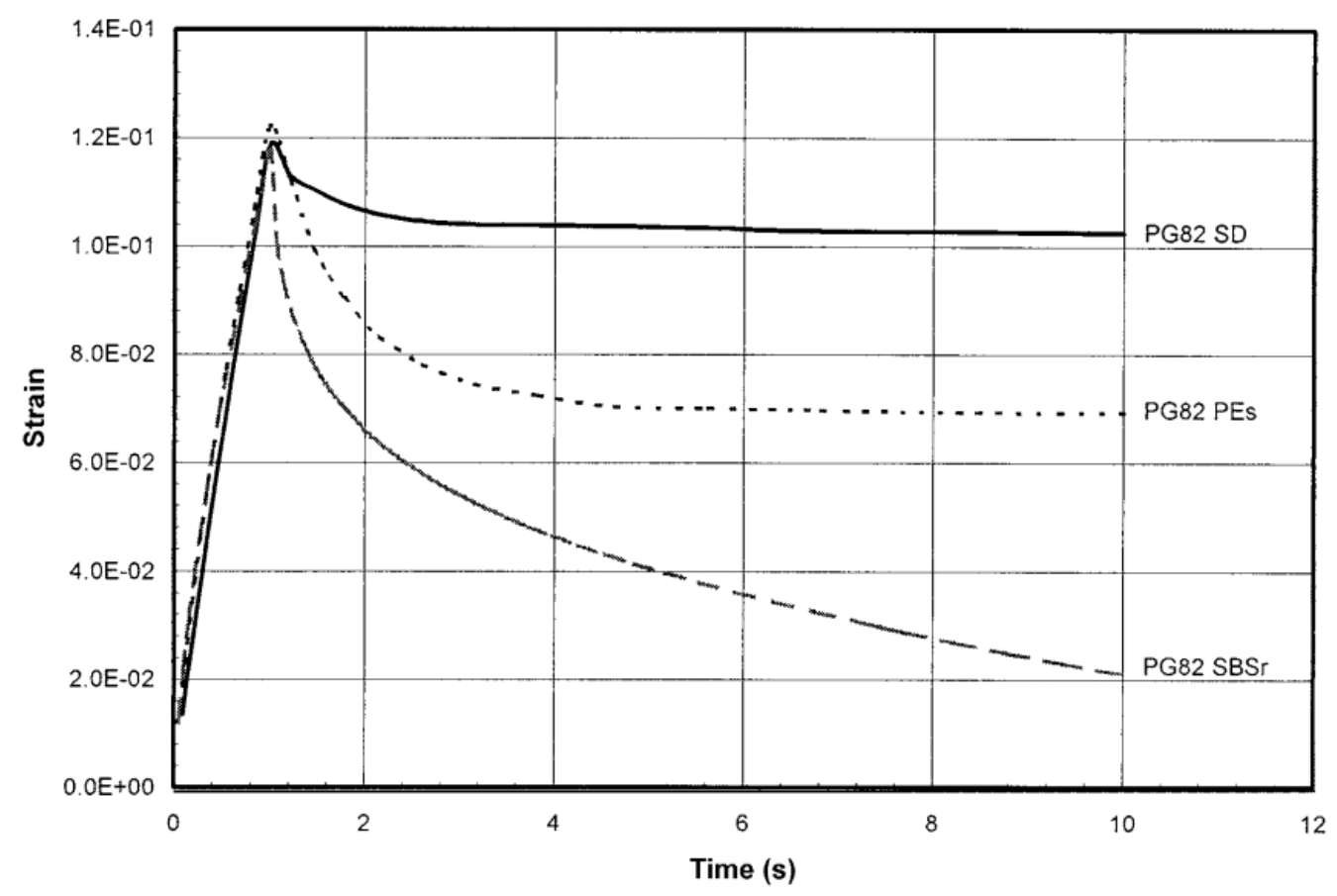

Figura 2.28. Deformaciones en el tiempo en ensayo de multicreep de varios asfaltos para el ciclo de carga $\mathrm{N}^{\mathrm{o}} 100 .^{5}$

El ensayo de creep repetido se asocia al tipo de carga que se suscita en el pavimento. A partir de los estudios con este ensayo D’Angelo et al. (2007) desarrolló una nueva metodología denominada Multiple Stress Recovery test (MSCRT) la cual estudia la dependencia del asfalto a la variaciones de tensiones inducidas. Este método se ha incorporado dentro de la especificación SHRP para la clasificación de asfaltos modificados en el rango de temperaturas altas, deformaciones permanentes, en la normativa ASTM D 7405 (2010).

El MSCRT evalúa la capacidad de un asfalto modificado de mantener su respuesta elástica a diferentes niveles de tensión impuesta mientras se lo somete a ciclos de carga y descarga repetidos a diferentes niveles de tensión. La metodología aplica diez ciclos de carga de 1 s de duración y 9 s de descarga para dos niveles de tensión de 100 y $3200 \mathrm{~Pa}$. Durante el ensayo se miden las deformaciones a lo largo del tiempo para los dos niveles de tensión, figura 2.29.

Mediante este ensayo se evalúa la capacidad del asfalto de mantener su respuesta elástica frente a tensiones de corte importantes, como las que imponen cargas de tránsito elevadas. Por otro lado se evalúa la deformación total al final del ensayo que da una idea del nivel de deformaciones permanentes acumuladas.

\footnotetext{
${ }^{5}$ Figura tomada del reporte Nchrp 459.
} 


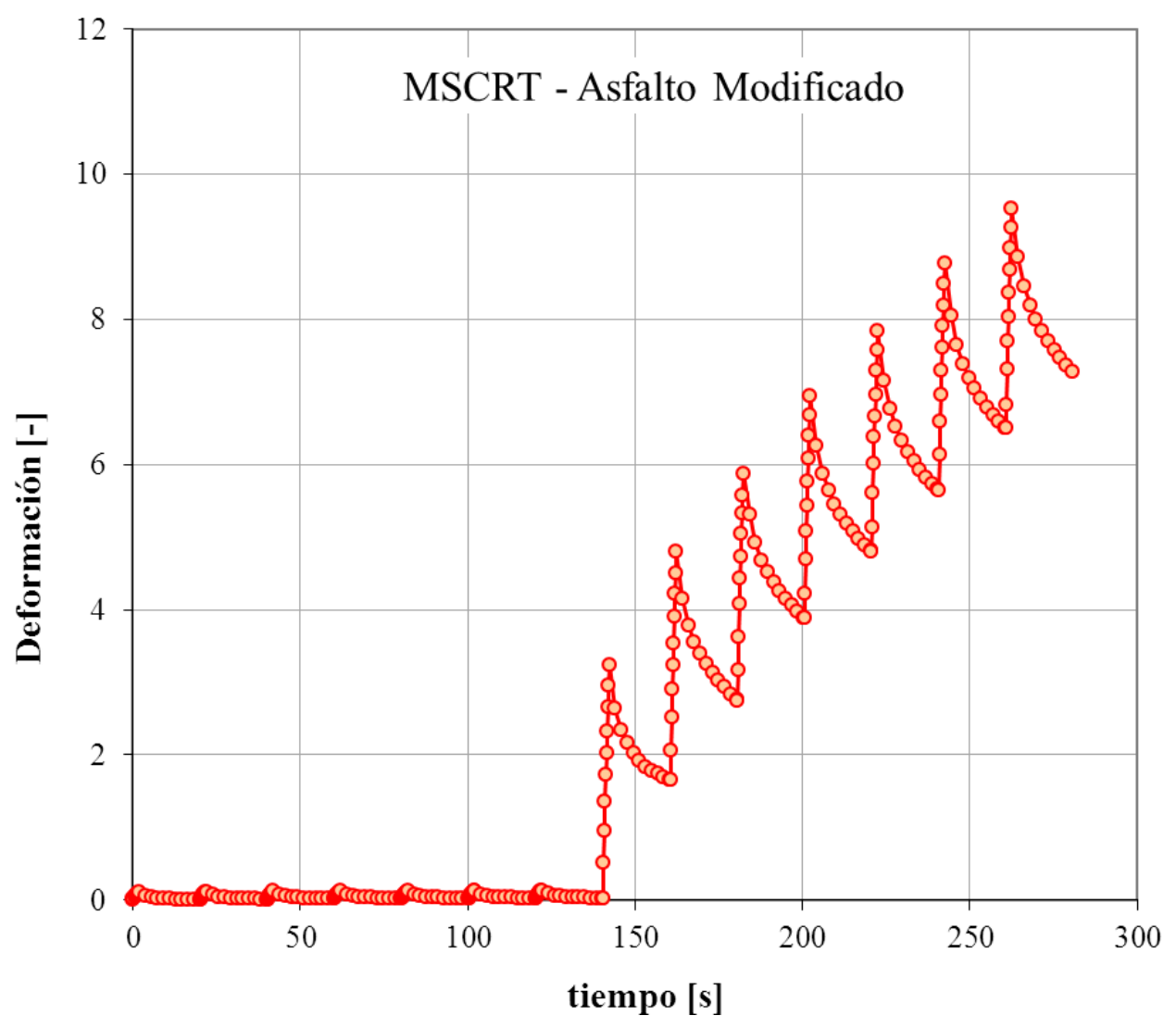

Figura 2.29. Deformaciones en el tiempo medidas en el MSCRT.

\subsubsection{Relación entre el G*/sen $\delta$ y la ZSV}

Rowe et al. (2002) estudiaron reemplazar dentro de la especificación SHRP el G*/sen $\delta$ por la ZSV como parámetro de especificación para las altas temperaturas en asfaltos modificados. En su estudio calcularon los valores de $\mathrm{G}^{*} / \mathrm{sen} \delta$ y ZSV de una serie de asfaltos, convencionales y modificados a diferentes temperaturas. En la figura 2.30 se muestra los valores de ZSV en función de los valores de G*/sen $\delta$ de los diferentes ligantes. Se observa como en para los asfaltos convencionales (AC-5, AC10, AC-20 y PG 64-22) existe una relación única entre la ZSV y el G*/sen $\delta$. Sin embargo los asfaltos modificados (AC-20P, Novasphalt y Styrelf) se alejan de esa representación. 


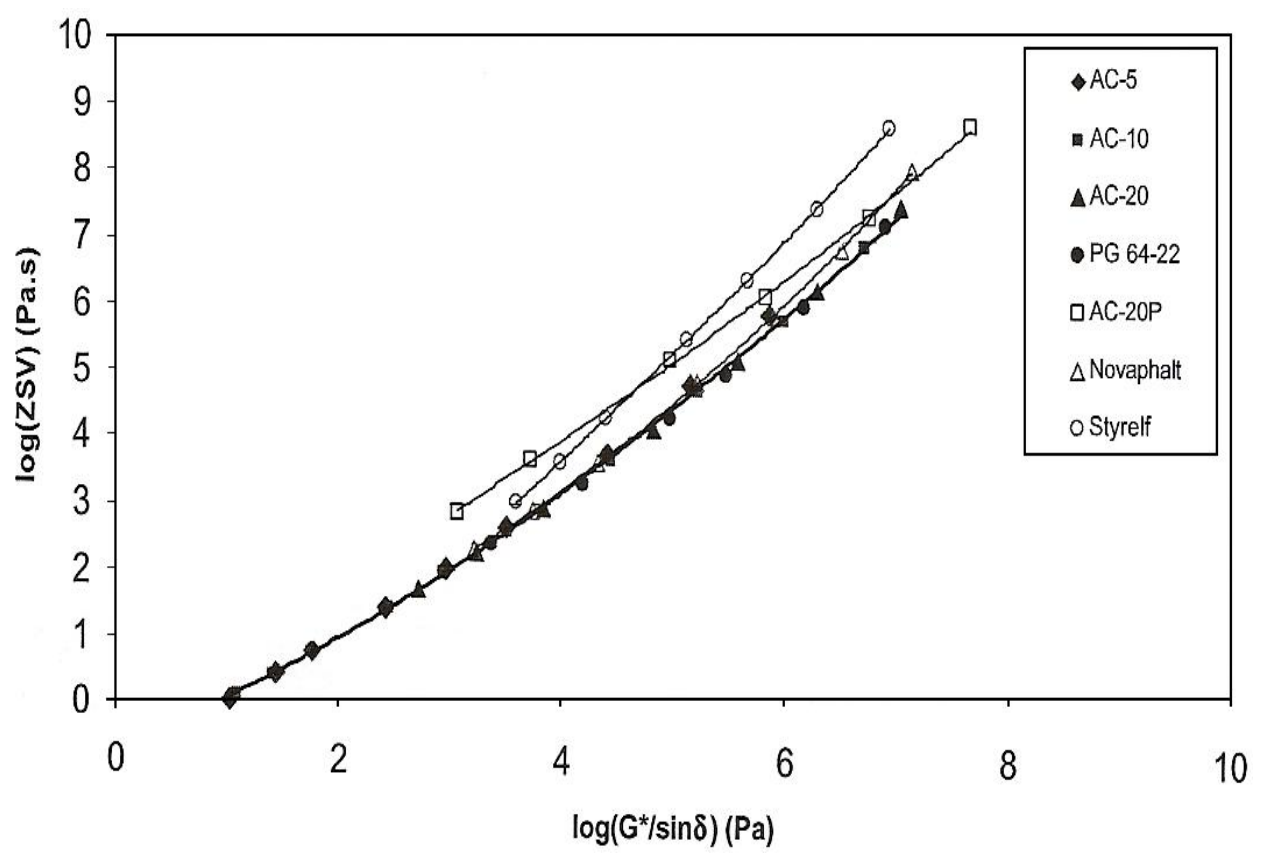

Figura 2.30. Relación de la ZSV con G*/sen $\delta$ de diferentes ligantes a diferentes temperaturas. ${ }^{6}$

A partir de la relación encontrada para los asfaltos convencionales y teniendo en cuenta que el parámetro $\mathrm{G} * / \operatorname{sen} \delta$ representa bien la contribución de los mismos frente a las deformaciones permanentes, se calcularon los valores de ZSV asociados a los valores de $\mathrm{G}^{*} / \mathrm{sen} \delta$ de $1 \mathrm{kPa}$ (asfalto original) y de 2,2 $\mathrm{kPa}$ (asfalto envejecido en RTFOT) respectivamente (ver tabla 2.2). Rowe y coautores proponen estos límites de ZSV que se deben calcular en los ligantes modificados para obtener la temperatura de alta del grado de desempeño. En base al criterio de ZSV los asfaltos modificados presentaron aproximadamente $12{ }^{\circ} \mathrm{C}$ más de temperaturas de alta a la obtenida a través del criterio tradicional del $\mathrm{G}^{*} / \mathrm{sen} \delta$. Esto equivale a un salto de dos grados en la valoración del grado de desempeño de los ligantes modificados.

Tabla 2.2. ZSV correspondientes a $\mathrm{G}^{*} / \mathrm{sen} \delta$ de 1 y $2,2 \mathrm{kPa}$.

\begin{tabular}{cc}
\hline $\begin{array}{c}\mathrm{G}^{*} / \mathrm{sen} \delta \\
{[\mathrm{kPa}]}\end{array}$ & $\begin{array}{c}\mathrm{ZSV} \\
{[\text { Pa.s }]}\end{array}$ \\
\hline 1,0 & 104,8 \\
2,2 & 252,7 \\
\hline
\end{tabular}

\subsubsection{Medición de las deformaciones permanentes en laboratorio}

El estudio y caracterización de las deformaciones permanentes en forma racional ha llevado al desarrollo de ensayos de laboratorio que tratan de reproducir el problema. Así surgen los ensayos de rueda cargada. Estos simulan el efecto del tránsito sobre el pavimento midiendo las deformaciones que sufre la mezcla asfáltica a través del tiempo

\footnotetext{
${ }^{6}$ Figura tomada del trabajo de Rowe et al. (2002)
} 
bajo condiciones extremas de tránsito y temperatura. La configuración del ensayo consta básicamente de una rueda, rígida o neumática en algunos casos, la cual aplica una carga sobre la mezcla asfáltica a la vez que circula sobre ésta. Existen a nivel mundial diferentes equipos que tienen configuraciones similares pero con variaciones de uno a otro. Dentro de los más conocidos a nivel mundial se encuentran los equipos de pista británico (BS 596 parte 110 1996), el español (NLT 173), el francés y el Asphalt Pavement Analyzer (APA) en Estados Unidos.

Actualmente los tres equipos europeos están contemplados dentro de la norma UNEEN 12697-22 (2006). El equipo de pista francés está identificado con la configuración de ensayo "large size device" y los equipos inglés y español dentro de la configuración de la norma "small size device". En la adecuación a la normativa el equipo francés no ha sufrido cambios en sus configuraciones de ensayo sin embargo los otros dos equipos han cambiado de su forma original.

El equipo inglés consiste en una rueda de goma maciza de $207 \mathrm{~mm}$ de diámetro y $47 \mathrm{~mm}$ de ancho, que cargada con $520 \mathrm{~N}$, se desplaza con movimiento alternativo dentro de un recorrido de $230 \mathrm{~mm}$ a razón de 21 ciclos por minuto, sobre una muestra de concreto asfáltico a una temperatura de $60{ }^{\circ} \mathrm{C}$. La duración del ensayo es de 60 minutos, durante este período se miden las deformaciones permanentes producidas en la mezcla asfáltica en intervalos de 1 minuto. La carga aplicada de $520 \mathrm{~N}$ equivale a una presión de contacto de $520 \mathrm{kPa}$.

En el equipo español se someten probetas, a una temperatura de $60^{\circ} \mathrm{C}$, al paso de una rueda cargada que ejerce una presión de $900 \mathrm{kPa}$ sobre la superficie de la muestra durante todo el ensayo. La probeta se somete al paso de la rueda durante 120 minutos, o hasta que la deformación total alcance los $15 \mathrm{~mm}$. Durante el ensayo se realizan mediciones periódicas de la deformación.

El equipo francés ensaya probetas usando una rueda de goma inflada a una presión de $600 \mathrm{kPa}$. Cada probeta tiene $500 \mathrm{~mm}$ de longitud por $180 \mathrm{~mm}$ de ancho con $50 \mathrm{~mm}$ de altura con un nivel de vacíos de $7 \%$. Se aplica una carga de $5000 \mathrm{~N}$ a una temperatura de $70{ }^{\circ} \mathrm{C}$, realizando un total de 20000 pasadas. La carga aplicada en conjunto con la presión de inflado generan una presión de contacto sobre la muestra asfáltica de $710 \mathrm{kPa}$.

En el APA se aplica una carga de $445 \mathrm{~N}$ sobre un tubo flexible de goma presurizado a $690 \mathrm{kPa}$. La carga es aplicada a través de una rueda rígida de aluminio directamente sobre el tubo de goma que apoya sobre la muestra de mezcla asfáltica. La muestra se mueve hacia delante y hacia atrás bajo la acción de la carga que se mantiene estacionaria. Durante el ensayo se aplican normalmente 8000 ciclos (un ciclo es el movimiento hacia delante y hacia atrás de la muestra bajo la rueda). El APA no sólo se utiliza para evaluar ahuellamiento sino que también se evalúan fatiga y daño por humedad de las mezclas asfálticas.

En la tabla 2.3 se incluyen a manera de resumen y de forma comparativa los datos más relevantes de cada uno de los equipos antes descriptos para medir las deformaciones permanentes en laboratorio. 
La carga de $520 \mathrm{~N}$ del equipo de pista inglés genera una presión de contacto equivalente a una carga máxima por eje de ruedas simples de 8 tn; está es similar a la carga permitida en Argentina para un eje simple. La nueva configuración de carga para los ensayos de rueda cargada dentro de la UNE 12697-22 es de $700 \mathrm{~N}$, lo que equivale a un eje de ruedas simple de 10,5 tn que correspondería a una sobrecarga en nuestro país.

Tabla 2.3. Diferentes equipos de rueda cargada.

\begin{tabular}{cccccc}
\hline \multicolumn{2}{c}{ Equipo } & Inglés & Español & Francés & USA \\
\hline \multicolumn{2}{c}{ Tipo de rueda } & Rígida & Rígida & Neumática & Neumática \\
$\begin{array}{c}\text { Dimensiones } \\
\text { de la probeta }\end{array}$ & {$[\mathrm{mm}]$} & $\begin{array}{c}300 \times 300 \\
\text { x } 50\end{array}$ & $\begin{array}{c}300 \times 300 \times \\
50\end{array}$ & $500 \times 180 \times$ & $300 \times 125 \times 1$ \\
$\begin{array}{c}\text { Temperatura } \\
\text { de ensayo }\end{array}$ & {$\left[{ }^{\circ} \mathrm{C}\right]$} & 45 ó 60 & 60 & 70 & 40 a 60 \\
Carga & {$[\mathrm{N}]$} & 520 & 900 & 700 & 445 \\
$\begin{array}{c}\text { Presión de } \\
\text { Contacto }\end{array}$ & {$[\mathrm{kPa}]$} & 520 & 900 & 710 & 454
\end{tabular}

Cada uno de los equipos tiene asociado límites para definir la aptitud de una mezcla. La especificación para el equipo francés define el límite de falla como aquel en el cual las deformaciones permanentes alcanzaron el $10 \%$ de la altura de la probeta. España en su pliego de especificaciones (PG 3 2004) indica para mezclas bituminosas en caliente y para micro aglomerados en caliente para capas de rodadura en zona térmica estival cálida una velocidad máxima de deformación comprendida entre 12 y $15 \mu \mathrm{m} / \mathrm{min}$ en el ensayo de pista dentro del intervalo entre 105 a 120 minutos (Norma NLT 173). El departamento de transporte de Virginia en EE.UU desarrolló para el APA un criterio de falla frente al ahuellamiento a partir de ensayos sobre testigos de mezclas asfálticas colocadas en diferentes caminos (Prowell 1999). A partir de un análisis estadístico se definió el criterio de límite máximo de ahuellamiento para un nivel de confianza del 95 \%. Dicho límite se dio para valores de deformación de 4 a 8 mm.

Agnusdei y coautores (2007a) establecieron un límite de deformaciones permanentes para el ensayo de rueda cargada en base a ensayos sobre testigos tomados de diferentes rutas. Este límite es válido para el equipo de rueda cargada con una carga de $520 \mathrm{~N}$ y una temperatura $60{ }^{\circ} \mathrm{C}$ y define estándares de buen comportamiento de mezclas asfálticas densas. En su trabajo algunos de los testigos estudiados pertenecían a caminos que presentaban serios ahuellamiento, mientras que los demás representaban caminos en buenas condiciones. En la figura 2.31 se observa los resultados del parámetro velocidad de deformación para 120 min obtenido para los diferentes testigos en el ensayo de rueda cargada. A partir de esos datos realizaron un análisis estadístico obteniendo el límite máximo de velocidad de deformación para un nivel de confianza del 95 \%. El mismo resulto un valor de $0,0052 \mathrm{~mm} / \mathrm{min}$. Dentro del análisis no se tuvieron en cuenta los datos de los testigos de rutas con ahuellamiento. 


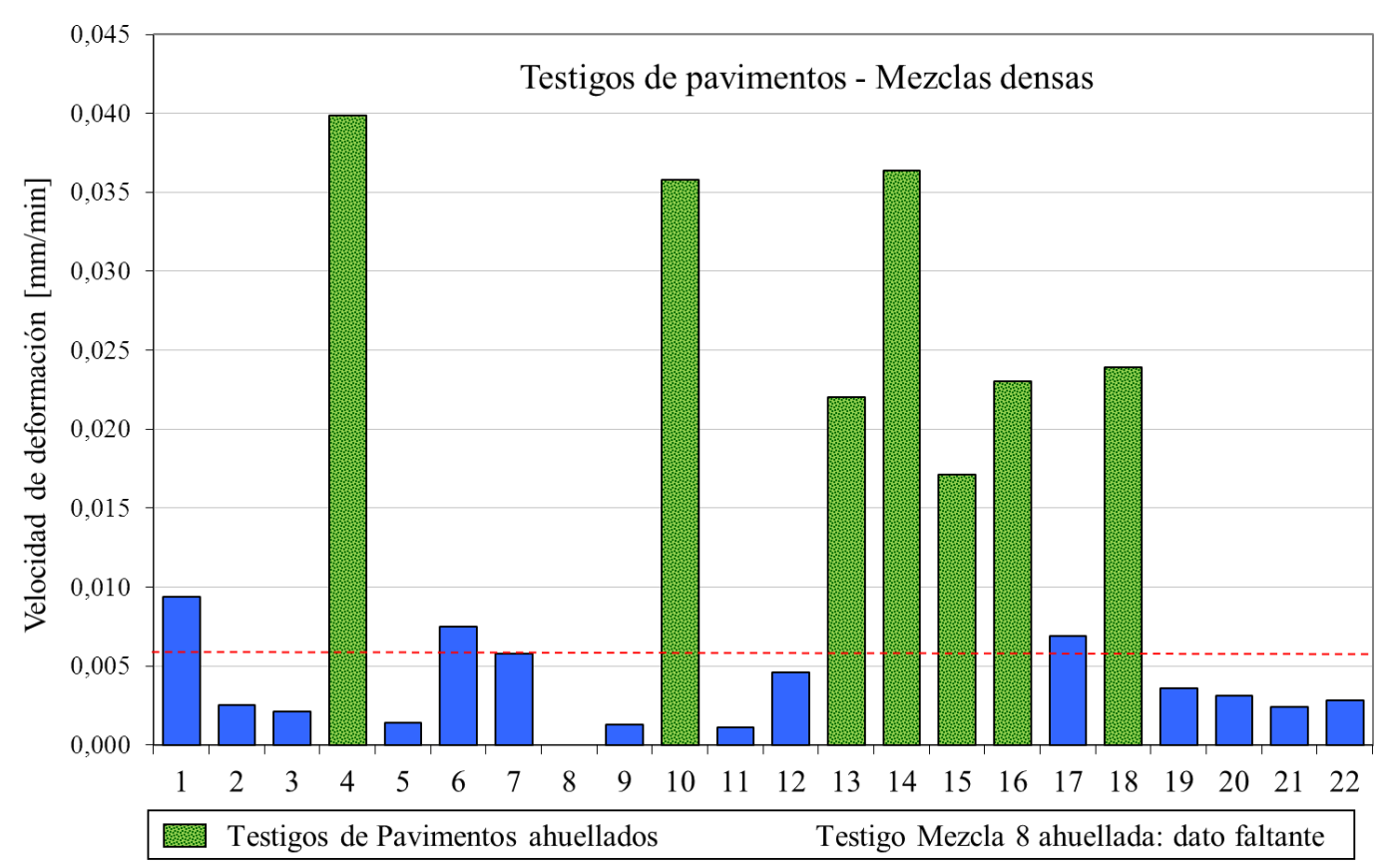

Figura 2.31. Resultados de velocidad de deformación de testigos de pavimentos ensayados en el equipo de rueda cargada.

Los límites de desempeño mencionados están determinados para condiciones de carga y temperatura especificas. Sin embargo en la realidad se dan condiciones de temperatura y carga que no siempre son las más extremas.

Es necesario conocer dentro del diseño de una mezcla asfáltica si la misma es susceptible al ahuellamiento para poder corregir el problema a tiempo y no verlo en el pavimento ya construido, con los inconvenientes que ello ocasiona. Con este propósito dentro del pliego de especificaciones técnicas de mezclas asfálticas (CPA 2006) se especifica al ensayo de rueda cargada como de determinación obligatoria. Este pliego todavía no está en vigencia pero es de importancia este aspecto de manera de tener una base de datos si se quiere especificar este ensayo y dar las pautas para que una mezcla no sufra deformaciones permanentes.

\subsection{Comentarios y consideraciones finales}

Este capítulo trató sobre el estado del conocimiento en los temas abordados en la tesis. Como objetivo principal aparece caracterizar el problema de las deformaciones permanentes en mezclas asfálticas tomando en cuenta las propiedades reológicas de los asfaltos considerando el desempeño de las mezclas asfálticas en función de la temperatura y las cargas que soportan los pavimentos por medio del ensayo de pista.

En primer lugar se desarrollaron los diferentes tipos de falla que afectan a un pavimento asfáltico haciendo un especial desarrollo sobre el problema de las deformaciones permanentes y los diferentes mecanismos de acción que generan este tipo de deterioro: temperaturas, carga de tránsito y materiales; en especial la debida a los ligantes asfálticos y sus propiedades reológicas. Luego se estudiaron métodos de medición de deformaciones permanentes en laboratorio en las diferentes variantes que existen a nivel mundial. 
A partir de todo lo visto surge que en Argentina y Latinoamérica existen pocos antecedentes acerca del estudio de las propiedades reológicas de los asfaltos y su relación con las deformaciones permanentes. No existen desarrollos de especificaciones para parámetros reológicos para caracterizar el aporte de los diferentes asfaltos en la resistencia al ahuellamiento.

El ensayo de pista, si bien no es una metodología nueva, no es utilizado normalmente como herramienta de comprobación dentro del diseño de las mezclas asfálticas en nuestro país. Resulta importante este ensayo como una parte ineludible del diseño.

El desempeño en los equipos de pista está determinado para condiciones de carga y temperatura especificas; sin embargo en la realidad las condiciones de temperatura y carga no son siempre las más extremas.

Las condiciones climáticas y del tránsito a las que va estar sometido el pavimento así como las propiedades reológicas de los asfaltos utilizados tienen un papel decisivo en el desempeño del concreto asfáltico. Resulta importante el estudio en conjunto del desempeño, la temperatura y las propiedades reológicas para asistir al diseño de mezclas asfálticas. De esta manera sería posible considerar las condiciones reinantes en el camino y realizar un adecuado diseño de la mezcla asfáltica.

Es común que las cargas máximas permitidas para el tránsito se superen, sobre todo en rutas de transporte de producción generando las consecuentes deformaciones en los caminos. Es importante conocer la respuesta de la mezcla asfáltica ante estas acciones y contemplarlas en el diseño. 


\section{Capítulo 3}

\section{Programa experimental}

\subsection{Introducción}

Como parte del programa experimental se estudiaron en primer término los parámetros reológicos del asfalto. Para ello y conforme lo expuesto en el estado del arte, el parámetro G*/sen $\delta$ y la ZSV o la LSV se presentan como las propiedades más idóneas para caracterizar el aporte de los asfalto sobre la resistencia frente a las deformaciones permanentes en mezclas asfálticas.

Para caracterizar las deformaciones permanentes en las mezclas asfálticas se seleccionó un equipo de rueda cargada. Este equipo es ideal para valorar los diferentes comportamientos en condiciones contraladas de laboratorio y aparece como una herramienta muy importante a la hora de estudiar las relaciones con las propiedades reológicas de los diferentes asfaltos y la incidencia de las principales variables externas.

En cuanto al estudio sobre los ligantes asfálticos, en una primera instancia se analizó una serie de asfaltos (convencionales y modificados) a través de la metodología SHRP de Estados Unidos (ASTM D 6373 1999). Esta instancia comprendió una caracterización completa de los ligantes para conocer sus propiedades, en especial el módulo complejo $\mathrm{G}^{*}$ y el ángulo de fase $\delta$, utilizando un reómetro de corte dinámico (DSR por sus siglas en inglés). Con estos datos se puede obtener el parámetro G*/sen $\delta$. Diferentes referencias (Oliver y Tredea 1998, Bahia et al. 2001 entre otros) indican que este parámetro no representa bien el aporte de los ligantes modificados con polímeros; para comprobar ese aspecto en los asfaltos argentinos se midió el parámetro $\mathrm{G} *$ sen $\delta$ considerando dos frecuencias, 0,6 y $10 \mathrm{rad} / \mathrm{s}$, comparables a velocidades de carga lenta y rápida respectivamente.

En una segunda etapa se estudiaron la Zero Shear Viscosity (ZSV) y la Low Shear Viscosity (LSV) sobre los mismos asfaltos. Se hizo la puesta a punto de ambos métodos de medición normalizados en Europa para las condiciones de esta tesis, a fin de definir el más conveniente en cuanto a tiempos de ensayo, repetitividad y reproductibilidad para la adecuada caracterización de los diferentes asfaltos. 
En cuanto al estudio de deformaciones permanentes en mezclas asfálticas se seleccionaron diferentes mezclas (densa, microaglomerado y SMA) de uso corriente en carpetas de rodamiento.

En primera instancia se estudió el proceso de ahuellamiento bajo condiciones normalizadas buscando observar la incidencia de las propiedades reológicas de los asfaltos utilizados en la caracterización de los ahuellamientos, empleando todos los asfaltos en la mezcla densa.

Cumplimentada esta etapa se estudió el desempeño a distintas temperaturas utilizando el ensayo de rueda cargada. Además del interés del estudio de la incidencia de la temperatura en materiales tan susceptibles a esta variable como los asfaltos, la extensión de nuestro país con sus diversas regiones y climas genera una aplicación inmediata de estos resultados.

El estudio incluyó tres tipos de asfaltos (convencional, multigrado y modificado con polímero SBS) representativos de los más usados actualmente.

Los $520 \mathrm{~N}$ de carga del ensayo de pista del laboratorio generan una presión de contacto similar a la que provocaría la carga nominal por eje simple (6 tn) permitida en nuestro país. Es común que estas cargas máximas se superen generando las consecuentes deformaciones en los caminos. Por tal motivo el plan de trabajo incluyó un análisis en el equipo de pista bajo una configuración de carga de 700 y $900 \mathrm{~N}$ (equivalentes a una carga máxima por eje simple de 10,5 y 13 th respectivamente); la carga de $700 \mathrm{~N}$ fue elegida pues es representativa de la utilizada en el ensayo de pista en Europa (constituye una sobrecarga en nuestro país), por su parte la carga de $900 \mathrm{~N}$ es la que utilizaba el equipo de pista español (norma NLT 173). De manera análoga al estudio de la respuesta ante diferentes temperaturas, los tres tipos de mezclas elaboradas con los tres asfaltos más comúnmente utilizados en carpetas de rodamiento, fueron analizadas bajo cargas crecientes.

\subsection{Materiales}

Ocho asfaltos de producción comercial en Argentina fueron seleccionados para este estudio, incluyendo cuatro asfaltos convencionales (C1, C2, C3 y C4), un asfalto multigrado (M) y tres asfaltos modificados con polímeros (MP1, MP2 y MP3).

Los diferentes ligantes fueron sometidos a procesos de envejecimiento en el RTFOT (Rolling Thin Film Oven Test) y PAV (Pressure Aging Vessel). Los asfaltos envejecidos en RTFOT representan un envejecimiento del ligante luego del proceso de elaboración de la mezcla en la planta asfáltica. El proceso de PAV representa un envejecimiento del ligante una vez en el pavimento durante la vida útil del mismo. Sobre los asfaltos envejecidos en RTFOT se midieron las propiedades reológicas de los asfaltos para observar la incidencia de este proceso sobre ellas. El material envejecido en PAV se utilizó en la caracterización de los asfaltos mediante la metodología SHRP.

Las principales características de los asfaltos se indican en la Tabla 3.1, incluyendo tanto las propiedades para los ligantes en estado original como luego de envejecido en RTFOT. Entre ellas aparecen los valores tradicionales de penetración y viscosidad Brookfield a $60{ }^{\circ} \mathrm{C}$ que se utilizan para las clasificaciones tradicionales por viscosidad y 
penetración. En esta tabla se volcaron también el punto de ablandamiento, ductilidad, índice de penetración (IP) y punto de inflamación, esta última relacionada a cuestiones de manejo y seguridad en la planta asfáltica de los ligantes.

Puede observarse en la tabla 3.1 el grado performance (PG) de la especificación de ligantes de Estados Unidos (ASTM D 6373) de los diferentes asfaltos en estudio que fue realizada como parte de caracterización de los mismos. Recordando lo que se comentara en el capítulo 2 el grado de performance PG se define con dos números, por ejemplo $64-22$, y representa el rango de temperaturas en el cual el asfalto brinda buenas prestaciones en lo que respecta a los modos de falla típicos de un pavimento. En el ejemplo el 64 representa la temperatura de alta y se relaciona con las máximas temperaturas en las que el ligante tendría buenas prestaciones frente a las deformaciones permanentes y fatiga. Por su parte el -22, temperatura de baja, es la mínima temperatura a la cual el ligante ofrece resistencia a la fisuración térmica. Estas temperaturas límites se obtienen a partir de mediciones reológicas sobre los ligantes, de hecho el $\mathrm{G}^{*} / \mathrm{sen} \delta$ se usa para definir la temperatura de alta. Más adelante se utilizaran los conceptos de PG y temperatura de alta para comparaciones de las propiedades reológicas junto con los análisis de deformaciones permanentes en mezclas.

Tabla 3.1. Principales propiedades de los ligantes asfálticos estudiados.

\begin{tabular}{|c|c|c|c|c|c|c|c|c|}
\hline Asfalto & $\mathrm{C} 1$ & $\mathrm{C} 2$ & $\mathrm{C} 3$ & $\mathrm{C} 4$ & $\mathrm{M}$ & MP1 & MP2 & MP3 \\
\hline Modificador & - & - & - & - & químico & EVA & SBS & SBS \\
\hline $\begin{array}{l}\text { Clasificación } \\
\text { IRAM } 6835\end{array}$ & CA-10 & CA-20 & CA-30 & - & - & AM2 & AM3-C & AM3-C \\
\hline \multicolumn{9}{|l|}{ Original } \\
\hline $\begin{array}{l}\text { Penetración a } \\
25^{\circ} \mathrm{C} \text { [dmm] }\end{array}$ & 89 & 60 & 58 & 17 & 60 & 64 & 71 & 64 \\
\hline $\begin{array}{c}\text { Punto de } \\
\text { ablandamiento } \\
{\left[{ }^{\circ} \mathrm{C}\right]}\end{array}$ & 47,4 & 54,2 & 51,8 & 65,7 & 58,3 & 69,2 & 88,5 & 95,5 \\
\hline Ductilidad [cm] & +150 & +150 & +150 & +150 & 85 & 42 & 106 & 118 \\
\hline IP & $-0,4$ & 0,2 & $-0,4$ & $-0,2$ & 1,2 & 3,4 & -1 & 6,9 \\
\hline $\begin{array}{c}\text { Punto de } \\
\text { inflamación }\left[{ }^{\circ} \mathrm{C}\right]\end{array}$ & 346 & 302 & 298 & -1 & 288 & 315 & 306 & 304 \\
\hline $\begin{array}{l}\text { Viscosidad } \\
\text { Brookfield a } \\
60^{\circ} \mathrm{C} \text { [Pa.s] }\end{array}$ & 147,2 & 256,0 & 297,6 & 2524 & 1224 & 270,4 & 7472 & -1 \\
\hline $\begin{array}{l}\text { Recuperación } \\
\text { Torsional [\%] }\end{array}$ & - & - & - & - & - & 67,2 & 76,7 & 77,2 \\
\hline
\end{tabular}


Tabla 3.1 (continuación). Principales propiedades de los ligantes asfálticos estudiados.

\begin{tabular}{|c|c|c|c|c|c|c|c|c|}
\hline Asfalto & C1 & $\mathrm{C} 2$ & C3 & C4 & M & MP1 & MP2 & MP3 \\
\hline \multicolumn{9}{|l|}{ RTFOT } \\
\hline $\begin{array}{l}\text { Penetración a } \\
25^{\circ} \mathrm{C}[\mathrm{dmm}]\end{array}$ & 59 & 44 & 37 & 11 & 42 & 45 & 53 & 46 \\
\hline $\begin{array}{c}\text { Punto de } \\
\text { ablandamiento } \\
{\left[{ }^{\circ} \mathrm{C}\right]}\end{array}$ & 51,8 & 58,2 & 56,8 & 69,4 & 67,8 & 69,4 & 74,2 & 90,0 \\
\hline Ductilidad [cm] & +150 & +150 & +150 & 24 & 18 & 18 & 91 & 96 \\
\hline $\begin{array}{l}\text { Viscosidad } \\
\text { Brookfield a } \\
\left.60^{\circ} \mathrm{C} \text { [Pa.s }\right]\end{array}$ & 262,4 & 480,0 & 724,0 & 5960 & 6760 & 1880 & $-{ }^{1}$ & -1 \\
\hline $\begin{array}{c}\text { Pérdida de masa } \\
{[\%]}\end{array}$ & 0,06 & 0,12 & 0,03 & 0,06 & 0,03 & 0,03 & 0,06 & $-0,30$ \\
\hline \multicolumn{9}{|c|}{ Temperaturas de elaboración $\left[{ }^{\circ} \mathrm{C}\right]^{2}$} \\
\hline Mezclado & 153 & 155 & 160 & 177 & 183 & 180 & 180 & 180 \\
\hline Compactación & 141 & 146 & 150 & 165 & 171 & 166 & 170 & 170 \\
\hline PG & $58-22$ & $64-22$ & $64-16$ & $76-10$ & $70-22$ & $70-28$ & $70-22$ & $70-22$ \\
\hline \multicolumn{9}{|l|}{${ }^{1}$ No se midió } \\
\hline${ }^{2}$ Según criterio d & equivis & sidad & & & & & & \\
\hline
\end{tabular}

\subsection{Mezclas asfálticas}

Se estudiaron tres mezclas asfálticas para carpeta de rodamiento, una mezcla densa de tamaño máximo $20 \mathrm{~mm}$ y dos tipos de mezcla para carpetas especiales, un microaglomerado discontinuo y una Stone Mastic Asphalt (SMA) ambas de tamaño máximo $10 \mathrm{~mm}$.

Estas mezclas representan los casos típicos de capas de rodamiento de pavimentos que se usan en nuestro país y a nivel mundial. Las mezclas densas son utilizadas en las calles urbanas y la mayoría de las rutas. Los microaglomerados y SMA son mezclas con altas prestaciones cuyo mayor uso se da en vías como autopistas o avenidas importantes de ciudad con alto nivel de tránsito y cargas.

\subsubsection{Agregados}

Las mezclas se elaboraron con agregados de origen granítico de la provincia de Buenos Aires, Argentina. Los agregados gruesos se utilizaron en las fracciones 6$20 \mathrm{~mm}$ y 6-12 mm y las arenas fueron de trituración de tamaño 0-6 mm y 0-3 mm. También se utilizaron filler y cal hidráulica, figura 3.1.

Para la fabricación de las mezclas SMA se utilizó fibras de celulosa en pellet, figura 3.2. La tabla 3.2 presenta las características de cada agregado incluyendo peso específico (Pe), absorción en agua (Abs.), desgaste Los Ángeles (LA), granulometría por vía húmeda de los agregados gruesos y finos y granulometría del filler y cal. 


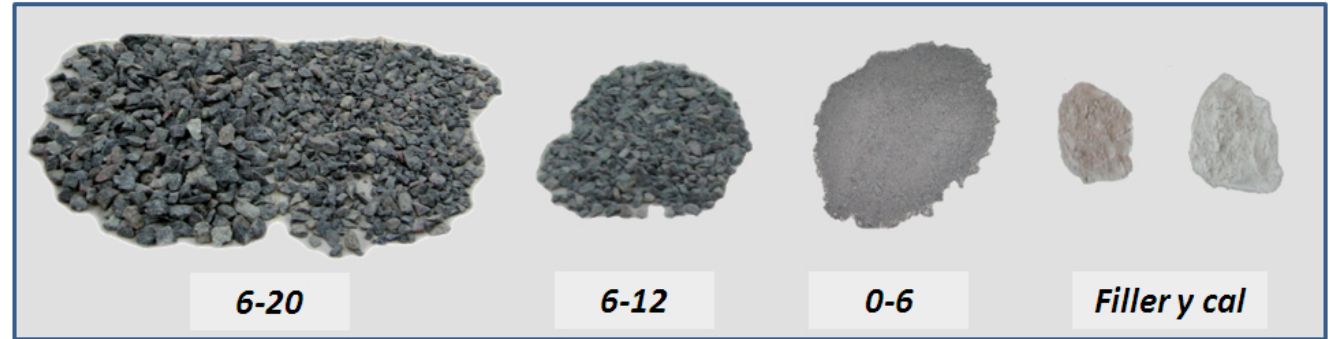

Figura 3.1. Agregados utilizados.

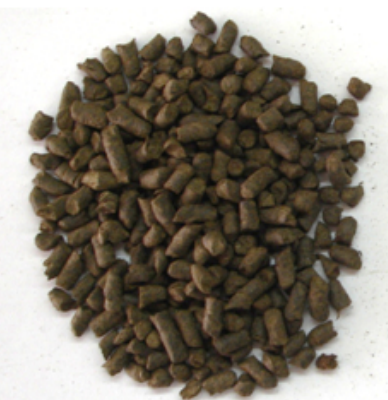

Pellets de fibras

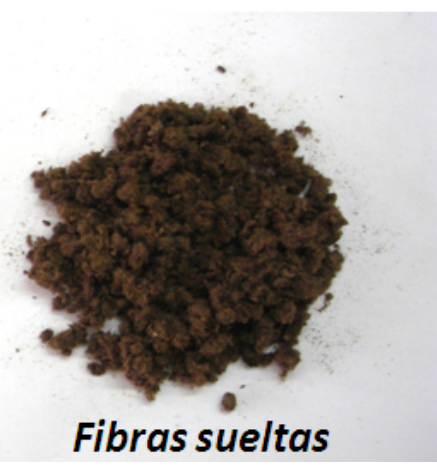

Fibras sueltas

Figura 3.2. Fibras utilizadas en la SMA.

Tabla 3.2. Principales propiedades de los agregados.

\begin{tabular}{|c|c|c|c|c|c|c|}
\hline & \multicolumn{6}{|c|}{ Agregado } \\
\hline & $6-20$ & $6-12$ & $0-6$ & $0-3$ & Filler & Cal \\
\hline Granulometría & \multirow{2}{*}{\multicolumn{6}{|c|}{ Pasa Tamiz [\%] }} \\
\hline Tamiz [mm] & & & & & & \\
\hline 25,40 (1”) & 100 & 100 & 100 & 100 & 100 & 100 \\
\hline 19,00 (3/4”) & 99,1 & 100 & 100 & 100 & 100 & 100 \\
\hline 12,50 (1/2”) & 60,4 & 99,8 & 100 & 100 & 100 & 100 \\
\hline 9,50 (3/8”) & 37,5 & 98,5 & 100 & 100 & 100 & 100 \\
\hline 4,75 (No 4) & 6,0 & 8,5 & 94,8 & 99,7 & 100 & 100 \\
\hline 2,36 ( $\left.\mathrm{N}^{\mathrm{o}} 8\right)$ & 2,8 & 3,1 & 65,4 & 86,3 & 100 & 100 \\
\hline 1,18 ( $\left.\mathrm{N}^{\circ} 16\right)$ & 2,2 & 2,2 & 45,7 & 62,4 & 100 & 100 \\
\hline $0,60\left(\mathrm{~N}^{\mathrm{o}} 30\right)$ & 1,9 & 1,7 & 32,8 & 45,5 & 100 & 100 \\
\hline $0,30\left(\mathrm{~N}^{\circ} 50\right)$ & 1,5 & 1,3 & 23,4 & 32,0 & 100 & 100 \\
\hline $0,15\left(\mathrm{~N}^{\circ} 100\right)$ & 1,1 & 0,9 & 15,9 & 21,1 & 95,1 & 95,7 \\
\hline $0,0075\left(\mathrm{~N}^{\mathrm{o}} 200\right)$ & 0,8 & 0,3 & 11,1 & 13,5 & 77,5 & 90,1 \\
\hline $\mathrm{Pe}\left[\mathrm{g} / \mathrm{cm}^{3}\right]$ & 2,727 & 2,724 & 2,521 & 2,640 & 2,778 & 2,702 \\
\hline Abs [\%] & 0,38 & 0,33 & 1,7 & 0,4 & - & - \\
\hline LA [\%] & 19,5 & 22,2 & - & - & - & - \\
\hline
\end{tabular}




\subsubsection{Diseño de las mezcla}

\subsubsection{Mezcla densa (D-20)}

El diseño de esta mezcla se hizo a partir del método Marshall. La misma presenta un tamaño máximo de agregado de $20 \mathrm{~mm}$, de allí su denominación como D-20. Esta mezcla es una de las mezclas densas más comúnmente usadas, está compuesta con las fracciones 6-20, 6-12 y 0-6 mm, filler y cal en las proporciones que se observan en la tabla 3.3 de manera que la curva resultante se encuentre dentro de los límites del huso de la especificación para concretos asfálticos densos, semidensos y gruesos en caliente redactado por la Comisión Permanente del Asfalto (2006), figura 3.3.

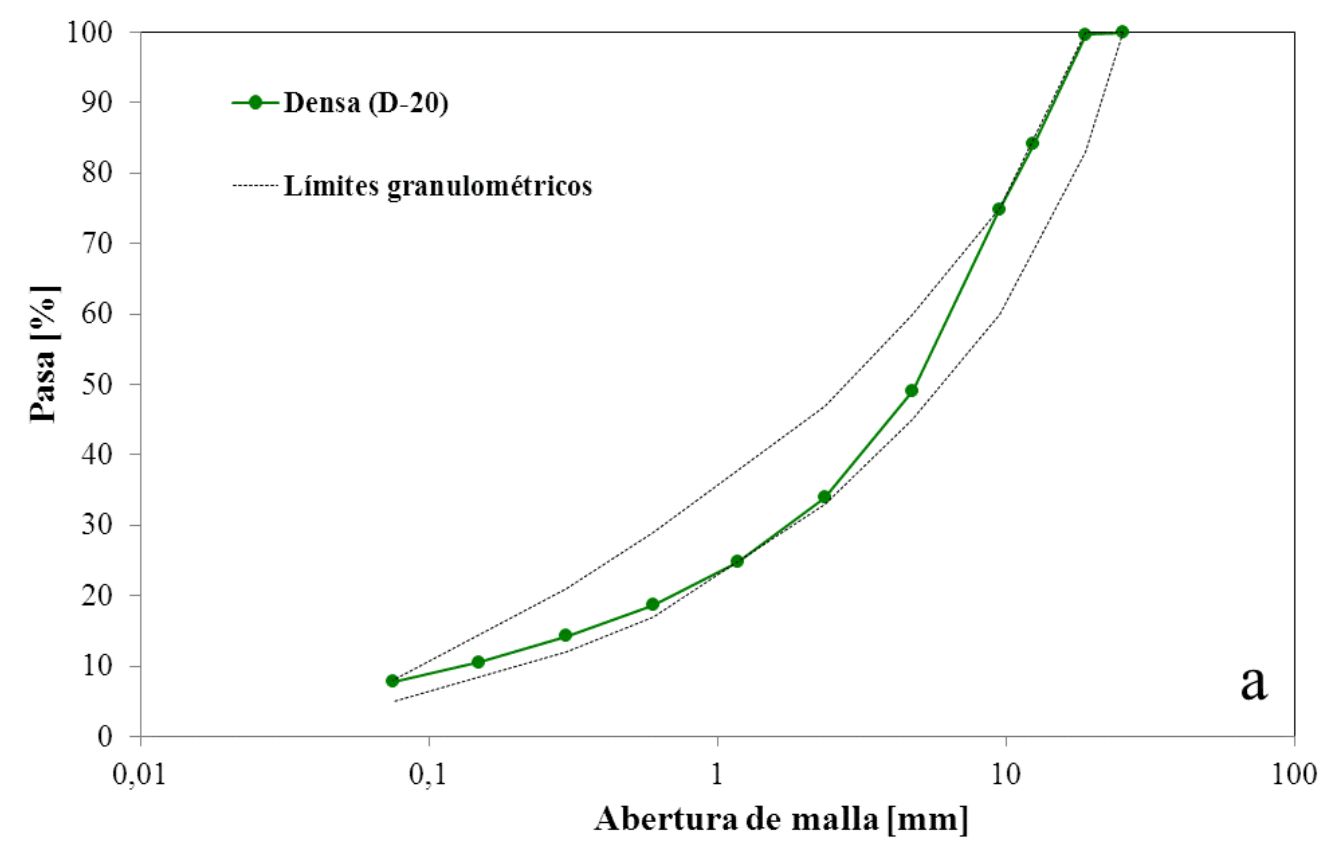

Figura 3.3. Gradación de la mezcla densa (D-20).

Tabla 3.3. Composición granulométrica de la mezcla D-20.

\begin{tabular}{cccccc}
\hline Fracción & $6-20 \mathrm{~mm}$ & $6-12 \mathrm{~mm}$ & $0-6 \mathrm{~mm}$ & Filler & Cal \\
\hline$\%$ & 40 & 12 & 45 & 2 & 1 \\
\hline
\end{tabular}

Para la elección del porcentaje óptimo de ligante se utilizó el asfalto C3 (CA-30) con el que se moldearon, para tres porcentajes de asfalto (4,5; 5,0 y 5,5\%), juegos de probetas con 75 golpes por cara como especifica el pliego de especificaciones técnicas generales de Vialidad Nación por medio del método Marshall (VN E9 y ASTM D 6926). Sobre las mezclas se determinó la densidad Rice y en las probetas la densidad por inmersión, el porcentaje de vacíos (\% V), la estabilidad (E) y la fluencia Marshall (F). En la tabla 3.4 se resumen los datos mencionados. 
Tabla 3.4. Diseño Marshall para la mezcla D-20.

\begin{tabular}{ccccc}
\hline \% asfalto & & $4,5 \%$ & $5,0 \%$ & $5,5 \%$ \\
\hline Densidad promedio & {$\left[\mathrm{g} / \mathrm{cm}^{3}\right]$} & 2,418 & 2,437 & 2,425 \\
Densidad Rice & {$\left[\mathrm{g} / \mathrm{cm}^{3}\right]$} & 2,554 & 2,526 & 2,499 \\
$\% \mathrm{~V}$ & {$[\%]$} & 5,3 & 3,5 & 2,1 \\
$\mathrm{E}_{\text {promedio }}$ & {$[\mathrm{kN}]$} & 14,7 & 16,5 & 15,6 \\
$\mathrm{~F}_{\text {promedio }}$ & {$[\mathrm{mm}]$} & 3,6 & 4,1 & 5,7 \\
Relación E/F* & {$[\mathrm{kN} / \mathrm{mm}]$} & 4,1 & 4,0 & 2,7 \\
\hline *Relación entre la estabilidad y la fluencia & & \\
\hline
\end{tabular}

A partir de estos datos el $5 \%$ de asfalto cumple con los requerimientos de máxima densidad, porcentaje de vacíos entre 3 y 5 \% y máxima estabilidad, figura 3.4. A su vez se verifican los requerimientos de vacíos del agregado mineral y la relación estabilidad fluencia entre $2,5-4,5 \mathrm{kN} / \mathrm{mm}$.
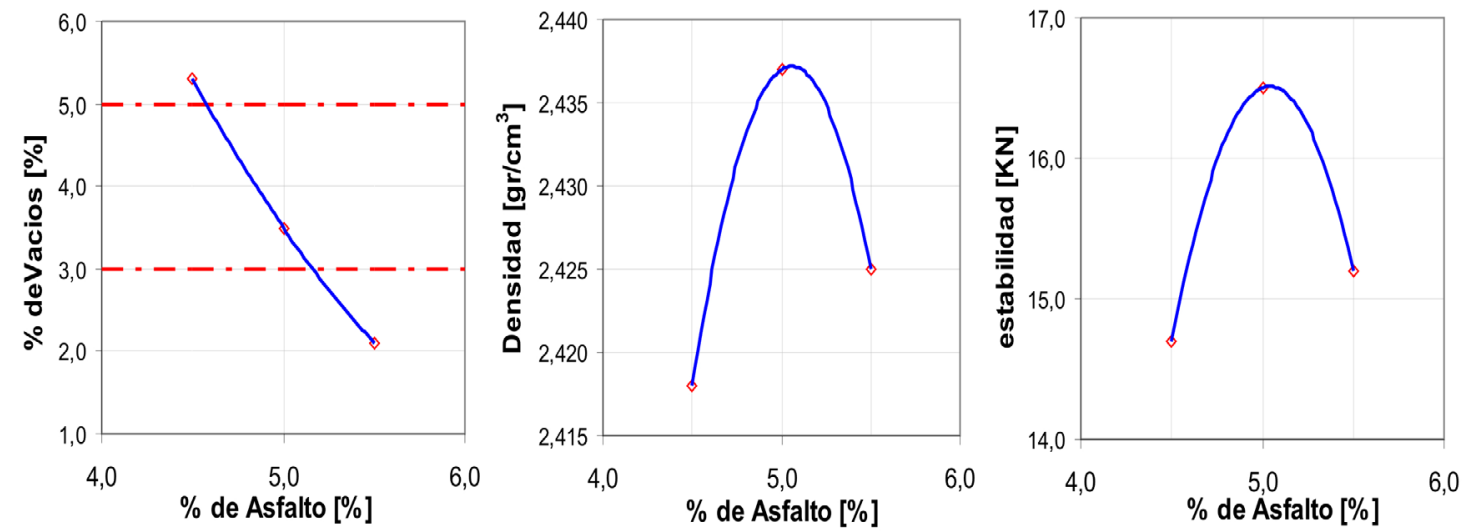

Figura 3.4. Gráficos del diseño Marshall de mezcla densa (D-20).

\subsubsection{Microaglomerado discontinuo (M-10)}

Esta mezcla presenta un tamaño máximo de agregado de $10 \mathrm{~mm}$. Está compuesta con las fracciones 6-12 mm, arena de trituración 0-3 mm, filler y cal en las proporciones que se observan en la tabla 3.5. La curva resultante se encuadra dentro de los límites del huso de la especificación para mezclas asfálticas en caliente de bajo espesor para carpeta de rodamiento redactado por la Comisión Permanente del Asfalto (CPA 2005), figura 3.5. Esta curva cumple con el requerimiento que el material que pasa el tamiz $\mathrm{N}^{\mathrm{o}} 4(4,75 \mathrm{~mm})$ y retiene el tamiz $\mathrm{N}^{\circ} 8(2,36 \mathrm{~mm})$ es menor al $8 \%$ del peso total de agregados que integra la composición. Esta discontinuidad es un requerimiento esencial para lograr una adecuada macro textura de la mezcla asfáltica. 
Tabla 3.5. Composición granulométrica del microaglomerado M-10.

\begin{tabular}{ccccc}
\hline Fracción & $6-12 \mathrm{~mm}$ & $0-3 \mathrm{~mm}$ & Filler & Cal \\
\hline$\%$ & 75 & 16 & 8 & 1 \\
\hline
\end{tabular}

Según el pliego de especificaciones técnicas (CPA 2005), estas mezclas deben ser elaboradas con ligantes modificados del tipo AM2 o AM3. El asfalto AM2 es un asfalto normalmente modificado con polímero EVA mientras el AM3 es un asfalto modificado con polímero SBS. A los efectos de estudio de esta tesis se realizaron mezclas de este tipo con los ligantes convencional y multigrado para observar el efecto de este tipo de asfaltos en estas mezclas.

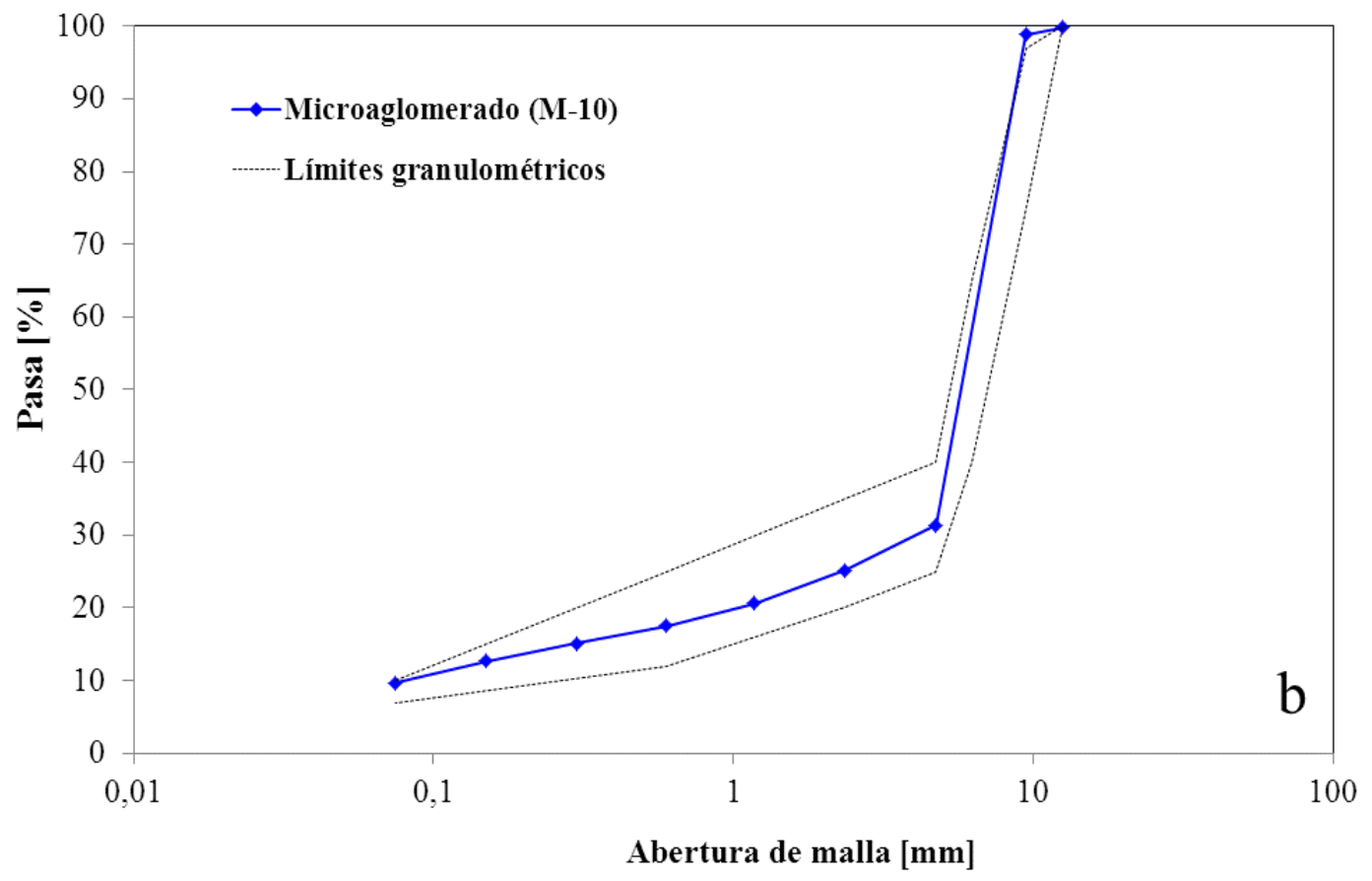

Figura 3.5. Gradación del microaglomerado (M-10).

Para el diseño de la mezcla y definir el porcentaje de ligante se utilizó el asfalto MP2 (del tipo AM3) con el que se moldearon juegos de probetas Marshall con 50 golpes por cara, como especifica el pliego de especificaciones técnicas de Vialidad Nación (1998), para dos porcentajes de asfalto (5,3 y 5,5 \%). Sobre las mezclas se determinó la densidad Rice y en las probetas la densidad en parafina, el porcentaje de vacíos y la resistencia a tracción indirecta a $25{ }^{\circ} \mathrm{C}$ (RTI). En la tabla 3.6 se resumen los datos mencionados. La densidad de estas mezclas se define en parafina ya que por su alta macro textura no es posible definir el estado a superficie seca de la metodología por inmersión.

Se observa en la tabla 3.6 que el porcentaje de 5,3\% de asfalto es el que cumple con los requerimientos de la especificación en cuanto a porcentaje de vacíos, por tanto este porcentaje fue él utilizado en las mezclas de microaglomerado. Es de destacar que el porcentaje mínimo de asfalto para estas mezclas es de 5,2 \% (especificaciones técnicas CPA, 2005). 
Tabla 3.6. Propiedades del microaglomerado M-10.

\begin{tabular}{ccccc}
\hline \% asfalto & & $5,3 \%$ & $5,5 \%$ & Requisitos* \\
\hline Densidad promedio & {$\left[\mathrm{g} / \mathrm{cm}^{3}\right]$} & 2,380 & 2.407 & - \\
Densidad Rice & {$\left[\mathrm{g} / \mathrm{cm}^{3}\right]$} & 2,501 & 2,488 & - \\
$\%$ V & {$[\%]$} & 4,9 & 3,3 & $4-7$ \\
RTI a $25{ }^{\circ} \mathrm{C}$ & {$[\mathrm{kPa}]$} & 983,8 & 977,3 & - \\
\hline
\end{tabular}

* Pliego de especificaciones de la Comisión Permanente del Asfalto (2005)

\subsubsection{Stone Mastic Asphalt (SMA-10)}

Esta mezcla presenta un tamaño máximo de agregado de $10 \mathrm{~mm}$. Está compuesta con las fracciones 6-12mm, arena de trituración 0-3 mm, filler y cal. Además presenta la incorporación de fibras de celulosa para permitir la incorporación de un mayor porcentaje de asfalto. Las proporciones de la misma se observan en la tabla 3.7. En la figura 3.6 se observa la curva resultante, esta se encuentra dentro de los límites del huso de la especificación para mezclas asfálticas en caliente de bajo espesor para carpeta de rodamiento redactado por la Comisión Permanente del Asfalto (2005).

Tabla 3.7. Composición granulométrica de la SMA-10.

\begin{tabular}{cccccc}
\hline Fracción & $6-12 \mathrm{~mm}$ & $0-3 \mathrm{~mm}$ & Filler & Cal & Fibras \\
\hline$\%$ & 75 & 15,5 & 8 & 1 & 0,5 \\
\hline
\end{tabular}

Estas mezclas normalmente son elaboradas con ligantes modificados del tipo AM3 debido a que el alto porcentaje de asfalto utilizado se necesita un asfalto de alta viscosidad y prestaciones. Sin embargo como el objetivo de esta tesis es estudiar los diferentes tipos de ligantes en diferentes tipos de mezclas se realizaron mezclas SMA con los asfaltos convencionales, multigrado y el modificado con polímero EVA.

Para definir el porcentaje de ligante y las principales características volumétricas de la mezcla se utilizó el asfalto MP2 (del tipo AM3) con el que se moldearon juegos de probetas Marshall con 50 golpes por cara, como define Vialidad Nación en sus especificaciones técnicas. Se probaron dos porcentajes de asfalto de 6,0 y 6,5\%. Sobre la mezcla se determinó la densidad Rice y porcentaje de escurrimiento de ligante. Sobre las probetas se determinó la densidad por inmersión, el porcentaje de vacíos y la resistencia a tracción indirecta a $25{ }^{\circ} \mathrm{C}$. En la tabla 3.8 se resumen los datos mencionados. Se observa allí que la mezcla con $6 \%$ de asfalto cumple el requerimiento de Vacíos de la especificación y a su vez la mayor resistencia a tracción indirecta a $25{ }^{\circ} \mathrm{C}$. Es importante mencionar que el porcentaje mínimo de ligante para esta mezcla se estipula en 6,5\% (pliego CPA 2005) pero para este porcentaje de asfalto la mezcla resulta con un muy bajo porcentaje de vacíos para la granulometría que cumple con los límites del huso para los agregados usados en esta tesis. En consecuencia el 6\% de asfalto fue el porcentaje de ligante utilizado en todas las mezclas SMA. 


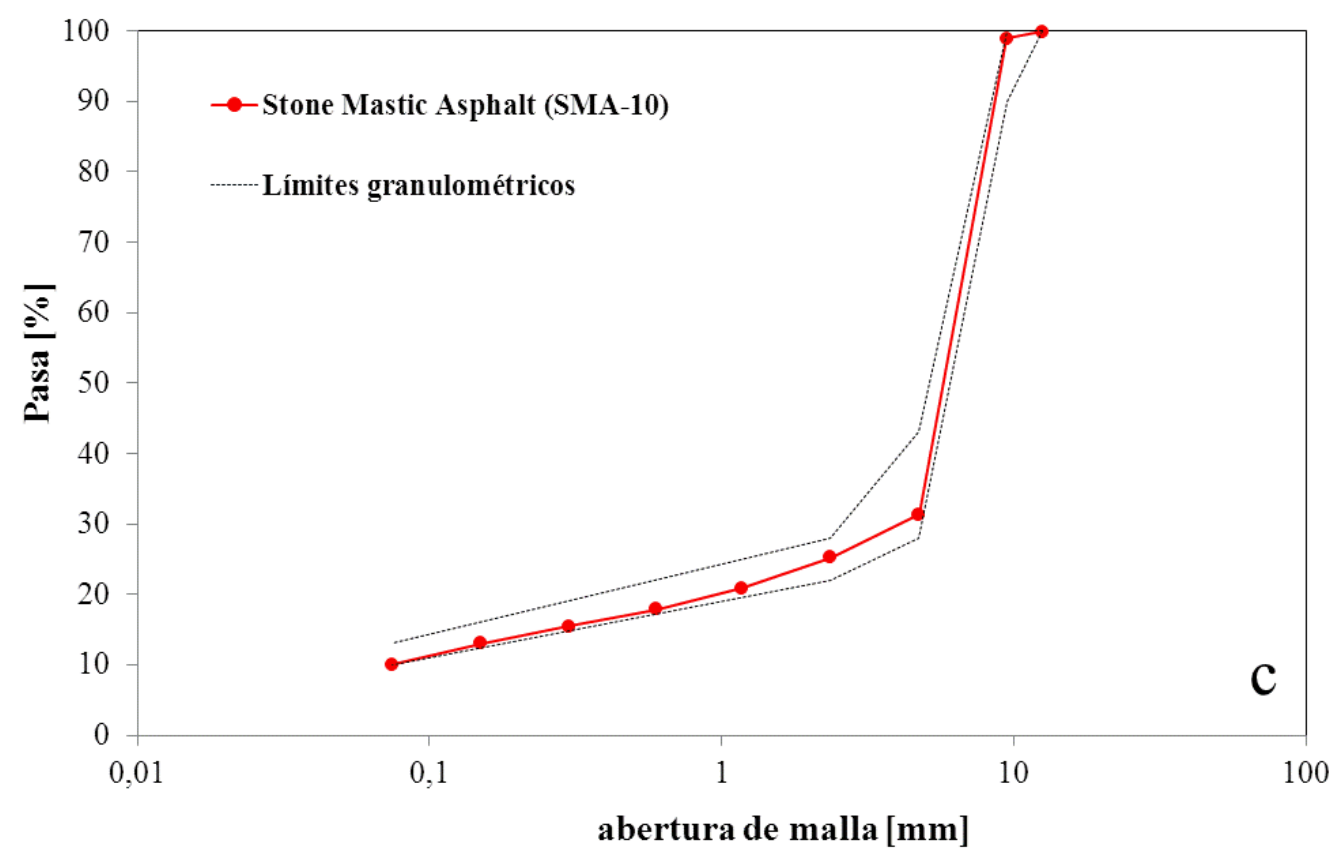

Figura 3.6. Gradación de la SMA (SMA-10).

Tabla 3.8. Propiedades de la SMA-10.

\begin{tabular}{ccccc}
\hline \% asfalto & & $6,0 \%$ & $6,5 \%$ & Requisitos* $^{*} \%$ \\
\hline Densidad promedio & {$\left[\mathrm{g} / \mathrm{cm}^{3}\right]$} & 2,400 & 2.429 & - \\
Densidad Rice & {$\left[\mathrm{g} / \mathrm{cm}^{3}\right]$} & 2,482 & 2,467 & - \\
$\% \mathrm{~V}$ & {$[\%]$} & 3,3 & 1,6 & $2-4$ \\
Escurrimiento** & {$[\%]$} & 0,16 & 0,18 & $<0,3$ \\
RTI a $25{ }^{\circ} \mathrm{C}$ & {$[\mathrm{kPa}]$} & 1018,5 & 947,4 & - \\
\hline
\end{tabular}

* Pliego de especificaciones de la Comisión Permanente del Asfalto (2005)

**Ensayo según Anexo SMA III del pliego de la Comisión Permanente del Asfalto (2005)

\subsection{Metodologías de ensayo}

En este apartado se indican los métodos de ensayo empleados a lo largo de la tesis. Se detallan en especial aquellas técnicas utilizadas para la caracterización reológica así como los métodos de evaluación de las deformaciones permanentes en mezclas asfálticas. Para la determinación del resto de las propiedades físicas y mecánicas de los asfaltos y de las mezclas se utilizaron los métodos normalizados de laboratorio de uso corriente. Un listado de los mismos y sus respectivas normas de ensayo de incorpora al final del capítulo.

\subsubsection{Métodos de envejecimiento de asfaltos}

El proceso natural de envejecimiento de un ligante asfáltico se debe mayormente a la perdida de compuestos livianos de la estructura del asfalto y por otro a la oxidación 
producto de la reacción con el oxígeno del aire. En el proceso de elaboración y colocación de una mezcla asfáltica en caliente se somete al ligante a las altas temperaturas y aire lo que produce un envejecimiento acelerado debido a los dos mecanismos mencionados. Una vez colocado en el camino la mezcla asfáltica se ve sometida a un envejecimiento leve pero continuo por oxidación producto del aire y la radiación solar.

El ensayo en horno de película delgada rotativa, Rolling Thin Film Oven Test (RTFOT) en inglés (ASTM D 2872), simula el envejecimiento producido durante la elaboración y colocación de la mezcla mientras que el ensayo de envejecimiento en cámara a presión, Pressure Aging Vessel (PAV) en inglés (ASTM D 6521), simula el proceso de envejecimiento en el pavimento.

\subsubsection{Envejecimiento en horno de película delgada rotativa (RTFOT)}

En este ensayo se expone una delgada película de ligante a calor y aire, simulando aproximadamente la exposición del asfalto durante el proceso de elaboración y manipulación. El ligante a envejecer se coloca en recipientes de vidrio, figura 3.7 izquierda, los que se introducen en un horno de convección calentado eléctricamente, que posee un carrusel en su interior y una boquilla para soplar aire sobre cada recipiente a medida que el carrusel gira dentro del horno, figura 3.7 derecha. Se colocan en el horno ocho recipientes con $35 \pm 0,5 \mathrm{~g}$ de ligante cada uno. El envejecimiento se lleva a cabo a una temperatura de $163 \pm 0,5{ }^{\circ} \mathrm{C}$ durante un lapso de $85 \mathrm{~min}$. El carrusel gira a $15 \pm 0,2 \mathrm{rpm}$ y el flujo de aire es de $4000 \pm 200 \mathrm{ml} / \mathrm{min}$.
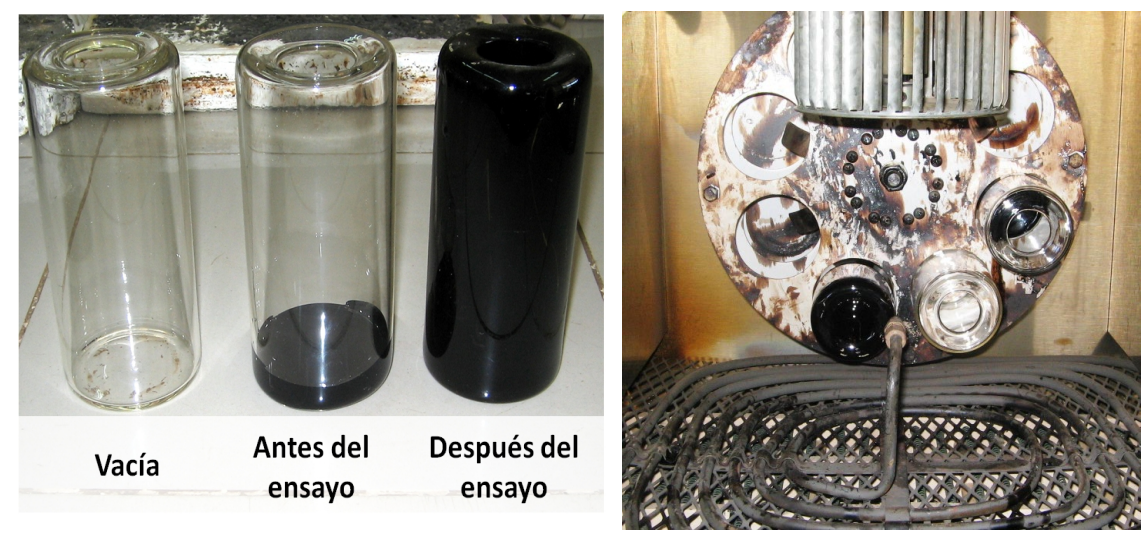

Figura 3.7. Ensayo RTFOT. Recipientes de ensayo (Izquierda), Vista interior (Derecha).

Una vez trascurrido el ensayo el asfalto es retirado de los recipientes de vidrio por simple escurrimiento del ligante no raspando el interior de las mismas.

De los ocho recipientes, si se requiere, dos son destinados a determinar la pérdida de masa (volátiles) como indica la ecuación 3.1. La pérdida de masa indica el grado de envejecimiento durante el ensayo. Algunos asfaltos pueden experimentar un aumento en su masa debido a efectos de oxidación durante el ensayo, ver tabla 3.1 asfalto MP3.

$$
\text { Perdida de Masa }[\%]=100 . \frac{\text { Peso }_{\text {inicial }}-\text { Peso }_{\text {final }}}{\text { Peso }_{\text {inicial }}}
$$




\subsubsection{Envejecimiento en cámara a presión (PAV)}

Este ensayo expone el asfalto a la acción de calor y presión para recrear, en pocas horas, años de envejecimiento en el pavimento. Los asfaltos utilizados para este ensayo deben haber sido previamente sometidos al ensayo de RTFOT como es lógico ya que la mezcla antes de sufrir el envejecimiento en el pavimento pasa por el envejecimiento ocurrido en la elaboración.

El equipo consiste en una cámara que somete a la muestra a temperatura y presión, figura 3.21. La cámara ejerce una presión de $2070 \mathrm{kPa}$ a una temperatura que puede ser de 90,100 o $110^{\circ} \mathrm{C}$. Las diferentes temperaturas tratan de simular distintas condiciones climáticas a las que pueda estar sometido el asfalto en el pavimento. Condiciones climáticas moderadas y extremas son simuladas por los 90 y $100{ }^{\circ} \mathrm{C}$ respectivamente mientras los $110^{\circ} \mathrm{C}$ se utilizan en asfaltos que serán sometidos a climas desérticos.

Las muestras de asfalto son colocadas en bandejas que se colocan dentro de la cámara en un bastidor, figura 3.8. Una vez alcanzada la temperatura requerida se aplica la presión a la cámara durante un lapso de 20 horas para luego despresurizar lentamente. Una vez finalizada esta etapa las bandejas se colocan en estufa a $163{ }^{\circ} \mathrm{C}$ por 30 min para liberar el aire atrapado en la muestra. De esta manera ya se tiene el asfalto en condiciones para los ensayos requeridos.
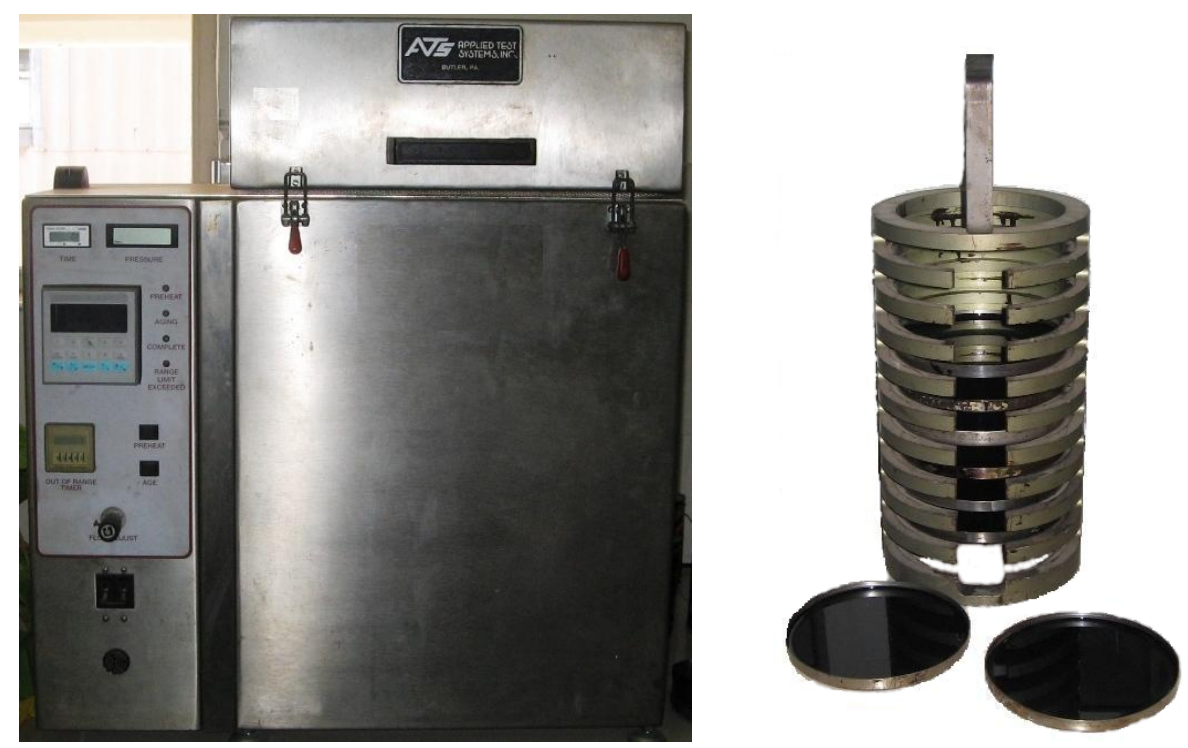

Figura 3.8. Equipo PAV. Vista general (Izquierda). Bandejas y bastidor (Derecha).

\subsubsection{Mediciones reológicas}

La respuesta reológica de los ligantes se determinó en un Reómetro de Corte Dinámico (DSR) de Paar Physica SM-KP con un Rheolab MC-100, figura 3.9. El equipo posee un termo estabilizador que permite variar la temperatura de ensayo entre 0 y $90{ }^{\circ} \mathrm{C}$ por medio de un sistema de circulación de agua a través de dos cabezales que rodean la muestra de ligante, figura 3.10 izquierda. Incluye distintos accesorios necesarios para su utilización en función de las características de los materiales en estudio y/o la temperatura de ensayo, figura 3.10 derecha. Este equipo posee la 
versatilidad de operar en diferentes condiciones permitiendo variar la frecuencia de carga, las deformaciones impuestas o aplicar carga de corte constante.

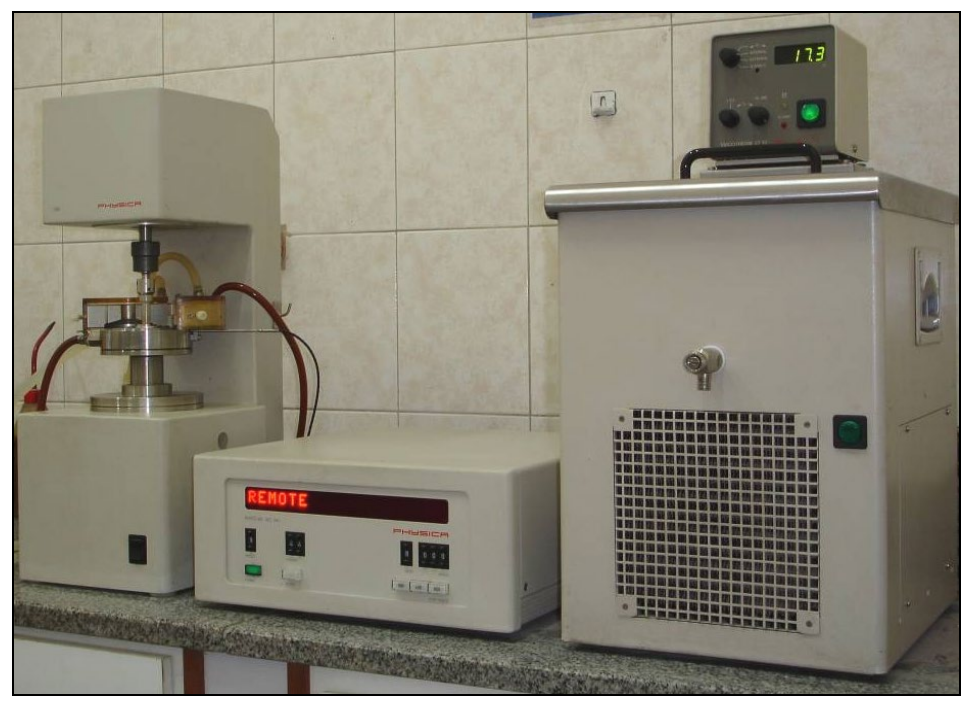

Figura 3.9.Reómetro de Corte Dinámico (DSR).

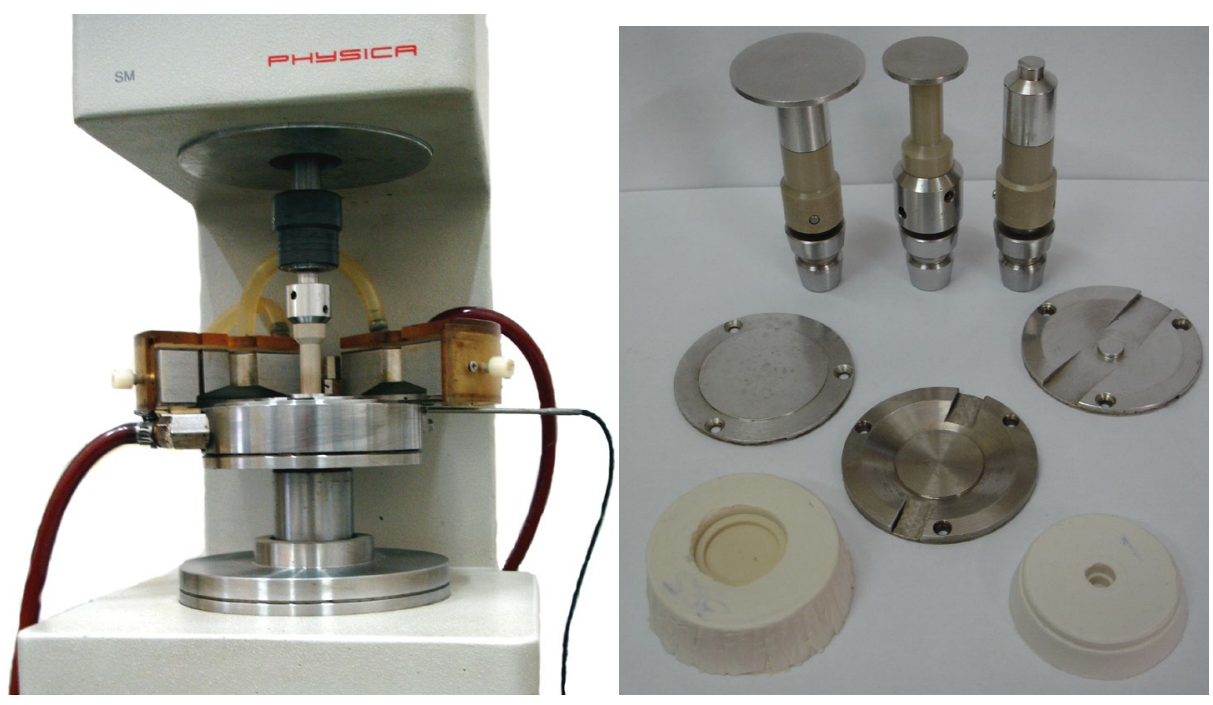

Figura 3.10.Vista del plato de carga con cabezales de calentamiento (izquierda). Diferentes accesorios del equipo (derecha).

\subsubsection{Mediciones de $G^{*} / \operatorname{sen} \delta$}

Para realizar las determinaciones de $\mathrm{G}^{*} / \mathrm{sen} \delta$ la operatoria de análisis es sencilla, una muestra del ligante en estudio es colocada entre los dos platos paralelos del DSR; uno de estos platos es fijo y el otro es móvil, figura 3.11. El plato móvil rota en ambos sentidos aplicando tensión de corte $\tau$ a la muestra hasta una deformación determinada a una frecuencia de oscilación establecida. El tipo de carga que se genera es del tipo sinusoidal como se observa en la figura 3.12 en la cual se alcanza una tensión de corte máxima. Las deformaciones que ocurren producto de la aplicación de cargas también siguen una ley sinusoidal y en particular por ser el asfalto un material viscoelástico se 
presentan con un cierto desfasaje $\delta$ respecto a la aplicación de la carga como se indica en la figura 3.12. Ese desfasaje es variable en función de la temperatura, la velocidad de carga y del material en sí. Por ejemplo, a bajas temperaturas el asfalto se comporta como un sólido elástico no habiendo un desfasaje entre la aplicación de carga y la deformación mientras que a altas temperaturas el asfalto es un fluido viscoso con un desfasaje entre la aplicación de carga y la consiguiente deformación.

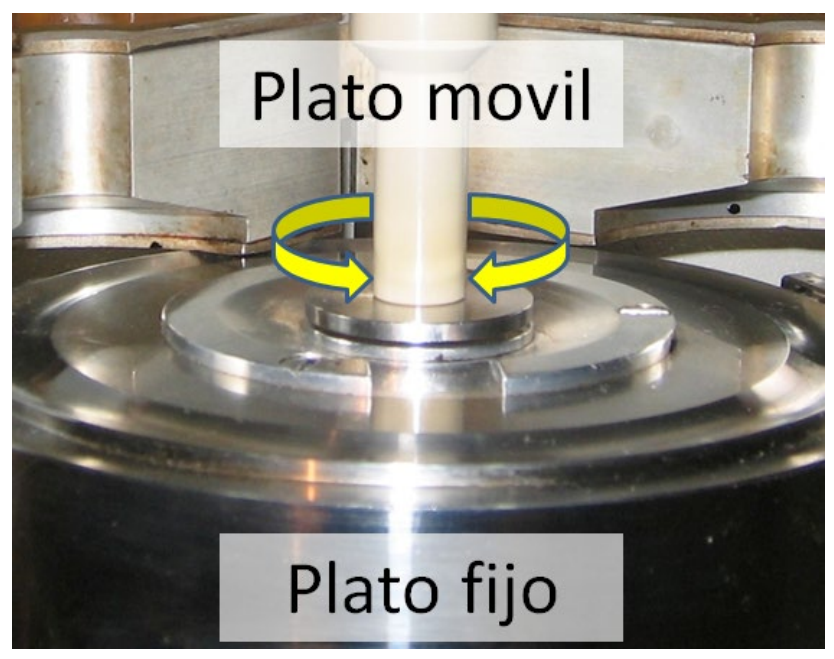

Figura 3.11. Detalle del plato de carga.

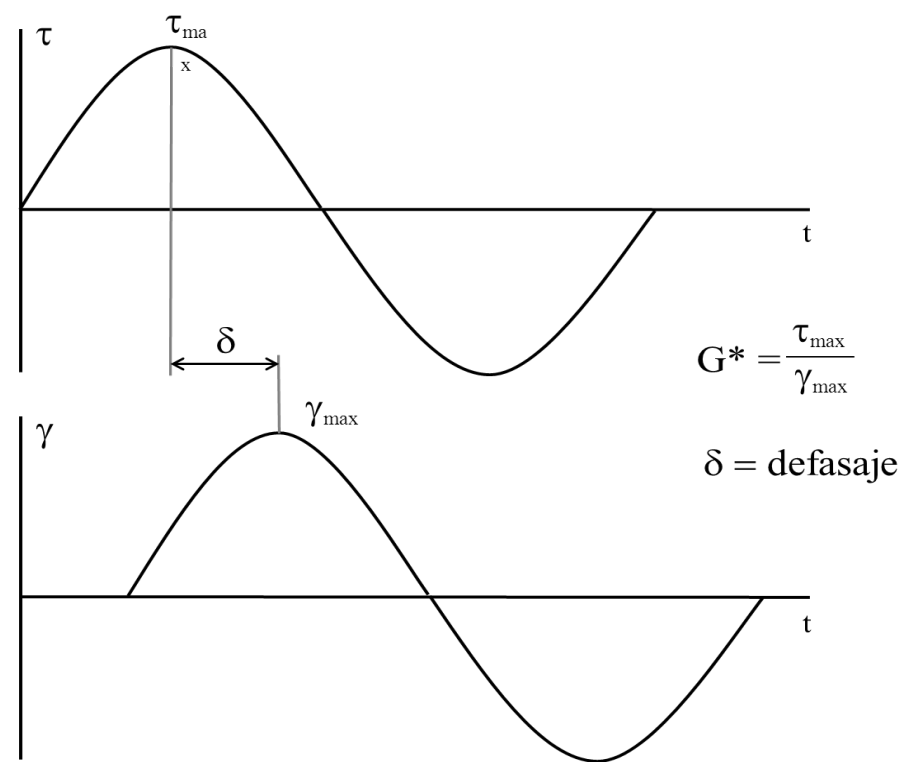

Figura 3.12. Respuesta esfuerzo deformación.

El aparato se encarga de medir el torque aplicado para lograr la deformación requerida para cada oscilación a la frecuencia especificada y los ángulos de rotación que se producen en función del tiempo recopilando las diferentes mediciones para calcular, por medio de un software, los valores de $\tau_{\max } \mathrm{y} \gamma_{\max }$ a partir de las ecuaciones 3.2 y 3.3. 


$$
\begin{gathered}
\tau_{\text {max }}=\frac{2 T_{\max }}{\pi r^{3}} \\
\gamma_{\text {max }}=\frac{\theta r}{h}
\end{gathered}
$$

donde

$T_{\max }=$ máximo torque aplicado.

$r=$ radio del plato de ensayo.

$\theta$ = ángulo de rotación.

$h=$ espesor de la muestra.

Si bien el software calcula de manera automática estos valores es de suma importancia que el radio de la muestra sea de las dimensiones del plato utilizado y el espesor de la muestra sea el especificado ya que el software la toma por defecto en un valor fijado por el operario previo al ensayo. A partir de las mediciones realizadas por el equipo se calcula:

El Módulo complejo $\left(\mathrm{G}^{*}\right)$ que expresa la resistencia total del material a deformarse. Definido como el cociente entre el torque máximo aplicado y la deformación máxima experimentada que en este ensayo esta impuesta previamente, figura 3.12.

El ángulo de fase $(\delta)$ que muestra la respuesta del material a partir de la diferencia en el tiempo entre que aparecen las deformaciones y el torque impuesto. Este parámetro da una idea del comportamiento visco elástico del material, es decir, la relación de deformación que es recuperable o elástica y la no recuperable o viscosa, figura 3.12.

Como se mencionara la muestra es sometida a una amplitud de deformación fija en cada ciclo de oscilación. Esa amplitud de deformación debe ser tal de asegurar que el material se encuentra dentro del régimen lineal visco-elástico. Con valores de amplitud de deformación por corte entre 1 a $12 \%$ se asegura estar dentro de este régimen. La elección de esta amplitud es función de la rigidez del material. Materiales blandos o ensayados a altas temperaturas serán sometidos a valores de entre 10 y $12 \%$ de deformación mientras materiales rígidos o ensayados a bajas temperaturas serán sometidos a deformaciones cercanas al $1 \%$.

Con los datos aportados por el reómetro de corte se obtiene el parámetro G*/sen $\delta$ de cada asfalto para las condiciones de frecuencia y temperatura impuestas.

Los diferentes asfaltos en estudio fueron sometidos a un barrido de temperaturas entre $40{ }^{\circ} \mathrm{C}$ y $80{ }^{\circ} \mathrm{C}$ a las frecuencias de $\omega_{1}=101 / \mathrm{s}$ y $\omega_{2}=0,61 / \mathrm{s}$. Este barrido de temperaturas se llevó a cabo sobre el material en estado original y luego de envejecido en RTFOT.

La frecuencia $\omega_{1}$ es la elegida por las especificaciones SRHP para los ensayos de caracterización de ligante en el DSR comparable a un vehículo circulando a $80 \mathrm{Km} / \mathrm{h}$. 
La $\omega_{2}$ fue elegida para aproximarse a la frecuencia correspondiente a la velocidad de circulación de la rueda del equipo de rueda cargada de forma de poder comparar los resultados.

Los ensayos en el DSR se llevaron a cabo en todos los casos con el plato de $25 \mathrm{~mm}$ y $1 \mathrm{~mm}$ de espesor de la muestra. Las amplitudes impuestas fueron tales de asegurar estar dentro del límite lineal visco elásticos de cada ligante.

\subsubsection{Medición de ZSV - Ensayo de Creep}

Las ZSV de los ligantes en estudio se determinaron en ensayos de creep en el DSR siguiendo la norma CEN prEN 15325. En este protocolo un ensayo de creep a tensión y temperatura constantes es llevado a cabo durante un lapso especificado. Las deformaciones ocurridas a lo largo del tiempo en la muestra son medidas y transformadas en compliance. Como se mencionara en el inciso 2.3.4.2.b en el capítulo 2 el compliance se define como la deformación medida dividida la tensión aplicada. De esta forma se independiza las mediciones del nivel de tensión aplicado sí se está dentro del rango lineal visco-elástico del ligante.

A partir de la curva de compliance en el tiempo la ZSV se determina a partir de los últimos 15 minutos tal como indica la ecuación 3.4.

$$
Z S V=\frac{900}{J_{\text {final }}-J_{\text {final }-15 \min }}[\text { Pa.s }]
$$

donde

$\mathrm{J}_{\text {final }}$ es el compliance al final de la etapa de fluencia

$\mathrm{J}_{\text {final-15min }}$ es el compliance 15 minutos previos al final del ensayo

El tiempo de creep es variable dependiendo del tipo de asfalto, se busca alcanzar un estado estable de flujo el cual se reconoce a partir de que existe una tasa de deformación en función del tiempo constante. La norma específica un tiempo de una hora para asfaltos convencionales y de cuatro horas para asfaltos modificados. Estos tiempos de ensayo deben ser suficientes como para alcanzar un estado estable de flujo. Los asfaltos convencionales no presentan inconvenientes en alcanzar un estado estable de flujo en menos de una hora, en cambio los asfaltos modificados si luego de cuatro horas no se alcanzó el estado estable, el ensayo se continúa por cuatro horas más. Si pasado este tiempo sigue sin alcanzarse el estado estable, se da por finalizado el ensayo y se toma la viscosidad calculada denotando que no se alcanzó el estado de flujo estable.

El nivel de tensiones aplicado se debe elegir de manera de estar dentro del régimen visco-elástico lineal del asfalto. Para definirlo se realiza un ensayo exploratorio de la respuesta del asfalto a diferentes niveles de tensión desde 500 a $20 \mathrm{~Pa}$. Se mide la viscosidad estable para cada nivel, si se está dentro del rango lineal viscoelástico las viscosidades no diferirán más de un $5 \%$. Para esta tesis, dada las características de resolución del DSR, no se pudieron aplicar tensiones más bajas que $100 \mathrm{~Pa}$. Con estos valores igualmente la respuesta de los asfaltos en estudio estuvo dentro del rango viscoelástico lineal. 


\subsubsection{Barrido de deformaciones}

Este ensayo es complementario del barrido de frecuencias para asegurar que las mediciones de este ensayo se hagan dentro del rango lineal visco-elástico del asfalto, Para ello la amplitud de oscilación impuesta en el DSR no debe ser excesiva. El límite de la deformación máxima aplicable se define en un barrido de deformaciones realizado en el DSR en donde la muestra del ligante asfáltico es sometida a amplitudes variables a una frecuencia y temperatura determinadas. Las mediciones de modulo complejo $\mathrm{G}^{*}$ para las distintas amplitudes impuestas, figura 3.13, se mantiene constante a bajas deformaciones hasta un determinado valor de para el que empieza a disminuir. Airey (2002) define el límite linear visco-elástico como aquella deformación para la cual el valor de G* disminuye a un 95 \% del máximo valor medido.

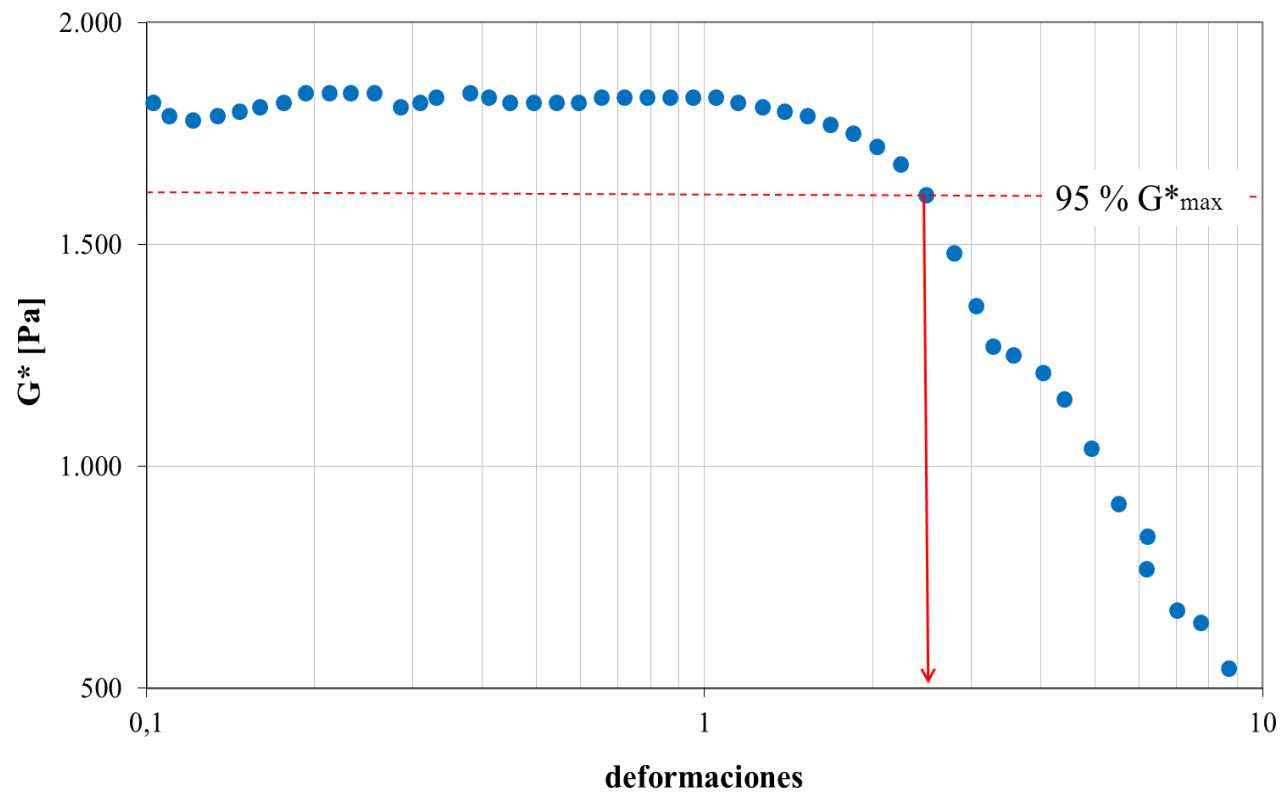

Figura 3.13. Módulo complejo (G*) versus deformaciones.

\subsubsection{Medición de la LSV - Ensayo de barrido de frecuencias}

Para determinar la LSV se empleó el método de barrido de frecuencias. Los barridos de frecuencias se realizaron para las temperaturas 10 a $80^{\circ} \mathrm{C}$ en pasos de $10{ }^{\circ} \mathrm{C}$ cada vez. Dependiendo de la temperatura de ensayo se varió la geometría del accesorio a utilizar. Para las temperaturas de 10 a $30{ }^{\circ} \mathrm{C}$ se utilizó la configuración de dos platos paralelos de $8 \mathrm{~mm}$ de diámetro y $2 \mathrm{~mm}$ de espesor de la muestra abarcando un rango de frecuencias de 0,5 a $10 \mathrm{~Hz}$. Para las temperaturas de 40 a $80{ }^{\circ} \mathrm{C}$ se utilizó la configuración de platos paralelos de $25 \mathrm{~mm}$ de diámetro y $1 \mathrm{~mm}$ de espesor de la muestra en un rango de frecuencias de 1 a $10 \mathrm{~Hz}$. Estos cambios de geometría responden a lograr una óptima medición por parte del DSR teniendo en cuenta las resoluciones del mismo y la rigidez de los ligantes.

El DSR recopila los valores de G* a las distintas frecuencias para cada temperatura de ensayo. A modo de ejemplo en la figura 3.14 se observa el resultado de los barridos de frecuencia realizados sobre el ligante $\mathrm{C} 1$ en estado original en el rango de temperaturas de 10 a $70{ }^{\circ} \mathrm{C}$. 


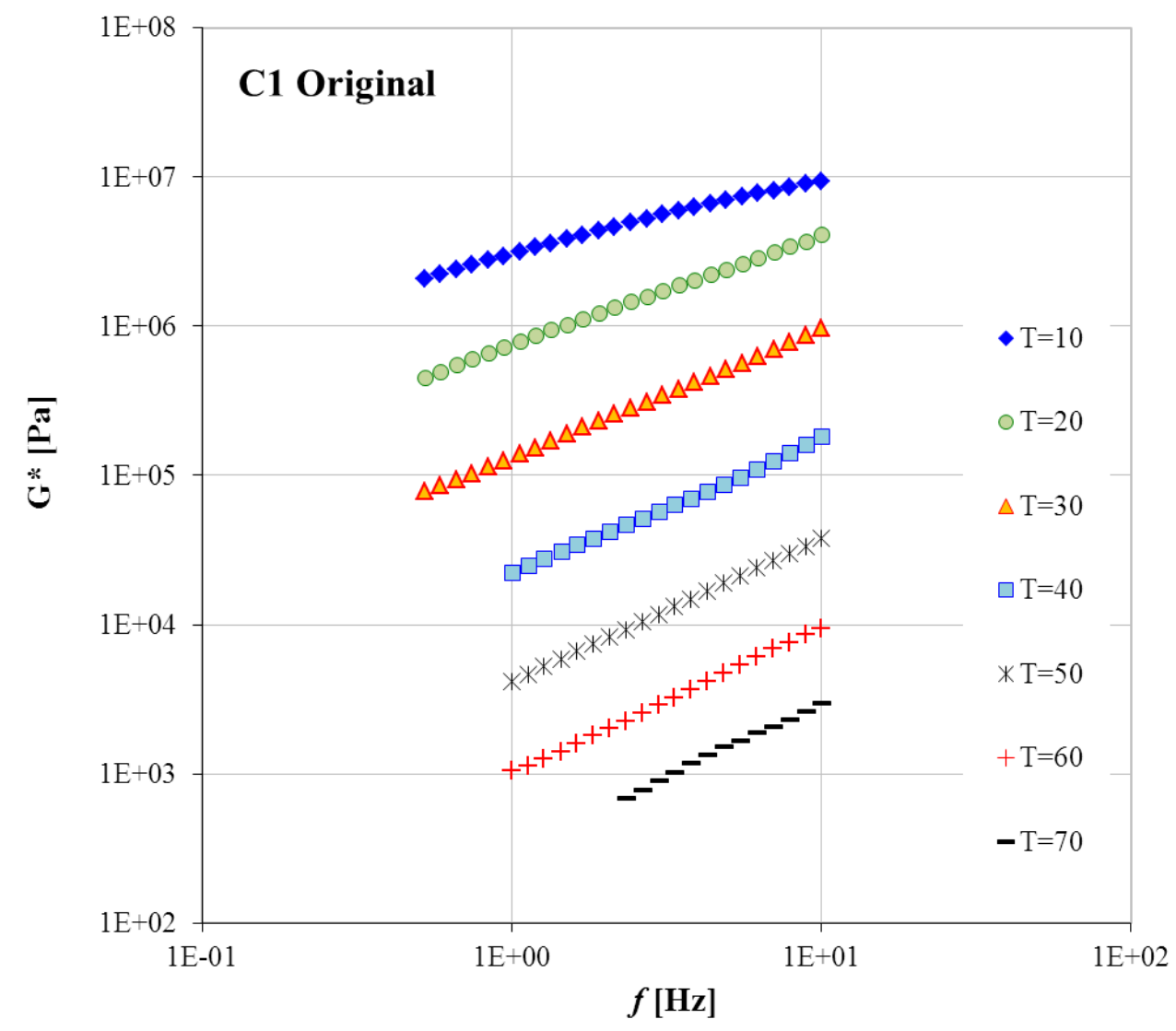

Figura 3.14. Resultado de un barrido de frecuencias en el DSR.

Todas las mediciones se realizaron asegurando estar dentro del rango lineal viscoelástico de cada ligante. Para ello se realizaron previamente barridos de deformaciones para conocer los valores de deformaciones admisibles para asegurar dicho régimen.

Con los barridos de frecuencia a diferentes temperaturas se construyeron curvas maestras del módulo G* en función de la frecuencia para las temperaturas de referencia de 50, 60, 70 y $80^{\circ} \mathrm{C}$. Para ello se utilizó el principio de superposición TiempoTemperatura (Ferry 1980, Airey 2002, Lesueur 2009), por medio del cual el efecto de incrementar la velocidad de carga (o disminuir la frecuencia) sobre las propiedades de un material es equivalente a incrementar la temperatura. De esta forma no es necesario aplicar un amplio rango de frecuencias, se puede tomar el mismo rango de frecuencias para distintas temperaturas y luego generar corrimientos de los efectos hacia las bajas o altas frecuencias, dependiendo del caso, tomando una temperatura como referencia y obtener la curva de comportamiento para un mayor rango de frecuencias al estudiado, figura 3.15 . 


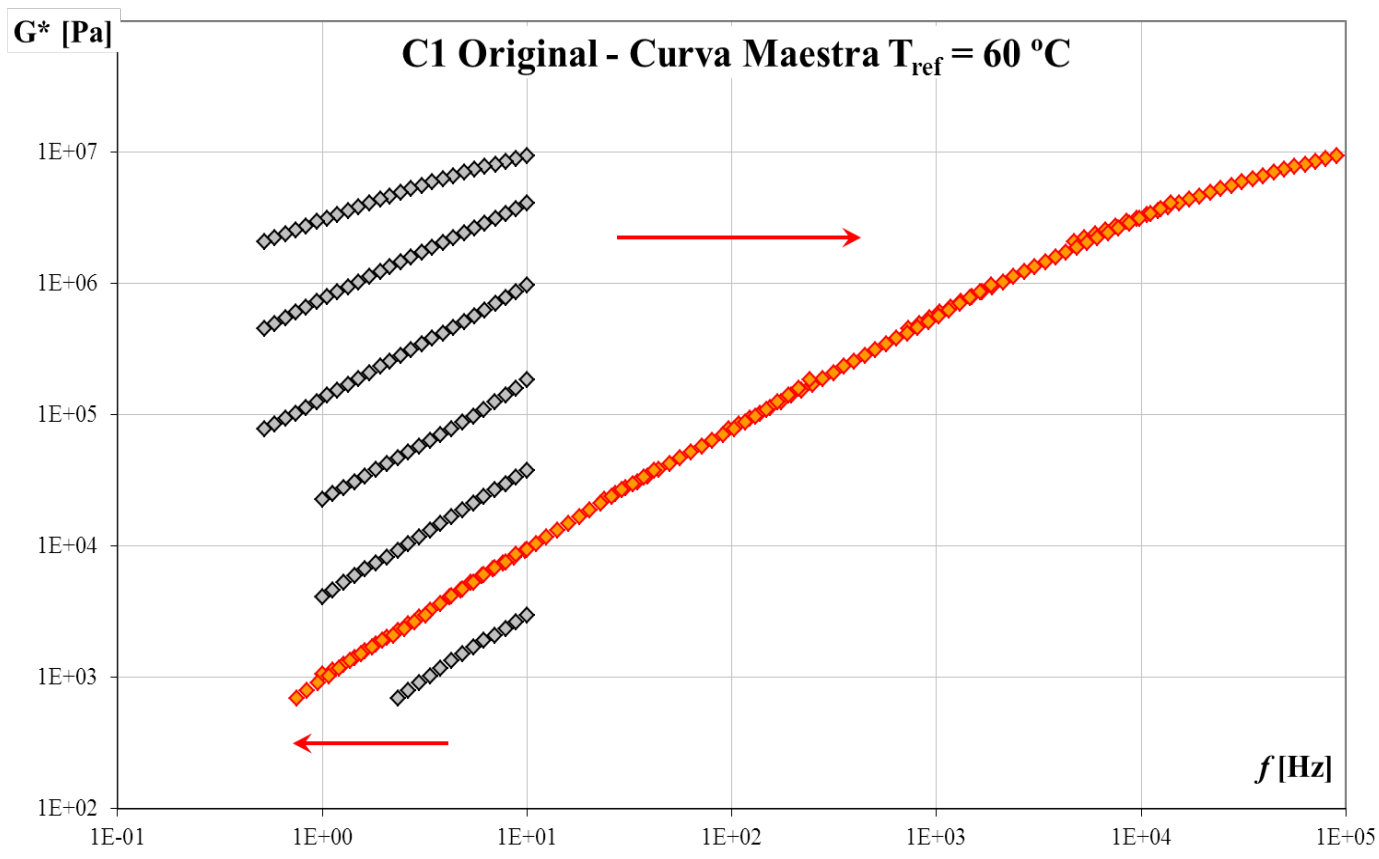

Figura 3.15. Curva maestra generada por corrimientos de los barridos de frecuencias.

Los valores de $\mathrm{G}^{*}$ se convierten en viscosidad compleja como se indica en la ecuación 3.5 y se obtiene una curva maestra de la viscosidad a la temperatura de referencia citada. Luego los datos de viscosidad compleja en función de la frecuencia se ajustaron utilizando el modelo de Cross, ecuación 3.6.

La LSV es una viscosidad a una velocidad de corte o frecuencia reducida. En esta tesis, siguiendo el criterio de De Visscher et al. (2009), se calcularon los valores de LSV a la frecuencia de $0,001 \mathrm{~Hz}$ para cada temperatura de referencia a partir de utilizar los ajustes obtenidos con el modelo de Cross.

$$
\begin{gathered}
\eta^{\prime}=\frac{G^{*}}{\omega} 7 \\
\eta^{\prime}=\eta_{\infty}^{\prime}+\frac{\eta_{0}^{\prime}-\eta_{\infty}^{\prime}}{1+(k . \omega)^{n}}
\end{gathered}
$$

donde

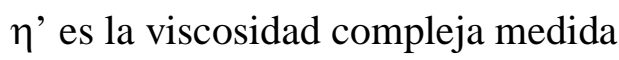

$\eta_{0}$ ' es la ZSV

$\eta_{\infty}$ ' es la viscosidad a frecuencia infinita

K y n son constantes del modelo

$\omega$ es la frecuencia

\footnotetext{
${ }^{7} \omega$ es la frecuencia expresada en $\mathrm{rad} / \mathrm{s}$.
} 


\subsubsection{Medición de deformaciones permanentes sobre mezclas asfálticas}

La medición en laboratorio de las deformaciones permanentes se realizó en condiciones controladas de carga y temperatura en un equipo de rueda cargada. Las probetas utilizadas en este ensayo se compactaron en un compactador de placa, especialmente diseñado para ello. A continuación se describen las metodologías de compactación de las probetas de mezcla asfáltica y el ensayo de rueda cargada.

\subsubsection{Compactación con compactador de placa}

Este equipo está especificado en la norma UNE 12697-33 (2006) y es utilizado para moldear placas de mezcla asfáltica para usarse en el ensayo de pista o bien para aserrar vigas para ensayos de fatiga. En él una cantidad de mezcla prefijada es compactada sobre un molde rectangular y sometida a la acción de una carga generada por un rodillo liso o equivalente, figura 3.16. El rodillo se desplaza sobre la mezcla generando un efecto de amasado a velocidad constante. Esta metodología se asemeja al procedimiento en obra y permite reproducir una amplia gama de presiones de compactación similares a la de los equipos de campo. A partir de este equipo es posible obtener probetas otorgando una energía de compactación controlada o bien hasta que se obtiene un volumen especificado y por tanto un volumen de vacíos determinado.
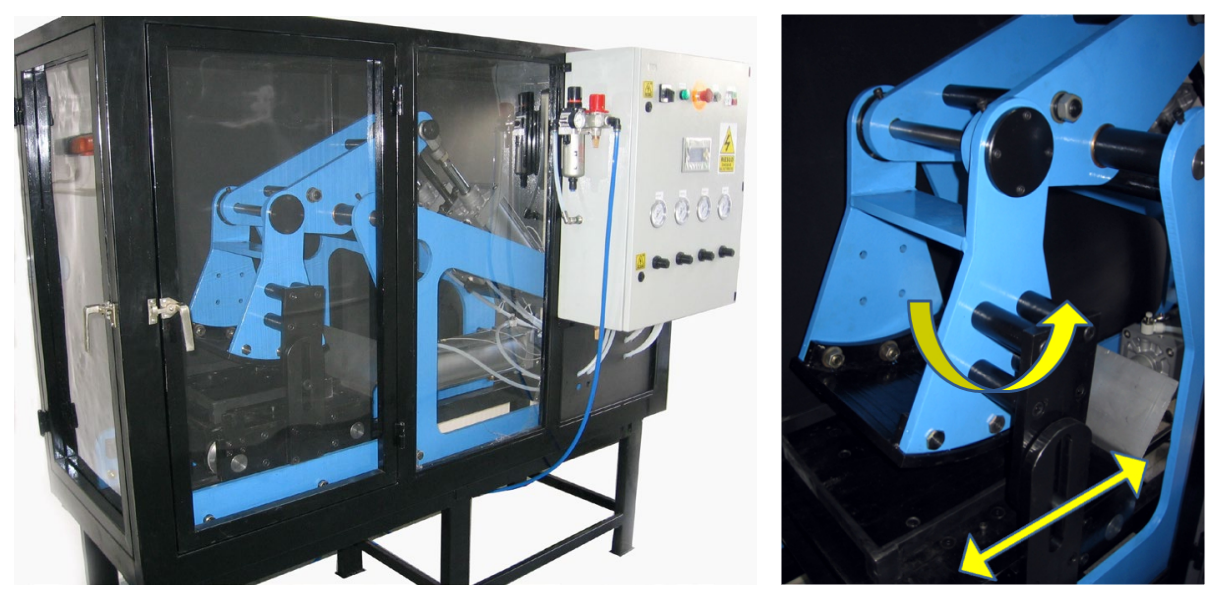

Figura 3.16. Equipo compactador de placa.

Las probetas de laboratorio para los ensayos deben tener dimensiones de $300 \mathrm{~mm}$ de lado con $50 \mathrm{~mm}$ de espesor y se compactaron en moldes específicos, figura 3.17, cuya función es la contención del material durante la compactación y las posteriores maniobras de manipuleo y ensayo.

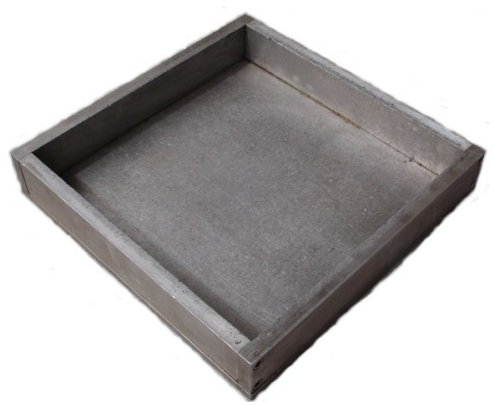

Figura 3.17. Molde para probetas de ensayo de rueda cargada. 
Las probetas se compactan para obtener un volumen previamente especificado. La masa a colocar es función de la densidad máxima de la mezcla, las dimensiones del molde, el espesor de la placa requerido y el porcentaje de vacíos buscado, ecuación 3.7. Esta masa a temperatura de compactación se vuelca sobre el molde sin segregarse y se distribuye en forma uniforme.

$$
M=1 \times 10^{-3} \cdot \text { L.l.e. } \rho_{\max } \cdot\left(\frac{100-v}{100}\right)
$$

donde

$M$ es masa de la mezcla en $\mathrm{Kg}$

$L, l$ y $e$ las dimensiones del molde en $\mathrm{mm}$

$\rho_{\text {máx }}$ densidad máxima de la mezcla en $\mathrm{Kg} / \mathrm{m}^{3}$

$v$ el porcentaje de vacíos.

Con la mezcla colocada en el molde se aplica una determinada presión mediante una placa y por medio de movimientos de la mesa inferior hacia atrás y adelante, figura 3.18, se genera un amasado de la mezcla asfáltica la cual se acomoda dentro del molde hasta lograr que toda la mezcla entre en él. Este movimiento alternativo hacia atrás y adelante equivale a una pasada. La norma UNE 12697-33 específica que todo el proceso de compactación se debe llevar a cabo con 20 a 50 pasadas.
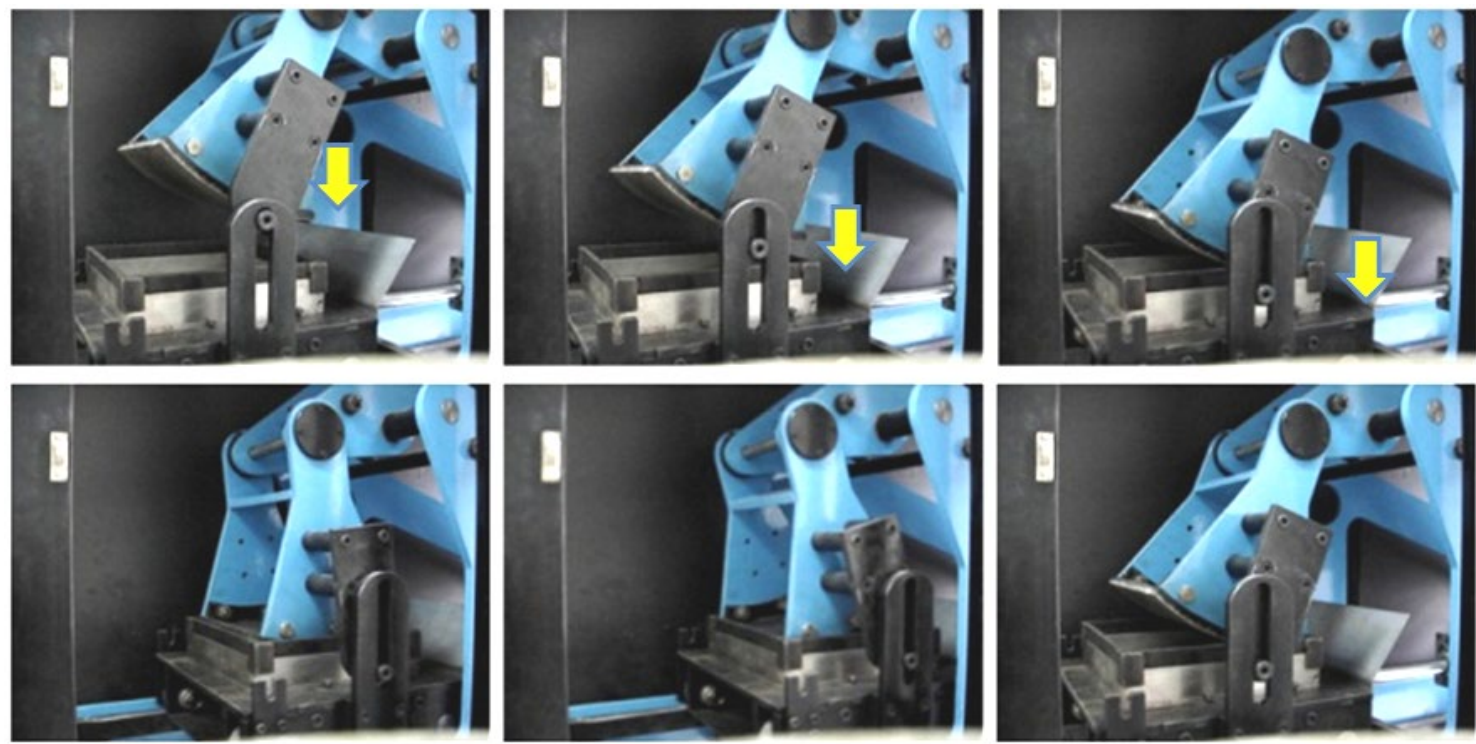

Figura 3.18. Detalle de la placa compactando.

Para un control de compactación las probetas fueron desmoldadas y se evaluaron las densidades por inmersión para asegurar que al menos se obtuvo un 98 \% de la densidad buscada. 


\subsubsection{Ensayo de rueda cargada}

El ensayo de rueda cargada se utilizó para caracterizar el desempeño frente a las deformaciones permanentes de las mezclas asfálticas en condiciones controladas de laboratorio. El equipo de ensayo, figura 3.19, responde al especificado en la norma B.S. 598 parte 110 y consiste en una rueda de goma maciza de $207 \mathrm{~mm}$ de diámetro y $47 \mathrm{~mm}$ de ancho, que cargada con $520 \pm 5 \mathrm{~N}$, se desplaza sobre una muestra de concreto asfáltico con movimiento alternativo dentro de un recorrido de $230 \mathrm{~mm}$ a razón de 21 ciclos por minuto. La norma especifica una duración del ensayo de 60 min o hasta alcanzar una profundidad de huella de $15 \mathrm{~mm}$ y una temperatura de ensayo de 45 o $60{ }^{\circ} \mathrm{C}$ con una variación de $\pm 1{ }^{\circ} \mathrm{C}$ preferentemente. En esta tesis la duración del ensayo fue de 120 minutos y las temperaturas seleccionadas fueron $50,60,70$ y $80^{\circ} \mathrm{C}$; estas temperaturas se seleccionaron ya que representan el rango de temperaturas donde se manifiestan los problemas de deformaciones permanentes en mezclas asfálticas. Durante el ensayo se midieron las deformaciones permanentes producidas en la mezcla asfáltica en intervalos de 1 minuto por medio de adquisición electrónica a través de un LVDT, figura 3.19 .
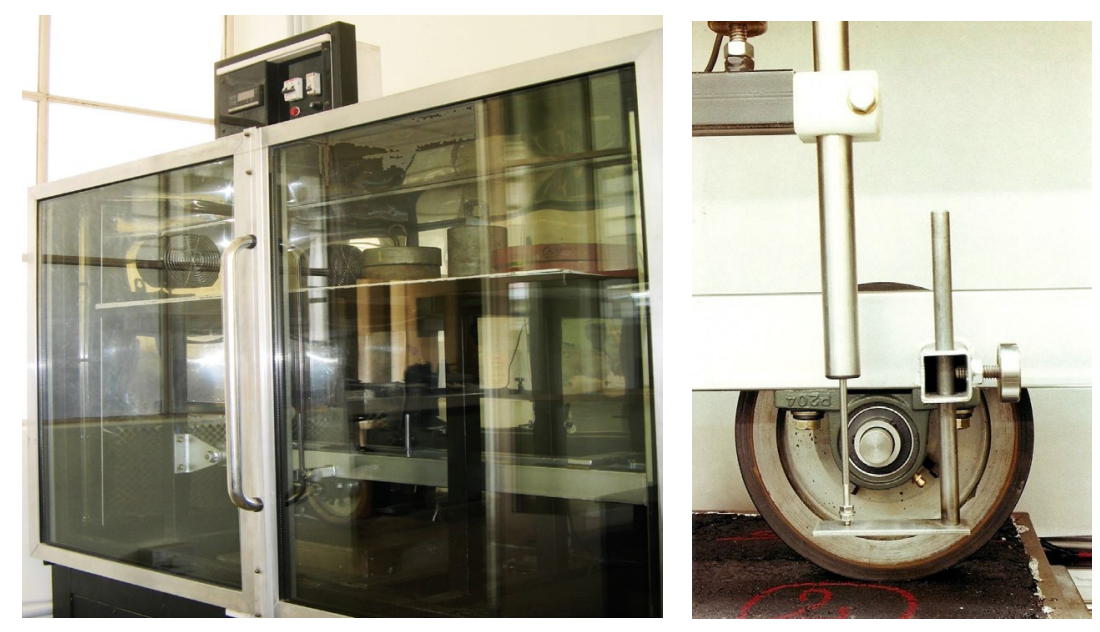

Figura 3.19: Equipo de rueda cargada. Vista general (izquierda); Detalle LVDT (derecha).

En la figura 3.20 se observa una curva típica de deformaciones permanentes $\left(\varepsilon_{p}\right)$ en función del tiempo obtenida en un ensayo de rueda cargada. El proceso de ahuellamiento en el ensayo presenta dos etapas bien diferenciadas una zona primaria en los primeros minutos del ensayo donde las deformaciones aumentan rápidamente con cambios de volumen producto de un acomodamiento inicial del material. Luego se produce una zona secundaria en la cual las deformaciones se estabilizan y la velocidad de deformación tiende a ser constante con pocos cambios de volumen. Aquí las deformaciones son del material y dependen de la resistencia que ofrezca la mezcla a deformarse, por tanto las deformaciones en esta etapa están relacionadas a las características resistentes de los materiales. Es posible que ocurra una zona de flujo terciario en donde las deformaciones vuelven a incrementarse rápidamente. Este flujo terciario es una inestabilidad asociada a deformaciones con cambio de volumen 
producto de una excesiva deformación. Este flujo terciario es difícil que ocurra en los ensayos de rueda cargada encontrándose siempre las dos primeras zonas.

El objetivo perseguido en esta tesis es evaluar las características resistentes que ofrecen los materiales frente al ahuellamiento y por lo tanto se centraran los estudios en la zona secundaria en donde la velocidad de deformación tiende a un valor constante.

A partir de los datos de deformaciones permanentes recopilados, los mismos se ajustaron al modelo potencial, ecuación 3.8. Los 10 primeros datos se descartaron ya que afectan significativamente el resultado del ajuste.

$$
\varepsilon_{p}=a \cdot t^{b}
$$

donde

$\varepsilon_{\mathrm{p}}$ son las deformaciones permanentes medidas

t es el tiempo

a y b las constantes de ajuste

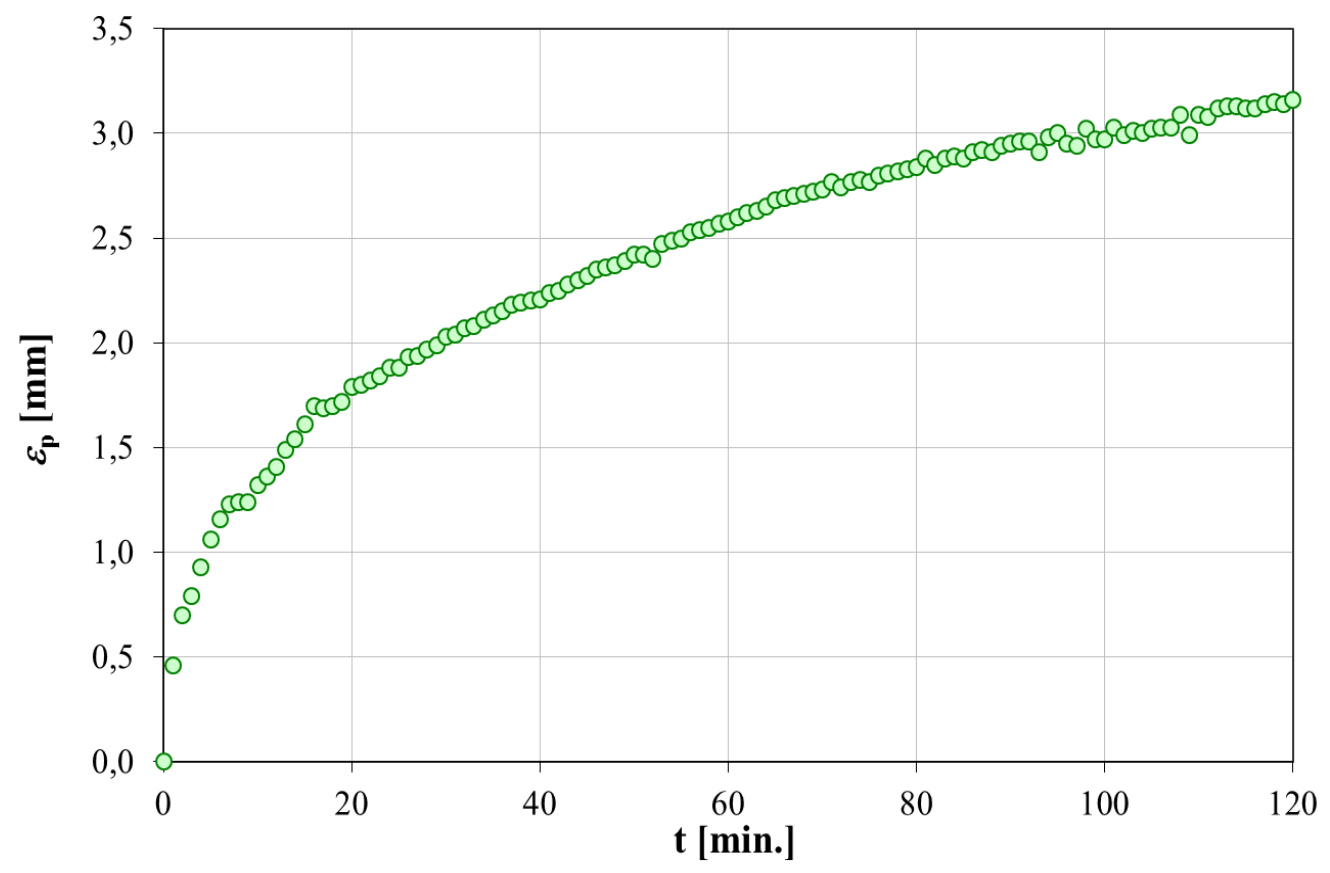

Figura 3.20. Curva típica de deformaciones permanentes en función del tiempo obtenida en un ensayo de rueda cargada.

De los datos ajustados se calcula el parámetro velocidad de deformación al final del ensayo $\left(\mathrm{Vd}_{120}\right)$. La $\mathrm{Vd}_{120}$ define la tasa de crecimiento de la profundidad de huella. Esta se determina con la ecuación 3.9, donde $\mathrm{D}_{120}$ y $\mathrm{D}_{105}$ corresponden a la deformación para 120 y 105 minutos respectivamente.

$$
V d_{120}=\frac{D_{120}-D_{105}}{15 \min }\left[\frac{\mu m}{\min }\right]
$$


La velocidad de deformación $\mathrm{Vd}_{120}$ evaluada aquí representa la respuesta de la mezcla a la condiciones impuesta en el último periodo de ensayo. Durante esta etapa el aumento de deformaciones se estabiliza tendiendo a una velocidad de crecimiento constante. Es posible calcular una velocidad de deformación para la primera parte del ensayo $\left(\mathrm{Vd}_{60}\right)$ como indica la ecuación 3.10, donde $\mathrm{D}_{60}$ y $\mathrm{D}_{45}$ corresponden a la deformación para 60 y 45 minutos respectivamente. Los valores de $\mathrm{Vd}_{60}$ son siempre mayores a los de $\mathrm{Vd}_{120}$ (Agnusdei et al. 2006 y 2007a) y se correlacionan de manera excelente con los de $\mathrm{Vd}_{120}$. Además al tomar la $\mathrm{Vd}_{60}$ es posible que esta se vea afectada por las deformaciones de la zona primaria de acomodamiento del material.

$$
V d_{60}=\frac{D_{60}-D_{45}}{15 \min }\left[\frac{\mu m}{\min }\right]
$$

En este estudio se tomara la $\mathrm{Vd}_{120}$ como parámetro distintivo de la resistencia de las mezclas asfálticas al ahuellamiento y en adelante será denominada como Velocidad de deformación ( $\mathrm{Vd}$ ), cabe aclarar también que en adelante cuando se nombre a los ahuellamientos de las mezclas se estará haciendo referencia a la Vd obtenida en el ensayo de rueda cargada.

Se podría haber elegido para la evaluación de los ahuellamientos la deformación al final del ensayo. Sin embargo este valor está afectado de un error muy variable dependiendo de las condiciones de moldeo de la probeta de ensayo y de características particulares de la misma. Al respecto es posible tener dos ensayos de una misma mezcla que presentan valores muy distintos de deformación al final del ensayo, por tanto diferente comportamiento. Sin embargo si se analizan con la Velocidad de deformación se observa que en realidad ambas probetas muestran comportamientos similares. En consecuencia la velocidad de deformación es un parámetro más confiable para caracterizar la resistencia al ahuellamiento de las mezclas en el ensayo de rueda cargada.

Las normas BS 598 y CEN 12697 permiten calcular lo que se denomina como ahuellamiento proporcional, proportional Rut depth en inglés, a partir de dividir la deformación permanente al final del ensayo por la altura de la probeta. Este parámetro en definitiva no es diferente de tomar la deformación de la probeta al final del ensayo con las implicancias mencionadas anteriormente.

Bajo la configuración de la norma BS 598 los 520 N de carga se aplican sobre una impronta de la rueda de aproximadamente $1000 \mathrm{~mm}^{2}$ que generan una presión de contacto de $520 \mathrm{kPa}$ sobre el concreto asfáltico.

En esta tesis se estudiaron dos configuraciones más de carga de 700 y $900 \mathrm{~N}$ que se corresponden con 700 y 900 kPa de presión de contacto aproximadamente. Para generar estas dos configuraciones de mayor carga sólo fue necesario aumentar el peso en la viga cantiléver. En la figura 3.21 se observan los pesos de las diferentes configuraciones de carga y en la figura 3.22 los mismos colocados en el equipo de pista. 


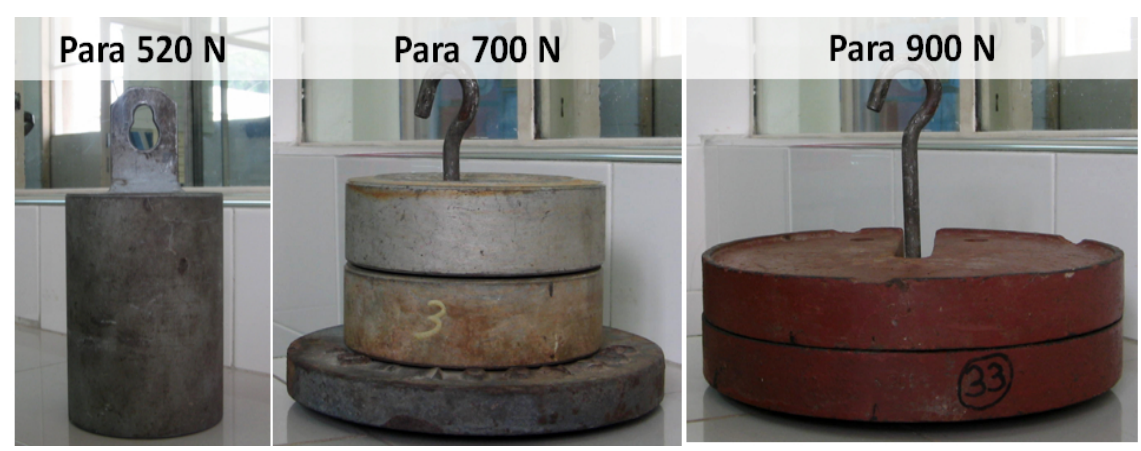

Figura 3.21.Pesos de las diferentes configuraciones de carga.
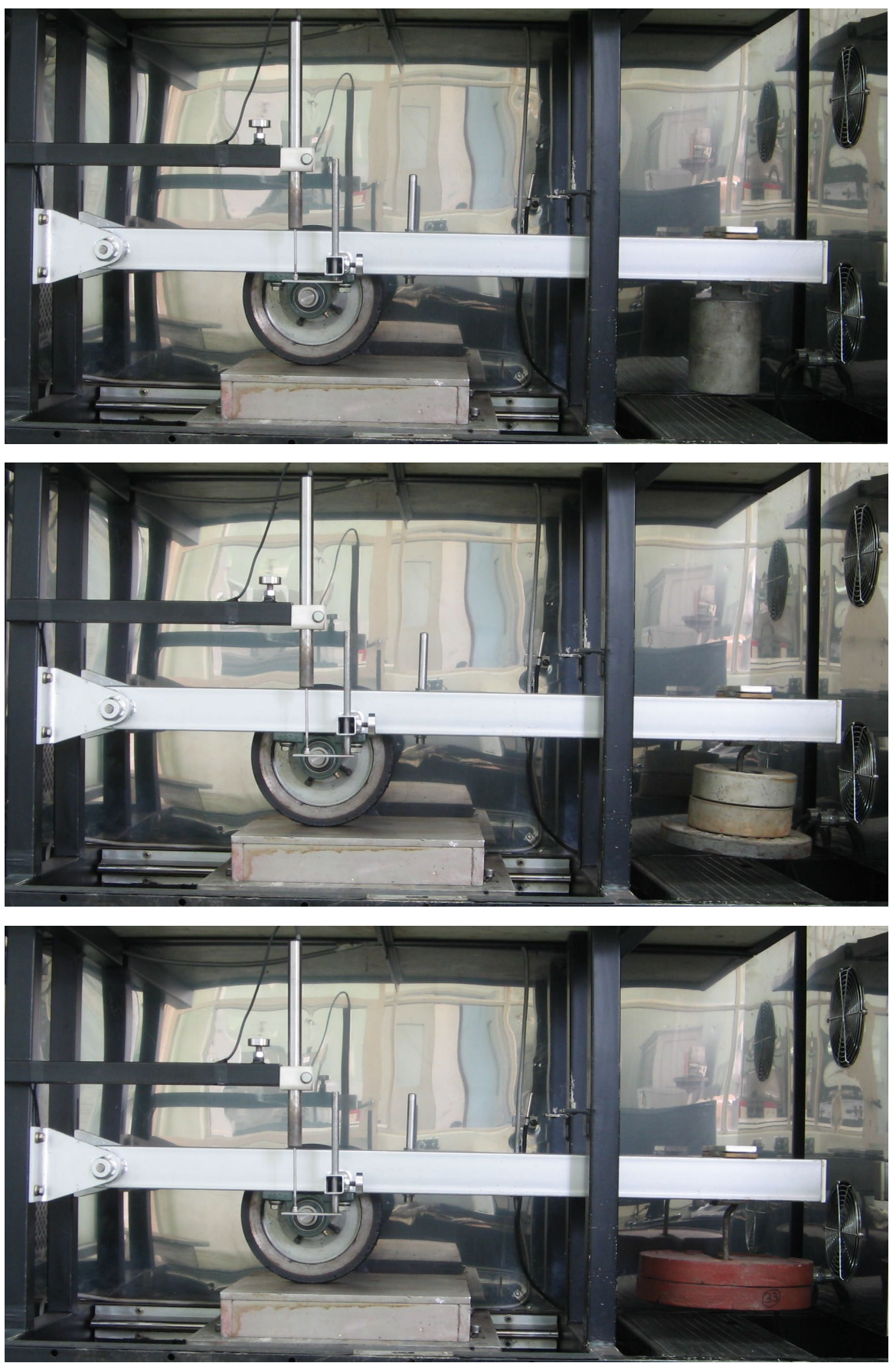

Figura 3.22. Detalle de las diferentes configuraciones de carga. 
La carga de $520 \mathrm{~N}$ del equipo de pista inglés genera una presión de contacto equivalente a una carga máxima por eje de ruedas simples de 8 tn; está es similar a la carga permitida en Argentina para un eje simple (6 tn). En Europa la nueva configuración de carga para los ensayos de rueda cargada dentro de la UNE 12697-22 es de $700 \mathrm{~N}$, lo que equivale a un eje de ruedas simple de 10,5 tn que correspondería a una sobrecarga en nuestro país. Es por eso que en este estudio se seleccionó como principal el ensayo de rueda cargada con $520 \mathrm{~N}$ y como estudio complementario el aumento de carga a $700 \mathrm{~N}$ manteniendo la velocidad de la rueda y el tiempo de ensayo de la BS 598. Por otro lado existe una vasta experiencia en el país con el equipo de rueda cargada según la norma BS 598 parte 110 (Agnusdei et al. 2006, 2007a y b, 2008).

\subsection{Otras propiedades físicas y mecánicas de los asfaltos y de las mezclas}

Otras propiedades físicas y mecánicas de asfaltos y mezclas fueron utilizadas en el desarrollo de la tesis para el diseño y caracterización. Estos métodos se encuentran normalizados y son extensamente conocidos en el campo vial. En la Tabla 3.9 se indican los métodos empleados y sus respectivas normas o recomendaciones de ensayo.

Dentro de las determinaciones tradicionales se realizaron mediciones de viscosidad Brookfield a altas temperaturas (135, 150, 170 y $190{ }^{\circ} \mathrm{C}$ ) para la obtención de las curvas de viscosidad en función de la temperatura que se utilizaron para definir las temperaturas de mezclado y compactación de las mezclas elaboradas con los diferentes ligantes según el criterio de equiviscosidad. Según este criterio las temperaturas de mezclado y compactación se definen para una viscosidad de 0,28 y 0,17 Pa.s.

Tabla 3.9. Restantes ensayos realizados sobre asfaltos, agregados y mezclas asfálticas.

\begin{tabular}{lll}
\hline Ensayos & Norma & Observaciones \\
\hline Asfaltos & \\
\hline Penetración a $25^{\circ} \mathrm{C}$ & IRAM 6576 \\
& ASTM D 5 \\
Punto de ablandamiento & IRAM 6841 \\
& ASTM D 36 \\
Viscosidad Brookfield & IRAM 6837 \\
& ASTM D 4402 \\
Punto de inflamación & IRAM 6555 \\
& ASTM D 92 \\
Ductilidad a $25^{\circ} \mathrm{C}$ & IRAM 6579 \\
Índice de penetración (IP) & ASTM D 113 \\
Recuperación elástica por torsión & IRAM 6604 \\
\hline
\end{tabular}


Tabla 3.9 (continuación). Restantes ensayos realizados sobre asfaltos, agregados y mezclas asfálticas.

\begin{tabular}{|c|c|c|}
\hline Ensayos & Norma & Observaciones \\
\hline \multicolumn{3}{|l|}{ Asfaltos } \\
\hline $\begin{array}{l}\text { Determinación del módulo complejo } \\
\left(G^{*}\right) \text { y ángulo de fase }(\delta) \text { con el DSR }\end{array}$ & ASTM D 7175 & $\begin{array}{l}\text { Normas de referencia para la } \\
\text { determinación del PG }\end{array}$ \\
\hline $\begin{array}{l}\text { Determinación de la temperatura de baja } \\
\text { con el Binder Beam Rheometer (BBR) }\end{array}$ & ASTM D 6816 & $\begin{array}{l}\text { Normas de referencia para la } \\
\text { determinación del PG }\end{array}$ \\
\hline $\begin{array}{l}\text { Determinación del módulo de creep en } \\
\text { flexión - BBR }\end{array}$ & ASTM D 6648 & $\begin{array}{l}\text { Normas de referencia para la } \\
\text { determinación del PG }\end{array}$ \\
\hline $\begin{array}{l}\text { Propiedades de fractura - Direct Tensile } \\
\text { Test (DTT) }\end{array}$ & ASTM D 6723 & $\begin{array}{l}\text { Normas de referencia para la } \\
\text { determinación del PG }\end{array}$ \\
\hline \multicolumn{3}{|l|}{ Agregados } \\
\hline $\begin{array}{l}\text { Peso específico y absorción Agregado } \\
\text { grueso }\end{array}$ & $\begin{array}{l}\text { IRAM } 1533 \\
\text { ASTM C } 127\end{array}$ & \\
\hline $\begin{array}{l}\text { Peso específico y absorción Agregado } \\
\text { fino }\end{array}$ & IRAM 1520 & \\
\hline Peso específico filler y cal & NLT 179 & \\
\hline Desgaste Los Ángeles & $\begin{array}{l}\text { IRAM } 1532 \\
\text { ASTM C } 131\end{array}$ & \\
\hline Granulometría filler y cal & ASTM D 546 & \\
\hline Equivalente arena & $\begin{array}{l}\text { IRAM } 1682 \\
\text { ASTM D } 2419\end{array}$ & \\
\hline Concentración crítica del filler & IRAM 1542 & \\
\hline \multicolumn{3}{|l|}{ Mezclas } \\
\hline Densidad por inmersión en agua & ASTM D 2726 & \\
\hline Densidad en parafina & ASTM D 1188 & \\
\hline Densidad máxima Rice & ASTM D 2041 & Norma IRAM en estudio \\
\hline Moldeo Marshall** & ASTM D 6926 & Norma IRAM en estudio \\
\hline Estabilidad y fluencia Marshall** & ASTM D 6927 & Norma IRAM en estudio \\
\hline Resistencia a tracción indirecta & $\begin{array}{l}\text { IRAM } 6846 \\
\text { ASTM D } 6931\end{array}$ & \\
\hline
\end{tabular}

* NLT. Normativa española

**Procedimiento dentro de las especificaciones de Vialidad Nación (VN E9-86) 



\section{Capítulo 4}

\section{Estudio en los asfaltos de las propiedades reológicas vinculadas a las deformaciones permanentes}

\subsection{Introducción}

En este capítulo se estudian las propiedades reológicas G*/sen $\delta$, ZSV y LSV de los diferentes ligantes que serán posteriormente empleados en la elaboración de concretos asfálticos. Como fuera presentado en el capítulo 3, ocho asfaltos de producción comercial en Argentina fueron seleccionados para este estudio, incluyendo cuatro asfaltos convencionales (C1, C2, C3 y C4), un asfalto multigrado (M) y tres asfaltos modificados con polímeros (MP1, MP2 y MP3).

Sobre los diferentes asfaltos se estudió, en primer lugar los resultados del parámetro de la especificación SHRP para un rango de temperaturas dentro del cual se producen las deformaciones permanentes y se discute sobre los valores obtenidos. Luego se vuelcan los resultados obtenidos de ZSV y LSV y se comparan los diferentes métodos de medición para definir un protocolo de ensayo para las condiciones de esta tesis definiéndose cuál de ellos es el más conveniente en cuanto a tiempos de ensayo, repetitividad y reproductibilidad así como para una adecuada caracterización de los diferentes asfaltos. Finalmente se concluye con una comparación entre las propiedades reológicas estudiadas.

\subsection{Parámetro G*/sen $\delta$}

El parámetro G*/sen $\delta$ se midió en el DSR para dos frecuencias de ensayo, la especificada en la norma ASTM D 6373 de $10 \mathrm{rad} / \mathrm{s}$, correspondiente a un vehículo circulando a $80 \mathrm{~km} / \mathrm{h}$, y otra de 0,6 rad/s similar a la velocidad de la rueda en el ensayo de rueda cargada.

La elección de la frecuencia de ensayo de 0,6 rad/s se tomó en cuenta debido a que la frecuencia propuesta por SHRP de $10 \mathrm{rad} / \mathrm{s}$ no representa bien el comportamiento de todos los tipos de asfalto (Bahia et al. 2001) y además es una frecuencia asociada a 
velocidades de carga rápida que no son las que de hecho ocasionan los problemas de deformaciones permanentes en los pavimentos.

Por su parte la velocidad de la rueda del equipo de pista se puede asimilar a una frecuencia de 0,1 rad/s aproximadamente. Si bien se pretendió estudiar los valores de $\mathrm{G}^{*} / \operatorname{sen} \delta$ a una frecuencia igual a la de la velocidad de la rueda, esto no fue posible debido a la resolución del reómetro. La frecuencia de 0,6 rad/s fue la menor frecuencia que se pudo aplicar en el DSR de manera que los datos medidos sean confiables y estén dentro de los valores admisibles para el equipo.

En las tablas 4.1 y 4.2 se volcaron los valores obtenidos del G*/sen $\delta$ para el rango de temperatura entre 50 y $80{ }^{\circ} \mathrm{C}$ a las frecuencias mencionadas respectivamente. Se presenta aquí los resultados para los asfaltos en estado original y luego de envejecido en RTFOT.

Tabla 4.1. Resultados de $\mathrm{G}^{*} / \mathrm{sen} \delta[\mathrm{Pa}]$ a $\omega=10 \mathrm{rad} / \mathrm{s}$.

\begin{tabular}{|c|c|c|c|c|c|c|c|c|}
\hline $\mathrm{T}\left[{ }^{\circ} \mathrm{C}\right]$ & C1 & $\mathrm{C} 2$ & C3 & C4 & M & MP1 & MP2 & MP3 \\
\hline \multicolumn{9}{|c|}{ Original } \\
\hline 50 & 5366 & 8652 & 11807 & 59715 & 21571 & 13062 & 9438 & 13333 \\
\hline 60 & 1513 & 2142 & 2829 & 11540 & 6906 & 4465 & 3194 & 4821 \\
\hline 70 & 519 & 658 & 845 & 2875 & 2637 & 1802 & 1278 & 2040 \\
\hline 80 & - & - & - & 862 & 1145 & 821 & 578 & 968 \\
\hline$a^{*}$ & $-6,945$ & $-7,658$ & $-7,838$ & $-9,545$ & $-6,247$ & $-5,887$ & $-5,943$ & $-5,580$ \\
\hline$b^{*}$ & 12,529 & 13,948 & 14,388 & 18,135 & 11,947 & 11,118 & 11,071 & 10,605 \\
\hline $\mathrm{R}^{2}$ & 0,996 & 0,997 & 0,997 & 0,996 & 0,995 & 0,980 & 0,999 & 0,999 \\
\hline \multicolumn{9}{|c|}{ Envejecido en RTFOT } \\
\hline 50 & 9724 & 16166 & 23538 & 119937 & 38460 & 25298 & 17463 & 19234 \\
\hline 60 & 2568 & 3948 & 5496 & 21602 & 12371 & 7470 & 6124 & 6197 \\
\hline 70 & 833 & 1199 & 1607 & 5071 & 4742 & 2663 & 2525 & 2378 \\
\hline 80 & - & - & - & 1445 & 2066 & 1090 & 1172 & 1037 \\
\hline $\mathrm{a}$ & $-7,303$ & $-7,733$ & $-7,979$ & $-9,402$ & $-6,221$ & $-6,690$ & $-5,747$ & $-6,213$ \\
\hline b & 13,396 & 14,346 & 14,927 & 18,053 & 12,154 & 12,770 & 11,006 & 11,839 \\
\hline $\mathrm{R}^{2}$ & 0,992 & 0,998 & 0,999 & 0,996 & 0,995 & 0,996 & 0,994 & 0,999 \\
\hline
\end{tabular}

*Parámetros de ajuste de datos al modelo $\log (G * / \operatorname{sen} \delta)=a \cdot \log (T)+b$ 
Tabla 4.2. Resultados de $\mathrm{G} * / \mathrm{sen} \delta[\mathrm{Pa}]$ a $\omega=0,6 \mathrm{rad} / \mathrm{s}$.

\begin{tabular}{ccccccccc}
\hline $\mathrm{T}\left[{ }^{\circ} \mathrm{C}\right]$ & $\mathrm{C} 1$ & $\mathrm{C} 2$ & $\mathrm{C} 3$ & $\mathrm{C} 4$ & $\mathrm{M}$ & $\mathrm{MP} 1$ & $\mathrm{MP} 2$ & $\mathrm{MP3}$ \\
\hline \multicolumn{7}{c}{ Original } \\
\hline 50 & 575 & 1044 & 1314 & 5946 & 2619 & 1952 & 1746 & 1802 \\
60 & 199 & 329 & 496 & 1091 & 765 & 471 & 988 & 891 \\
70 & 82 & 127 & 217 & 260 & 270 & 141 & 610 & 344 \\
80 & - & - & - & - & 110 & - & 403 & 178 \\
\hline $\mathrm{a}$ & $-5,832$ & $-6,333$ & $-4,565$ & $-9,301$ & -6.066 & $-7,799$ & $-3,125$ & $-4,923$ \\
$\mathrm{~b}$ & 9,669 & 10,779 & 7,903 & 16,577 & 10,726 & 13,541 & 5,552 & 8,619 \\
$\mathrm{R}^{2}$ & 0,995 & 0,995 & 0,931 & 0,999 & 0,999 & 0,999 & 0,916 & 0,985 \\
\hline & Envejecido en RTFOT & & & & & \\
\hline 50 & 972 & 1648 & 2140 & 9818 & 7674 & 3282 & 1837 & 2590 \\
60 & 272 & 453 & 631 & 1829 & 2230 & 1243 & 550 & 979 \\
70 & 92 & 152 & 189 & 442 & 784 & 547 & 199 & 430 \\
80 & - & - & - & - & 317 & 269 & - & 211 \\
\hline $\mathrm{a}$ & $-7,001$ & $-7,087$ & $-7,219$ & $-9,219$ & $-6,778$ & $-5,326$ & $-6,613$ & $-5,334$ \\
$\mathrm{~b}$ & 11,883 & 12,257 & 12,596 & 16,654 & 12,401 & 9,565 & 11,500 & 9,476 \\
$\mathrm{R}^{2}$ & 0,992 & 0,994 & 0,994 & 0,997 & 0,998 & 0,996 & 0,999 & 0,983 \\
\hline
\end{tabular}

Al realizar un análisis simplificado de los resultados obtenidos tomando valores individuales de diferentes ligantes en estado original se observa que a la temperatura de $60{ }^{\circ} \mathrm{C}$ los ligantes C3 y MP2 presentan valores similares de G*/sen $\delta$ para la frecuencia de $10 \mathrm{rad} / \mathrm{s}$, iguales a 2829 y $3124 \mathrm{~Pa}$ respectivamente. Esto indicaría que ambos asfaltos tendrían un comportamiento similar frente a las deformaciones permanentes en una mezcla asfáltica. Sin embargo la realidad marca que el asfalto MP2 es de mejores prestaciones en un pavimento colocado; en consecuencia es posible afirmar que a priori el parámetro $\mathrm{G}^{*} / \mathrm{sen} \delta$ a $10 \mathrm{rad} / \mathrm{s}$ no brinda una buena (o al menos completa) caracterización de los asfaltos modificados. Por el contrario, al considerar los valores de $\mathrm{G} * /$ sen $\delta$ para los mismos asfaltos y a la misma temperatura (C3 y MP2 a $60{ }^{\circ} \mathrm{C}$ ) pero a la frecuencia de 0,6 rad/s se observa que ahora sí el ligante MP2 tendría un mejor comportamiento ya que el valor de $\mathrm{G}^{*} / \mathrm{sen} \delta$ duplica al del ligante C3, $988 \mathrm{~Pa}$ contra 496 Pa respectivamente.

En las figuras 4.1 y 4.2 se muestra la variación del parámetro G*/sen $\delta$ para la frecuencia de $10 \mathrm{rad} / \mathrm{s}$ en función de la temperatura de los diferentes asfaltos estudiados en estado original y luego de envejecidos en RTFOT respectivamente. En primera instancia surge como los asfaltos modificados presentan menor susceptibilidad térmica que los asfaltos convencionales. Tomando los límites de la especificación SHRP de 1 y 
2,2 kPa para el estado original y envejecido respectivamente (figuras 4.1 y 4.2) se observa que los asfaltos modificados presentan un rango de temperaturas más amplio que los asfaltos convencionales en donde tienen buenas prestaciones frente a las deformaciones permanentes como es de esperarse salvo el caso del asfalto C4. Este hecho se refleja en los valores de temperatura de alta de los asfaltos en el grado de desempeño (PG), tabla 3.1 del capítulo 3, en donde los asfaltos modificados tienen valores de temperatura de alta de $70{ }^{\circ} \mathrm{C}$ o mayores mientras que los convencionales, salvo el caso del C4, presentan temperaturas de alta por debajo de $64{ }^{\circ} \mathrm{C}$.

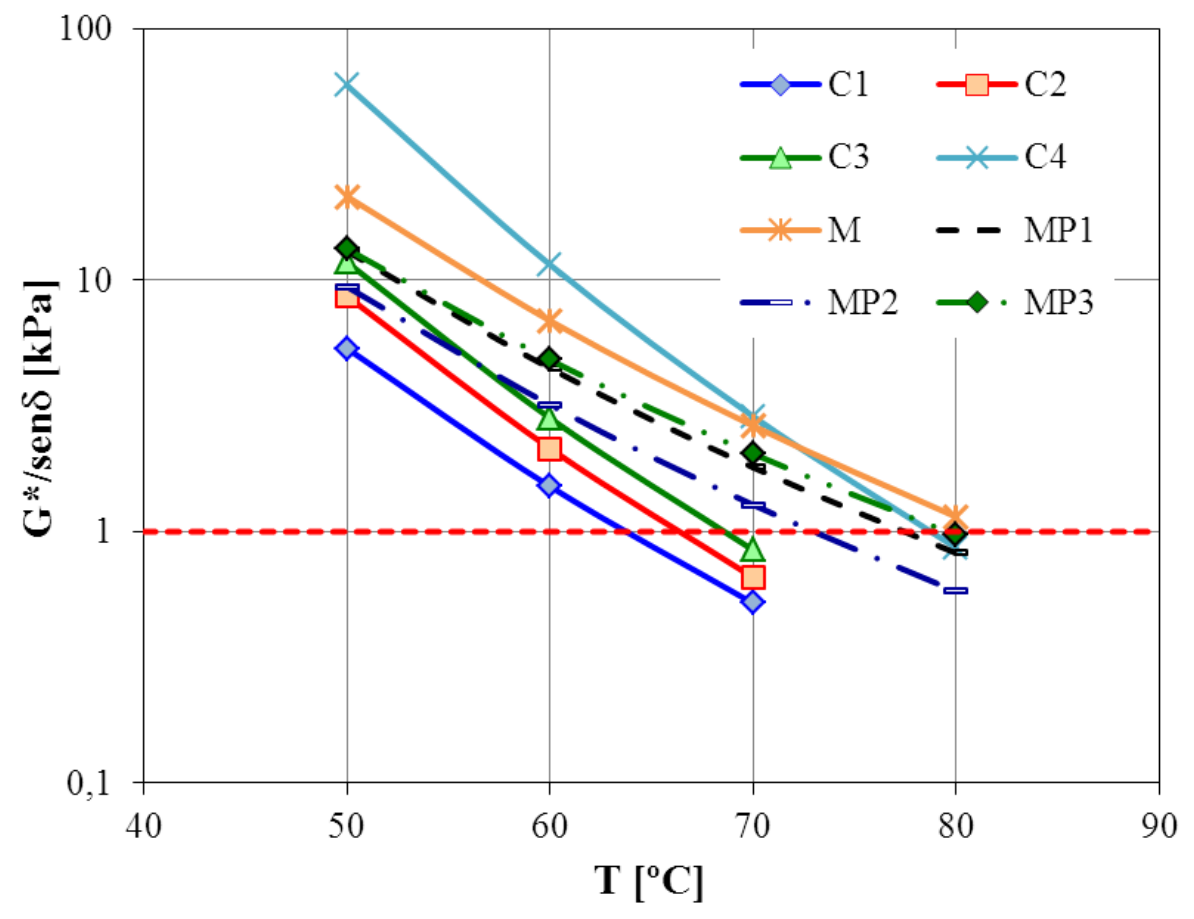

Figura 4.1. $\mathrm{G} * / \mathrm{sen} \delta$ vs $\mathrm{T}-\omega_{1}=10 \mathrm{rad} / \mathrm{s}$. Asfaltos en estado original.

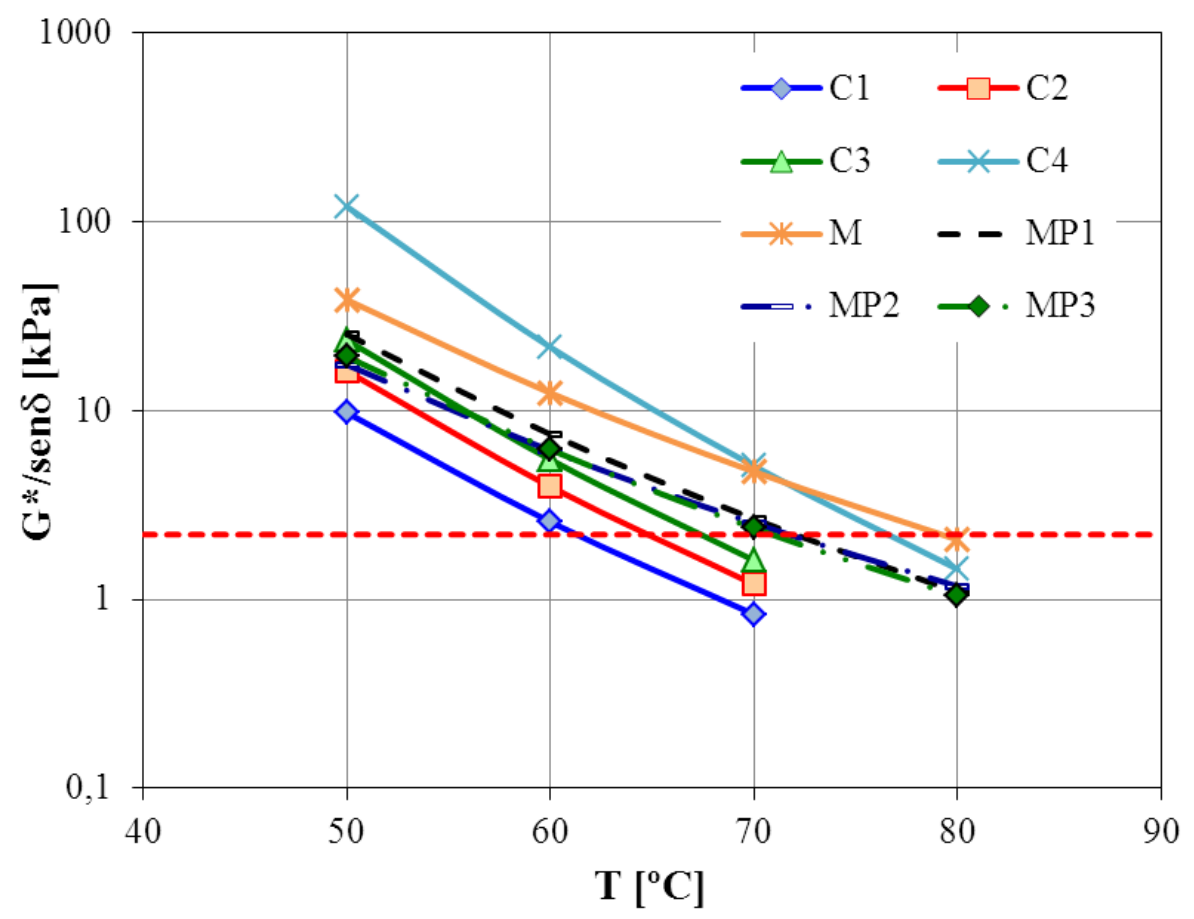

Figura 4.2. G*/sen $\delta$ vs $\mathrm{T}-\omega_{1}=10 \mathrm{rad} / \mathrm{s}$. Asfaltos envejecidos en RTFOT. 
Las figuras 4.3 y 4.4 muestran los datos de $\mathrm{G}^{*} / \mathrm{sen} \delta$ para la frecuencia de $0,6 \mathrm{rad} / \mathrm{s}$ en función de la temperatura de los diferentes asfaltos estudiados en estado original y luego de envejecidos en RTFOT respectivamente. Se observa que los valores medidos son menores que los valores para la frecuencia de $10 \mathrm{rad} / \mathrm{s}$. Esto se debe a la naturaleza visco-elástica de los asfaltos. Al imponer una menor velocidad de carga el material tiene la posibilidad de relajar las tensiones y por tanto presenta una menor rigidez, un menor modulo $G^{*}$. En definitiva esto es lo que se buscaba al usar una menor frecuencia de carga, poner de manifiesto la respuesta del asfalto bajo velocidades de carga lenta donde el problema de las deformaciones permanentes es importante.

Se observa en la figura 4.3 como la menor frecuencia de carga mejora la respuesta de los ligantes MP2 y MP3, ambos modificados con polímero SBS, respecto a los convencionales debido a su menor susceptibilidad térmica. La menor velocidad de carga permite que la gran recuperación visco-elástica retardada que poseen estos ligantes se manifieste y sea tenida en cuenta dentro del parámetro $G^{*} /$ sen $\delta$ ya sea por un aumento en el valor de $\mathrm{G}^{*}$ o en la disminución de $\delta$. En el caso del MP1 (modificado con EVA), figura 4.3, se observa que la susceptibilidad térmica aumenta siendo aún mayor que la de los ligantes convencionales. Este es un comportamiento indeseable de un asfalto, más si es modificado con polímero.

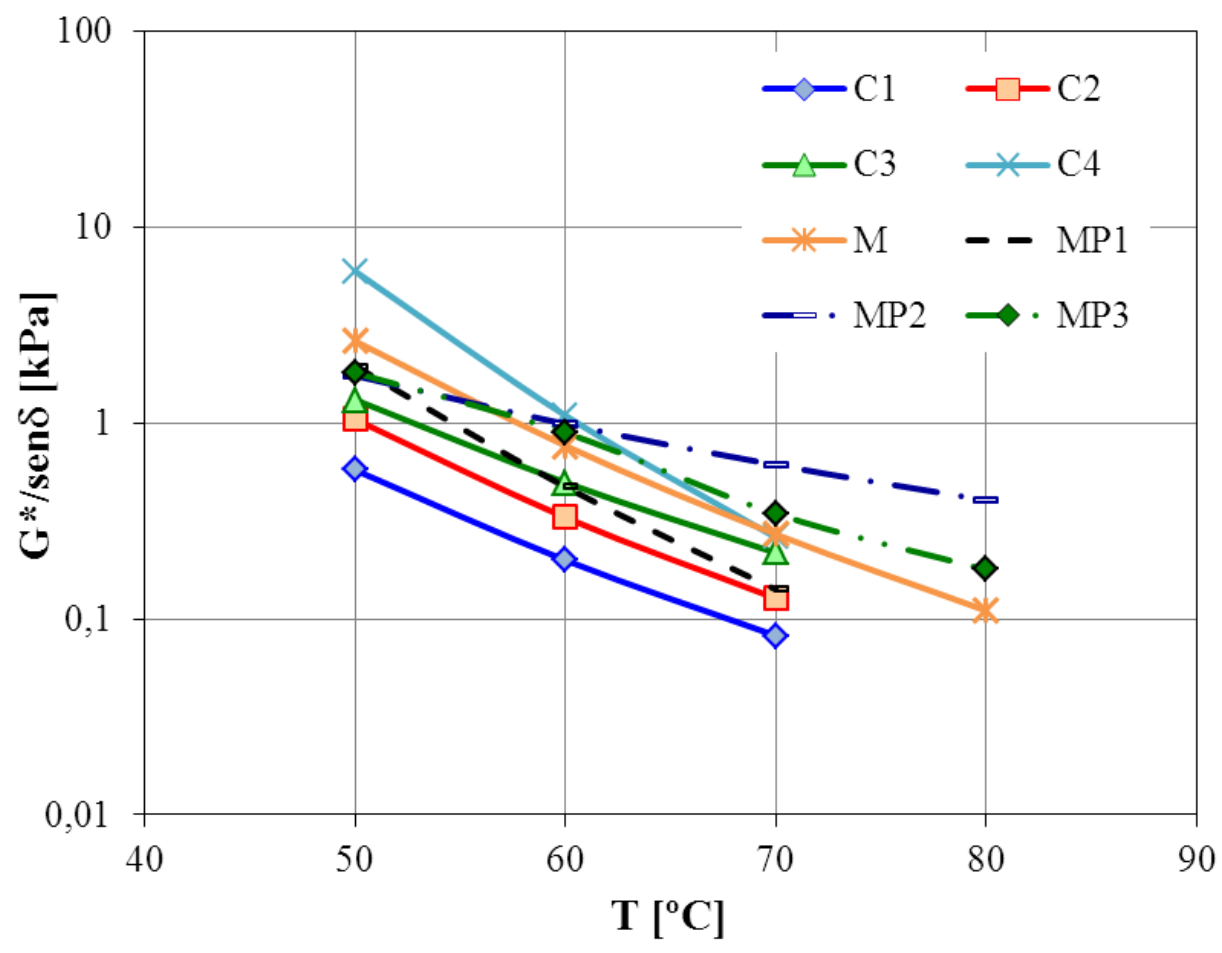

Figura 4.3. $\mathrm{G} * / \operatorname{sen} \delta$ vs $\mathrm{T}-\omega_{2}=0,61 / \mathrm{s}$. Asfaltos en estado original. 


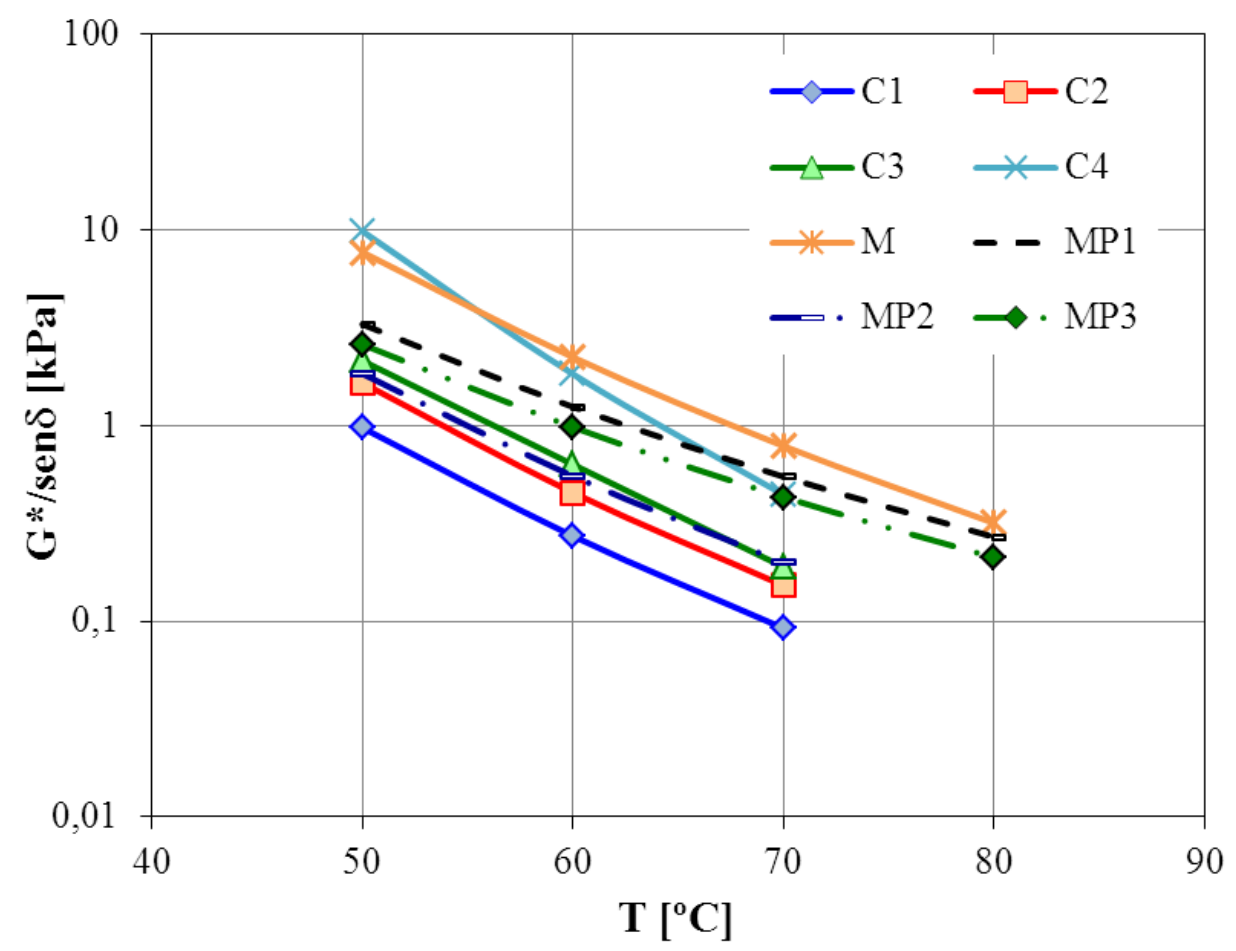

Figura 4.4. $\mathrm{G} * / \operatorname{sen} \delta$ vs T $-\omega_{2}=0,61 / \mathrm{s}$. Asfaltos envejecidos en RTFOT.

Un hecho interesante es el que se observó en el caso de MP2 (modificado con polímero SBS). Este asfalto en estado original para la frecuencia de 0,6 rad/s presentó uno de los mejores comportamientos para todo el rango de temperaturas con valores altos de $\mathrm{G}^{*} / \mathrm{sen} \delta$. Sin embargo luego de envejecido en RTFOT su comportamiento decayó notablemente en comparación con los demás ligantes, siendo similar al de C3. Este hecho no se vió reflejado en este asfalto a la frecuencia de $10 \mathrm{rad} / \mathrm{s}$. De manera opuesta el ligante MP1 (modificado con polímero EVA) mostró una mejora en el comportamiento con el envejecimiento en RTFOT respecto al estado original para la frecuencia de $0,6 \mathrm{rad} / \mathrm{s}$.

Como conclusión preliminar la frecuencia de $0,6 \mathrm{rad} / \mathrm{s}$ se presenta como una mejor alternativa para la caracterización de los asfaltos al representar una velocidad de carga lenta y permite manifestar las diferencias en el comportamiento de los distintos ligantes. La frecuencia de $10 \mathrm{rad} / \mathrm{s}$ representa una velocidad de carga rápida que, si la tuviere, no permite que se manifieste la recuperación visco-elástica retardada del ligante como es el caso de los asfaltos modificados con polímero.

\subsection{Medición de la ZSV y la LSV}

Uno de los objetivos específicos de la tesis era comparar los resultados de ZSV y LSV medidos respectivamente por medio de los métodos de creep y del barrido de frecuencias sobre diferentes ligantes de producción comercial en Argentina. Por tal motivo sobre cada ligante se repitieron 7 ensayos para cada método para poder realizar un análisis estadístico. En dicha comparación se utilizaron seis asfaltos; tres convencionales (C1, C2 y C3), uno multigrado (M) y dos modificados con polímeros (MP1 y MP2 con polímeros EVA y SBS respectivamente). En todos los ensayos se tomó $60{ }^{\circ} \mathrm{C}$ como temperatura de referencia por ser una de las más altas temperaturas 
que se pueden suscitar en un pavimento, y por ser la más comúnmente empleada en ensayos de caracterización de ligantes asfálticos.

Previo a los ensayos de barrido de frecuencias y siguiendo la propuesta de Airey (2002), se llevaron a cabo sobre todos los ligantes ensayos de barridos de deformaciones para las frecuencias de 1 y $10 \mathrm{~Hz}$ (figura 4.5) con el propósito de definir las deformaciones límites del régimen visco-elástico de cada ligante. La tabla 4.3 muestra los límites de deformación máxima obtenidos.
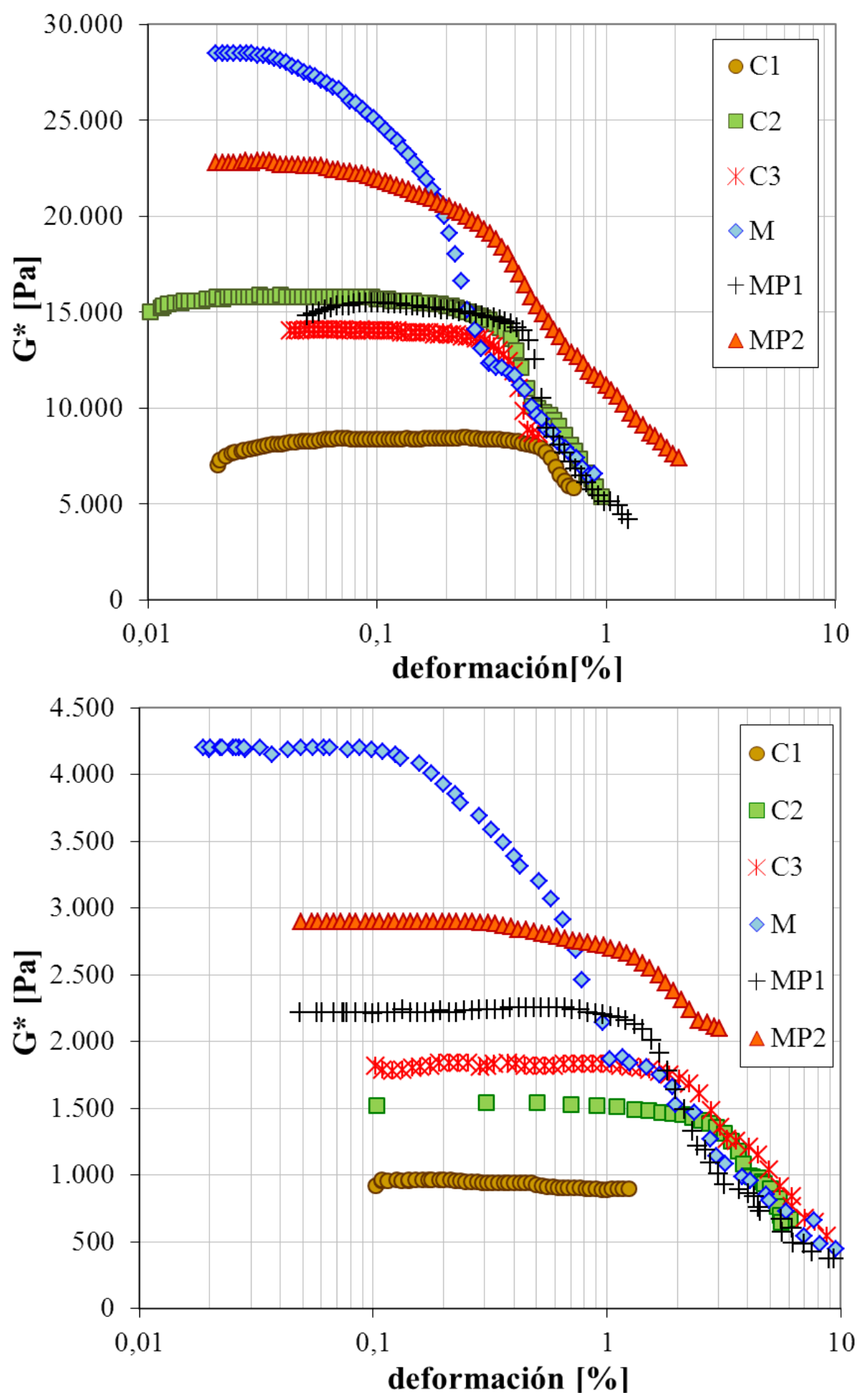

Figura 4.5. $\mathrm{G}^{*}$ versus deformaciones. $f=10 \mathrm{~Hz}$ (arriba); $f=1 \mathrm{~Hz}$ (abajo). 
Tabla 4.3. Límites de deformación máxima.

\begin{tabular}{ccccccc}
\hline & \multicolumn{6}{c}{ Límite de deformación[\%] } \\
Asfalto & C1 & C2 & C3 & M & MP1 & MP2 \\
\hline$f=1 \mathrm{~Hz}$ & 55,7 & 191,0 & 185,0 & 20,0 & 112,0 & 56,7 \\
$f=10 \mathrm{~Hz}$ & 47,3 & 23,5 & 17,7 & 5,7 & 32,3 & 11,5 \\
\hline
\end{tabular}

La tabla 4.4 muestra los valores medios de ZSV y LSV obtenidos por los métodos de creep y barrido de frecuencias (BF). También incluyen los valores de los respectivos coeficientes de variación (CV) de cada método para los diferentes asfaltos. Los ensayos de creep sobre el asfalto MP2 (modificado con polímero SBS) fueron descartados del análisis debido a que no fue posible obtener una medida confiable de ZSV. Sobre tres ensayos realizados sobre MP2 se obtuvieron valores de ZSV muy disimiles entre si e irrealmente altos. En este caso la principal causa para no obtener una medida confiable se debió a la resolución del DSR.

Tabla 4.4. Resultados de ensayo y análisis de varianza (ANOVA).

\begin{tabular}{|c|c|c|c|c|c|c|c|c|}
\hline Asfalto & ensayo & $\begin{array}{c}\mathrm{N}^{\mathrm{o}} \text { de } \\
\text { ensayos }\end{array}$ & $\begin{array}{l}\text { Media } \\
{[\text { Pa.s] }}\end{array}$ & $\begin{array}{c}\text { DS } \\
{[\mathrm{Pa} . \mathrm{s}]}\end{array}$ & $\begin{array}{l}\mathrm{CV} \\
{[\%]}\end{array}$ & $\mathrm{TN}$ & TVI & $\mathrm{P}$ \\
\hline \multirow[t]{2}{*}{ C1 } & Creep & 7 & 140,3 & 12,59 & 8,9 & Pasó & Pasó & \multirow{2}{*}{0,717} \\
\hline & $\mathrm{BF}$ & 7 & 142,5 & 9,66 & 6,7 & $(\mathrm{P}=0,195)$ & $(\mathrm{P}=0,480)$ & \\
\hline \multirow[t]{2}{*}{ C2 } & Creep & 7 & 226,0 & 19,04 & 8,4 & Pasó & Pasó & \multirow{2}{*}{0,740} \\
\hline & $\mathrm{BF}$ & 7 & 229,0 & 11,60 & 5,1 & $(P=0,468)$ & $(\mathrm{P}=0,130)$ & \\
\hline \multirow[t]{2}{*}{ C3 } & Creep & 7 & 290,0 & 26,92 & 9,3 & Pasó & Pasó & \multirow{2}{*}{0,389} \\
\hline & $\mathrm{BF}$ & 7 & 279,5 & 15,95 & 5,7 & $(\mathrm{P}=0,837)$ & $(\mathrm{P}=0,232)$ & \\
\hline \multirow[t]{2}{*}{ M } & Creep & 7 & 1463,0 & 280,75 & 16,5 & Pasó & Pasó & \multirow{2}{*}{0,993} \\
\hline & $\mathrm{BF}$ & 7 & 1461,7 & 216,94 & 14,7 & $(\mathrm{P}=0,453)$ & $(\mathrm{P}=0,353)$ & \\
\hline \multirow[t]{2}{*}{ MP1 } & Creep & 7 & 570,2 & 93,95 & 19,1 & Pasó & Pasó & \multirow{2}{*}{0,426} \\
\hline & $\mathrm{BF}$ & 7 & 610,7 & 89,81 & 14,8 & $(\mathrm{P}=0,326)$ & $(\mathrm{P}=0,642)$ & \\
\hline \multirow[t]{2}{*}{ MP2 } & Creep* & - & - & - & - & \multirow{2}{*}{ - } & & \multirow{2}{*}{ - } \\
\hline & $\mathrm{BF}$ & 7 & 1485,3 & 114,37 & 7,7 & & & \\
\hline
\end{tabular}

DS: Desviación Standard. CV: Coeficiente de variación. TN: Test de Normalidad. TVI: Test varianzas iguales. P: Probabilidad de estar en un error en concluir que existe diferencias significativas entre las medias de los grupos. (P-value $>0.05)$

*La resolución del DSR no permitió obtener una medición apropiada. 
En la tabla 4.4 se observa que, exceptuando al asfalto MP2, ambos métodos de ensayo dan resultados similares, como muestran los gráficos de caja presentados en la figura 4.6. Es importante destacar que los gráficos de caja no presentan valores extremos atípicos.

Excluyendo los resultados de los ensayos de creep sobre el asfalto MP2, la repetitividad de ensayo fue buena. Los CV para los asfaltos convencionales fueron menores al $10 \%$ y entre 15 y $20 \%$ en el caso de los asfaltos M y MP1 para ambos métodos. Por su parte para el método de barrido de frecuencias los resultados del ligante MP2 fueron comparables a los obtenidos para los asfaltos convencionales.

Las mediciones para asfaltos convencionales presentaron menores CV que en los asfaltos M y MP1. Este hecho se puede explicar a partir de considerar que los ligantes modificados tienen un comportamiento complejo. La medición es muy sensible a la concentración y distribución de polímero en la muestra, afectando los valores obtenidos. El arreglo de la red de polímero juega un papel importante en la variabilidad de los resultados de ensayo. Sin embargo, la presencia del polímero SBS no tuvo un gran efecto sobre la repetitividad de ensayo en el barrido de frecuencias en el ligante MP2. Los CVs obtenidos fueron similares a aquellos reportados por otros autores (Round Robin CEN prEN 15325 2006; Dezmanes et al. 2002; Nigen Chaidron 2007). Los barridos de frecuencia muestran menores $\mathrm{CV}$ que los ensayos de creep en los casos donde ambos métodos pudieron realizarse.

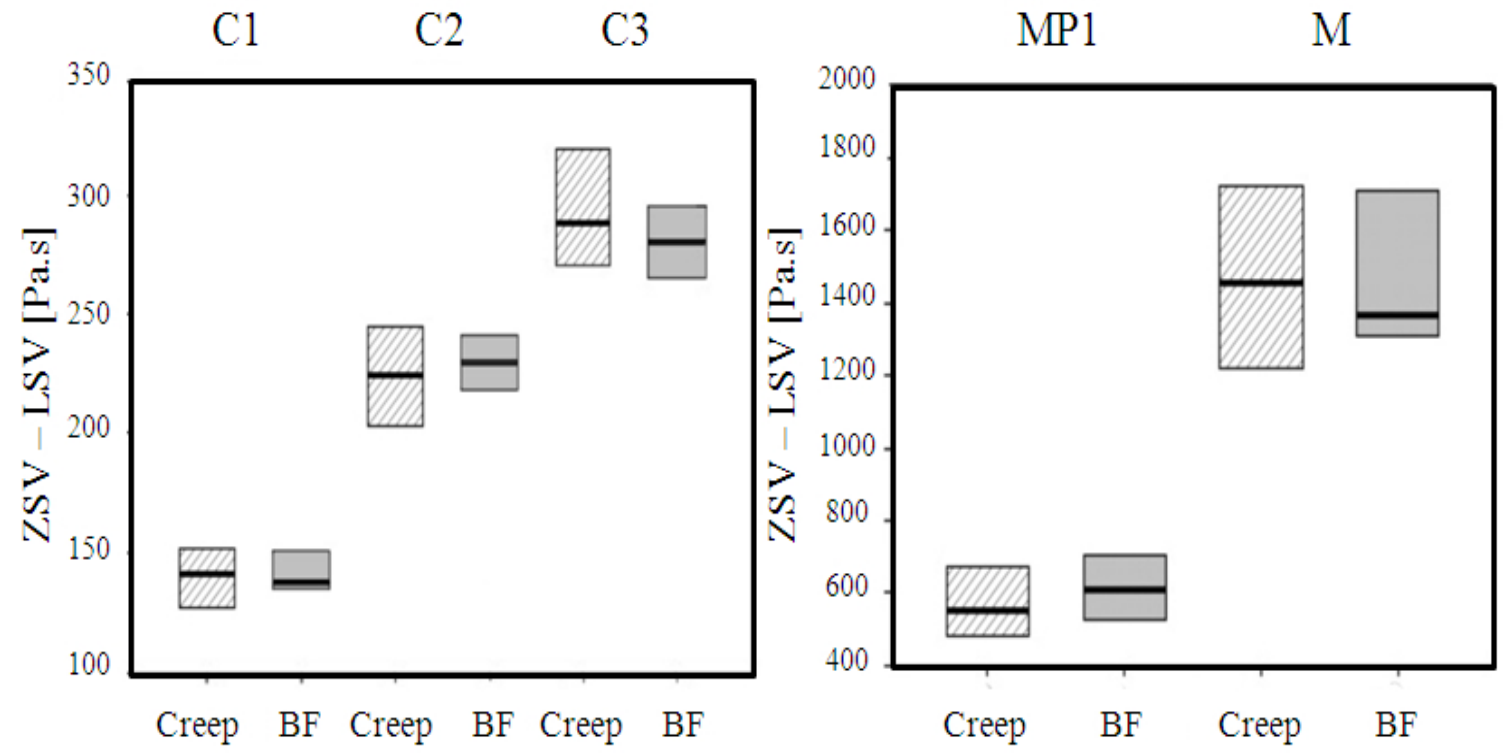

Figura 4.6. Análisis comparativo de los resultados de los ensayos de Creep y

Barrido de frecuencias (BF). Izquierda: asfaltos convencionales; derecha: asfaltos modificados.

Los resultados de los ensayos de barrido de frecuencia para el asfalto MP2 muestran muy buena repetitividad. Sin embargo, debido a que no se obtuvo la región de meseta durante el procedimiento de ensayo (valores de viscosidad constante), no es apropiado asumir que el valor obtenido de LSV en el ensayo es comparable a la ZSV del asfalto. En la figura 4.7 se muestran los datos de los siete ensayos realizados en el ligante MP2 al igual que los respectivos ajustes realizados con el modelo de Cross. Se observa allí 
que los diferentes barridos arrojan resultados similares, pero lejos de presentar una región de valores asintóticos o de meseta. Se observa también en la figura 4.7 que el modelo de Cross ajusta eficientemente los datos pero los valores de ZSV del ajuste son muy dispares entre sí, efecto de que los datos obtenidos no presentan una tendencia a valores asintóticos de viscosidad, por tanto en esas condiciones se puede generar valores erróneos de ZSV a partir del ajuste con el modelo de Cross. En consecuencia no se puede definir que la LSV sea similar a la ZSV al menos bajo las condiciones de resultados descriptos. Es importante destacar que al calcular la LSV a una frecuencia cercana a las frecuencias de los barridos se obtiene una buena repetitividad en los resultados cosa que no se observa entre los valores de ZSV obtenidos del ajuste al modelo de Cross.

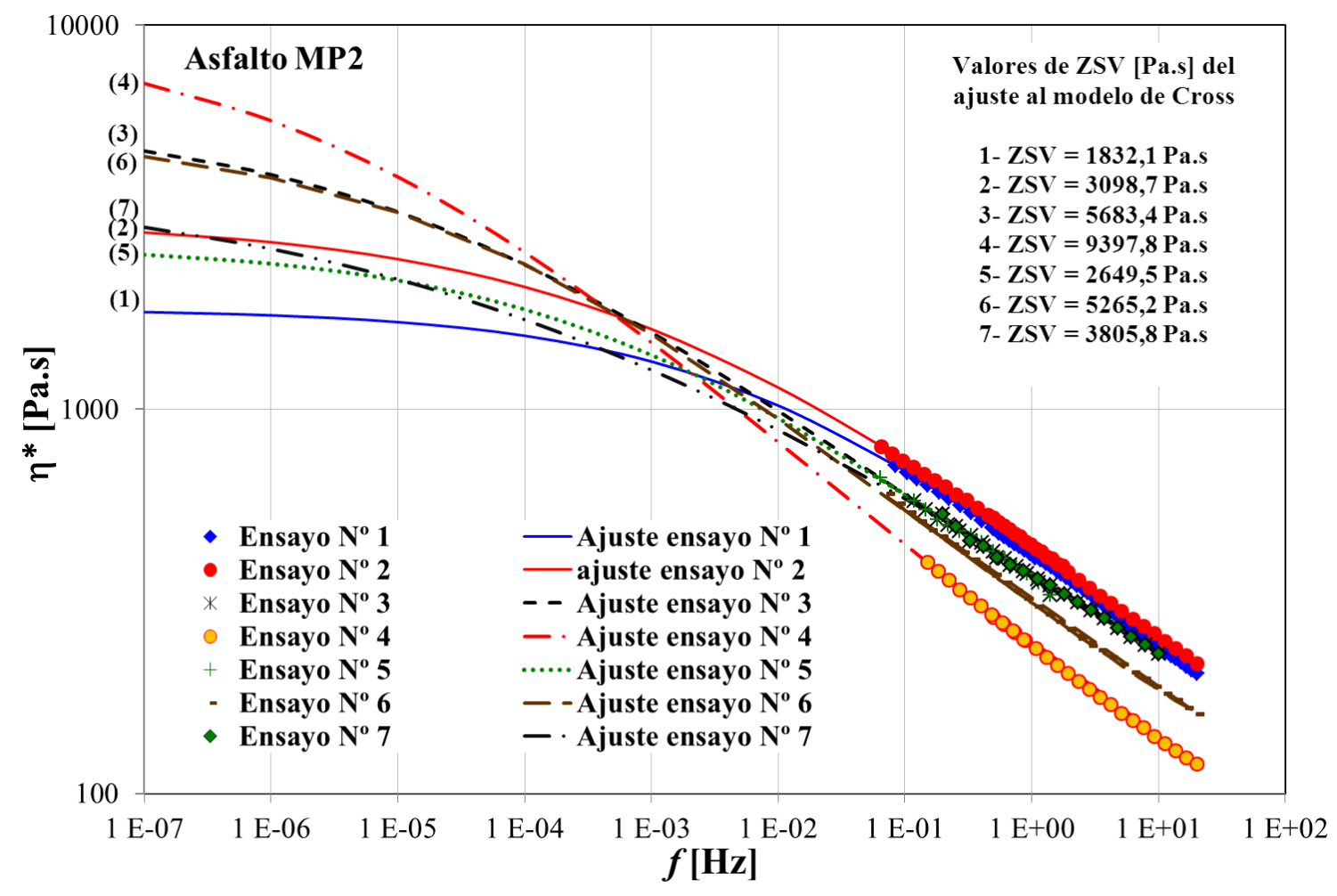

Figura 4.7. Viscosidad en función de la frecuencia para las muestras del asfalto MP2.

En la figura 4.8 y 4.9 se muestran los datos de los siete ensayos realizados en los ligantes C2 y C3 respectivamente junto con los ajustes realizados con el modelo de Cross de cada ensayo. Se observa en las figuras como los diferentes barridos arrojan resultados similares presentándose una tendencia clara hacia la región de valores asintóticos o de meseta para las bajas frecuencias. Al igual que en el ligante MP2 el modelo de Cross ajusta eficientemente los datos pero existe una baja dispersión de los resultados de ZSV que son los mismos de LSV a la frecuencia 0,001 Hz. 


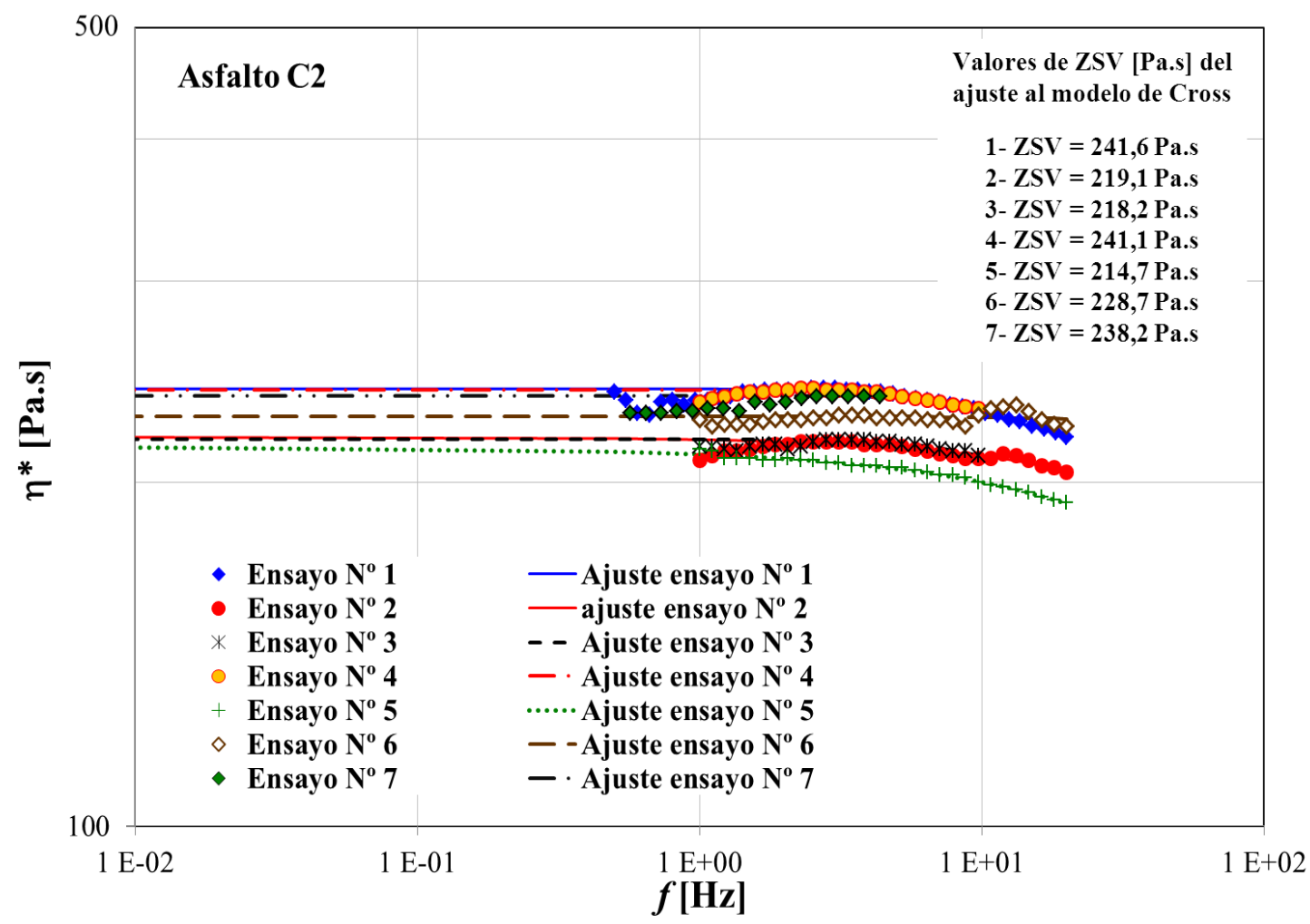

Figura 4.8. Viscosidad en función de la frecuencia para las muestras del asfalto C2.

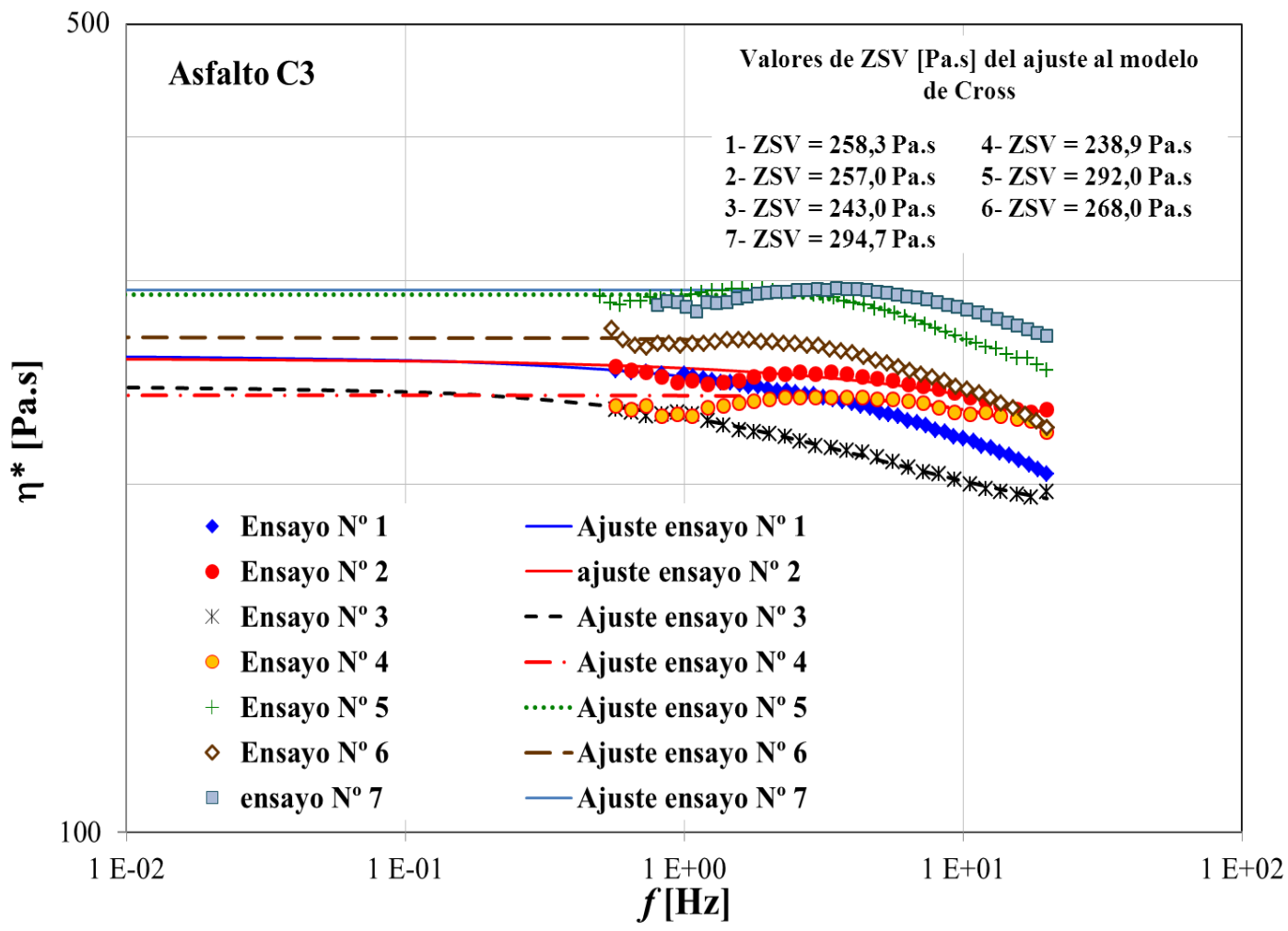

Figura 4.9. Viscosidad en función de la frecuencia para las muestras del asfalto C3. 
En lo que respecta al resto de los resultados y para confirmar que los valores medios arrojados por ambos métodos son representativos de la misma población se realizó un análisis de varianza (ANOVA) tal como indica la tabla 4.4. El análisis ANOVA muestra que las diferencias en los valores de las medias a lo largo de los grupos no son suficientemente grandes como para excluir la posibilidad que se deben a la variabilidad en el muestreo y por tanto constituyen una insignificancia estadística (en todos los casos los valores de P son más grandes que 0,05). Como consecuencia se puede concluir que los métodos de barrido de frecuencias y creep dan resultados igualmente confiables.

En lo referente a los protocolos de ensayo, el tiempo que conlleva la realización de un ensayo fue una diferencia importante entre métodos. Los barridos de frecuencia requieren un máximo de dos horas entre preparación de la muestra y el ensayo en sí mismo en todos los asfaltos estudiados, mientras que para los ensayos de creep el tiempo de ensayo depende del tipo de asfalto. Para los asfaltos convencionales se requirió una hora de ensayo, en cambio en los asfaltos modificados M y MP1 se necesitaron cuatro horas para alcanzar el estado estable de fluir. En el caso particular del asfalto MP2 el estado estable no pudo ser alcanzado incluso después de ocho horas de creep; y aún peor, la estructura del asfalto se vio afectada. En la figura 4.10 se observa la pérdida de la alta capacidad cohesiva que dicho asfalto normalmente posee. Esta afectación se debe a la alteración de la estructura interna que forma las cadenas de polímero SBS.

En los últimos años la ZSV y la LSV han sido estudiadas en Europa como parámetros para caracterizar la contribución del asfalto en el comportamiento frente al ahuellamiento en un concreto asfáltico. Estos ensayos de especificación se deben llevar a cabo de manera regular, por tanto su robustez y repetitividad constituyen cualidades deseables de tales determinaciones. El ensayo de barrido de frecuencias es rápido y fácil de llevar a cabo y se presenta como un método más práctico que el ensayo de creep a los fines de una especificación. Sin embargo, los resultados deben ser cuidadosamente estudiados en el caso de los asfaltos modificados con polímeros.

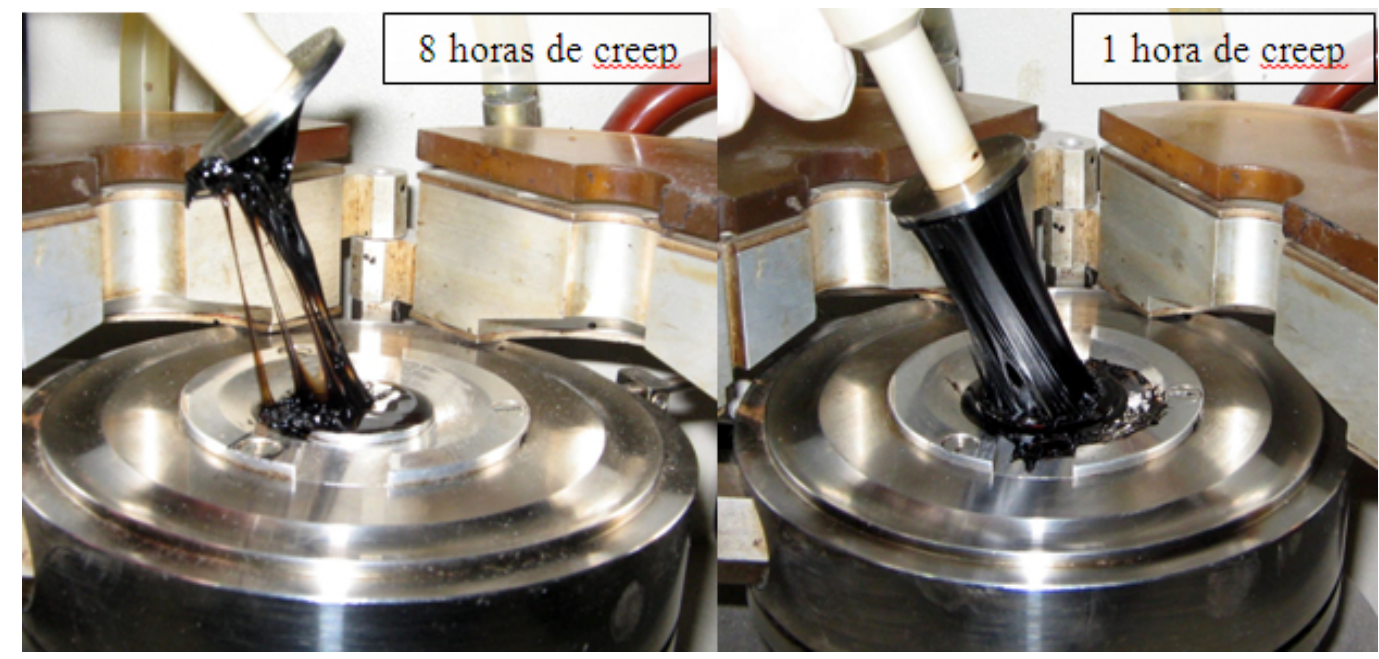

Figura 4.10. Detalle de dos muestras de asfalto MP2 luego de estar sometidas a diferentes tiempos en el ensayo de creep. 
A partir de los resultados obtenidos surge claramente que el ensayo de barrido de frecuencias se presenta como un ensayo más práctico que el de creep ya que ambos métodos arrojan valores comparables de LSV y ZSV para los asfaltos aquí estudiados, pero el barrido de frecuencias conlleva menores tiempos de ensayo. Esto lo posiciona como una mejor herramienta como ensayo de caracterización. En adelante en esta tesis se hablara de la LSV de los asfaltos. Esto último no quita que el ensayo de creep constituya una herramienta útil, de hecho lo es con los ligantes convencionales.

\subsection{Parámetro LSV}

La LSV de los diferentes asfaltos se calculó para las temperaturas de referencia de 50, 60, 70 y $80{ }^{\circ} \mathrm{C}$ utilizando la metodología de barrido de frecuencias explicada en el capítulo 3. En todos estos ensayo se aseguró estar dentro de los límites lineal viscoelástico de cada ligante para lo cual se llevaron a cabo los barridos de deformaciones pertinentes. En las tablas 4.5 y 4.6 se volcaron los resultados de LSV de los asfaltos en estado original y luego de envejecidos en el RTFOT.

Tabla 4.5. LSV de los asfaltos convencionales.

\begin{tabular}{ccccccccc}
\hline \multicolumn{10}{c}{ LSV [Pa.s] } \\
\hline $\mathrm{T}$ & \multicolumn{2}{c}{ C1 } & \multicolumn{2}{c}{ C2 } & \multicolumn{2}{c}{ C3 } & \multicolumn{2}{c}{ C4 } \\
{$\left[{ }^{\circ} \mathrm{C}\right]$} & Original & RTFOT & Original & RTFOT & Original & RTFOT & Original & RTFOT \\
\hline 50 & 554,1 & 1024,3 & 1024,1 & 1642,0 & 1012,4 & 2674,5 & 8143,1 & 23728,3 \\
60 & 163,8 & 234,7 & 346,3 & 412,3 & 252,5 & 559,3 & 1106,4 & 2970,4 \\
70 & 49,9 & 73,5 & 71,1 & 101,3 & 83,2 & 159,5 & 234,0 & 570,8 \\
80 & - & - & - & - & 34,3 & 58,4 & 69,8 & 154,2 \\
\hline
\end{tabular}

Tabla 4.6. LSV de los asfaltos modificados.

\begin{tabular}{ccccccccc}
\hline \multicolumn{10}{c}{ LSV [Pa.s] } \\
\hline $\mathrm{T}$ & \multicolumn{9}{c}{ M } & \multicolumn{2}{c}{ MP1 } & \multicolumn{2}{c}{ MP2 } & \multicolumn{2}{c}{ MP3 } \\
{$\left[{ }^{\circ} \mathrm{C}\right]$} & Original & RTFOT & Original & RTFOT & Original & RTFOT & Original & RTFOT \\
\hline 50 & 3631,1 & 15267,4 & 3534,4 & 4465,5 & 5998,7 & 17922,1 & 7669,9 & 24952,9 \\
60 & 947,5 & 3199,4 & 595,0 & 1043,0 & 2642,1 & 6461,5 & 2459,3 & 5169,0 \\
70 & 308,1 & 863,9 & 147,7 & 313,3 & 1257,2 & 2590,7 & 911,3 & 1367,7 \\
80 & 120,5 & 288,5 & 49,7 & 115,9 & 641,6 & 1142,5 & 383,1 & 445,0 \\
\hline
\end{tabular}


Cuanto más grande sea la LSV a una temperatura dada el ligante tiene mayor consistencia $\mathrm{y}$, en teoría, ofrece mejor resistencia frente a las deformaciones permanentes. En un primer análisis se observa que la LSV clasifica mejor que el $\mathrm{G}^{*} / \mathrm{sen} \delta$ a los diferentes asfaltos valorando con una mejor condición a los ligantes modificados con polímero por sobre los convencionales. Se observa que la LSV ofrece una mejor clasificación a los asfaltos MP2 y MP3 (modificados con polímero SBS) que el parámetro $\mathrm{G}^{*} / \mathrm{sen} \delta$.

Al comparar entre los valores originales y luego del envejecido en RTFOT no se observan resultados atípicos en el comportamiento o algún cambio en la clasificación de los ligantes. Es de mencionar el hecho de que en el ligante MP3 luego de envejecido a $80{ }^{\circ} \mathrm{C}$ no tuvo un aumento significativo de LSV, como ocurrió a las demás temperaturas. Este hecho se puede deber a que el ensayo de envejecimiento en RTFOT es inadecuado para el envejecimiento de los asfaltos modificados con polímero (Bahia et al. 2001 y Jia et al. 2005).

\subsection{Comparación entre el parámetro G*/sen $\delta$ y la LSV}

En la figura 4.11 se observa la relación entre los valores de $G^{*} / \operatorname{sen} \delta$ (medido a $\omega=$ $10 \mathrm{rad} / \mathrm{s}$ ) y la LSV de todos los asfaltos obtenidos a las diferentes temperaturas analizadas, para los asfaltos en estado original. En carácter general ambas propiedades reológicas presentan una buena relación cuando se consideran los asfaltos convencionales (C1, C2, C3 y C4), el asfalto multigrado (M) e inclusive el ligante modificado MP1 (modificado con polímero EVA). Sin embargo se observa que el G*/sen $\delta$ subestima a los asfaltos modificados con polímero SBS (MP2 y MP3) respecto a la LSV. Este análisis coincide con lo comentado anteriormente cuando se consideraron los resultados del parámetro G*/sen $\delta$ en la sección 4.2 de este capítulo. Este hecho se repite cuando se comparan estas propiedades en los asfaltos envejecidos en RTFOT, figura 4.12. En las figuras 4.11 y 4.12 se observa un buen ajuste entre los valores de $\mathrm{G}^{*} / \mathrm{sen} \delta$ y la LSV para los ligantes convencionales y el multigrado $\left(\mathrm{R}^{2}\right.$ de 0,98 y 0,96 respectivamente). 


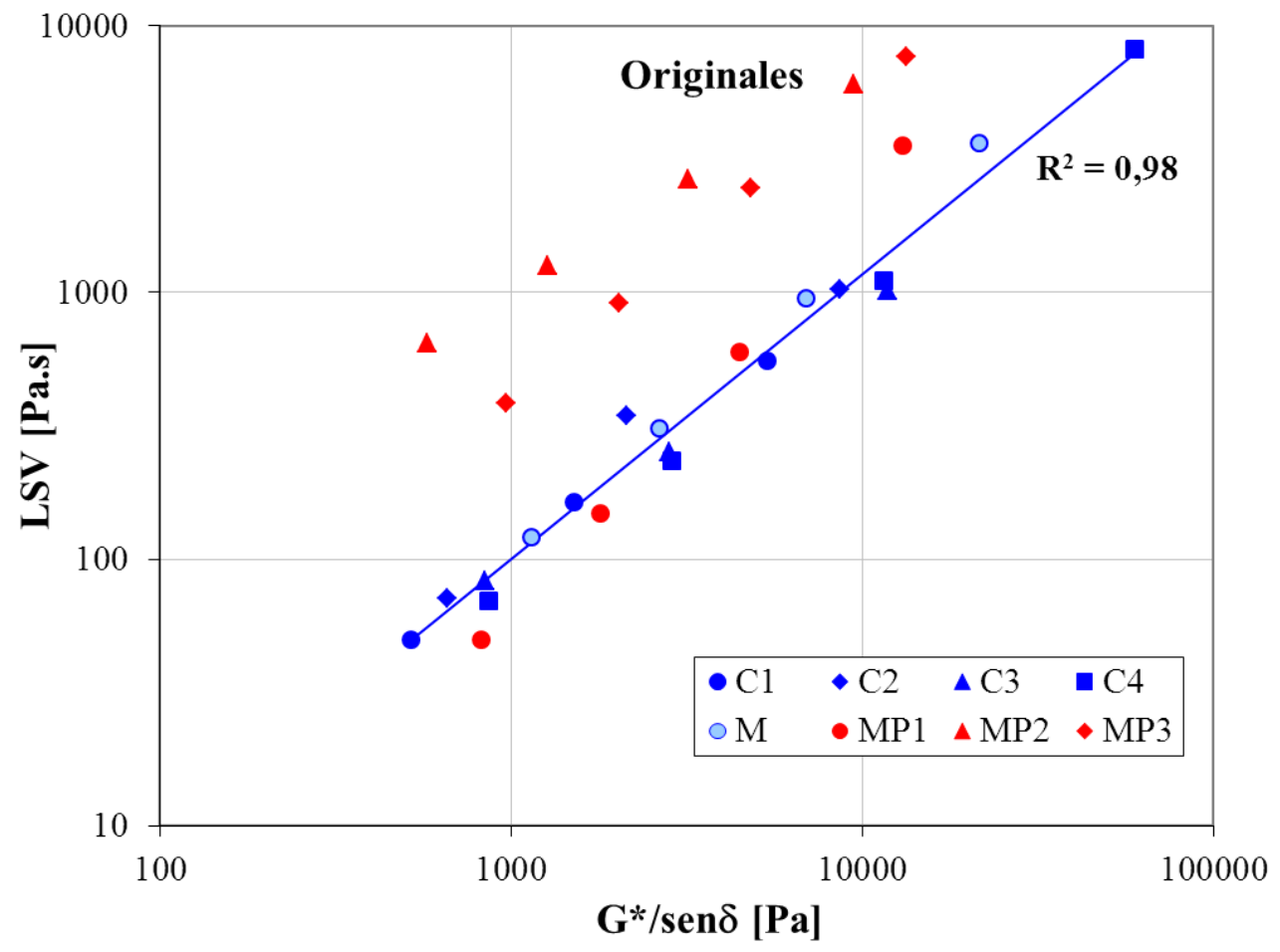

Figura 4.11. LSV versus $\mathrm{G}^{*} / \mathrm{sen} \delta(\omega=10 \mathrm{rad} / \mathrm{s})$. Asfaltos en estado original.

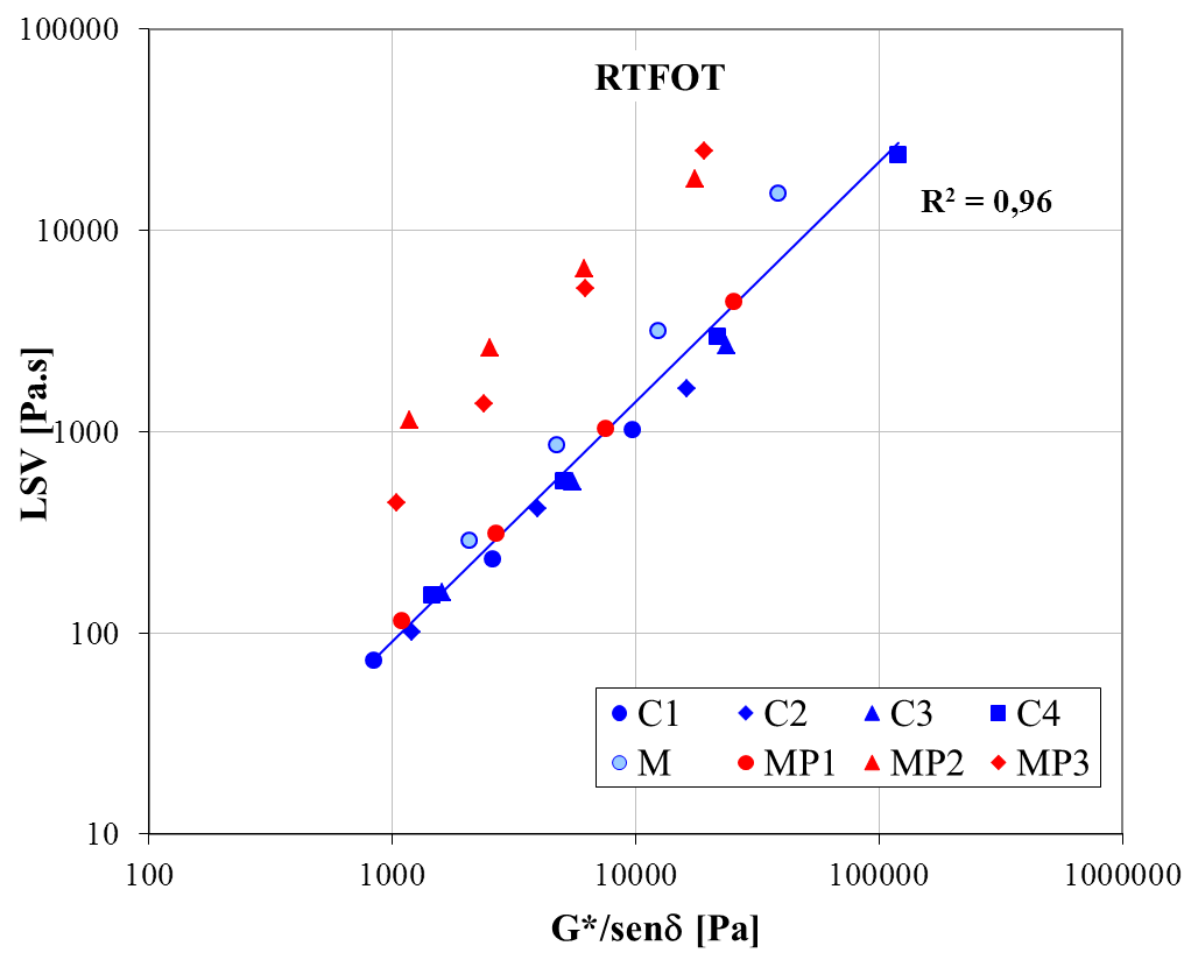

Figura 4.12. LSV versus $\mathrm{G}^{*} / \mathrm{sen} \delta(\omega=10 \mathrm{rad} / \mathrm{s})$. Asfaltos envejecidos.

Rowe et al. (2002) estudiaron la relación entre $G * / s e n \delta$ de la especificación SHRP y la ZSV. Para los asfaltos convencionales ellos encontraron, al igual que en esta tesis, una relación entre la ZSV y el G*/sen $\delta(\omega=10 \mathrm{rad} / \mathrm{s})$. Sin embargo los asfaltos modificados se alejaban de esa representación. Ellos proponen a partir de la relación encontrada para 
los asfaltos convencionales, y teniendo en cuenta que el parámetro G*/sen $\delta$ representa bien la contribución de los mismos frente al ahuellamiento, calcular los valores de ZSV asociados a los valores de especificación de $\mathrm{G}^{*} / \mathrm{sen} \delta$ de $1 \mathrm{kPa}$ en asfaltos originales y hacerlo a un valor de 2,2 kPa en asfaltos envejecidos en RTFOT (ver tabla 2.2 capítulo 2). Los valores de LSV asociados a 1 y 2,2 kPa de G*/sen $\delta$ obtenidos de la relación para los asfaltos de esta tesis son de 100 y 232,5 Pa.s respectivamente. Ambos similares a los encontrados por Rowe et al.

Dentro de la especificación de ligantes SHRP se calcula la temperatura a la cual el ligante presenta un valores de $\mathrm{G}^{*} / \mathrm{sen} \delta$ de $1 \mathrm{kPa}$ para el estado original. En esta tesis se determinaron los grados PG de los ligantes y se obtuvo esta temperatura para los ligantes estudiados, tabla 4.7. Esta temperatura se denomina temperatura de alta del grado de desempeño, siendo esta la máxima temperatura del pavimento a la cual el ligante ofrecería una buena resistencia frente a las deformaciones permanentes. Tomando en cuenta los valores de LSV calculados anteriormente que se relacionan con este valor de $\mathrm{G}^{*}$ sen $\delta$ y haciendo uso de las relaciones LSV-Temperatura de la tabla 4.5 se puede calcular, por interpolación, la temperatura a la cual cada asfalto presenta una LSV de 100 Pa.s. Esta sería la temperatura máxima asociada con la LSV, tabla 4.7. En la tabla 4.7 se volcaron también las diferencias de temperatura $(\Delta T)$ que aparecen entre ambos criterios. De manera similar se puede analizar para los asfaltos envejecidos en RTFOT tomando como límite 2,2 kPa para el parámetro G*/sen $\delta$ y 232,5 Pa.s para la LSV, tabla 4.7. A partir de este análisis se observa que para los ligantes convencionales, el multigrado y el modificado con polímero EVA (MP1) ambos criterios dan valores de temperaturas máximas similares. En cambio para los dos ligantes modificados con polímero SBS (MP2 y MP3) se observa que el criterio de G*/sen $\delta$ subestima por mucho la temperatura máxima de estos asfaltos respecto a la LSV.

Tabla 4.7. Temperaturas de alta asociadas a la LSV y el G*/sen $\delta$.

\begin{tabular}{|c|c|c|c|c|c|c|c|c|c|}
\hline & & C1 & $\mathrm{C} 2$ & C3 & C4 & M & MP1 & MP2 & MP3 \\
\hline \multirow{3}{*}{ 矛 } & $\begin{array}{c}\mathrm{T}\left[{ }^{\circ} \mathrm{C}\right] \\
(\mathrm{LSV}=100 \text { Pa.s) }\end{array}$ & 63,7 & 67,9 & 68,7 & 76,7 & 81,8 & 73,4 & 118,9 & 98,8 \\
\hline & $\begin{array}{c}\mathrm{T}\left[{ }^{\circ} \mathrm{C}\right] \\
\left(\mathrm{G}^{*} / \operatorname{sen} \delta=1,0 \mathrm{kPa}\right)\end{array}$ & 63,7 & 66,1 & 68,3 & 78,6 & 81,8 & 77,3 & 73,1 & 79,7 \\
\hline & $\Delta \mathrm{T}\left[{ }^{\circ} \mathrm{C}\right]$ & 0,0 & 1,8 & 0,4 & $-1,9$ & 0,0 & $-3,8$ & 45,8 & 19,1 \\
\hline \multirow{3}{*}{ 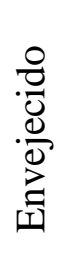 } & $\begin{array}{c}\mathrm{T}\left[{ }^{\circ} \mathrm{C}\right] \\
(\mathrm{LSV}=232,5 \text { Pa.s })\end{array}$ & 60,2 & 63,6 & 67,0 & 76,5 & 82,0 & 72,7 & 105,2 & 86,5 \\
\hline & $\begin{array}{c}\mathrm{T}\left[{ }^{\circ} \mathrm{C}\right] \\
\left(\mathrm{G}^{*} / \mathrm{sen} \delta=2,2 \mathrm{kPa}\right)\end{array}$ & 61,3 & 64,9 & 67,5 & 76,7 & 79,0 & 72,3 & 71,7 & 70,8 \\
\hline & $\Delta \mathrm{T}\left[{ }^{\circ} \mathrm{C}\right]$ & $-1,1$ & $-1,3$ & $-0,5$ & $-0,2$ & 3,0 & 0,5 & 33,5 & 15,6 \\
\hline
\end{tabular}

No considerar este último aspecto mencionado en la elección del ligante asfáltico podría tener implicancias prácticas durante el diseño de la mezcla. Recordemos que dentro del programa SHRP la selección del asfalto se realiza a partir de considerar las 
temperaturas extremas que se suscitan en el pavimento. El asfalto a utilizar en la mezcla debe asegurar buenas prestaciones dentro de ese rango de temperaturas teniendo un grado de desempeño que incluya a las temperaturas extremas, vale recordar que el grado de desempeño representa las temperaturas extremas en las que el ligante tiene buenas prestaciones frente a los distintos modos de falla de un pavimento. Para el ahuellamientos la temperatura de alta del ligante a seleccionar debe superar la máxima de la zona de pavimento para no tener problemas de deformaciones permanentes.

Tomando en consideración los resultados encontrados en la tabla 4.7, el ligante MP2 no se podría utilizar en zonas donde la temperatura del pavimento es superior a $70^{\circ} \mathrm{C}$ si

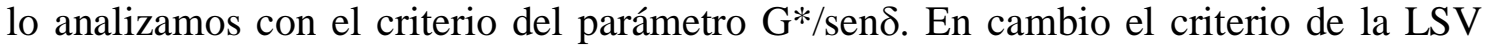
brinda una mejor caracterización y una idea más real de la máxima temperatura en el que este ligante se puede utilizar.

Todo lo hasta aquí analizado fue para los valores de G*/sen $\delta$ medidos en el DSR a la frecuencia de $10 \mathrm{rad} / \mathrm{s}$. En la figura 4.13 se muestra la relación de la LSV y el G*/sen $\delta$ medido a la frecuencia de 0,6 rad/s para los asfaltos en estado original. Se observa para esta frecuencia una aceptable relación entre ambos parámetros, $\mathrm{R}^{2}=0,87$, para todos los asfaltos. Sin embargo cuando se relacionan los resultados de los asfaltos envejecidos en RTFOT se observa como los asfaltos modificados MP2 y MP3 son subestimados nuevamente por el parámetro $\mathrm{G}^{*} / \mathrm{sen} \delta$, figura 4.14. Se observa allí que el ajuste para todos los asfaltos en conjunto es pobre $\left(\mathrm{R}^{2}=0,51\right)$ mientras que si se saca del ajuste a los ligantes modificados con polímero SBS el ajuste mejora notablemente $\left(R^{2}=0,86\right)$.

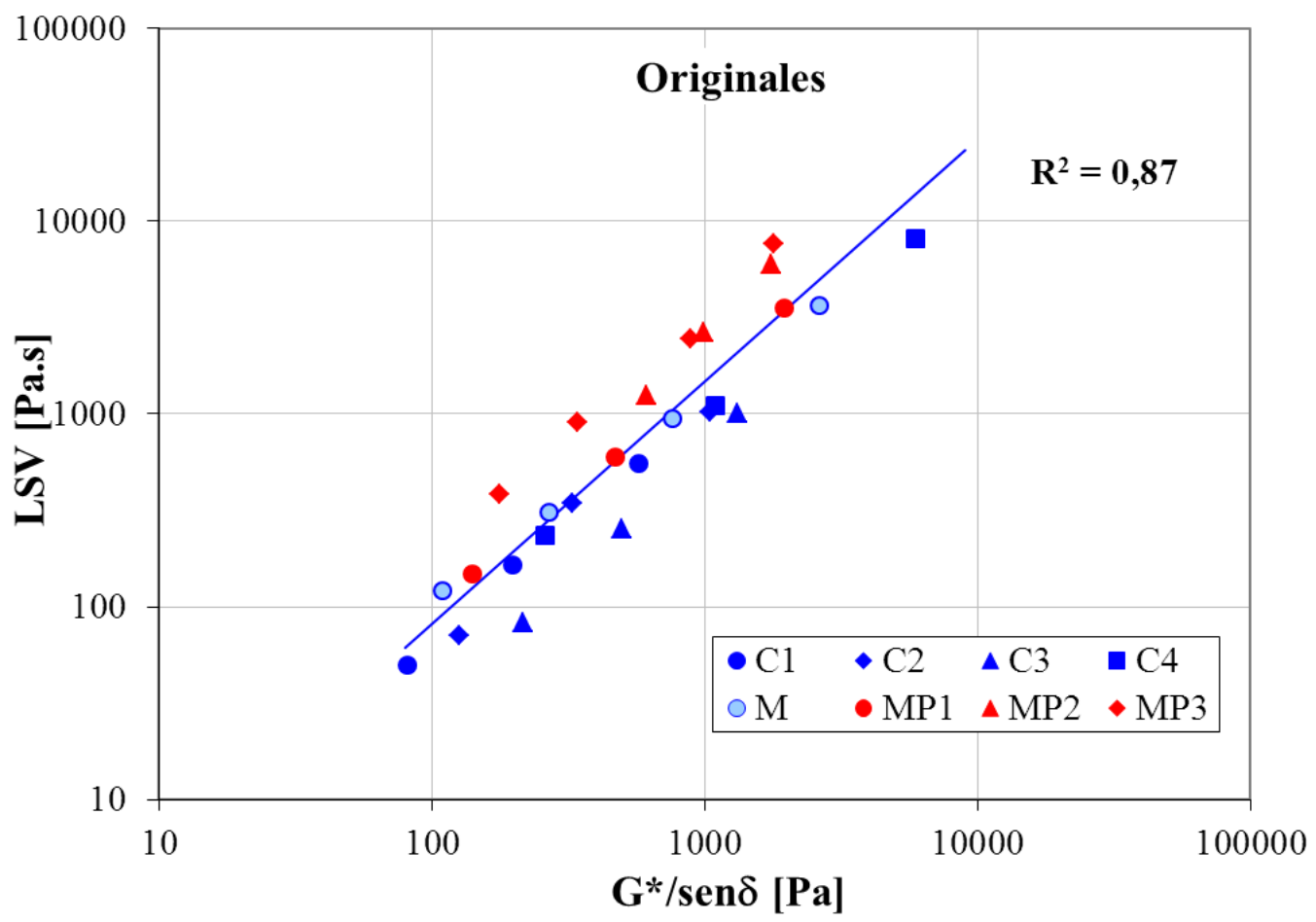

Figura 4.13. LSV versus $\mathrm{G}^{*} / \mathrm{sen} \delta(\omega=0,6 \mathrm{rad} / \mathrm{s})$. Asfaltos en estado original. 


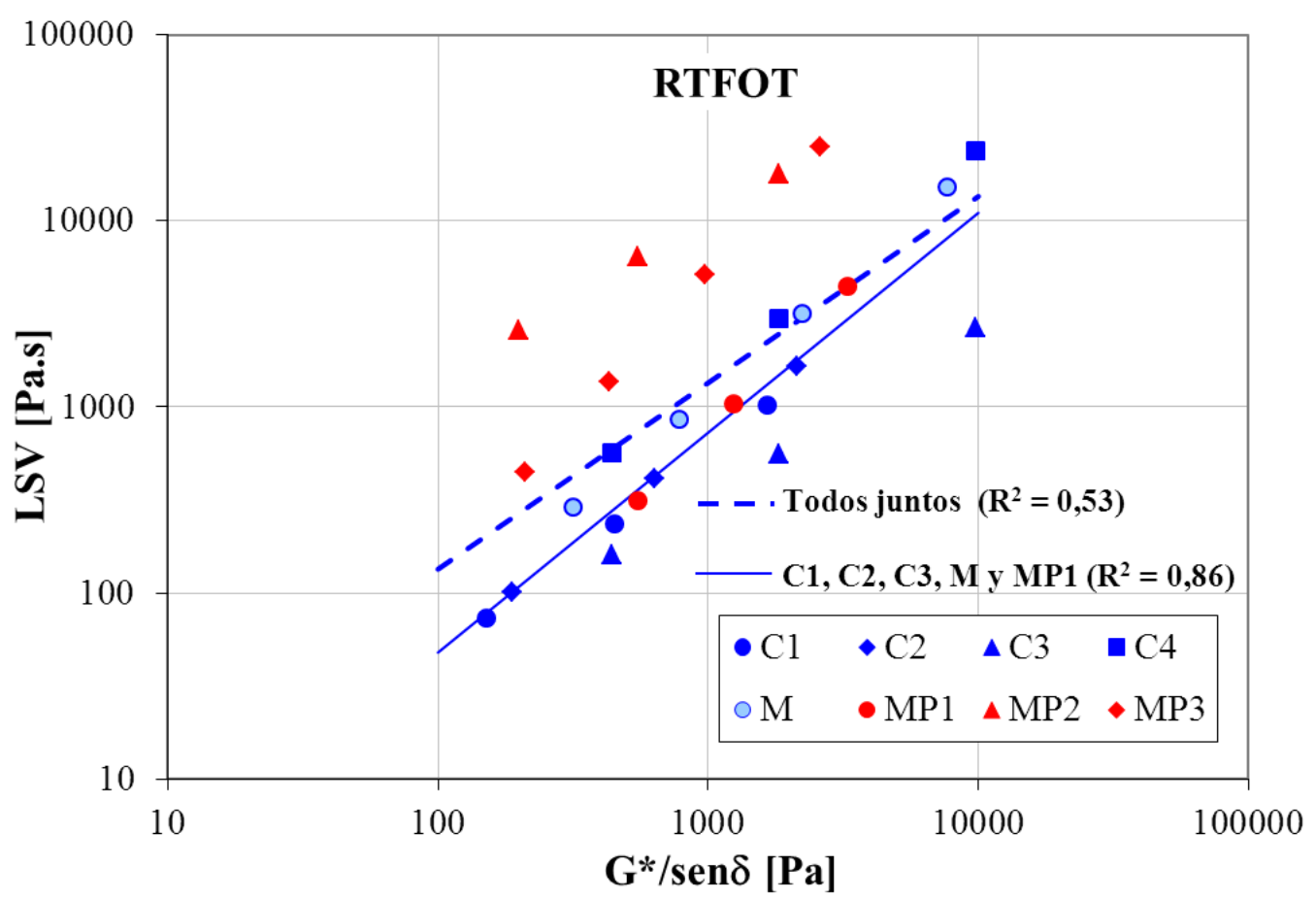

Figura 4.14. LSV versus $\mathrm{G}^{*} / \mathrm{sen} \delta(\omega=0,6 \mathrm{rad} / \mathrm{s})$. Asfaltos envejecidos en RTFOT.

A partir de estos resultados surge que el parámetro $\mathrm{G}^{*} / \mathrm{sen} \delta$ medido a la frecuencia de $0,6 \mathrm{rad} / \mathrm{s}$ no describe eficientemente el comportamiento de diferentes tipos de asfaltos. Se observa que aún persiste el problema de caracterizar a los ligantes modificados con polímero SBS al igual que con el G*/sen $\delta$ medido a la frecuencia de $10 \mathrm{rad} / \mathrm{s}$.

\subsection{Conclusiones y comentarios sobre las propiedades reológicas de los asfaltos vinculadas a las deformaciones permanentes}

Como principal conclusión de este capítulo surge que la medición del G*/sen $\delta$ con la menor frecuencia de carga clasifica mejor la respuesta de los ligantes MP2 y MP3, ambos modificados con polímero SBS, que la frecuencia de $10 \mathrm{rad} / \mathrm{s}$. Esto se puede explicar a partir del hecho que la menor velocidad de carga permite que se manifieste la gran recuperación visco-elástica retardada que estos ligantes poseen y sea tenida en cuenta dentro del parámetro $\mathrm{G} * /$ sen $\delta$.

Por tanto de manera preliminar la frecuencia de $0,6 \mathrm{rad} / \mathrm{s}$ se presenta como una mejor alternativa para la caracterización de los asfaltos al representar una velocidad de carga lenta y permite manifestar las diferencias en el comportamiento de los distintos ligantes.

La frecuencia de $10 \mathrm{rad} / \mathrm{s}$ representa una velocidad de carga rápida que no permite que se manifieste la recuperación visco-elástica retardada del ligante, si la tuviere, como es el caso de los asfaltos modificados con polímero.

A partir de los resultados obtenidos en la medición de ZSV y LSV surge claramente que el ensayo de barrido de frecuencias se presenta como un ensayo más práctico que el de creep ya que ambos métodos arrojan valores comparables de LSV y ZSV respectivamente para los asfaltos aquí estudiados y el barrido de frecuencias conlleva 
menores tiempos de ensayo. Esto lo posiciona como una mejor herramienta de caracterización y en adelante en esta tesis se tomará la LSV de los asfaltos. Esto último no descarta al ensayo de creep como una herramienta útil.

Cuando se compararon el G*/sen $\delta$ (a 10rad/s) y la LSV se observó una buena relación cuando se consideran los asfaltos convencionales (C1, C2, C3 y C4), el asfalto multigrado (M) e inclusive el ligante modificado MP1 (modificado con polímero EVA). Sin embargo se observa que el $\mathrm{G}^{*} / \mathrm{sen} \delta$ subestima a los asfaltos modificados con polímero SBS (MP2 y MP3) con respecto a los valores que alcanza la LSV.

La relación entre el $\mathrm{G}^{*} / \mathrm{sen} \delta$ (a 0,6 rad/s) y la LSV presentó una buena relación para todos los asfaltos cuando se analizaron los ligantes en estado original. Sin embargo volvió a aparecer la desestimación de los ligantes modificados con polímero SBS cuando se analizaron los asfaltos envejecidos en RTFOT. 

Capítulo 5

\section{Mediciones de ahuellamientos en el ensayo de rueda cargada. Caracterización mediante propiedades reológicas}

\subsection{Introducción}

El ensayo de rueda cargada es una simulación a escala de laboratorio que fue desarrollada para reproducir los efectos que las cargas del tránsito y la temperatura producen sobre una mezcla asfáltica, es decir, generar de manera acelerada deformaciones permanentes en la mezcla. Este ensayo permite conocer en laboratorio la performance de una dada mezcla asfáltica antes de ser colocada en el pavimento, lo que lo convierte en una herramienta importante a la hora del diseño de una mezcla asfáltica. Sin embargo en nuestro país no es normalmente utilizada en esta etapa sino como comprobación una vez que surgen problemas en el camino.

Las propiedades reológicas se utilizan para caracterizar a los ligantes asfálticos en relación con el desempeño de las mezclas en lo referente a los modos de falla que se suscitan en el pavimento. Las propiedades del asfalto G*/sen $\delta$ y LSV son dos propiedades asociadas a las deformaciones permanentes.

En el capítulo anterior se centró el estudio a nivel de los ligantes asfálticos. En el presente capítulo se estudia el proceso de ahuellamiento a escala del material compuesto, esto es en concretos asfálticos. Los mismos se analizan bajo condiciones normalizadas buscando observar la incidencia de los parámetros de los asfaltos G*/sen $\delta$ (medidos a las frecuencias de 10 y $0,6 \mathrm{rad} / \mathrm{s}$ ) y LSV para la caracterización de las deformaciones permanentes; las experiencias se realizan empleando todos los asfaltos en mezclas densa del tipo D-20. El objetivo es definir cuál de estas propiedades pondera con mayor eficacia el aporte de los diferentes tipos de asfalto en cuanto a la resistencia al ahuellamiento.

Es importante reiterar que todos los ensayos de rueda cargada que forman parte de este capítulo se realizaron bajo condiciones normalizadas de temperatura y carga, $60^{\circ} \mathrm{C}$ y 
$520 \mathrm{~N}$ respectivamente; de igual manera los valores de $\mathrm{G}^{*} / \mathrm{sen} \delta$, en cualquiera de sus variantes, y de LSV de los asfaltos se consideraron a la misma temperatura.

La valoración de las deformaciones permanentes sobre las diferentes mezclas se realizó a partir del parámetro velocidad de deformación (Vd) obtenido de los datos de deformación medidos en función del tiempo en los ensayos de rueda cargada.

\subsection{Deformaciones permanentes en mezclas y el parámetro $G * / \operatorname{sen} \delta$}

Numerosos investigadores han estudiado las relaciones entre el parámetro G*/sen $\delta$, de la especificación SHRP, y las deformaciones permanentes en mezclas asfálticas encontrando que dicho parámetro no representa bien el comportamiento de los asfaltos modificados con polímero (Oliver y Tredea 1998, Bahia et al. 2001, Le Hir 2003, Dressen et al. 2009). Sin embargo dado que en Argentina y Latinoamérica no existen trabajos que relacionen la propiedad reológica $\left(G^{*} / \mathrm{sen} \delta\right)$ con los ahuellamientos medidos en mezclas asfálticas se consideró importante estudiar y verificar las relaciones existentes entre el $G^{*} / \operatorname{sen} \delta$ y medidas de deformaciones permanentes en el equipo de pista para los ligantes Argentinos en estudio.

En la tabla 5.1 se observan los resultados del $\mathrm{G}^{*} / \mathrm{sen} \delta$ de los distintos asfaltos y los correspondientes valores de $\mathrm{Vd}$ de las mezclas obtenidos con el equipo de pista. Se incluyen los resultados del parámetro SHRP para los ligantes en estado original y luego de envejecido en RTFOT para las dos frecuencias de carga establecidas (10 y 0,6 rad/s).

Tabla 5.1. Resultados de $\mathrm{G}^{*} / \operatorname{sen} \delta$ y $\mathrm{Vd}$ a $60^{\circ} \mathrm{C}$.

\begin{tabular}{|c|c|c|c|c|c|}
\hline \multirow[t]{3}{*}{ Asfalto } & \multicolumn{4}{|c|}{$\begin{array}{c}\text { G*/sen } \delta \\
{[\mathrm{kPa}]}\end{array}$} & \multirow{3}{*}{$\begin{array}{c}\mathrm{Vd} . \\
{[\mu \mathrm{m} / \mathrm{min}]}\end{array}$} \\
\hline & \multicolumn{2}{|c|}{$\omega=10 \mathrm{rad} / \mathrm{s}$} & \multicolumn{2}{|c|}{$\omega=0,6 \mathrm{rad} / \mathrm{s}$} & \\
\hline & Original & RTFOT & Original & RTFOT & \\
\hline C1 & 1,51 & 2,57 & 0,20 & 0,27 & 12,4 \\
\hline $\mathrm{C} 2$ & 2,14 & 3,95 & 0,33 & 0,45 & 6,7 \\
\hline C3 & 2,83 & 5,50 & 0,50 & 0,63 & 9,6 \\
\hline $\mathrm{C} 4$ & 11,54 & 21,60 & 1,09 & 1,83 & 2,8 \\
\hline M & 6,91 & 12,37 & 0,77 & 2,23 & 3,4 \\
\hline MP1 & 4,50 & 7,47 & 0,47 & 1,24 & 3,7 \\
\hline MP2 & 3,19 & 6,12 & 0,99 & 0,55 & 2,7 \\
\hline MP3 & 4,82 & 6,20 & 0,89 & 0,98 & 3,0 \\
\hline
\end{tabular}


En la figura 5.1 se muestra la relación entre los valores de Vd obtenidos de las mezclas asfálticas y el parámetro $\mathrm{G}^{*} / \mathrm{sen} \delta$ para la frecuencia de $10 \mathrm{rad} / \mathrm{s}$ de los asfaltos en estado original. Se observa una mala correlación $\left(\mathrm{R}^{2}=0,60\right)$ que indica que el $\mathrm{G}^{*} / \mathrm{sen} \delta$ no caracteriza bien el comportamiento de todos los asfalto en cuanto a su aporte en la resistencia frente a las deformaciones permanentes. Esto ocurre sobre todo para el ligante MP2, modificado con polímero SBS; se observa en la figura que la mezcla elaborada con este ligante presentó el menor valor de $\mathrm{Vd}$, por lo tanto el menor ahuellamiento, sin embargo el valor de $\mathrm{G}^{*} / \operatorname{sen} \delta$ no denota esa mayor resistencia, sino que la subestima. Es interesante notar que el valor de $\mathrm{G}^{*} / \mathrm{sen} \delta$ a $10 \mathrm{rad} / \mathrm{s}$ del asfalto MP2 original es similar al del C3, sin embargo las mezclas elaboradas con dichos asfaltos presentan comportamientos muy dispares. Finalmente la mezcla con C3 tiene mayores deformaciones permanentes y peor desempeño que la mezcla con MP2.

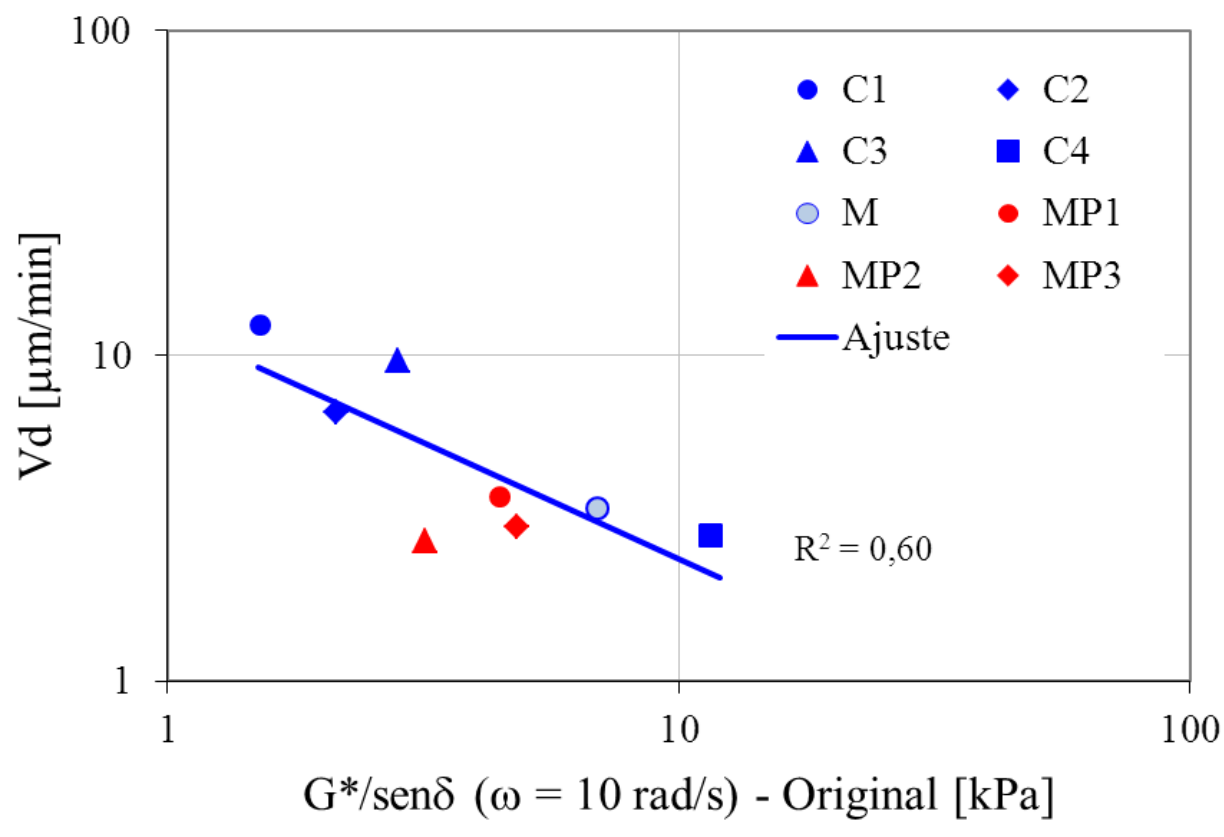

Figura 5.1. Vd en función del $\mathrm{G} * / \mathrm{sen} \delta(\omega=10 \mathrm{rad} / \mathrm{s})$ en asfalto original.

En la figura 5.2 se comparan los valores de Vd de las diferentes mezclas con los resultados de $\mathrm{G}^{*} / \mathrm{sen} \delta$ a la frecuencia de $10 \mathrm{rad} / \mathrm{s}$ de los ligantes envejecidos. Nuevamente se observa una pobre correlación entre los resultados y en este caso los dos ligantes modificados con polímero SBS, MP2 y MP3, presentan comparativamente bajos valores de $\mathrm{Vd}$ en el ensayo de rueda cargada con respecto a lo que podría estimarse en base a los datos de $\mathrm{G} * / \operatorname{sen} \delta$ si se siguiera la tendencia general del resto de los asfaltos estudiados.

En consecuencia se observa que el proceso de envejecimiento en RTFOT generó discrepancias entre resultados de $\mathrm{G}^{*} / \mathrm{sen} \delta$ de un mismo asfalto, en lo que se refiere a su capacidad para caracterizar y estimar la resistencia al ahuellamiento en las mezclas. En estado original el ligante MP3 no subestima el ahuellamiento como si lo hace cuando se considera el G*/sen $\delta$ del asfalto envejecido.

Es de destacar en ambas figuras, 5.1 y 5.2, que para el resto de los asfaltos el parámetro $\mathrm{G}^{*} / \mathrm{sen} \delta$ caracteriza eficientemente el aporte del ligante frente a las deformaciones permanentes. Además no se observan discrepancias con las relaciones 
entre los ligantes en estado original y luego de envejecidos en RTFOT. Excluyendo a los ligantes MP2 y MP3, los coeficientes de ajuste mejoran notablemente, $\mathrm{R}^{2}=0,85 \mathrm{y}$ 0,81 considerando los $\mathrm{G}^{*} / \mathrm{sen} \delta$ en estado original y envejecido respectivamente.

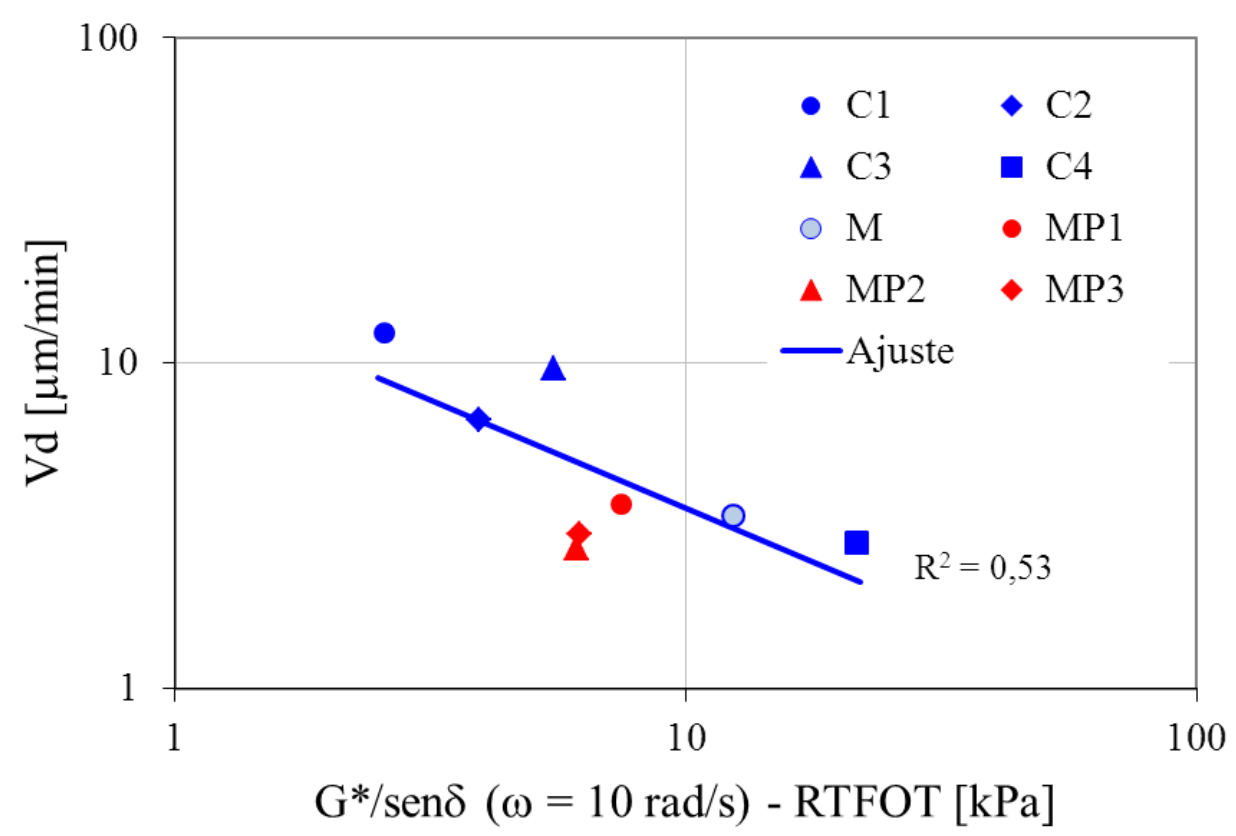

Figura 5.2. Vd en función del $\mathrm{G} * / \operatorname{sen} \delta(\omega=10 \mathrm{rad} / \mathrm{s})$ en asfalto envejecido.

En la figura 5.3 se grafica la relación entre los valores de Vd obtenidos de las mezclas asfálticas en función del $\mathrm{G}^{*} / \mathrm{sen} \delta$ para la frecuencia de 0,6 rad/s para los asfaltos en estado original. Se observa una mejora aceptable en la correlación Vd-G*/sen $\delta,\left(\mathrm{R}^{2}=\right.$ $0,78)$, sin embargo la misma correlación es mala $\left(R^{2}=0,51\right)$ cuando se considera el $\mathrm{G}^{*} / \mathrm{sen} \delta$ de los asfaltos envejecidos, figura 5.4. Nuevamente, como se observa en dicha figura, se vuelve a subestimar la resistencia que ofrece el ligante MP2 frente a las deformaciones permanentes.

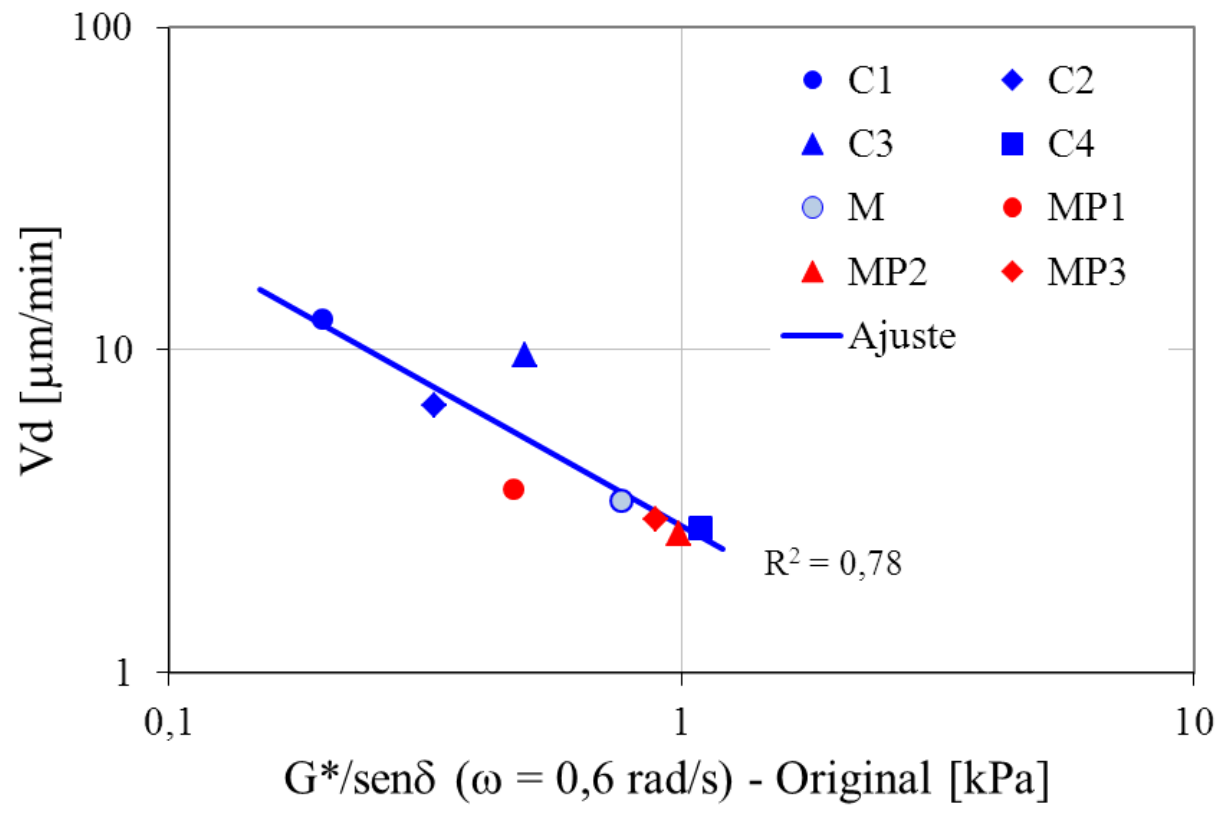

Figura 5.3. Vd en función del G*/sen $\delta(\omega=0,6 \mathrm{rad} / \mathrm{s})$ en asfalto original. 


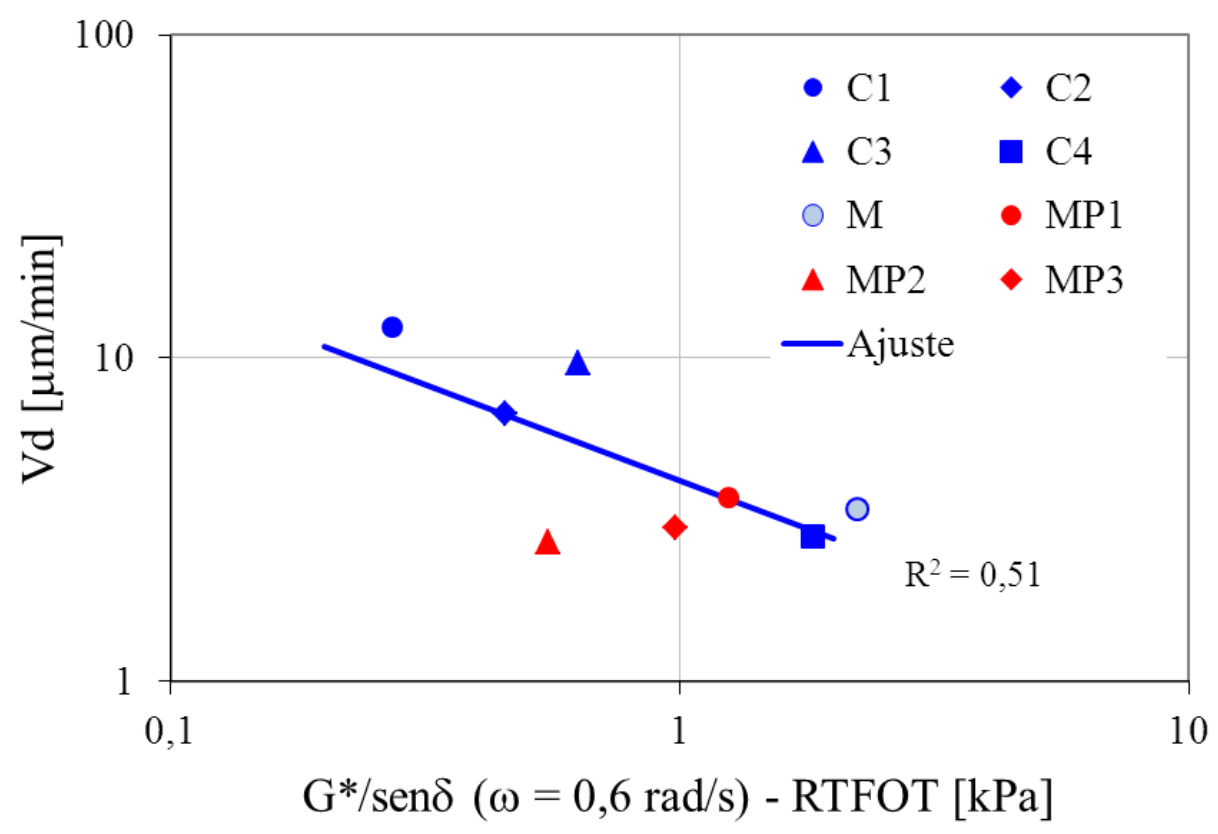

Figura 5.4. Vd en función del $\mathrm{G} * / \mathrm{sen} \delta(\omega=0,6 \mathrm{rad} / \mathrm{s})$ en asfalto envejecido.

Como principales conclusiones se constata que el $\mathrm{G}^{*} / \mathrm{sen} \delta$ a la frecuencia de $10 \mathrm{rad} / \mathrm{s}$ no caracteriza el aporte en la resistencia al ahuellamiento de los ligantes modificados con polímero SBS. Como ya se explicara en el capítulo anterior los $10 \mathrm{rad} / \mathrm{s}$ son una velocidad de carga rápida que no permite se manifieste la recuperación visco-elástica retardada del ligante. Además se observan para este tipo de ligantes discrepancias en la caracterización entre los resultados con las condiciones en estado original y envejecido en RTFOT.

La frecuencia de $0,6 \mathrm{rad} / \mathrm{s}$ se presenta como una mejor alternativa para la caracterización de los asfaltos cuando se toma el G*/sen $\delta$ en estado original no así en el caso de considerar el $\mathrm{G}^{*} / \mathrm{sen} \delta$ de los ligantes envejecidos. A partir de estos resultados se aprecia que el parámetro $\mathrm{G}^{*} / \mathrm{sen} \delta$ medido a la frecuencia de $0,6 \mathrm{rad} / \mathrm{s}$ no clasifica eficientemente el comportamiento de los diferentes tipos de asfaltos. Se observa que aún persiste el problema de caracterizar a los ligantes modificados con polímero SBS al igual que con el G*/sen $\delta$ medido a la frecuencia de $10 \mathrm{rad} / \mathrm{s}$.

\subsection{Deformaciones permanentes en mezclas y la medida de la LSV}

En el siguiente apartado se relacionan los ahuellamientos en concretos asfálticos densos en función de la LSV de cada ligante.

En la tabla 5.2 se incluyen los resultados de la LSV a la temperatura de $60{ }^{\circ} \mathrm{C}$ para cada uno de los diferentes ligantes en estudio tanto en estado original como luego del proceso de envejecimiento en RTFOT. Como referencia se presentan nuevamente los valores de $\mathrm{Vd}$, mostrados en la tabla 5.1, obtenidos para las diferentes mezclas a partir de los ensayos de rueda cargada. 
Tabla 5.2. Resultados de LSV y Vd a $60^{\circ} \mathrm{C}$.

\begin{tabular}{cccc}
\hline Asfalto & \multicolumn{2}{c}{ LSV } & Vd. \\
& OPa.s] & {$[\mu \mathrm{m} / \mathrm{min}]$} \\
& Original & RTFOT & \\
\hline C1 & 163,8 & 234,7 & 12,4 \\
C2 & 346,3 & 412,3 & 6,7 \\
C3 & 252,2 & 559,3 & 9,6 \\
C4 & 1106,4 & 2970,4 & 2,8 \\
M & 947,5 & 3199,4 & 3,4 \\
MP1 & 595,0 & 1043,0 & 3,7 \\
MP2 & 2642,1 & 6461,5 & 2,7 \\
MP3 & 2459,3 & 5169,0 & 3,0
\end{tabular}

En la figura 5.5 se observa la relación entre los resultados de Vd y la LSV de los asfaltos en estado original. La correlación obtenida es buena $\left(\mathrm{R}^{2}=0,86\right)$ lo que permite afirmar que la LSV caracteriza eficientemente el comportamiento de la mezcla asfáltica en lo que se refiere a su resistencia al ahuellamiento; a medida que crece la LSV de los asfaltos la resistencia al ahuellamiento es mayor dando lugar a una menor velocidad de deformación.

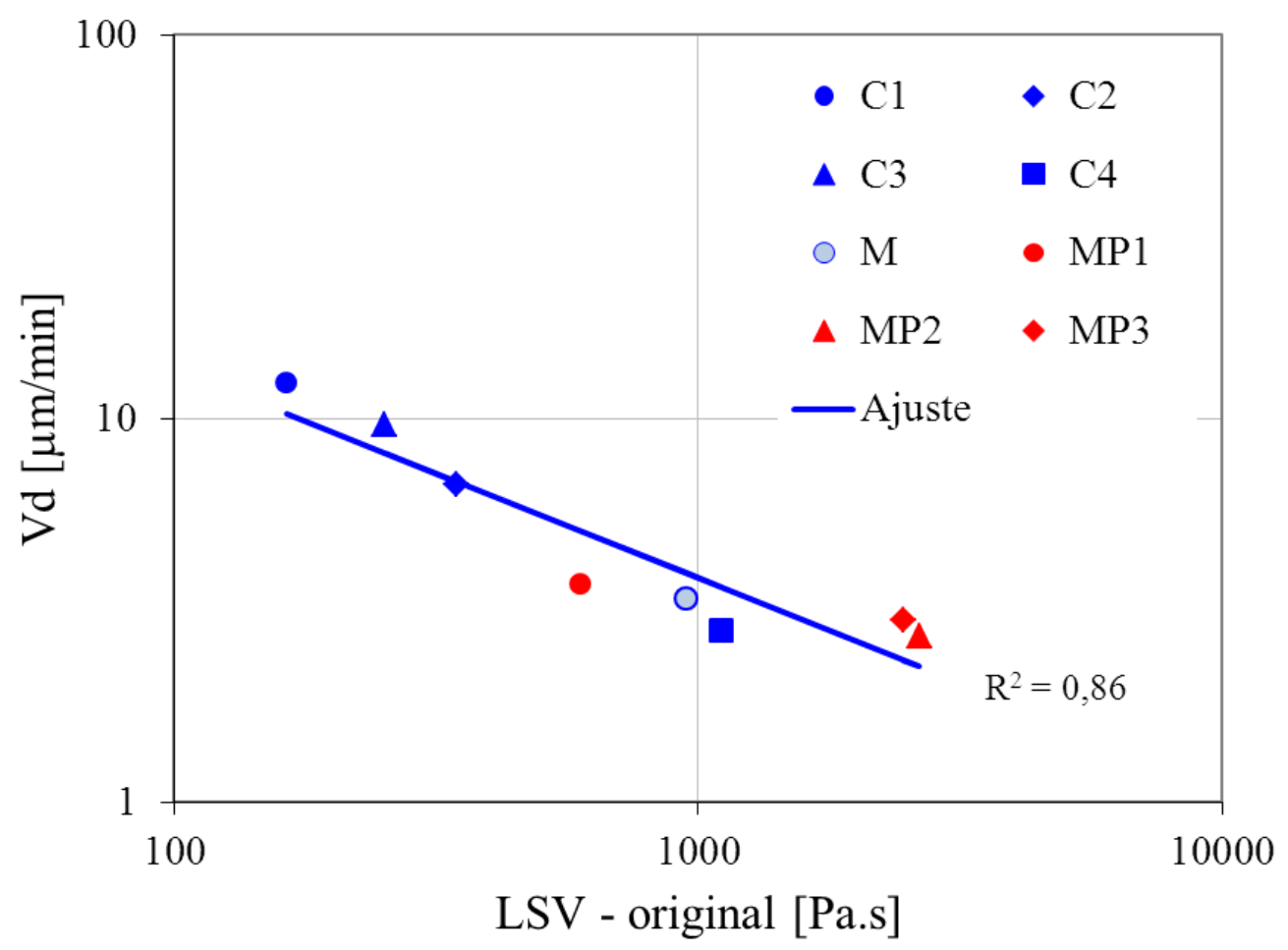

Figura 5.5. Vd en función de la LSV en asfalto original. 
Al igual que con el asfalto en estado original la LSV de los asfaltos envejecidos caracteriza de la misma manera los diferentes ahuellamientos, figura 5.6. Esto indica que el proceso de envejecimiento en RTFOT no genera discrepancias en los resultados de LSV que puedan traducirse en una errónea caracterización de la resistencia al ahuellamiento.

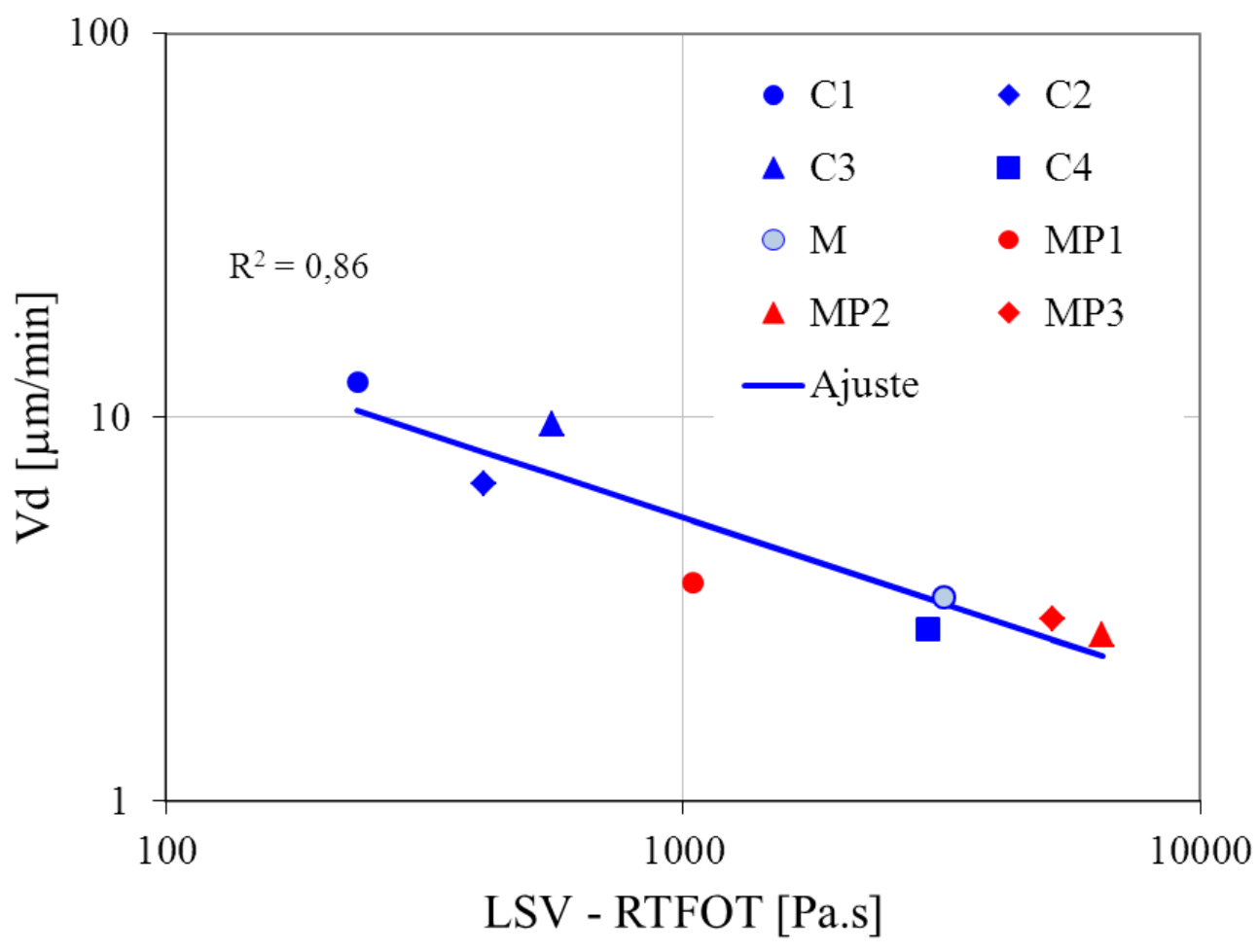

Figura 5.6. Vd en función de la LSV en asfalto envejecido.

Es importante destacar que los ahuellamientos medidos en los concretos asfálticos elaborados con los ligantes modificados con polímero SBS (MP2 yMP3) fueron bien caracterizados por la LSV. Se observa en la tabla 5.2 que, a diferencia de lo ocurrido con el parámetro $\mathrm{G} * / \mathrm{sen} \delta$, en este caso ambos ligantes presentan los mayores valores de LSV que siguen una tendencia coherente con los menores ahuellamientos observados (menor Vd) en el ensayo de rueda cargada.

Por todo lo dicho la LSV constituye un parámetro más versátil ya que clasifica a todo tipo de ligante asfáltico en lo que respecta al aporte en la resistencia a las deformaciones permanentes en las mezclas indistintamente de sean asfaltos convencionales 0 modificados.

Para observar las relaciones de las propiedades reológicas con los ahuellamientos en mezclas los datos fueron ajustados de manera preliminar a un modelo potencial de la forma expresada en la ecuación 5.1.

$$
V d[\mu \mathrm{m} / \mathrm{min}]=A \cdot L S V^{B}
$$

El modelo potencial no caracteriza eficientemente la relación Vd-LSV, a medida que aumenta la LSV la Vd disminuye, sin embargo los valores de Vd obtenidos del ajuste de la ecuación 5.1 son siempre decrecientes, es decir se llega un momento en que la Vd seria cero indicando que la mezcla es un sólido elástico. Eso nunca es así, las mezclas 
asfálticas son materiales visco-elásticos por lo que presentaran al menos algún tipo de deformación permanente. La realidad es que el modelo debe presentar una tendencia hacia un valor de Vd constante. Por lo dicho se procedió al ajuste de datos adoptando un modelo como el que indica la ecuación 5.2, utilizando técnicas de regresión no lineal. El ajuste de datos se realizó con un software estadístico.

$$
V d[\mu \mathrm{m} / \mathrm{min}]=a+\frac{b}{L S V}
$$

En la tabla 5.3 se muestran los parámetros de ajuste (a, b y su respectivo $\mathrm{R}^{2}$ ) obtenidos para las relaciones de $\mathrm{Vd}$ en función de los asfaltos en estado original y envejecido respectivamente. En la figuras 5.7 y 5.8 se observan gráficamente estos ajustes.

Tabla 5.3. Parámetros de ajuste por regresión no lineal - relación Vd-LSV.

\begin{tabular}{ccc}
\hline & Original & Envejecido (RTFOT) \\
\hline $\mathrm{a}$ & 1,628 & 2,451 \\
$\mathrm{~b}$ & 1798,05 & 2364,93 \\
$\mathrm{R}^{2}$ & 0,97 & 0,87 \\
\hline
\end{tabular}

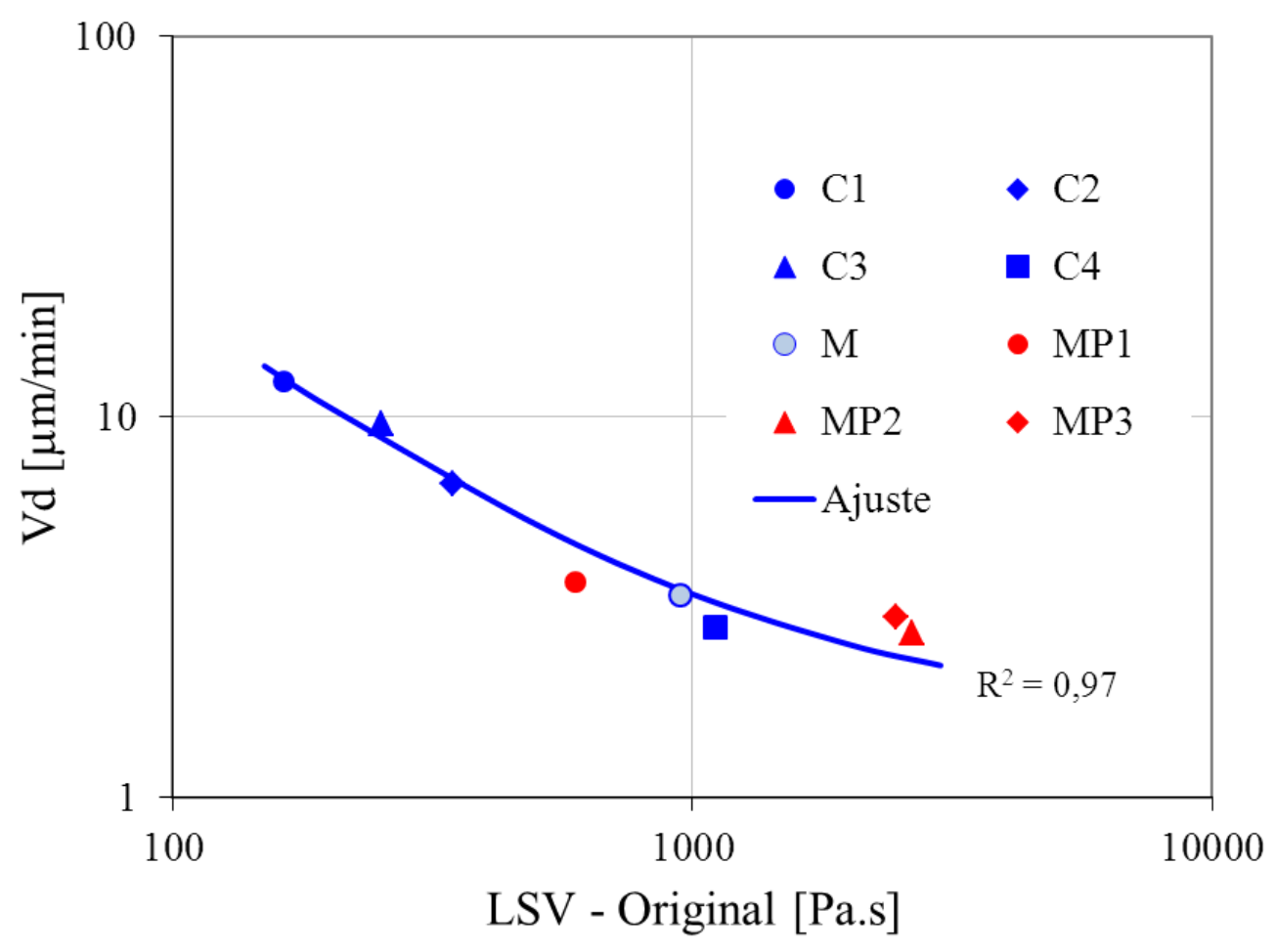

Figura 5.7. Relaciones Vd-LSV de los asfaltos en estado original. 


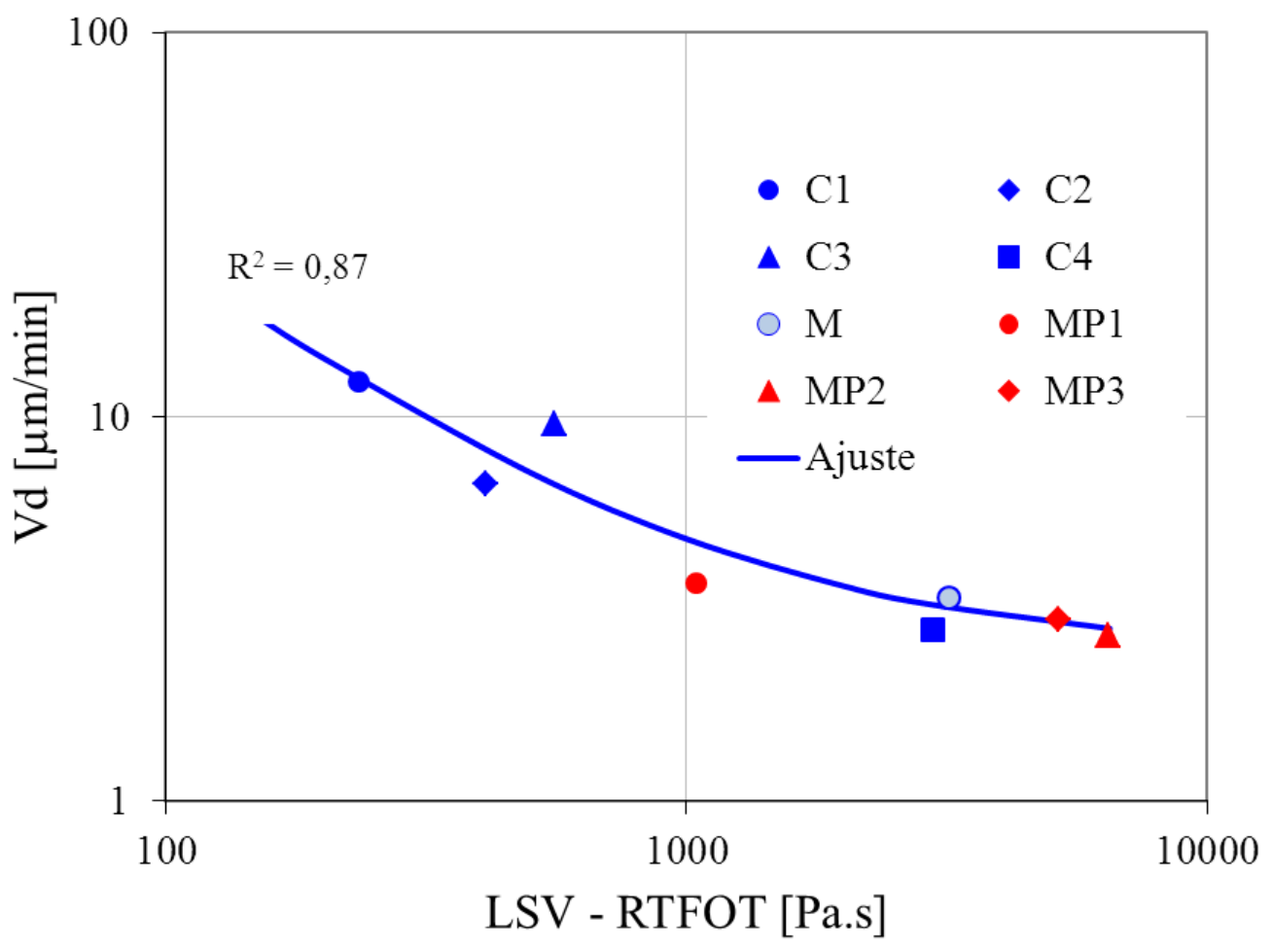

Figura 5.8. Relaciones Vd-LSV de los Asfaltos envejecidos en RTFOT.

Se observa en la figura 5.7 que a bajos valores de LSV (entre 100 y 1000 Pa.s) los cambios en los valores de $\mathrm{Vd}$ son importantes, de 12 hasta $3 \mu \mathrm{m} / \mathrm{min}$ aproximadamente, mientras los ahuellamientos ya no presentan mayores diferencias para valores de LSV mayores a 1000 pa.s. Este cambio de comportamiento se produce en un rango de valores de LSV donde el ligante empieza a controlar el proceso de deformaciones permanentes en la mezcla asfáltica evitando que las mismas se produzcan de manera excesiva lo que ocasionaría una pérdida de prestaciones del pavimento. Este aspecto se estudiará más profundamente en el siguiente capítulo en donde se involucrará un rango más amplio de temperaturas de ensayo tanto para la LSV de los asfaltos como en los ensayos de rueda cargada, así como el estudio en otras mezclas diferentes al tipo D-20.

\subsection{Conclusiones y comentarios al capítulo}

Como principales conclusiones se observa que el parámetro $\mathrm{G} * /$ sen $\delta$ a la frecuencia de $10 \mathrm{rad} / \mathrm{s}$ no caracteriza eficientemente el aporte de todos los tipos de ligantes en lo que se refiere a la resistencia al Ahuellamiento de las mezclas asfálticas. La mayor carencia se da en el caso de los ligantes modificados con polímero SBS.

Se verifica que las medidas de $\mathrm{G} * /$ sen $\delta$ son afectadas por el proceso de envejecimiento en RTFOT en determinados asfaltos lo que constituye una nueva limitación para el uso de este parámetro.

Tampoco se observaron mejoras al considerar el $\mathrm{G}^{*} / \mathrm{sen} \delta$ a la frecuencia de 0,6 rad/s en lo relativo a la caracterización de los ahuellamientos de las mezclas. Este hecho refuta lo mencionado en el capítulo 4, donde se analizaron los resultados a nivel de los ligantes únicamente y de donde surgía que el G*/sen $\delta$ a $0,6 \mathrm{rad} / \mathrm{s}$ parecería caracterizar mejor el aporte de los asfaltos en la resistencia al Ahuellamiento. Los resultados en este 
capítulo indican que aún persiste el problema de caracterizar a los ligantes modificados con polímero SBS al igual que con el G*/sen $\delta$ medido a la frecuencia de $10 \mathrm{rad} / \mathrm{s}$.

Por el contrario se encontraron muy buenas relaciones entre los ahuellamientos de las mezclas en el ensayo de rueda cargada y los valores de LSV de los ligantes. De esto surge que esta propiedad reológica caracteriza apropiadamente la contribución del asfalto en la resistencia a las deformaciones permanentes en las mezclas asfálticas para todos los ligantes estudiados incluyendo a los ligantes modificados con polímero.

Los resultados obtenidos permiten afirmar que la LSV es la propiedad reológica más conveniente para caracterizar los ligantes asfálticos en lo referente a la resistencia frente al ahuellamiento de las mezclas.

Por tal motivo, en adelante en esta tesis se trabajará con esta propiedad para discutir la relación entre las mediciones en el equipo de rueda cargada y las características de los ligantes asfálticos considerando temperaturas y niveles de carga diferentes a los normalizados $\left(60^{\circ} \mathrm{C}\right.$ y $\left.520 \mathrm{~N}\right)$ como así también diferentes tipos de mezclas asfálticas. De este modo se procura una mayor generalización acerca de la estimación y diseño del concreto asfáltico en lo relativo a la problemática de las deformaciones permanentes y la resistencia al ahuellamiento en particular. 


\section{Capítulo 6}

\section{Efecto de la temperatura y el nivel de carga sobre el desarrollo del ahuellamiento en el ensayo de rueda cargada}

\subsection{Introducción}

La temperatura del pavimento y las cargas de tránsito son dos variables que tienen un rol preponderante en el desarrollo de deformaciones permanentes en los pavimentos. El ensayo de rueda cargada tiene en cuenta estas variables pero establece condiciones estandarizadas que no son siempre las que ocurren en un pavimento asfáltico.

Es evidente que al momento de seleccionar el mejor ligante para una dada aplicación ambas variables, temperatura y cargas a las que estará expuesto el pavimento, serán determinantes. Por tal motivo es de interés evaluar la sensibilidad del ensayo de rueda cargada y de los límites establecidos para el ahuellamiento para cada una de ellas.

En este capítulo se utilizó el ensayo de rueda cargada para el estudio de desempeño de mezclas expuestas a diferentes temperaturas; tales resultados se analizan en relación a la LSV de los asfaltos para plantear una relación que las vincule. El objetivo es poder predecir el desempeño de diferentes mezclas asfálticas a partir de conocer la LSV del asfalto con la cual se elabora tomando en cuenta la temperatura a la que se verá sometida la mezcla en el pavimento. Posteriormente se observa el desempeño de las mismas mezclas bajo diferentes niveles de carga. Finalmente se completa el análisis con el estudio de los desempeños a diferentes temperaturas y cargas conjuntamente con la LSV.

Para ello se seleccionaron las tres gradaciones para mezclas asfálticas de carpeta de rodamiento antes diseñadas; la mezcla densa (D-20), el microaglomerado (M-10) y el Stone mastic asphalt (SMA-10).

En cuanto al tipo de ligante el estudio incluye mezclas elaboradas con el asfalto convencional (C3), el asfalto multigrado (M) y el modificado con polímero SBS (MP3). 
Estos tres ligantes asfálticos representan adecuadamente a los asfaltos más usados en la actualidad.

Cabe destacar que es importante para una correcta caracterización del ligante asfáltico considerar las propiedades del mismo en estado original y luego de envejecido. Por lo tanto las relaciones planteadas se analizan para ambas condiciones.

\subsection{Efecto de la temperatura}

La performance de las mezclas elaboradas fue estudiada en condiciones controladas de laboratorio en el equipo de rueda cargada realizado a temperaturas de 50, 60, 70 y $80^{\circ} \mathrm{C}$. Estas temperaturas se seleccionaron ya que representan el rango de temperaturas donde se manifiestan los problemas de deformaciones permanentes en mezclas asfálticas.

En forma paralela y con el fin de establecer la vinculación con las propiedades del asfalto, sobre cada ligante en estado original y envejecido en RTFOT se midió la LSV para las mismas temperaturas de referencia $\left(50,60,70\right.$ y $\left.80{ }^{\circ} \mathrm{C}\right)$.

\subsubsection{Análisis de los resultados}

En primer lugar es importante describir características de las mezclas en estudio que servirán de apoyo a lo largo del análisis de resultados. La mezcla D-20 es una mezcla densa continua que lleva un $5 \%$ de asfalto mientras que las mezclas M-10 y SMA-10 tienen gradaciones abiertas (casi monogranulares) muy similares. Este tipo de granulometría les confiere una gran macrotextura. Los porcentajes de asfalto para estas mezclas son 5,3 y $6 \%$ respectivamente. La otra diferencia que se presenta entre las mezclas M-10 y SMA-10 es la incorporación de 0,5 \% de fibras de celulosa a la SMA con la finalidad de poder incorporar el mayor porcentaje de asfalto que lleva sin que se escurra. Todas las mezclas presentan un porcentaje de cal del $1 \%$.

En la tabla 6.1 se presentan los resultados de la velocidad de ahuellamiento (Vd) conjuntamente con la LSV de los asfaltos de las mezclas estudiadas, incluyendo resultados de LSV para el estado original y luego de envejecido en RTFOT. Las mezclas se identifican en función del tipo de gradación, el asfalto utilizado, la temperatura de ensayo y la carga aplicada.

Es de destacar la baja LSV que presenta el ligante MP3 envejecido en RTFOT para la temperatura de $80{ }^{\circ} \mathrm{C}$, tabla 6.1. Esta LSV es prácticamente del mismo orden que la del asfalto en estado original. El asfalto envejecido en RTFOT representa el estado en que el ligante se encuentra luego de la fabricación de la mezcla, por tanto es esperable un mayor valor de LSV luego del envejecimiento. Sin embargo este no es el caso del ligante MP3 sobre todo a la temperatura de $80^{\circ} \mathrm{C}$.

Diferentes estudios ponen de manifiesto que el ensayo de RTFOT no representa el envejecimiento realmente ocurrido durante la elaboración de la mezcla de algunos asfaltos modificados con polímero (Bahia et al. 2001 y Jia et al. 2005). A la temperatura fijada para el proceso $\left(163{ }^{\circ} \mathrm{C}\right)$, la elevada viscosidad de estos asfaltos genera que no roten dentro del recipiente de vidrio por lo que no se forma una delgada capa de ligante durante el ensayo. Bajo este escenario no se representan las condiciones de exposición a 
las que se ve sometido el ligante en la planta asfáltica. Por otro lado normalmente los asfaltos modificados son expuestos a severas condiciones durante la elaboración con lo que el RTFOT no representa adecuadamente las condiciones reales a las que se ve expuesto el asfalto. En esta tesis la temperatura de preparación de las mezclas para el ligante MP3 fue de $180{ }^{\circ} \mathrm{C}$. A esta temperatura se produce un envejecimiento importante del asfalto. Esto explicaría por qué el ligante MP3 luego de ser sometido al RTFOT tiene una baja LSV a $80^{\circ} \mathrm{C}$.

Tabla 6.1. Resultados de LSV de los asfaltos y Vd de las diferentes mezclas

\begin{tabular}{|c|c|c|c|c|c|c|}
\hline Asfalto & $\begin{array}{c}\mathrm{T} \\
{\left[{ }^{\circ} \mathrm{C}\right]}\end{array}$ & $\begin{array}{c}\text { LSV } \\
\text { original } \\
\text { [Pa.s] }\end{array}$ & $\begin{array}{c}\text { LSV } \\
\text { RTFOT } \\
\text { [Pa.s] }\end{array}$ & D-20 & $\begin{array}{l}\mathrm{M}-10 \\
{[\mu \mathrm{m} / \mathrm{m}}\end{array}$ & SMA-10 \\
\hline \multirow{4}{*}{ C3 } & 50 & 1012,4 & 2674,5 & 3,9 & 4,2 & 3,4 \\
\hline & 60 & 252,5 & 559,3 & 9,5 & 14,8 & 11,2 \\
\hline & 70 & 83,2 & 159,5 & 23,8 & 37,9 & 24,0 \\
\hline & 80 & 34,3 & 58,4 & -* & $-*$ & $-*$ \\
\hline \multirow{4}{*}{ M } & 50 & 3631,1 & 15267,4 & 2,4 & 1,8 & 2,1 \\
\hline & 60 & 947,5 & 3199,4 & 3,2 & 3,2 & 3,3 \\
\hline & 70 & 308,1 & 863,9 & 6,7 & 10,4 & 8,4 \\
\hline & 80 & 120,5 & 288,5 & 14,1 & 30,0 & 16,7 \\
\hline \multirow{4}{*}{ MP3 } & 50 & 7669,9 & 24952,9 & 2,3 & 1,4 & 1,8 \\
\hline & 60 & 2459,3 & 5169,0 & 3,0 & 1,8 & 1,9 \\
\hline & 70 & 911,3 & 1367,7 & 3,5 & 2,6 & 3,0 \\
\hline & 80 & 383,1 & 445,0 & 4,9 & 4,1 & 3,8 \\
\hline
\end{tabular}

* No se midió

Debido a la posibilidad de una inadecuada caracterización de la LSV del asfalto MP3 en RTFOT, se estudiaron diferentes modificaciones del ensayo normalizado. Una de ellas fue la introducción de una varilla helicoidal de acero dentro del recipiente de vidrio para fomentar el giro del ligante, figura 6.1 (Agnusdei y Iosco 2000). La otra variante estudiada fue la realización del ensayo a $180{ }^{\circ} \mathrm{C}$, temperatura de mezclado del MP3, para disminuir la viscosidad del mismo. Paralelamente se procedió a la recuperación del ligantes asfáltico MP3 de una probeta de mezcla elaborada en condiciones regulares para contrastar los resultados de las condiciones planteadas con el envejecimiento realmente ocurrido. La recuperación del asfalto se realizó con la metodología especificada en la norma ASTM D 1856.

Sobre los diferentes ligantes envejecidos se realizaron mediciones de LSV a las temperaturas de 50, 60, 70 y $80^{\circ} \mathrm{C}$. En la tabla 6.2 se muestran estos resultados junto con los valores para el MP3 luego del RTFOT estándar. Se observa allí que la LSV del MP3 recuperado de mezcla es mayor que la obtenida del asfalto luego del RTFOT 
tradicional, poniendo de manifiesto el problema planteado originalmente. A su vez de las dos variantes estudiadas, la que arrojó valores similares de LSV al MP3 recuperado fue aquella en la cual se aumentó la temperatura. La incorporación de la varilla helicoidal no produjo cambios apreciables en los resultados de LSV.

En función de los resultados encontrados en adelante se considera para el asfalto MP3 los resultados de LSV del asfalto recuperado de mezcla.
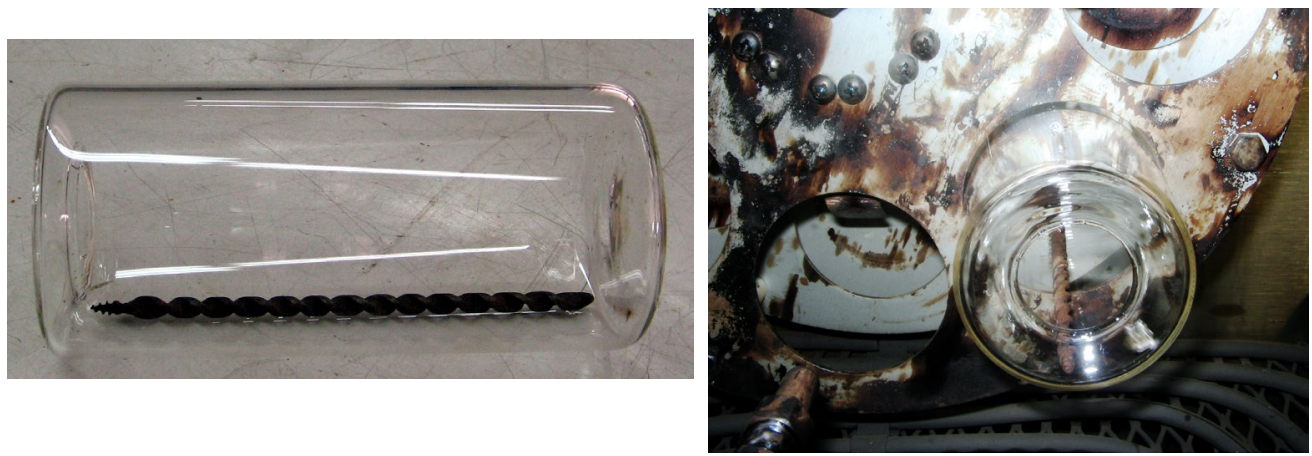

Figura 6.1. Varilla helicoidal dentro del recipiente de vidrio del RTFOT.

Tabla 6.2. LSV del asfalto MP3 de diferentes procesos de envejecimiento en RTFOT y recuperado de mezcla.

\begin{tabular}{ccccc}
\hline T $\left[{ }^{\circ} \mathrm{C}\right]$ & RTFOT $^{(1)}$ & RTFOT $^{(2)}$ & RTFOT $^{(3)}$ & $\begin{array}{c}\text { Recuperado } \\
\text { de mezcla }\end{array}$ \\
\hline 50 & 24952,9 & 8073,9 & 21881,6 & 35824,8 \\
60 & 5169,0 & 2306,0 & 6471,5 & 9103,7 \\
70 & 1367,7 & 784,2 & 2220,4 & 2766,8 \\
80 & 445,0 & 309,9 & 867,9 & 982,5 \\
\hline
\end{tabular}

(1) RTFOT realizado a $163^{\circ} \mathrm{C}$ durante 85 min.

(2) RTFOT a $163^{\circ} \mathrm{C}$ durante 85 min. con varilla Helicoidal.

(3) RTFOT a $180^{\circ} \mathrm{C}$ durante $85 \mathrm{~min}$.

Para analizar los resultados de la tabla 6.1 en lo que se refiere al efecto de la temperatura sobre el ahuellamiento en las figuras 6.2 a 6.4 se muestran los resultados de la $\mathrm{Vd}$ en función de la temperatura de ensayo. Considerando los resultados correspondientes a las mezclas tipo D-20 (figura 6.2) elaboradas con un mismo ligante se observa como a medida que aumenta la temperatura de ensayo se verifica como era de esperar una merma en el desempeño, incrementando Vd y los ahuellamientos. Sin embargo al comparar la respuesta de mezclas elaboradas con diferentes asfaltos se observa que $\mathrm{Vd}$ se incrementa muy rápidamente para la mezcla con el asfalto C3 en menor medida con el asfalto $\mathrm{M}$ y la sensibilidad a los cambios de temperatura dentro del rango estudiado es muy baja para el caso de MP3. En conclusión una misma mezcla presenta distintas susceptibilidad térmica dependiendo del tipo de ligante. Asimismo es de resaltar que también parece modificar el umbral de temperatura para la cual se 
produce un rápido incremento del ahuellamiento, en este caso parece abarcar todo el rango estudiado en el C3, resulta del orden de $60{ }^{\circ} \mathrm{C}$ para $\mathrm{M}$ y mayor a $70{ }^{\circ} \mathrm{C}$ para MP3.

Un análisis similar puede hacerse a partir de los resultados en las mezclas tipo M-10 y SMA-10 con idénticas conclusiones a las mencionadas para las mezclas D-20. En la figura 6.3 se aprecia que las mezclas M-10 con C3 y M presentan una susceptibilidad térmica más marcada que las otras mezclas no habiendo diferencias apreciables cuando se considera al asfalto MP3. Se observa que una vez superado el umbral de temperatura antes mencionado este tipo de mezclas presentan una marcada inestabilidad con rápido incremento de ahuellamientos.

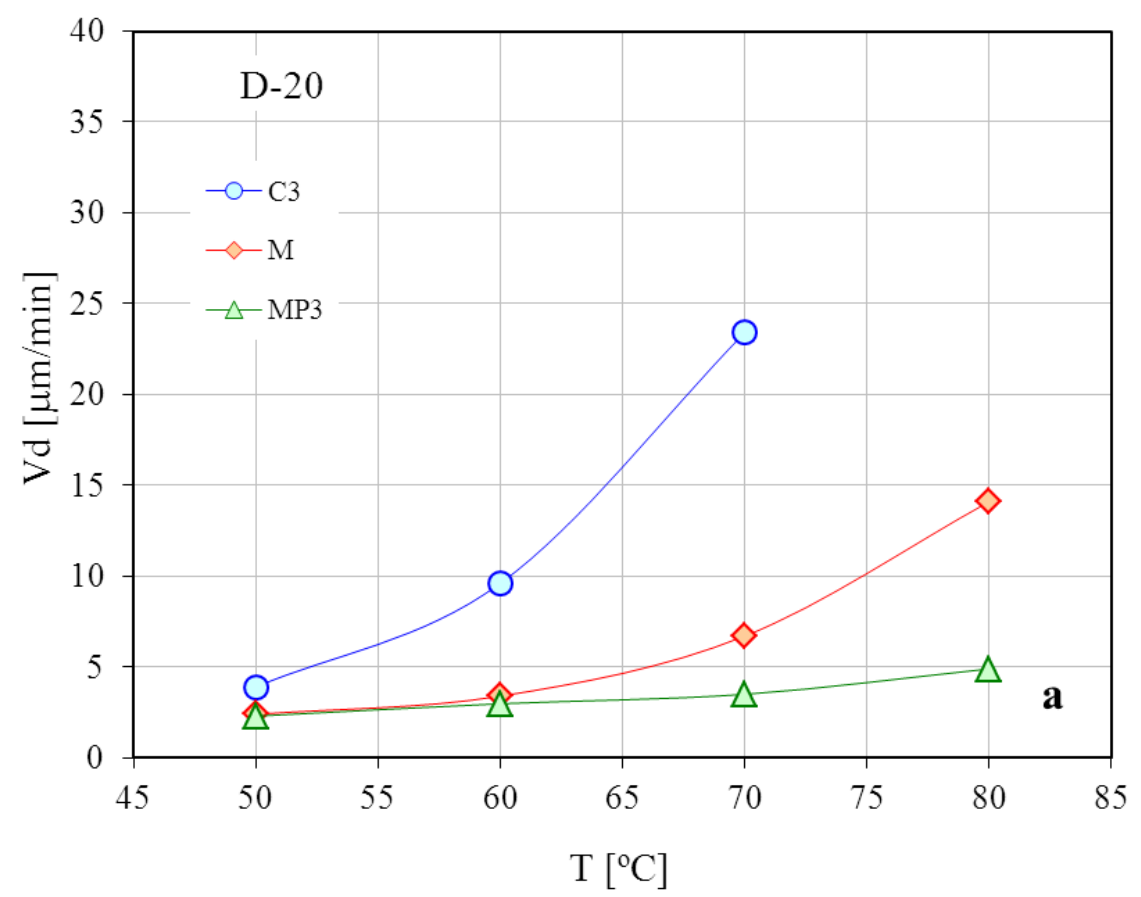

Figura 6.2. Relación Vd-Temperatura con los distintos asfaltos de la mezcla D-20.

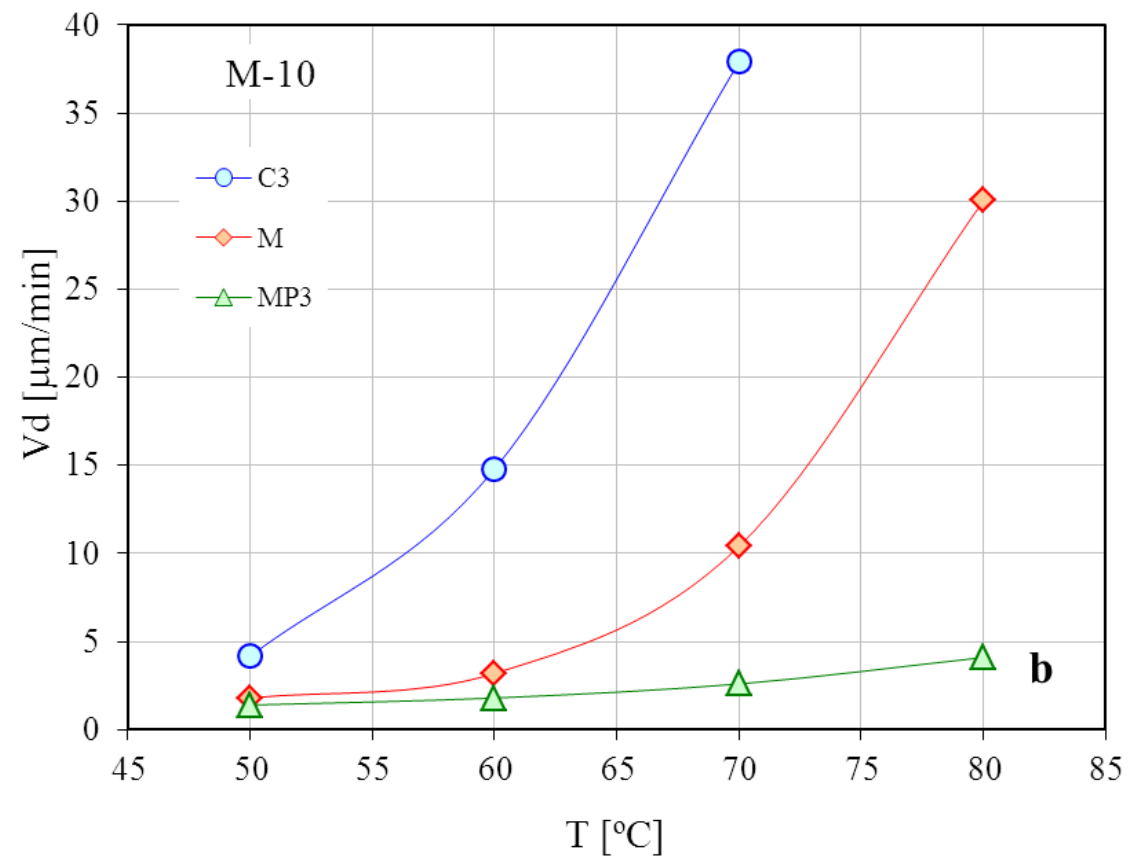

Figura 6.3. Relación Vd-Temperatura con los distintos asfaltos de la mezcla M-10. 


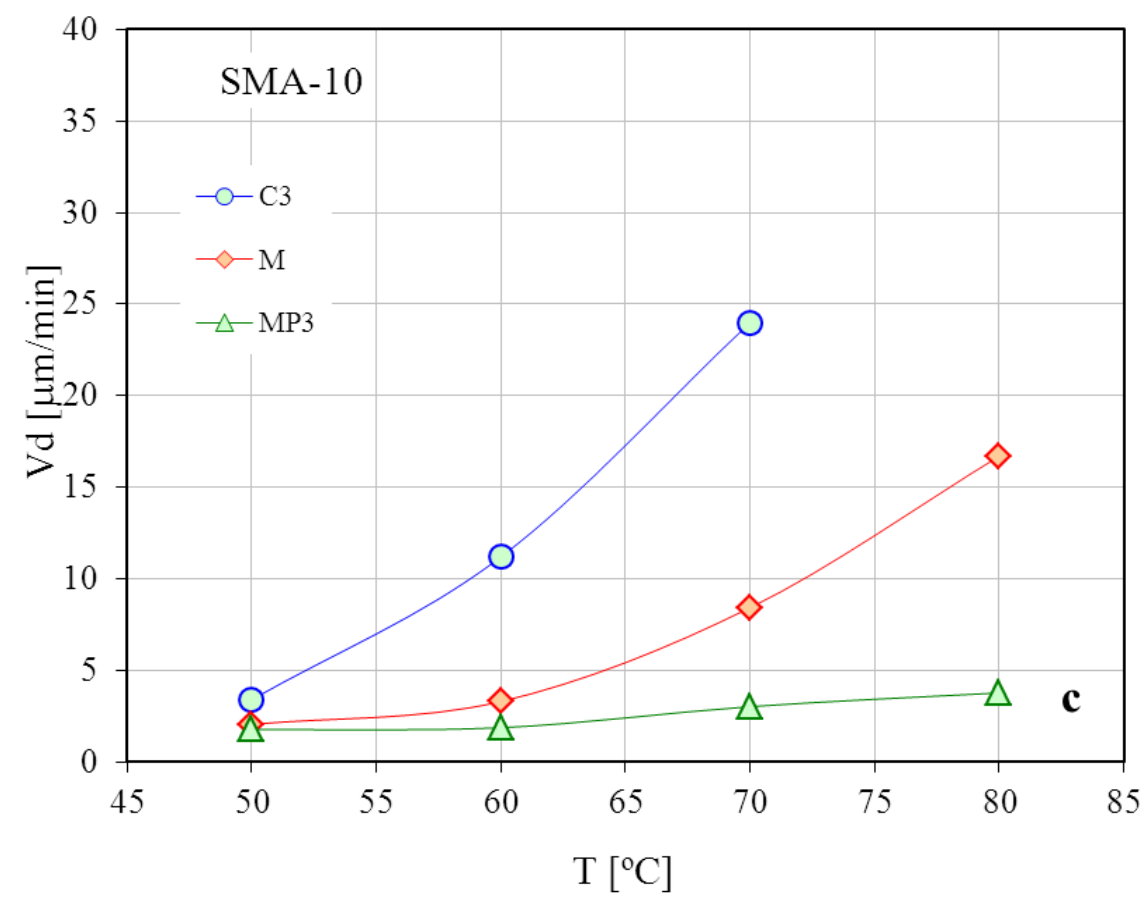

Figura 6.4. Relación Vd-Temperatura con los distintos asfaltos de la mezcla SM A-10.

En la figura 6.5 se observan fotografías de la mezcla M-10 elaborada con el asfalto C3 y de la mezcla SMA-10 elaborada con el asfalto MP3 luego del ensayo. Se aprecia que conforme el tipo de mezcla y ligante empleados se producen diferencias significativas en las deformaciones permanentes.
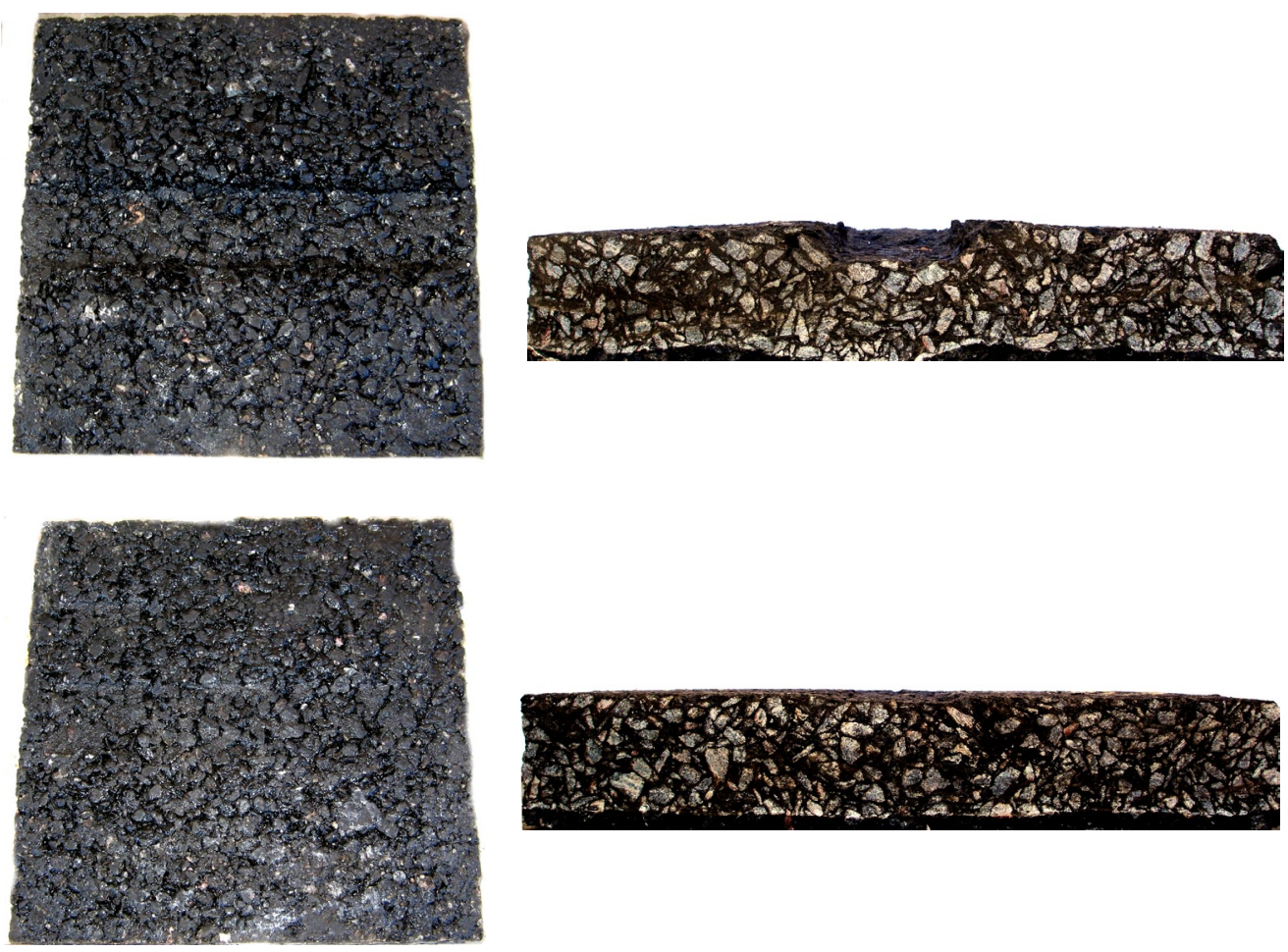

Figura 6.5. Aspecto de diferentes muestras después del ensayo de rueda cargada. Mezcla M-10 C3 (Arriba), mezcla SMA-10 MP3 (Abajo). 
La inestabilidad observada en las mezclas M-10 C3 y M-10 M se debe a la baja viscosidad del ligante (a altas temperaturas) que cumple una función de lubricante entre agregados, favorecida por el alto porcentaje de asfalto (5,3\%), que no mantiene cohesionada la estructura pétrea casi monogranular que esta gradación posee. Por lo tanto se producen excesivas deformaciones y un mayor ahuellamiento (Vd alto). La mezcla SMA utilizada en esta tesis presenta, como ya se mencionara, una configuración granulométrica similar al microaglomerado y por tanto seria susceptible de sufrir una falla similar a bajos valores de viscosidad, efecto que no se observa en los resultados. Una posible explicación sea que las fibras que posee la SMA aumenten la viscosidad del mastico asfáltico (asfalto, más finos y fibras en el caso de la SMA) y permiten mantener la cohesión de la mezcla con un nivel más bajo de ahuellamiento que en la mezcla M-10. Es importante destacar que las mezclas elaboradas con MP3 presentaron muy bajos valores de $\mathrm{Vd}$ para todo el rango de temperaturas independientemente del tipo de mezcla considerado.

Con el fin de establecer una relación con las propiedades del ligante dentro del rango de temperaturas estudiadas, en la figura 6.6 se representa la Vd, de la mezcla tipo D-20, en función de la LSV de los asfaltos en estado original para cada temperatura. Se observa que independientemente del tipo de asfalto las mezclas presentan una tendencia de comportamiento. Para incrementos de la LSV, relacionadas a menores temperaturas (tabla 6.1), corresponden menores $\mathrm{Vd}$ en el ensayo de rueda cargada. Las mezclas del tipo M-10 y SMA-10 presentan el mismo comportamiento como se observa en las figuras 6.7 y 6.8 .

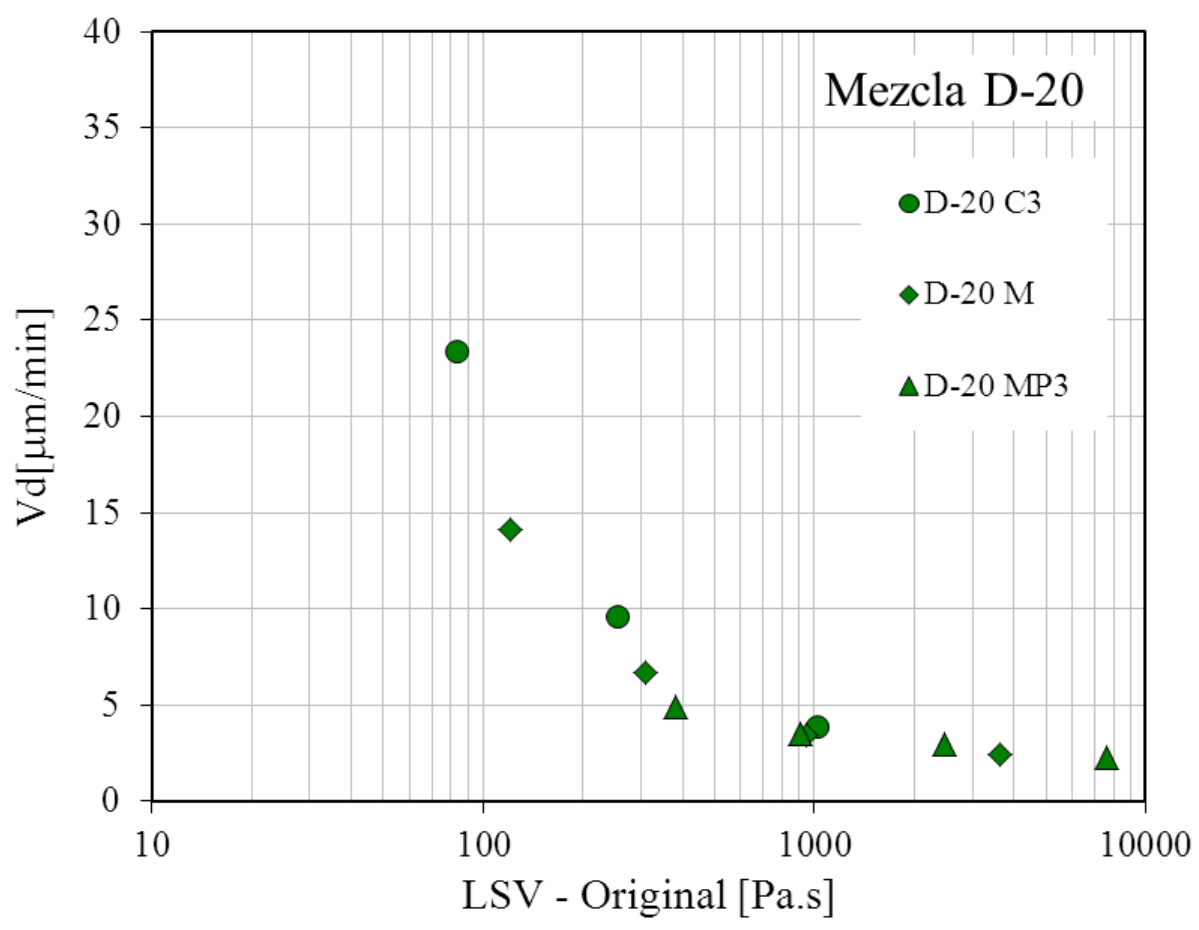

Figura 6.6. Vd de las mezclas D-20 en función de la LSV de los asfaltos. 


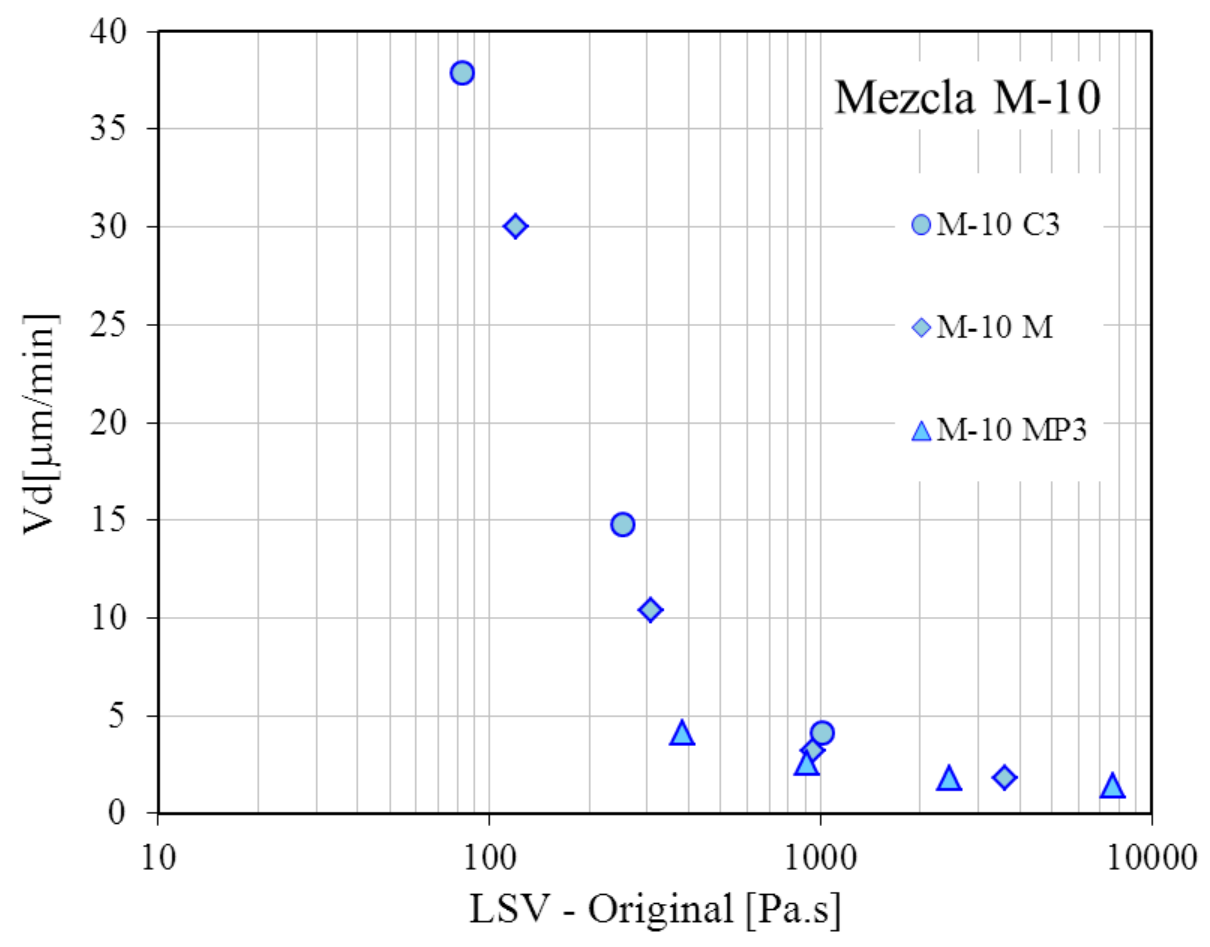

Figura 6.7. Vd de las mezclas M-10 en función de la LSV de los asfaltos.

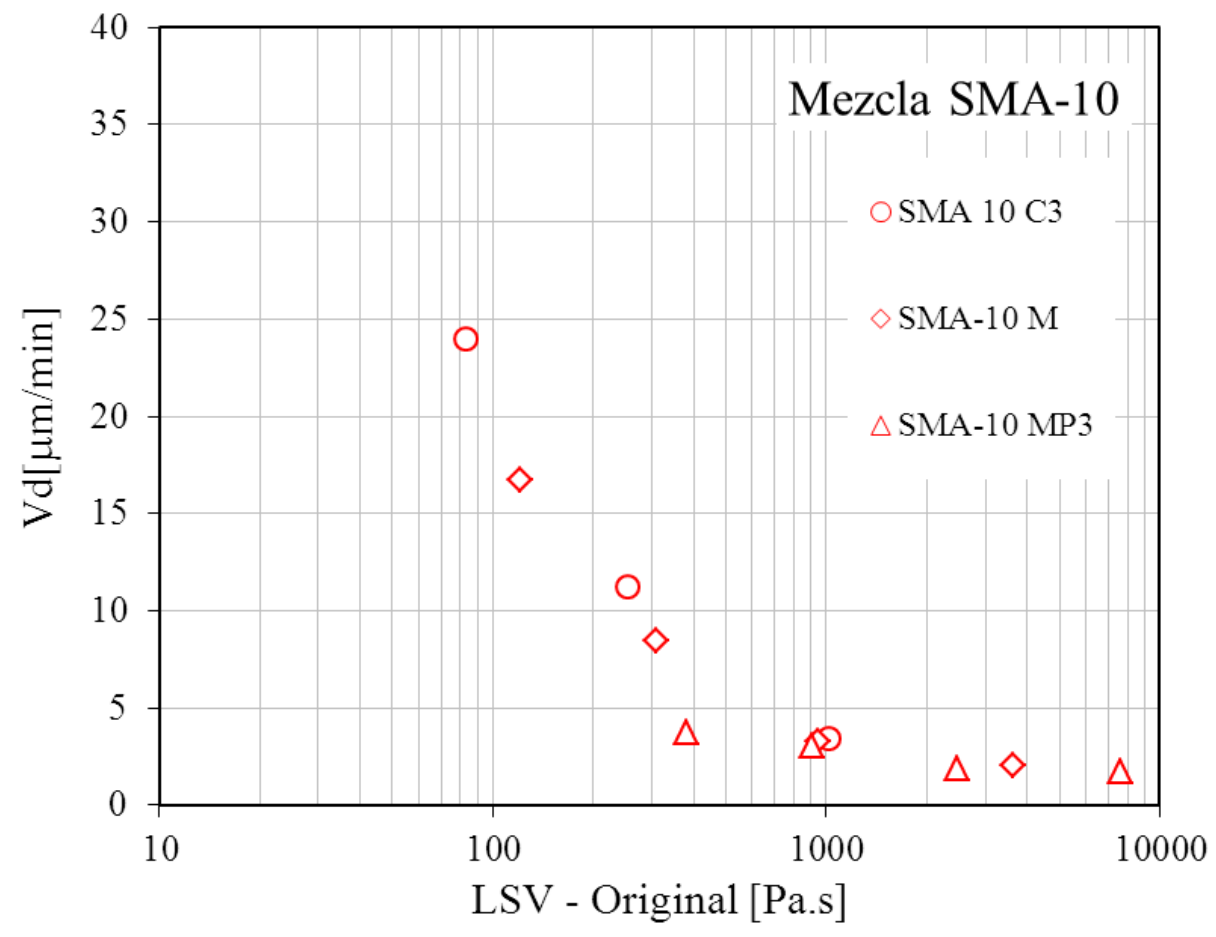

Figura 6.8. Vd de las mezclas SMA-10 en función de la LSV de los asfaltos.

En la figura 6.9 se muestra de manera conjunta las relaciones de Vd-LSV anteriores, se observa que los tres tipos de mezclas estudiadas siguen una tendencia similar. Además se observa en la figura 6.9 como para bajos valores de LSV se produce un manifiesto cambio en la Vd. En el capítulo 5 se observó este comportamiento y se anticipó el estudio de este aspecto en este apartado. En esta oportunidad con mayor cantidad de resultados en diferentes mezclas y a distintas temperaturas surge que, con valores de LSV en el ligante original menores de 500 Pa.s aparecen cambios 
significativos en la resistencia frente a las deformaciones permanentes de las mezclas para todo el rango de temperaturas y ligantes estudiados.

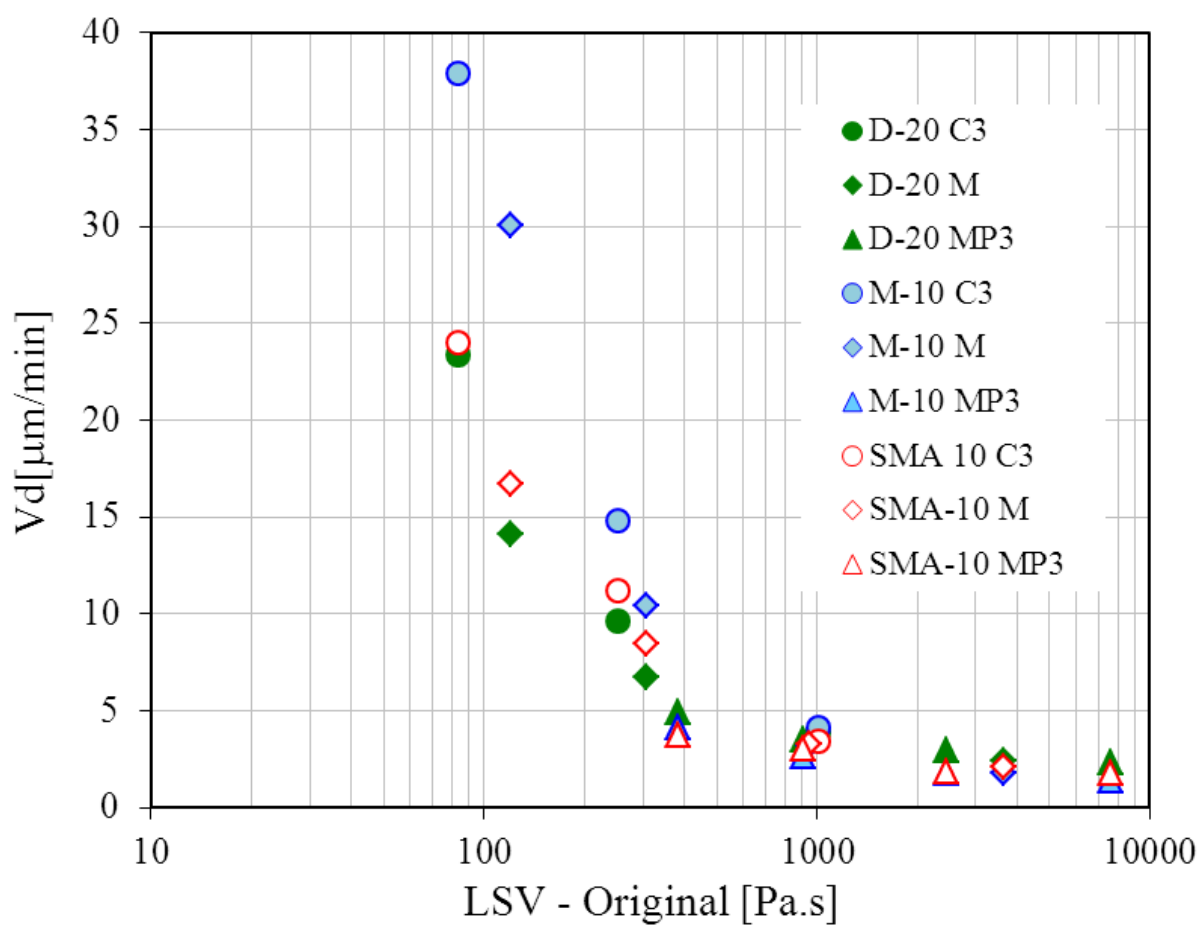

Figure 6.9. Vd versus LSV del asfalto para las diferentes mezclas.

Es importante para una correcta caracterización del ligante asfáltico considerar las propiedades del mismo en estado original y luego de envejecido. Por otro lado a veces solo se cuenta con muestras de mezcla de pavimento directamente u obtenidas de la planta asfáltica. En consecuencia resulta de interés conocer las relaciones de los ahuellamientos con las propiedades del ligante envejecido. En la figura 6.10 se representa la Vd en función de la LSV de los asfaltos luego del proceso de RTFOT para cada temperatura. Cabe aclarar que los valores de LSV del MP3 pertenecen a los resultados obtenidos del asfalto recuperado de mezcla debido al inadecuado envejecimiento presentado por este asfalto en el ensayo de RTFOT. Volviendo al estudio de la figura 6.10 se observa allí como nuevamente las distintas mezclas siguen una tendencia general solo que el cambio en el comportamiento de la velocidad de deformación (Vd) se produce para valores alrededor de los 2000 Pa.s.

Los valores de 500 y 2000 Pa.s de LSV del asfalto representan un límite, para cada condición del ligante (original o envejecido), en el aporte del asfalto en la resistencia a las deformaciones permanentes. Además el cambio observado en el comportamiento se produce independientemente del tipo de ligante. Sin embargo cada asfalto presentara esas viscosidades a diferentes temperaturas y en función de esta varia el umbral donde la mezcla ya no tiene resistencia al ahuellamiento. Por lo tanto esta representa la máxima temperatura aceptable del pavimento. Similar a este razonamiento es el concepto de la especificación de asfalto ASTM D 6373 (1999) para obtener la temperatura de alta del grado de desempeño (PG) con la diferencia de que la propiedad reológica utilizada es el parámetro $\mathrm{G}^{*} / \mathrm{sen} \delta$ que tiene como valores límites a los 1 y 2,2 kPa para el asfalto original y envejecido respectivamente. 


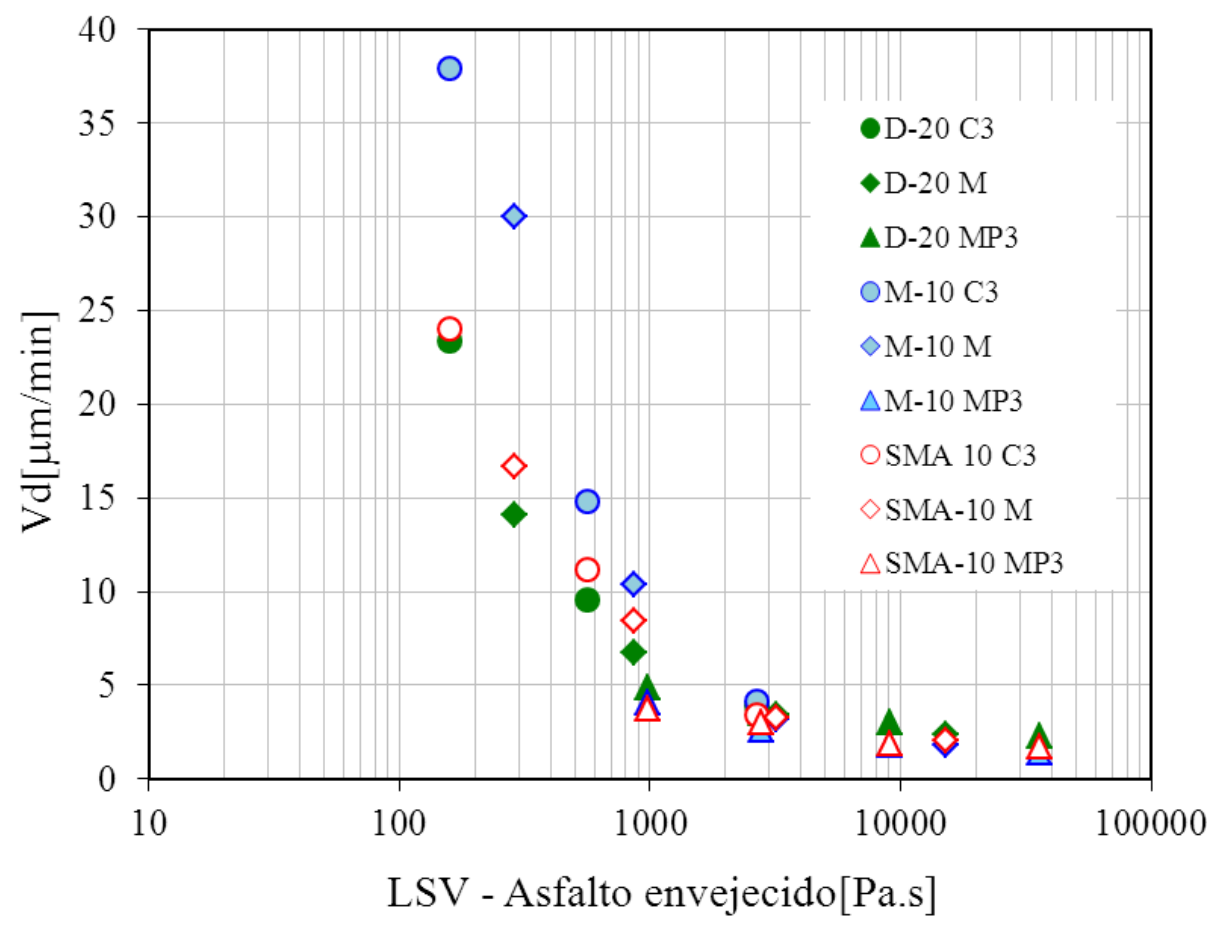

Figura 6.10. Vd versus LSV del asfalto envejecido.

En las figuras 6.11 y 6.12 se representan las curvas de LSV de los asfaltos, en estado original y envejecido, en función de la temperatura. A partir de los resultados obtenidos es posible calcular a qué temperatura cada uno de los ligantes estudiados tiene una LSV de 500 y 2000 Pa.s ( $T_{500}$ y $T_{2000}$ respectivamente). Tomando en consideración estas dos temperaturas se define la máxima temperatura del pavimento en la que el ligante puede utilizarse en una mezcla asfáltica sin que sufra deformaciones permanentes excesivas. Los valores de $\mathrm{T}_{500}$ y $\mathrm{T}_{2000}$ obtenidos para los asfalto C3, M y MP3 se observan en la tabla 6.3.

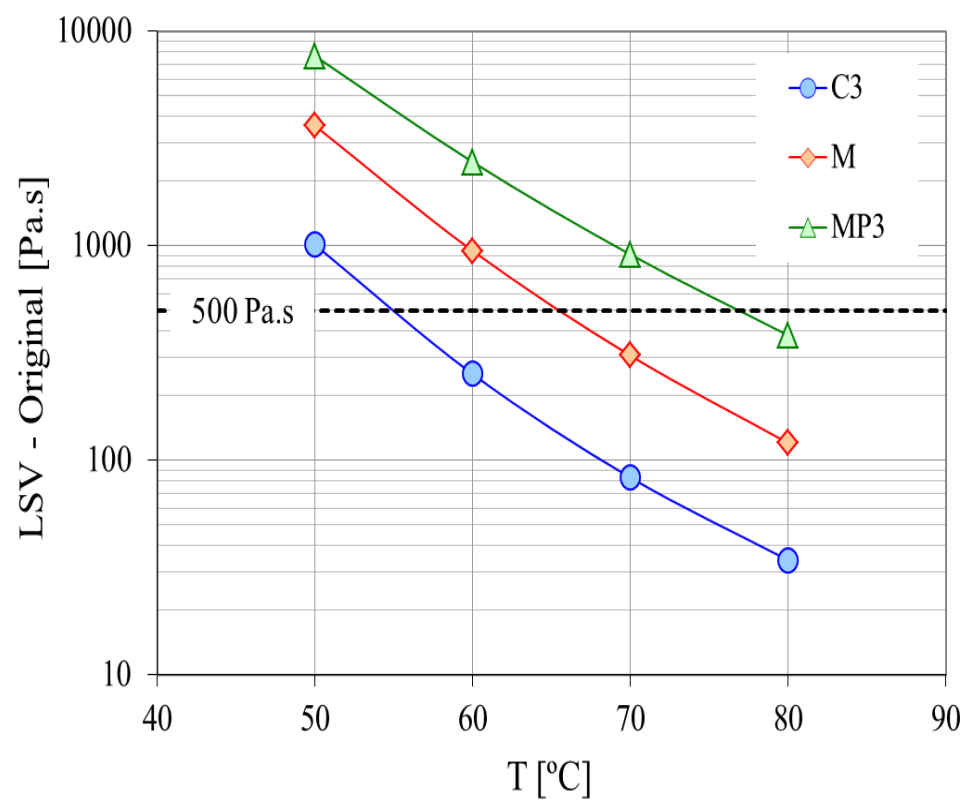

Figura 6.11.Variación de la LSV de los asfaltos en estado original en función de la temperatura. 


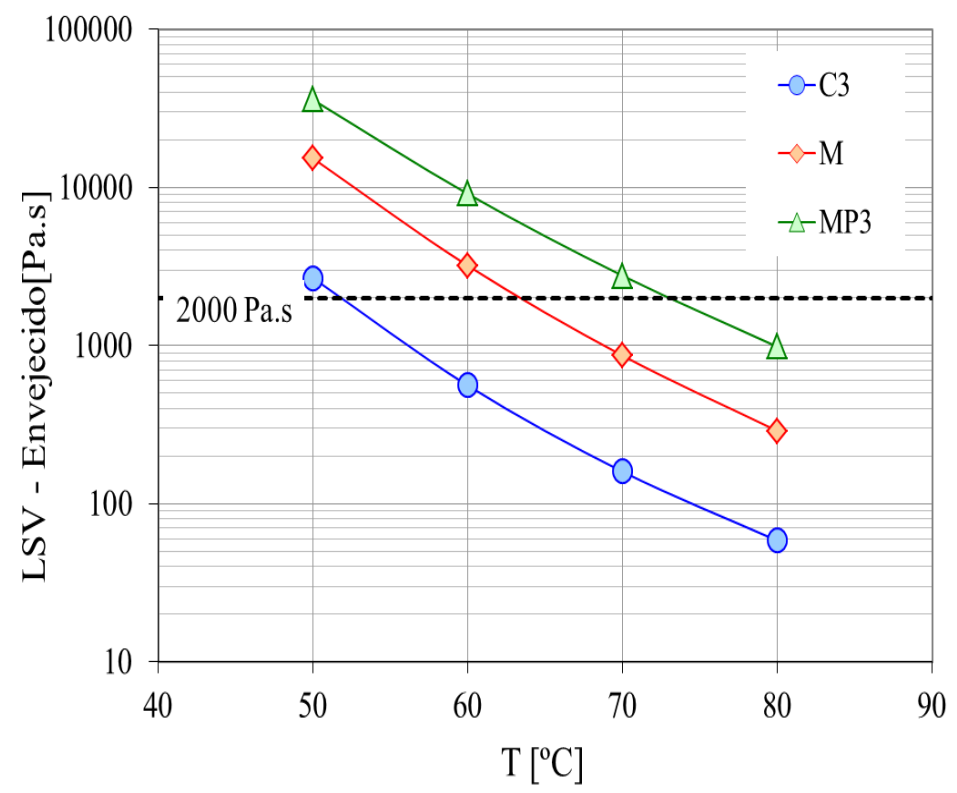

Figura 6.12. Variación de la LSV de los asfaltos envejecidos en función de la temperatura.

Tabla 6.3. Temperaturas de alta relacionadas a los conceptos de $\mathrm{T}_{500} \mathrm{y}_{2000}$.

\begin{tabular}{cccc}
\hline Criterio & \multicolumn{3}{c}{ Asfalto } \\
& C3 & M & MP3 \\
\hline $\mathrm{T}_{500}$ (original) $\left[{ }^{\circ} \mathrm{C}\right]$ & 54,8 & 65,5 & 76,8 \\
$\mathrm{~T}_{2000}$ (envejecido) $\left[{ }^{\circ} \mathrm{C}\right]$ & 51,7 & 63,4 & 73,0 \\
\hline
\end{tabular}

Del análisis de los valores de la tabla 6.3 se puede explicar el por qué las mezclas asfálticas elaboradas con C3 presentan mayor susceptibilidad frente a la temperatura de ensayo realizada que los ligantes M y MP3. Se observa para el ligante C3 que la máxima temperatura del pavimento aceptable para no sufrir deformaciones permanentes es cercana a $50{ }^{\circ} \mathrm{C}$, la más baja temperatura a la que se ensayaron las mezclas en el equipo de rueda cargada. Las temperaturas de 60 y $70{ }^{\circ} \mathrm{C}$ dan lugar a ahuellamientos marcadamente mayores. Por su parte el ligante $\mathrm{M}$ tiene una temperatura máxima dentro del rango estudiado, algunas mezclas tienen buen desempeño otras no y el limite parece ubicarse en torno a las $65^{\circ} \mathrm{C}$. Para el asfalto MP3 se encontró una temperatura máxima que supera los $70{ }^{\circ} \mathrm{C}$, de allí el buen desempeño para todo el rango de temperaturas estudiado.

El concepto desarrollado de temperatura límite a partir de la LSV se utiliza en la norma CEN 15324 (2006) para obtener una equiviscous temperature (EVT), inciso 2.3.4.2 capítulo 2. La EVT se define como la temperatura a la cual el asfalto presenta una LSV de 2000 Pa.s. La norma especifica este límite tanto para asfaltos originales como envejecidos y se relaciona con la contribución del ligante asfáltico en la resistencia al ahuellamiento. En función de los resultados obtenidos y de los estudios presentados hasta aquí no es lógico adoptar el mismo límite de LSV para ambas 
condiciones del ligante (original y envejecido). Analizando la figura 6.9, el límite de 2000 Pa.s de LSV para los asfaltos originales es en extremo riguroso. La mayoría de las mezclas tendrían ahuellamientos excesivos. Solo algunas mezclas elaboradas con los ligantes M y MP3 a temperaturas de ensayo de 50 o $60^{\circ} \mathrm{C}$ cumplirían con tener ahuellamientos aceptables, es decir, viscosidades mayores a los 2000 Pa.s de los ligantes

En el inciso 4.4 del capítulo 4 se estudió la relación entre el G*/sen $\delta$ a $10 \mathrm{rad} / \mathrm{s}$ y la LSV. Se encontró allí que valores de LSV de 100 y 232,5 Pa.s están asociados a los límites de la especificación SHRP de 1 y 2,2 kPa (asfaltos originales y envejecidos respectivamente) de $\mathrm{G}^{*} / \mathrm{sen} \delta$ para los asfaltos de esta tesis. En función de los resultados encontrados, valores de LSV del asfalto como esos se asocian con altos e inaceptables valores de ahuellamiento. Esto último se puede asociar una vez más en una deficiencia del concepto de $\mathrm{G}^{*} / \mathrm{sen} \delta$ para caracterizar los asfaltos en cuanto a su aporte en la resistencia al ahuellamiento, inclusive los convencionales. Analizando el ligante C3, este es un PG 64-22, es decir, que hasta temperaturas de $64{ }^{\circ} \mathrm{C}$ este ligante aportara resistencia al ahuellamiento, según el criterio SHRP. Como se desprende de las figuras 6.1, 6.2 y 6.3 para esta temperatura, $64^{\circ} \mathrm{C}$, los resultados del ensayo de rueda cargada para el asfalto C3 presentan valores de Vd de entre 15 y $25 \mu \mathrm{m} / \mathrm{min}$ que representan ahuellamientos importantes.

\subsubsection{Predicción del desempeño a partir de la LSV}

Las propiedades reológicas del asfalto así como la temperatura de ensayo tienen un rol preponderante en el desempeño final de la mezcla asfáltica. Es de orden práctico que un ensayo se realice a una determinada temperatura a los fines de normalizar el mismo. En el ensayo de rueda cargada normalmente esta temperatura es de $60{ }^{\circ} \mathrm{C}$, siendo una de las más altas que se pueden encontrar en un pavimento asfáltico. Como se observa en las figuras 6.2 a 6.3 a esa temperatura no todas las mezclas presentan un desempeño adecuado, dependiendo del ligante con el que fueron elaboradas. Sin embargo presentan buen comportamiento a temperaturas menores. Tomando en consideración lo hasta aquí citado resulta importante relacionar el desempeño medido en las mezclas asfálticas en conjunto con la LSV tomando en consideración la temperatura.

Como se observaba en las figuras 6.9 y 6.10 para asfaltos en estado original y envejecido respectivamente la Vd en función de LSV resulta una curva única para cada tipo de mezcla con todos los ligantes. Al igual que como se hiciera en el capítulo 5 los valores de Vd en función de la LSV se ajustaron por regresión no lineal al modelo de la ecuación 5.2. Se realizó el ajuste de los datos de Vd en relación a la LSV del asfalto en estado original y luego de envejecido. Se realizaron los ajustes de cada tipo de mezcla (D-20, M-10 y SMA-10) por separado y las de los datos tomados en conjunto.

En la tabla 6.4 se resumen los valores de los coeficientes de ajuste y $\mathrm{R}^{2}$ obtenidos. Se observa como los coeficientes de las mezclas D-20 y SMA-10 son de un orden similar. También surge que el ajuste para los datos de las tres mezclas en conjunto es bueno $\left(\mathrm{R}^{2}\right.$ alcanza valores de 0,87 y 0,86 para el asfalto en condición original y envejecido respectivamente) lo que permitiría predecir el desempeño de diferentes tipos de mezclas a partir de esta única ecuación. En las figuras 6.5 y 6.7 se observan que los valores de 
Vd de todas las mezclas se confunden para valores elevados de LSV teniendo una clara divergencia para valores de Vd entre 5 y $10 \mu \mathrm{m} / \mathrm{min}$. Sobre este aspecto se comentara en el siguiente punto.

Tabla 6.4. Coeficientes de ajuste de las mezclas estudiadas

\begin{tabular}{ccccc}
\hline Mezcla & & $\mathrm{a}$ & $\mathrm{b}$ & $\mathrm{R}^{2}$ \\
\hline \multirow{2}{*}{ D-20 } & Original & 1,76 & 1698,4 & 0,98 \\
& Envejecido & 2,42 & 3379,9 & 0,99 \\
\multirow{2}{*}{ SMA-10 } & Original & 1,36 & 1896,5 & 0,98 \\
& Envejecido & 1,53 & 6378,4 & 0,95 \\
\multirow{2}{*}{ M-10 } & Original & 0,07 & 3269,0 & 0,98 \\
& Envejecido & 2,16 & 3725,4 & 0,96 \\
\multirow{2}{*}{ Todas } & Original & 1.06 & 2287,9 & 0,87 \\
& Envejecido & 2,04 & 4494,5 & 0,86 \\
\hline
\end{tabular}

En lo que se refiere a las posibilidades de aplicación de este desarrollo cabe indicar que las relaciones de Vd-LSV se pueden utilizar para predecir el desempeño de mezcla asfáltica bajo diferentes condiciones de temperaturas del pavimento solo conociendo el valor de LSV del ligante a la temperatura considerada. Esto permitiría estimar el desempeño y optimizar la selección del asfalto a la hora del diseño tomando en cuenta el tipo de aplicación y las condiciones ambientales que se suscitan en el pavimento. Por ejemplo, utilizando el mapa de temperaturas viales, figura 2.14, se puede conocer la temperatura máxima de la zona geográfica donde se ubica el pavimento. A partir de estudios reológicos del ligante asfáltico que se quiere utilizar en la mezcla asfáltica se puede conocer la LSV a esa temperatura máxima. Si la LSV de este asfalto a esa temperatura es menor a los 500 Pa.s en estado original o a 2000 Pa.s en el estado envejecido claramente surge que éste no es el ligante más idóneo a utilizar en esas condiciones pudiendo tener la mezcla problemas de ahuellamientos. Por otra parte de presentar un valor de LSV superior a los límites se puede predecir el desempeño de la mezcla a partir de las relaciones aquí encontradas, pudiéndose usar esta información para optimizar la elección del ligante en función de otras consideraciones como ser mayores volúmenes de tránsito, mayores cargas o velocidades del tránsito lentas.

Tomando en consideración lo observado en cuanto al desempeño de las mezclas estudiadas respecto a valores límite de LSV se puede calcular con las relaciones encontradas el valor de Vd asociado a niveles de 500 y 2000 Pa.s de LSV para las condiciones de asfalto original y envejecido respectivamente. Este valor puede tomarse como límite de desempeño para los ensayos de rueda cargada bajo condiciones normalizadas de ensayo (520 N de carga y $60{ }^{\circ} \mathrm{C}$ de temperatura de ensayo). En el caso de las mezclas estudiadas este límite es un valor de $\mathrm{Vd}=5,2$ y 4,3 $\mu \mathrm{m} / \mathrm{min}$ para las condiciones de estado original y envejecido respectivamente. Por consideraciones prácticas el límite se puede definir en $5 \mu \mathrm{m} / \mathrm{min}$. Valores de Vd superiores a este límite obtenidos en un ensayo denotan que el ligante no es el adecuado a utilizar a tan 
extremas temperaturas debiendo estudiar el ligante a través de los criterios de $\mathrm{T}_{500} \mathrm{y}$ $\mathrm{T}_{2000}$ para así definir la máxima temperatura posible de utilización en el pavimento.

Agnusdei y coautores (2007) proponen un límite de buen comportamiento para el ensayo de rueda cargada con una carga de $520 \mathrm{~N}$ a $60{ }^{\circ} \mathrm{C}$ a partir de estudios realizados con testigos de mezclas densas y especiales obtenidos de pavimentos existentes. Los testigos analizados pertenecían algunos a caminos que presentaban deformaciones permanentes excesivas y otros que no. Dicho límite se definió, por medio de análisis estadístico de los datos, en base a los ensayos sobre testigos de rutas sin ahuellamiento eliminando los datos de los testigos de rutas ahuelladas. El límite encontrado resultó ser $5,2 \mu \mathrm{m} / \mathrm{min}$, el mismo orden que el aquí encontrado a partir de estudios con la LSV de los asfaltos en estado original.

\subsubsection{Validación experimental}

Para corroborar la posibilidad de emplear la relación Vd-LSV para obtener un valor tentativo de la Vd de una mezcla soló conociendo las características reológicas del ligante, en particular la LSV, se ensayaron mezclas densas (D-20) con los asfaltos convencionales (C1, C2 y C4) y modificados con polímero (MP1 y MP2) a diferentes temperaturas en el equipo de rueda cargada. De estos ensayos se calculó la velocidad de deformación ( $\mathrm{Vd}_{\text {medido }}$ ) para cada mezcla. Sobre los asfaltos ya se midió la LSV en estado original a la temperatura de ensayo, con la que se estimó un valor de velocidad de deformación de cada mezcla $\left(\mathrm{Vd}_{\text {estimado }}\right)$ a partir de las relaciones encontradas en el inciso anterior. Se estimaron dos valores de Vd de las mezclas, una primera estimación a partir de la ecuación de ajuste de la mezcla D-20 (en adelante estimación particular) y una segunda estimación con la ecuación de ajuste de las tres mezclas juntas (en adelante estimación general).

En la tabla 6.5 se volcaron los datos de ensayos $\mathrm{T}_{\text {ensayo, }} \mathrm{LSV}$ y $\mathrm{Vd}_{\text {medido }}$ junto con los

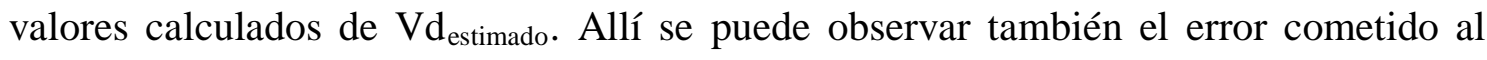
estimar la Vd a partir de la ecuación de ajuste general respecto a utilizar la ecuación de ajuste particular. Se observa que el error cometido no es grande. En la figura 6.13 se comparan los valores medidos, $\mathrm{Vd}_{\text {medido, }}$, en relación a los estimados, $\mathrm{Vd}_{\text {estimado, a partir }}$ de la ecuación de ajuste de la mezcla D-20. Se observa como los valores estimados a partir de la LSV predicen los valores obtenidos en el ensayo de rueda cargada de manera contundente. 
Tabla 6.5. Resultados de ensayos y valores calculados (etapa de validación)

\begin{tabular}{ccccccc}
\hline & $\begin{array}{c}\mathrm{T}_{\text {ensayo }} \\
{\left[{ }^{\circ} \mathrm{C}\right]}\end{array}$ & $\begin{array}{c}\mathrm{LSV} \\
{[\mathrm{Pa} . \mathrm{s}]}\end{array}$ & $\begin{array}{c}\mathrm{Vd}_{\text {medido }}{ }^{(1)} \\
{[\mu \mathrm{m} / \mathrm{min} .]}\end{array}$ & $\begin{array}{c}\mathrm{Vd}_{\text {estimado }}{ }^{(2)} \\
{[\mu \mathrm{m} / \mathrm{min} .]}\end{array}$ & $\begin{array}{c}\mathrm{Vd}_{\text {estimado }}{ }^{(3)} \\
{[\mu \mathrm{m} / \mathrm{min} .]}\end{array}$ & $\begin{array}{c}\mathrm{E} \\
{[\%]}\end{array}$ \\
\hline \multirow{2}{*}{$\mathrm{C} 1$} & 50 & 554,1 & 5,5 & 4,8 & 5,2 & 8 \\
& 60 & 163,8 & 12,4 & 12,1 & 15,0 & 24 \\
$\mathrm{C} 2$ & 50 & 1024,1 & 3,5 & 3,4 & 3,3 & 3 \\
& 60 & 346,3 & 6,7 & 6,7 & 7,7 & 15 \\
$\mathrm{C} 4$ & 60 & 1106,4 & 3,4 & 3,3 & 3,1 & 5 \\
& 50 & 3534,4 & 2,3 & 2,2 & 1,7 & 24 \\
MP1 & 60 & 595,0 & 3,7 & 4,6 & 4,9 & 6 \\
& 70 & 147,7 & 10,4 & 13,3 & 16,6 & 25 \\
\multirow{2}{*}{ MP2 } & 60 & 2642,1 & 2,7 & 2,4 & 1,9 & 20 \\
\hline
\end{tabular}

(1) Medida del ensayo, (2) Estimación particular, (3) Estimación general

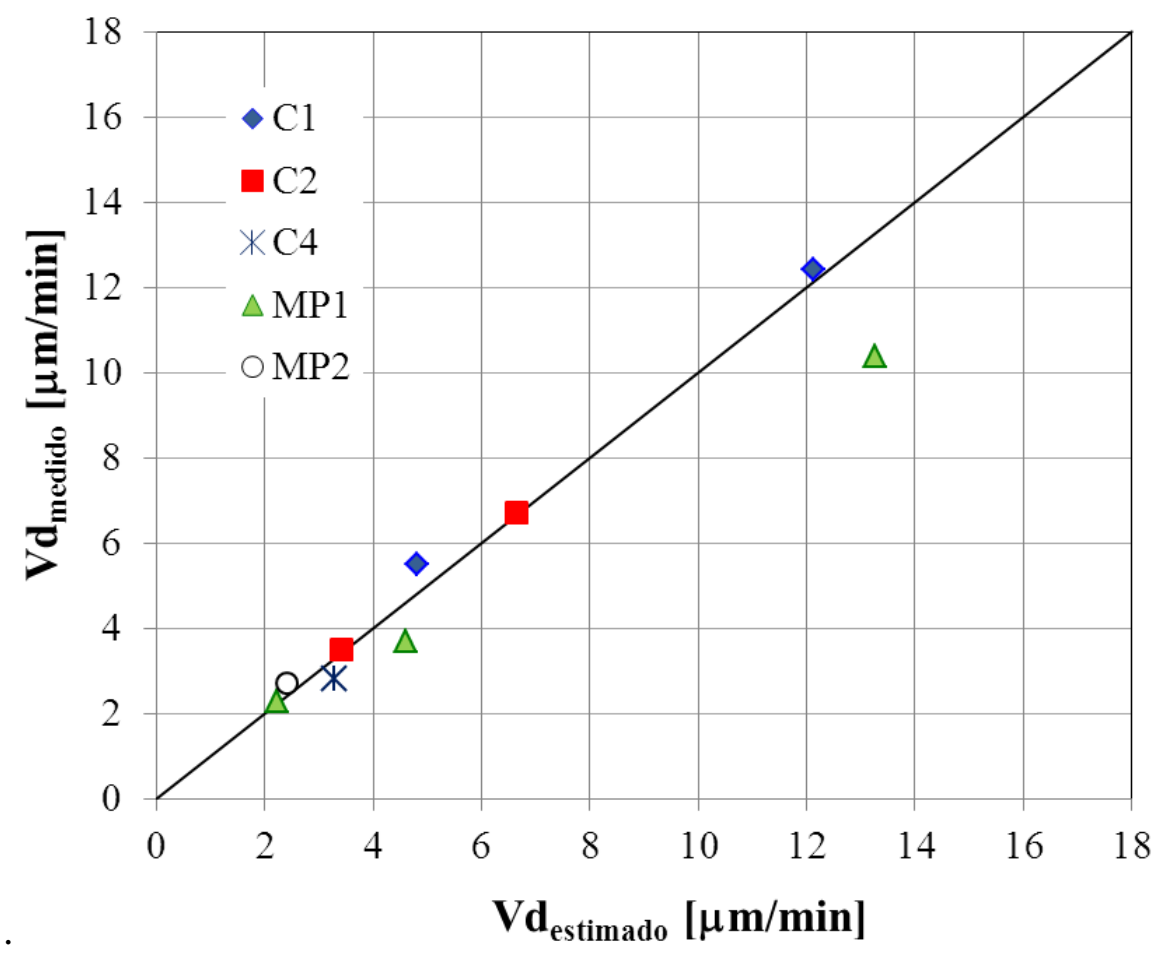

Figura 6.13. Vd medidas en el ensayo de rueda cargada versus Vd estimadas para la mezcla D-20.

La relación Vd-LSV gana preponderancia cuando se puede predecir el desempeño de cualquier tipo de mezcla. Por lo tanto es importante verificar la eficiencia de la relación encontrada para todas las mezclas en cuanto a su efectividad en la predicción del comportamiento al ahuellamientos.

En la figura 6.14 se comparan los valores medidos en las mezclas D-20 en relación a los estimados a partir de la ecuación de todas las mezclas. Se observa allí como la predicción con la ecuación de ajuste general es muy efectiva en un amplio rango de $\mathrm{Vd}$ 
(Vd $<8 \mu \mathrm{m} / \mathrm{min}$ ). Como se observa en la figura 6.9 los $8 \mu \mathrm{m} / \mathrm{min}$ es donde las curvas de desempeño de las tres mezclas empiezan a mostrar diferentes comportamientos. En consecuencia la estimación general para valores mayores a $8 \mu \mathrm{m} / \mathrm{min}$ se ven influenciadas con un mayor error. Igualmente de la misma figura 6.9 obtenemos que a esta velocidad de deformación (Vd) le corresponda una LSV de 300 Pa.s aproximadamente. Esta viscosidad resulta menor a los 500 Pa.s que define el límite de aporte del asfalto en la resistencia al ahuellamiento y por lo tanto se asocia con un ahuellamiento excesivo. Por lo tanto se toma como un límite de estimación.

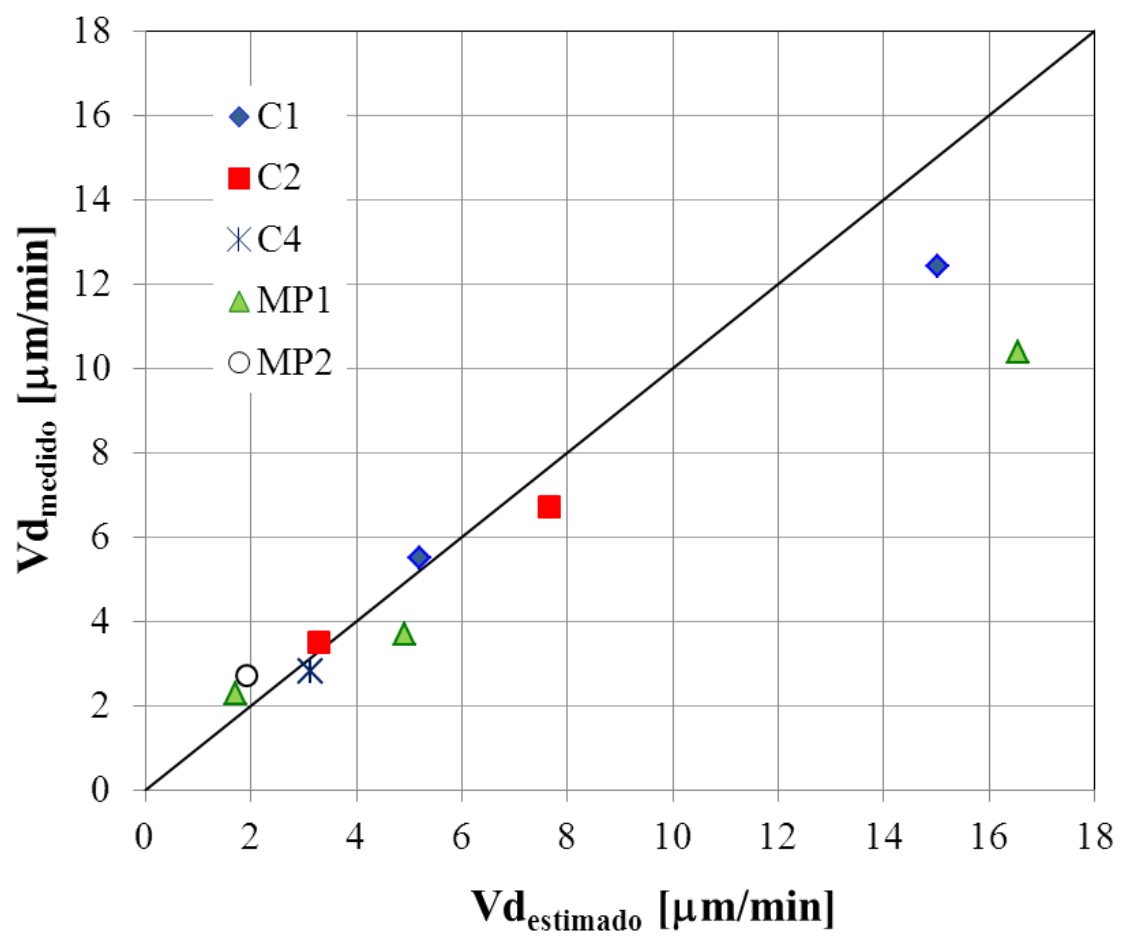

Figura 6.14. Vd medidas en el ensayo de rueda cargada versus Vd estimadas, con la ecuación de ajuste para todas las mezclas.

En este apartado se han estudiado tres tipos de mezclas comúnmente usadas en el ambiente vial elaboradas con tres diferentes tipos de ligantes de los más utilizados actualmente, por lo tanto y tomando en consideración los resultados obtenidos es posible utilizar la curva de predicción general para conocer el desempeño tentativo de cualquier tipo de mezcla sin con ello cometer grandes errores entendiendo como límite razonable de predicción un valor de $\mathrm{Vd}=8 \mu \mathrm{m} / \mathrm{min}$.

\subsubsection{Conclusiones sobre el efecto de la temperatura}

En este apartado se estudió el desempeño frente a las deformaciones permanentes en el ensayo de rueda cargada de mezclas asfáltica para carpeta de rodamiento elaboradas con tres diferentes asfaltos a las temperaturas de 50, 60, 70 y $80^{\circ} \mathrm{C}$; también se realizaron mediciones de LSV de los ligantes a diferentes temperaturas a través del ensayo de barrido de frecuencias. A partir de estos datos se analizaron los diferentes resultados de deformaciones permanentes para cada ligante en función de la temperatura y la LSV. Las principales conclusiones se indican a continuación. 
La Vd es dependiente del tipo de ligante utilizado en la mezcla y se obtiene una merma en el desempeño a medida que aumenta la temperatura de ensayo. La Vd se incrementa más rápidamente para las mezclas con el asfalto C3 seguidas de las mezclas con los asfaltos M y MP3 respectivamente.

Las Vd medidas en el ensayo de pista de todas las mezclas en función de la LSV de los asfaltos se alinean en una única curva.

Para valores de LSV de los asfaltos menores de 500 y 2000 Pa.s en estado original y envejecido respectivamente a las temperaturas de ensayo en el equipo de rueda cargada se observan en las mezclas un incremento muy marcado de la Vd. Para las mezclas estudiadas los 500 y los 2000 Pa.s de LSV pueden considerarse como un límite en la contribución parcial del asfalto en la resistencia frente a las deformaciones permanentes de mezclas asfálticas.

A partir de los valores de 500 y 2000 Pa.s se obtuvo la temperatura límite para la contribución parcial de los asfaltos respecto a la resistencia frente a las deformaciones permanentes de las mezclas asfálticas estudiadas.

De lo estudiado se desprende que resulta importante medir una propiedad como la LSV para la caracterización de un asfalto. A partir de esta propiedad se puede definir los valores $\mathrm{T}_{500} \mathrm{y} \mathrm{T}_{2000}$, para el asfalto original y envejecido respectivamente, asociados a temperatura de alta del asfalto que sirven como herramientas al diseño de una mezcla asfáltica.

El envejecimiento en RTFOT de manera normalizada no reflejó el verdadero envejecimiento del asfalto MP3 en la mezcla asfáltica. Por ello en este caso se consideraron las medidas de LSV del ligante envejecido que fue recuperado de una probeta de mezcla asfáltica ensayada en el equipo de rueda cargada.

Se encontró que un envejecimiento similar al que se produjo en la elaboración de la mezcla asfáltica con el ligante MP3 se obtuvo al aumentar la temperatura de ensayo del RTOFT de manera que se asemejara a las condiciones de elaboración reales de la mezcla.

Fue posible ajustar a una única curva de Vd-LSV el desempeño de diferentes mezclas preparadas con diferentes cementos asfálticos; la misma aparece como una herramienta que puede utilizarse para:

predecir el comportamiento frente a las deformaciones permanentes para diferentes condiciones de temperaturas del pavimento solo conociendo el valor de LSV del ligante a la temperatura considerada.

optimizar la selección del asfalto tomando en cuenta el tipo de aplicación y las condiciones ambientales que se suscitan en el pavimento.

Es posible utilizar la curva de predicción general sin cometer grandes errores tomando como límite de predicción un valor de $\mathrm{Vd}=8 \mu \mathrm{m} / \mathrm{min}$.

Se proponen límite de desempeño para el ensayo de rueda cargada a partir de la curvas de predicción de las mezclas considerando el límite de 500 y 2000 Pa.s de LSV resultando un valor límite de $\mathrm{Vd}=5 \mu \mathrm{m} / \mathrm{min}$. 


\subsection{Efecto de las cargas sobre el desempeño frente al ahuellamiento}

Los $520 \mathrm{~N}$ de carga del ensayo de rueda cargada generan aproximadamente una presión de $520 \mathrm{kPa}$ sobre la superficie de contacto de la rueda de $1000 \mathrm{~mm}^{2}$, que es similar a la que provocaría una rueda de un camión de eje simple de 6 tn, que representa la carga máxima permitida en Argentina. Es común que estos niveles de carga se superen generando deformaciones en los caminos.

En este apartado se estudia el desempeño de las mezclas en condiciones controladas de laboratorio en el equipo de rueda cargada considerando dos niveles de carga, 700 y $900 \mathrm{~N}$, que son superiores al especificado en la norma BS 598 part 110 (520 N). Estos niveles de carga se seleccionaron ya que representan las cargas de los equipos de rueda cargada de la actual normativa europea (UNE 12697-22) y antigua normativa española (NLT 173).

Estas presiones son equivalentes a cargas máximas de eje simple de 10,5 y 13 tn respectivamente.

Se emplearon las mezclas estudiadas en el apartado anterior (D-20, M-10 y SMA-10) elaboradas con los ligantes C3, M y MP3. En todos los casos dichas mezclas se ensayaron en el equipo de rueda cargada bajo las configuraciones de carga mencionadas anteriormente a la temperatura de $60{ }^{\circ} \mathrm{C}$.

\subsubsection{Resultados y discusión}

A modo comparativo se observa en la figura 6.15 las curvas de deformaciones permanentes obtenidas en el ensayo de rueda cargada de la mezcla D-20 elaborada con el asfalto C3 ensayada con los niveles de carga de 520 y $900 \mathrm{kPa}$. Se observa en la figura, como era de esperarse, que a medida que aumenta la carga se producen mayores deformaciones permanentes. En la figura 6.16 se presentan las fotos de aquellas mezclas luego del ensayo.

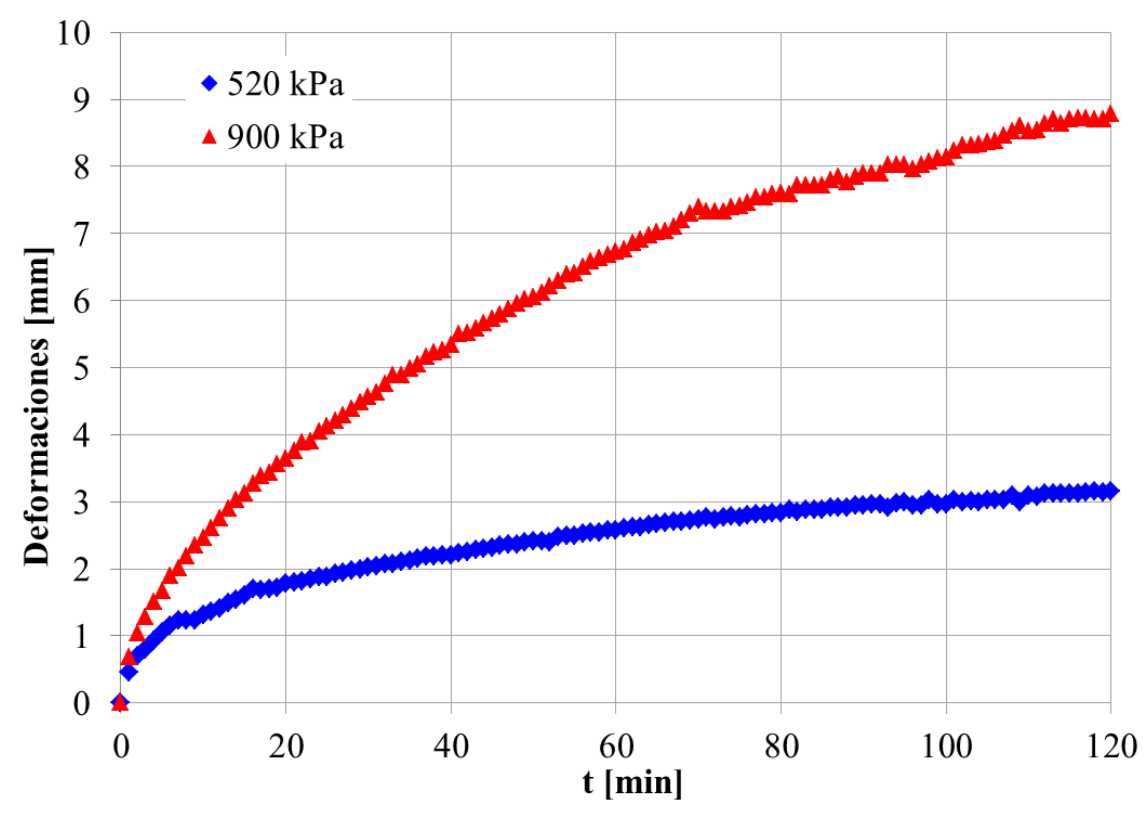

Figura 6.15: Comparación de curvas de deformación-tiempo de probetas ensayadas bajo diferentes niveles de carga. 


\section{$520 \mathrm{kPa}$}

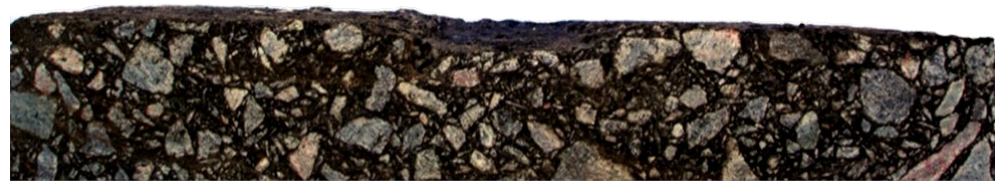

\section{$900 \mathrm{kPa}$}

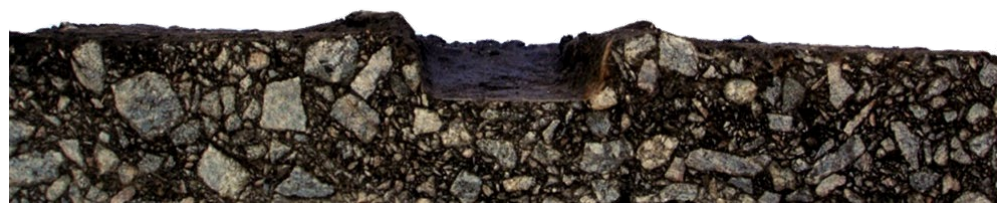

Figura 6.16. Fotos de probetas ensayadas bajo diferentes niveles de carga.

En la tabla 6.6 se muestran los valores de Vd para las diferentes condiciones de ensayo. Los diferentes niveles de carga están representados con la presión de contacto ejercida por la rueda del equipo sobre la mezcla asfáltica. Como referencia también se incluyen los resultados obtenidos para las diferentes mezclas con la presión de 520 kPa.

Tabla 6.6. Vd [ $\mu \mathrm{m} / \mathrm{min}]$ de diferentes mezclas elaboradas con los asfaltos C3, M y MP3 bajo diferentes presiones de contacto.

\begin{tabular}{cccccccccccc}
\hline $\begin{array}{c}\text { Mezcla } \\
\begin{array}{c}\text { Presión de } \\
\text { contacto [kPa] }\end{array}\end{array}$ & C3 & M & MP3 & C3 & M & MP3 & C3 & M & MP3 \\
\hline 520 & 9,5 & 3,2 & 3,0 & 14,8 & 3,2 & 1,8 & 11,2 & 3,3 & 1,9 \\
700 & 14,8 & 4,3 & 3,0 & 24,4 & 5,2 & 2,0 & 23,9 & 4,8 & 1,9 \\
900 & 40,2 & 7,1 & 4,1 & - & 6,0 & 3,2 & - & 7,8 & 2,9 \\
\hline
\end{tabular}

En la figura 6.17 se representan los resultados de $\mathrm{Vd}$ en función de la presión de contacto diferenciando las mezclas según el tipo de asfalto y composición. Se observa nuevamente que para un aumento de las condiciones de carga se produce un incremento de los ahuellamientos, mayores valores de velocidad de deformación ( $\mathrm{Vd}$ ), en cualquiera de las mezclas estudiadas.

El incremento de los ahuellamientos observado en la figura 6.17 es variable dependiendo del tipo de asfalto, siendo mayor en el caso de las mezclas elaboradas con el ligante C3 seguidas por el asfalto M y MP3. Se observa para un mismo ligante como las tres mezclas (D-20, M-10 y SMA-10) presentan respuestas similares. Del análisis de los resultados surge que en las mezclas con MP3 los ahuellamientos se incrementan con el aumento de carga de 700 a $900 \mathrm{kPa}$, mientras que no hay diferencias apreciables de comportamiento entre las condiciones de carga de 520 a $700 \mathrm{kPa}$. Esto refleja la diferente sensibilidad frente a las tensiones de carga que poseen los distintos asfaltos. 


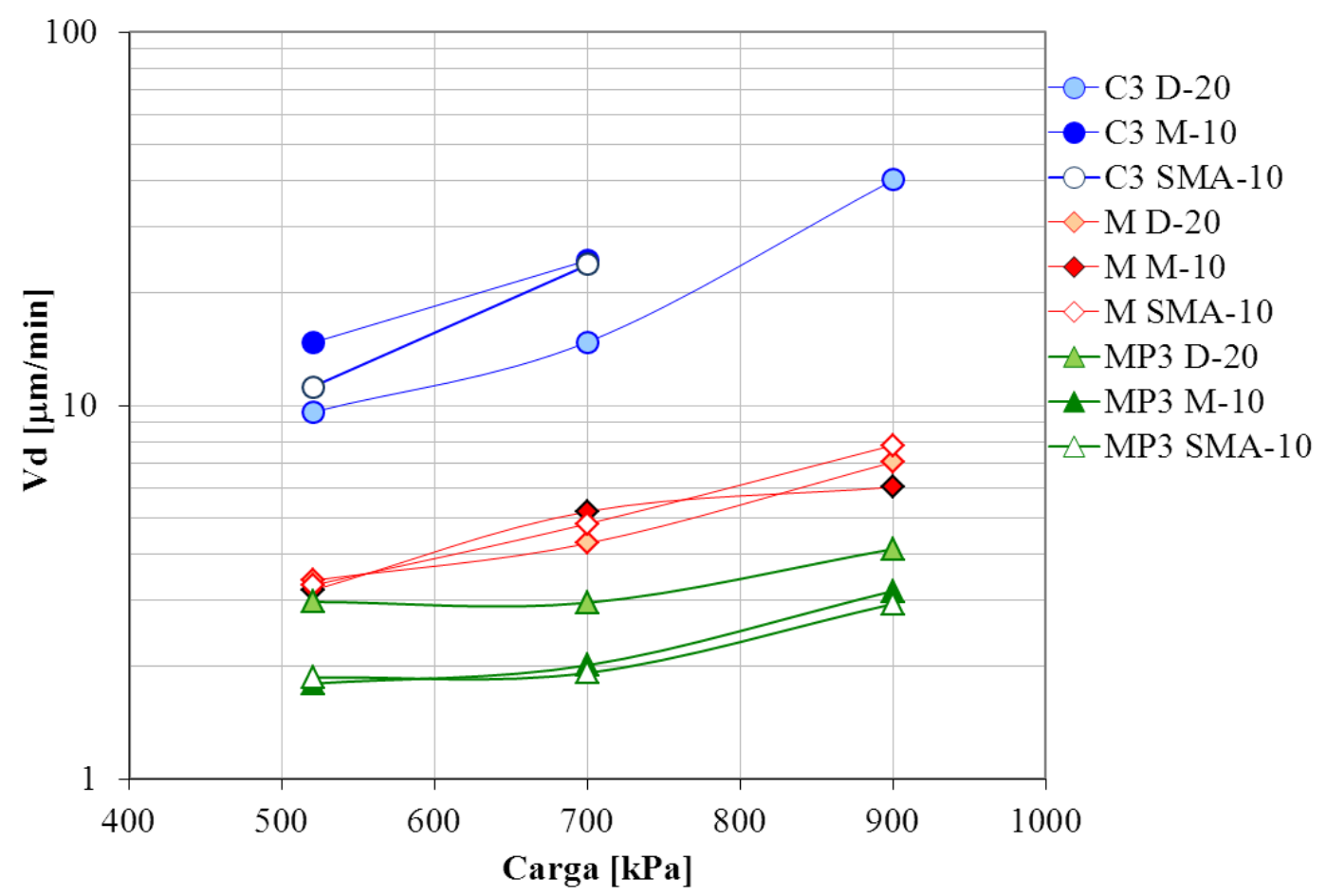

Figura 6.17. Vd en función de la presión de contacto de las diferentes mezclas.

Bahia y coautores (2009) estudiaron la sensibilidad frente a la tensión de carga de una serie de asfaltos a dos temperaturas, una moderada representativa de las medias de un verano $\left(46^{\circ} \mathrm{C}\right)$ y la otra, la temperatura de alta del grado de desempeño de los asfaltos $\left(64{ }^{\circ} \mathrm{C}\right)$. A la menor temperatura la mayoría de los ligantes no presentaron variaciones en su respuesta frente a los incrementos de tensiones, sin embargo a la temperatura de alta mostraron una mayor sensibilidad frente a la tensión aplicada. Esto explicaría la mayor sensibilidad del ligante C3 que tiene una temperatura de alta $\left(\cong 50^{\circ} \mathrm{C}\right.$, según el criterio de LSV) menor que la temperatura de ensayo $\left(60^{\circ} \mathrm{C}\right)$. Para los otros ligantes, el asfalto M posee una temperatura de alta similar a la de ensayo y el asfalto MP3 tiene una temperatura de alta superior a la de ensayo que se traduce en una moderada y muy baja sensibilidad a la tensión respectivamente.

La temperatura juega un rol preponderante en el desempeño a diferentes niveles de carga. Recordando la relación Vd-LSV observada anteriormente (figura 6.9) la variación de temperatura está implícitamente considerada en ella con la LSV. En la figura 6.18 se representan los resultados de velocidad de deformación de las mezclas D20 para los niveles de carga de 700 y 900 N en función de la LSV de los asfaltos. Se representa también allí la curva de ajuste obtenida para las mezclas con la carga de $520 \mathrm{~N}$. Se observa en la figura como el aumento de carga genera un corrimiento de la curva hacia la derecha. 


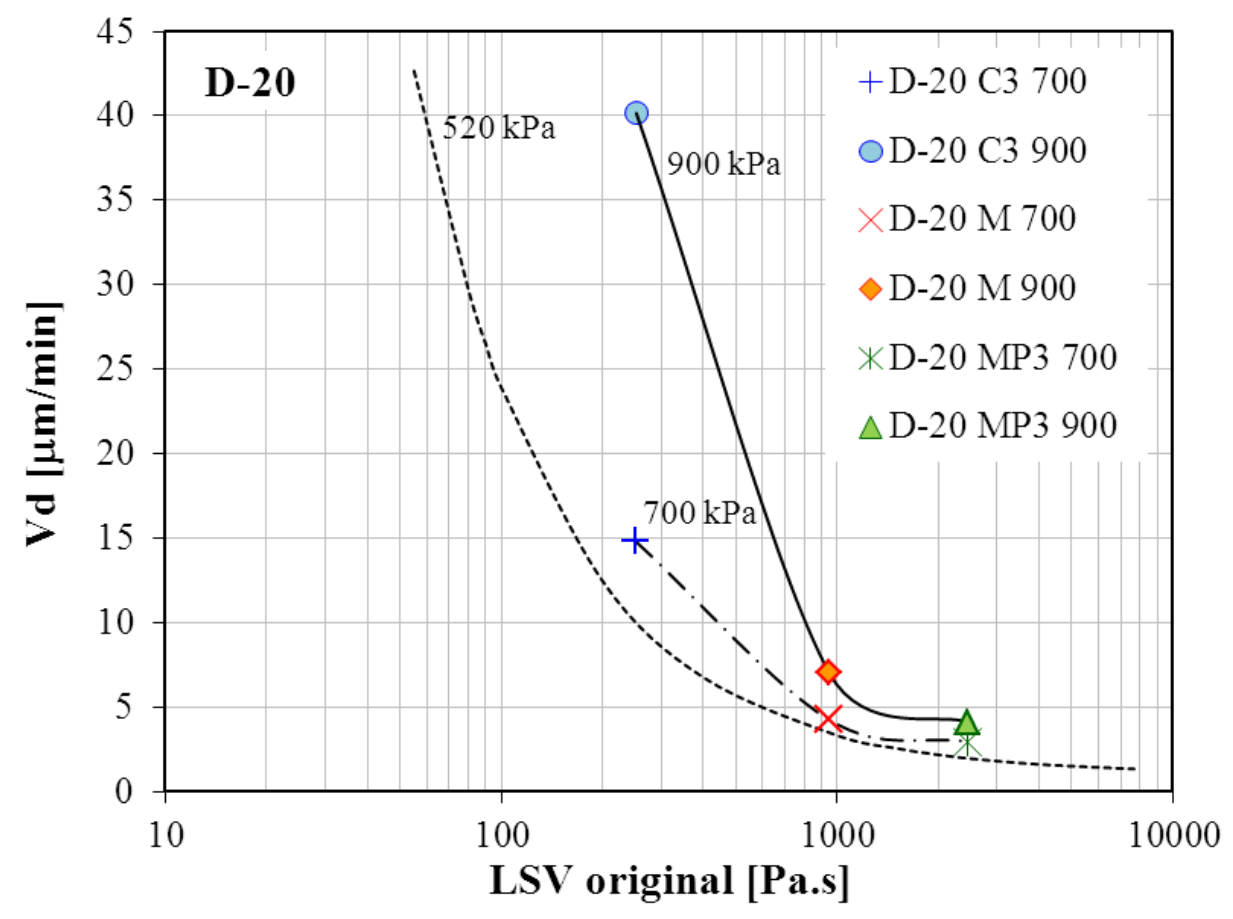

Figura 6.18. Vd en función en la LSV para diferentes niveles de carga. Mezcla D-20.

En las figuras 6.19 y 6.20 se representaron las relaciones Vd-LSV para los niveles de carga de 700 y $900 \mathrm{~N}$ de las mezclas M-10 y SMA-10 respectivamente. Considerando la carga de $700 \mathrm{~N}$ el corrimiento de la curva es más notorio en este tipo de mezclas que en la mezcla densa teniendo un papel más decisivo el asfalto en el proceso de ahuellamiento. Los datos del nivel de carga a $900 \mathrm{~N}$ son escasos para determinar un comportamiento, sin embargo se observa un corrimiento de los resultados.

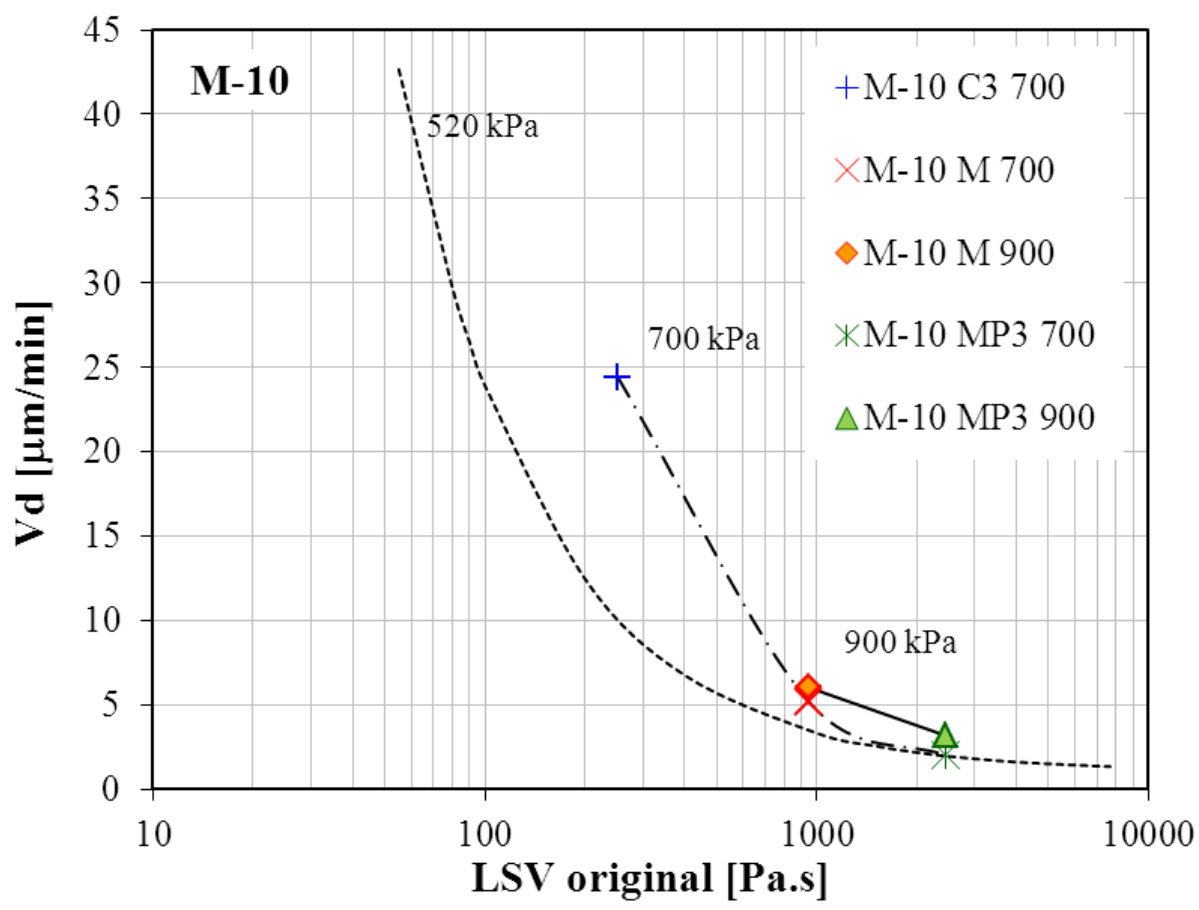

Figura 6.19. Vd en función en la LSV para diferentes niveles de carga. Mezcla M-10. 


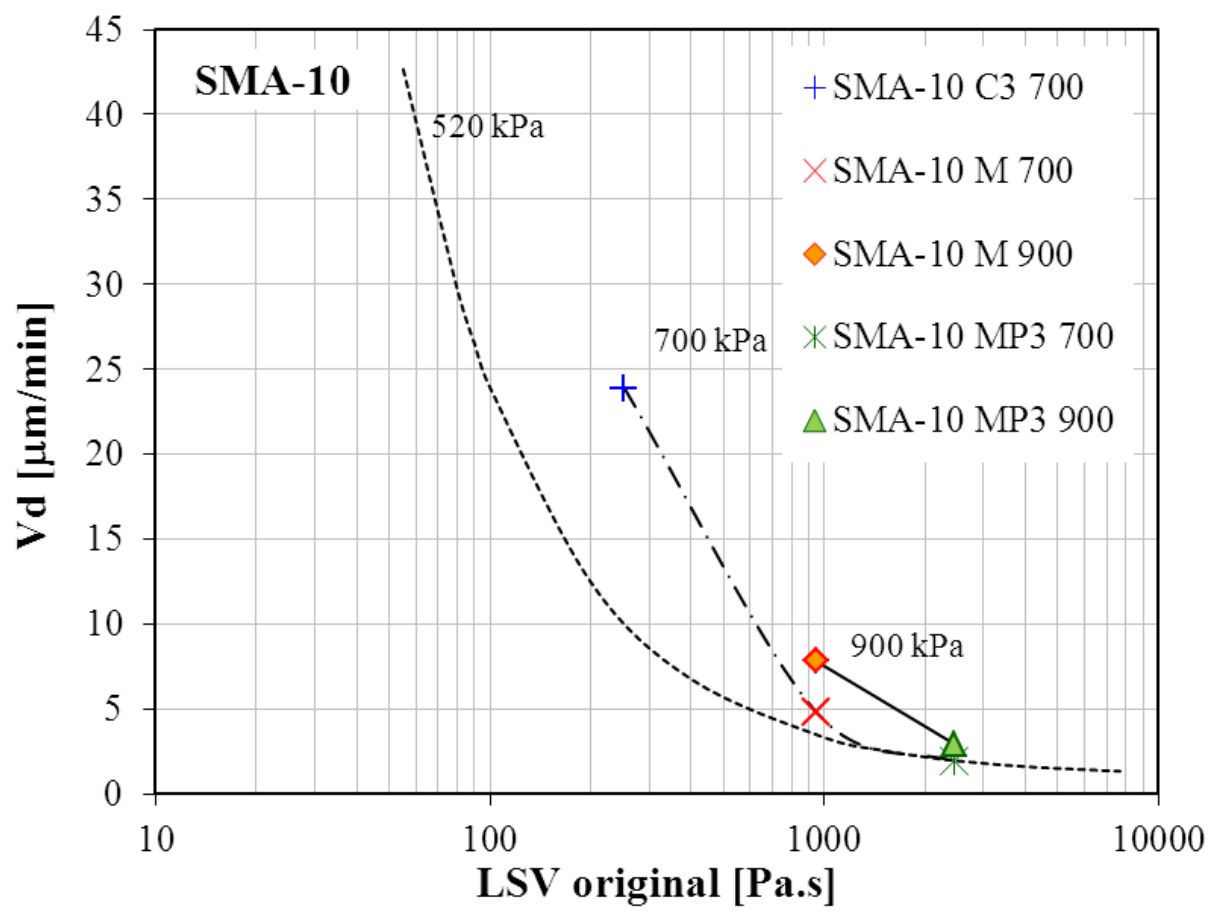

Figura 6.20. Vd en función en la LSV para diferentes niveles de carga. Mezcla SMA-10.

De las figuras 6.18, 6.19 y 6.20 surge que para mantener un mismo desempeño frente a un aumento del nivel de carga se necesita un asfalto más viscoso (mayor LSV) para una misma temperatura. Por otro lado se puede pensar el aumento de carga como un aumento de temperatura, disminución de la LSV del asfalto.

\subsubsection{Consideración de las sobrecargas dentro del diseño}

Las sobrecargas del tránsito son aquellas que superan la máxima permitida por la legislación, en Argentina la carga máxima por eje simple es de 6 tn que se corresponde aproximadamente con una presión de $520 \mathrm{kPa}$ en la superficie del pavimento.

Para poder considerar posibles sobrecargas dentro del diseño, se realizó para las mezclas estudiadas un análisis comparativo entre los desempeños a diferentes temperaturas y niveles de carga. En la tabla 6.7 se presentan los resultados de ahuellamientos para las condiciones mencionadas. Allí también se observan valores interpolados a partir de los datos de ahuellamientos a temperaturas intermedias a las ensayadas.

Del análisis de los resultados y considerando los valores interpolados surge que:

1) En las mezclas con el asfalto $\mathrm{C} 3$, el aumentar el nivel de carga de 520 a $700 \mathrm{kPa}$ equivale a un aumento de la temperatura de $4{ }^{\circ} \mathrm{C}$, respecto de los $60{ }^{\circ} \mathrm{C}$ del ensayo normalizado, para las mezclas D-20 y M-10 y de $10^{\circ} \mathrm{C}$ para la mezcla SMA- 10 .

2) En las mezclas con el asfalto $\mathrm{M}$, el aumentar la carga de 520 a $700 \mathrm{kPa}$ equivale a un aumento de temperatura de $3{ }^{\circ} \mathrm{C}$ en todas las mezclas. Por otro lado un incremento del nivel de carga de 520 a $900 \mathrm{kPa}$ equivale a un aumento de temperatura de $10^{\circ} \mathrm{C}$ para las mezclas D-20 y SMA 10. 
3) En las mezclas con el asfalto MP3, el aumentar la carga de 520 a $700 \mathrm{kPa}$ equivale nuevamente a un aumento de temperatura de $4{ }^{\circ} \mathrm{C}$ en todas las mezclas (D-20, M-10 y SMA-10), mientras el incremento del nivel de carga de 520 a $900 \mathrm{kPa}$ equivale a aumentar la temperatura entre 10 y $15{ }^{\circ} \mathrm{C}$.

Tabla 6.7. Resultados de Vd de todas las mezclas estudiadas bajo diferentes temperaturas y presiones de contacto.

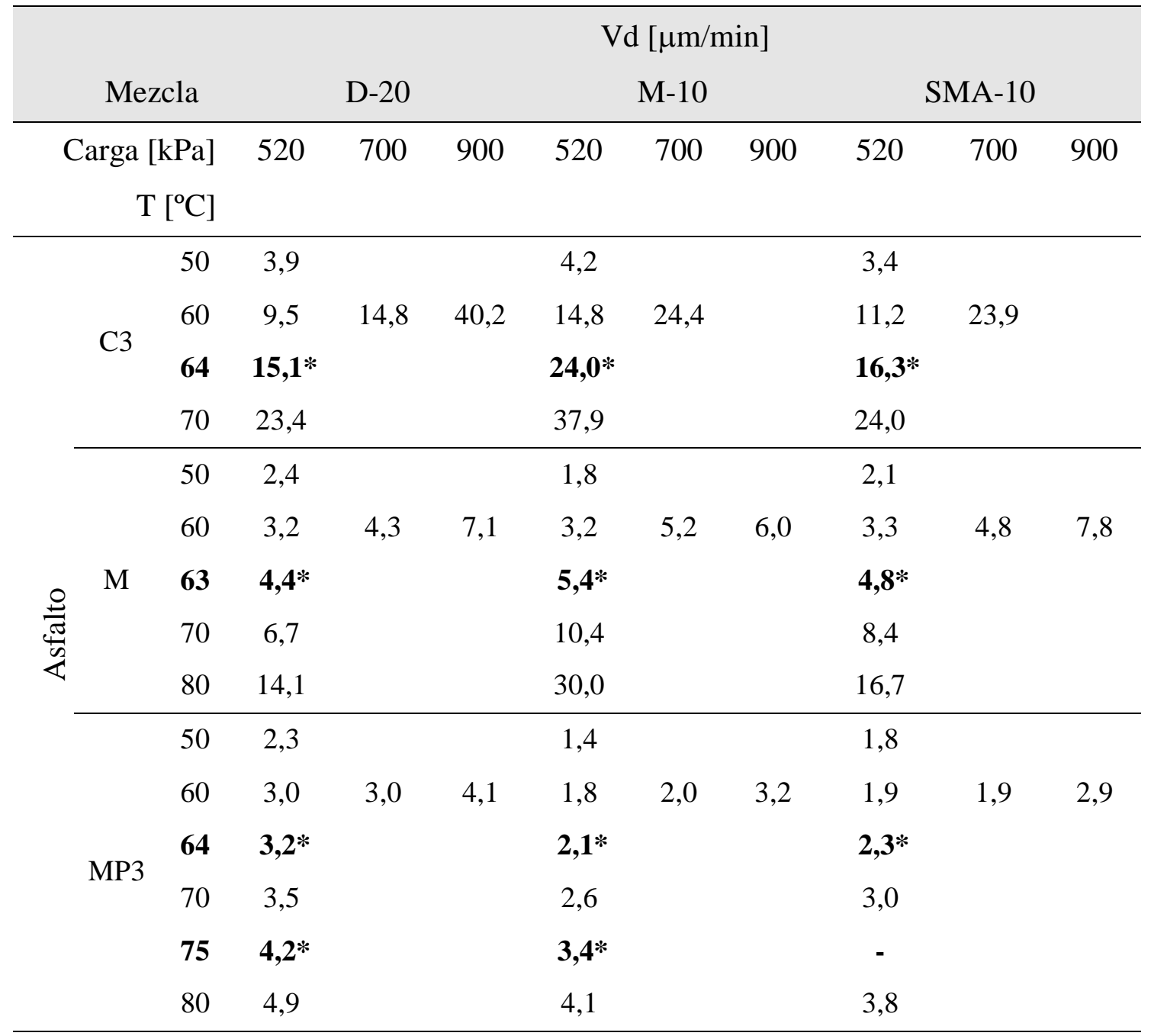

*Valor interpolado

Como conclusión general se observa que un incremento en el nivel de carga a $700 \mathrm{kPa}$ es equivalente a un aumento de la temperatura de alrededor de $4{ }^{\circ} \mathrm{C}$ y un aumento del nivel de carga a $900 \mathrm{kPa}$ es equivalente a un aumento en la temperatura de 10 a $15^{\circ} \mathrm{C}$.

Esto se puede utilizar como herramienta en el diseño de la mezcla asfáltica en la selección del asfalto para contemplar un posible aumento de los niveles de carga. Tomando en consideración la temperatura de alta obtenida en función de la zona geográfica del pavimento, es posible contemplar un aumento en los niveles de carga (sobrecarga) aumentando entre 5 y $10{ }^{\circ} \mathrm{C}$ la temperatura de alta que debe presentar el ligante asfáltico seleccionado para ofrecer un buen desempeño al ahuellamiento. Esto brindaría un margen de seguridad en el diseño de los pavimentos que no verían acortada 
su vida útil causada en una falta de confort prematura por efecto de la negligencia de los usuarios.

Utilizando la ecuación 2.2 presentada en el capítulo 2 es posible calcular un factor $\mathrm{r}$ conocido como factor de destrucción por aumento de las cargas. Este factor es la razón entre una carga cualquiera respecto a una que se toma como referencia elevada a la potencia cuarta. Teniendo de referencia la carga de $520 \mathrm{kPa}$, relacionada con la carga máxima permitida por la legislación Argentina, el factor $\mathrm{r}$ resulta igual a 3 para la carga de $700 \mathrm{kPa}$, mientras que el factor r es 9 para la carga de $900 \mathrm{kPa}$. Es interesante notar que las cargas de 700 y $900 \mathrm{kPa}$ son tres y nueve veces más destructivas que la carga de $520 \mathrm{kPa}$ siendo que sólo representan una sobrecarga de 35 y 73 \% respectivamente. De aquí la importancia de tener algún margen de seguridad aplicable durante el diseño de una mezcla asfáltica como el propuesto en esta tesis.

\subsubsection{Consideración de mayores volúmenes de tránsito dentro del diseño}

Rutas y autopistas presentan a veces volúmenes de tránsito importantes que implican más cargas repetida sobre la mezcla y mayor ahuellamiento. Por lo tanto es importante contemplar de alguna manera esos mayores volúmenes dentro del diseño de la mezcla.

En Argentina las mezclas densas se diseñan a partir de la metodología Marshall. Este método dispone del moldeo probetas con una determinada energía de compactación por medio de golpes (75 golpes por cara). El método Marshall no permite tener en cuenta el volumen real de tránsito dentro del diseño. Las mezclas tipo microaglomerados y SMA dentro de su diseño tampoco contemplan los volúmenes de tránsito siendo que son mezclas que se utilizan en autopistas primordialmente.

El Manual del Asphalt Institute (1993) asocia la energía de compactación de 75 golpes por cara a un nivel de tránsito de diseño mayor a $1 \times 10^{6}$ ejes simples de carga equivalente (ESAL). Sin embargo no se contemplan dentro de este límite cuanto mayor es ese volumen o como considerarlo en el diseño.

Recordando lo mencionado en el capítulo 2, dentro del programa SHRP los mayores volúmenes de tránsito se consideran a partir de aumentar la temperatura de alta del grado de desempeño (PG) para la elección del ligante asfáltico de un pavimento.

El factor r, mencionado anteriormente, se puede utilizar para calcular un número de ejes equivalentes necesarios para alcanzar un deterioro del pavimento con la carga de referencia $(520 \mathrm{kPa})$ respecto a otra carga cualquiera. Un deterioro determinado, para $700 \mathrm{kPa}$ de carga, lo generan un número de ejes. Haciendo uso del factor $\mathrm{r}$ son necesarios tres veces más ejes equivalentes $(520 \mathrm{kPa})$ para alcanzar el mismo deterioro. Para el caso de $900 \mathrm{kPa}$ el número de ejes equivalentes de $520 \mathrm{kPa}$ es nueve veces la cantidad de ejes de la primera carga para obtener el mismo deterioro.

En el caso de tener un volumen de diseño de $3 \times 10^{6}$ ESAL (520 kPa) se genera un deterioro equivalente con un volumen de $1 \times 10^{6}$ ejes de $700 \mathrm{kPa}$. Un incremento de 520 a $700 \mathrm{kPa}$ en la carga se contempla en un aumento en $5{ }^{\circ} \mathrm{C}$ en la temperatura de alta del asfalto dentro del diseño. Por lo tanto, en los casos que se tiene un tránsito de diseño tres veces superior al de referencia, ese mayor volumen se considera aumentando la temperatura de alta del asfalto a seleccionar en $5{ }^{\circ} \mathrm{C}$ y así evitar ahuellamientos. De 
manera similar con la carga de $900 \mathrm{kPa}$ se puede contemplar un aumento en el volumen de diseño de hasta nueve veces aumentando la temperatura de alta del asfalto en $10{ }^{\circ} \mathrm{C}$.

En la tabla 6.8 se presentan el aumento en la temperatura de alta $\left(\mathrm{T}_{\text {alta }}\right)$ a imponer al ligante para contemplar diferentes volúmenes de tránsito y así cubrir posibles ahuellamientos.

Tabla 6.8. Aumentos en la $\mathrm{T}_{\text {alta }}$ del asfalto por mayores volúmenes de tránsito.

\begin{tabular}{cc}
\hline Vol. De tránsito $[$ ESAL] & Aumento en la $\mathrm{T}_{\text {alta }}\left[{ }^{\circ} \mathrm{C}\right]$ \\
\hline$<1 \times 10^{6}$ & Sin incremento \\
$1 \times 10^{6}-3 \times 10^{6}$ & 5 \\
$>3 \times 10^{6}$ & 10 \\
\hline
\end{tabular}

\subsubsection{Conclusiones sobre la influencia del nivel de carga}

En este apartado se estudió el desempeño bajo incrementos de los niveles de carga. Se analizaron los resultados de deformaciones permanentes en distintas mezclas elaboradas con diferentes ligantes asfálticos. Las principales conclusiones se indican a continuación.

Como era de esperar para un aumento del nivel de carga se produce un incremento de los ahuellamientos en cualquiera de las mezclas estudiadas.

Se observa para un mismo ligante cómo las tres mezclas (D-20, M-10 y SMA-10) arrojan resultados comparables en relación al aumento del nivel de carga.

Se encontró, que la sensibilidad frente a incrementos de carga dependen de del tipo de ligante asfáltico.

La diferente sensibilidad de un asfalto frente a las cargas es función de la temperatura y en particular de la temperatura de alta de cada tipo de asfalto.

Los desempeños a diferentes temperaturas y cargas fueron relacionados encontrándose que aumentar la carga de 520 a $700 \mathrm{kPa}$ resulta equivalentes a aumentar la temperatura en alrededor de $4{ }^{\circ} \mathrm{C}$. Por su parte un incremento a $900 \mathrm{kPa}$ resulta equivalente a aumentos de 10 a $15^{\circ} \mathrm{C}$ en la temperatura.

La relación incremento de carga-temperatura se puede utilizar como herramienta en el diseño de mezclas para la seleccionar el asfalto contemplando posibles aumentos de los niveles de carga, considerando una mayor temperatura de alta del asfalto.

En función de los resultados obtenidos, cuando un pavimento tiene por diseño volúmenes de tránsito importantes este aspecto se puede tener en cuenta en la selección del ligante asfáltico aumentando en 5 o $10^{\circ} \mathrm{C}$ la temperatura de alta del asfalto. 


\subsection{Relación entre propiedades reológicas, temperatura y cargas}

La Low Shear Viscosity (LSV), la temperatura y las cargas son variables que afectan significativamente la respuesta de las mezclas asfálticas al ahuellamiento. Hasta aquí se desarrollaron criterios y metodologías para considerar estas variables dentro del diseño de mezclas y predecir el desempeño en base a la LSV.

Resulta importante el estudio de las variables mencionadas en conjunto de manera de tener una herramienta que las contemple a la hora de predecir el comportamiento de una mezcla.

Para ello se consideraron los resultados del ensayo de rueda cargada a diferentes temperaturas y cargas de las mezclas D-20, M-10 y SMA-10 elaboradas con los asfaltos C3, M y MP3 de los que se tienen mediciones de LSV.

\subsubsection{Análisis de resultados}

Para el análisis se consideraron la temperatura y carga de $60{ }^{\circ} \mathrm{C}$ y $520 \mathrm{~N}$ respectivamente como referencias $\left(\mathrm{T}_{0}\right.$ y $\left.\mathrm{P}_{0}\right)$. Los distintos desempeños son caracterizados por la velocidad de deformación obtenida del ensayo de rueda cargada. En carácter general se planteó obtener una relación que explique el desempeño de una mezcla con la forma de la ecuación 6.1.

$$
V d=f\left(L S V, \frac{T}{T_{0}}, \frac{P}{P_{0}}\right)
$$

En la tabla 6.9 se muestran los resultados de $\mathrm{Vd}$ a diferentes temperaturas y cargas de las mezclas estudiadas. Se observa también la medida de LSV del asfalto con la que se elaboró cada mezcla a la temperatura considerada. 
Tabla 6.9. Resultados de Vd a diferentes temperaturas y cargas de las mezclas.

\begin{tabular}{ccccccc}
\hline \multirow{2}{*}{ Asfalto } & LSV & $\mathrm{T}$ & $\mathrm{P}$ & \multicolumn{3}{c}{$\mathrm{Vd}[\mu \mathrm{m} / \mathrm{min}]$} \\
& {$[$ Pa.s $]$} & {$\left[{ }^{\circ} \mathrm{C}\right]$} & {$[\mathrm{N}]$} & $\mathrm{D}-20$ & $\mathrm{M}-10$ & SMA-10 \\
\hline \multirow{4}{*}{ C3 } & 1012,4 & 50 & 520 & 3,9 & 4,2 & 3,4 \\
& 252,5 & 60 & 520 & 9,6 & 14,8 & 11,2 \\
& 83,2 & 70 & 520 & 23,4 & 37,9 & 24,0 \\
& 252,5 & 60 & 700 & 14,8 & 24,4 & 23,9 \\
& 252,5 & 60 & 900 & 40,2 & - & - \\
& 3631,1 & 50 & 520 & 2,4 & 1,8 & 2,1 \\
& 947,5 & 60 & 520 & 3,4 & 3,2 & 3,3 \\
& 308,1 & 70 & 520 & 6,7 & 10,4 & 8,4 \\
& 120,5 & 80 & 520 & 14,1 & 30,0 & 16,7 \\
& 947,5 & 60 & 700 & 4,3 & 5,2 & 4,8 \\
& 947,5 & 60 & 900 & 7,1 & 6,0 & 7,8 \\
& 7669,9 & 50 & 520 & 2,3 & 1,4 & 1,8 \\
& 2459,3 & 60 & 520 & 3 & 1,8 & 1,9 \\
& 911,3 & 70 & 520 & 3,5 & 2,6 & 3,0 \\
\hline \multirow{4}{*}{ MP3 } & 383,1 & 80 & 520 & 4,9 & 4,1 & 3,8 \\
& 2459,3 & 60 & 700 & 3 & 2,0 & 1,9 \\
& 2459,3 & 60 & 900 & 4,1 & 3,2 & 2,9 \\
\hline
\end{tabular}

Para cada tipo de mezcla los resultados de Vd se ajustaron a la relación indicada en la ecuación 6.2 por regresión no lineal. El coeficiente k se relaciona con las características de cada tipo de mezcla mientras z y m marcan la sensibilidad del desempeño en función de la LSV del asfalto y las cargas respectivamente. Es importante destacar que en esta relación la variación de temperatura fue considerada con la LSV.

$$
V d=k . L S V_{i}{ }^{z} \cdot\left(\frac{P_{i}}{P_{0}}\right)^{m}
$$

En la tabla 6.10 se observan los coeficientes de ajuste y sus respectivos $\mathrm{R}^{2}$. Se observa que las tres mezclas poseen un buen ajuste al modelo. Del análisis de los coeficientes obtenidos se observa que la relación del desempeño con la LSV es inversamente proporcional ( $\mathrm{z} \cong-1$ ), como ya se había planteado en puntos anteriores. En cuanto a las mezclas D-20 y SMA-10 se observa que presentan una mayor sensibilidad frente a incrementos de carga. La mezcla M-10 posee una menor sensibilidad al incremento de cargas pero en contrapartida posee una constante k que duplica las de las mezclas D-20 y SMA-10 siendo susceptible de mayores ahuellamientos. De las tres mezclas la SMA10 es la que posee una menor constante $\mathrm{k}$, por tanto menores $\mathrm{Vd}$ y mayor resistencia al ahuellamiento. 
Tabla 6.10. Coeficientes de ajuste a la ecuación 6.2 para las mezclas estudiadas.

\begin{tabular}{ccccc}
\hline & $\mathrm{k}$ & $\mathrm{z}$ & $\mathrm{m}$ & $\mathrm{R}^{2}$ \\
\hline $\mathrm{D}-20$ & 2334 & $-1,05$ & 3,08 & 0,96 \\
$\mathrm{M}-10$ & 3910 & $-1,04$ & 1,85 & 0,97 \\
SMA-10 & 1760 & $-0,96$ & 2,71 & 0,93 \\
\hline
\end{tabular}

En la ecuación 6.2 se tomó la variación de temperatura al considerar la LSV de los ligantes a las diferentes temperaturas. Sin embargo resulta más practico considerar la variación de temperatura $\left(\mathrm{T}_{\mathrm{i}} / \mathrm{T}_{0}\right)$ y tomar las características del asfalto a partir de la LSV a una determinada temperatura $\left(60^{\circ} \mathrm{C}\right)$ en una relación como la indicada en la ecuación 6.3. Se decidió tomar la LSV a $60^{\circ} \mathrm{C}$ por ser esta la temperatura de referencia del ensayo de rueda cargada. En esta ecuación k y z representan al igual que en 6.2 las características del tipo de mezcla y las características del asfalto mientras que $C_{T}$ y $C_{P}$ marcan la sensibilidad de las mezclas frente a la variación de temperatura y carga respectivamente.

$$
V d=k \cdot L S V_{60^{\circ} \mathrm{C}}{ }^{\mathrm{z}} \cdot\left(\frac{T_{i}}{T_{0}}\right)^{C_{T}} \cdot\left(\frac{P_{i}}{P_{0}}\right)^{C_{P}}
$$

En la tabla 6.11 se observan los coeficientes de ajuste al modelo con buenos resultados $\left(\mathrm{R}^{2}\right.$ superiores a 0,90$)$. Se observa, en comparación con los resultados de la ecuación 6.2 , que $\mathrm{z}$ arroja nuevamente valores $\cong-1$. En consecuencia se puede aseverar que el comportamiento de las mezclas es inversamente proporcional a la LSV y tomar z $=-1$.

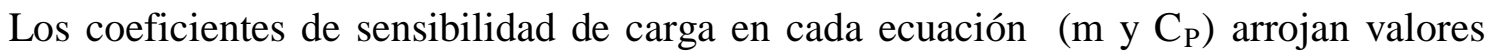
similares en los ajustes. En consecuencia los cambios realizados al modelo no afectan las consideraciones respecto a la sensibilidad del tipo de mezclas frente a incrementos de carga.

En el caso de la sensibilidad frente a la temperatura $\left(\mathrm{C}_{T}\right)$ la mezcla $\mathrm{M}-10$ es la que presenta mayor sensibilidad seguida por las mezclas D-20 y SMA-10 respectivamente.

Tabla 6.11. Coeficientes de ajuste a la ecuación 6.3 para las mezclas estudiadas.

\begin{tabular}{cccccc}
\hline & $\mathrm{K}$ & $\mathrm{z}$ & $\mathrm{C}_{\mathrm{T}}$ & $\mathrm{C}_{\mathrm{P}}$ & $\mathrm{R}^{2}$ \\
\hline $\mathrm{D}-20$ & 2961 & $-1,07$ & 7,06 & 2,91 & 0,96 \\
M-10 & 4904 & $-1,07$ & 7,27 & 1,80 & 0,97 \\
SMA-10 & 2924 & $-1,01$ & 5,51 & 2,21 & 0,93 \\
\hline
\end{tabular}


En un análisis rápido de los valores obtenidos se puede definir características del comportamiento de las mezclas. La SMA-10 es una mezcla de prestaciones mejores frente al ahuellamiento respecto de las otras dos estudiadas; esta presenta una más baja sensibilidad a la variación de temperatura y la más baja constante k de mezcla.

En la figura 6.21 se comparan los resultados de Vd obtenidos en el ensayo de rueda cargada para la mezcla D-20 versus las estimadas con las ecuaciones 6.2 y 6.3 respectivamente. Se observa como ambas ecuaciones estiman los resultados de manera similar. Es de destacar que para ambos ajustes sobreestiman los comportamientos para velocidades de deformación menores a $2,5 \mu \mathrm{m} / \mathrm{min}$. Esto no ocasiona grandes problemas ya que valores de Vd como estos representan buenos comportamientos de la mezcla. A esta Vd $(2,5 \mu \mathrm{m} / \mathrm{min})$ se asocia una LSV del asfalto en estado original, figura 6.9, mayor a 1000 Pa.s; valor que duplica el límite propuesto de LSV de 500 Pa.s.
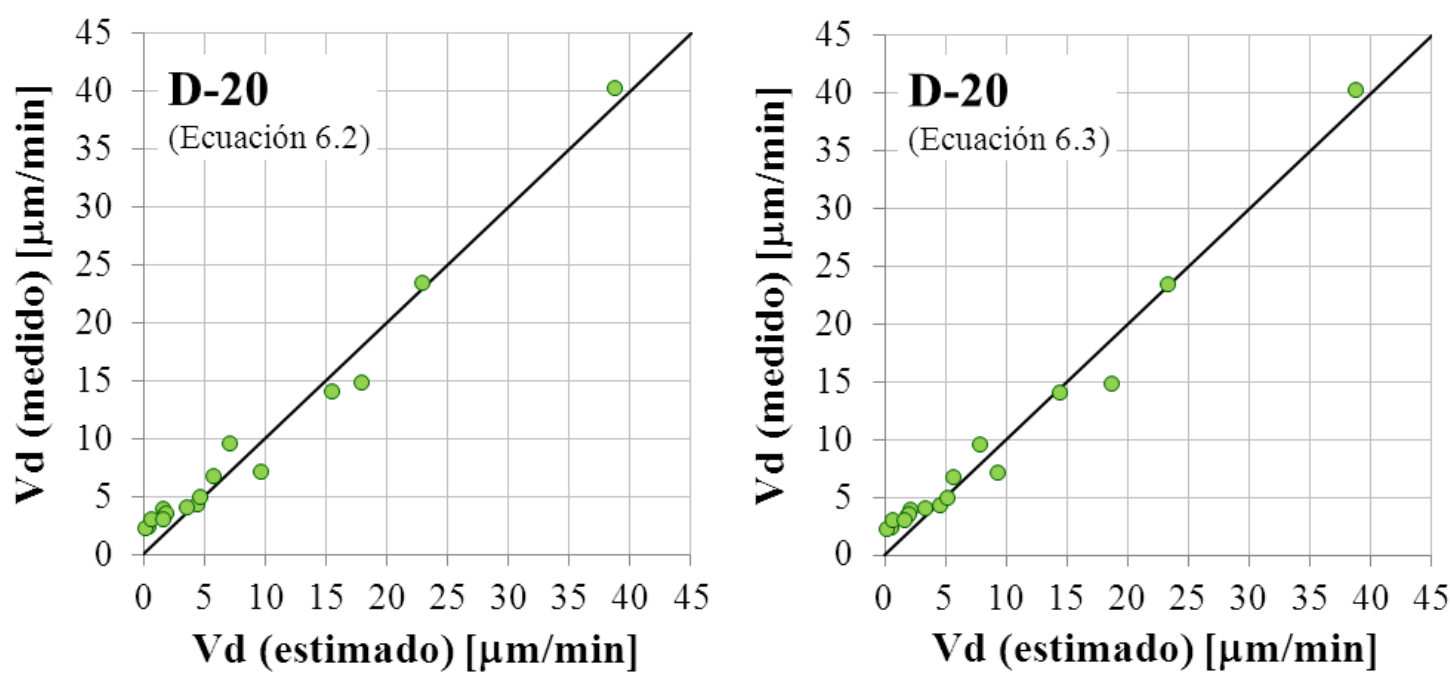

Figura 6.21. Vd del ensayo mezcla D-20 versus Vd estimadas. Izquierda: con la ecuación 6.2, derecha: con la ecuación 6.3.

En la figura 6.22 se presentan los resultados de $\mathrm{Vd}$ obtenidos en el ensayo de rueda cargada versus $\mathrm{Vd}$ estimadas con las ecuaciones 6.2 y 6.3 para las mezclas M-10 y SMA-10. Se observa nuevamente una muy buena estimación con cualquiera de los modelos propuestos. En estas mezclas se produjo el problema de sobreestimación de los resultados para valores de $\mathrm{Vd}<1,5 \mu \mathrm{m} / \mathrm{min}$. 

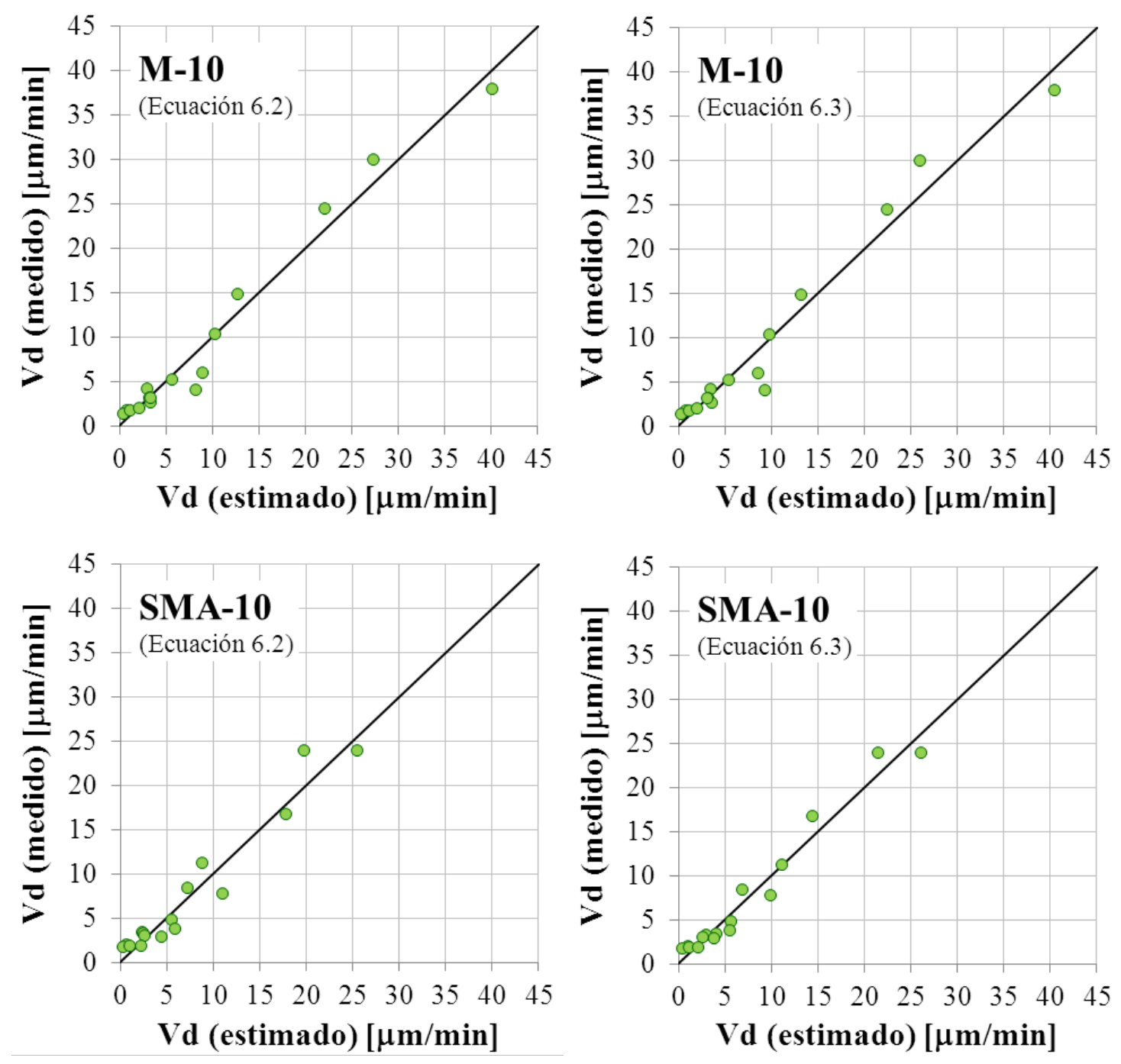

Figura 6.22. Vd del ensayo versus Vd estimadas (Izquierda: con la ecuación 6.2, derecha: con la ecuación 6.3). Arriba: mezcla M-10, abajo: mezcla SMA-10.

El modelo de la ecuación 6.3 resulta más práctico que el de la ecuación 6.2 ya que sólo se necesita una medición de la LSV para caracterizar al tipo de ligante. En la 6.2 se necesita tener una medición de la LSV para cada temperatura a la que se desea predecir un desempeño. Además se tiene una idea de la sensibilidad de la mezcla frente a la variación de temperatura con el factor $\mathrm{C}_{\mathrm{T}}$.

En función de que ambos modelos ajustan de manera similar los datos se analizó la relación entre los parámetros que se modificaron de un modelo al otro. En la figura 6.21 se representa la relación entre la LSV a diferentes temperaturas $\left(\mathrm{LSV}_{\mathrm{i}}\right)$ y el factor $\mathrm{LSV}_{60}{ }^{\circ} \mathrm{C} /\left(\mathrm{T} / \mathrm{T}_{0}\right)^{\mathrm{CT}}$ para cada mezcla. Se observa una clara relación entre ambos. Esto demuestra, para las mezclas estudiadas, que se puede considerar las características del ligante a través de una sola medición $\left(\mathrm{LSV}_{60}{ }^{\circ} \mathrm{C}\right) \sin$ afectar la predicción del desempeño de la mezcla asfáltica. Se observa además que el parámetro considerado para la ecuación 6.3 mantiene una relación casi univoca con la LSV $\mathrm{i}_{\mathrm{i}}$. 


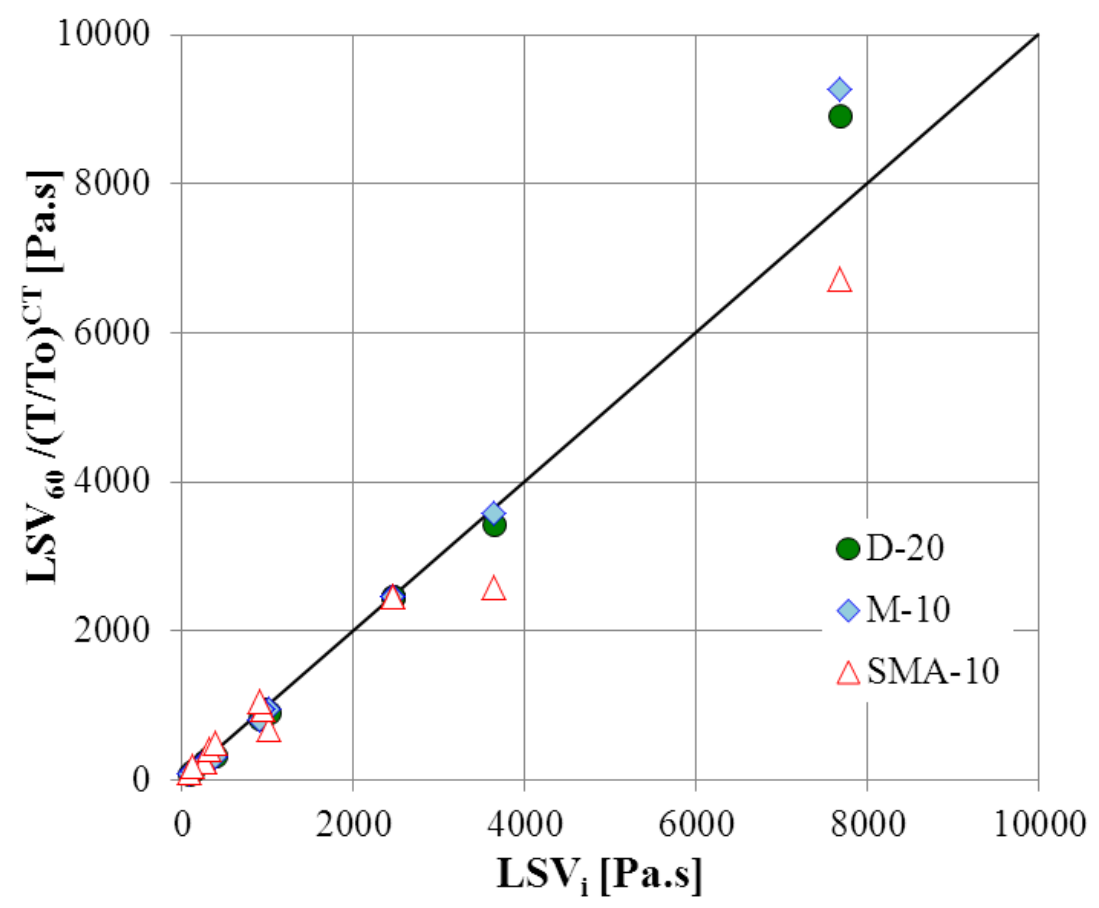

Figura 6.23. $\mathrm{LSV}_{\mathrm{i}}$ versus parámetro $\mathrm{LSV}_{60}{ }^{\circ} \mathrm{C} /\left(\mathrm{T} / \mathrm{T}_{0}\right)^{\mathrm{CT}}$.

\subsubsection{Consideraciones a la relación LSV-T-Carga.}

En este apartado se estudiaron el desempeño al ahuellamiento de mezclas asfáltica a diferentes temperaturas y cargas conjuntamente con características del ligante asfáltico (la LSV). Se analizaron de manera de obtener una relación para predecir el comportamiento de una mezcla. Las principales conclusiones se indican a continuación.

Se modelo el desempeño de forma práctica considerando en una única relación la sensibilidad a la variación de temperatura y carga de las mezclas estudiadas así como el comportamiento dependiendo del tipo de ligante a través de la LSV.

El modelo encontrado es práctico ya que sólo necesita una medición de la LSV a $60{ }^{\circ} \mathrm{C}$ para caracterizar al tipo de ligante siendo la relación con los desempeños inversamente proporcional. 



\section{Capítulo 7}

\section{Conclusiones}

Esta tesis contribuye al conocimiento, estudio y caracterización de las deformaciones permanentes en mezclas asfálticas para uso vial considerando las propiedades reológicas de los ligantes asfálticos y el desempeño de las mezclas. Se estudió el desempeño al ahuellamiento de diferentes tipos de mezclas; densas, microaglomerados y Stone Mastic Asphalt (SMA); a través de métodos de laboratorio como el ensayo de rueda cargada a diferentes temperaturas y niveles de carga. Se emplearon en la elaboración de las mezclas diferentes tipos de ligantes asfálticos de uso comercial en Argentina que abarcan asfaltos convencionales, multigrados y modificados con polímero. Se estudiaron las propiedades reológicas de los asfaltos asociadas al comportamiento y desempeño de las mezclas asfálticas frente a las deformaciones permanentes definiendo cual representa mejor la contribución del asfalto en la resistencia al ahuellamiento.

El estudio de los mecanismos y variables que inciden sobre las deformaciones permanentes dio lugar a resultados de aplicación específica en la selección del ligante en el diseño de mezclas teniendo en cuenta las condiciones climáticas y de carga a las que será expuesto el pavimento en base a las propiedades reológicas. En este capítulo se vuelcan las principales conclusiones así como algunas recomendaciones para estudios futuros sobre el tema.

Los estudios realizados con el equipo de rueda cargada resultaron significativos ya que brindaron mucha e importante información y este ensayo no es utilizado asiduamente por las personas que diseñan las mezclas asfálticas de los pavimentos de nuestro país como una herramienta durante el mismo.

\subsection{Conclusiones de la tesis}

Particularmente los estudios desarrollados dentro de esta tesis se dividieron en una primera etapa donde se analizaron diferentes propiedades reológicas relacionadas a la problemática de las deformaciones permanentes a nivel del ligante y una segunda etapa donde se relacionaron las anteriores con mediciones sobre mezclas asfálticas en el ensayo de rueda cargada. 
Inicialmente se seleccionaron diferentes asfaltos convencionales y modificados representativos de los tipos de ligante más empleados. Como propiedades reológicas se midieron el parámetro G*/sen $\delta$ de la metodología SHRP, la Zero Shear Viscosity (ZSV) y la Low Shear Viscosity (LSV).

El G*/sen $\delta$ se midió a dos diferentes frecuencias, una de $10 \mathrm{rad} / \mathrm{s}$ (según norma ASTM D 6373 1999) y otra de 0,6 rad/s similar a la frecuencia de circulación de la rueda del ensayo de rueda cargada. Al nivel ligante se observó que la menor frecuencia de carga permite una mejor clasificación de los asfaltos por medio del parámetro G*/sen $\delta$ y que se manifieste la recuperación visco-elástica retardada de los ligantes modificados con polímero SBS. Por su parte la frecuencia de $10 \mathrm{rad} / \mathrm{s}$ no permite una caracterización adecuada de los distintos tipos de ligantes.

La ZSV y la LSV son propiedades semejantes, evaluadas a partir de diferentes métodos. Parte de los propósitos de esta tesis era definir cuál era la metodología más confiable de medición dentro de estos métodos. De los resultados obtenidos surge claramente que el ensayo de barrido de frecuencias (LSV) es más práctico que el de creep con el que se obtiene la ZSV. Ambos métodos arrojaron valores comparables para los asfaltos estudiados pero el barrido de frecuencias conlleva menores tiempos de ensayo. Esto lo posiciona de mejor manera para la caracterización de los asfaltos. Tomando en consideración lo mencionado se recomienda a la LSV para la caracterización con fines de especificación.

Al comparar las propiedades reológicas se encontró una buena relación entre el G*/sen $\delta$ (a $10 \mathrm{rad} / \mathrm{s}$ ) y la LSV para los asfaltos convencionales e inclusive algunos ligantes modificados. Sin embargo el $\mathrm{G}^{*} / \mathrm{sen} \delta$ subestima a los asfaltos modificados con polímero SBS respecto a la LSV.

$\mathrm{Al}$ medir $\mathrm{G} /$ sen $\delta$ se observaron discrepancias en la caracterización entre el ligante en estado original y luego de envejecido en RTFOT en determinados asfaltos, en consecuencia la medición del $\mathrm{G} * /$ sen $\delta$ se ve afectada por el proceso de envejecimiento.

Considerando la relación entre el G*/sen $\delta$ (a 0,6 rad/s) y la LSV se encontró una buena relación para todos los asfaltos en estado original. Sin embargo cuando se analizaron los asfaltos envejecidos en RTFOT se da una pobre estimación de los ligantes modificados con polímero SBS por parte del parámetro G*/sen $\delta$.

A fin de observar como las propiedades reológicas seleccionadas, G*/sen $\delta$ y LSV, caracterizaban la capacidad de resistir las deformaciones permanentes de los asfaltos estudiados, se midieron los desempeños de mezclas asfálticas densas utilizando el ensayo de rueda cargada bajo condiciones normalizadas $\left(60{ }^{\circ} \mathrm{C}\right.$ de temperatura y $520 \mathrm{~N}$ de carga). Se encontró que el $\mathrm{G}^{*} / \mathrm{sen} \delta$ a la frecuencia de $10 \mathrm{rad} / \mathrm{s}$ no caracteriza el aporte de todos los tipos de ligante en la resistencia al ahuellamiento. En especial para los ligantes modificados con polímero SBS. En este sentido se verifica para los ligantes empleados en nuestro país resultados similares a los obtenidos a nivel mundial.

Al analizar la relación entre los ahuellamientos en mezclas y el G*/sen $\delta$ a la frecuencia de 0,6 rad/s se encontró que los desempeños de las mezclas asfálticas no fueron correctamente caracterizados por esta propiedad. Aún persiste el problema de 
caracterizar a los ligantes modificados con polímero SBS al igual que con el G*/sen $\delta$ medido a la frecuencia de $10 \mathrm{rad} / \mathrm{s}$.

Las relaciones entre los ahuellamientos y la LSV arrojaron muy buenos resultados. La LSV caracteriza apropiadamente la contribución de todos los ligantes estudiados para resistir las deformaciones permanentes en las mezclas, inclusive los ligantes modificados con polímero.

En síntesis se encontró que la propiedad reológica más conveniente para caracterizar los ligantes asfálticos en cuanto a su resistencia al ahuellamiento es la LSV. En los estudios subsiguientes se relacionó esta propiedad con las mediciones en el equipo de rueda cargada considerando temperaturas y niveles de carga diferentes a los normalizados $\left(60{ }^{\circ} \mathrm{C}\right.$ y $520 \mathrm{~N}$ ) e incorporando diferentes tipos de mezclas.

Se estudió el desempeño de mezclas asfálticas para carpeta de rodamiento con tres tipos de asfalto para temperaturas de 50, 60, 70 y $80^{\circ} \mathrm{C}$ en el ensayo de rueda cargada. Estos desempeños se compararon con mediciones de LSV de los ligantes a las mismas temperaturas, tomando la LSV de los asfaltos para el asfalto original y luego de envejecido.

Considerando el efecto de la temperatura se observó que la velocidad de ahuellamiento $(\mathrm{Vd})$ depende del tipo de ligante utilizado en la mezcla y se produce como era de esperarse una merma en el desempeño a medida que aumenta la temperatura. Se encontró que la Vd se incrementa más rápidamente para las mezclas con asfalto convencional seguidas por las mezclas con asfaltos modificados, multigrado y con polímero SBS.

Las Vd medidas en el ensayo de pista de diferentes mezclas (densa, microaglomerado y SMA) se agrupan y siguen una única curva en función de la LSV de los asfaltos.

A partir de las curvas Vd vs LSV se encontró que para LSV de los asfaltos menores a 500 y 2000 Pa.s en estado original y envejecido respectivamente a las temperaturas de ensayo se produce un fuerte incremento de la velocidad de ahuellamiento (Vd). Para las mezclas estudiadas valores de LSV de 500 y 2000 Pa.s se recomiendan como límites en la contribución parcial del asfalto en la resistencia frente a las deformaciones permanentes de mezclas asfálticas.

Del párrafo anterior se desprende que la temperatura para la cual cada asfalto alcanza valores de LSV iguales a 500 y 2000 Pa.s para el estado original y envejecido representa la temperatura extrema $\left(\mathrm{T}_{\text {alta }}\right)$ hasta la cual el asfalto ofrece resistencia al ahuellamiento dentro de la mezcla asfáltica. La $\mathrm{T}_{\text {alta }}$ es una herramienta en el diseño de una mezcla para considerar las condiciones climáticas de la ubicación geográfica del pavimento.

Por todo lo dicho la LSV constituye una propiedad determinante para la caracterización de un asfalto.

Se observó que el envejecimiento en RTFOT de manera normalizada no reflejó el envejecimiento sufrido en la mezcla de uno de los asfaltos modificados con polímero SBS. Al considerar las medidas de LSV del ligante recuperado de la mezcla asfáltica se 
encontró un envejecimiento similar al que se produjo en la elaboración al aumentar la temperatura de ensayo del RTFOT reproduciendo las condiciones de elaboración reales.

Uno de los propósitos de esta tesis era predecir las deformaciones permanentes a partir de las características del ligante utilizado, más concretamente sus propiedades reológicas, teniendo en consideración las condiciones de temperatura a las cuales será expuesto en el pavimento. En función de los resultados obtenidos fue posible ajustar a una única curva Vd vs LSV el desempeño de diferentes tipos de mezclas preparadas con diferentes cementos asfálticos. Esta curva constituye una herramienta para:

predecir el comportamiento frente a deformaciones permanentes para diferentes condiciones de temperaturas del pavimento sólo conociendo la LSV del ligante a la temperatura considerada.

> optimizar la selección del asfalto tomando en cuenta el tipo de aplicación y las condiciones ambientales a las que estará expuesto en el pavimento.

La relación Vd vs LSV fue validada en estudios posteriores de desempeño; se encontró que es posible utilizar la curva sin grandes errores tomando como límite de predicción una $\mathrm{Vd}=8 \mu \mathrm{m} / \mathrm{min}$.

Tomando en consideración la relación Vd vs LSV y los valores LSV límites se propone un límite de desempeño para el ensayo de rueda cargada bajo condiciones normalizas ( $60{ }^{\circ} \mathrm{C}, 520 \mathrm{~N}$ y $120 \mathrm{~min}$.) de $\mathrm{Vd}=5 \mu \mathrm{m} / \mathrm{min}$. Valores de $\mathrm{Vd}$ superiores a este límite obtenidos en cualquier ensayo denotan que el ligante no es el adecuado a utilizar a tan extremas temperaturas.

Otro de los objetivos fue el estudio del desempeño de diferentes mezclas a niveles de carga mayores al normalizado de $520 \mathrm{~N}$ en el ensayo de rueda cargada. Se evaluaron mezclas sometidas a 700 y $900 \mathrm{~N}$, niveles de carga que representan los utilizados por los equipos de rueda cargada en la actual normativa europea (UNE 12697-22) y antigua normativa española (NLT 173).

Como era de esperarse aumentos en el nivel de carga produjeron incrementos de ahuellamientos en cualquiera de las mezclas estudiadas, el efecto del nivel de carga fue similar en distintos tipos de mezclas (densa, microaglomerado y SMA) elaboradas con un mismo ligante.

Sin embargo conforme el tipo de ligante asfáltico es diferente la respuesta frente a los incrementos de carga en lo que se refiere a la sensibilidad al ahuellamiento. El asfalto convencional tiene una sensibilidad importante mientras que en el ligante modificado con polímero SBS mostró una baja sensibilidad frente al aumento de la tensión de carga.

Se encontró que la mayor o menor sensibilidad que posee un ligante asfáltico y por tanto la mezcla con él elaborada dependen de la temperatura de ensayo y se relacionan con la temperatura de alta, definida a partir de la LSV correspondiente al asfalto.

Al relacionar los ahuellamiento a distintas temperaturas con los resultados obtenidos por incrementos en el nivel de carga, se encontró que los ahuellamientos generados por aumento de la carga de 520 a $700 \mathrm{~N}$ son equivalentes a los que provocaría un aumento de la temperatura cercano a $4{ }^{\circ} \mathrm{C}$ a partir de los $60{ }^{\circ} \mathrm{C}$; mientras que un aumento del nivel de carga a $900 \mathrm{~N}$ es equivalente a un aumento en la temperatura de 10 a $15^{\circ} \mathrm{C}$. 
Esta vinculación entre incrementos de cargas y sus equivalentes de temperatura, se puede utilizar como herramienta en el diseño de mezclas asfálticas para evitar deformaciones permanentes por efecto de mayores cargas. A partir de los estudios realizados se propone al seleccionar el asfalto contemplar:

1. Las sobrecargas en el pavimento a través de considerar una mayor $\mathrm{T}_{\text {alta }}$ del asfalto de entre 5 y $10{ }^{\circ} \mathrm{C}$.

2. Los volúmenes de tránsito importantes aumentando en 5 o $10^{\circ} \mathrm{C}$ la $\mathrm{T}_{\text {alta }}$ necesaria del asfalto.

Al analizar diferentes niveles de carga se calculó el factor de destrucción (r) para relacionarlos con la carga normalizada. Se encontró que las cargas de 700 y $900 \mathrm{~N}$ son tres y nueve veces más destructivas que la carga de $520 \mathrm{~N}$ siendo que sólo representan aumentos de carga de 35 y 73 \% respectivamente respecto a la carga normalizada.

Finalmente se estudió el desempeño al ahuellamiento de mezclas asfáltica a diferentes temperaturas y cargas conjuntamente con características del ligante asfáltico (LSV) de manera de obtener una relación para predecir el comportamiento de una mezcla.

Se encontró un modelo que considera la sensibilidad a la variación de temperatura y carga de las mezclas estudiadas así como el comportamiento dependiendo del tipo de ligante a través de la LSV. Este modelo resulta práctico ya que sólo necesita una medición de la LSV a $60{ }^{\circ} \mathrm{C}$ para caracterizar al tipo de ligante siendo la relación con los desempeños inversamente proporcional.

\subsection{Recomendaciones de estudios futuros}

En esta tesis se definió un método efectivo para la seleccionar el tipo de asfalto capaz de resistir deformaciones permanentes en una mezcla. El mismo parte de conocer una propiedad reológica: la LSV. En este estudio la medición de la LSV se ha desarrollado en base a un DSR. Este equipo es muy costoso, al menos para Latinoamérica, por lo que sería interesante desarrollar estudios que relacionen la LSV de los asfaltos con medidas reológicas más sencillas. En este sentido considerando que los viscosímetros Brookfield están muy extendidos a nivel mundial, una relación LSV-viscosidad ofrecería un amplio espectro de utilización de los conceptos volcados en esta tesis.

Un aporte de esta tesis fue el límite propuesto de 500 Pa.s de LSV para la condición de los ligantes en estado original para caracterizar la resistencia de los asfaltos al ahuellamiento. Además se encontró el valor de 2000 Pa.s como límite para los ligantes envejecidos. Ambos valores son de importancia en la caracterización de un ligante dentro del diseño de mezclas asfálticas. Sería importante el desarrollo de una especificación en la cual se contemple la caracterización de los ligantes a partir de límites como el encontrado que se relacionan con propiedades reológicas del ligantes; además la misma se relaciona con el comportamiento al ahuellamiento en mezclas obtenido en el ensayo de rueda cargada.

En base a los resultados obtenidos en el equipo de rueda cargada se han propuesto límites para asegurar un buen desempeño. Sin embargo en argentina aún no existen 
normativas ni límites asociados y definidos para este ensayo. Sería interesante precisar las condiciones de ensayo y elaborar una normativa nacional.

Dentro de esta tesis se estudió el desempeño de mezclas asfálticas con la carga de la norma Europea $(700 \mathrm{~N})$ para las condiciones de tiempo de ensayo y velocidad de la rueda de la norma BS 598 (120 min. y 21 ciclos/min); no se analizaron los desempeños para 360 min y 26 ciclos/min de la CEN 12697-22. Resultaría interesante comparar los resultados de desempeño según ambas normativas.

Existen otras metodologías de ensayo basadas en propiedades reológicas de los asfaltos asociadas a la problemática de las deformaciones permanentes que no han sido estudiadas en esta tesis. Entre las que resultaría interesante abordar aparece el Multiple Stress Creep Recovery Test (MSCRT) que involucra, además de la temperatura a la que está expuesto el asfalto, variaciones en el nivel de tensión aplicado que se puede asociar a diferentes niveles de carga en una mezcla asfáltica.

A partir del estudio realizado para esta tesis surge que la especificación SHRP propone grados de desempeño para caracterizar los ligantes asfálticos, sin embargo el parámetro seleccionado para las deformaciones permanentes $\left(G^{*} / \operatorname{sen} \delta\right)$ no representa el comportamiento de todos los asfaltos, salvo algunos cambios menores para tratar de caracterizar a los asfaltos modificados con polímero. Por su parte en Europa está normalizada la medición de la LSV pero no existen especificaciones de ligantes para caracterizar el desempeño de mezclas frente a las deformaciones permanentes a partir de esta propiedad ni se incluye como parámetro de diseño de mezclas asfálticas. En esta tesis se trata de cubrir las falencias que tienen ambas líneas de investigación potenciando los aspectos positivos que presentan con el objetivo de considerarlas dentro del diseño y evaluación del comportamiento de mezclas asfálticas. 


\section{Capítulo 8}

\section{Referencias}

Agnusdei J., Iosco O. (2000). Envejecimiento de asfaltos modificados con polímero a corto y largo plazo. Proc. de la XXXI Reunión del asfalto. Tomo I: 297-312.

Agnusdei J., Iosco O., Jair M., Morea F. (2006). Correlación entre medidas de Ahuellamiento “in situ” y ensayos de laboratorio. Proc. XXXIV Reunión del Asfalto. $13 \mathrm{p}$.

Agnusdei J., Iosco O., Jair M., Morea F. (2007a). Correlación entre medidas de Ahuellamiento "in situ” y ensayos de laboratorio (2 ${ }^{\text {da }}$ Parte). Proc. XIV Congreso Iberoamericano del Asfalto. $13 \mathrm{p}$.

Agnusdei J., Iosco O., Jair M., Morea F. (2007b). Correlación entre ensayos que miden deformaciones bajo tránsito en mezclas asfálticas. Proc. XIV Congreso Argentino de Vialidad y tránsito. 17 p.

Agnusdei J., Iosco O., Jair M., Morea F. (2008). Efecto sobre el ahuellamiento de las temperaturas de preparación y compactación de mezclas preparadas con asfaltos modificados. Proc. XXXV Reunión del Asfalto. 16 p.

Airey G., Rahimzadeh B., Collop A. (2002). Linear Viscoelastic Limits o Bituminous Binders. Asphalt Paving technology No 69: 89-115.

Anderson D. A., Christensen D. W., Bahia H. U., Dongré R., Sharma M. G., Button J. (1994). Binder Characterization and Evaluation, Volume 3: Physical Characterization. Report N ${ }^{o}$ SHRP-A-369, the Strategic Highway Research Program, National Research Council. ISBN 0-309-05767-1. 475 p.

Anderson, D., Le Hir, Y.M., Planche, J.P., Martín, D. (2002). Zero Shear Viscosity of Asphalt Binders. Transportation Research Boards Annual Meeting, paper 02-4113. $22 \mathrm{p}$.

ASTM C 1252 (1993). Standard test method for uncompacted void content of fine aggregate (as influenced by particle shape, surface texture and grading). Annual Book of ASTM standards. 4 p. 
ASTM D 7405 (2010). Standard test method for multi stress creep recovery (MSCR) of asphalt binder using a dynamic shear rheometer. 3 p.

ASTM D 2419 (2002). Sand equivalent value of soils and fine aggregates. Annual Book of ASTM standards. Vol. 04.03: 219-227.

ASTM D 4402 (2006). Viscosity determination of unfilled asphalts using the Brookfield thermosel apparatus. 3 p.

ASTM D 5821 (2006). Standard test method for determining the percentage of fractured particles in coarse aggregate. Vol. 04.03: 645-649.

ASTM D 6373 (1999). Standard specification for performance grade asphalt binder. Vol. 04.03: 713-715.

Bahia H. U., Delgadillo R, Motamed A., Christensen D. (2009). Performance of modified asphalt binder and mixture under increseased truck loading limits. Proc. Efficient transportation and pavement systems, 421-439. ISBN 978-0-415-48979-9.

Bahia H. U., Zhai, H., Zeng, M., Hu, Y., Turner, P. (2001). Development of binder specification parameters based on characterization of damage behavior. Asphalt paving technology $\mathrm{N}^{\mathrm{o}} 70$ : 442-470.

Bahia H., Daranga C. (2007). Advancements in Characterization of polymer Modified Asphalt. Proc del $5^{\circ}$ Congreso Mexicano del Asfalto. 19 p.

Bahia H., Hanson D., Zeng M., Zhai H., Khatri M., Anderson (2001). Characterization of Modified Asphalt Binders in Superpave Mix Design. NCHRP 9-10 report 459. ISSN 0077-5614. 93 p.

Bahia, H. U. (1995). Critical Evaluation of Asphalt Modification Using the SHRP Concepts. Transportation Research Record No 1488: 82-88.

Biro S., Gandhi T., Amirkhanian S. (2009). Determination of zero shear viscosity of warm asphalt binders. Construction and Building Materials $\mathrm{N}^{\circ}$ 23-5: 2080-2086. Doi: 10.1016/j.conbuildmat.2008.08.015.

Brown, E. R., and Basset, C. E. (1990). Effects of Maximum Aggregate Size on Rutting Potential and Other Properties of Asphalt-Aggregate Mixtures. Transportation Research Record 1259: 107-119.

CEN prEN 15324 (2006). Bitumen and Bituminous Binders - Determination of Equiviscous Temperature Based on Low Shear Viscosity using a Dynamic Shear Rheometer in Low Frequency Oscillation Mode. 28 p.

CEN prEN 15325 Standard (2006). Bitumen and Bituminous Binders - Determination of Zero Shear Viscosity (ZSV) using a Shear Stress Rheometer in Creep Mode. 20 p.

D’Angelo J., Kluttz R., Dongré R., Stephens K., Zanzotto L. (2007). Revision of the Superpave high temperature binder specification: the multiple stress creep recovery test. Asphalt Paving technology No 76: 123-157.

De Visscher J., Vanelstraete A. (2004). Practical Test Methods for Measuring the Zero Shear Viscosity of Bituminous Binders. Materials and Structures No 37: 360 364. Doi: 10.1007/BF02481684. 
De Visscher J., Vanelstraete A. (2009). Equiviscous temperature based on low shear viscosity: evaluation as binder indicator for rutting and critical discussion of the test procedure. Proc Advance testing and characterization of bitumious materials. Vol II: 1009-1018. ISBN 978-0-415-55854-9.

Dezmanes C., Lecomte M., Leseur D. and Phillips M. (2002). A protocol for reliable measurement of Zero Shear Viscosity in order to evaluate the anti rutting performance of binders. Proc $2^{\text {nd }}$ Euroaspahlt and Eurobitumen congress. Vol I: 203:211.

Dreessen S., Planche J.P., Gardel V. (2009). A new performance related test method for rutting prediction: MSCRT. Proc Advance testing and characterization of bitumious materials. Vol. II : 971-980. ISBN 978-0-415-55854-9.

Especificación Española (2004). Pliego de prescripciones técnicas generales para obras de carreteras y Puentes PG 3.719 p.

Fabb, T. (2000). Performance-related bitumen specifications for Europe: simple and soon. Proc $2^{\text {nd }}$ Euroaspahlt and Euro bitumen congress. Tomo I: 248-254.

Ferry J. (1980). Viscoelastic Properties of Polymers. $3^{\text {rd }}$ edition, John Wiley and Sons, New York. 672 p.

Groupement Professionnel des Bitumes, Laboratories Central des Punts et Chaussées (2002). Bitumen and Bituminous Binders: Determination of the Steady-State Viscosity by the Creep Method. 8 p.

Highway Research Board (1962). The AASHO road test. Special report $61 \mathrm{E}$ Pavement research. Washington DC.

Iosco O., Agnusdei J. (1997). Mapa de temperaturas viales de la República Argentina para el diseño d mezclas asfálticas por el sistema Superpave. Procedente del $9^{\circ}$ Congreso Ibero Latinoamericano del Asfalto.15 p.

IRAM 1682 (1992). Agregado Fino: Método de determinación del equivalente arena. $12 \mathrm{p}$.

IRAM 1851 (1998). Agregados. Determinación en una mezcla de la proporción de agregado grueso con dos o más caras de fractura por trituración. 10 p.

IRAM 6576 (2004). Asfaltos. Determinación de la penetración utilizando un penetrómetro de aguja. $12 \mathrm{p}$.

IRAM 6841 (2002). Asfaltos para uso vial. Determinación del punto de ablandamiento. Método del anillo y la esfera. 13 p.

Jia J., Zhang X., Yuan Y. (2005). Rolling thin film oven test investigation for polymer modified asphalt. Harbin Institute of Technology No 12-6: 635-638.

Khedaywi T. S., Tons E. (1998). Aggregate Rugosity and Size Effect on Bituminous Mixes. Transportation Research Record No 1619: 26-36.

Kim Y. R. (2009). Modelling of Asphalt Concrete. Editorial McGraw-Hill. ISBN: 0-07146462-X. DOI: 10.1036/007146462X. 460 p. 
Le Hir Y., Anderson D., Planche J. P., Martin D. (2003). Rheological characterization of bituminous binder to predict pavement rutting. Proc $6^{\text {th }}$ RILEM Symp: Performance Testing and Evaluation of Bituminous Materials, p. 117-123.

Lesueur D. (2009). The colloidal structure of bitumen: Consequences on the rheology and on the mechanisms of bitumen modification. Advances in Colloid and Interface Science $\mathrm{N}^{\mathrm{0}}$ 145: 42-82.

Ley 24449 (1995). Ley de tránsito Argentina. 72 p.

Little D. N., Jones IV D. R. (2003). Chemical and Mechanical processes of moisture damage in hot mix asphalt pavement. In Moisture Sensitive of asphalt pavement: a national seminary p. 37-70. ISBN 0-309-09450-X. 341.

Manual of Asphalt Institute - SUPERPAVE (1994). Performance Graded Asphalt Binder Specification and Testing. Superpave Series N 1(SP-1).69 p.

Manual of Asphalt Institute - SUPERPAVE (1995). Superpave level 1 mix design. Superpave Series $\mathrm{N}^{\circ} 2$ (SP-2). 119 p.

Manual of Asphalt Institute (1993). Mix design method for asphalt concrete and other hot mix types (MS-2). $141 \mathrm{p}$.

Massachusetts Highway department (1995). How vehicles load affects pavement performance. Tech note $\mathrm{N}^{\mathrm{o}} 6$ Federal Highway Administration. 4 p.

McGennis R.B., Anderson R.M., Kennedy T.W., Solaimanian M. (1995). Background of Superpave asphalt mixture design and analysis. Report FHWASA-95-003. 160 p.

Morea F., Agnusdei J., Zerbino R. (2010). Comparison of Method for Measuring Zero Shear Viscosity (ZSV) in Asphalts. Materials and Structures No 43: 499507 Doi: 10.1617/s11527-009-9506-y.

Morton B.S., Luttig E., Horak E., Visser A.T. (2004). The effect of axle load spectra and tyre inflation preassures on standard pavement design methods. Proc $8^{\text {th }}$ Conference on Asphalt Pavements for Southern Africa. ISBN 1-920-01718-6. 15 p.

NLT 173/84 (1992). Resistencia a la deformación plástica de las mezclas bituminosas mediante la pista de ensayo de laboratorio. 9 p.

Oliver, J. W., Tredrea, P. F. (1998). Relationship between Asphalt Rut Resistance and Binder Rheological Properties. Asphalt Paving technology Nº 67: 623-643.

Perraton D., Di Benedetto H., De la Roche C. (2010). Rutting of bituminous mixtures: wheel tracking tests campaign analysis. Materials and Structures. On-line DOI 10.1617/s11527-010-9680-y.

Phillips M., Robertus C. (1996). Binder Rheology and Asphaltic Pavement Permanent Deformation, the Zero Shear Viscosity Concept. Proc del $1^{\text {st }}$ Euroaspahlt and Euro bitumen congress - paper 5134 .

Pliego de especificaciones técnicas de mezclas asfálticas en caliente de bajo espesor para carpetas de rodamiento (2005). Comisión Permanente del Asfalto (CPA). Versión 3. 22 p. 
Prowell B. (1999). Development of Rutting Criteria for the Asphalt Pavement Analyzer. International Conference on Accelerated Pavement Testing. Paper CS6-4:117.

Prowell B. D., Zhang J., Brown E. R. (2005). Aggregate Properties and the Performance of Superpave - Designed Hot Mix Asphalt. NCHRP report 539. ISBN 0309-08825-9.101 p.

Romero, P. and Mogawer, W., (1998). Evaluation of the Superpave Shear Tester's Ability to Discern Two Mixtures with Different Size Aggregates using the Federal Highway Administration's Accelerated Loading Facility. Proc $77^{\text {th }}$ Annual Meeting of the Transportation Research Board.

Rowe, G.M., D’angelo, J.A. and Sharrock, M.J. (2002). Use of the Zero Shear Viscosity as a Parameter for the High Temperature Binder Specification Parameter. Applied Asphalt Binder Technology No 2.23 p.

Salem H. (2008). Effect of excess axle weights on pavement life. Emirates Journal for engineering research. $\mathrm{N}^{\mathrm{o}}$ 13: 21-28.

Shenoy A. (2001). Refinement of the SUPERPAVE Specification Parameter for Performance Grading of Asphalt. Transportation Engineer No 127: 357-362.

Shenoy, A. (2000). Validating the Generality and Predictive Ability of Unified Rheological Curves for Unmodified Paving Asphalts. Construction and Building Materials $N^{\circ} 4$ : 325-339.

Stastna J., Zonzotto L., Vacin O.J. (2003). Viscosity function in polymer-modified asphalts. Colloid and Interface Science $N^{\circ}$ 259: 200-207.

Stuart, K., Mogawer, W. and Romero, P. (2000). Evaluation of the Superpave Asphalt Binders Especification for High-Temperature Pavement Performance. Asphalt Paving technology $\mathrm{N}^{\circ}$ 69: 148-176.

Stuart, K., Mogawer, W. and Romero, P. (2000). Validation of Asphalt Binder and Mixture Test that Measure Rutting Susceptibility. Report FWHA-RD-99-204.

Superpave mixture design guide. (2001). WesTrack Forensic Team Consensus Report FHWA-RD-01-052.

Sybilski, D. (1994). Relationship between Absolute Viscosity of Polymer-modified Bitumen and Rutting Resistance of Pavement. Materials and Structures N ${ }^{\circ} 27: 110-120$.

Sybilski, D. (1996). Zero Shear Viscosity of Bituminous Binders and Its Relation to Bituminous Mixture’s resistance. Transportation Research Record No 1535: 15-21. Doi: 103141/1535-03.

Topal A., Sengoz B. (2005). Determination of fine aggregate angularity in relation with the resistance to rutting of hot-mix asphalt. Construction and Building Materials $\mathrm{N}^{0} 19$ : 155-163.

Tschoegl N. (1989). The Phenomenological Theory of Linear Viscoelastic Behavior. Springer Verlag, Berlin. 769 p. 
UNE 12697-22 (2006). Bituminous mixtures. Test method for hot mix asphalts. Part 22: Wheel tracking test. $24 \mathrm{p}$.

UNE 12697-33 (2006). Bituminous mixtures. Test method for hot mix asphalts. Part 33: specimen prepared by roller compactor. $22 \mathrm{p}$.

Wang F., Machemehl R. (2006). Predicting Truck Tire Pressure Effects Upon Pavement Performance. Research Report SWUTC/06/167864-1, Southwest Region University Transportation Center.153 p.

White T., Haddock J., Hand A., Fang H. (2002). Contributions of Pavement Structural Layers to Rutting of Hot Mix Asphalt Pavements. NCHRP report 468. 65 p.

White T., Haddock J., Rismantojo E. (2006). Aggregate Tests for Hot-Mix Asphalt Mixtures Used in Pavements. NCHRP report 557. 48 p. 


\section{Anexo I}

Ensayos de barrido de frecuencias. 

En el siguiente anexo se vuelcan los datos recopilados en los barridos de frecuencias a diferentes temperaturas de los asfaltos estudiados en forma tabular. Para cada ligante asfáltico se muestran los valores obtenidos para las condiciones de original y envejecido y a continuación los gráficos respectivos.

\section{Asfalto C1}

\begin{tabular}{|c|c|c|c|c|c|c|}
\hline & \multicolumn{3}{|c|}{ Original } & \multicolumn{3}{|c|}{ Envejecido } \\
\hline $\mathrm{T}$ & $f$ & $\mathrm{G}^{*}$ & $\delta$ & $f$ & $\mathrm{G}^{*}$ & $\delta$ \\
\hline$\left[{ }^{\circ} \mathrm{C}\right]$ & {$[\mathrm{Hz}]$} & {$[\mathrm{Pa}]$} & [o] & {$[\mathrm{Hz}]$} & {$[\mathrm{Pa}]$} & [o] \\
\hline \multirow[t]{30}{*}{10} & 10,00 & 9400000 & 46,2 & 10,00 & 28100000 & 37,9 \\
\hline & 8,89 & 8950000 & 46,6 & 9,02 & 26100000 & 38,8 \\
\hline & 7,92 & 8540000 & 47,0 & 8,14 & 24800000 & 39,4 \\
\hline & 7,02 & 8130000 & 47,4 & 7,34 & 23700000 & 39,8 \\
\hline & 6,25 & 7760000 & 47,7 & 6,63 & 22700000 & 40,3 \\
\hline & 5,54 & 7370000 & 48,1 & 5,97 & 21700000 & 40,7 \\
\hline & 4,93 & 7000000 & 48,5 & 5,38 & 20800000 & 41,1 \\
\hline & 4,38 & 6630000 & 49,0 & 4,86 & 19900000 & 41,5 \\
\hline & 3,89 & 6270000 & 49,4 & 4,38 & 19100000 & 41,8 \\
\hline & 3,46 & 5920000 & 49,8 & 3,95 & 18200000 & 42,2 \\
\hline & 3,07 & 5580000 & 50,3 & 3,56 & 17500000 & 42,5 \\
\hline & 2,73 & 5250000 & 50,7 & 3,21 & 16700000 & 42,8 \\
\hline & 2,43 & 4940000 & 51,1 & 2,90 & 16000000 & 43,2 \\
\hline & 2,15 & 4640000 & 51,5 & 2,61 & 15300000 & 43,5 \\
\hline & 1,92 & 4360000 & 52,0 & 2,36 & 14600000 & 43,9 \\
\hline & 1,70 & 4090000 & 52,5 & 2,12 & 13900000 & 44,1 \\
\hline & 1,51 & 3830000 & 52,9 & 1,92 & 13300000 & 44,5 \\
\hline & 1,34 & 3590000 & 53,3 & 1,73 & 12700000 & 44,8 \\
\hline & 1,19 & 3370000 & 53,7 & 1,56 & 12100000 & 45,1 \\
\hline & 1,06 & 3150000 & 54,2 & 1,41 & 11600000 & 45,4 \\
\hline & 0,94 & 2950000 & 54,5 & 1,27 & 11000000 & 45,7 \\
\hline & 0,84 & 2750000 & 55,0 & 1,14 & 10500000 & 46,1 \\
\hline & 0,74 & 2570000 & 55,3 & 1,03 & 9990000 & 46,4 \\
\hline & 0,66 & 2400000 & 55,9 & 0,93 & 9510000 & 46,6 \\
\hline & 0,59 & 2240000 & 56,2 & 0,84 & 9050000 & 47,0 \\
\hline & 0,52 & 2090000 & 56,6 & 0,76 & 8600000 & 47,3 \\
\hline & & & & 0,68 & 8180000 & 47,6 \\
\hline & & & & 0,62 & 7770000 & 47,9 \\
\hline & & & & 0,55 & 7380000 & 48,2 \\
\hline & & & & 0,50 & 7010000 & 48,5 \\
\hline \multirow[t]{5}{*}{20} & 10,00 & 4100000 & 53,4 & 10,00 & 9310000 & 48,0 \\
\hline & 8,89 & 3730000 & 54,3 & 9,02 & 8640000 & 48,8 \\
\hline & 7,92 & 3430000 & 55,0 & 8,14 & 8070000 & 49,3 \\
\hline & 7,02 & 3140000 & 55,7 & 7,34 & 7560000 & 49,8 \\
\hline & 6,25 & 2880000 & 56,3 & 6,63 & 7090000 & 50,2 \\
\hline
\end{tabular}




\begin{tabular}{|c|c|c|c|c|c|c|}
\hline \multirow{2}{*}{$\begin{array}{c}\mathbf{C 1} \\
\mathrm{T}\end{array}$} & \multicolumn{3}{|c|}{ Original } & \multicolumn{3}{|c|}{ Envejecido } \\
\hline & $f$ & $\mathrm{G}^{*}$ & $\delta$ & $f$ & $\mathrm{G}^{*}$ & $\delta$ \\
\hline$\left[{ }^{\circ} \mathrm{C}\right]$ & {$[\mathrm{Hz}]$} & {$[\mathrm{Pa}]$} & [o] & {$[\mathrm{Hz}]$} & {$[\mathrm{Pa}]$} & [o] \\
\hline \multirow[t]{25}{*}{20} & 5,54 & 2640000 & 56,9 & 5,97 & 6630000 & 50,6 \\
\hline & 4,93 & 2420000 & 57,4 & 5,38 & 6210000 & 51,0 \\
\hline & 4,38 & 2220000 & 57,9 & 4,86 & 5820000 & 51,5 \\
\hline & 3,89 & 2040000 & 58,4 & 4,38 & 5460000 & 51,8 \\
\hline & 3,46 & 1880000 & 58,9 & 3,95 & 5120000 & 52,2 \\
\hline & 3,07 & 1730000 & 59,3 & 3,56 & 4810000 & 52,5 \\
\hline & 2,73 & 1590000 & 59,8 & 3,21 & 4520000 & 52,9 \\
\hline & 2,43 & 1460000 & 60,3 & 2,90 & 4230000 & 53,2 \\
\hline & 2,15 & 1340000 & 60,7 & 2,61 & 3970000 & 53,6 \\
\hline & 1,92 & 1230000 & 61,2 & 2,36 & 3710000 & 53,9 \\
\hline & 1,70 & 1130000 & 61,6 & 2,12 & 3480000 & 54,2 \\
\hline & 1,51 & 1030000 & 62,1 & 1,92 & 3260000 & 54,5 \\
\hline & 1,34 & 946000 & 62,6 & 1,73 & 3050000 & 54,8 \\
\hline & 1,19 & 864000 & 63,0 & 1,56 & 2840000 & 55,2 \\
\hline & 1,06 & 791000 & 63,4 & 1,41 & 2660000 & 55,4 \\
\hline & 0,94 & 723000 & 64,0 & 1,27 & 2480000 & 55,8 \\
\hline & 0,84 & 662000 & 64,2 & 1,14 & 2320000 & 56,1 \\
\hline & 0,74 & 602000 & 64,5 & 1,03 & 2170000 & 56,5 \\
\hline & 0,66 & 549000 & 65,0 & 0,93 & 2030000 & 56,6 \\
\hline & 0,59 & 498000 & 66,1 & 0,84 & 1900000 & 56,9 \\
\hline & 0,52 & 451000 & 67,0 & 0,76 & 1770000 & 57,3 \\
\hline & & & & 0,68 & 1660000 & 57,6 \\
\hline & & & & 0,62 & 1540000 & 58,0 \\
\hline & & & & 0,55 & 1440000 & 58,2 \\
\hline & & & & 0,50 & 1340000 & 58,4 \\
\hline \multirow[t]{18}{*}{30} & 10,00 & 966000 & 64,3 & 10,00 & 2110000 & 59,8 \\
\hline & 8,89 & 865000 & 65,2 & 9,02 & 1930000 & 60,6 \\
\hline & 7,92 & 781000 & 65,8 & 8,14 & 1770000 & 61,1 \\
\hline & 7,02 & 699000 & 66,3 & 7,34 & 1630000 & 61,6 \\
\hline & 6,25 & 630000 & 66,8 & 6,63 & 1500000 & 62,0 \\
\hline & 5,54 & 567000 & 67,2 & 5,97 & 1380000 & 62,2 \\
\hline & 4,93 & 512000 & 67,5 & 5,38 & 1270000 & 62,5 \\
\hline & 4,38 & 463000 & 67,9 & 4,86 & 1170000 & 62,7 \\
\hline & 3,89 & 419000 & 68,2 & 4,38 & 1090000 & 62,9 \\
\hline & 3,46 & 380000 & 68,4 & 3,95 & 1000000 & 63,1 \\
\hline & 3,07 & 344000 & 68,7 & 3,56 & 924000 & 63,3 \\
\hline & 2,73 & 312000 & 68,9 & 3,21 & 856000 & 63,4 \\
\hline & 2,43 & 283000 & 69,0 & 2,90 & 792000 & 63,6 \\
\hline & 2,15 & 257000 & 69,5 & 2,61 & 733000 & 63,7 \\
\hline & 1,92 & 233000 & 70,0 & 2,36 & 677000 & 64,2 \\
\hline & 1,70 & 210000 & 70,4 & 2,12 & 625000 & 64,7 \\
\hline & 1,51 & 189000 & 70,9 & 1,92 & 577000 & 65,0 \\
\hline & 1,34 & 171000 & 71,3 & 1,73 & 532000 & 65,2 \\
\hline
\end{tabular}




\begin{tabular}{|c|c|c|c|c|c|c|}
\hline \multirow{2}{*}{$\begin{array}{c}\mathbf{C 1} \\
\mathrm{T}\end{array}$} & \multicolumn{3}{|c|}{ Original } & \multicolumn{3}{|c|}{ Envejecido } \\
\hline & $F$ & $\mathrm{G}^{*}$ & $\delta$ & $f$ & $\mathrm{G}^{*}$ & $\delta$ \\
\hline$\left[{ }^{\circ} \mathrm{C}\right]$ & {$[\mathrm{Hz}]$} & {$[\mathrm{Pa}]$} & [o] & {$[\mathrm{Hz}]$} & {$[\mathrm{Pa}]$} & {$[0]$} \\
\hline \multirow[t]{12}{*}{30} & 1,19 & 154000 & 72,3 & 1,56 & 489000 & 66,0 \\
\hline & 1,06 & 140000 & 71,9 & 1,41 & 452000 & 66,2 \\
\hline & 0,94 & 126000 & 73,4 & 1,27 & 418000 & 66,4 \\
\hline & 0,84 & 114000 & 74,1 & 1,14 & 385000 & 67,1 \\
\hline & 0,74 & 103000 & 74,7 & 1,03 & 352000 & 69,0 \\
\hline & 0,66 & 93800 & 75,8 & 0,93 & 325000 & 69,0 \\
\hline & 0,59 & 85600 & 79,0 & 0,84 & 303000 & 69,6 \\
\hline & 0,52 & 78600 & 82,8 & 0,76 & 278000 & 71,8 \\
\hline & & & & 0,68 & 258000 & 71,8 \\
\hline & & & & 0,62 & 236000 & 71,7 \\
\hline & & & & 0,55 & 218000 & 73,6 \\
\hline & & & & 0,50 & 201000 & 76,9 \\
\hline \multirow[t]{20}{*}{40} & 10,00 & 184000 & 73,0 & 10,00 & 219000 & 73,0 \\
\hline & 8,89 & 160000 & 73,9 & 8,89 & 195000 & 73,9 \\
\hline & 7,87 & 142000 & 74,7 & 7,87 & 177000 & 74,7 \\
\hline & 6,96 & 125000 & 75,4 & 6,96 & 160000 & 75,4 \\
\hline & 6,17 & 110000 & 76,1 & 6,17 & 146000 & 76,1 \\
\hline & 5,47 & 97900 & 76,6 & 5,47 & 132000 & 76,6 \\
\hline & 4,84 & 87400 & 77,2 & 4,84 & 120000 & 77,2 \\
\hline & 4,29 & 78300 & 77,7 & 4,29 & 109000 & 77,7 \\
\hline & 3,80 & 70500 & 78,2 & 3,80 & 98900 & 78,2 \\
\hline & 3,36 & 63500 & 78,6 & 3,36 & 89600 & 78,6 \\
\hline & 2,98 & 57300 & 79,1 & 2,98 & 81200 & 79,1 \\
\hline & 2,64 & 51700 & 79,5 & 2,64 & 73600 & 79,5 \\
\hline & 2,34 & 46700 & 79,8 & 2,34 & 66600 & 79,8 \\
\hline & 2,07 & 42100 & 80,2 & 2,07 & 60200 & 80,2 \\
\hline & 1,83 & 38000 & 80,5 & 1,83 & 54400 & 80,5 \\
\hline & 1,62 & 34300 & 80,9 & 1,62 & 49200 & 80,9 \\
\hline & 1,44 & 30900 & 81,2 & 1,44 & 44400 & 81,2 \\
\hline & 1,27 & 27800 & 81,5 & 1,27 & 40100 & 81,5 \\
\hline & 1,13 & 25000 & 81,8 & 1,13 & 36100 & 81,8 \\
\hline & 1,00 & 22500 & 82,0 & 1,00 & 32500 & 82,0 \\
\hline \multirow[t]{11}{*}{50} & 10,00 & 37600 & 81,1 & 10,00 & 49900 & 81,1 \\
\hline & 8,89 & 33600 & 81,4 & 8,89 & 45000 & 81,4 \\
\hline & 7,87 & 29900 & 81,8 & 7,87 & 39900 & 81,8 \\
\hline & 6,96 & 26700 & 82,1 & 6,96 & 35800 & 82,1 \\
\hline & 6,17 & 23900 & 82,4 & 6,17 & 32200 & 82,4 \\
\hline & 5,47 & 21300 & 82,7 & 5,47 & 28900 & 82,7 \\
\hline & 4,84 & 18900 & 82,9 & 4,84 & 26000 & 82,9 \\
\hline & 4,29 & 16800 & 83,2 & 4,29 & 23300 & 83,2 \\
\hline & 3,80 & 14900 & 83,4 & 3,80 & 21000 & 83,4 \\
\hline & 3,36 & 13200 & 83,6 & 3,36 & 18800 & 83,6 \\
\hline & 2,98 & 11700 & 83,8 & 2,98 & 16800 & 83,8 \\
\hline
\end{tabular}




\begin{tabular}{|c|c|c|c|c|c|c|}
\hline \multirow{2}{*}{$\frac{\mathbf{C 1}}{\mathrm{T}}$} & \multicolumn{3}{|c|}{ Original } & \multicolumn{3}{|c|}{ Envejecido } \\
\hline & $f$ & $\mathrm{G}^{*}$ & $\delta$ & $f$ & $\mathrm{G}^{*}$ & $\delta$ \\
\hline$\left[{ }^{\circ} \mathrm{C}\right]$ & {$[\mathrm{Hz}]$} & {$[\mathrm{Pa}]$} & [o] & {$[\mathrm{Hz}]$} & {$[\mathrm{Pa}]$} & {$[0]$} \\
\hline \multirow[t]{9}{*}{50} & 2,64 & 10400 & 84,0 & 2,64 & 15100 & 84,0 \\
\hline & 2,34 & 9260 & 84,1 & 2,34 & 13500 & 84,1 \\
\hline & 2,07 & 8250 & 84,3 & 2,07 & 12100 & 84,3 \\
\hline & 1,83 & 7410 & 84,4 & 1,83 & 10800 & 84,4 \\
\hline & 1,62 & 6660 & 84,5 & 1,62 & 9660 & 84,5 \\
\hline & 1,44 & 5910 & 84,7 & 1,44 & 8620 & 84,7 \\
\hline & 1,27 & 5250 & 84,9 & 1,27 & 7690 & 84,9 \\
\hline & 1,13 & 4650 & 85,1 & 1,13 & 6860 & 85,1 \\
\hline & 1,00 & 4130 & 85,3 & 1,00 & 6100 & 85,3 \\
\hline \multirow[t]{20}{*}{60} & 10,00 & 9410 & 83,0 & 10,00 & 13100 & 83,0 \\
\hline & 8,89 & 8580 & 83,3 & 8,89 & 11800 & 83,3 \\
\hline & 7,87 & 7490 & 83,6 & 7,87 & 10500 & 83,6 \\
\hline & 6,96 & 6850 & 84,0 & 6,96 & 9340 & 84,0 \\
\hline & 6,17 & 6040 & 84,2 & 6,17 & 8340 & 84,2 \\
\hline & 5,47 & 5310 & 84,2 & 5,47 & 7420 & 84,2 \\
\hline & 4,84 & 4690 & 84,2 & 4,84 & 6600 & 84,2 \\
\hline & 4,29 & 4150 & 84,2 & 4,29 & 5860 & 84,2 \\
\hline & 3,80 & 3640 & 84,0 & 3,80 & 5210 & 84,0 \\
\hline & 3,36 & 3240 & 84,1 & 3,36 & 4630 & 84,1 \\
\hline & 2,98 & 2880 & 83,8 & 2,98 & 4110 & 83,8 \\
\hline & 2,64 & 2550 & 83,7 & 2,64 & 3650 & 83,7 \\
\hline & 2,34 & 2260 & 83,6 & 2,34 & 3250 & 83,6 \\
\hline & 2,07 & 2000 & 84,4 & 2,07 & 2880 & 84,4 \\
\hline & 1,83 & 1790 & 85,8 & 1,83 & 2570 & 85,8 \\
\hline & 1,62 & 1580 & 86,4 & 1,62 & 2280 & 86,4 \\
\hline & 1,44 & 1400 & 87,7 & 1,44 & 2030 & 87,7 \\
\hline & 1,27 & 1260 & 89,4 & 1,27 & 1810 & 89,4 \\
\hline & 1,13 & 1130 & 88,8 & 1,13 & 1610 & 88,8 \\
\hline & 1,00 & 1050 & 89,9 & 1,00 & 1460 & 89,9 \\
\hline \multirow[t]{13}{*}{70} & 10,00 & 2990 & 86,3 & 10,00 & 3760 & 86,3 \\
\hline & 8,89 & 2620 & 85,1 & 8,89 & 3410 & 85,1 \\
\hline & 7,87 & 2340 & 84,6 & 7,87 & 3030 & 84,6 \\
\hline & 6,96 & 2090 & 83,8 & 6,96 & 2680 & 83,8 \\
\hline & 6,17 & 1910 & 83,7 & 6,17 & 2390 & 83,7 \\
\hline & 5,47 & 1690 & 83,4 & 5,47 & 2140 & 83,4 \\
\hline & 4,84 & 1520 & 83,6 & 4,84 & 1880 & 83,6 \\
\hline & 4,29 & 1350 & 82,9 & 4,29 & 1650 & 82,9 \\
\hline & 3,80 & 1180 & 82,5 & 3,80 & 1450 & 82,5 \\
\hline & 3,36 & 1030 & 81,8 & 3,36 & 1280 & 81,8 \\
\hline & 2,98 & 905 & 80,9 & 2,98 & 1130 & 80,9 \\
\hline & 2,64 & 790 & 80,1 & 2,64 & 966 & 80,1 \\
\hline & 2,34 & 697 & 79,7 & 2,34 & 843 & 79,7 \\
\hline
\end{tabular}



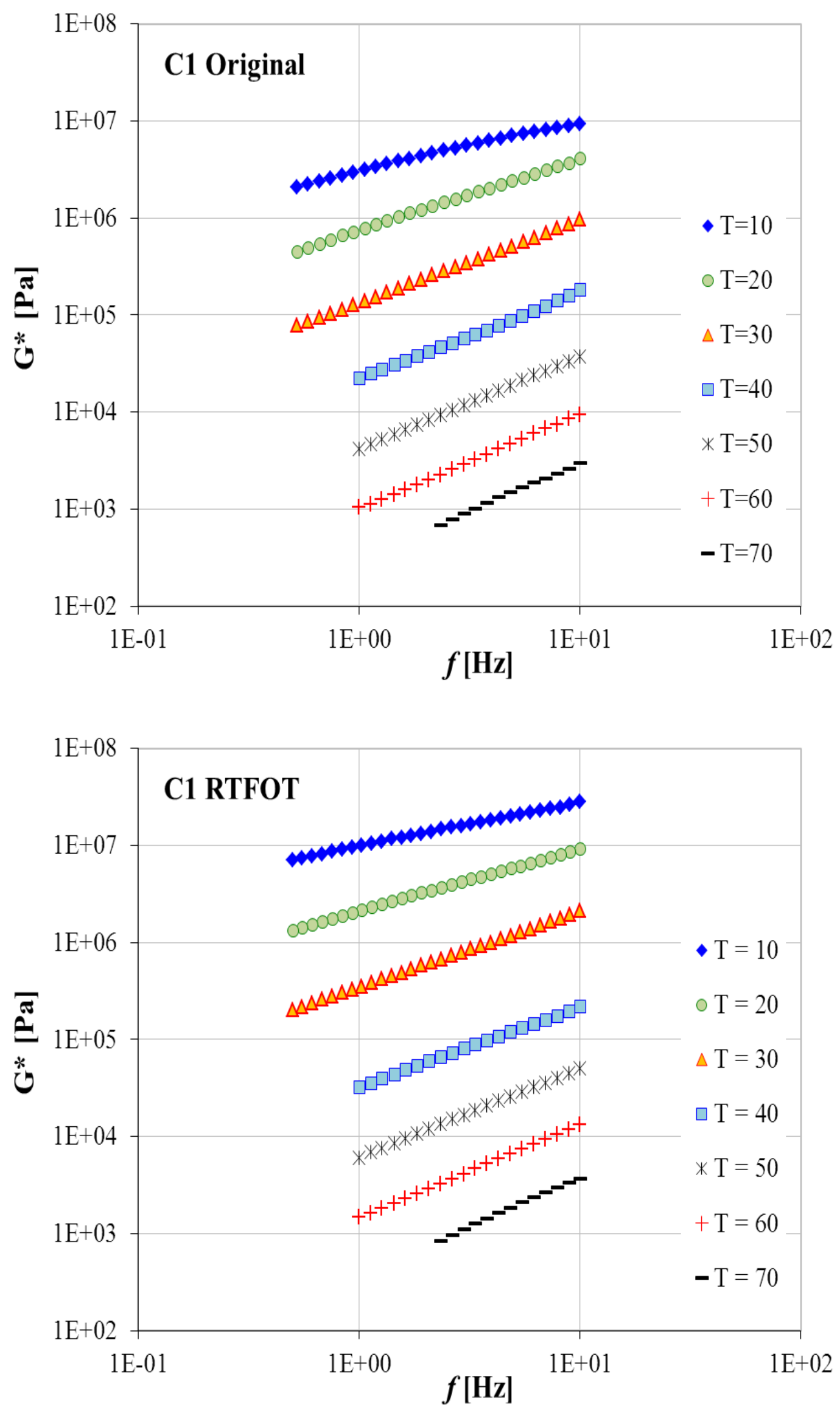
Asfalto C2

\begin{tabular}{|c|c|c|c|c|c|c|}
\hline & \multicolumn{3}{|c|}{ Original } & \multicolumn{3}{|c|}{ Envejecido } \\
\hline $\mathrm{T}$ & $f$ & $\mathrm{G}^{*}$ & $\delta$ & $f$ & $\mathrm{G}^{*}$ & $\delta$ \\
\hline$\left[{ }^{\circ} \mathrm{C}\right]$ & {$[\mathrm{Hz}]$} & {$[\mathrm{Pa}]$} & [o] & {$[\mathrm{Hz}]$} & {$[\mathrm{Pa}]$} & [o] \\
\hline \multirow[t]{30}{*}{10} & 10,00 & 30800000 & 42,1 & 10,00 & 56700000 & 33,7 \\
\hline & 9,02 & 29400000 & 42,7 & 9,02 & 54200000 & 34,3 \\
\hline & 8,14 & 28300000 & 43,1 & 8,14 & 52200000 & 34,8 \\
\hline & 7,34 & 27300000 & 43,4 & 7,34 & 50400000 & 35,2 \\
\hline & 6,63 & 26200000 & 43,8 & 6,63 & 48600000 & 35,6 \\
\hline & 5,97 & 25200000 & 44,3 & 5,97 & 46800000 & 36,0 \\
\hline & 5,38 & 24200000 & 44,7 & 5,38 & 45100000 & 36,4 \\
\hline & 4,86 & 23200000 & 45,1 & 4,86 & 43400000 & 36,7 \\
\hline & 4,38 & 22200000 & 45,5 & 4,38 & 41800000 & 37,1 \\
\hline & 3,95 & 21300000 & 45,9 & 3,95 & 40100000 & 37,5 \\
\hline & 3,56 & 20300000 & 46,4 & 3,56 & 38500000 & 37,9 \\
\hline & 3,21 & 19400000 & 46,8 & 3,21 & 37000000 & 38,3 \\
\hline & 2,90 & 18500000 & 47,2 & 2,90 & 35500000 & 38,7 \\
\hline & 2,61 & 17600000 & 47,7 & 2,61 & 34100000 & 39,1 \\
\hline & 2,36 & 16800000 & 48,1 & 2,36 & 32700000 & 39,4 \\
\hline & 2,12 & 16000000 & 48,5 & 2,12 & 31300000 & 39,8 \\
\hline & 1,92 & 15200000 & 48,9 & 1,92 & 30000000 & 40,2 \\
\hline & 1,73 & 14500000 & 49,3 & 1,73 & 28700000 & 40,6 \\
\hline & 1,56 & 13800000 & 49,7 & 1,56 & 27500000 & 41,0 \\
\hline & 1,41 & 13100000 & 50,1 & 1,41 & 26300000 & 41,4 \\
\hline & 1,27 & 12500000 & 50,5 & 1,27 & 25200000 & 41,8 \\
\hline & 1,14 & 11800000 & 50,9 & 1,14 & 24100000 & 42,2 \\
\hline & 1,03 & 11200000 & 51,3 & 1,03 & 23000000 & 42,6 \\
\hline & 0,93 & 10700000 & 51,7 & 0,93 & 22000000 & 43,0 \\
\hline & 0,84 & 10100000 & 52,1 & 0,84 & 21000000 & 43,4 \\
\hline & 0,76 & 9580000 & 52,5 & 0,76 & 20000000 & 43,8 \\
\hline & 0,68 & 9070000 & 52,9 & 0,68 & 19100000 & 44,2 \\
\hline & 0,62 & 8570000 & 53,3 & 0,62 & 18200000 & 44,6 \\
\hline & 0,55 & 8100000 & 53,7 & 0,55 & 17300000 & 45,0 \\
\hline & 0,50 & 7650000 & 54,1 & 0,50 & 16500000 & 45,4 \\
\hline \multirow[t]{8}{*}{20} & 10,00 & 11400000 & 52,5 & 10,00 & 20400000 & 44,7 \\
\hline & 9,02 & 10400000 & 53,5 & 9,02 & 19100000 & 45,5 \\
\hline & 8,14 & 9650000 & 54,2 & 8,14 & 17900000 & 46,1 \\
\hline & 7,34 & 8960000 & 54,8 & 7,34 & 16900000 & 46,6 \\
\hline & 6,63 & 8330000 & 55,3 & 6,63 & 16000000 & 47,1 \\
\hline & 5,97 & 7750000 & 55,9 & 5,97 & 15000000 & 47,5 \\
\hline & 5,38 & 7230000 & 56,4 & 5,38 & 14200000 & 48,0 \\
\hline & 4,86 & 6750000 & 56,8 & 4,86 & 13400000 & 48,4 \\
\hline
\end{tabular}




\begin{tabular}{|c|c|c|c|c|c|c|}
\hline \multirow{2}{*}{$\begin{array}{c}\mathbf{C} 2 \\
\mathrm{~T}\end{array}$} & \multicolumn{3}{|c|}{ Original } & \multicolumn{3}{|c|}{ Envejecido } \\
\hline & $f$ & $\mathrm{G}^{*}$ & $\delta$ & $f$ & $\mathrm{G}^{*}$ & $\delta$ \\
\hline$\left[{ }^{\circ} \mathrm{C}\right]$ & {$[\mathrm{Hz}]$} & {$[\mathrm{Pa}]$} & [o] & {$[\mathrm{Hz}]$} & {$[\mathrm{Pa}]$} & [o] \\
\hline \multirow[t]{20}{*}{20} & 4,38 & 6300000 & 57,3 & 4,38 & 12600000 & 48,9 \\
\hline & 3,21 & 5130000 & 58,5 & 3,21 & 10700000 & 50,1 \\
\hline & 2,90 & 4810000 & 58,9 & 2,90 & 10100000 & 50,6 \\
\hline & 2,61 & 4500000 & 59,2 & 2,61 & 9490000 & 51,0 \\
\hline & 2,36 & 4200000 & 59,6 & 2,36 & 8950000 & 51,4 \\
\hline & 2,12 & 3920000 & 59,9 & 2,12 & 8430000 & 51,8 \\
\hline & 1,92 & 3660000 & 60,3 & 1,92 & 7950000 & 52,2 \\
\hline & 1,73 & 3410000 & 60,6 & 1,73 & 7490000 & 52,6 \\
\hline & 1,56 & 3180000 & 60,9 & 1,56 & 7040000 & 53,1 \\
\hline & 1,41 & 2960000 & 61,3 & 1,41 & 6630000 & 53,4 \\
\hline & 1,27 & 2760000 & 61,5 & 1,27 & 6240000 & 53,8 \\
\hline & 1,14 & 2580000 & 61,8 & 1,14 & 5870000 & 54,2 \\
\hline & 1,03 & 2390000 & 62,1 & 1,03 & 5520000 & 54,5 \\
\hline & 0,93 & 2230000 & 62,4 & 0,93 & 5180000 & 55,0 \\
\hline & 0,84 & 2070000 & 62,6 & 0,84 & 4870000 & 55,4 \\
\hline & 0,76 & 1930000 & 62,8 & 0,76 & 4570000 & 55,7 \\
\hline & 0,68 & 1790000 & 63,0 & 0,68 & 4290000 & 56,1 \\
\hline & 0,62 & 1660000 & 63,2 & 0,62 & 4020000 & 56,4 \\
\hline & 0,55 & 1550000 & 63,4 & 0,55 & 3770000 & 56,7 \\
\hline & 0,50 & 1450000 & 63,8 & 0,50 & 3520000 & 57,1 \\
\hline \multirow[t]{21}{*}{30} & 10,00 & 1638956 & 63,6 & 10,00 & 4750000 & 57,5 \\
\hline & 9,02 & 1512158 & 64,4 & 9,02 & 4330000 & 58,3 \\
\hline & 8,14 & 1395699 & 64,7 & 8,14 & 3990000 & 58,9 \\
\hline & 7,34 & 1287408 & 65,1 & 7,34 & 3690000 & 59,5 \\
\hline & 6,63 & 1189113 & 65,4 & 6,63 & 3420000 & 60,0 \\
\hline & 5,97 & 1095647 & 65,7 & 5,97 & 3160000 & 60,5 \\
\hline & 5,38 & 1010158 & 65,9 & 5,38 & 2930000 & 60,9 \\
\hline & 4,86 & 933092 & 66,2 & 4,86 & 2720000 & 61,3 \\
\hline & 4,38 & 860332 & 66,5 & 4,38 & 2520000 & 61,8 \\
\hline & 3,95 & 793653 & 66,7 & 3,95 & 2350000 & 62,1 \\
\hline & 3,56 & 731787 & 66,8 & 3,56 & 2180000 & 62,5 \\
\hline & 3,21 & 674988 & 66,9 & 3,21 & 2030000 & 62,9 \\
\hline & 2,90 & 623536 & 66,9 & 2,90 & 1880000 & 63,3 \\
\hline & 2,61 & 574300 & 67,0 & 2,61 & 1750000 & 63,6 \\
\hline & 2,36 & 530884 & 67,0 & 2,36 & 1620000 & 64,0 \\
\hline & 2,12 & 490000 & 67,0 & 2,12 & 1510000 & 64,4 \\
\hline & 1,92 & 450000 & 67,0 & 1,92 & 1400000 & 64,8 \\
\hline & 1,73 & 414000 & 66,8 & 1,73 & 1300000 & 65,3 \\
\hline & 1,56 & 381000 & 66,7 & 1,56 & 1200000 & 65,6 \\
\hline & 1,41 & 350000 & 66,6 & 1,41 & 1110000 & 65,9 \\
\hline & 1,27 & 323000 & 66,5 & 1,27 & 1030000 & 66,4 \\
\hline
\end{tabular}




\begin{tabular}{|c|c|c|c|c|c|c|}
\hline \multirow{2}{*}{$\begin{array}{c}\mathbf{C 2} \\
\mathrm{T}\end{array}$} & \multicolumn{3}{|c|}{ Original } & \multicolumn{3}{|c|}{ Envejecido } \\
\hline & $f$ & $\mathrm{G}^{*}$ & $\delta$ & $f$ & $\mathrm{G}^{*}$ & $\delta$ \\
\hline$\left[{ }^{\circ} \mathrm{C}\right]$ & {$[\mathrm{Hz}]$} & {$[\mathrm{Pa}]$} & [o] & {$[\mathrm{Hz}]$} & {$[\mathrm{Pa}]$} & [o] \\
\hline \multirow[t]{9}{*}{30} & 1,14 & 297000 & 66,4 & 1,14 & 955000 & 66,6 \\
\hline & 1,03 & 275000 & 66,2 & 1,03 & 883000 & 67,0 \\
\hline & 0,93 & 255000 & 66,0 & 0,93 & 817000 & 67,4 \\
\hline & 0,84 & 236000 & 65,8 & 0,84 & 756000 & 67,9 \\
\hline & 0,76 & 218000 & 65,1 & 0,76 & 699000 & 68,0 \\
\hline & 0,68 & 202000 & 64,8 & 0,68 & 645000 & 68,6 \\
\hline & 0,62 & 187000 & 64,9 & 0,62 & 597000 & 68,8 \\
\hline & 0,55 & 173000 & 64,0 & 0,55 & 550000 & 69,6 \\
\hline & 0,50 & 161000 & 63,6 & 0,50 & 508000 & 69,5 \\
\hline \multirow[t]{20}{*}{40} & 10,00 & 294000 & 64,8 & 10,00 & 339000 & 57,5 \\
\hline & 8,89 & 263000 & 66,4 & 8,89 & 306000 & 59,2 \\
\hline & 7,87 & 237000 & 67,8 & 7,87 & 277000 & 60,7 \\
\hline & 6,96 & 213000 & 69,1 & 6,96 & 251000 & 62,1 \\
\hline & 6,17 & 192000 & 70,3 & 6,17 & 228000 & 63,3 \\
\hline & 5,47 & 171000 & 71,4 & 5,47 & 207000 & 64,4 \\
\hline & 4,84 & 152000 & 72,4 & 4,84 & 188000 & 65,5 \\
\hline & 4,29 & 135000 & 73,3 & 4,29 & 171000 & 66,4 \\
\hline & 3,80 & 121000 & 74,1 & 3,80 & 155000 & 67,3 \\
\hline & 3,36 & 108000 & 74,8 & 3,36 & 141000 & 68,1 \\
\hline & 2,98 & 97500 & 75,4 & 2,98 & 128000 & 68,9 \\
\hline & 2,64 & 87600 & 76,0 & 2,64 & 116000 & 69,6 \\
\hline & 2,34 & 78900 & 76,6 & 2,34 & 106000 & 70,3 \\
\hline & 2,07 & 71100 & 77,1 & 2,07 & 96100 & 70,9 \\
\hline & 1,83 & 64100 & 77,6 & 1,83 & 87200 & 71,5 \\
\hline & 1,62 & 57800 & 78,0 & 1,62 & 79200 & 72,1 \\
\hline & 1,44 & 52200 & 78,4 & 1,44 & 71900 & 72,7 \\
\hline & 1,27 & 47100 & 78,8 & 1,27 & 65100 & 73,2 \\
\hline & 1,13 & 42500 & 79,1 & 1,13 & 59100 & 73,7 \\
\hline & 1,00 & 38400 & 79,5 & 1,00 & 53500 & 74,1 \\
\hline \multirow[t]{12}{*}{50} & 10,00 & 64000 & 78,8 & 10,00 & 78000 & 73,7 \\
\hline & 8,89 & 56900 & 79,3 & 8,89 & 69900 & 74,4 \\
\hline & 7,87 & 50600 & 79,7 & 7,87 & 62800 & 74,9 \\
\hline & 6,96 & 45200 & 80,1 & 6,96 & 56400 & 75,4 \\
\hline & 6,17 & 40500 & 80,5 & 6,17 & 50800 & 75,9 \\
\hline & 5,47 & 36300 & 80,8 & 5,47 & 45700 & 76,4 \\
\hline & 4,84 & 32400 & 81,1 & 4,84 & 41100 & 76,8 \\
\hline & 4,29 & 29000 & 81,3 & 4,29 & 37000 & 77,2 \\
\hline & 3,80 & 26000 & 81,5 & 3,80 & 33300 & 77,6 \\
\hline & 3,36 & 23200 & 81,7 & 3,36 & 29900 & 78,0 \\
\hline & 2,98 & 20800 & 81,9 & 2,98 & 26900 & 78,3 \\
\hline & 2,64 & 18600 & 82,1 & 2,64 & 24200 & 78,7 \\
\hline
\end{tabular}




\begin{tabular}{|c|c|c|c|c|c|c|}
\hline \multirow{2}{*}{$\begin{array}{c}\mathbf{C} 2 \\
\mathrm{~T}\end{array}$} & \multicolumn{3}{|c|}{ Original } & \multicolumn{3}{|c|}{ Envejecido } \\
\hline & $f$ & $\mathrm{G}^{*}$ & $\delta$ & $f$ & $\mathrm{G}^{*}$ & $\delta$ \\
\hline \multirow[t]{9}{*}[{}^{\circ}\mathrm{C}]{} & {$[\mathrm{Hz}]$} & {$[\mathrm{Pa}]$} & [o] & {$[\mathrm{Hz}]$} & {$[\mathrm{Pa}]$} & [o] \\
\hline & 2,34 & 16600 & 82,2 & 2,34 & 21700 & 79,0 \\
\hline & 2,07 & 14800 & 82,3 & 2,07 & 19500 & 79,3 \\
\hline & 1,83 & 13200 & 82,3 & 1,83 & 17500 & 79,6 \\
\hline & 1,62 & 11800 & 82,3 & 1,62 & 15700 & 79,9 \\
\hline & 1,44 & 10500 & 82,3 & 1,44 & 14100 & 80,2 \\
\hline & 1,27 & 9410 & 82,3 & 1,27 & 12600 & 80,5 \\
\hline & 1,13 & 8400 & 82,1 & 1,13 & 11300 & 80,7 \\
\hline & 1,00 & 7490 & 82,0 & 1,00 & 10100 & 81,0 \\
\hline \multirow[t]{20}{*}{60} & 10,00 & 12000 & 83,2 & 10,00 & 19300 & 79,8 \\
\hline & 8,89 & 10700 & 83,7 & 8,89 & 17300 & 80,2 \\
\hline & 7,87 & 9480 & 83,9 & 7,87 & 15500 & 80,5 \\
\hline & 6,96 & 8390 & 84,1 & 6,96 & 13800 & 80,9 \\
\hline & 6,17 & 7440 & 84,2 & 6,17 & 12400 & 81,2 \\
\hline & 5,47 & 6590 & 84,3 & 5,47 & 11000 & 81,5 \\
\hline & 4,84 & 5840 & 84,5 & 4,84 & 9860 & 81,7 \\
\hline & 4,29 & 5180 & 84,5 & 4,29 & 8790 & 81,9 \\
\hline & 3,80 & 4580 & 84,5 & 3,80 & 7840 & 82,2 \\
\hline & 3,36 & 4050 & 84,5 & 3,36 & 6970 & 82,4 \\
\hline & 2,98 & 3580 & 84,6 & 2,98 & 6200 & 82,6 \\
\hline & 2,64 & 3170 & 84,4 & 2,64 & 5520 & 82,7 \\
\hline & 2,34 & 2800 & 84,5 & 2,34 & 4910 & 83,0 \\
\hline & 2,07 & 2470 & 85,2 & 2,07 & 4360 & 83,2 \\
\hline & 1,83 & 2170 & 85,1 & 1,83 & 3870 & 83,8 \\
\hline & 1,62 & 1920 & 86,0 & 1,62 & 3430 & 84,4 \\
\hline & 1,44 & 1700 & 87,1 & 1,44 & 3030 & 84,4 \\
\hline & 1,27 & 1510 & 88,6 & 1,27 & 2640 & 85,4 \\
\hline & 1,13 & 1330 & 88,0 & 1,13 & 2230 & 89,0 \\
\hline & 1,00 & 1210 & 89,9 & 1,00 & 1960 & 88,5 \\
\hline \multirow[t]{13}{*}{70} & 10,00 & 4380 & 80,4 & 10,00 & 5570 & 84,2 \\
\hline & 8,89 & 4010 & 79,9 & 8,89 & 5050 & 84,1 \\
\hline & 7,87 & 3560 & 79,2 & 7,87 & 4500 & 84,1 \\
\hline & 6,96 & 3150 & 78,3 & 6,96 & 4000 & 84,1 \\
\hline & 6,17 & 2810 & 77,4 & 6,17 & 3550 & 84,1 \\
\hline & 5,47 & 2500 & 76,5 & 5,47 & 3140 & 84,0 \\
\hline & 4,84 & 2240 & 75,4 & 4,84 & 2760 & 84,0 \\
\hline & 4,29 & 2010 & 74,0 & 4,29 & 2430 & 83,8 \\
\hline & 3,80 & 1810 & 72,6 & 3,80 & 2140 & 83,5 \\
\hline & 3,36 & 1630 & 71,0 & 3,36 & 1880 & 83,1 \\
\hline & 2,98 & 1470 & 69,2 & 2,98 & 1650 & 82,8 \\
\hline & & & & 2,64 & 1440 & 82,5 \\
\hline & & & & 2,34 & 1230 & 82,8 \\
\hline
\end{tabular}


DEFORMACIONES PERMANENTES EN MEZCLAS ASFÁLTICAS.

Efecto de la reología de los asfaltos, la temperatura y las condiciones de carga

\begin{tabular}{ccccccc}
\hline C2 & & Original & & \multicolumn{3}{c}{ Envejecido } \\
\hline $\mathrm{T}$ & $f$ & $\mathrm{G}^{*}$ & $\delta$ & $f$ & $\mathrm{G}^{*}$ & $\delta$ \\
{$\left[{ }^{\circ} \mathrm{C}\right]$} & {$[\mathrm{Hz}]$} & {$[\mathrm{Pa}]$} & {$[\mathrm{o}]$} & {$[\mathrm{Hz}]$} & {$[\mathrm{Pa}]$} & {$[\mathrm{o}]$} \\
\hline & & & 2,07 & 1070 & 88,3 \\
& & & 1,83 & 906 & 89,9 \\
& & & 1,62 & 771 & 89,8 \\
\hline
\end{tabular}



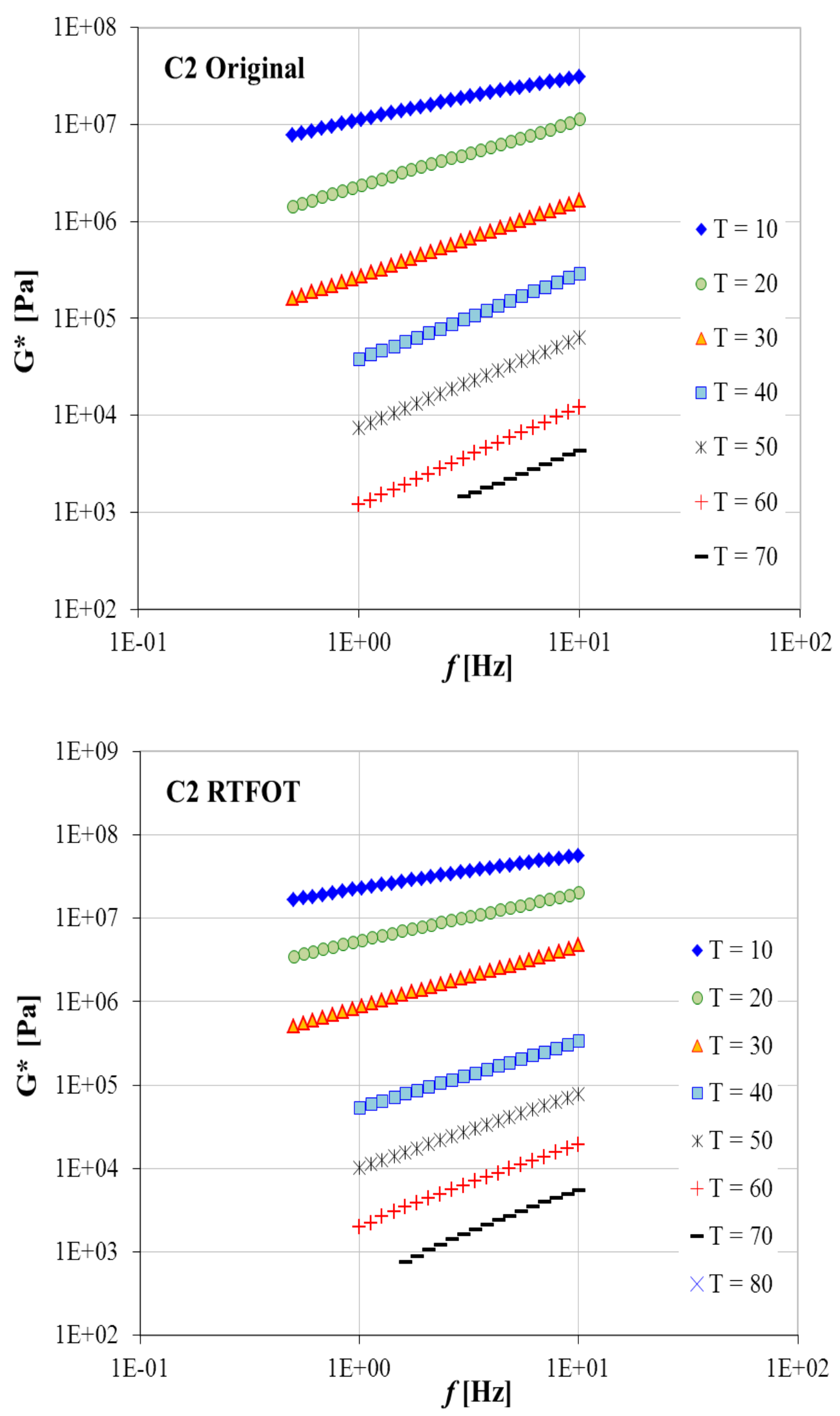
Asfalto C3

\begin{tabular}{|c|c|c|c|c|c|c|}
\hline & \multicolumn{3}{|c|}{ Original } & \multicolumn{3}{|c|}{ Envejecido } \\
\hline $\mathrm{T}$ & $f$ & $\mathrm{G}^{*}$ & $\delta$ & $f$ & $\mathrm{G}^{*}$ & $\delta$ \\
\hline$\left[{ }^{\circ} \mathrm{C}\right]$ & {$[\mathrm{Hz}]$} & {$[\mathrm{Pa}]$} & [o] & {$[\mathrm{Hz}]$} & {$[\mathrm{Pa}]$} & [o] \\
\hline \multirow[t]{30}{*}{10} & 10,00 & 36500000 & 38,4 & 10,00 & 45600000 & 33,7 \\
\hline & 8,86 & 33300000 & 39,6 & 9,02 & 43200000 & 34,4 \\
\hline & 7,79 & 30900000 & 40,5 & 8,14 & 41400000 & 34,9 \\
\hline & 6,88 & 29000000 & 41,4 & 7,34 & 39600000 & 35,4 \\
\hline & 6,08 & 27300000 & 42,2 & 6,63 & 37900000 & 35,9 \\
\hline & 5,37 & 25900000 & 42,8 & 5,97 & 36300000 & 36,3 \\
\hline & 4,73 & 24600000 & 43,4 & 5,38 & 34900000 & 36,7 \\
\hline & 4,17 & 23400000 & 44,0 & 4,86 & 33600000 & 37,1 \\
\hline & 3,69 & 22300000 & 44,4 & 4,38 & 32300000 & 37,5 \\
\hline & 3,25 & 21200000 & 44,9 & 3,95 & 31000000 & 37,9 \\
\hline & 2,87 & 20200000 & 45,2 & 3,56 & 29900000 & 38,3 \\
\hline & 2,53 & 19200000 & 45,6 & 3,21 & 28700000 & 38,6 \\
\hline & 2,24 & 18300000 & 46,0 & 2,90 & 27600000 & 39,0 \\
\hline & 1,97 & 17300000 & 46,3 & 2,61 & 26500000 & 39,3 \\
\hline & 1,74 & 16400000 & 46,6 & 2,36 & 25500000 & 40,0 \\
\hline & 1,54 & 15600000 & 47,0 & 2,12 & 24500000 & 40,0 \\
\hline & 1,36 & 14700000 & 47,0 & 1,92 & 23500000 & 40,0 \\
\hline & 1,20 & 13900000 & 48,0 & 1,73 & 22500000 & 41,0 \\
\hline & 1,06 & 13100000 & 48,0 & 1,56 & 21600000 & 41,0 \\
\hline & 0,93 & 12400000 & 48,0 & 1,41 & 20700000 & 41,0 \\
\hline & 0,82 & 11700000 & 48,8 & 1,27 & 19800000 & 41,5 \\
\hline & 0,73 & 11000000 & 49,2 & 1,14 & 18900000 & 41,9 \\
\hline & 0,64 & 10300000 & 49,6 & 1,03 & 18100000 & 42,2 \\
\hline & 0,57 & 9690000 & 50,0 & 0,93 & 17300000 & 42,6 \\
\hline & 0,50 & 9090000 & 50,5 & 0,84 & 16500000 & 43,0 \\
\hline & & & & 0,76 & 15800000 & 43,3 \\
\hline & & & & 0,68 & 15100000 & 43,7 \\
\hline & & & & 0,62 & 14400000 & 44,0 \\
\hline & & & & 0,55 & 13700000 & 44,4 \\
\hline & & & & 0,50 & 13100000 & 44,7 \\
\hline \multirow[t]{8}{*}{20} & 10,00 & 16200000 & 46,6 & 10,00 & 15700000 & 44,5 \\
\hline & 8,86 & 14800000 & 47,5 & 9,02 & 14600000 & 45,2 \\
\hline & 7,79 & 13600000 & 48,2 & 8,14 & 13800000 & 45,7 \\
\hline & 6,88 & 12500000 & 48,9 & 7,34 & 13000000 & 46,2 \\
\hline & 6,08 & 11600000 & 49,5 & 6,63 & 12200000 & 46,7 \\
\hline & 5,37 & 10700000 & 50,1 & 5,97 & 11500000 & 47,1 \\
\hline & 4,73 & 9900000 & 50,7 & 5,38 & 10900000 & 47,6 \\
\hline & 4,17 & 9160000 & 51,3 & 4,86 & 10300000 & 48,0 \\
\hline
\end{tabular}




\begin{tabular}{|c|c|c|c|c|c|c|}
\hline \multirow{2}{*}{$\begin{array}{c}\text { C3 } \\
\mathrm{T}\end{array}$} & \multicolumn{3}{|c|}{ Original } & \multicolumn{3}{|c|}{ Envejecido } \\
\hline & $f$ & $\mathrm{G}^{*}$ & $\delta$ & $f$ & $\mathrm{G}^{*}$ & $\delta$ \\
\hline$\left[{ }^{\circ} \mathrm{C}\right]$ & {$[\mathrm{Hz}]$} & {$[\mathrm{Pa}]$} & [o] & {$[\mathrm{Hz}]$} & {$[\mathrm{Pa}]$} & [o] \\
\hline \multirow[t]{22}{*}{20} & 3,69 & 8480000 & 51,9 & 4,38 & 9710000 & 48,4 \\
\hline & 3,25 & 7840000 & 52,4 & 3,95 & 9170000 & 48,8 \\
\hline & 2,87 & 7260000 & 52,9 & 3,56 & 8670000 & 49,2 \\
\hline & 2,53 & 6710000 & 53,4 & 3,21 & 8180000 & 49,6 \\
\hline & 2,24 & 6210000 & 53,9 & 2,90 & 7720000 & 50,0 \\
\hline & 1,97 & 5730000 & 54,5 & 2,61 & 7290000 & 50,4 \\
\hline & 1,74 & 5290000 & 54,9 & 2,36 & 6890000 & 50,8 \\
\hline & 1,54 & 4870000 & 55,5 & 2,12 & 6500000 & 51,1 \\
\hline & 1,36 & 4480000 & 56,1 & 1,92 & 6130000 & 51,5 \\
\hline & 1,20 & 4130000 & 56,6 & 1,73 & 5780000 & 51,8 \\
\hline & 1,06 & 3790000 & 57,1 & 1,56 & 5450000 & 52,2 \\
\hline & 0,93 & 3480000 & 57,6 & 1,41 & 5120000 & 53,0 \\
\hline & 0,82 & 3200000 & 58,2 & 1,27 & 4820000 & 53,0 \\
\hline & 0,73 & 2930000 & 58,8 & 1,14 & 4540000 & 53,0 \\
\hline & 0,64 & 2690000 & 59,4 & 1,03 & 4270000 & 54,0 \\
\hline & 0,57 & 2470000 & 60,0 & 0,93 & 4010000 & 54,0 \\
\hline & 0,50 & 2250000 & 60,5 & 0,84 & 3760000 & 54,4 \\
\hline & & & & 0,76 & 3530000 & 54,7 \\
\hline & & & & 0,68 & 3320000 & 55,0 \\
\hline & & & & 0,62 & 3110000 & 55,3 \\
\hline & & & & 0,55 & 2920000 & 55,7 \\
\hline & & & & 0,50 & 2730000 & 56,1 \\
\hline \multirow[t]{18}{*}{30} & 10,00 & 4350000 & 58,6 & 10,00 & 3650000 & 56,1 \\
\hline & 8,86 & 3820000 & 59,5 & 9,02 & 3340000 & 57,0 \\
\hline & 7,79 & 3370000 & 60,1 & 8,14 & 3080000 & 57,5 \\
\hline & 6,88 & 3000000 & 60,7 & 7,34 & 2850000 & 58,0 \\
\hline & 6,08 & 2660000 & 61,3 & 6,63 & 2650000 & 58,4 \\
\hline & 5,37 & 2380000 & 61,8 & 5,97 & 2450000 & 58,8 \\
\hline & 4,73 & 2130000 & 62,3 & 5,38 & 2280000 & 59,2 \\
\hline & 4,17 & 1920000 & 62,8 & 4,86 & 2120000 & 59,6 \\
\hline & 3,69 & 1730000 & 63,2 & 4,38 & 1970000 & 60,0 \\
\hline & 3,25 & 1560000 & 63,6 & 3,95 & 1830000 & 60,3 \\
\hline & 2,87 & 1410000 & 64,0 & 3,56 & 1710000 & 60,6 \\
\hline & 2,53 & 1280000 & 64,4 & 3,21 & 1590000 & 60,9 \\
\hline & 2,24 & 1160000 & 64,7 & 2,90 & 1480000 & 61,2 \\
\hline & 1,97 & 1040000 & 65,3 & 2,61 & 1380000 & 61,5 \\
\hline & 1,74 & 940000 & 65,8 & 2,36 & 1280000 & 61,8 \\
\hline & 1,54 & 851000 & 66,4 & 2,12 & 1190000 & 62,2 \\
\hline & 1,36 & 767000 & 66,8 & 1,92 & 1110000 & 62,7 \\
\hline & 1,20 & 690000 & 67,2 & 1,73 & 1030000 & 62,9 \\
\hline
\end{tabular}




\begin{tabular}{|c|c|c|c|c|c|c|}
\hline \multirow{2}{*}{$\begin{array}{c}\text { C3 } \\
\mathrm{T}\end{array}$} & \multicolumn{3}{|c|}{ Original } & \multicolumn{3}{|c|}{ Envejecido } \\
\hline & $f$ & $\mathrm{G}^{*}$ & $\delta$ & $f$ & $\mathrm{G}^{*}$ & $\delta$ \\
\hline$\left[{ }^{\circ} \mathrm{C}\right]$ & {$[\mathrm{Hz}]$} & {$[\mathrm{Pa}]$} & [o] & {$[\mathrm{Hz}]$} & {$[\mathrm{Pa}]$} & [o] \\
\hline \multirow[t]{12}{*}{30} & 1,06 & 622000 & 67,7 & 1,56 & 958000 & 63,3 \\
\hline & 0,93 & 559000 & 68,6 & 1,41 & 889000 & 63,6 \\
\hline & 0,82 & 503000 & 68,8 & 1,27 & 826000 & 63,9 \\
\hline & 0,73 & 451000 & 69,5 & 1,14 & 767000 & 64,4 \\
\hline & 0,64 & 404000 & 70,2 & 1,03 & 712000 & 64,6 \\
\hline & 0,57 & 363000 & 71,2 & 0,93 & 660000 & 64,9 \\
\hline & 0,50 & 325000 & 72,5 & 0,84 & 613000 & 65,3 \\
\hline & & & & 0,76 & 569000 & 65,6 \\
\hline & & & & 0,68 & 527000 & 66,2 \\
\hline & & & & 0,62 & 486000 & 66,8 \\
\hline & & & & 0,55 & 450000 & 66,8 \\
\hline & & & & 0,50 & 415000 & 67,0 \\
\hline \multirow[t]{20}{*}{40} & 10,00 & 265000 & 64,4 & 10,00 & 314000 & 56,3 \\
\hline & 8,89 & 237000 & 65,9 & 8,89 & 283000 & 58,0 \\
\hline & 7,87 & 208000 & 67,5 & 7,87 & 257000 & 59,5 \\
\hline & 6,96 & 176000 & 69,0 & 6,96 & 234000 & 60,7 \\
\hline & 6,17 & 150000 & 70,3 & 6,17 & 214000 & 61,8 \\
\hline & 5,47 & 129000 & 71,4 & 5,47 & 195000 & 62,7 \\
\hline & 4,84 & 113000 & 72,2 & 4,84 & 178000 & 63,6 \\
\hline & 4,29 & 99500 & 73,0 & 4,29 & 163000 & 64,4 \\
\hline & 3,80 & 88400 & 73,7 & 3,80 & 149000 & 65,2 \\
\hline & 3,36 & 78900 & 74,2 & 3,36 & 136000 & 65,9 \\
\hline & 2,98 & 70700 & 74,8 & 2,98 & 124000 & 66,6 \\
\hline & 2,64 & 63500 & 75,3 & 2,64 & 113000 & 67,2 \\
\hline & 2,34 & 57100 & 75,7 & 2,34 & 103000 & 67,8 \\
\hline & 2,07 & 51600 & 76,1 & 2,07 & 93900 & 68,3 \\
\hline & 1,83 & 46500 & 76,6 & 1,83 & 85500 & 68,9 \\
\hline & 1,62 & 42000 & 76,9 & 1,62 & 77900 & 69,4 \\
\hline & 1,44 & 38000 & 77,3 & 1,44 & 71000 & 69,9 \\
\hline & 1,27 & 34400 & 77,6 & 1,27 & 64600 & 70,3 \\
\hline & 1,13 & 31200 & 77,9 & 1,13 & 58800 & 70,7 \\
\hline & 1,00 & 28300 & 78,1 & 1,00 & 53400 & 71,2 \\
\hline \multirow[t]{8}{*}{50} & 10,00 & 68200 & 77,1 & 10,00 & 78100 & 71,3 \\
\hline & 8,89 & 60500 & 77,6 & 8,89 & 70500 & 71,8 \\
\hline & 7,87 & 53800 & 78,1 & 7,87 & 63700 & 72,3 \\
\hline & 6,96 & 48000 & 78,5 & 6,96 & 57400 & 72,7 \\
\hline & 6,17 & 43200 & 78,9 & 6,17 & 52000 & 73,1 \\
\hline & 5,47 & 38900 & 79,2 & 5,47 & 47000 & 73,5 \\
\hline & 4,84 & 35100 & 79,5 & 4,84 & 42400 & 73,9 \\
\hline & 4,29 & 31500 & 79,8 & 4,29 & 38300 & 74,2 \\
\hline
\end{tabular}




\begin{tabular}{|c|c|c|c|c|c|c|}
\hline \multirow{2}{*}{$\begin{array}{c}\text { C3 } \\
\mathrm{T}\end{array}$} & \multicolumn{3}{|c|}{ Original } & \multicolumn{3}{|c|}{ Envejecido } \\
\hline & $f$ & $\mathrm{G}^{*}$ & $\delta$ & $f$ & $\mathrm{G}^{*}$ & $\delta$ \\
\hline$\left[{ }^{\circ} \mathrm{C}\right]$ & {$[\mathrm{Hz}]$} & {$[\mathrm{Pa}]$} & [o] & {$[\mathrm{Hz}]$} & {$[\mathrm{Pa}]$} & {$[0]$} \\
\hline \multirow[t]{12}{*}{50} & 3,80 & 28300 & 80,0 & 3,80 & 34600 & 74,5 \\
\hline & 3,36 & 25500 & 80,3 & 3,36 & 31300 & 74,8 \\
\hline & 2,98 & 22900 & 80,5 & 2,98 & 28300 & 75,0 \\
\hline & 2,64 & 20600 & 80,6 & 2,64 & 25500 & 75,3 \\
\hline & 2,34 & 18400 & 80,7 & 2,34 & 23000 & 75,5 \\
\hline & 2,07 & 16500 & 80,8 & 2,07 & 20700 & 75,7 \\
\hline & 1,83 & 14800 & 80,9 & 1,83 & 18700 & 75,8 \\
\hline & 1,62 & 13300 & 80,9 & 1,62 & 16800 & 76,0 \\
\hline & 1,44 & 11900 & 80,9 & 1,44 & 15200 & 76,1 \\
\hline & 1,27 & 10600 & 80,9 & 1,27 & 13700 & 76,2 \\
\hline & 1,13 & 9500 & 80,8 & 1,13 & 12300 & 76,2 \\
\hline & 1,00 & 8490 & 80,6 & 1,00 & 11100 & 76,2 \\
\hline \multirow[t]{20}{*}{60} & 10,00 & 18500 & 81,3 & 10,00 & 20100 & 77,4 \\
\hline & 8,89 & 16600 & 81,4 & 8,89 & 18100 & 77,5 \\
\hline & 7,87 & 14800 & 81,5 & 7,87 & 16300 & 77,6 \\
\hline & 6,96 & 13200 & 81,6 & 6,96 & 14600 & 77,7 \\
\hline & 6,17 & 11800 & 81,6 & 6,17 & 13200 & 77,7 \\
\hline & 5,47 & 10600 & 81,6 & 5,47 & 11800 & 77,7 \\
\hline & 4,84 & 9430 & 81,5 & 4,84 & 10600 & 77,7 \\
\hline & 4,29 & 8430 & 81,3 & 4,29 & 9540 & 77,5 \\
\hline & 3,80 & 7510 & 81,1 & 3,80 & 8560 & 77,4 \\
\hline & 3,36 & 6700 & 80,9 & 3,36 & 7690 & 77,2 \\
\hline & 2,98 & 5980 & 80,6 & 2,98 & 6910 & 76,9 \\
\hline & 2,64 & 5330 & 80,2 & 2,64 & 6190 & 76,6 \\
\hline & 2,34 & 4750 & 79,7 & 2,34 & 5570 & 76,3 \\
\hline & 2,07 & 4240 & 79,3 & 2,07 & 5000 & 75,9 \\
\hline & 1,83 & 3770 & 78,8 & 1,83 & 4470 & 75,6 \\
\hline & 1,62 & 3370 & 78,1 & 1,62 & 4010 & 75,2 \\
\hline & 1,44 & 3010 & 77,2 & 1,44 & 3600 & 74,7 \\
\hline & 1,27 & 2690 & 76,3 & 1,27 & 3230 & 74,1 \\
\hline & 1,13 & 2400 & 75,8 & 1,13 & 2900 & 73,5 \\
\hline & 1,00 & 2150 & 75,0 & 1,00 & 2600 & 72,7 \\
\hline \multirow[t]{8}{*}{70} & 10,00 & 6310 & 87,0 & 10,00 & 5900 & 78,0 \\
\hline & 8,89 & 5580 & 87,0 & 8,89 & 5360 & 77,6 \\
\hline & 7,87 & 4930 & 87,0 & 7,87 & 4800 & 77,1 \\
\hline & 6,96 & 4360 & 87,0 & 6,96 & 4300 & 76,3 \\
\hline & 6,17 & 3860 & 86,0 & 6,17 & 3890 & 75,7 \\
\hline & 5,47 & 3410 & 86,4 & 5,47 & 3490 & 74,9 \\
\hline & 4,84 & 2860 & 85,6 & 4,84 & 3140 & 74,0 \\
\hline & 4,29 & 2630 & 85,6 & 4,29 & 2820 & 72,8 \\
\hline
\end{tabular}


DEFORMACIONES PERMANENTES EN MEZCLAS ASFÁLTICAS.

Efecto de la reología de los asfaltos, la temperatura y las condiciones de carga

\begin{tabular}{|c|c|c|c|c|c|c|}
\hline \multirow{2}{*}{$\begin{array}{c}\text { C3 } \\
\mathrm{T}\end{array}$} & \multicolumn{3}{|c|}{ Original } & \multicolumn{3}{|c|}{ Envejecido } \\
\hline & $f$ & $\mathrm{G}^{*}$ & $\delta$ & $f$ & $\mathrm{G}^{*}$ & $\delta$ \\
\hline$\left[{ }^{\circ} \mathrm{C}\right]$ & {$[\mathrm{Hz}]$} & {$[\mathrm{Pa}]$} & [o] & {$[\mathrm{Hz}]$} & {$[\mathrm{Pa}]$} & [o] \\
\hline \multirow[t]{12}{*}{70} & 3,80 & 2310 & 85,2 & 3,80 & 2530 & 71,7 \\
\hline & 3,36 & 2020 & 84,9 & 3,36 & 2280 & 70,2 \\
\hline & 2,98 & 1770 & 84,5 & 2,98 & 2050 & 68,7 \\
\hline & 2,64 & 1560 & 84,3 & 2,64 & 1840 & 67,2 \\
\hline & 2,34 & 1320 & 87,8 & 2,34 & 1650 & 67,0 \\
\hline & 2,07 & 1140 & 86,6 & 2,07 & 1480 & 67,5 \\
\hline & 1,83 & 1010 & 88,9 & 1,83 & 1340 & 66,2 \\
\hline & 1,62 & 950 & 89,9 & 1,62 & 1210 & 66,5 \\
\hline & 1,44 & 846 & 84,6 & 1,44 & 1100 & 64,2 \\
\hline & 1,27 & 770 & 86,2 & & & \\
\hline & 1,13 & 684 & 86,8 & & & \\
\hline & 1,00 & 729 & 71,5 & & & \\
\hline \multirow[t]{16}{*}{80} & 10,00 & 2140 & 70,0 & & & \\
\hline & 8,89 & 2000 & 69,0 & & & \\
\hline & 7,87 & 1770 & 68,0 & & & \\
\hline & 6,96 & 1590 & 67,0 & & & \\
\hline & 6,17 & 1450 & 66,0 & & & \\
\hline & 5,47 & 1290 & 64,0 & & & \\
\hline & 4,84 & 1160 & 62,0 & & & \\
\hline & 4,29 & 1050 & 60,0 & & & \\
\hline & 3,80 & 951 & 57,0 & & & \\
\hline & 3,36 & 867 & 55,0 & & & \\
\hline & 2,98 & 798 & 52,1 & & & \\
\hline & 2,64 & 737 & 49,3 & & & \\
\hline & 2,34 & 681 & 47,1 & & & \\
\hline & 2,07 & 625 & 46,4 & & & \\
\hline & 1,83 & 584 & 44,2 & & & \\
\hline & 1,62 & 491 & 47,9 & & & \\
\hline
\end{tabular}



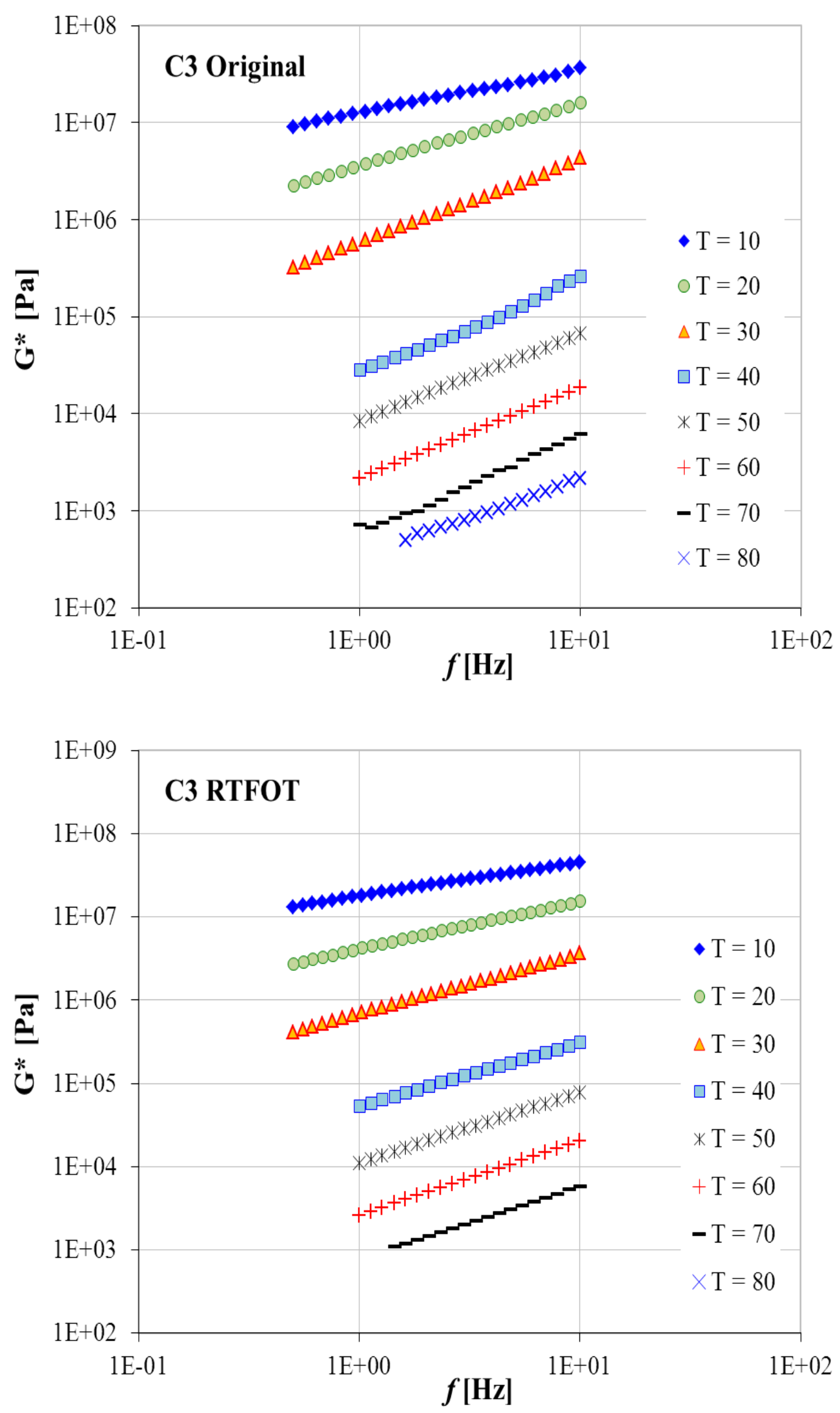


\section{Asfalto C4}

\begin{tabular}{|c|c|c|c|c|c|c|}
\hline & \multicolumn{3}{|c|}{ Original } & \multicolumn{3}{|c|}{ Envejecido } \\
\hline $\mathrm{T}$ & $f$ & $\mathrm{G}^{*}$ & $\delta$ & $f$ & $\mathrm{G}^{*}$ & $\delta$ \\
\hline$\left[{ }^{\circ} \mathrm{C}\right]$ & {$[\mathrm{Hz}]$} & {$[\mathrm{Pa}]$} & [o] & {$[\mathrm{Hz}]$} & {$[\mathrm{Pa}]$} & [o] \\
\hline \multirow[t]{20}{*}{10} & 10,00 & 97700000 & 27,7 & 10,00 & 95200000 & 22,3 \\
\hline & 8,54 & 94400000 & 28,2 & 8,54 & 92100000 & 22,8 \\
\hline & 7,29 & 91200000 & 28,8 & 7,29 & 89600000 & 23,2 \\
\hline & 6,22 & 87900000 & 29,3 & 6,22 & 86700000 & 23,5 \\
\hline & 5,31 & 84600000 & 29,8 & 5,31 & 83700000 & 24,0 \\
\hline & 4,53 & 81200000 & 30,4 & 4,53 & 80800000 & 24,6 \\
\hline & 3,86 & 77700000 & 31,0 & 3,86 & 77800000 & 25,1 \\
\hline & 3,29 & 74200000 & 31,7 & 3,29 & 74700000 & 25,8 \\
\hline & 2,81 & 70700000 & 32,4 & 2,81 & 71900000 & 26,2 \\
\hline & 2,40 & 67200000 & 33,1 & 2,40 & 69000000 & 26,6 \\
\hline & 2,04 & 63900000 & 33,8 & 2,04 & 66100000 & 27,2 \\
\hline & 1,74 & 60700000 & 34,5 & 1,74 & 63100000 & 28,0 \\
\hline & 1,49 & 57500000 & 35,2 & 1,49 & 60400000 & 28,3 \\
\hline & 1,27 & 54400000 & 35,9 & 1,27 & 57700000 & 28,9 \\
\hline & 1,08 & 51500000 & 36,7 & 1,08 & 55100000 & 29,0 \\
\hline & 0,92 & 48600000 & 37,4 & 0,92 & 52500000 & 30,0 \\
\hline & 0,79 & 45800000 & 38,1 & 0,79 & 50100000 & 31,0 \\
\hline & 0,67 & 43200000 & 38,9 & 0,67 & 47600000 & 31,0 \\
\hline & 0,57 & 40600000 & 39,6 & 0,57 & 45400000 & 32,0 \\
\hline & 0,49 & 38200000 & 40,4 & 0,49 & 43100000 & 32,0 \\
\hline \multirow[t]{18}{*}{20} & 10,00 & 39700000 & 42,1 & 10,00 & 60700000 & 28,6 \\
\hline & 8,54 & 36900000 & 43,0 & 8,54 & 56700000 & 29,5 \\
\hline & 7,29 & 34700000 & 43,8 & 7,29 & 53100000 & 30,4 \\
\hline & 6,22 & 32700000 & 44,5 & 6,22 & 49900000 & 31,2 \\
\hline & 5,31 & 30800000 & 45,2 & 5,31 & 46800000 & 32,0 \\
\hline & 4,53 & 29000000 & 45,8 & 4,53 & 44000000 & 32,9 \\
\hline & 3,86 & 27200000 & 46,5 & 3,86 & 41200000 & 33,6 \\
\hline & 3,29 & 25500000 & 47,2 & 3,29 & 38800000 & 34,4 \\
\hline & 2,81 & 23800000 & 47,9 & 2,81 & 36300000 & 35,1 \\
\hline & 2,40 & 22200000 & 48,6 & 2,40 & 34100000 & 35,8 \\
\hline & 2,04 & 20600000 & 49,3 & 2,04 & 31900000 & 36,7 \\
\hline & 1,74 & 19200000 & 50,0 & 1,74 & 29800000 & 37,3 \\
\hline & 1,49 & 17800000 & 50,8 & 1,49 & 27800000 & 38,1 \\
\hline & 1,27 & 16500000 & 51,5 & 1,27 & 26000000 & 38,9 \\
\hline & 1,08 & 15200000 & 52,2 & 1,08 & 24200000 & 39,7 \\
\hline & 0,92 & 14100000 & 52,9 & 0,92 & 22500000 & 40,5 \\
\hline & 0,79 & 13000000 & 53,6 & 0,79 & 20900000 & 41,2 \\
\hline & 0,67 & 12000000 & 54,4 & 0,67 & 19400000 & 41,9 \\
\hline
\end{tabular}




\begin{tabular}{|c|c|c|c|c|c|c|}
\hline \multirow{2}{*}{$\frac{\mathbf{C 4}}{\mathrm{T}}$} & \multicolumn{3}{|c|}{ Original } & \multicolumn{3}{|c|}{ Envejecido } \\
\hline & $f$ & $\mathrm{G}^{*}$ & $\delta$ & $f$ & $\mathrm{G}^{*}$ & $\delta$ \\
\hline$\left[{ }^{\circ} \mathrm{C}\right]$ & {$[\mathrm{Hz}]$} & {$[\mathrm{Pa}]$} & [o] & {$[\mathrm{Hz}]$} & {$[\mathrm{Pa}]$} & [o] \\
\hline \multirow[t]{2}{*}{20} & 0,57 & 11000000 & 55,0 & 0,57 & 18000000 & 42,8 \\
\hline & 0,49 & 10200000 & 55,7 & 0,49 & 16600000 & 44,0 \\
\hline \multirow[t]{20}{*}{30} & 10,00 & 21900000 & 48,9 & 10,00 & 23000000 & 41,6 \\
\hline & 8,54 & 19700000 & 50,1 & 8,54 & 20700000 & 43,0 \\
\hline & 7,29 & 17900000 & 51,1 & 7,29 & 18900000 & 44,1 \\
\hline & 6,22 & 16200000 & 52,1 & 6,22 & 17300000 & 45,0 \\
\hline & 5,31 & 14700000 & 53,0 & 5,31 & 15900000 & 45,9 \\
\hline & 4,53 & 13200000 & 54,0 & 4,53 & 14500000 & 46,7 \\
\hline & 3,86 & 12000000 & 54,9 & 3,86 & 13300000 & 47,6 \\
\hline & 3,29 & 10800000 & 55,8 & 3,29 & 12200000 & 48,4 \\
\hline & 2,81 & 9770000 & 56,7 & 2,81 & 11100000 & 49,1 \\
\hline & 2,40 & 8790000 & 57,5 & 2,40 & 10200000 & 49,9 \\
\hline & 2,04 & 7900000 & 58,3 & 2,04 & 9290000 & 50,7 \\
\hline & 1,74 & 7110000 & 59,2 & 1,74 & 8470000 & 51,4 \\
\hline & 1,49 & 6380000 & 60,0 & 1,49 & 7710000 & 52,2 \\
\hline & 1,27 & 5710000 & 60,7 & 1,27 & 6990000 & 53,0 \\
\hline & 1,08 & 5100000 & 61,5 & 1,08 & 6350000 & 53,7 \\
\hline & 0,92 & 4550000 & 62,3 & 0,92 & 5740000 & 54,4 \\
\hline & 0,79 & 4060000 & 63,1 & 0,79 & 5180000 & 55,3 \\
\hline & 0,67 & 3600000 & 63,8 & 0,67 & 4670000 & 56,1 \\
\hline & 0,57 & 3200000 & 64,5 & 0,57 & 4200000 & 56,9 \\
\hline & 0,49 & 2830000 & 65,3 & 0,49 & 3760000 & 57,7 \\
\hline \multirow[t]{18}{*}{40} & 10,00 & 5200000 & 63,8 & 10,00 & 5260000 & 59,9 \\
\hline & 8,54 & 4540000 & 64,8 & 8,89 & 4820000 & 60,5 \\
\hline & 7,29 & 3990000 & 65,6 & 7,92 & 4460000 & 61,0 \\
\hline & 6,22 & 3490000 & 66,4 & 7,02 & 4130000 & 61,4 \\
\hline & 5,31 & 3060000 & 67,2 & 6,25 & 3850000 & 61,8 \\
\hline & 4,53 & 2670000 & 67,9 & 5,54 & 3570000 & 62,2 \\
\hline & 3,86 & 2340000 & 68,6 & 4,93 & 3310000 & 62,7 \\
\hline & 3,29 & 2050000 & 69,2 & 4,38 & 3070000 & 63,2 \\
\hline & 2,81 & 1790000 & 69,8 & 3,89 & 2840000 & 63,7 \\
\hline & 2,40 & 1570000 & 70,4 & 3,46 & 2620000 & 64,1 \\
\hline & 2,04 & 1370000 & 71,0 & 3,07 & 2420000 & 64,6 \\
\hline & 1,74 & 1200000 & 71,6 & 2,73 & 2230000 & 65,0 \\
\hline & 1,49 & 1050000 & 72,2 & 2,43 & 2050000 & 65,4 \\
\hline & 1,27 & 908000 & 72,9 & 2,15 & 1890000 & 65,8 \\
\hline & 1,08 & 790000 & 73,4 & 1,92 & 1740000 & 66,2 \\
\hline & & & & 1,70 & 1600000 & 66,7 \\
\hline & & & & 1,51 & 1470000 & 67,1 \\
\hline & & & & 1,34 & 1350000 & 67,5 \\
\hline
\end{tabular}




\begin{tabular}{|c|c|c|c|c|c|c|}
\hline \multirow{2}{*}{$\begin{array}{c}\mathbf{C 4} \\
\mathrm{T}\end{array}$} & \multicolumn{3}{|c|}{ Original } & \multicolumn{3}{|c|}{ Envejecido } \\
\hline & $f$ & $\mathrm{G}^{*}$ & $\delta$ & $f$ & $\mathrm{G}^{*}$ & $\delta$ \\
\hline$\left[{ }^{\circ} \mathrm{C}\right]$ & {$[\mathrm{Hz}]$} & {$[\mathrm{Pa}]$} & [o] & {$[\mathrm{Hz}]$} & {$[\mathrm{Pa}]$} & [o] \\
\hline \multirow[t]{2}{*}{40} & & & & 1,19 & 1240000 & 67,9 \\
\hline & & & & 1,06 & 1140000 & 68,2 \\
\hline \multirow[t]{20}{*}{50} & 10,00 & 260000 & 67,4 & 10,00 & 529000 & 51,2 \\
\hline & 8,89 & 232000 & 68,8 & 8,89 & 488000 & 53,2 \\
\hline & 7,87 & 208000 & 70,1 & 7,87 & 448000 & 55,1 \\
\hline & 6,96 & 185000 & 71,3 & 6,96 & 412000 & 56,9 \\
\hline & 6,17 & 164000 & 72,4 & 6,17 & 378000 & 58,5 \\
\hline & 5,47 & 144000 & 73,4 & 5,47 & 346000 & 60,1 \\
\hline & 4,84 & 126000 & 74,4 & 4,84 & 316000 & 61,6 \\
\hline & 4,29 & 111000 & 75,2 & 4,29 & 289000 & 63,0 \\
\hline & 3,80 & 97600 & 76,0 & 3,80 & 263000 & 64,3 \\
\hline & 3,36 & 86500 & 76,7 & 3,36 & 239000 & 65,5 \\
\hline & 2,98 & 77100 & 77,3 & 2,98 & 218000 & 66,7 \\
\hline & 2,64 & 68800 & 77,8 & 2,64 & 198000 & 67,7 \\
\hline & 2,34 & 61600 & 78,4 & 2,34 & 180000 & 68,7 \\
\hline & 2,07 & 55100 & 78,9 & 2,07 & 164000 & 69,6 \\
\hline & 1,83 & 49300 & 79,3 & 1,83 & 148000 & 70,5 \\
\hline & 1,62 & 44200 & 79,7 & 1,62 & 134000 & 71,3 \\
\hline & 1,44 & 39700 & 80,1 & 1,44 & 122000 & 72,1 \\
\hline & 1,27 & 35600 & 80,5 & 1,27 & 110000 & 72,8 \\
\hline & 1,13 & 32000 & 80,9 & 1,13 & 99300 & 73,5 \\
\hline & 1,00 & 28700 & 81,2 & 1,00 & 89700 & 74,1 \\
\hline \multirow[t]{18}{*}{60} & 10,00 & 57700 & 79,9 & 10,00 & 142000 & 71,9 \\
\hline & 8,89 & 51400 & 80,4 & 8,89 & 128000 & 72,8 \\
\hline & 7,87 & 45800 & 80,8 & 7,87 & 115000 & 73,6 \\
\hline & 6,96 & 40800 & 81,2 & 6,96 & 103000 & 74,3 \\
\hline & 6,17 & 36500 & 81,6 & 6,17 & 92600 & 74,9 \\
\hline & 5,47 & 32800 & 81,9 & 5,47 & 83200 & 75,6 \\
\hline & 4,84 & 29300 & 82,2 & 4,84 & 74800 & 76,2 \\
\hline & 4,29 & 26200 & 82,5 & 4,29 & 67200 & 76,7 \\
\hline & 3,80 & 23500 & 82,8 & 3,80 & 60400 & 77,2 \\
\hline & 3,36 & 21000 & 83,0 & 3,36 & 54300 & 77,7 \\
\hline & 2,98 & 18700 & 83,3 & 2,98 & 48700 & 78,1 \\
\hline & 2,64 & 16800 & 83,5 & 2,64 & 43700 & 78,6 \\
\hline & 2,34 & 15000 & 83,7 & 2,34 & 39200 & 79,0 \\
\hline & 2,07 & 13400 & 83,9 & 2,07 & 35200 & 79,4 \\
\hline & 1,83 & 12000 & 84,1 & 1,83 & 31600 & 79,8 \\
\hline & 1,62 & 10800 & 84,3 & 1,62 & 28400 & 80,1 \\
\hline & 1,44 & 9620 & 84,5 & 1,44 & 25400 & 80,4 \\
\hline & 1,27 & 8590 & 84,6 & 1,27 & 22700 & 80,6 \\
\hline
\end{tabular}




\begin{tabular}{|c|c|c|c|c|c|c|}
\hline \multirow{2}{*}{$\frac{\mathbf{C 4}}{\mathrm{T}}$} & \multicolumn{3}{|c|}{ Original } & \multicolumn{3}{|c|}{ Envejecido } \\
\hline & $f$ & $\mathrm{G}^{*}$ & $\delta$ & $f$ & $\mathrm{G}^{*}$ & $\delta$ \\
\hline$\left[{ }^{\circ} \mathrm{C}\right]$ & {$[\mathrm{Hz}]$} & {$[\mathrm{Pa}]$} & [o] & {$[\mathrm{Hz}]$} & {$[\mathrm{Pa}]$} & [o] \\
\hline \multirow[t]{2}{*}{60} & 1,13 & 7670 & 84,8 & 1,13 & 20300 & 80,9 \\
\hline & 1,00 & 6830 & 84,9 & 1,00 & 18200 & 81,2 \\
\hline \multirow[t]{20}{*}{70} & 10,00 & 15400 & 84,8 & 10,00 & 35400 & 80,4 \\
\hline & 8,89 & 13900 & 85,0 & 8,89 & 31900 & 80,8 \\
\hline & 7,87 & 12400 & 85,2 & 7,87 & 28500 & 81,2 \\
\hline & 6,96 & 11000 & 85,3 & 6,96 & 25500 & 81,5 \\
\hline & 6,17 & 9830 & 85,4 & 6,17 & 22800 & 81,8 \\
\hline & 5,47 & 8810 & 85,5 & 5,47 & 20400 & 82,1 \\
\hline & 4,84 & 7890 & 85,4 & 4,84 & 18200 & 82,3 \\
\hline & 4,29 & 6980 & 85,4 & 4,29 & 16300 & 82,6 \\
\hline & 3,80 & 6190 & 85,3 & 3,80 & 14600 & 82,8 \\
\hline & 3,36 & 5400 & 85,6 & 3,36 & 13100 & 83,0 \\
\hline & 2,98 & 4530 & 85,4 & 2,98 & 11700 & 83,2 \\
\hline & 2,64 & 4010 & 85,7 & 2,64 & 10400 & 83,4 \\
\hline & 2,34 & 3690 & 84,5 & 2,34 & 9270 & 83,5 \\
\hline & 2,07 & 3310 & 79,5 & 2,07 & 8260 & 83,7 \\
\hline & 1,83 & 2960 & 79,0 & 1,83 & 7360 & 83,8 \\
\hline & 1,62 & 2660 & 78,3 & 1,62 & 6560 & 83,9 \\
\hline & 1,44 & 2370 & 77,3 & 1,44 & 5820 & 84,1 \\
\hline & 1,27 & 2120 & 77,1 & 1,27 & 5180 & 84,1 \\
\hline & 1,13 & 1900 & 76,5 & 1,13 & 4620 & 84,3 \\
\hline & 1,00 & 1710 & 75,1 & 1,00 & 4110 & 84,4 \\
\hline \multirow[t]{18}{*}{80} & 10,00 & 4740 & 80,1 & 10,00 & 5070 & 85,2 \\
\hline & 8,89 & 4270 & 79,3 & 8,89 & 4290 & 84,9 \\
\hline & 7,87 & 3820 & 78,6 & 7,87 & 3760 & 84,8 \\
\hline & 6,96 & 3410 & 77,7 & 6,96 & 3370 & 84,5 \\
\hline & 6,17 & 3050 & 76,7 & 6,17 & 2920 & 84,2 \\
\hline & 5,47 & 2740 & 75,7 & 5,47 & 2540 & 84,1 \\
\hline & 4,84 & 2440 & 74,4 & 4,84 & 2210 & 83,8 \\
\hline & 4,29 & 2200 & 73,0 & 4,29 & 1960 & 83,5 \\
\hline & 3,80 & 1960 & 71,3 & 3,80 & 1720 & 83,1 \\
\hline & 3,36 & 1760 & 69,7 & 3,36 & 1520 & 82,5 \\
\hline & 2,98 & 1590 & 67,7 & 2,98 & 1340 & 82,2 \\
\hline & 2,64 & 1430 & 66,2 & 2,64 & 1180 & 82,0 \\
\hline & 2,34 & 1280 & 67,4 & 2,34 & 1090 & 83,0 \\
\hline & 2,07 & 1160 & 67,5 & 2,07 & 1040 & 85,5 \\
\hline & 1,83 & 1050 & 65,2 & 1,83 & 951 & 88,7 \\
\hline & 1,62 & 960 & 62,7 & 1,62 & 694 & 81,8 \\
\hline & 1,44 & 881 & 61,2 & 1,44 & 785 & 47,1 \\
\hline & 1,27 & 817 & 58,2 & 1,27 & 885 & 69,3 \\
\hline
\end{tabular}


DEFORMACIONES PERMANENTES EN MEZCLAS ASFÁLTICAS.

Efecto de la reología de los asfaltos, la temperatura y las condiciones de carga

\begin{tabular}{ccccccc}
\hline C4 & \multicolumn{3}{c}{ Original } & & \multicolumn{3}{c}{ Envejecido } \\
\hline $\mathrm{T}$ & $f$ & $\mathrm{G}^{*}$ & $\delta$ & $f$ & $\mathrm{G}^{*}$ & $\delta$ \\
{$\left[{ }^{\circ} \mathrm{C}\right]$} & {$[\mathrm{Hz}]$} & {$[\mathrm{Pa}]$} & {$[\mathrm{o}]$} & {$[\mathrm{Hz}]$} & {$[\mathrm{Pa}]$} & {$[\mathrm{o}]$} \\
\hline 80 & 1,13 & 730 & 56,7 & 1,13 & 720 & 37,7 \\
& 1,00 & 679 & 66,3 & & & \\
\hline
\end{tabular}



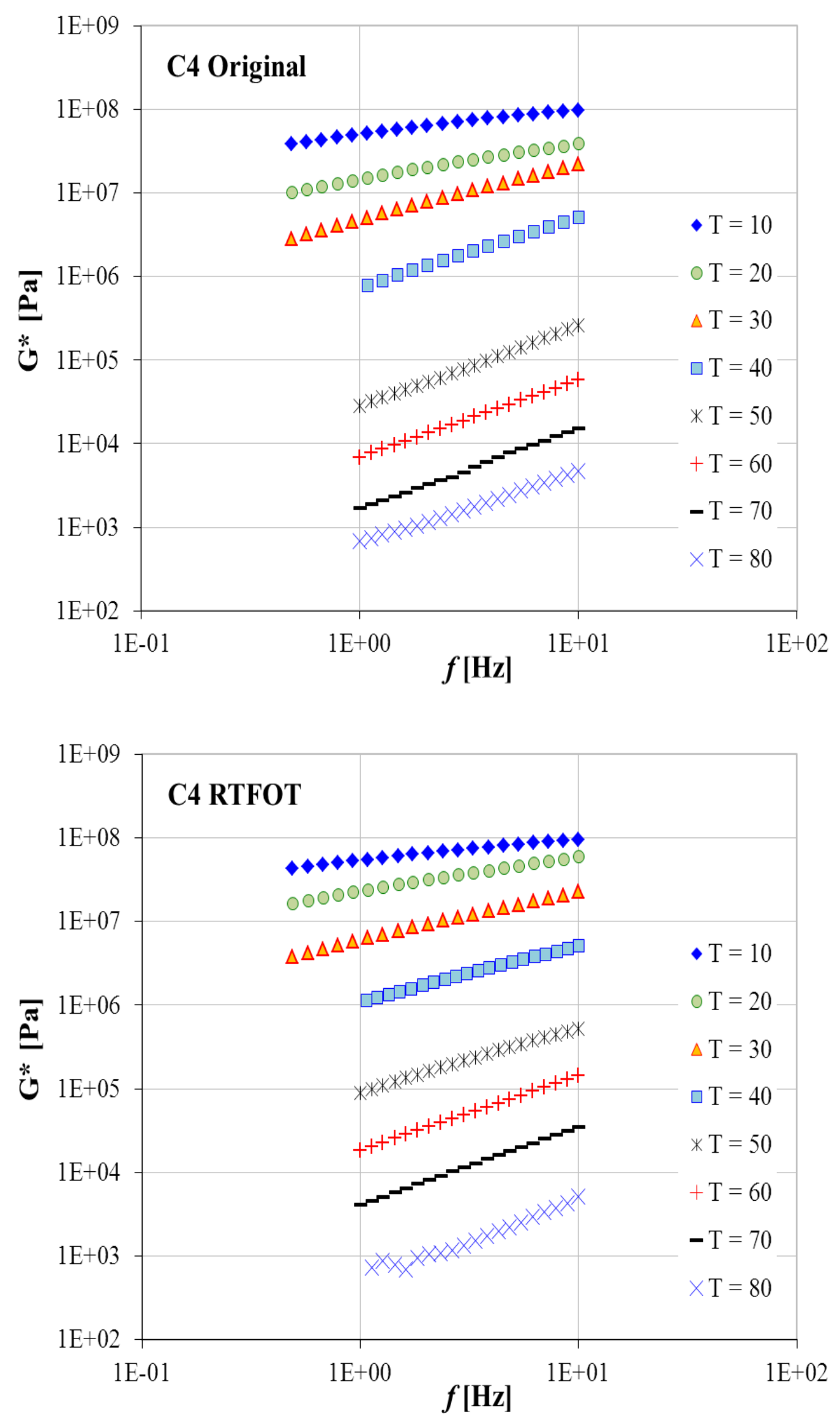


\section{Asfalto M}

\begin{tabular}{|c|c|c|c|c|c|c|}
\hline & \multicolumn{3}{|c|}{ Original } & \multicolumn{3}{|c|}{ Envejecido } \\
\hline $\mathrm{T}$ & $f$ & $\mathrm{G}^{*}$ & $\delta$ & $f$ & $\mathrm{G}^{*}$ & $\delta$ \\
\hline$\left[{ }^{\circ} \mathrm{C}\right]$ & {$[\mathrm{Hz}]$} & {$[\mathrm{Pa}]$} & {$[0]$} & {$[\mathrm{Hz}]$} & {$[\mathrm{Pa}]$} & {$[0]$} \\
\hline \multirow[t]{30}{*}{10} & 10,00 & 9240000 & 49,2 & 10,00 & 32200000 & 33,8 \\
\hline & 8,89 & 8440000 & 50,0 & 9,02 & 29900000 & 34,7 \\
\hline & 7,87 & 7800000 & 50,5 & 8,14 & 28400000 & 35,2 \\
\hline & 6,96 & 7300000 & 50,8 & 7,34 & 27200000 & 35,6 \\
\hline & 6,17 & 6790000 & 51,1 & 6,63 & 26000000 & 35,9 \\
\hline & 5,47 & 6320000 & 51,4 & 5,97 & 25000000 & 36,2 \\
\hline & 4,84 & 5890000 & 51,7 & 5,38 & 24000000 & 36,5 \\
\hline & 4,29 & 5530000 & 51,9 & 4,86 & 23100000 & 36,7 \\
\hline & 3,80 & 5130000 & 52,2 & 4,38 & 22300000 & 36,9 \\
\hline & 3,36 & 4820000 & 52,4 & 3,95 & 21500000 & 37,1 \\
\hline & 2,98 & 4470000 & 52,6 & 3,56 & 20700000 & 37,3 \\
\hline & 2,64 & 4180000 & 52,8 & 3,21 & 19900000 & 37,5 \\
\hline & 2,34 & 3920000 & 53,0 & 2,90 & 19100000 & 37,7 \\
\hline & 2,07 & 3650000 & 53,1 & 2,61 & 18400000 & 37,9 \\
\hline & 1,83 & 3380000 & 53,4 & 2,36 & 17700000 & 38,0 \\
\hline & 1,62 & 3200000 & 53,5 & 2,12 & 17000000 & 38,0 \\
\hline & 1,44 & 3020000 & 53,7 & 1,92 & 16300000 & 38,0 \\
\hline & 1,27 & 2840000 & 53,8 & 1,73 & 15700000 & 39,0 \\
\hline & 1,13 & 2630000 & 54,0 & 1,56 & 15100000 & 39,0 \\
\hline & 1,00 & 2470000 & 54,1 & 1,41 & 14500000 & 39,0 \\
\hline & 0,93 & 1924327 & 54,2 & 1,27 & 13900000 & 39,3 \\
\hline & 0,82 & 1792822 & 54,3 & 1,14 & 13400000 & 39,5 \\
\hline & 0,73 & 1670363 & 54,3 & 1,03 & 12800000 & 39,7 \\
\hline & 0,64 & 1557064 & 54,3 & 0,93 & 12300000 & 39,8 \\
\hline & 0,57 & 1451540 & 55,0 & 0,84 & 11800000 & 40,0 \\
\hline & 0,50 & 1352005 & 55,7 & 0,76 & 11300000 & 40,2 \\
\hline & & & & 0,68 & 10800000 & 40,4 \\
\hline & & & & 0,62 & 10400000 & 40,6 \\
\hline & & & & 0,55 & 9970000 & 40,8 \\
\hline & & & & 0,50 & 9550000 & 41,0 \\
\hline \multirow[t]{9}{*}{20} & 10,00 & 4250000 & 53,9 & 10,00 & 14600000 & 39,8 \\
\hline & 8,89 & 3800000 & 55,0 & 9,02 & 13600000 & 40,5 \\
\hline & 7,87 & 3450000 & 55,4 & 8,14 & 12700000 & 41,0 \\
\hline & 6,96 & 3150000 & 55,7 & 7,34 & 12000000 & 41,4 \\
\hline & 6,17 & 2910000 & 56,0 & 6,63 & 11300000 & 41,7 \\
\hline & 5,47 & 2700000 & 56,3 & 5,97 & 10600000 & 42,0 \\
\hline & 4,84 & 2500000 & 56,5 & 5,38 & 10000000 & 42,3 \\
\hline & 4,29 & 2320000 & 56,8 & 4,86 & 9500000 & 42,6 \\
\hline & 3,80 & 2160000 & 57,0 & 4,38 & 9000000 & 42,9 \\
\hline
\end{tabular}




\begin{tabular}{|c|c|c|c|c|c|c|}
\hline \multirow{2}{*}{$\begin{array}{c}\mathbf{M} \\
\mathrm{T}\end{array}$} & \multicolumn{3}{|c|}{ Original } & \multicolumn{3}{|c|}{ Envejecido } \\
\hline & $f$ & $\mathrm{G}^{*}$ & $\delta$ & $f$ & $\mathrm{G}^{*}$ & $\delta$ \\
\hline$\left[{ }^{\circ} \mathrm{C}\right]$ & {$[\mathrm{Hz}]$} & {$[\mathrm{Pa}]$} & [o] & {$[\mathrm{Hz}]$} & {$[\mathrm{Pa}]$} & [o] \\
\hline \multirow[t]{21}{*}{20} & 3,36 & 2010000 & 57,2 & 3,95 & 8530000 & 43,1 \\
\hline & 2,98 & 1860000 & 57,4 & 3,56 & 8080000 & 43,3 \\
\hline & 2,64 & 1730000 & 57,6 & 3,21 & 7660000 & 43,6 \\
\hline & 2,34 & 1620000 & 57,7 & 2,90 & 7270000 & 43,8 \\
\hline & 2,07 & 1500000 & 57,9 & 2,61 & 6910000 & 44,0 \\
\hline & 1,83 & 1390000 & 58,1 & 2,36 & 6560000 & 44,2 \\
\hline & 1,62 & 1290000 & 58,3 & 2,12 & 6220000 & 44,4 \\
\hline & 1,44 & 1200000 & 58,5 & 1,92 & 5900000 & 44,6 \\
\hline & 1,27 & 1110000 & 58,7 & 1,73 & 5600000 & 44,8 \\
\hline & 1,13 & 1030000 & 58,9 & 1,56 & 5310000 & 45,0 \\
\hline & 1,00 & 959000 & 59,1 & 1,41 & 5040000 & 45,1 \\
\hline & 0,93 & 908739 & 59,3 & 1,27 & 4780000 & 45,4 \\
\hline & 0,82 & 840159 & 60,0 & 1,14 & 4530000 & 45,5 \\
\hline & 0,73 & 776785 & 61,0 & 1,03 & 4300000 & 45,7 \\
\hline & 0,64 & 718599 & 61,5 & 0,93 & 4070000 & 45,9 \\
\hline & 0,57 & 664816 & 62,3 & 0,84 & 3860000 & 46,2 \\
\hline & 0,50 & 614473 & 63,0 & 0,76 & 3650000 & 46,3 \\
\hline & & & & 0,68 & 3460000 & 46,5 \\
\hline & & & & 0,62 & 3290000 & 46,7 \\
\hline & & & & 0,55 & 3110000 & 47,1 \\
\hline & & & & 0,50 & 2960000 & 47,2 \\
\hline \multirow[t]{20}{*}{30} & 10,00 & 1640000 & 59,4 & 10,00 & 4590000 & 48,3 \\
\hline & 8,89 & 1470000 & 60,8 & 8,89 & 4120000 & 49,4 \\
\hline & 7,87 & 1290000 & 61,3 & 7,92 & 3800000 & 49,9 \\
\hline & 6,96 & 1150000 & 61,6 & 7,02 & 3490000 & 50,3 \\
\hline & 6,17 & 1030000 & 61,9 & 6,25 & 3230000 & 50,6 \\
\hline & 5,47 & 930000 & 62,1 & 5,54 & 2990000 & 50,9 \\
\hline & 4,84 & 843000 & 62,3 & 4,93 & 2780000 & 51,2 \\
\hline & 4,29 & 769000 & 62,4 & 4,38 & 2580000 & 51,4 \\
\hline & 3,80 & 706000 & 62,5 & 3,89 & 2410000 & 51,7 \\
\hline & 3,36 & 649000 & 62,6 & 3,46 & 2250000 & 51,9 \\
\hline & 2,98 & 598000 & 62,6 & 3,07 & 2110000 & 52,1 \\
\hline & 2,64 & 551000 & 62,6 & 2,73 & 1960000 & 52,3 \\
\hline & 2,34 & 508000 & 62,7 & 2,43 & 1830000 & 52,5 \\
\hline & 2,07 & 468000 & 62,8 & 2,15 & 1710000 & 52,7 \\
\hline & 1,83 & 432000 & 63,0 & 1,92 & 1590000 & 53,0 \\
\hline & 1,62 & 398000 & 63,2 & 1,70 & 1490000 & 53,1 \\
\hline & 1,44 & 367000 & 63,3 & 1,51 & 1390000 & 53,3 \\
\hline & 1,27 & 339000 & 63,4 & 1,34 & 1290000 & 53,5 \\
\hline & 1,13 & 314000 & 63,5 & 1,19 & 1200000 & 53,7 \\
\hline & 1,00 & 291000 & 63,5 & 1,06 & 1120000 & 53,9 \\
\hline
\end{tabular}




\begin{tabular}{|c|c|c|c|c|c|c|}
\hline \multirow{2}{*}{$\frac{\mathbf{M}}{\mathrm{T}}$} & \multicolumn{3}{|c|}{ Original } & \multicolumn{3}{|c|}{ Envejecido } \\
\hline & $f$ & $\mathrm{G}^{*}$ & $\delta$ & $f$ & $\mathrm{G}^{*}$ & $\delta$ \\
\hline$\left[{ }^{\circ} \mathrm{C}\right]$ & {$[\mathrm{Hz}]$} & {$[\mathrm{Pa}]$} & [o] & {$[\mathrm{Hz}]$} & {$[\mathrm{Pa}]$} & {$[0]$} \\
\hline \multirow[t]{7}{*}{30} & 0,93 & 263610 & 64,0 & 0,94 & 1050000 & 54,1 \\
\hline & 0,82 & 240468 & 64,7 & 0,84 & 973000 & 54,3 \\
\hline & 0,73 & 219366 & 65,2 & 0,74 & 904000 & 54,4 \\
\hline & 0,64 & 200250 & 66,0 & 0,66 & 840000 & 54,8 \\
\hline & 0,57 & 182814 & 66,8 & 0,59 & 783000 & 54,9 \\
\hline & 0,50 & 166710 & 67,3 & 0,52 & 729000 & 54,9 \\
\hline & & & & 0,46 & 682000 & 55,0 \\
\hline \multirow[t]{20}{*}{40} & 10,00 & 167000 & 59,8 & 10,00 & 438000 & 42,8 \\
\hline & 8,89 & 141000 & 61,9 & 8,89 & 401000 & 44,5 \\
\hline & 7,87 & 128000 & 62,6 & 7,87 & 370000 & 45,9 \\
\hline & 6,96 & 116000 & 63,1 & 6,96 & 342000 & 47,1 \\
\hline & 6,17 & 105000 & 63,6 & 6,17 & 316000 & 48,3 \\
\hline & 5,47 & 96000 & 64,0 & 5,47 & 291000 & 49,4 \\
\hline & 4,84 & 87600 & 64,4 & 4,84 & 268000 & 50,5 \\
\hline & 4,29 & 80300 & 64,6 & 4,29 & 247000 & 51,5 \\
\hline & 3,80 & 73800 & 64,9 & 3,80 & 229000 & 52,3 \\
\hline & 3,36 & 67800 & 65,1 & 3,36 & 213000 & 52,9 \\
\hline & 2,98 & 62400 & 65,3 & 2,98 & 198000 & 53,6 \\
\hline & 2,64 & 57600 & 65,5 & 2,64 & 184000 & 54,1 \\
\hline & 2,34 & 53100 & 65,6 & 2,34 & 171000 & 54,7 \\
\hline & 2,07 & 48900 & 65,8 & 2,07 & 159000 & 55,2 \\
\hline & 1,83 & 45200 & 65,9 & 1,83 & 148000 & 55,7 \\
\hline & 1,62 & 41700 & 66,0 & 1,62 & 138000 & 56,2 \\
\hline & 1,44 & 38500 & 66,1 & 1,44 & 128000 & 56,7 \\
\hline & 1,27 & 35500 & 66,2 & 1,27 & 119000 & 57,1 \\
\hline & 1,13 & 32800 & 66,2 & 1,13 & 110000 & 57,5 \\
\hline & 1,00 & 30300 & 66,3 & 1,00 & 103000 & 57,9 \\
\hline \multirow[t]{14}{*}{50} & 10,00 & 60400 & 65,4 & 10,00 & 141000 & 57,3 \\
\hline & 8,89 & 52400 & 66,5 & 8,89 & 126000 & 58,4 \\
\hline & 7,87 & 47500 & 66,8 & 7,87 & 115000 & 59,0 \\
\hline & 6,96 & 43300 & 67,1 & 6,96 & 105000 & 59,5 \\
\hline & 6,17 & 39700 & 67,2 & 6,17 & 96000 & 59,9 \\
\hline & 5,47 & 36300 & 67,4 & 5,47 & 88200 & 60,3 \\
\hline & 4,84 & 33200 & 67,5 & 4,84 & 81100 & 60,7 \\
\hline & 4,29 & 30500 & 67,5 & 4,29 & 74700 & 61,1 \\
\hline & 3,80 & 28000 & 67,6 & 3,80 & 68900 & 61,4 \\
\hline & 3,36 & 25700 & 67,6 & 3,36 & 63500 & 61,8 \\
\hline & 2,98 & 23700 & 67,6 & 2,98 & 58600 & 62,1 \\
\hline & 2,64 & 21800 & 67,7 & 2,64 & 54100 & 62,4 \\
\hline & 2,34 & 20000 & 67,7 & 2,34 & 49900 & 62,7 \\
\hline & 2,07 & 18400 & 67,6 & 2,07 & 46000 & 63,0 \\
\hline
\end{tabular}




\begin{tabular}{|c|c|c|c|c|c|c|}
\hline \multirow{2}{*}{$\frac{\mathbf{M}}{\mathrm{T}}$} & \multicolumn{3}{|c|}{ Original } & \multicolumn{3}{|c|}{ Envejecido } \\
\hline & $f$ & $\mathrm{G}^{*}$ & $\delta$ & $f$ & $\mathrm{G}^{*}$ & $\delta$ \\
\hline & {$[\mathrm{Hz}]$} & {$[\mathrm{Pa}]$} & [o] & {$[\mathrm{Hz}]$} & {$[\mathrm{Pa}]$} & [o] \\
\hline \multirow[t]{6}{*}{50} & 1,83 & 16900 & 67,6 & 1,83 & 42400 & 63,2 \\
\hline & 1,62 & 15500 & 67,6 & 1,62 & 39100 & 63,5 \\
\hline & 1,44 & 14300 & 67,5 & 1,44 & 36100 & 63,8 \\
\hline & 1,27 & 13100 & 67,4 & 1,27 & 33200 & 64,0 \\
\hline & 1,13 & 12100 & 67,3 & 1,13 & 30600 & 64,4 \\
\hline & 1,00 & 11100 & 67,2 & 1,00 & 28300 & 64,7 \\
\hline \multirow[t]{20}{*}{60} & 10,00 & 21900 & 68,8 & 10,00 & 47600 & 64,1 \\
\hline & 8,89 & 19000 & 69,5 & 8,89 & 43300 & 64,5 \\
\hline & 7,87 & 17200 & 69,6 & 7,87 & 39500 & 64,8 \\
\hline & 6,96 & 15600 & 69,6 & 6,96 & 36100 & 65,0 \\
\hline & 6,17 & 14200 & 69,6 & 6,17 & 33100 & 65,2 \\
\hline & 5,47 & 13000 & 69,5 & 5,47 & 30300 & 65,4 \\
\hline & 4,84 & 11900 & 69,4 & 4,84 & 27700 & 65,5 \\
\hline & 4,29 & 10900 & 69,3 & 4,29 & 25400 & 65,6 \\
\hline & 3,80 & 9960 & 69,2 & 3,80 & 23300 & 65,7 \\
\hline & 3,36 & 9110 & 69,0 & 3,36 & 21300 & 65,8 \\
\hline & 2,98 & 8350 & 68,8 & 2,98 & 19500 & 65,9 \\
\hline & 2,64 & 7650 & 68,5 & 2,64 & 17900 & 66,0 \\
\hline & 2,34 & 7020 & 68,3 & 2,34 & 16400 & 66,0 \\
\hline & 2,07 & 6430 & 68,1 & 2,07 & 15000 & 66,1 \\
\hline & 1,83 & 5890 & 67,9 & 1,83 & 13700 & 66,1 \\
\hline & 1,62 & 5400 & 67,5 & 1,62 & 12500 & 66,1 \\
\hline & 1,44 & 4940 & 67,2 & 1,44 & 11500 & 66,1 \\
\hline & 1,27 & 4540 & 66,9 & 1,27 & 10500 & 66,0 \\
\hline & 1,13 & 4170 & 66,5 & 1,13 & 9600 & 66,0 \\
\hline & 1,00 & 3830 & 66,1 & 1,00 & 8790 & 65,8 \\
\hline \multirow[t]{15}{*}{70} & 10,00 & 9340 & 69,2 & 10,00 & 17100 & 68,0 \\
\hline & 8,89 & 8200 & 69,4 & 8,89 & 15500 & 68,2 \\
\hline & 7,87 & 7410 & 69,3 & 7,87 & 14000 & 68,3 \\
\hline & 6,96 & 6730 & 69,1 & 6,96 & 12800 & 68,2 \\
\hline & 6,17 & 6140 & 68,9 & 6,17 & 11700 & 68,2 \\
\hline & 5,47 & 5600 & 68,5 & 5,47 & 10600 & 68,1 \\
\hline & 4,84 & 5100 & 68,1 & 4,84 & 9700 & 68,0 \\
\hline & 4,29 & 4660 & 67,6 & 4,29 & 8860 & 67,8 \\
\hline & 3,80 & 4260 & 67,1 & 3,80 & 8070 & 67,6 \\
\hline & 3,36 & 3890 & 66,6 & 3,36 & 7360 & 67,4 \\
\hline & 2,98 & 3560 & 66,0 & 2,98 & 6710 & 67,1 \\
\hline & 2,64 & 3260 & 65,3 & 2,64 & 6100 & 66,8 \\
\hline & 2,34 & 2990 & 64,7 & 2,34 & 5570 & 66,4 \\
\hline & 2,07 & 2740 & 64,3 & 2,07 & 5060 & 66,2 \\
\hline & 1,83 & 2500 & 64,0 & 1,83 & 4610 & 65,9 \\
\hline
\end{tabular}


DEFORMACIONES PERMANENTES EN MEZCLAS ASFÁLTICAS.

Efecto de la reología de los asfaltos, la temperatura y las condiciones de carga

\begin{tabular}{ccccccc}
\hline $\mathbf{M}$ & & Original & & \multicolumn{3}{c}{ Envejecido } \\
\hline $\mathrm{T}$ & $f$ & $\mathrm{G}^{*}$ & $\delta$ & $f$ & $\mathrm{G}^{*}$ & $\delta$ \\
{$\left[{ }^{\circ} \mathrm{C}\right]$} & {$[\mathrm{Hz}]$} & {$[\mathrm{Pa}]$} & {$[\mathrm{o}]$} & {$[\mathrm{Hz}]$} & {$[\mathrm{Pa}]$} & {$[\mathrm{o}]$} \\
\hline 70 & 1,62 & 2290 & 63,3 & 1,62 & 4210 & 65,4 \\
& 1,44 & 2110 & 63,0 & 1,44 & 3840 & 65,1 \\
& 1,27 & 1940 & 61,9 & 1,27 & 3500 & 64,5 \\
& 1,13 & 1780 & 61,7 & 1,13 & 3200 & 63,7 \\
& 1,00 & 1650 & 61,0 & 1,00 & 2930 & 62,9 \\
\hline 80 & 10,00 & 2300 & 66,8 & 10,00 & 3450 & 66,0 \\
& 8,89 & 2060 & 67,5 & 8,89 & 3170 & 65,4 \\
& 7,87 & 1820 & 67,3 & 7,92 & 2900 & 64,1 \\
& 6,96 & 1650 & 64,7 & 7,02 & 2650 & 62,9 \\
& 6,17 & 1480 & 64,4 & 6,25 & 2430 & 61,7 \\
& 5,47 & 1340 & 63,4 & 5,54 & 2220 & 60,2 \\
& 4,84 & 1190 & 63,3 & 4,93 & 2040 & 58,7 \\
& 4,29 & 1060 & 62,7 & 4,38 & 1880 & 57,0 \\
& 3,80 & 941 & 61,7 & 3,89 & 1730 & 55,3 \\
& 3,36 & 835 & 60,6 & 3,46 & 1600 & 53,4 \\
& 2,98 & 750 & 59,9 & 3,07 & 1480 & 51,8 \\
& 2,64 & 689 & 70,1 & 2,73 & 1370 & 50,4 \\
& 2,34 & 607 & 68,4 & 2,43 & 1260 & 49,7 \\
& 2,07 & 542 & 68,4 & 2,15 & 1170 & 48,8 \\
& & & & 1,92 & 1080 & 47,6 \\
& & & & 1,70 & 977 & 48,1 \\
\hline
\end{tabular}



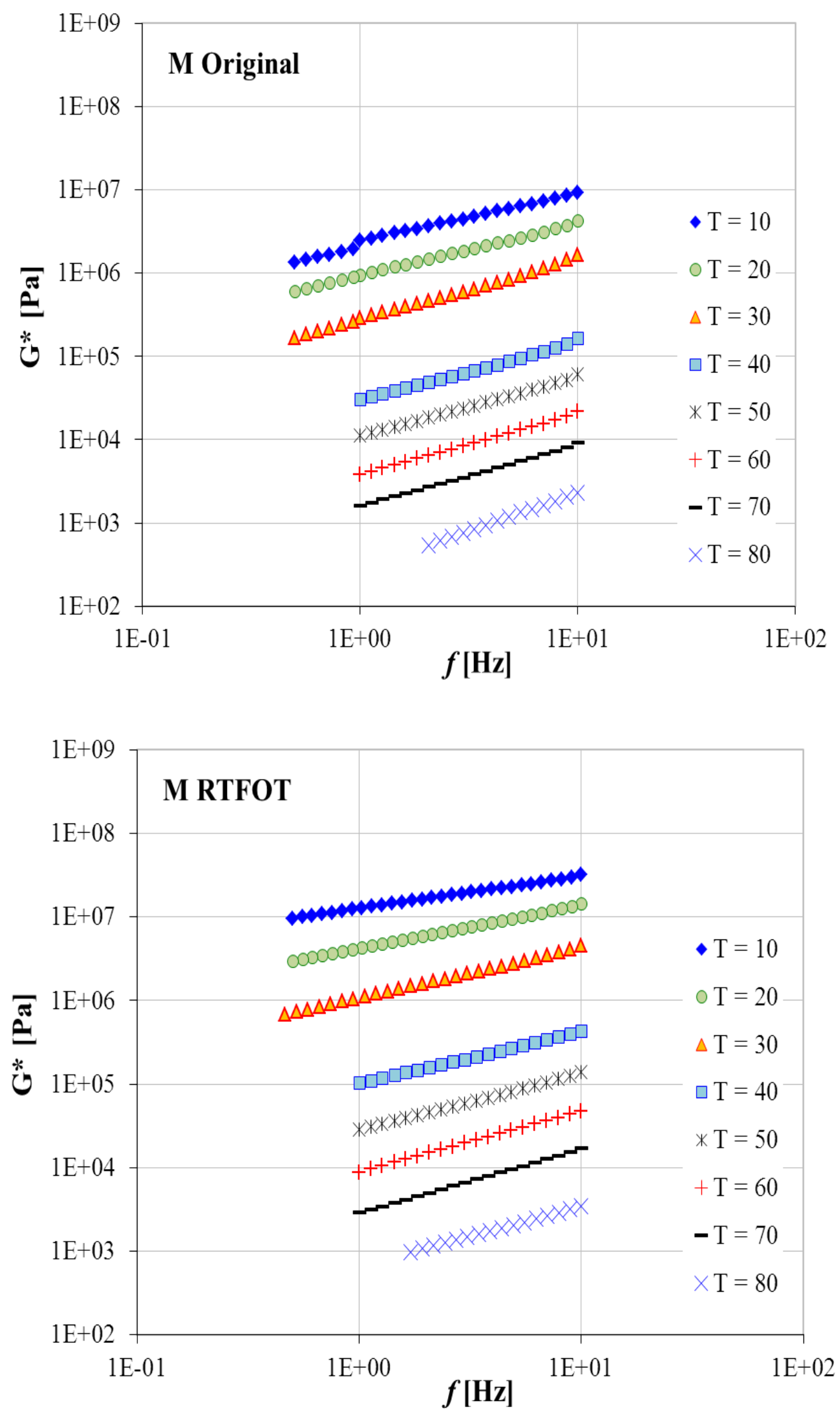


\section{Asfalto MP1}

\begin{tabular}{|c|c|c|c|c|c|c|}
\hline & \multicolumn{3}{|c|}{ Original } & \multicolumn{3}{|c|}{ Envejecido } \\
\hline $\mathrm{T}$ & $f$ & $\mathrm{G}^{*}$ & $\delta$ & $f$ & $\mathrm{G}^{*}$ & $\delta$ \\
\hline$\left[{ }^{\circ} \mathrm{C}\right]$ & {$[\mathrm{Hz}]$} & [Pa] & [o] & {$[\mathrm{Hz}]$} & {$[\mathrm{Pa}]$} & [o] \\
\hline \multirow[t]{30}{*}{10} & 10,00 & 21800000 & 40,6 & 10,00 & 21900000 & 37,8 \\
\hline & 7,77 & 19500000 & 41,4 & 9,02 & 20700000 & 38,4 \\
\hline & 6,00 & 17400000 & 42,0 & 8,14 & 19800000 & 38,7 \\
\hline & 4,64 & 15500000 & 42,7 & 7,34 & 19000000 & 39,0 \\
\hline & 3,60 & 13800000 & 43,3 & 6,63 & 18200000 & 39,3 \\
\hline & 2,78 & 12200000 & 43,9 & 5,97 & 17400000 & 39,6 \\
\hline & 2,15 & 10800000 & 44,5 & 5,38 & 16700000 & 39,8 \\
\hline & 1,67 & 9530000 & 45,1 & 4,86 & 16000000 & 40,0 \\
\hline & 1,29 & 8380000 & 45,7 & 4,38 & 15300000 & 40,3 \\
\hline & 1,00 & 7370000 & 46,2 & 3,95 & 14600000 & 40,5 \\
\hline & 0,82 & 6274879 & 46,4 & 3,56 & 14000000 & 40,7 \\
\hline & 0,64 & 5449725 & 46,8 & 3,21 & 13400000 & 40,9 \\
\hline & 0,50 & 4732016 & 47,2 & 2,90 & 12800000 & 41,1 \\
\hline & & & & 2,61 & 12200000 & 41,4 \\
\hline & & & & 2,36 & 11700000 & 42,0 \\
\hline & & & & 2,12 & 11200000 & 42,0 \\
\hline & & & & 1,92 & 10700000 & 42,0 \\
\hline & & & & 1,73 & 10200000 & 42,0 \\
\hline & & & & 1,56 & 9720000 & 42,0 \\
\hline & & & & 1,41 & 9270000 & 42,0 \\
\hline & & & & 1,27 & 8850000 & 42,6 \\
\hline & & & & 1,14 & 8440000 & 42,8 \\
\hline & & & & 1,03 & 8050000 & 43,0 \\
\hline & & & & 0,93 & 7680000 & 43,1 \\
\hline & & & & 0,84 & 7330000 & 43,2 \\
\hline & & & & 0,76 & 6980000 & 43,4 \\
\hline & & & & 0,68 & 6660000 & 43,5 \\
\hline & & & & 0,62 & 6340000 & 43,7 \\
\hline & & & & 0,55 & 6040000 & 43,8 \\
\hline & & & & 0,50 & 5750000 & 43,9 \\
\hline \multirow[t]{9}{*}{20} & 10,00 & 6050000 & 50,4 & 10,00 & 7030000 & 44,7 \\
\hline & 7,87 & 5350000 & 50,8 & 9,02 & 6560000 & 45,2 \\
\hline & 6,17 & 4710000 & 51,2 & 8,14 & 6160000 & 45,6 \\
\hline & 4,84 & 4140000 & 51,5 & 7,34 & 5790000 & 45,9 \\
\hline & 3,80 & 3630000 & 51,7 & 6,63 & 5460000 & 46,1 \\
\hline & 2,98 & 3180000 & 51,9 & 5,97 & 5140000 & 46,4 \\
\hline & 2,34 & 2770000 & 52,1 & 5,38 & 4850000 & 46,6 \\
\hline & 1,83 & 2410000 & 52,3 & 4,86 & 4570000 & 46,8 \\
\hline & 1,44 & 2100000 & 52,4 & 4,38 & 4320000 & 47,0 \\
\hline
\end{tabular}




\begin{tabular}{|c|c|c|c|c|c|c|}
\hline MP1 & & Original & & & nvejecido & \\
\hline $\mathrm{T}$ & $f$ & $\mathrm{G}^{*}$ & $\delta$ & $f$ & $\mathrm{G}^{*}$ & $\delta$ \\
\hline$\left[{ }^{\circ} \mathrm{C}\right]$ & {$[\mathrm{Hz}]$} & {$[\mathrm{Pa}]$} & [o] & {$[\mathrm{Hz}]$} & {$[\mathrm{Pa}]$} & [o] \\
\hline 20 & 0,70 & 1370000 & 52,3 & 3,21 & 3640000 & 47,4 \\
\hline & 0,55 & 1180000 & 52,2 & 2,90 & 3440000 & 47,6 \\
\hline & & & & 2,61 & 3240000 & 47,8 \\
\hline & & & & 2,36 & 3070000 & 47,9 \\
\hline & & & & 2,12 & 2890000 & 48,1 \\
\hline & & & & 1,92 & 2730000 & 48,2 \\
\hline & & & & 1,73 & 2580000 & 48,3 \\
\hline & & & & 1,56 & 2430000 & 48,4 \\
\hline & & & & 1,41 & 2290000 & 48,0 \\
\hline & & & & 1,27 & 2160000 & 49,0 \\
\hline & & & & 1,14 & 2040000 & 49,0 \\
\hline & & & & 1,03 & 1920000 & 49,0 \\
\hline & & & & 0,93 & 1810000 & 49,0 \\
\hline & & & & 0,84 & 1700000 & 49,2 \\
\hline & & & & 0,76 & 1600000 & 49,2 \\
\hline & & & & 0,68 & 1510000 & 49,5 \\
\hline & & & & 0,62 & 1420000 & 49,7 \\
\hline & & & & 0,55 & 1340000 & 49,6 \\
\hline & & & & 0,50 & 1260000 & 49,7 \\
\hline 30 & 10,00 & 1250000 & 60,4 & 10,00 & 1790000 & 51,1 \\
\hline & 8,89 & 1090000 & 61,5 & 9,02 & 1670000 & 53,1 \\
\hline & 7,87 & 973000 & 62,0 & 8,14 & 1590000 & 50,9 \\
\hline & 6,96 & 872000 & 62,3 & 7,34 & 1500000 & 50,6 \\
\hline & 6,17 & 789000 & 62,5 & 6,63 & 1420000 & 50,6 \\
\hline & 5,47 & 719000 & 62,7 & 5,97 & 1330000 & 50,5 \\
\hline & 4,84 & 656000 & 62,9 & 5,38 & 1250000 & 50,3 \\
\hline & 4,29 & 601000 & 63,1 & 4,86 & 1170000 & 50,3 \\
\hline & 3,80 & 553000 & 63,3 & 4,38 & 1100000 & 50,0 \\
\hline & 3,36 & 508000 & 63,4 & 3,95 & 1030000 & 49,8 \\
\hline & 2,98 & 469000 & 63,5 & 3,56 & 977000 & 49,7 \\
\hline & 2,64 & 432000 & 63,6 & 3,21 & 919000 & 49,3 \\
\hline & 2,34 & 396000 & 63,7 & 2,90 & 865000 & 49,1 \\
\hline & 2,07 & 363000 & 63,2 & 2,61 & 815000 & 48,7 \\
\hline & 1,83 & 335000 & 62,9 & 2,36 & 767000 & 48,4 \\
\hline & 1,62 & 309000 & 62,7 & 2,12 & 720000 & 48,5 \\
\hline & 1,44 & 285000 & 62,7 & 1,92 & 678000 & 48,3 \\
\hline & 1,27 & 263000 & 62,6 & 1,73 & 639000 & 48,0 \\
\hline & 1,13 & 242000 & 63,2 & 1,56 & 602000 & 48,0 \\
\hline & 1,00 & 223000 & 63,1 & 1,41 & 568000 & 47,6 \\
\hline & 0,93 & 206097 & 63,5 & 1,27 & 535000 & 47,4 \\
\hline & 0,82 & 188241 & 63,8 & 1,14 & 504000 & 46,9 \\
\hline
\end{tabular}




\begin{tabular}{|c|c|c|c|c|c|c|}
\hline \multirow{2}{*}{$\frac{\text { MP1 }}{\mathrm{T}}$} & \multicolumn{3}{|c|}{ Original } & \multicolumn{3}{|c|}{ Envejecido } \\
\hline & $f$ & $\mathrm{G}^{*}$ & $\delta$ & $f$ & $\mathrm{G}^{*}$ & $\delta$ \\
\hline$\left[{ }^{\circ} \mathrm{C}\right]$ & {$[\mathrm{Hz}]$} & {$[\mathrm{Pa}]$} & [o] & {$[\mathrm{Hz}]$} & {$[\mathrm{Pa}]$} & [o] \\
\hline \multirow[t]{8}{*}{30} & 0,73 & 171940 & 64,0 & 1,03 & 476000 & 46,6 \\
\hline & 0,64 & 157154 & 64,5 & 0,93 & 451000 & 46,3 \\
\hline & 0,57 & 143651 & 64,9 & 0,84 & 426000 & 45,9 \\
\hline & 0,50 & 131163 & 65,3 & 0,76 & 402000 & 45,3 \\
\hline & & & & 0,68 & 380000 & 46,3 \\
\hline & & & & 0,62 & 361000 & 44,7 \\
\hline & & & & 0,55 & 342000 & 44,3 \\
\hline & & & & 0,50 & 323000 & 44,7 \\
\hline \multirow[t]{20}{*}{40} & 9,72 & 303000 & 61,0 & 10,00 & 215000 & 53,7 \\
\hline & 7,64 & 262000 & 62,5 & 8,89 & 200000 & 55,0 \\
\hline & 6,00 & 225000 & 63,3 & 7,87 & 186000 & 55,2 \\
\hline & 4,72 & 191000 & 63,1 & 6,96 & 173000 & 55,7 \\
\hline & 3,71 & 161000 & 63,1 & 6,17 & 161000 & 56,2 \\
\hline & 2,91 & 134000 & 63,3 & 5,47 & 150000 & 56,6 \\
\hline & 2,29 & 113000 & 62,9 & 4,84 & 140000 & 57,1 \\
\hline & 1,80 & 94400 & 62,2 & 4,29 & 130000 & 57,0 \\
\hline & 1,41 & 78800 & 61,5 & 3,80 & 120000 & 58,0 \\
\hline & 1,11 & 65200 & 61,5 & 3,36 & 112000 & 58,0 \\
\hline & & & & 2,98 & 103000 & 58,0 \\
\hline & & & & 2,64 & 96000 & 59,0 \\
\hline & & & & 2,34 & 88900 & 59,0 \\
\hline & & & & 2,07 & 82300 & 59,0 \\
\hline & & & & 1,83 & 76200 & 59,0 \\
\hline & & & & 1,62 & 70500 & 60,0 \\
\hline & & & & 1,44 & 65200 & 60,0 \\
\hline & & & & 1,27 & 60300 & 60,0 \\
\hline & & & & 1,13 & 55800 & 60,0 \\
\hline & & & & 1,00 & 51600 & 60,0 \\
\hline \multirow[t]{13}{*}{50} & 10,00 & 56000 & 67,5 & 10,00 & 66400 & 60,3 \\
\hline & 8,89 & 50800 & 67,8 & 8,89 & 61400 & 60,8 \\
\hline & 7,87 & 46300 & 68,0 & 7,87 & 56900 & 61,0 \\
\hline & 6,96 & 42200 & 68,1 & 6,96 & 52600 & 61,2 \\
\hline & 6,17 & 38500 & 68,3 & 6,17 & 48900 & 61,4 \\
\hline & 5,47 & 35100 & 68,3 & 0,47 & 45200 & 61,6 \\
\hline & 4,84 & 32000 & 68,4 & 4,84 & 41800 & 61,7 \\
\hline & 4,29 & 29200 & 68,4 & 4,29 & 38600 & 61,8 \\
\hline & 3,80 & 26600 & 68,4 & 3,80 & 35600 & 61,9 \\
\hline & 3,36 & 24200 & 68,5 & 3,36 & 32900 & 62,0 \\
\hline & 2,98 & 22100 & 68,4 & 2,98 & 30400 & 62,0 \\
\hline & 2,64 & 20100 & 68,4 & 2,64 & 28000 & 62,1 \\
\hline & 2,34 & 18300 & 68,4 & 2,34 & 25800 & 62,1 \\
\hline
\end{tabular}




\begin{tabular}{|c|c|c|c|c|c|c|}
\hline \multirow{2}{*}{$\frac{\text { MP1 }}{\mathrm{T}}$} & \multicolumn{3}{|c|}{ Original } & \multicolumn{3}{|c|}{ Envejecido } \\
\hline & $f$ & $\mathrm{G}^{*}$ & $\delta$ & $f$ & $\mathrm{G}^{*}$ & $\delta$ \\
\hline$\left[{ }^{\circ} \mathrm{C}\right]$ & {$[\mathrm{Hz}]$} & {$[\mathrm{Pa}]$} & [o] & {$[\mathrm{Hz}]$} & {$[\mathrm{Pa}]$} & [o] \\
\hline \multirow[t]{7}{*}{50} & 2,07 & 16700 & 68,3 & 2,07 & 23800 & 62,2 \\
\hline & 1,83 & 15200 & 68,2 & 1,83 & 21900 & 62,2 \\
\hline & 1,62 & 13800 & 68,2 & 1,62 & 20200 & 62,3 \\
\hline & 1,44 & 12600 & 68,1 & 1,44 & 18600 & 62,3 \\
\hline & 1,27 & 11500 & 67,9 & 1,27 & 17100 & 62,3 \\
\hline & 1,13 & 10500 & 67,8 & 1,13 & 15800 & 62,3 \\
\hline & 1,00 & 9540 & 67,7 & 1,00 & 14500 & 62,0 \\
\hline \multirow[t]{20}{*}{60} & 10,00 & 14300 & 71,7 & 10,00 & 21100 & 65,0 \\
\hline & 7,84 & 12200 & 72,4 & 8,89 & 18700 & 65,5 \\
\hline & 6,14 & 10400 & 73,0 & 7,87 & 16900 & 65,7 \\
\hline & 4,81 & 8770 & 73,6 & 6,96 & 15300 & 65,9 \\
\hline & 3,76 & 7330 & 74,2 & 6,17 & 14000 & 66,0 \\
\hline & 2,95 & 6080 & 74,7 & 5,47 & 12800 & 66,0 \\
\hline & 2,31 & 5020 & 75,2 & 4,84 & 11700 & 66,1 \\
\hline & 1,81 & 4120 & 75,7 & 4,29 & 10700 & 66,2 \\
\hline & 1,41 & 3370 & 76,1 & 3,80 & 9830 & 66,1 \\
\hline & 1,11 & 2750 & 76,4 & 3,36 & 8980 & 66,0 \\
\hline & & & & 2,98 & 8210 & 66,0 \\
\hline & & & & 2,64 & 7480 & 66,0 \\
\hline & & & & 2,34 & 6820 & 66,1 \\
\hline & & & & 2,07 & 6220 & 66,0 \\
\hline & & & & 1,83 & 5690 & 65,6 \\
\hline & & & & 1,62 & 5190 & 65,8 \\
\hline & & & & 1,44 & 4750 & 65,0 \\
\hline & & & & 1,27 & 4340 & 65,2 \\
\hline & & & & 1,13 & 3960 & 65,0 \\
\hline & & & & 1,00 & 3630 & 64,4 \\
\hline \multirow[t]{14}{*}{70} & 10,00 & 4870 & 75,2 & 10,00 & 11200 & 68,6 \\
\hline & 8,89 & 4370 & 75,3 & 8,89 & 9030 & 68,5 \\
\hline & 7,87 & 3920 & 75,3 & 7,87 & 7770 & 68,5 \\
\hline & 6,96 & 3500 & 75,1 & 6,96 & 6810 & 68,5 \\
\hline & 6,17 & 3150 & 75,0 & 6,17 & 6060 & 68,4 \\
\hline & 5,47 & 2820 & 74,8 & 5,47 & 5410 & 68,3 \\
\hline & 4,84 & 2530 & 74,7 & 4,84 & 4860 & 68,1 \\
\hline & 4,29 & 2270 & 74,4 & 4,29 & 4380 & 68,0 \\
\hline & 3,80 & 2030 & 74,1 & 3,80 & 3950 & 67,7 \\
\hline & 3,36 & 1820 & 73,8 & 3,36 & 3570 & 67,4 \\
\hline & 2,98 & 1630 & 73,3 & 2,98 & 3220 & 67,0 \\
\hline & 2,64 & 1450 & 73,1 & 2,64 & 2920 & 66,5 \\
\hline & 2,34 & 1280 & 75,1 & 2,34 & 2630 & 66,6 \\
\hline & 2,07 & 1150 & 77,9 & 2,07 & 2370 & 66,1 \\
\hline
\end{tabular}


DEFORMACIONES PERMANENTES EN MEZCLAS ASFÁLTICAS.

Efecto de la reología de los asfaltos, la temperatura y las condiciones de carga

\begin{tabular}{|c|c|c|c|c|c|c|}
\hline \multirow{2}{*}{$\frac{\text { MP1 }}{\mathrm{T}}$} & \multicolumn{3}{|c|}{ Original } & \multicolumn{3}{|c|}{ Envejecido } \\
\hline & $f$ & $\mathrm{G}^{*}$ & $\delta$ & $f$ & $\mathrm{G}^{*}$ & $\delta$ \\
\hline$\left[{ }^{\circ} \mathrm{C}\right]$ & {$[\mathrm{Hz}]$} & {$[\mathrm{Pa}]$} & [o] & {$[\mathrm{Hz}]$} & {$[\mathrm{Pa}]$} & [o] \\
\hline \multirow[t]{6}{*}{70} & 1,83 & 1020 & 78,7 & 1,83 & 2140 & 65,9 \\
\hline & 1,62 & 936 & 80,7 & 1,62 & 1940 & 65,2 \\
\hline & 1,44 & 849 & 81,3 & 1,44 & 1750 & 65,5 \\
\hline & 1,27 & 790 & 83,3 & 1,27 & 1580 & 64,7 \\
\hline & 1,13 & 706 & 84,2 & 1,13 & 1440 & 64,2 \\
\hline & 1,00 & 657 & 87,8 & 1,00 & 1310 & 64,6 \\
\hline \multirow[t]{20}{*}{80} & 10,00 & 2540 & 78,5 & 10,00 & 5780 & 77,7 \\
\hline & 7,84 & 2090 & 78,8 & 8,89 & 4730 & 77,3 \\
\hline & 6,14 & 1700 & 79,0 & 7,87 & 4070 & 77,3 \\
\hline & 4,81 & 1380 & 79,0 & 6,96 & 3560 & 77,2 \\
\hline & 3,76 & 1110 & 78,9 & 6,17 & 3170 & 77,2 \\
\hline & 2,95 & 891 & 78,4 & 5,47 & 2820 & 77,3 \\
\hline & 2,31 & 710 & 77,6 & 4,84 & 2510 & 77,3 \\
\hline & 1,81 & 564 & 77,0 & 4,29 & 2240 & 77,4 \\
\hline & 1,41 & 448 & 76,0 & 3,80 & 2000 & 77,2 \\
\hline & 1,11 & 355 & 74,7 & 3,36 & 1780 & 77,2 \\
\hline & & & & 2,98 & 1590 & 77,0 \\
\hline & & & & 2,64 & 1420 & 77,1 \\
\hline & & & & 2,34 & 1280 & 77,0 \\
\hline & & & & 2,07 & 1140 & 78,8 \\
\hline & & & & 1,83 & 1020 & 80,7 \\
\hline & & & & 1,62 & 915 & 84,1 \\
\hline & & & & 1,44 & 826 & 87,9 \\
\hline & & & & 1,27 & 735 & 85,6 \\
\hline & & & & 1,13 & 675 & 89,9 \\
\hline & & & & 1,00 & 649 & 65,4 \\
\hline
\end{tabular}



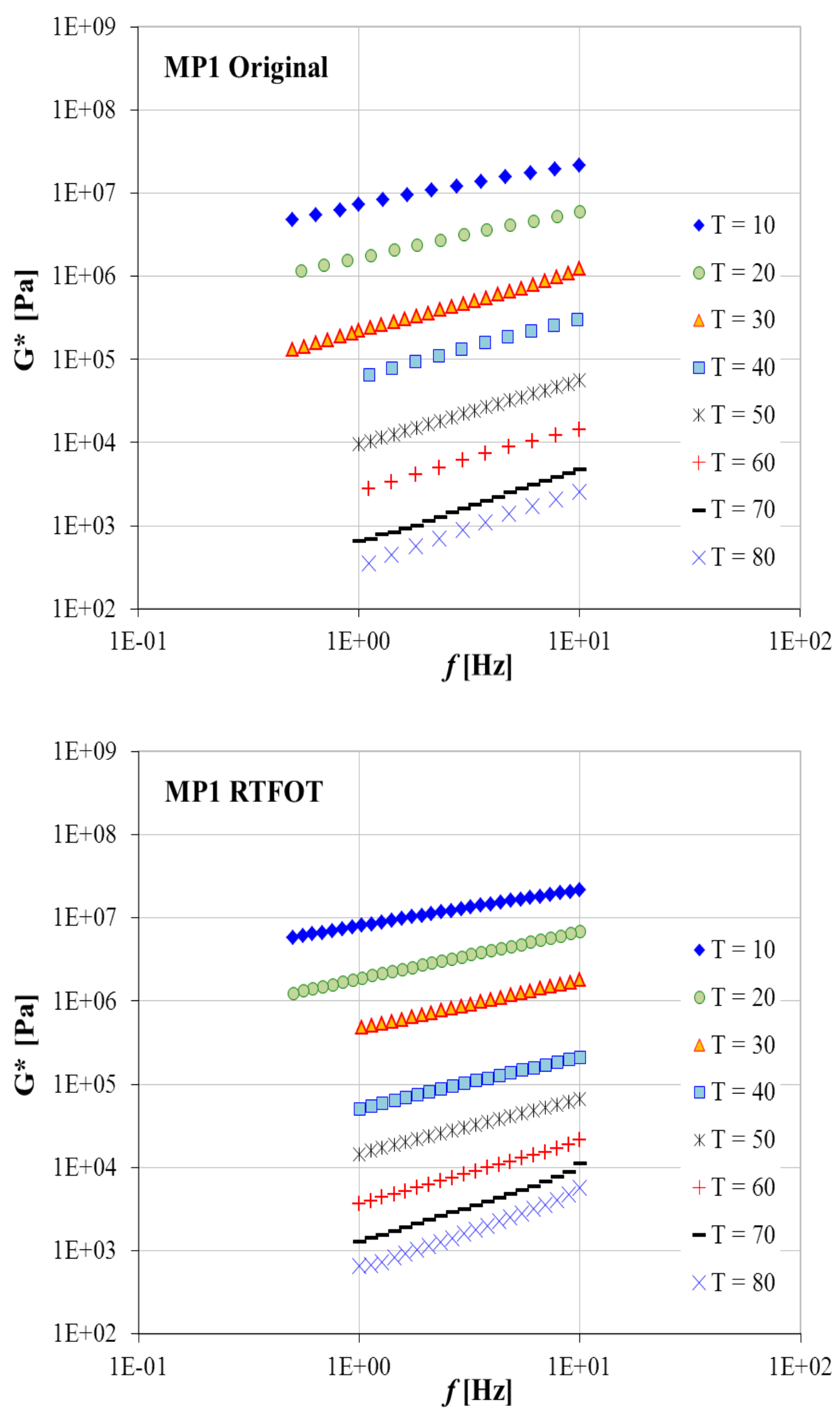


\section{Asfalto MP2}

\begin{tabular}{|c|c|c|c|c|c|c|}
\hline & \multicolumn{3}{|c|}{ Original } & \multicolumn{3}{|c|}{ Envejecido } \\
\hline $\mathrm{T}$ & $f$ & $\mathrm{G}^{*}$ & $\delta$ & $f$ & $\mathrm{G}^{*}$ & $\delta$ \\
\hline$\left[{ }^{\circ} \mathrm{C}\right]$ & {$[\mathrm{Hz}]$} & [Pa] & [o] & {$[\mathrm{Hz}]$} & {$[\mathrm{Pa}]$} & [o] \\
\hline \multirow[t]{30}{*}{10} & 10,00 & 24100000 & 43,8 & 10,00 & 18100000 & 41,5 \\
\hline & 7,77 & 21400000 & 44,8 & 9,02 & 17100000 & 42,2 \\
\hline & 6,00 & 18900000 & 45,9 & 8,14 & 16300000 & 42,7 \\
\hline & 4,64 & 16600000 & 46,9 & 7,34 & 15500000 & 43,1 \\
\hline & 3,60 & 14600000 & 47,9 & 6,63 & 14800000 & 43,5 \\
\hline & 2,78 & 12700000 & 49,0 & 5,97 & 14100000 & 43,9 \\
\hline & 2,15 & 11000000 & 50,0 & 5,38 & 13400000 & 44,3 \\
\hline & 1,67 & 9570000 & 51,0 & 4,86 & 12800000 & 44,6 \\
\hline & 1,29 & 8260000 & 52,1 & 4,38 & 12200000 & 45,0 \\
\hline & 1,00 & 7100000 & 53,0 & 3,95 & 11600000 & 45,4 \\
\hline & 0,82 & 6316071 & 53,1 & 3,56 & 11000000 & 45,7 \\
\hline & 0,64 & 5531971 & 54,0 & 3,21 & 10500000 & 46,1 \\
\hline & 0,50 & 4844188 & 54,5 & 2,90 & 9970000 & 46,5 \\
\hline & & & & 2,61 & 9470000 & 46,8 \\
\hline & & & & 2,36 & 8990000 & 47,0 \\
\hline & & & & 2,12 & 8540000 & 48,0 \\
\hline & & & & 1,92 & 8110000 & 48,0 \\
\hline & & & & 1,73 & 7690000 & 48,0 \\
\hline & & & & 1,56 & 7290000 & 49,0 \\
\hline & & & & 1,41 & 6910000 & 49,0 \\
\hline & & & & 1,27 & 6550000 & 49,3 \\
\hline & & & & 1,14 & 6200000 & 49,7 \\
\hline & & & & 1,03 & 5870000 & 50,0 \\
\hline & & & & 0,93 & 5550000 & 50,4 \\
\hline & & & & 0,84 & 5240000 & 50,8 \\
\hline & & & & 0,76 & 4960000 & 51,1 \\
\hline & & & & 0,68 & 4680000 & 51,5 \\
\hline & & & & 0,62 & 4420000 & 51,8 \\
\hline & & & & 0,55 & 4180000 & 52,1 \\
\hline & & & & 0,50 & 3940000 & 52,5 \\
\hline \multirow[t]{9}{*}{20} & 10,00 & 5760000 & 57,5 & 10,00 & 6560000 & 49,9 \\
\hline & 7,87 & 5020000 & 58,3 & 9,02 & 6050000 & 50,5 \\
\hline & 6,17 & 4340000 & 59,1 & 8,14 & 5610000 & 51,1 \\
\hline & 4,84 & 3750000 & 59,8 & 7,34 & 5210000 & 51,6 \\
\hline & 3,80 & 3230000 & 60,5 & 6,63 & 4870000 & 52,0 \\
\hline & 2,98 & 2760000 & 61,1 & 5,97 & 4520000 & 52,5 \\
\hline & 2,34 & 2350000 & 61,6 & 5,38 & 4220000 & 52,9 \\
\hline & 1,83 & 2000000 & 62,2 & 4,86 & 3940000 & 53,2 \\
\hline & 1,44 & 1690000 & 62,8 & 4,38 & 3680000 & 53,6 \\
\hline
\end{tabular}




\begin{tabular}{|c|c|c|c|c|c|c|}
\hline MP2 & & Original & & & nvejecido & \\
\hline $\mathrm{T}$ & $f$ & $\mathrm{G}^{*}$ & $\delta$ & $f$ & $\mathrm{G}^{*}$ & $\delta$ \\
\hline$\left[{ }^{\circ} \mathrm{C}\right]$ & {$[\mathrm{Hz}]$} & {$[\mathrm{Pa}]$} & [o] & {$[\mathrm{Hz}]$} & {$[\mathrm{Pa}]$} & [o] \\
\hline 20 & 1,13 & 1430000 & 63,3 & 3,95 & 3440000 & 54,0 \\
\hline & 0,89 & 1200000 & 63,8 & 3,56 & 3220000 & 54,3 \\
\hline & 0,70 & 1010000 & 64,2 & 3,21 & 3010000 & 54,7 \\
\hline & 0,55 & 841000 & 64,6 & 2,90 & 2810000 & 55,0 \\
\hline & 0,43 & 703000 & 64,8 & 2,61 & 2630000 & 55,4 \\
\hline & & & & 2,36 & 2450000 & 55,7 \\
\hline & & & & 2,12 & 2290000 & 56,1 \\
\hline & & & & 1,92 & 2140000 & 56,4 \\
\hline & & & & 1,73 & 2000000 & 56,7 \\
\hline & & & & 1,56 & 1860000 & 57,2 \\
\hline & & & & 1,41 & 1730000 & 57,0 \\
\hline & & & & 1,27 & 1620000 & 58,0 \\
\hline & & & & 1,14 & 1510000 & 58,0 \\
\hline & & & & 1,03 & 1400000 & 58,0 \\
\hline & & & & 0,93 & 1310000 & 58,0 \\
\hline & & & & 0,84 & 1220000 & 58,7 \\
\hline & & & & 0,76 & 1140000 & 59,4 \\
\hline & & & & 0,68 & 1060000 & 59,3 \\
\hline & & & & 0,62 & 984000 & 59,7 \\
\hline & & & & 0,55 & 916000 & 59,9 \\
\hline & & & & 0,50 & 848000 & 60,0 \\
\hline 30 & & & & 10,00 & 1730000 & 58,2 \\
\hline & & & & 8,76 & 1520000 & 59,4 \\
\hline & & & & 7,64 & 1350000 & 60,2 \\
\hline & & & & 6,67 & 1210000 & 60,7 \\
\hline & & & & 5,83 & 1080000 & 61,1 \\
\hline & & & & 5,08 & 964000 & 61,5 \\
\hline & & & & 4,44 & 866000 & 61,8 \\
\hline & & & & 3,88 & 780000 & 62,1 \\
\hline & & & & 3,39 & 702000 & 62,4 \\
\hline & & & & 2,96 & 633000 & 62,7 \\
\hline & & & & 2,58 & 571000 & 62,9 \\
\hline & & & & 2,26 & 511000 & 63,8 \\
\hline & & & & 1,97 & 458000 & 64,5 \\
\hline & & & & 1,72 & 412000 & 65,6 \\
\hline & & & & 1,50 & 370000 & 66,2 \\
\hline & & & & 1,31 & 333000 & 66,7 \\
\hline & & & & 1,15 & 300000 & 67,9 \\
\hline & & & & 1,00 & 269000 & 69,0 \\
\hline & & & & 0,87 & 243000 & 70,1 \\
\hline & & & & 0,76 & 215000 & 74,9 \\
\hline
\end{tabular}




\begin{tabular}{|c|c|c|c|c|c|c|}
\hline MP2 & & Original & & & ivejecido & \\
\hline $\mathrm{T}$ & $f$ & $\mathrm{G}^{*}$ & $\delta$ & $f$ & $\mathrm{G}^{*}$ & $\delta$ \\
\hline$\left[{ }^{\circ} \mathrm{C}\right]$ & {$[\mathrm{Hz}]$} & {$[\mathrm{Pa}]$} & [o] & {$[\mathrm{Hz}]$} & {$[\mathrm{Pa}]$} & [o] \\
\hline 30 & & & & 0,67 & 195000 & 76,3 \\
\hline & & & & 0,58 & 178000 & 73,8 \\
\hline & & & & 0,51 & 162000 & 74,1 \\
\hline 40 & 11,50 & 165000 & 65,6 & 10,00 & 258000 & 59,7 \\
\hline & 8,96 & 137000 & 66,5 & 8,89 & 234000 & 60,6 \\
\hline & 6,98 & 113000 & 67,2 & 7,87 & 215000 & 61,4 \\
\hline & 5,43 & 93900 & 67,7 & 6,96 & 197000 & 62,0 \\
\hline & 4,23 & 77600 & 68,1 & 6,17 & 181000 & 62,6 \\
\hline & 3,30 & 64000 & 68,3 & 5,47 & 166000 & 63,1 \\
\hline & 2,57 & 52800 & 68,4 & 4,84 & 152000 & 63,6 \\
\hline & 2,00 & 43500 & 68,4 & 4,29 & 139000 & 64,0 \\
\hline & 1,56 & 35900 & 68,3 & 3,80 & 127000 & 64,4 \\
\hline & 1,21 & 29600 & 68,1 & 3,36 & 116000 & 64,7 \\
\hline & 0,95 & 24500 & 67,9 & 2,98 & 107000 & 65,0 \\
\hline & & & & 2,64 & 97500 & 65,2 \\
\hline & & & & 2,34 & 89200 & 65,5 \\
\hline & & & & 2,07 & 81600 & 65,6 \\
\hline & & & & 1,83 & 74600 & 65,7 \\
\hline & & & & 1,62 & 68200 & 65,9 \\
\hline & & & & 1,44 & 62400 & 66,0 \\
\hline & & & & 1,27 & 57000 & 66,0 \\
\hline & & & & 1,13 & 52100 & 66,0 \\
\hline & & & & 1,00 & 47600 & 66,0 \\
\hline 50 & 10,00 & 56000 & 68,4 & 10,00 & 71800 & 66,9 \\
\hline & 8,89 & 50800 & 68,3 & 8,89 & 65300 & 67,0 \\
\hline & 7,87 & 46300 & 68,3 & 7,87 & 59400 & 67,1 \\
\hline & 6,96 & 42200 & 68,1 & 6,96 & 54100 & 67,1 \\
\hline & 6,17 & 38500 & 68,0 & 6,17 & 49300 & 67,0 \\
\hline & 5,47 & 35100 & 68,0 & 5,47 & 45000 & 67,0 \\
\hline & 4,84 & 32000 & 67,8 & 4,84 & 41000 & 66,9 \\
\hline & 4,29 & 29200 & 67,8 & 4,29 & 37500 & 66,8 \\
\hline & 3,80 & 26600 & 67,7 & 3,80 & 34200 & 66,7 \\
\hline & 3,36 & 24200 & 67,6 & 3,36 & 31200 & 66,6 \\
\hline & 2,98 & 22100 & 67,3 & 2,98 & 28500 & 66,4 \\
\hline & 2,64 & 20100 & 67,2 & 2,64 & 26000 & 66,3 \\
\hline & 2,34 & 18300 & 67,0 & 2,34 & 23700 & 66,1 \\
\hline & 2,07 & 16700 & 66,8 & 2,07 & 21700 & 65,9 \\
\hline & 1,83 & 15200 & 66,7 & 1,83 & 19800 & 65,6 \\
\hline & 1,62 & 13800 & 66,5 & 1,62 & 18100 & 65,4 \\
\hline & 1,44 & 12600 & 66,4 & 1,44 & 16600 & 65,2 \\
\hline & 1,27 & 11500 & 66,3 & 1,27 & 15100 & 65,0 \\
\hline
\end{tabular}




\begin{tabular}{|c|c|c|c|c|c|c|}
\hline \multirow{2}{*}{$\frac{\text { MP2 }}{\mathrm{T}}$} & \multicolumn{3}{|c|}{ Original } & \multicolumn{3}{|c|}{ Envejecido } \\
\hline & $f$ & $\mathrm{G}^{*}$ & $\delta$ & $f$ & $\mathrm{G}^{*}$ & $\delta$ \\
\hline$\left[{ }^{\circ} \mathrm{C}\right]$ & {$[\mathrm{Hz}]$} & {$[\mathrm{Pa}]$} & [o] & {$[\mathrm{Hz}]$} & {$[\mathrm{Pa}]$} & [o] \\
\hline \multirow[t]{2}{*}{50} & 1,13 & 10500 & 66,1 & 1,13 & 13800 & 64,7 \\
\hline & 1,00 & 9540 & 65,9 & 1,00 & 12700 & 64,4 \\
\hline \multirow[t]{20}{*}{60} & 10,00 & 14500 & 66,3 & 10,00 & 22900 & 66,9 \\
\hline & 7,84 & 12000 & 69,3 & 8,89 & 20900 & 66,7 \\
\hline & 6,14 & 9880 & 68,7 & 7,87 & 19200 & 66,5 \\
\hline & 4,81 & 8160 & 68,2 & 6,96 & 17500 & 66,2 \\
\hline & 3,76 & 6740 & 67,6 & 6,17 & 16000 & 65,9 \\
\hline & 2,95 & 5560 & 67,1 & 5,47 & 14600 & 65,5 \\
\hline & 2,31 & 4570 & 66,5 & 4,84 & 13300 & 65,2 \\
\hline & 1,81 & 3750 & 66,0 & 4,29 & 12100 & 64,8 \\
\hline & 1,41 & 3080 & 66,0 & 3,80 & 11100 & 64,4 \\
\hline & 1,11 & 2520 & 66,0 & 3,36 & 10100 & 64,0 \\
\hline & & & & 2,98 & 9240 & 63,6 \\
\hline & & & & 2,64 & 8450 & 63,1 \\
\hline & & & & 2,34 & 7720 & 62,6 \\
\hline & & & & 2,07 & 7050 & 62,4 \\
\hline & & & & 1,83 & 6460 & 61,9 \\
\hline & & & & 1,62 & 5910 & 61,5 \\
\hline & & & & 1,44 & 5410 & 61,3 \\
\hline & & & & 1,27 & 4960 & 60,6 \\
\hline & & & & 1,13 & 4550 & 59,8 \\
\hline & & & & 1,00 & 4170 & 59,6 \\
\hline \multirow[t]{19}{*}{70} & 10,00 & 4870 & 62,9 & 10,00 & 8750 & 64,9 \\
\hline & 8,89 & 4370 & 62,3 & 8,89 & 8050 & 64,5 \\
\hline & 7,87 & 3920 & 61,4 & 7,87 & 7380 & 64,0 \\
\hline & 6,96 & 3500 & 60,5 & 6,96 & 6750 & 63,4 \\
\hline & 6,17 & 3150 & 59,6 & 6,17 & 6210 & 63,0 \\
\hline & 5,47 & 2820 & 58,8 & 5,47 & 5690 & 62,3 \\
\hline & 4,84 & 2530 & 58,1 & 4,84 & 5200 & 61,6 \\
\hline & 4,29 & 2270 & 57,1 & 4,29 & 4770 & 60,9 \\
\hline & 3,80 & 2030 & 56,2 & 3,80 & 4370 & 60,2 \\
\hline & 3,36 & 1820 & 55,4 & 3,36 & 4020 & 59,4 \\
\hline & 2,98 & 1630 & 54,7 & 2,98 & 3690 & 58,6 \\
\hline & 2,64 & 1450 & 55,2 & 2,64 & 3390 & 57,8 \\
\hline & 2,34 & 1280 & 57,0 & 2,34 & 3110 & 57,5 \\
\hline & 2,07 & 1150 & 59,3 & 2,07 & 2840 & 57,0 \\
\hline & 1,83 & 1020 & 56,8 & 1,83 & 2610 & 56,8 \\
\hline & 1,62 & 936 & 57,7 & 1,62 & 2390 & 56,7 \\
\hline & 1,44 & 849 & 61,6 & 1,44 & 2210 & 55,7 \\
\hline & 1,27 & 790 & 79,7 & 1,27 & 2030 & 54,7 \\
\hline & 1,13 & 706 & 61,3 & 1,13 & 1870 & 55,1 \\
\hline
\end{tabular}


DEFORMACIONES PERMANENTES EN MEZCLAS ASFÁLTICAS.

Efecto de la reología de los asfaltos, la temperatura y las condiciones de carga

\begin{tabular}{|c|c|c|c|c|c|c|}
\hline MP2 & & riginal & & & vejecic & \\
\hline $\mathrm{T}$ & $f$ & $\mathrm{G}^{*}$ & $\delta$ & $f$ & $\mathrm{G}^{*}$ & $\delta$ \\
\hline$\left[{ }^{\circ} \mathrm{C}\right]$ & [Hz] & {$[\mathrm{Pa}]$} & {$[0]$} & {$[\mathrm{Hz}]$} & {$[\mathrm{Pa}]$} & [o] \\
\hline 70 & 1,00 & 657 & 61,3 & 1,00 & 1730 & 54,0 \\
\hline 80 & 10,00 & 2880 & 67,8 & 10,00 & 2350 & 56,4 \\
\hline & 8,16 & 2540 & 64,9 & 8,89 & 2180 & 54,9 \\
\hline & 6,63 & 2170 & 63,5 & 7,92 & 2040 & 53,6 \\
\hline & 5,39 & 1850 & 63,0 & 7,02 & 1910 & 52,1 \\
\hline & 4,40 & 1580 & 62,5 & 6,25 & 1760 & 49,9 \\
\hline & 3,58 & 1340 & 61,8 & 5,54 & 1630 & 48,1 \\
\hline & 2,91 & 1150 & 61,2 & 4,93 & 1520 & 46,1 \\
\hline & 2,37 & 976 & 60,5 & 4,38 & 1430 & 44,6 \\
\hline & 1,93 & 817 & 62,6 & 3,89 & 1350 & 42,9 \\
\hline & 1,57 & 692 & 64,2 & 3,46 & 1280 & 40,6 \\
\hline & 1,28 & 582 & 63,2 & 3,07 & 1200 & 38,5 \\
\hline & 1,04 & 500 & 67,7 & 2,73 & 1150 & 37,2 \\
\hline & & & & 2,43 & 1040 & 37,5 \\
\hline & & & & 2,15 & 996 & 35,4 \\
\hline & & & & 1,92 & 911 & 36,8 \\
\hline & & & & 1,70 & 828 & 36,0 \\
\hline & & & & 1,51 & 769 & 34,5 \\
\hline & & & & 1,34 & 807 & 59,6 \\
\hline & & & & 1,19 & 612 & 51,6 \\
\hline
\end{tabular}



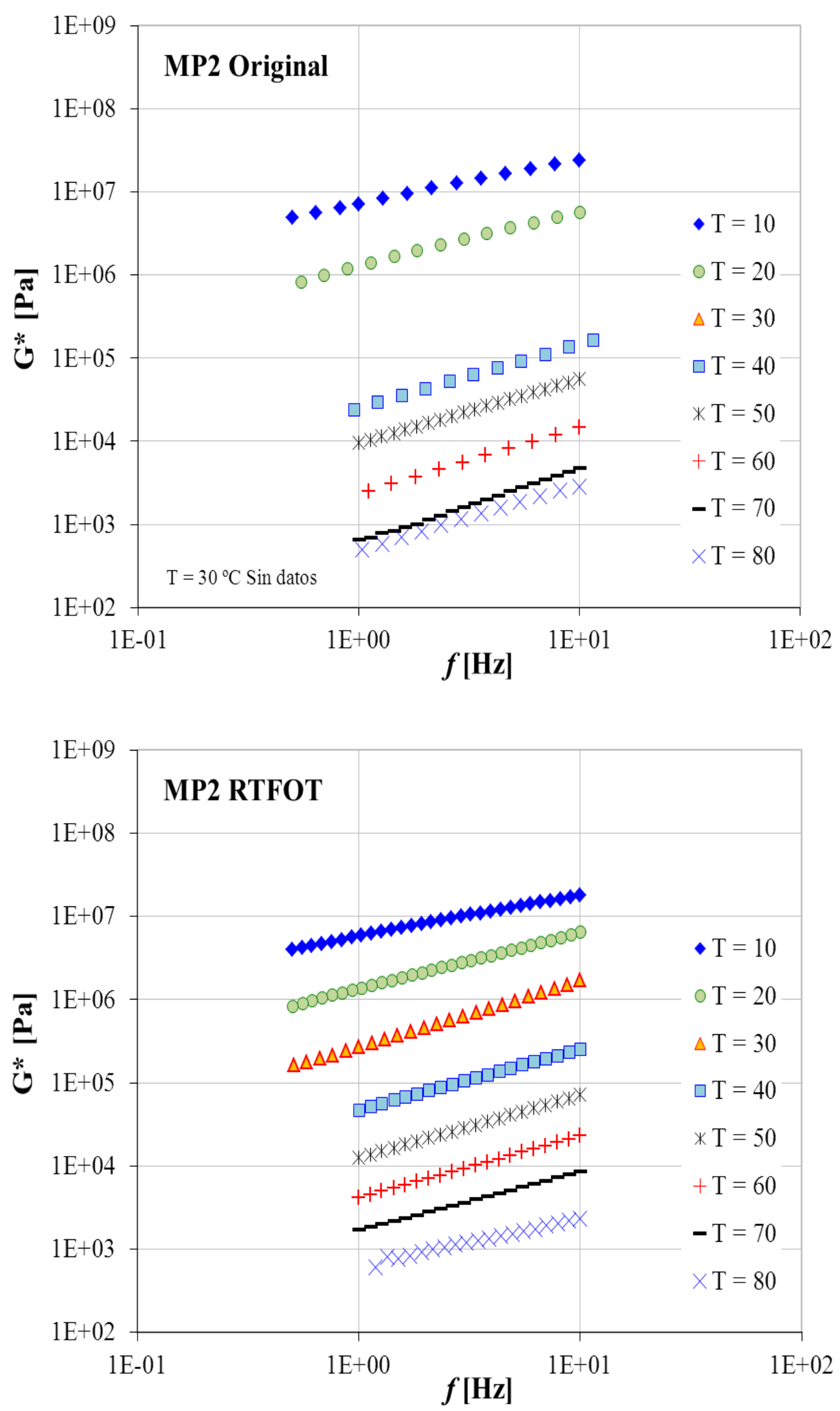


\section{Asfalto MP3}

\begin{tabular}{|c|c|c|c|c|c|c|}
\hline & \multicolumn{3}{|c|}{ Original } & \multicolumn{3}{|c|}{ Envejecido } \\
\hline $\mathrm{T}$ & $f$ & $\mathrm{G}^{*}$ & $\delta$ & $f$ & $\mathrm{G}^{*}$ & $\delta$ \\
\hline$\left[{ }^{\circ} \mathrm{C}\right]$ & {$[\mathrm{Hz}]$} & {$[\mathrm{Pa}]$} & [o] & {$[\mathrm{Hz}]$} & {$[\mathrm{Pa}]$} & [o] \\
\hline \multirow[t]{30}{*}{10} & 10,00 & 15000000 & 48,1 & 10,00 & 19000000 & 39,0 \\
\hline & 8,89 & 14100000 & 48,8 & 9,02 & 18100000 & 39,6 \\
\hline & 7,87 & 13200000 & 49,3 & 8,14 & 17300000 & 40,0 \\
\hline & 6,96 & 12400000 & 49,9 & 7,34 & 16600000 & 40,4 \\
\hline & 6,17 & 11600000 & 50,4 & 6,63 & 15900000 & 40,7 \\
\hline & 5,47 & 10800000 & 50,9 & 5,97 & 15200000 & 41,1 \\
\hline & 4,84 & 10200000 & 51,4 & 5,38 & 14600000 & 41,5 \\
\hline & 4,29 & 9480000 & 51,9 & 4,86 & 13900000 & 41,8 \\
\hline & 3,80 & 8870000 & 52,4 & 4,38 & 13300000 & 42,1 \\
\hline & 3,36 & 8270000 & 52,9 & 3,95 & 12700000 & 42,5 \\
\hline & 2,98 & 7720000 & 53,4 & 3,56 & 12200000 & 42,8 \\
\hline & 2,64 & 7200000 & 53,8 & 3,21 & 11600000 & 43,2 \\
\hline & 2,34 & 6710000 & 54,3 & 2,90 & 11100000 & 43,6 \\
\hline & 2,07 & 6240000 & 54,7 & 2,61 & 10500000 & 44,0 \\
\hline & 1,83 & 5810000 & 55,2 & 2,36 & 10100000 & 44,3 \\
\hline & 1,62 & 5390000 & 55,7 & 2,12 & 9570000 & 44,7 \\
\hline & 1,44 & 5020000 & 56,1 & 1,92 & 9100000 & 45,1 \\
\hline & 1,27 & 4660000 & 56,5 & 1,73 & 8660000 & 45,5 \\
\hline & 1,13 & 4320000 & 56,9 & 1,56 & 8230000 & 45,8 \\
\hline & 1,00 & 4010000 & 57,3 & 1,41 & 7820000 & 46,2 \\
\hline & 0,93 & 3846632 & 58,0 & 1,27 & 7440000 & 46,5 \\
\hline & 0,82 & 3580304 & 58,1 & 1,14 & 7070000 & 46,9 \\
\hline & 0,73 & 3332534 & 58,5 & 1,03 & 6710000 & 47,2 \\
\hline & 0,64 & 3103520 & 58,7 & 0,93 & 6370000 & 47,6 \\
\hline & 0,57 & 2890425 & 59,2 & 0,84 & 6040000 & 47,9 \\
\hline & 0,50 & 2689616 & 59,3 & 0,76 & 5720000 & 48,3 \\
\hline & & & & 0,68 & 5420000 & 48,7 \\
\hline & & & & 0,62 & 5130000 & 48,9 \\
\hline & & & & 0,55 & 4860000 & 49,3 \\
\hline & & & & 0,50 & 4600000 & 49,6 \\
\hline \multirow[t]{9}{*}{20} & 10,00 & 5520000 & 56,6 & 10,00 & 7390000 & 47,4 \\
\hline & 8,89 & 5010000 & 57,4 & 9,02 & 6860000 & 48,0 \\
\hline & 7,87 & 4620000 & 58,0 & 8,14 & 6390000 & 48,5 \\
\hline & 6,96 & 4240000 & 58,6 & 7,34 & 5960000 & 49,0 \\
\hline & 6,17 & 3910000 & 59,0 & 6,63 & 5570000 & 49,5 \\
\hline & 5,47 & 3610000 & 59,5 & 5,97 & 5200000 & 49,9 \\
\hline & 4,84 & 3320000 & 59,9 & 5,38 & 4860000 & 50,4 \\
\hline & 4,29 & 3060000 & 60,3 & 4,86 & 4550000 & 50,7 \\
\hline & 3,80 & 2810000 & 60,7 & 4,38 & 4260000 & 51,1 \\
\hline
\end{tabular}




\begin{tabular}{|c|c|c|c|c|c|c|}
\hline \multirow{2}{*}{$\frac{\text { MP3 }}{\mathrm{T}}$} & \multicolumn{3}{|c|}{ Original } & \multicolumn{3}{|c|}{ Envejecido } \\
\hline & $f$ & $\mathrm{G}^{*}$ & $\delta$ & $f$ & $\mathrm{G}^{*}$ & $\delta$ \\
\hline$\left[{ }^{\circ} \mathrm{C}\right]$ & {$[\mathrm{Hz}]$} & {$[\mathrm{Pa}]$} & [o] & {$[\mathrm{Hz}]$} & {$[\mathrm{Pa}]$} & [o] \\
\hline \multirow[t]{21}{*}{20} & 3,36 & 2590000 & 61,0 & 3,95 & 4000000 & 51,5 \\
\hline & 2,98 & 2390000 & 61,4 & 3,56 & 3740000 & 51,8 \\
\hline & 2,64 & 2200000 & 61,7 & 3,21 & 3510000 & 52,2 \\
\hline & 2,34 & 2020000 & 62,0 & 2,90 & 3290000 & 52,5 \\
\hline & 2,07 & 1860000 & 62,3 & 2,61 & 3080000 & 52,9 \\
\hline & 1,83 & 1700000 & 62,6 & 2,36 & 2890000 & 53,3 \\
\hline & 1,62 & 1560000 & 63,0 & 2,12 & 2700000 & 53,7 \\
\hline & 1,44 & 1440000 & 63,2 & 1,92 & 2530000 & 53,9 \\
\hline & 1,27 & 1320000 & 63,5 & 1,73 & 2370000 & 54,3 \\
\hline & 1,13 & 1210000 & 63,8 & 1,56 & 2220000 & 54,6 \\
\hline & 1,00 & 1110000 & 63,9 & 1,41 & 2070000 & 54,9 \\
\hline & 0,93 & 954013 & 64,0 & 1,27 & 1930000 & 55,3 \\
\hline & 0,82 & 875048 & 64,3 & 1,14 & 1800000 & 55,6 \\
\hline & 0,73 & 802653 & 64,9 & 1,03 & 1680000 & 55,9 \\
\hline & 0,64 & 736708 & 65,2 & 0,93 & 1570000 & 56,0 \\
\hline & 0,57 & 676232 & 65,7 & 0,84 & 1460000 & 56,5 \\
\hline & 0,50 & 620069 & 65,9 & 0,76 & 1360000 & 56,7 \\
\hline & & & & 0,68 & 1280000 & 56,9 \\
\hline & & & & 0,62 & 1190000 & 57,4 \\
\hline & & & & 0,55 & 1110000 & 57,5 \\
\hline & & & & 0,50 & 1030000 & 57,9 \\
\hline \multirow[t]{20}{*}{30} & 10,00 & 1510000 & 64,8 & 10,00 & 1910000 & 57,9 \\
\hline & 8,89 & 1340000 & 65,5 & 8,76 & 1700000 & 58,6 \\
\hline & 7,87 & 1210000 & 65,9 & 7,64 & 1530000 & 59,2 \\
\hline & 6,96 & 1100000 & 66,3 & 6,67 & 1370000 & 59,7 \\
\hline & 6,17 & 1010000 & 66,6 & 5,83 & 1230000 & 60,1 \\
\hline & 5,47 & 914000 & 66,8 & 5,08 & 1110000 & 60,4 \\
\hline & 4,84 & 834000 & 67,0 & 4,44 & 998000 & 60,6 \\
\hline & 4,29 & 760000 & 67,1 & 3,88 & 900000 & 60,9 \\
\hline & 3,80 & 693000 & 67,3 & 3,39 & 813000 & 61,0 \\
\hline & 3,36 & 632000 & 67,4 & 2,96 & 735000 & 61,2 \\
\hline & 2,98 & 577000 & 67,5 & 2,58 & 665000 & 61,3 \\
\hline & 2,64 & 526000 & 67,5 & 2,26 & 599000 & 61,5 \\
\hline & 2,34 & 481000 & 67,6 & 1,97 & 539000 & 62,4 \\
\hline & 2,07 & 439000 & 67,5 & 1,72 & 485000 & 62,9 \\
\hline & 1,83 & 400000 & 67,4 & 1,50 & 437000 & 63,6 \\
\hline & 1,62 & 365000 & 67,4 & 1,31 & 392000 & 64,8 \\
\hline & 1,44 & 333000 & 67,4 & 1,15 & 355000 & 64,7 \\
\hline & 1,27 & 303000 & 67,4 & 1,00 & 319000 & 66,1 \\
\hline & 1,13 & 277000 & 67,5 & 0,87 & 287000 & 65,5 \\
\hline & 1,00 & 252000 & 67,7 & 0,76 & 259000 & 66,8 \\
\hline
\end{tabular}




\begin{tabular}{|c|c|c|c|c|c|c|}
\hline \multirow{2}{*}{$\frac{\text { MP3 }}{\mathrm{T}}$} & \multicolumn{3}{|c|}{ Original } & \multicolumn{3}{|c|}{ Envejecido } \\
\hline & $f$ & $\mathrm{G}^{*}$ & $\delta$ & $f$ & $\mathrm{G}^{*}$ & $\delta$ \\
\hline$\left[{ }^{\circ} \mathrm{C}\right]$ & {$[\mathrm{Hz}]$} & {$[\mathrm{Pa}]$} & [o] & {$[\mathrm{Hz}]$} & {$[\mathrm{Pa}]$} & [o] \\
\hline \multirow[t]{6}{*}{30} & 0,93 & 238519 & 67,9 & 0,67 & 234000 & 67,4 \\
\hline & 0,82 & 216722 & 68,2 & 0,58 & 211000 & 70,0 \\
\hline & 0,73 & 196926 & 68,3 & 0,51 & 192000 & 71,3 \\
\hline & 0,64 & 179062 & 68,5 & & & \\
\hline & 0,57 & 162833 & 68,6 & & & \\
\hline & 0,50 & 147902 & 68,7 & & & \\
\hline \multirow[t]{20}{*}{40} & 10,00 & 202000 & 63,4 & 10,00 & 286000 & 57,9 \\
\hline & 8,89 & 180000 & 64,0 & 8,89 & 257000 & 59,1 \\
\hline & 7,87 & 164000 & 64,5 & 7,87 & 234000 & 60,0 \\
\hline & 6,96 & 149000 & 65,0 & 6,96 & 215000 & 60,8 \\
\hline & 6,17 & 136000 & 65,4 & 6,17 & 197000 & 61,5 \\
\hline & 5,47 & 124000 & 65,8 & 5,47 & 181000 & 62,1 \\
\hline & 4,84 & 113000 & 66,1 & 4,84 & 166000 & 62,7 \\
\hline & 4,29 & 103000 & 66,3 & 4,29 & 152000 & 63,2 \\
\hline & 3,80 & 94500 & 66,5 & 3,80 & 139000 & 63,7 \\
\hline & 3,36 & 86200 & 66,7 & 3,36 & 127000 & 64,1 \\
\hline & 2,98 & 78600 & 66,8 & 2,98 & 117000 & 64,5 \\
\hline & 2,64 & 71800 & 66,9 & 2,64 & 107000 & 64,7 \\
\hline & 2,34 & 65500 & 67,0 & 2,34 & 97800 & 65,0 \\
\hline & 2,07 & 59800 & 67,1 & 2,07 & 89500 & 65,3 \\
\hline & 1,83 & 54600 & 67,0 & 1,83 & 81900 & 65,4 \\
\hline & 1,62 & 49900 & 67,0 & 1,62 & 74800 & 65,7 \\
\hline & 1,44 & 45500 & 67,0 & 1,44 & 68400 & 65,8 \\
\hline & 1,27 & 41600 & 67,0 & 1,27 & 62600 & 65,9 \\
\hline & 1,13 & 38000 & 67,0 & 1,13 & 57200 & 66,0 \\
\hline & 1,00 & 34700 & 67,0 & 1,00 & 52300 & 66,1 \\
\hline \multirow[t]{15}{*}{50} & 10,00 & 55800 & 68,3 & 10,00 & 76300 & 66,6 \\
\hline & 8,89 & 50500 & 68,2 & 8,89 & 69300 & 66,8 \\
\hline & 7,87 & 45800 & 68,2 & 7,87 & 63000 & 66,9 \\
\hline & 6,96 & 41600 & 68,1 & 6,96 & 57300 & 67,0 \\
\hline & 6,17 & 37900 & 68,0 & 6,17 & 52200 & 67,1 \\
\hline & 5,47 & 34600 & 68,0 & 5,47 & 47600 & 67,1 \\
\hline & 4,84 & 31600 & 67,9 & 4,84 & 43300 & 67,2 \\
\hline & 4,29 & 28800 & 67,8 & 4,29 & 39500 & 67,1 \\
\hline & 3,80 & 26200 & 67,6 & 3,80 & 36100 & 67,1 \\
\hline & 3,36 & 23900 & 67,5 & 3,36 & 32900 & 67,1 \\
\hline & 2,98 & 21800 & 67,3 & 2,98 & 30000 & 67,1 \\
\hline & 2,64 & 19900 & 67,2 & 2,64 & 27400 & 67,0 \\
\hline & 2,34 & 18200 & 67,0 & 2,34 & 25000 & 67,0 \\
\hline & 2,07 & 16600 & 66,8 & 2,07 & 22800 & 66,9 \\
\hline & 1,83 & 15200 & 66,6 & 1,83 & 20800 & 66,8 \\
\hline
\end{tabular}




\begin{tabular}{|c|c|c|c|c|c|c|}
\hline MP3 & & Driginal & & & vejecid & \\
\hline $\mathrm{T}$ & $f$ & $\mathrm{G}^{*}$ & $\delta$ & $f$ & $\mathrm{G}^{*}$ & $\delta$ \\
\hline$\left[{ }^{\circ} \mathrm{C}\right]$ & {$[\mathrm{Hz}]$} & {$[\mathrm{Pa}]$} & [o] & {$[\mathrm{Hz}]$} & {$[\mathrm{Pa}]$} & {$[\mathrm{o}]$} \\
\hline 50 & 1,62 & 13900 & 66,5 & 1,62 & 19000 & 66,7 \\
\hline & 1,44 & 12700 & 66,3 & 1,44 & 17400 & 66,7 \\
\hline & 1,27 & 11600 & 66,1 & 1,27 & 15900 & 66,6 \\
\hline & 1,13 & 10700 & 65,9 & 1,13 & 14600 & 66,5 \\
\hline & 1,00 & 9740 & 65,7 & 1,00 & 13300 & 66,4 \\
\hline 60 & 10,00 & 18600 & 67,9 & 10,00 & 23900 & 66,9 \\
\hline & 8,89 & 17000 & 67,6 & 8,89 & 21900 & 66,7 \\
\hline & 7,87 & 15500 & 67,3 & 7,87 & 20000 & 66,5 \\
\hline & 6,96 & 14100 & 67,1 & 6,96 & 18300 & 66,4 \\
\hline & 6,17 & 12800 & 66,8 & 6,17 & 16700 & 66,3 \\
\hline & 5,47 & 11700 & 66,6 & 5,47 & 15200 & 66,2 \\
\hline & 4,84 & 10700 & 66,3 & 4,84 & 13900 & 66,0 \\
\hline & 4,29 & 9740 & 66,1 & 4,29 & 12700 & 65,9 \\
\hline & 3,80 & 8910 & 65,8 & 3,80 & 11500 & 65,7 \\
\hline & 3,36 & 8130 & 65,5 & 3,36 & 10500 & 65,6 \\
\hline & 2,98 & 7430 & 65,2 & 2,98 & 9630 & 65,4 \\
\hline & 2,64 & 6800 & 64,9 & 2,64 & 8800 & 65,3 \\
\hline & 2,34 & 6230 & 64,6 & 2,34 & 8050 & 65,1 \\
\hline & 2,07 & 5690 & 64,4 & 2,07 & 7330 & 65,1 \\
\hline & 1,83 & 5200 & 64,1 & 1,83 & 6700 & 65,0 \\
\hline & 1,62 & 4750 & 64,0 & 1,62 & 6130 & 64,8 \\
\hline & 1,44 & 4360 & 63,7 & 1,44 & 5600 & 64,8 \\
\hline & 1,27 & 3980 & 63,7 & 1,27 & 5120 & 64,7 \\
\hline & 1,13 & 3650 & 63,4 & 1,13 & 4680 & 64,6 \\
\hline & 1,00 & 3340 & 63,4 & 1,00 & 4290 & 64,3 \\
\hline 70 & 10,00 & 7310 & 66,0 & 10,00 & 9000 & 65,0 \\
\hline & 8,89 & 6690 & 65,6 & 8,89 & 8230 & 65,3 \\
\hline & 7,87 & 6110 & 65,3 & 7,87 & 7500 & 65,4 \\
\hline & 6,96 & 5590 & 64,9 & 6,96 & 6830 & 65,4 \\
\hline & 6,17 & 5100 & 64,4 & 6,17 & 6230 & 65,4 \\
\hline & 5,47 & 4660 & 64,1 & 5,47 & 5690 & 65,3 \\
\hline & 4,84 & 4270 & 63,6 & 4,84 & 5190 & 65,3 \\
\hline & 4,29 & 3900 & 63,2 & 4,29 & 4740 & 65,2 \\
\hline & 3,80 & 3580 & 62,8 & 3,80 & 4330 & 65,0 \\
\hline & 3,36 & 3270 & 62,3 & 3,36 & 3950 & 64,9 \\
\hline & 2,98 & 2990 & 61,9 & 2,98 & 3610 & 64,8 \\
\hline & 2,64 & 2740 & 61,4 & 2,64 & 3290 & 65,0 \\
\hline & 2,34 & 2510 & 61,1 & 2,34 & 3000 & 65,0 \\
\hline & 2,07 & 2290 & 61,3 & 2,07 & 2730 & 65,9 \\
\hline & 1,83 & 2090 & 61,8 & 1,83 & 2490 & 65,8 \\
\hline & 1,62 & 1910 & 62,3 & 1,62 & 2260 & 66,8 \\
\hline
\end{tabular}


DEFORMACIONES PERMANENTES EN MEZCLAS ASFÁLTICAS.

Efecto de la reología de los asfaltos, la temperatura y las condiciones de carga

\begin{tabular}{|c|c|c|c|c|c|c|}
\hline \multirow{2}{*}{$\frac{\text { MP3 }}{\mathrm{T}}$} & \multicolumn{3}{|c|}{ Original } & \multicolumn{3}{|c|}{ Envejecido } \\
\hline & $f$ & $\mathrm{G}^{*}$ & $\delta$ & $f$ & $\mathrm{G}^{*}$ & $\delta$ \\
\hline$\left[{ }^{\circ} \mathrm{C}\right]$ & {$[\mathrm{Hz}]$} & {$[\mathrm{Pa}]$} & [o] & {$[\mathrm{Hz}]$} & {$[\mathrm{Pa}]$} & [o] \\
\hline \multirow[t]{4}{*}{70} & 1,44 & 1740 & 62,8 & 1,44 & 2070 & 67,0 \\
\hline & 1,27 & 1600 & 62,0 & 1,27 & 1890 & 67,6 \\
\hline & 1,13 & 1460 & 62,1 & 1,13 & 1720 & 67,6 \\
\hline & 1,00 & 1350 & 62,5 & 1,00 & 1570 & 68,9 \\
\hline \multirow[t]{20}{*}{80} & 10,00 & 3450 & 62,9 & 10,00 & 2340 & 62,7 \\
\hline & 8,89 & 3160 & 62,3 & 8,89 & 2210 & 63,1 \\
\hline & 7,87 & 2880 & 61,4 & 7,87 & 2010 & 63,6 \\
\hline & 6,96 & 2640 & 60,5 & 6,96 & 1850 & 65,2 \\
\hline & 6,17 & 2420 & 59,6 & 6,17 & 1650 & 62,9 \\
\hline & 5,47 & 2220 & 58,8 & 5,47 & 1510 & 60,1 \\
\hline & 4,84 & 2030 & 58,1 & 4,84 & 1320 & 60,4 \\
\hline & 4,29 & 1860 & 57,1 & 4,29 & 1200 & 57,9 \\
\hline & 3,80 & 1710 & 56,2 & 3,80 & 1040 & 43,8 \\
\hline & 3,36 & 1570 & 55,4 & 3,36 & 960 & 42,3 \\
\hline & 2,98 & 1440 & 54,7 & 2,98 & 860 & 42,3 \\
\hline & 2,64 & 1300 & 55,2 & 2,64 & 750 & 42,1 \\
\hline & 2,34 & 1170 & 57,0 & 2,34 & 639 & 42,9 \\
\hline & 2,07 & 1050 & 59,3 & 2,07 & 574 & 42,9 \\
\hline & 1,83 & 962 & 56,8 & 1,83 & 496 & 40,0 \\
\hline & 1,62 & 876 & 57,7 & 1,62 & 443 & 42,9 \\
\hline & 1,44 & 780 & 61,6 & 1,44 & 327 & 58,5 \\
\hline & & & & 1,27 & 379 & 63,6 \\
\hline & & & & 1,13 & 516 & 68,0 \\
\hline & & & & 1,00 & 237 & 47,6 \\
\hline
\end{tabular}



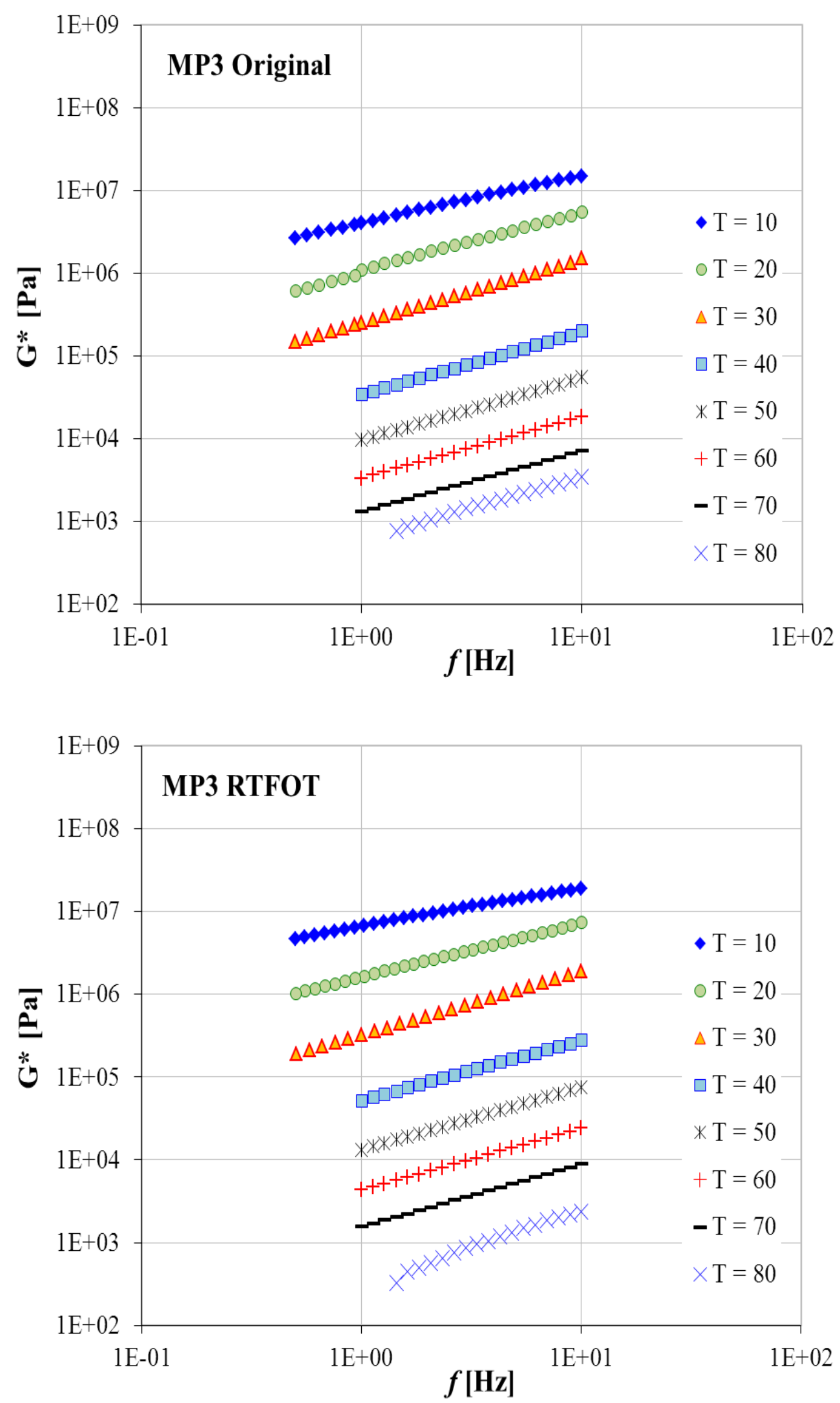



\section{Anexo II}

Curvas de deformación-tiempo.

Ensayos de rueda cargada. 



\section{Mezcla Densa (D-20) \\ Ensayos a distintas temperaturas}





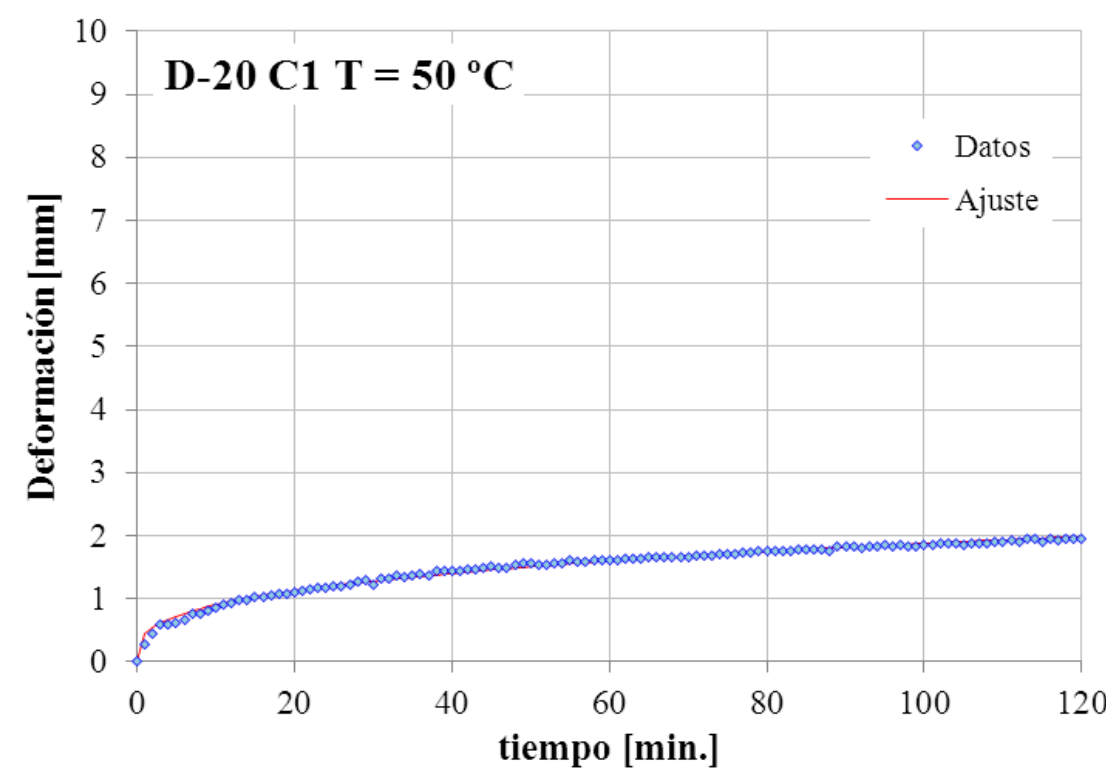

Mezcla (D-20)

Asfalto C1

$\mathbf{T}_{\text {ensayo }}=50^{\circ} \mathrm{C}$

Carga $=520 \mathrm{~N}$

Ajuste

$\mathbf{a}=0,4350, \mathbf{b}=0,3173$

$\mathbf{R}^{2}=0,99$

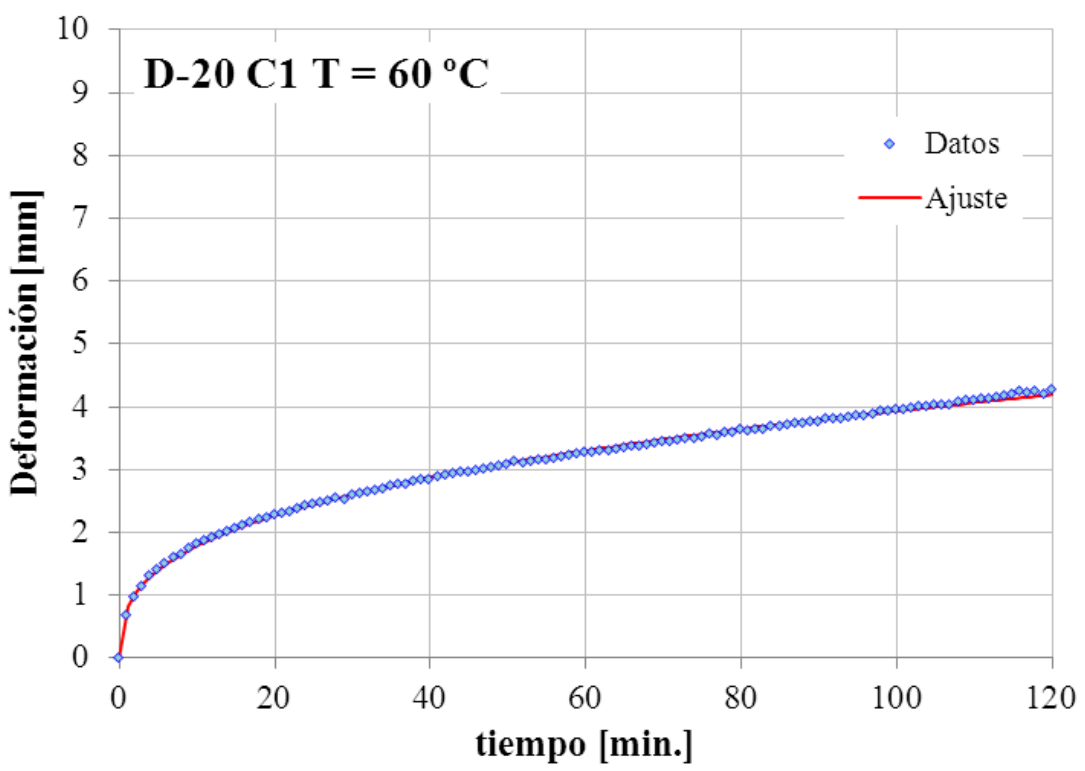

Mezcla (D-20)

Asfalto C1

$\mathbf{T}_{\text {ensayo }}=60^{\circ} \mathrm{C}$

Carga $=520 \mathrm{~N}$

Ajuste

$\mathbf{a}=0,8153 ; \mathbf{b}=0,3417$

$\mathbf{R}^{2}=0,99$

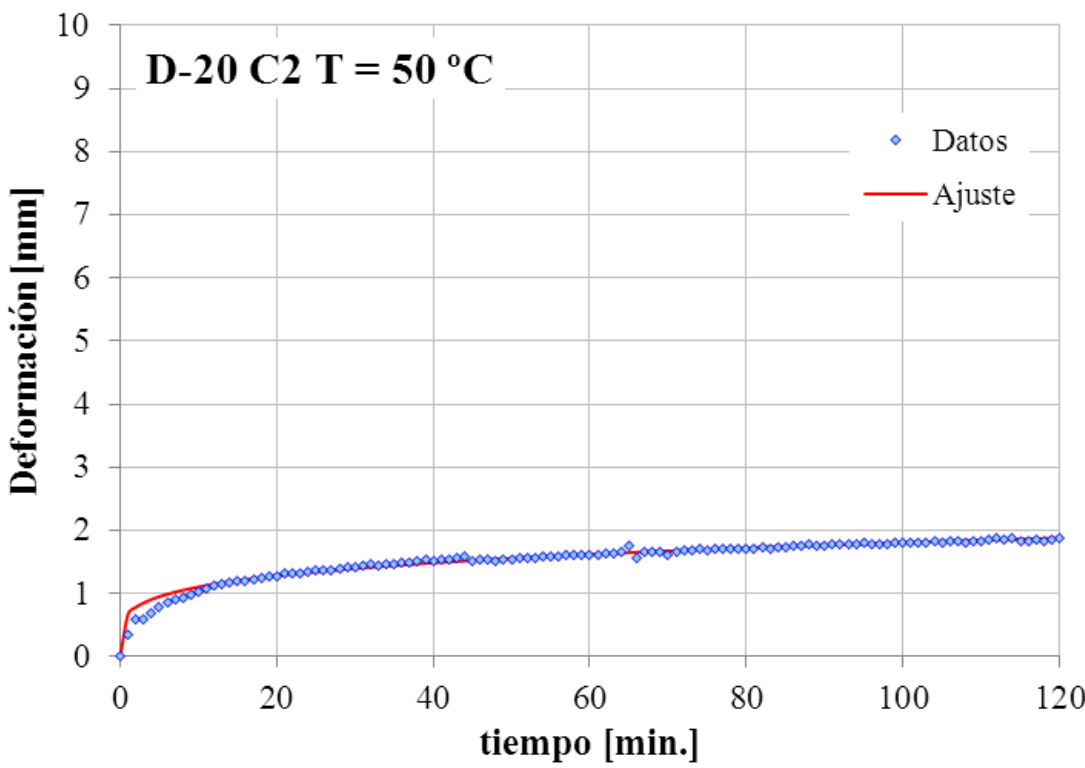

Mezcla (D-20)

Asfalto C2

$\mathbf{T}_{\text {ensayo }}: 50^{\circ} \mathrm{C}$

Carga: $520 \mathrm{~N}$

Ajuste

$\mathbf{a}=0,6754 ; \mathbf{b}=0,2138$

$\mathbf{R}^{2}=0,98$ 


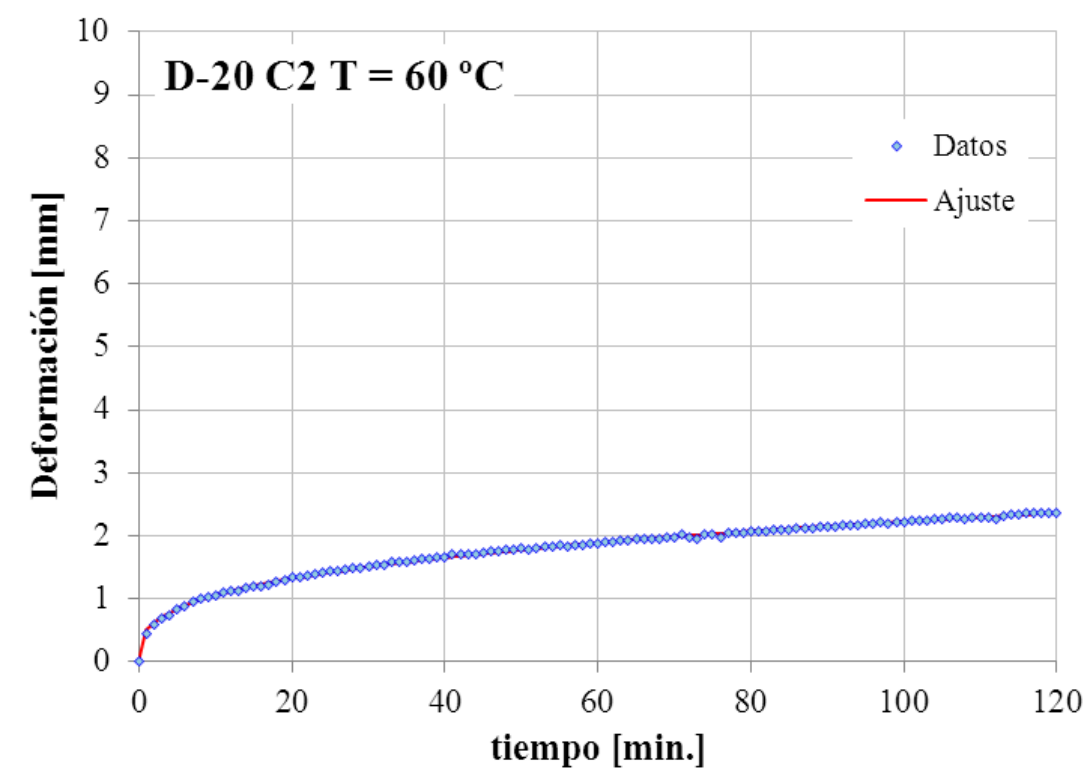

\section{Mezcla (D-20) \\ Asfalto C2}

$\mathbf{T}_{\text {ensayo }}=60^{\circ} \mathrm{C}$

Carga $=520 \mathrm{~N}$

\section{Ajuste}

$\mathbf{a}=0,5015 ; \mathbf{b}=0,3238$

$\mathbf{R}^{2}=0,99$

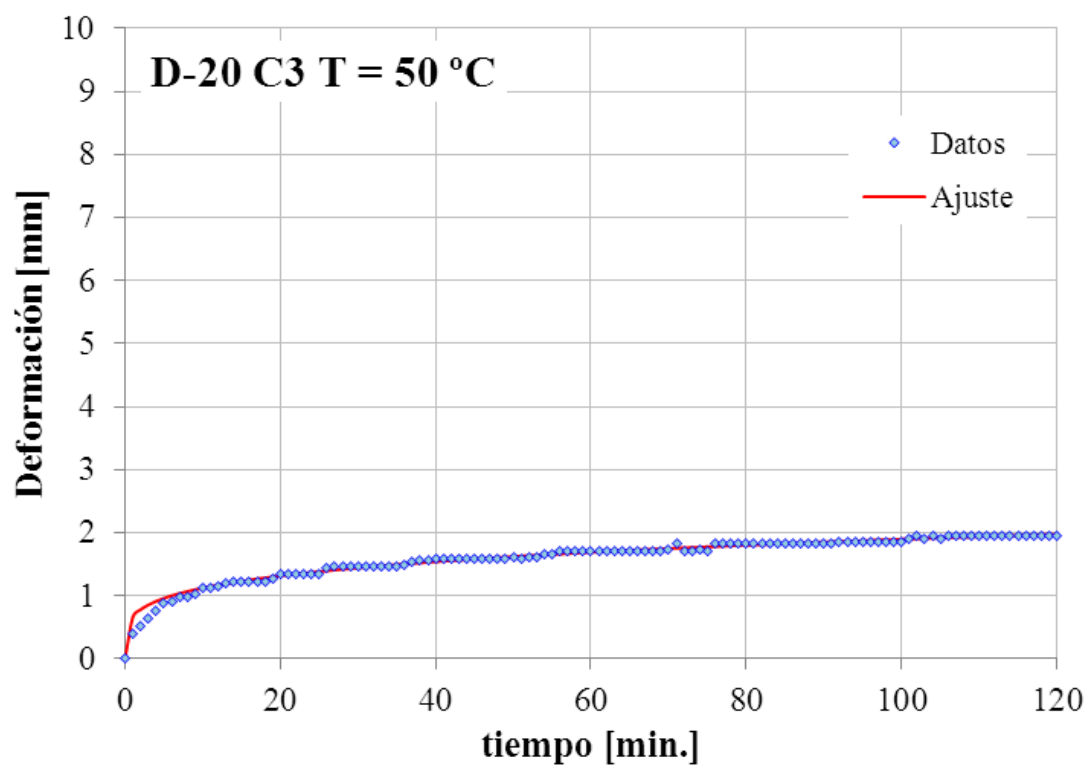

Mezcla (D-20)

Asfalto C3

$\mathbf{T}_{\text {ensayo }}=50^{\circ} \mathrm{C}$

Carga $=520 \mathrm{~N}$

\section{Ajuste}

$\mathbf{a}=0,6671 ; \mathbf{b}=0,2269$

$\mathbf{R}^{2}=0,99$

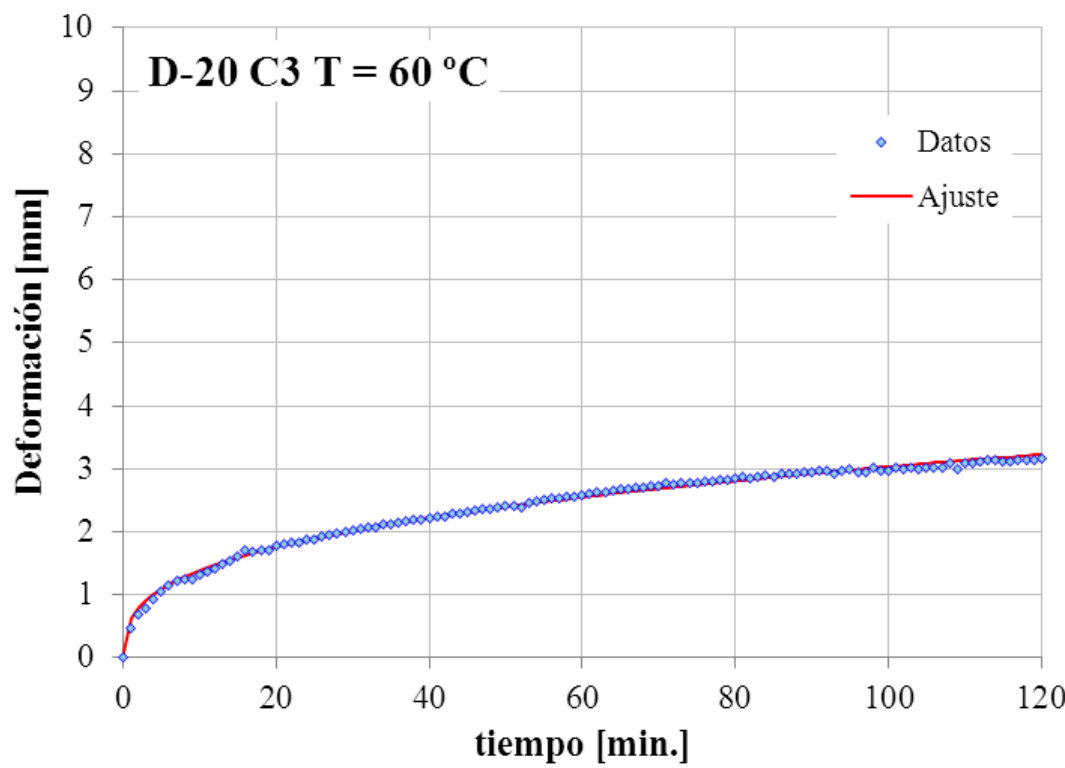

Mezcla (D-20)

Asfalto C3

$\mathbf{T}_{\text {ensayo }}=60^{\circ} \mathrm{C}$

Carga $=520 \mathrm{~N}$

\section{Ajuste}

$\mathbf{a}=0,6376 ; \mathbf{b}=0,3386$

$\mathbf{R}^{2}=0,99$ 


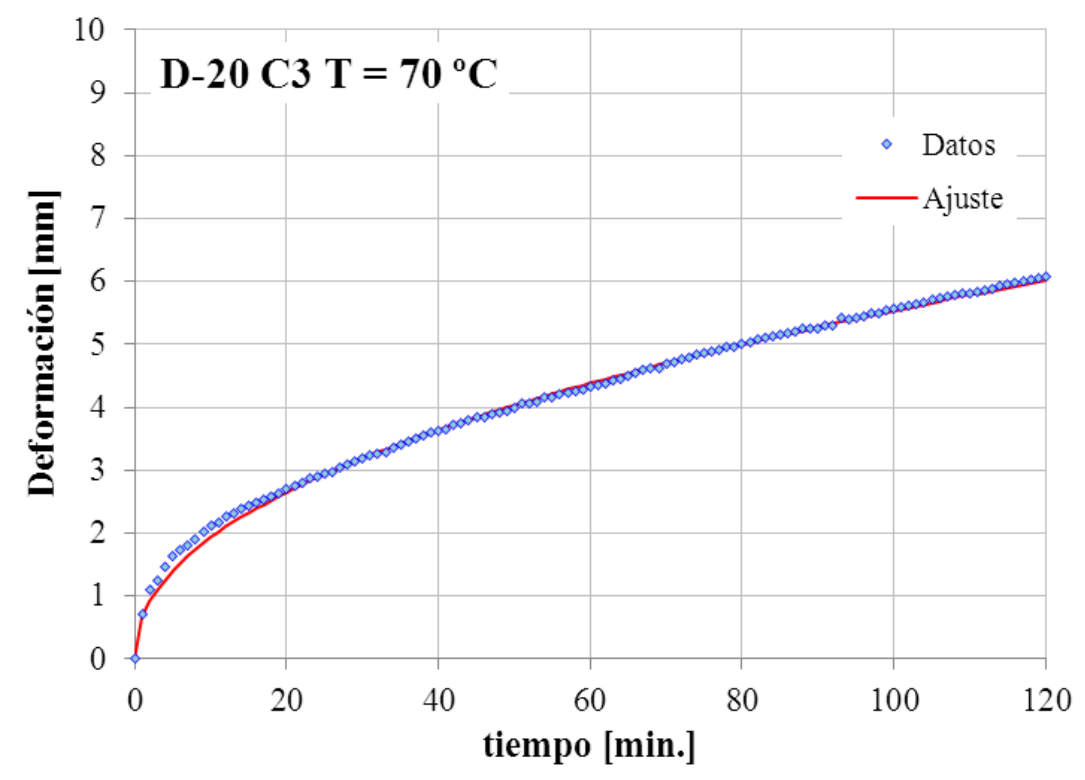

Mezcla (D-20)

Asfalto C3

$\mathbf{T}_{\text {ensayo }}=70^{\circ} \mathrm{C}$

Carga $=520 \mathrm{~N}$

\section{Ajuste}

$\mathbf{a}=0,6724, \mathbf{b}=0,4579$

$\mathbf{R}^{2}=0,99$

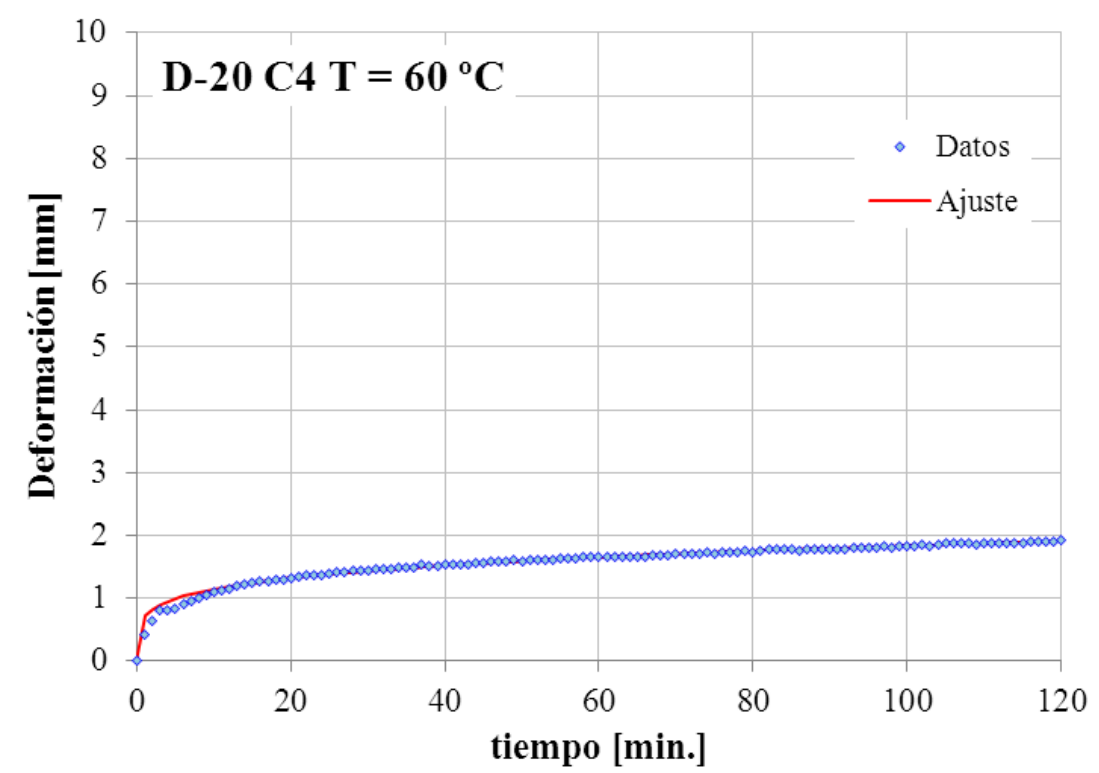

Mezcla (D-20)

Asfalto C4

$\mathbf{T}_{\text {ensayo }}=60^{\circ} \mathrm{C}$

Carga $=520 \mathrm{~N}$

\section{Ajuste}

$\mathbf{a}=0,7148 ; \mathbf{b}=0,2049$

$\mathbf{R}^{2}=0,99$

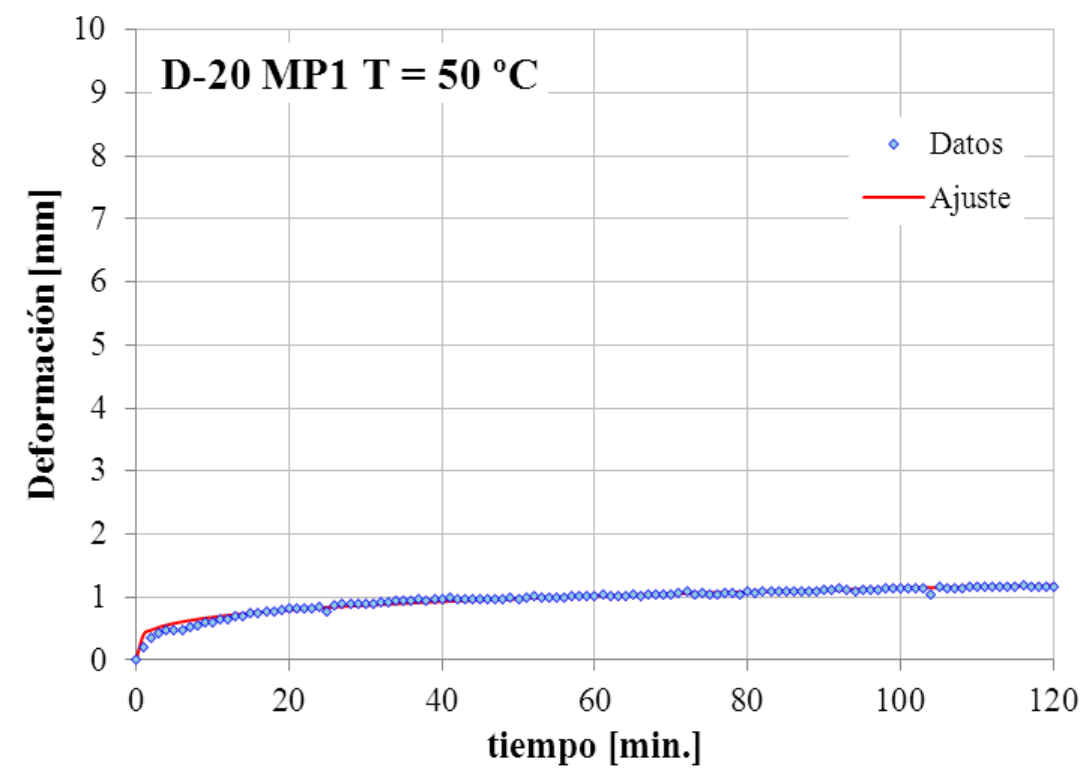

Mezcla (D-20)

Asfalto MP1

$\mathbf{T}_{\text {ensayo }}=50^{\circ} \mathrm{C}$

Carga $=520 \mathrm{~N}$

\section{Ajuste}

$\mathbf{a}=0,4084 ; \mathbf{b}=0,2227$

$\mathbf{R}^{2}=0,96$ 


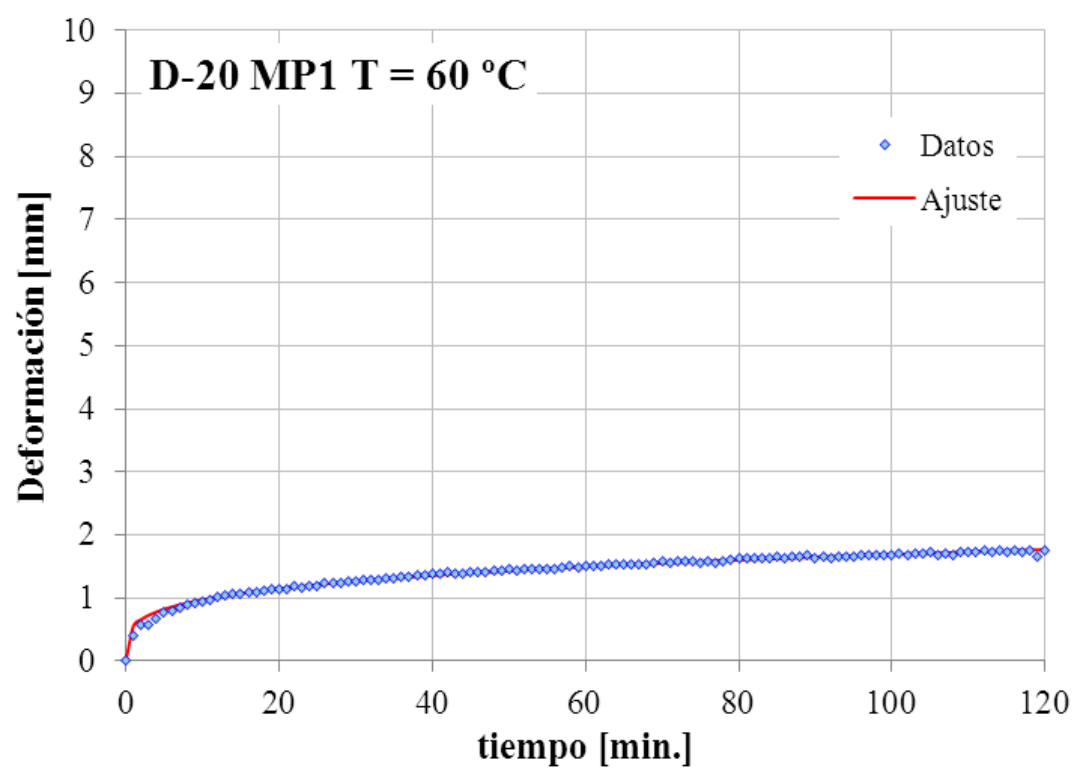

Mezcla (D-20)

Asfalto MP1

$\mathbf{T}_{\text {ensayo }}=60^{\circ} \mathrm{C}$

Carga $=520 \mathrm{~N}$

\section{Ajuste}

$\mathbf{a}=0,5580, \mathbf{b}=0,2408$

$\mathbf{R}^{2}=0,99$

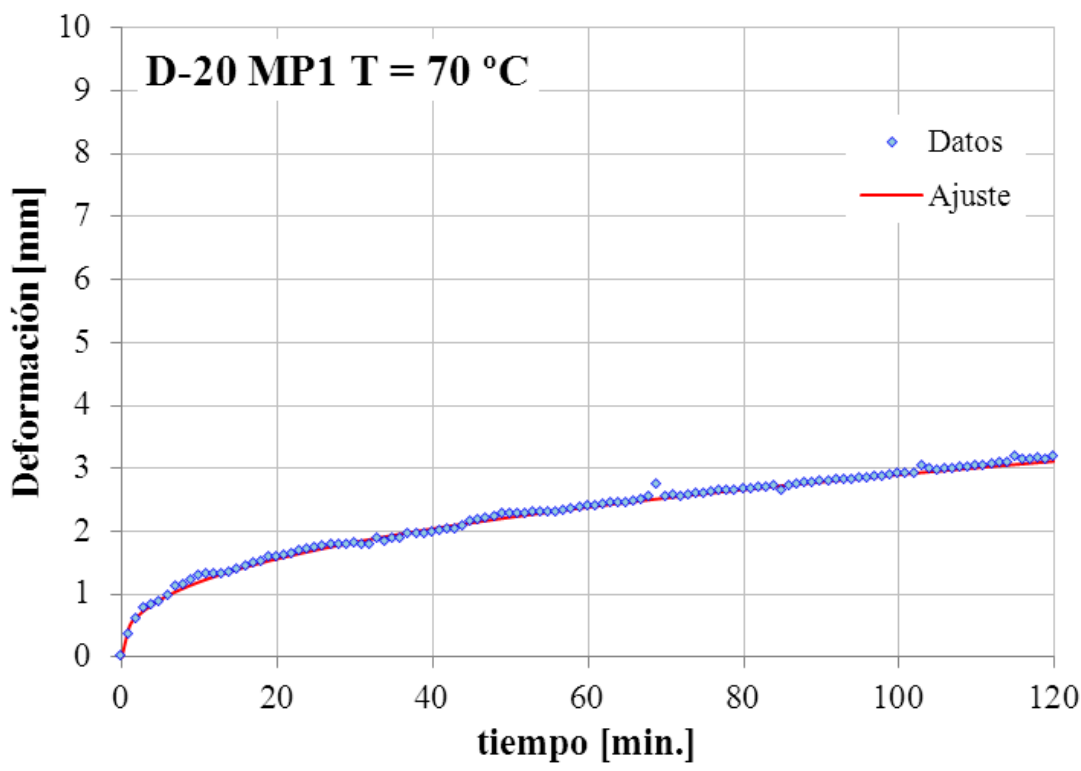

Mezcla (D-20)

Asfalto MP1

$\mathbf{T}_{\text {ensayo }}=70^{\circ} \mathrm{C}$

Carga $=520 \mathrm{~N}$

\section{Ajuste}

$\mathbf{a}=0,4953 ; \mathbf{b}=0,3840$

$\mathbf{R}^{2}=0,99$

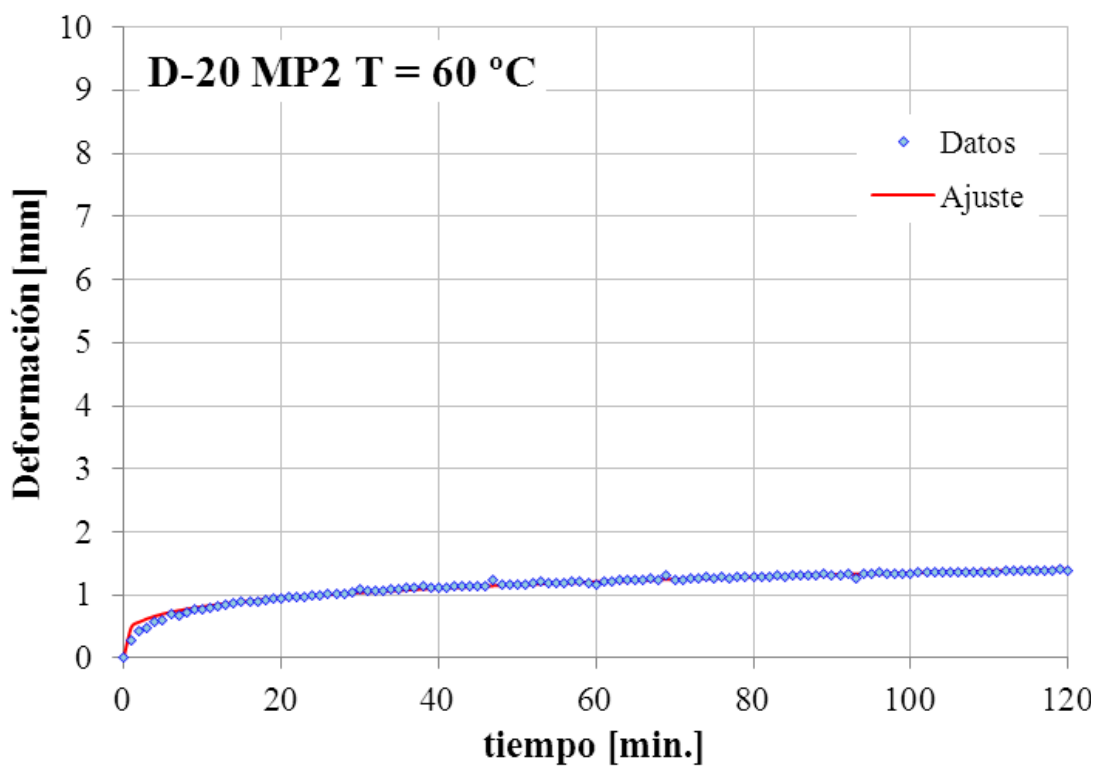

Mezcla (D-20)

Asfalto MP2

$T_{\text {ensayo }}: 60^{\circ} \mathrm{C}$

Carga: $520 \mathrm{~N}$

\section{Ajuste}

$\mathbf{a}=0,4911 ; \mathbf{b}=0,2202$

$\mathbf{R}^{2}=0,99$ 


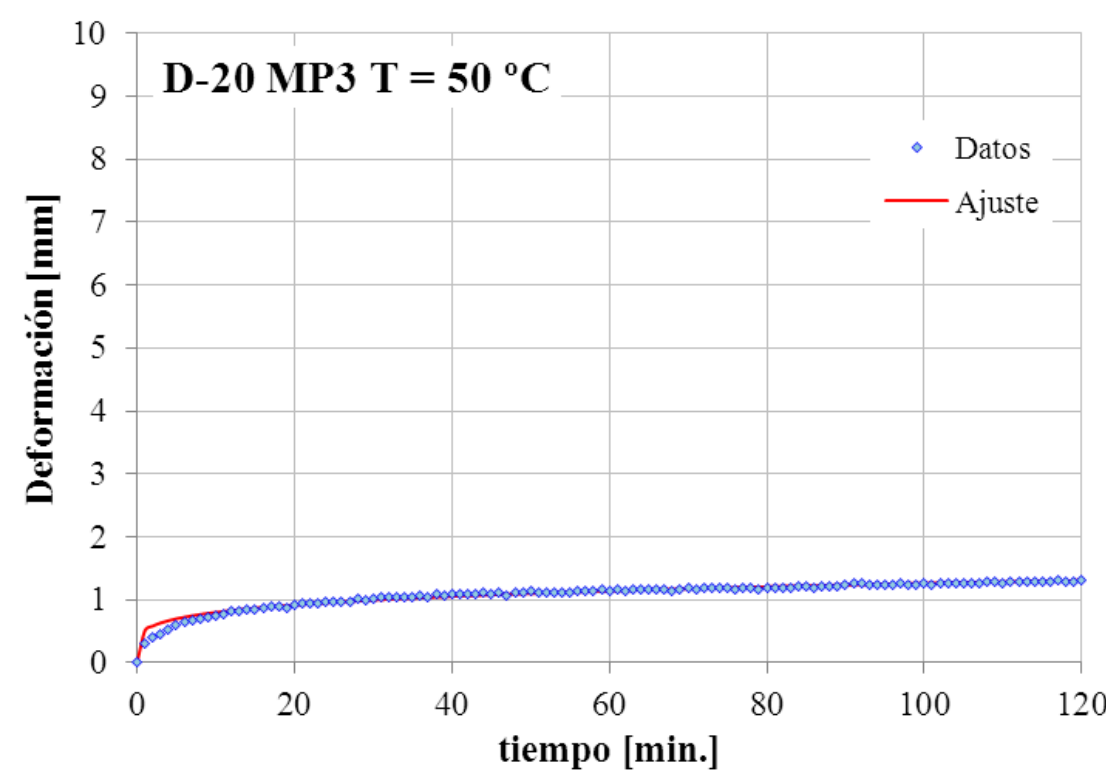

Mezcla (D-20)

Asfalto MP3

$\mathbf{T}_{\text {ensayo }}=50^{\circ} \mathrm{C}$

Carga $=520 \mathrm{~N}$

Ajuste

$\mathbf{a}=0,5096, \mathbf{b}=0,1970$

$\mathbf{R}^{2}=0,98$

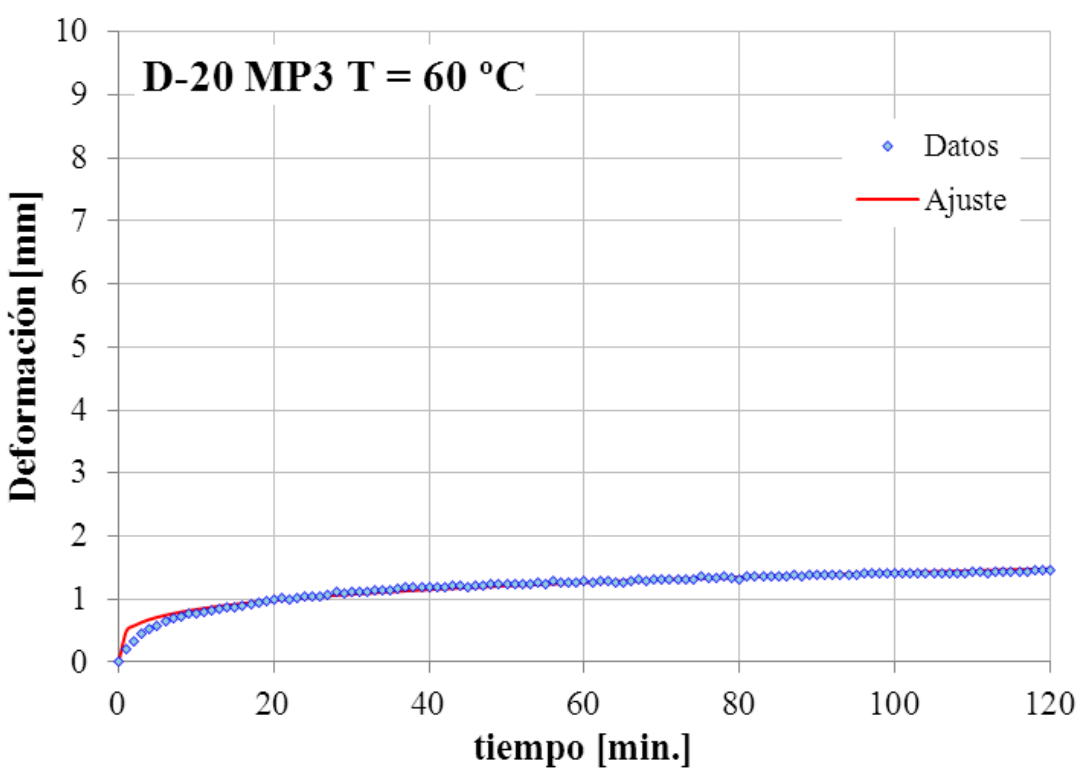

Mezcla (D-20)

Asfalto MP3

$\mathbf{T}_{\text {ensayo }}=60^{\circ} \mathrm{C}$

Carga $=520 \mathrm{~N}$

\section{Ajuste}

$\mathbf{a}=0,4933 ; \mathbf{b}=0,2295$

$\mathbf{R}^{2}=0,98$

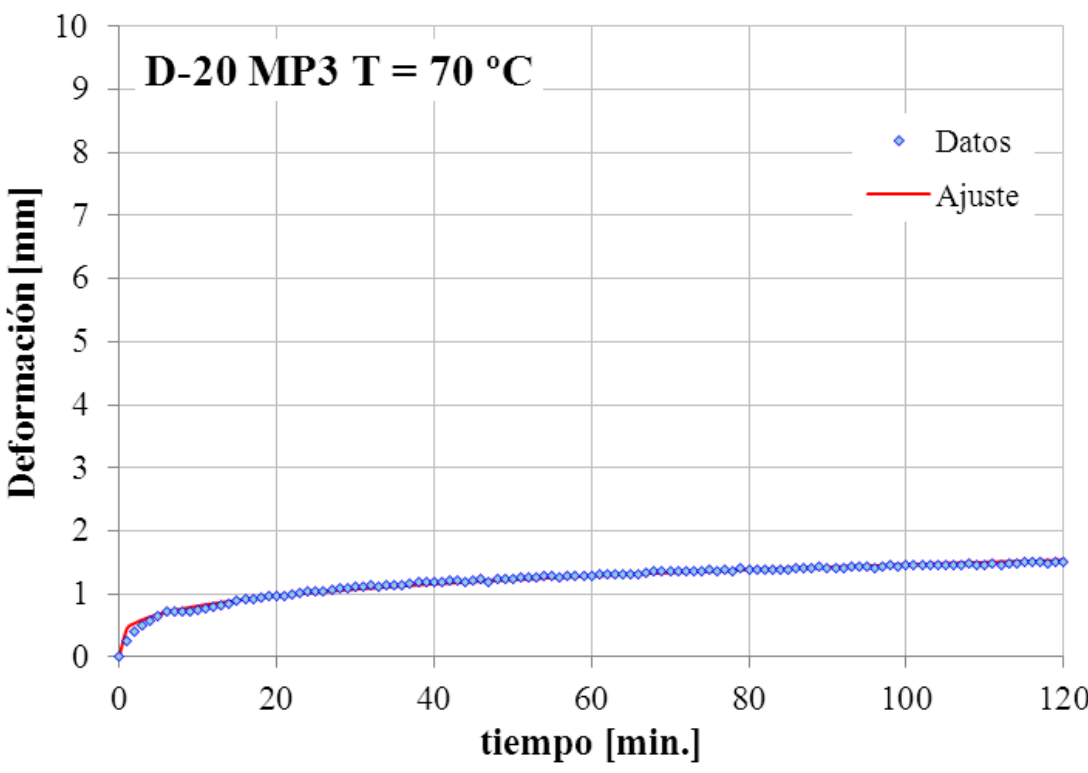

Mezcla (D-20)

Asfalto MP3

$T_{\text {ensayo }}: 70^{\circ} \mathrm{C}$

Carga: $520 \mathrm{~N}$

\section{Ajuste}

$\mathbf{a}=0,4478 ; \mathbf{b}=0,2576$

$\mathbf{R}^{2}=0,98$ 


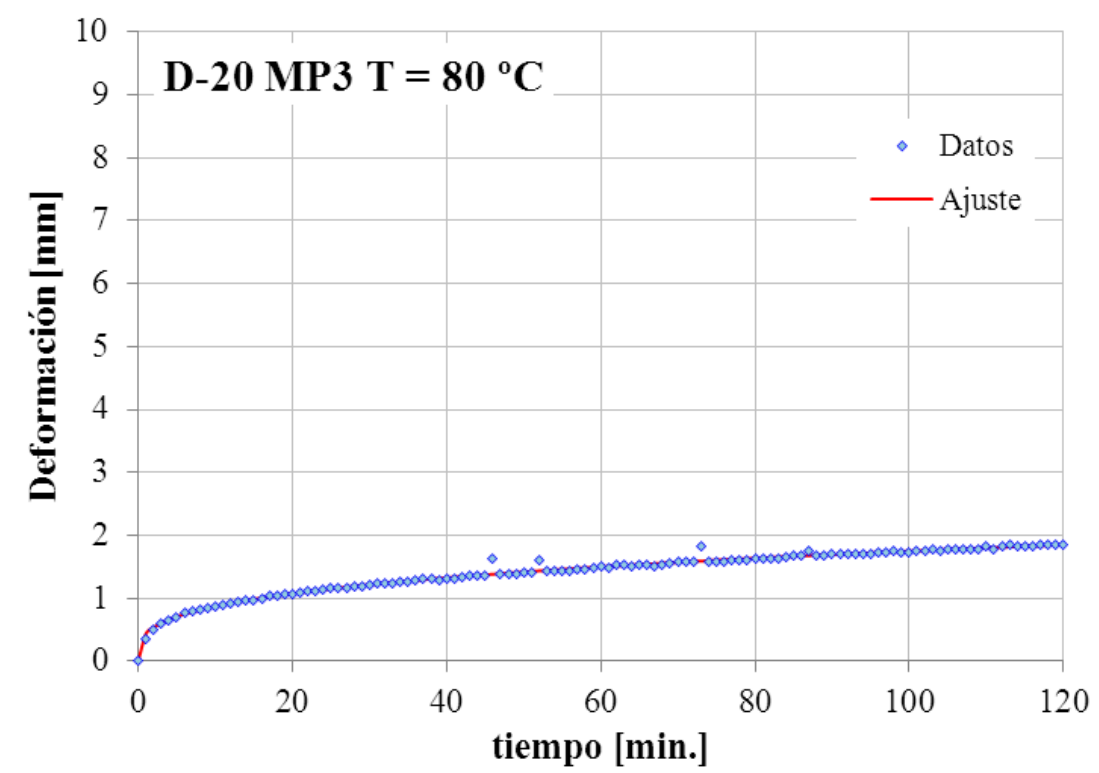

Mezcla (D-20)

Asfalto MP3

$\mathbf{T}_{\text {ensayo }}=80^{\circ} \mathrm{C}$

Carga $=520 \mathrm{~N}$

\section{Ajuste}

$\mathbf{a}=0,4362, \mathbf{b}=0,3018$

$\mathbf{R}^{2}=0,98$

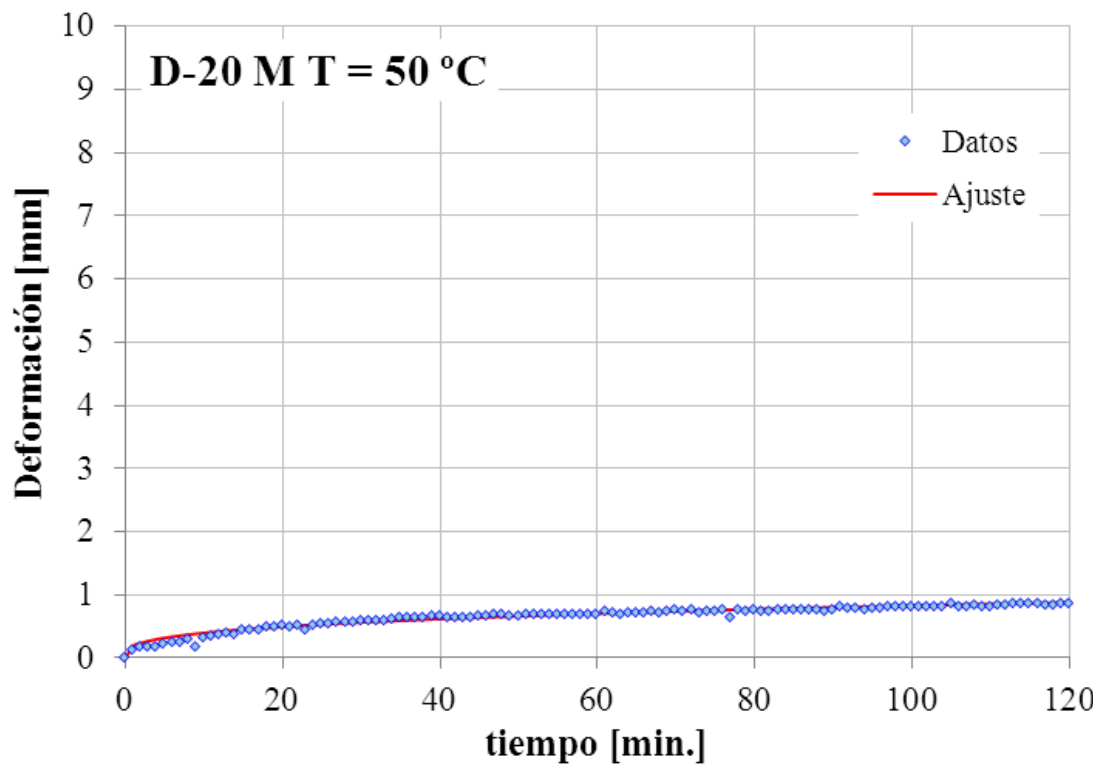

Mezcla (D-20)

Asfalto $\mathrm{M}$

$\mathbf{T}_{\text {ensayo }}=50^{\circ} \mathrm{C}$

Carga $=520 \mathrm{~N}$

\section{Ajuste}

$\mathbf{a}=0,1900 ; \mathbf{b}=0,3194$

$\mathbf{R}^{2}=0,95$

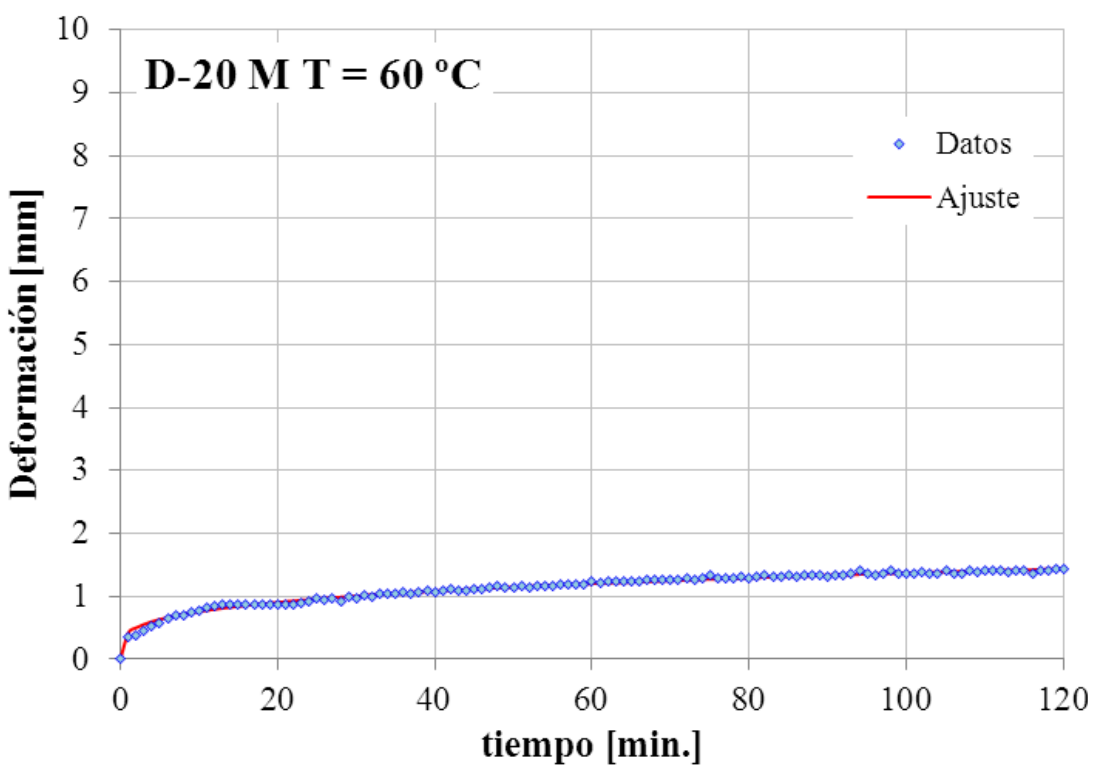

Mezcla (D-20)

Asfalto M

$T_{\text {ensayo }}: 60^{\circ} \mathrm{C}$

Carga: $520 \mathrm{~N}$

\section{Ajuste}

$\mathbf{a}=0,4194 ; \mathbf{b}=0,2571$

$\mathbf{R}^{2}=0,98$ 


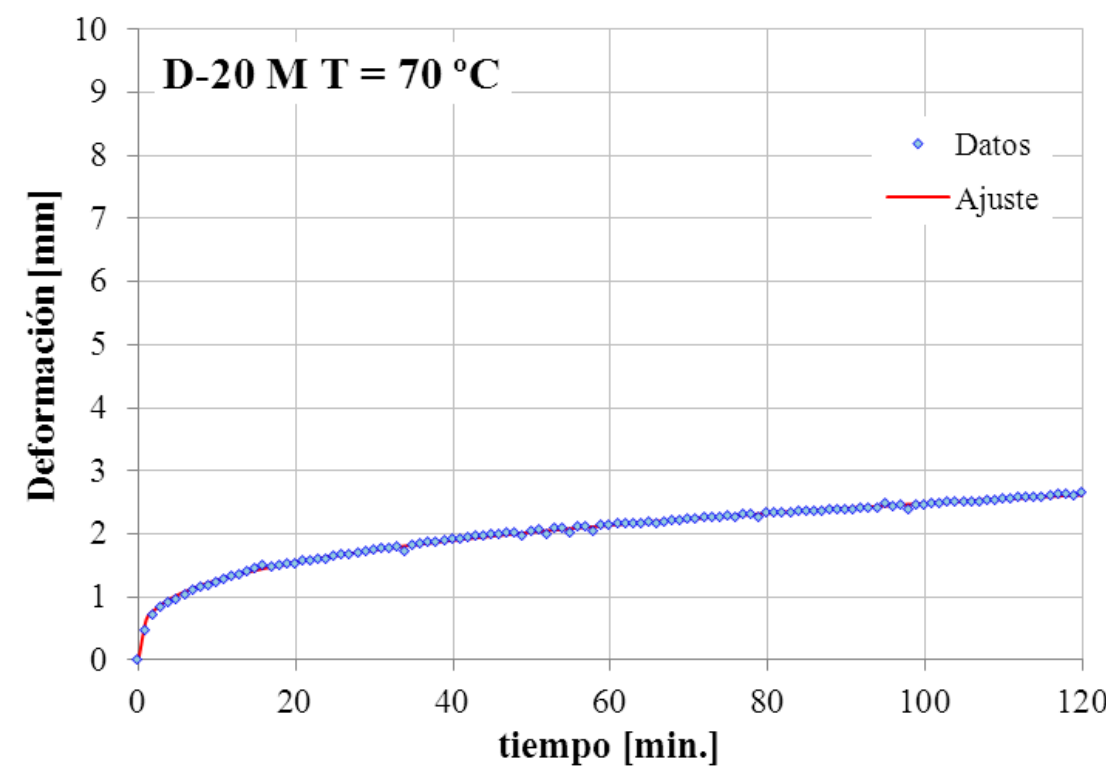

Mezcla (D-20)

Asfalto M

$\mathbf{T}_{\text {ensayo }}=70^{\circ} \mathrm{C}$

Carga $=520 \mathrm{~N}$

Ajuste

$\mathbf{a}=0,6456, \mathbf{b}=0,2926$

$\mathbf{R}^{2}=0,99$

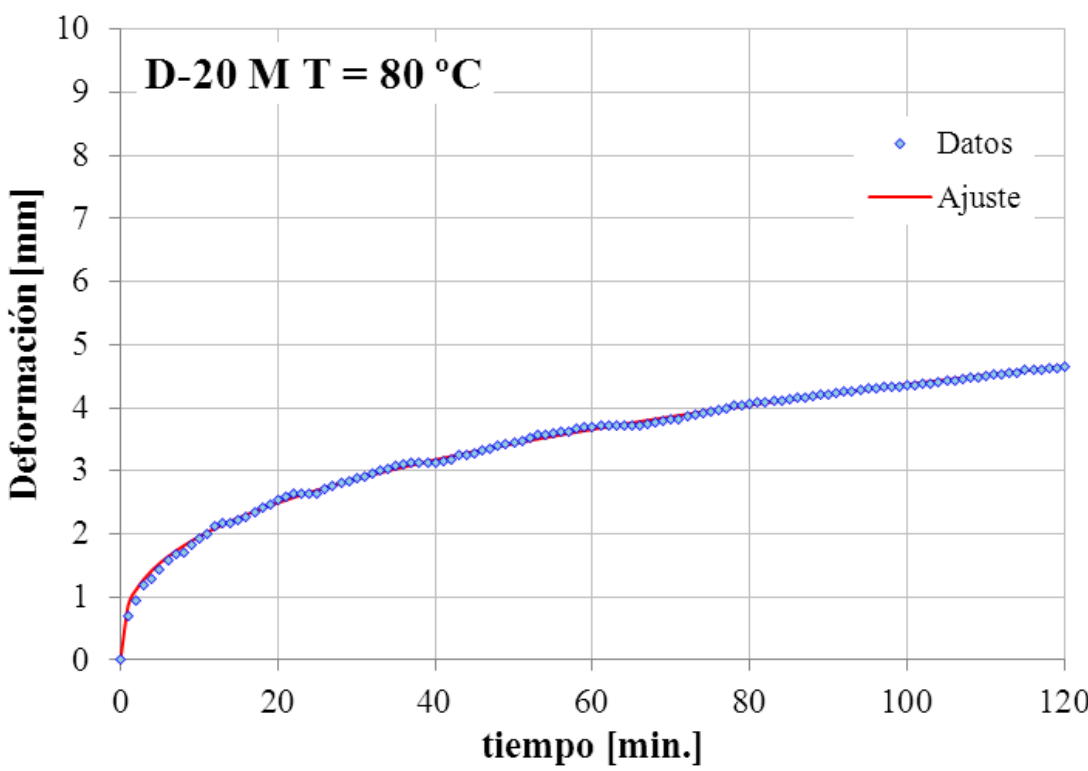

Mezcla (D-20)

Asfalto $M$

$\mathbf{T}_{\text {ensayo }}=80^{\circ} \mathrm{C}$

Carga $=520 \mathrm{~N}$

Ajuste

$\mathbf{a}=0,8770 ; \mathbf{b}=0,3488$

$\mathbf{R}^{2}=0,99$ 
DEFORMACIONES PERMANENTES EN MEZCLAS ASFÁLTICAS.

Efecto de la reología de los asfaltos, la temperatura y las condiciones de carga

\section{Curvas comparativas a distintas temperaturas}
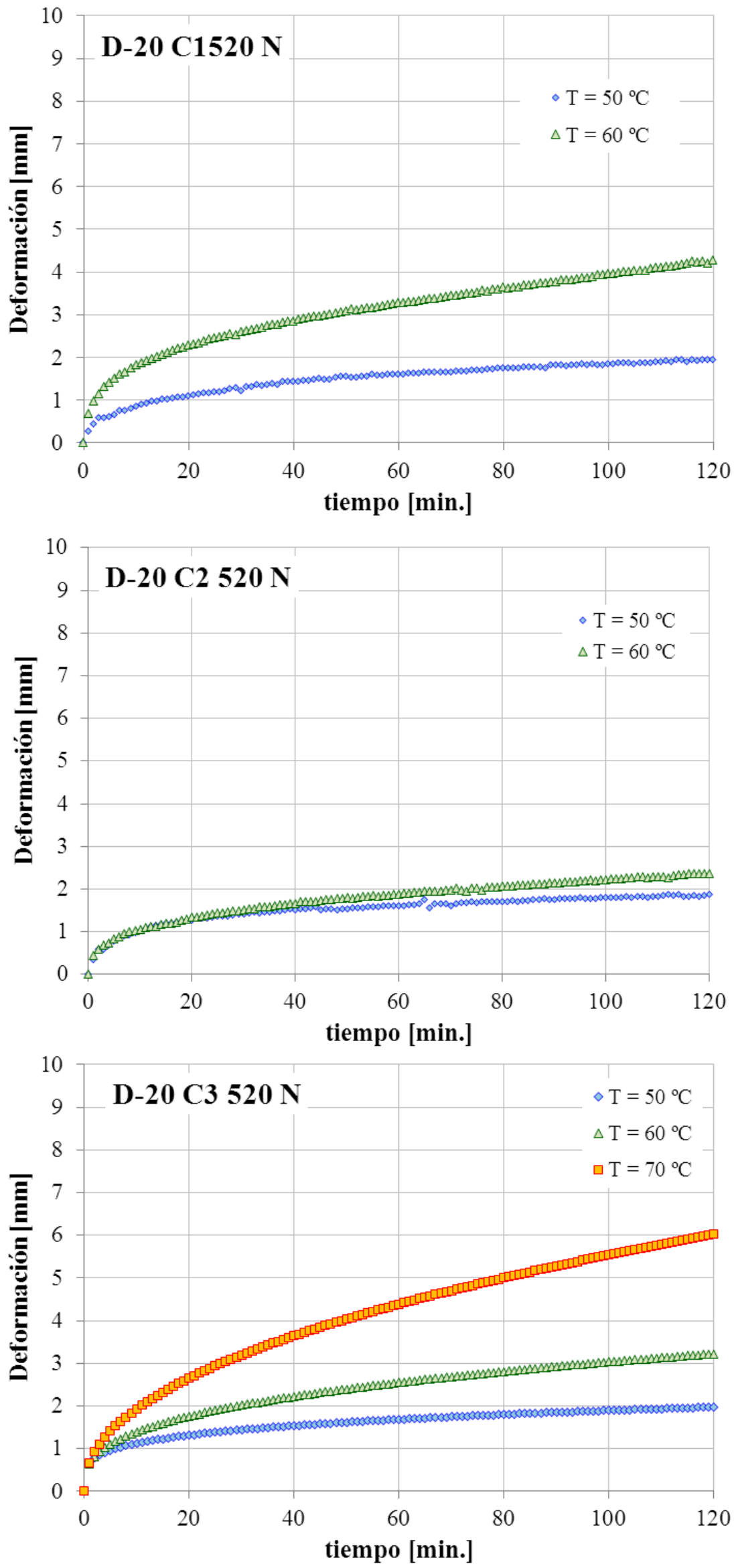

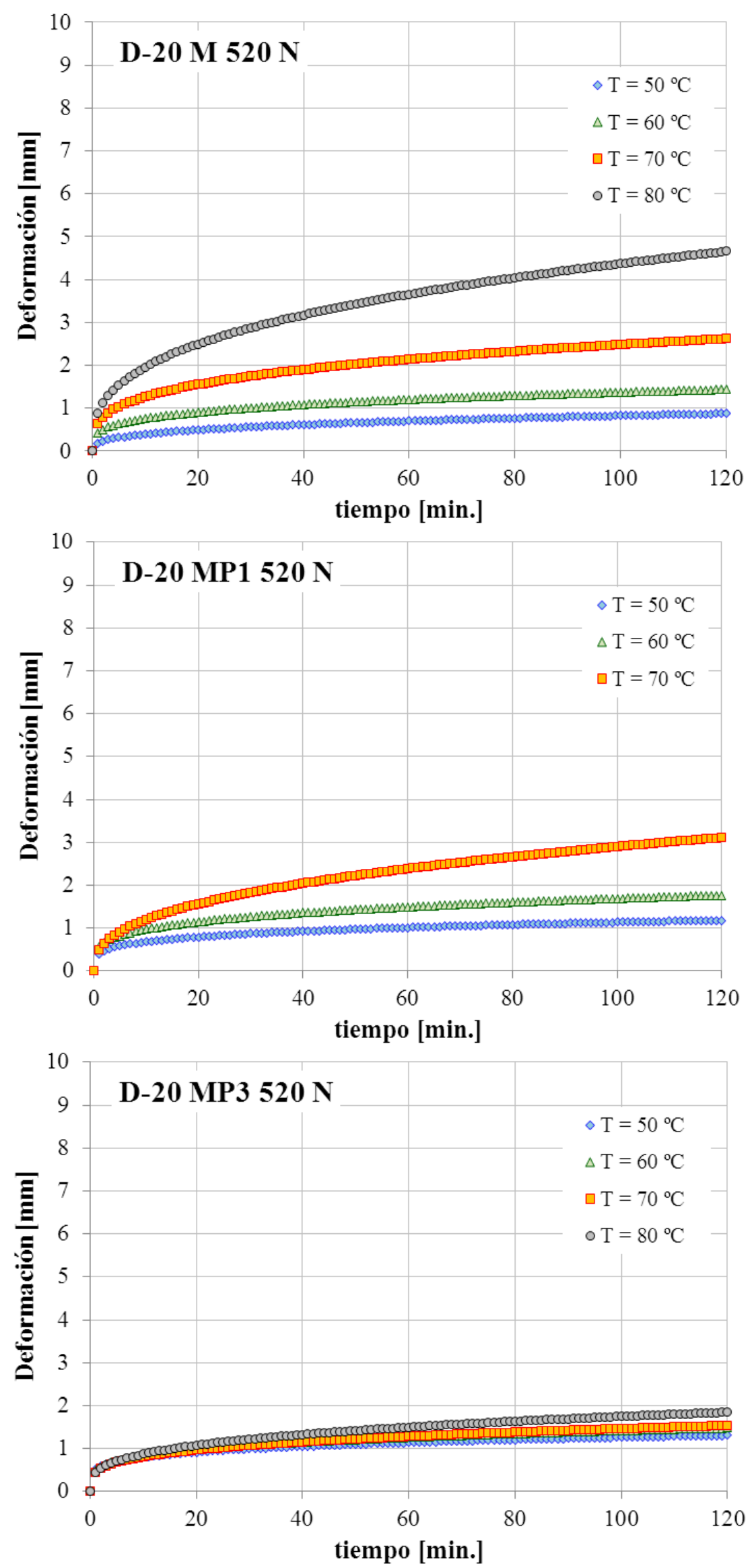



\section{Mezcla Densa (D-20) \\ Ensayos a diferentes niveles de carga}




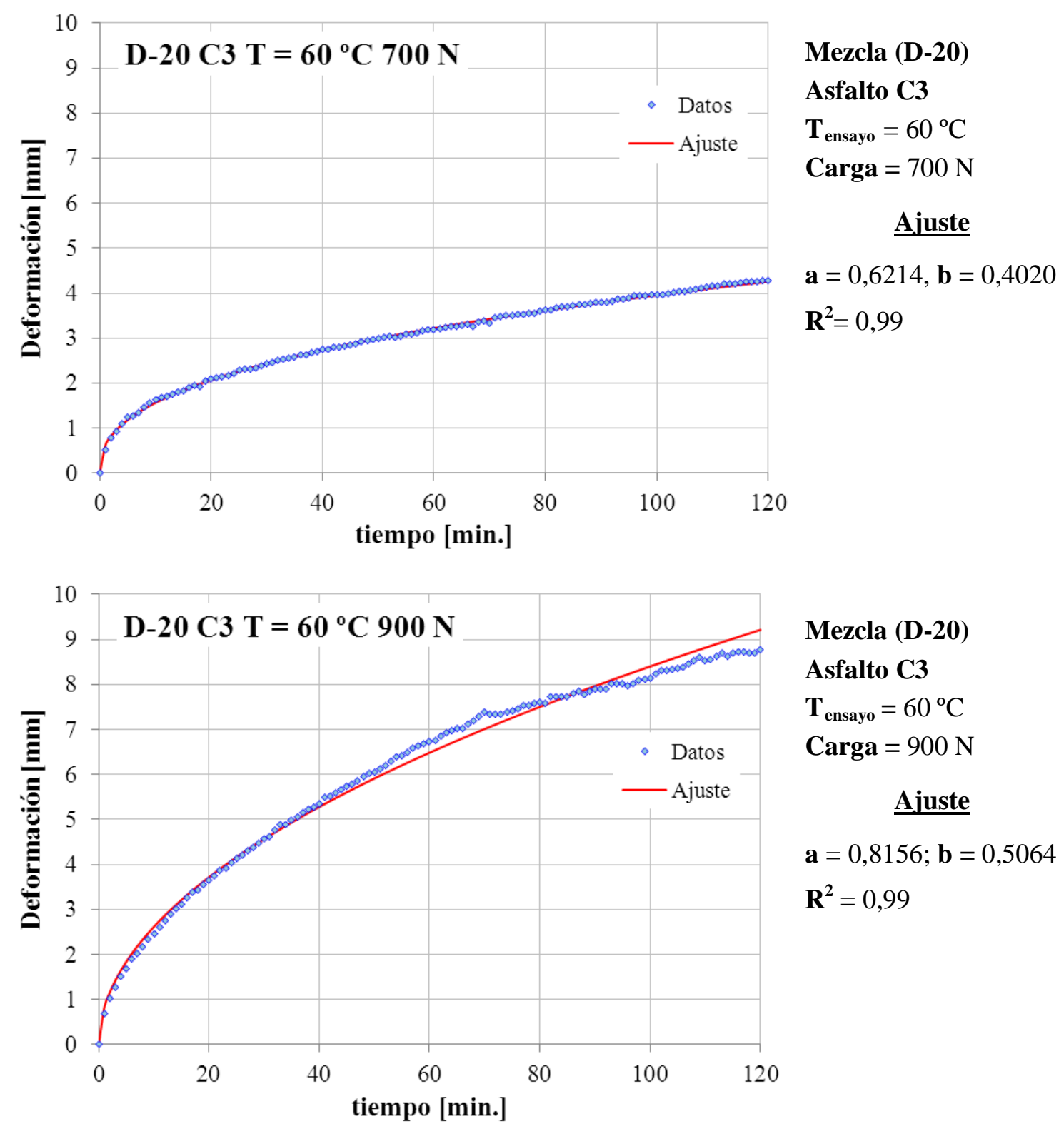

Mezcla (D-20)

Asfalto C3

$\mathbf{T}_{\text {ensayo }}=60^{\circ} \mathrm{C}$

Carga $=900 \mathrm{~N}$

\section{Ajuste}

$\mathbf{a}=0,8156 ; \mathbf{b}=0,5064$

$\mathbf{R}^{2}=0,99$

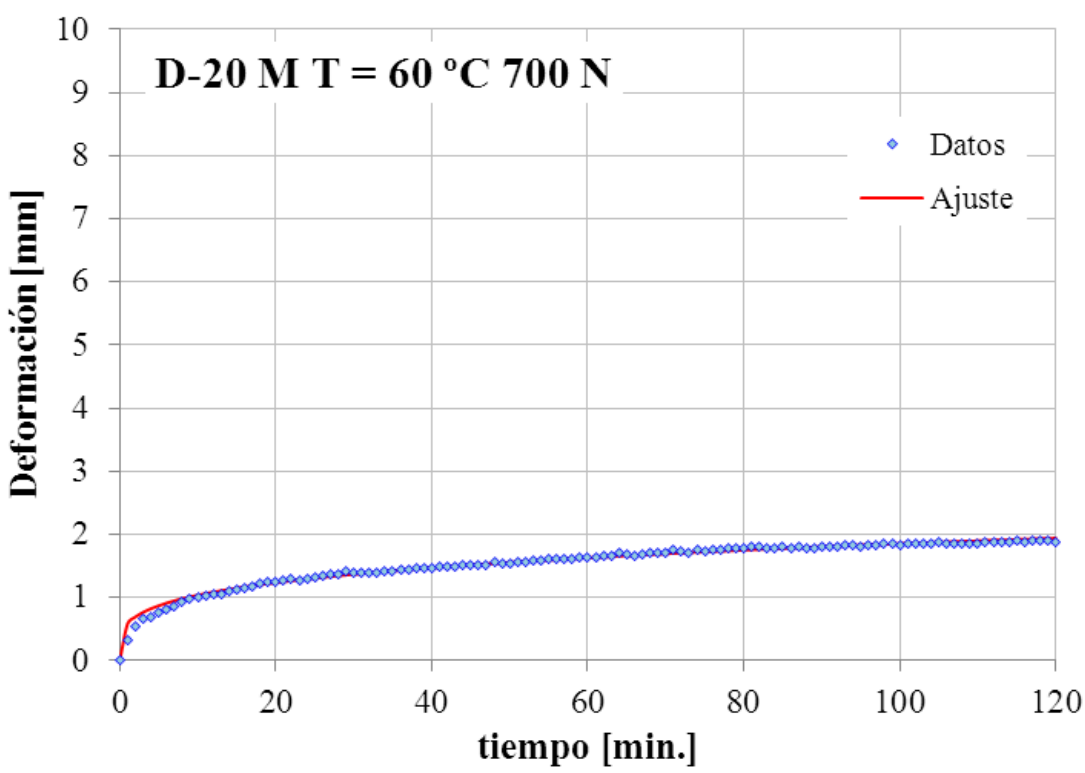

Mezcla (D-20)

Asfalto $\mathrm{M}$

$\mathbf{T}_{\text {ensayo }}=60^{\circ} \mathrm{C}$

Carga $=700 \mathrm{~N}$

Ajuste

$\mathbf{a}=0,5819 ; \mathbf{b}=0,2516$

$\mathbf{R}^{2}=0,99$ 


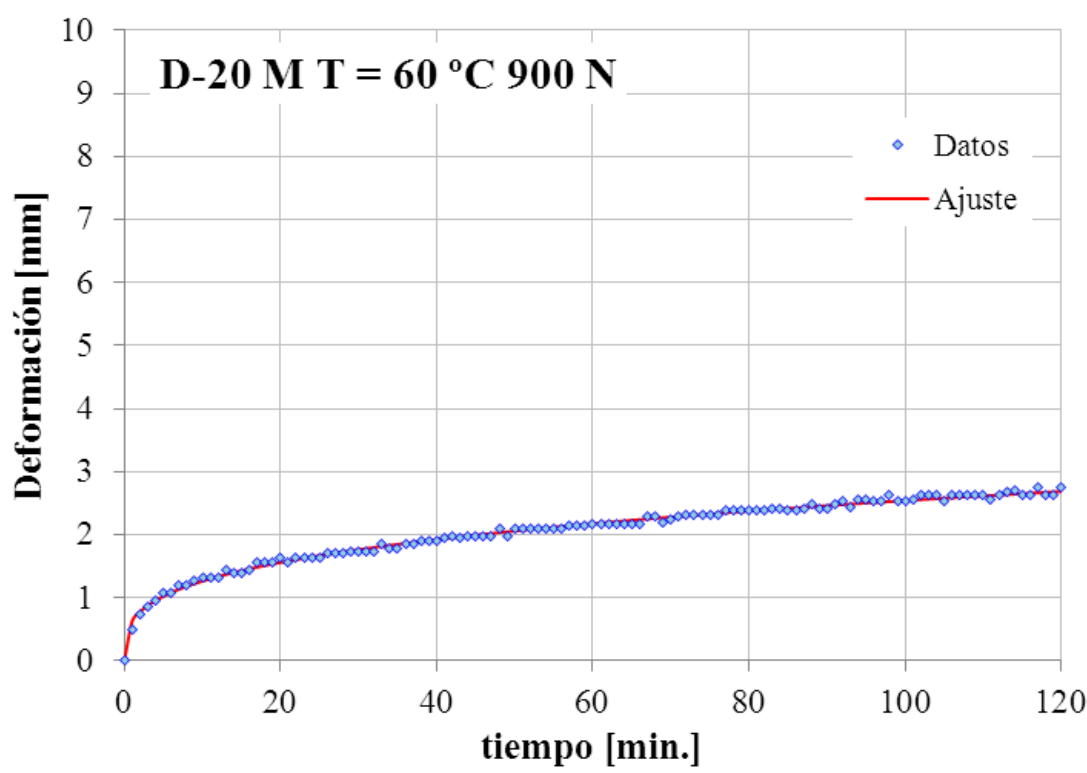

\section{Mezcla (D-20) \\ Asfalto M \\ $\mathbf{T}_{\text {ensayo }}=60^{\circ} \mathrm{C}$ \\ Carga $=900 \mathrm{~N}$}

\section{Ajuste}

$\mathbf{a}=0,6299, \mathbf{b}=0,3029$

$\mathbf{R}^{2}=0,99$

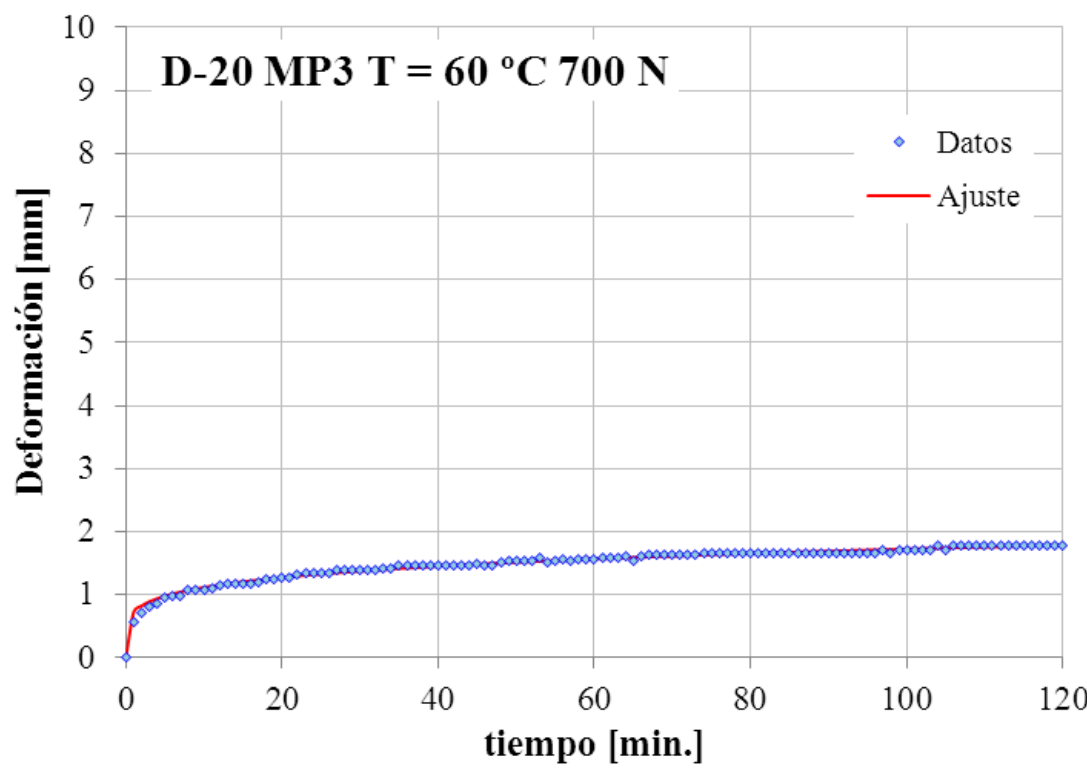

Mezcla (D-20)

Asfalto MP3

$\mathbf{T}_{\text {ensayo }}=60^{\circ} \mathrm{C}$

Carga $=700 \mathrm{~N}$

\section{Ajuste}

$\mathbf{a}=0,7240 ; \mathbf{b}=0,1887$

$\mathbf{R}^{2}=0,98$

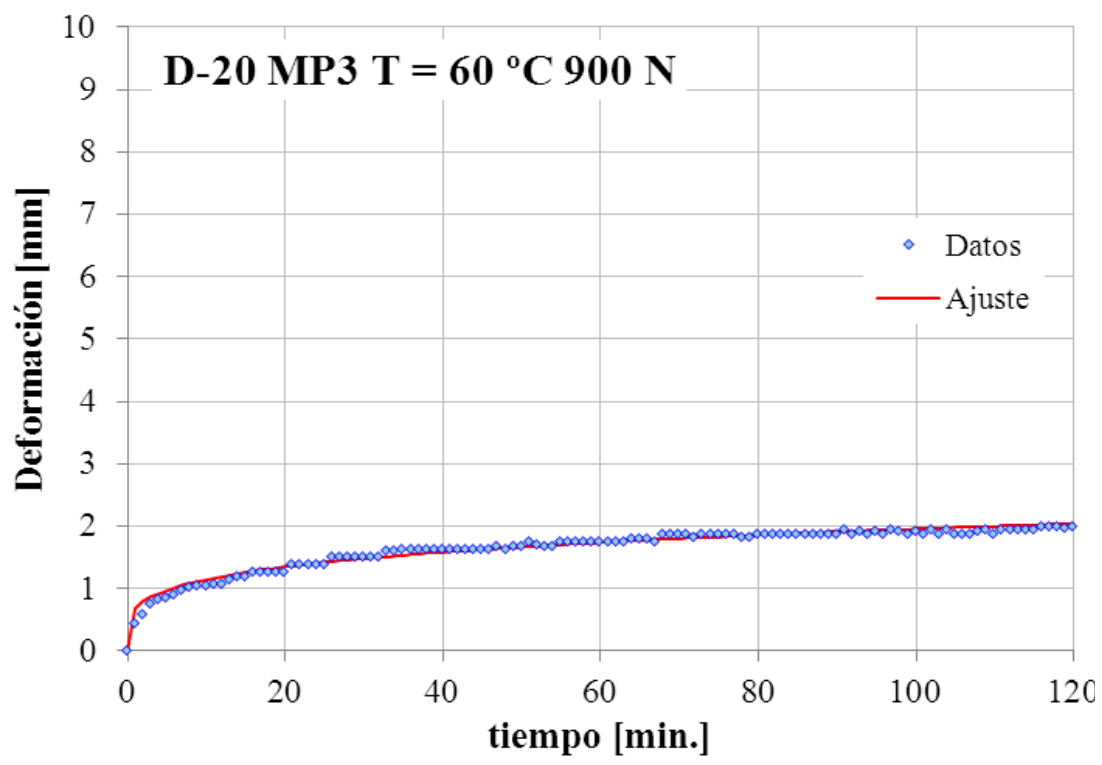

Mezcla (D-20)

Asfalto MP3

$\mathbf{T}_{\text {ensayo }}=60^{\circ} \mathrm{C}$

Carga $=900 \mathrm{~N}$

\section{Ajuste}

$\mathbf{a}=0,6747 ; \mathbf{b}=0,2310$

$\mathbf{R}^{2}=0,95$ 


\section{Curvas comparativas diferentes niveles de carga}
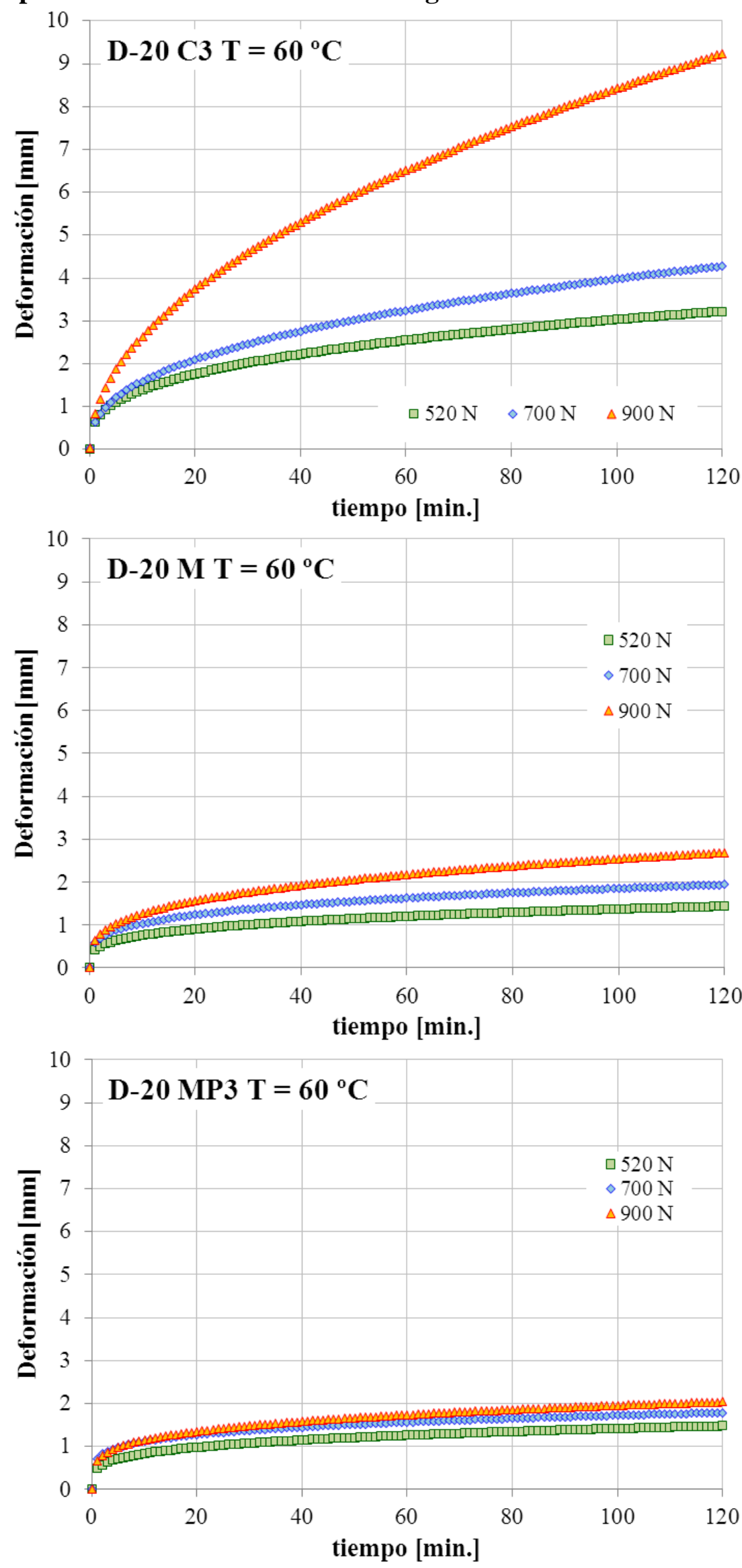



\section{Microaglomerado (M-10) \\ Ensayos a distintas temperaturas}





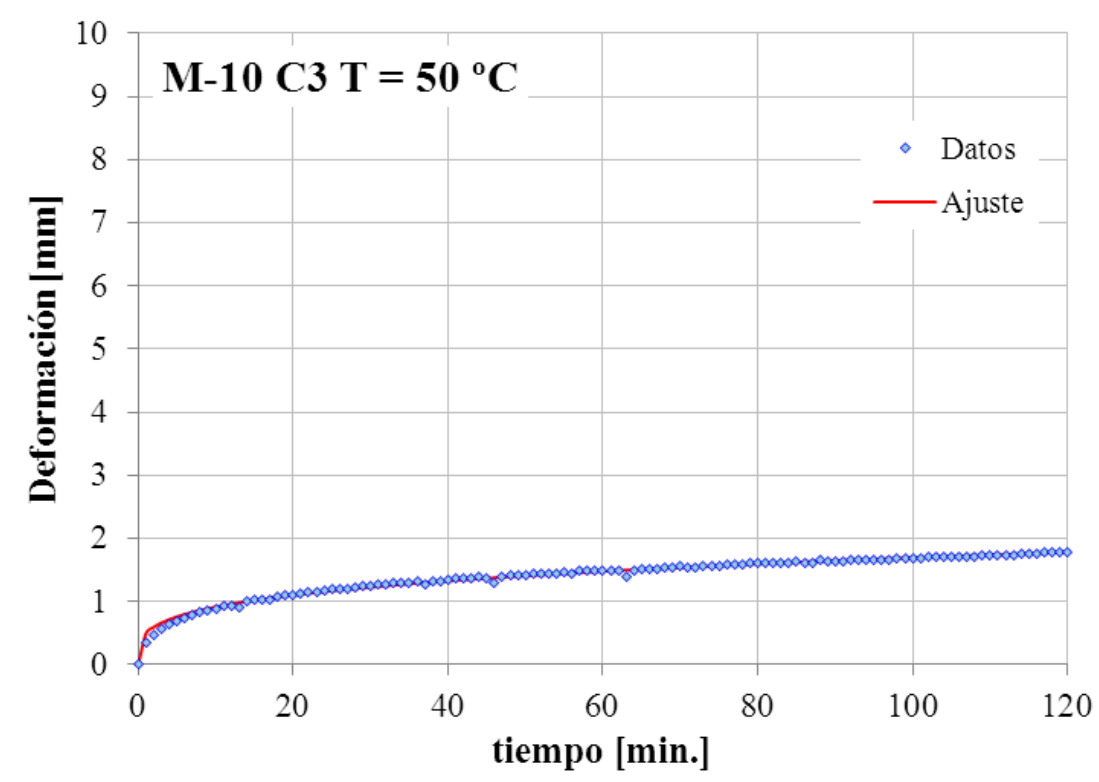

Mezcla (M-10)

Asfalto C3

$\mathbf{T}_{\text {ensayo }}=50^{\circ} \mathrm{C}$

Carga $=520 \mathrm{~N}$

Ajuste

$\mathbf{a}=0,4948, \mathbf{b}=0,2674$

$\mathbf{R}^{2}=0,99$

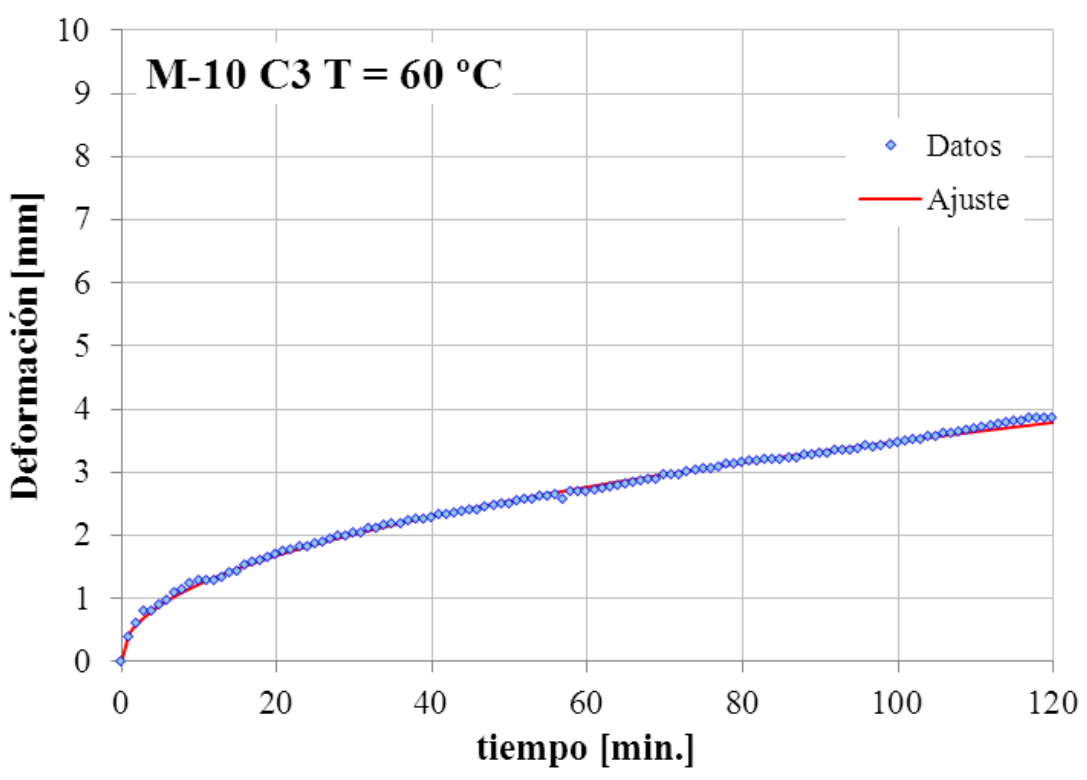

Mezcla (M-10)

Asfalto C3

$\mathbf{T}_{\text {ensayo }}=60^{\circ} \mathrm{C}$

Carga $=520 \mathrm{~N}$

\section{Ajuste}

$\mathbf{a}=0,4324 ; \mathbf{b}=0,4534$

$\mathbf{R}^{2}=0,99$

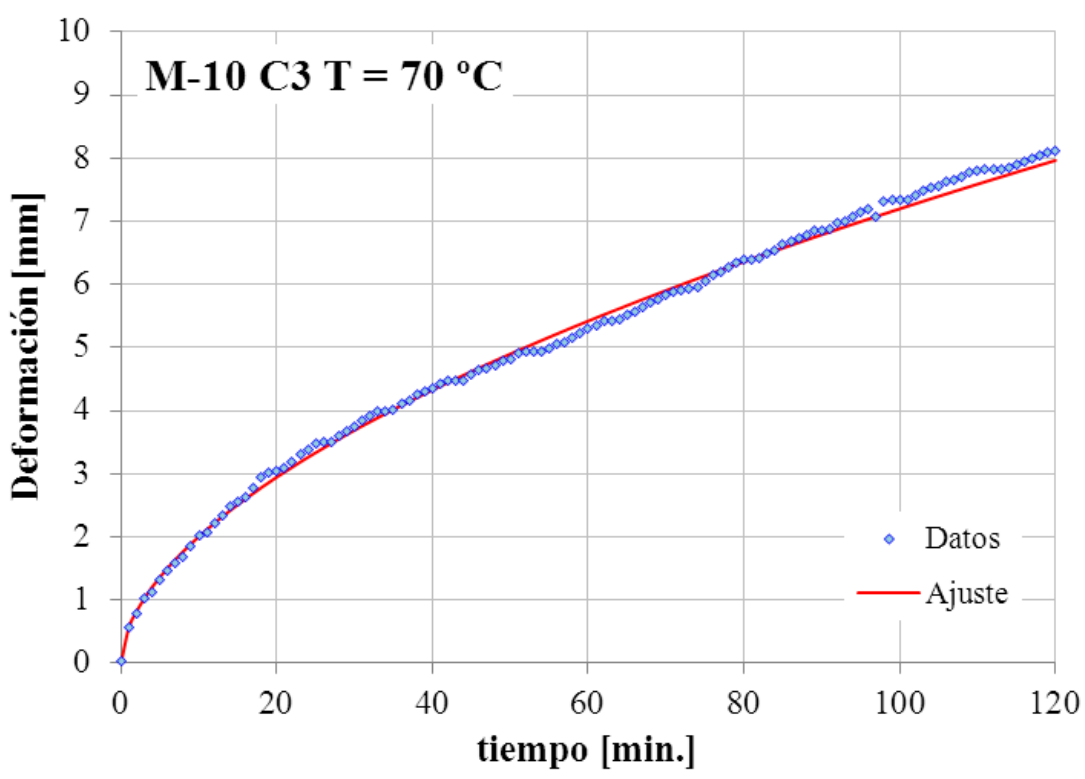

Mezcla (M-10)

Asfalto C3

$\mathbf{T}_{\text {ensayo }}=70^{\circ} \mathrm{C}$

Carga $=520 \mathrm{~N}$

\section{Ajuste}

$\mathbf{a}=0,5590 ; \mathbf{b}=0,5549$

$\mathbf{R}^{2}=0,99$ 


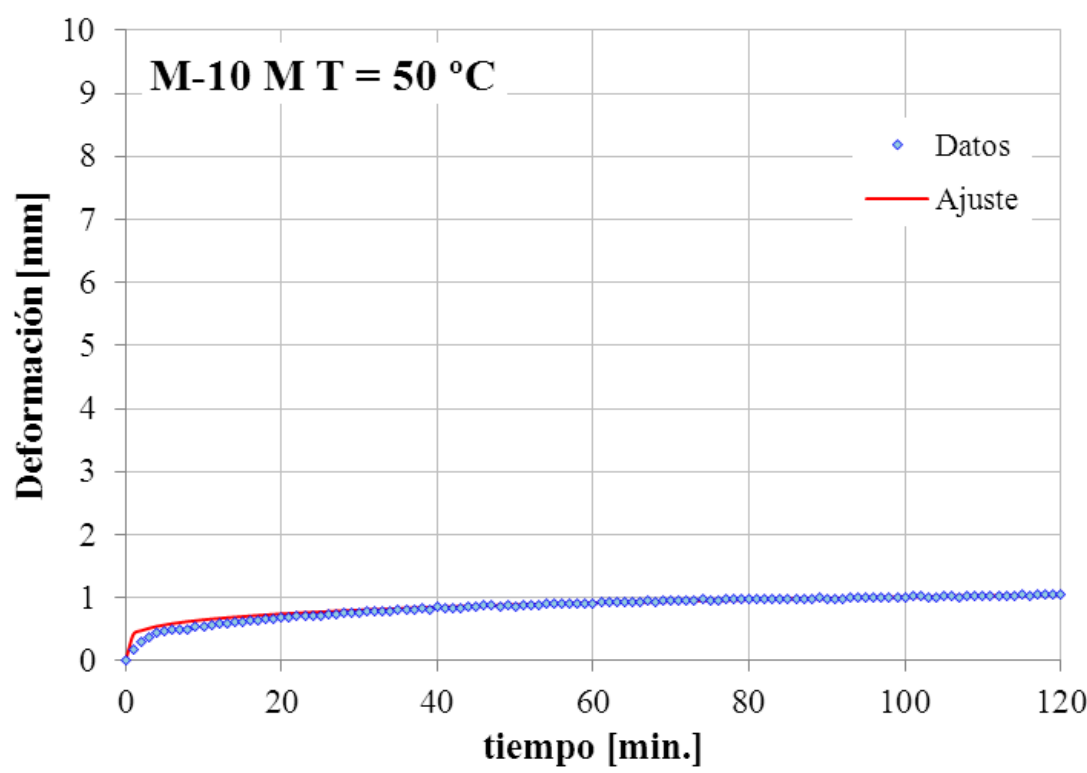

\section{Mezcla (M-10) \\ Asfalto M \\ $\mathbf{T}_{\text {ensayo }}=50^{\circ} \mathrm{C}$ \\ Carga $=520 \mathrm{~N}$}

\section{Ajuste}

$\mathbf{a}=0,4190 ; \mathbf{b}=0,1916$

$\mathbf{R}^{2}=0,98$

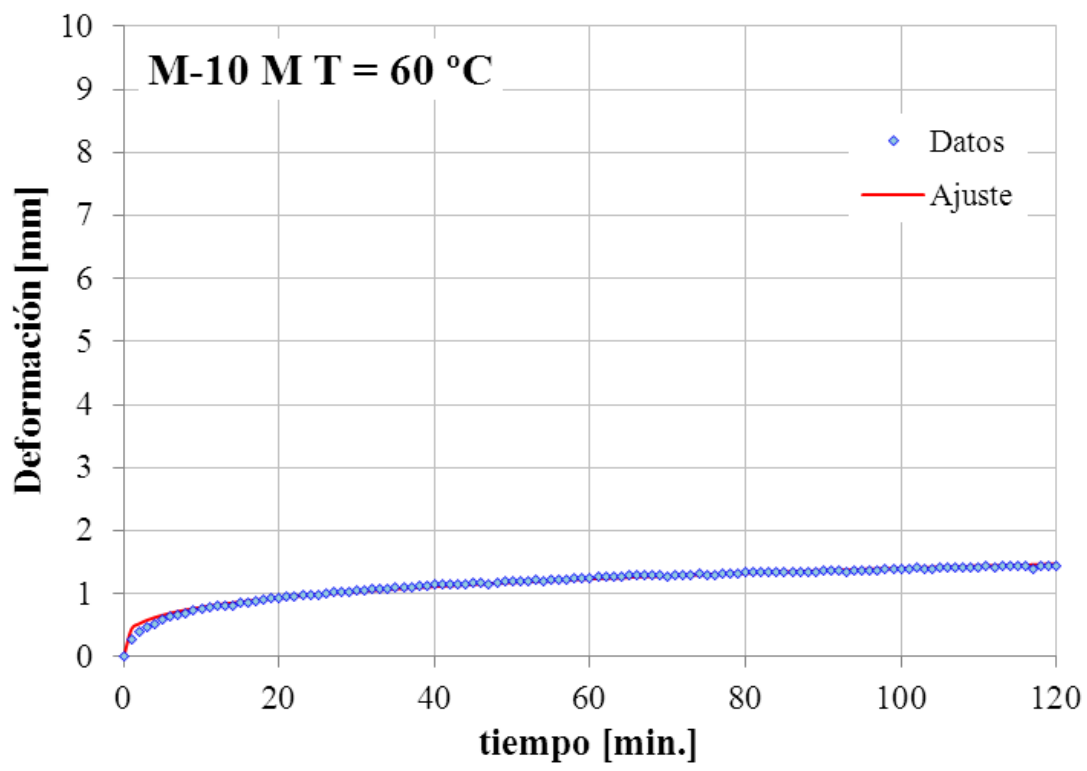

Mezcla (M-10)

Asfalto $\mathrm{M}$

$\mathbf{T}_{\text {ensayo }}=60^{\circ} \mathrm{C}$

Carga $=520 \mathrm{~N}$

\section{Ajuste}

$\mathbf{a}=0,4409 ; \mathbf{b}=0,2516$

$\mathbf{R}^{2}=0,99$

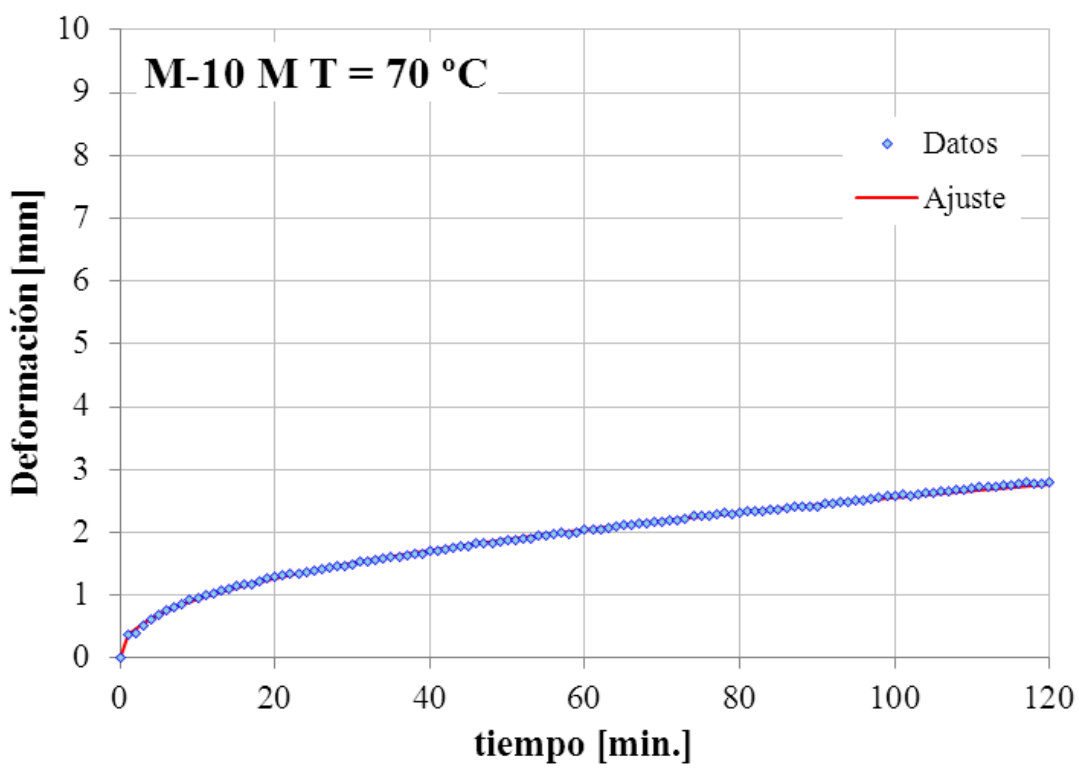

Mezcla (M-10)

Asfalto $\mathrm{M}$

$\mathbf{T}_{\text {ensayo }}=70^{\circ} \mathrm{C}$

Carga $=520 \mathrm{~N}$

\section{Ajuste}

$\mathbf{a}=0,3455 ; \mathbf{b}=0,4345$

$\mathbf{R}^{2}=0,99$ 


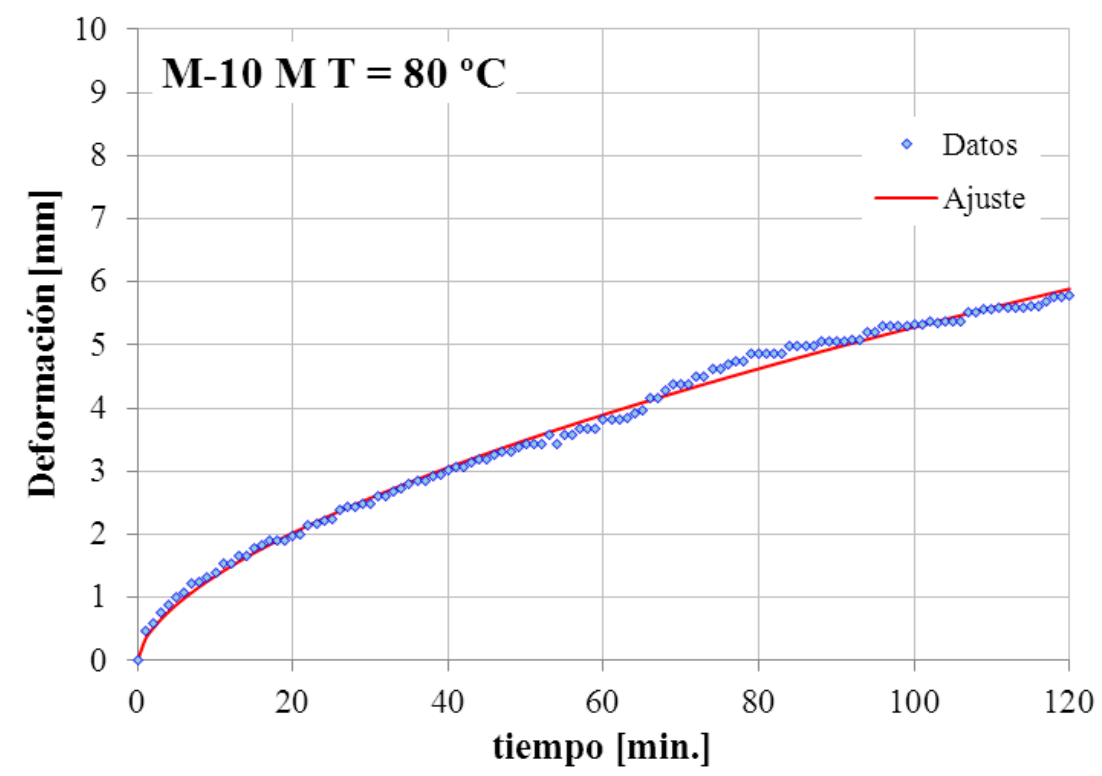

Mezcla (M-10)

Asfalto M

$\mathbf{T}_{\text {ensayo }}=80^{\circ} \mathrm{C}$

Carga $=520 \mathrm{~N}$

\section{Ajuste}

$\mathbf{a}=0,3397 ; \mathbf{b}=0,5959$

$\mathbf{R}^{2}=0,99$

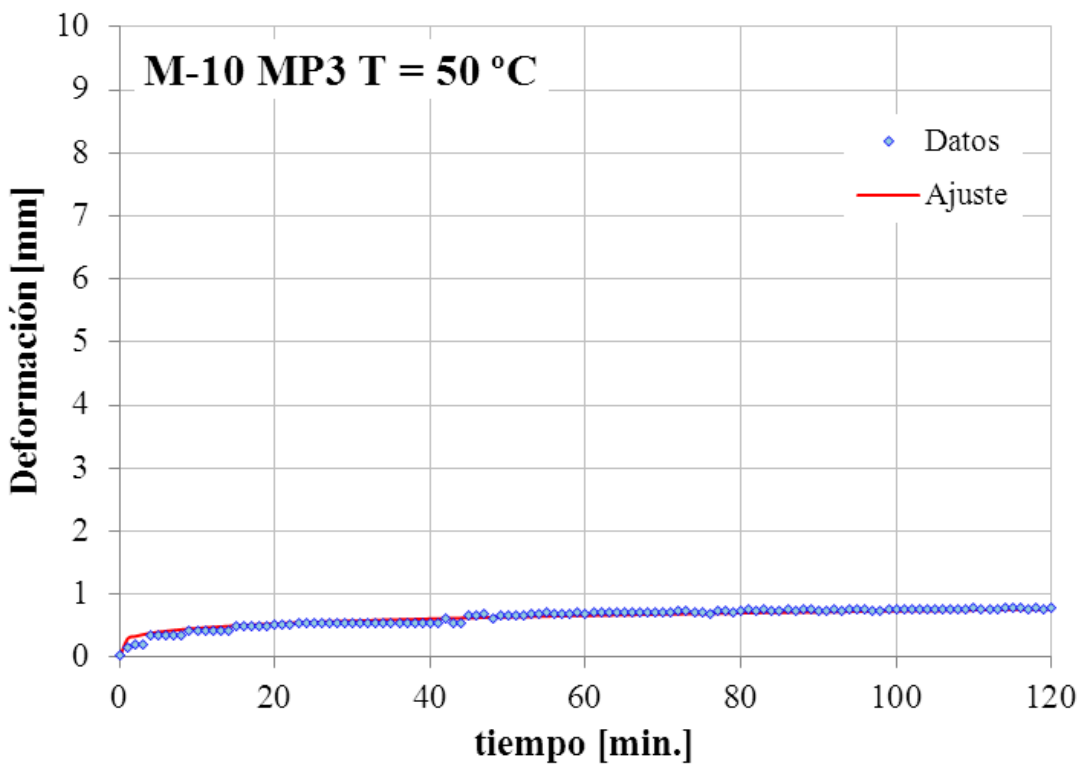

Mezcla (M-10)

Asfalto MP3

$\mathbf{T}_{\text {ensayo }}=50^{\circ} \mathrm{C}$

Carga $=520 \mathrm{~N}$

\section{Ajuste}

$\mathbf{a}=0,2902 ; \mathbf{b}=0,2021$

$\mathbf{R}^{2}=0,70$

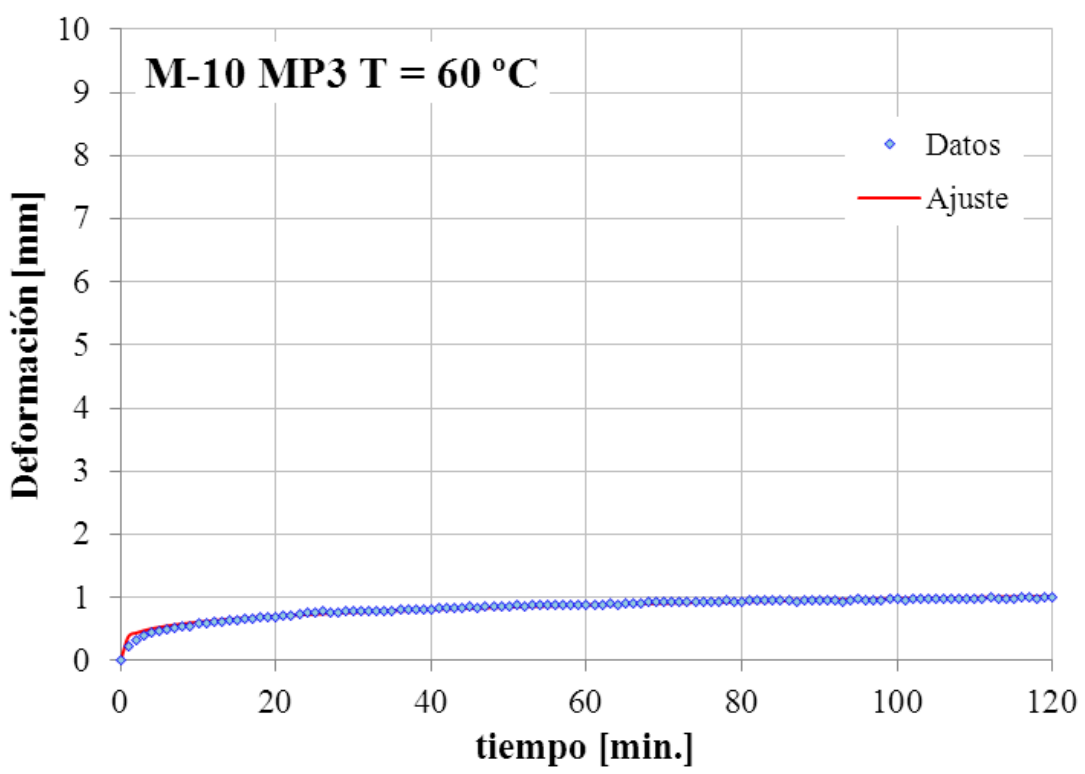

Mezcla (M-10)

Asfalto MP3

$\mathbf{T}_{\text {ensayo }}=60^{\circ} \mathrm{C}$

Carga $=520 \mathrm{~N}$

Ajuste

$\mathbf{a}=0,3817 ; \mathbf{b}=0,2048$

$\mathbf{R}^{2}=0,98$ 


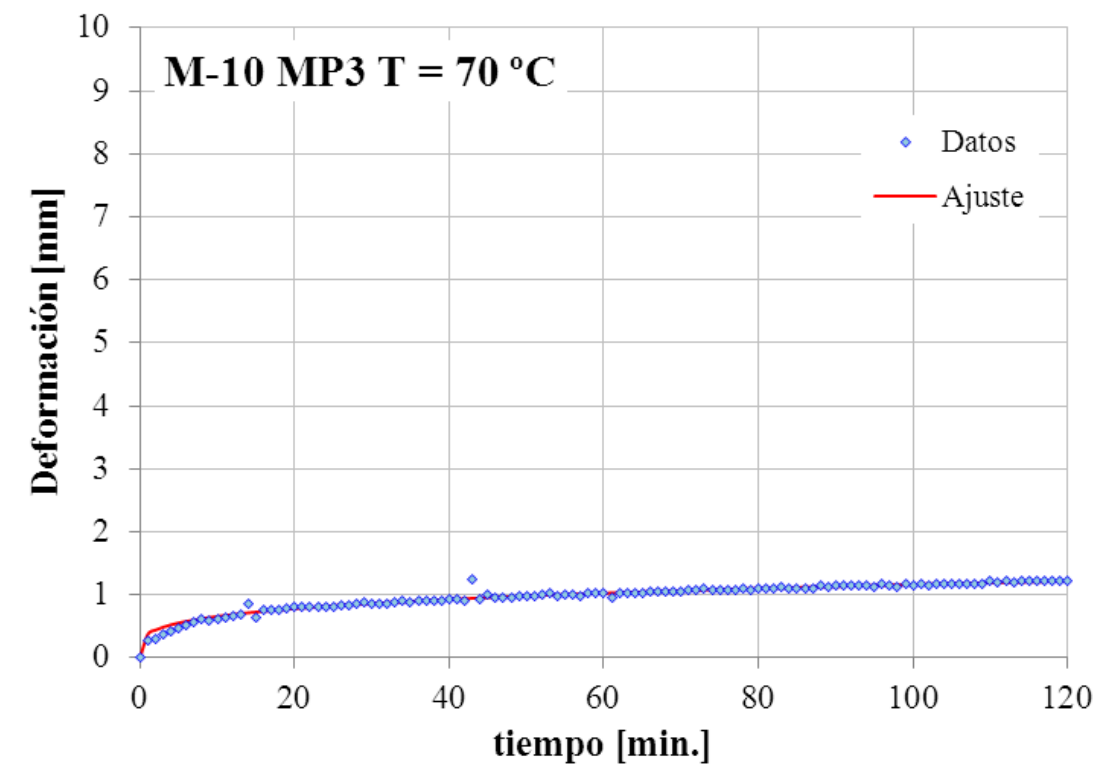

$$
\begin{aligned}
& \text { Mezcla (M-10) } \\
& \text { Asfalto MP3 } \\
& \mathbf{T}_{\text {ensayo }}=70^{\circ} \mathrm{C} \\
& \text { Carga }=520 \mathrm{~N}
\end{aligned}
$$

\section{Ajuste}

$\mathbf{a}=0,3731 ; \mathbf{b}=0,2473$

$\mathbf{R}^{2}=0,95$

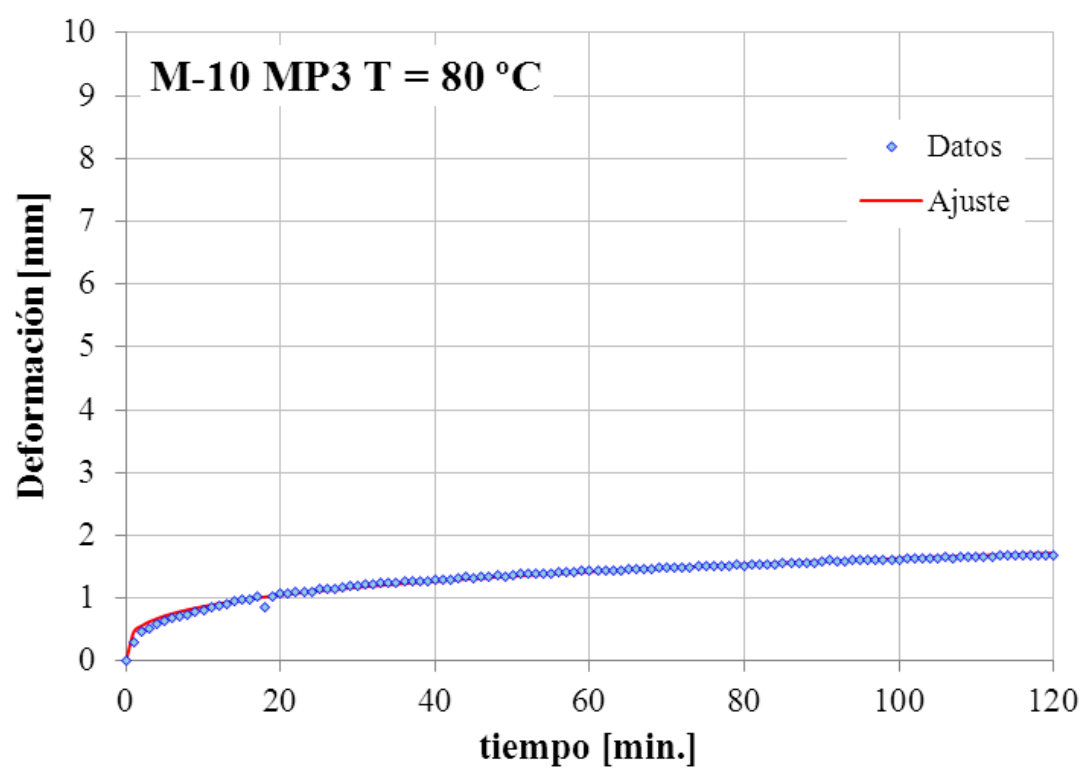

Mezcla (M-10)

Asfalto MP3

$\mathbf{T}_{\text {ensayo }}=80^{\circ} \mathrm{C}$

Carga $=520 \mathrm{~N}$

\section{Ajuste}

$\mathbf{a}=0,4643 ; \mathbf{b}=0,2734$

$\mathbf{R}^{2}=0,98$ 


\section{Curvas comparativas a distintas temperaturas}
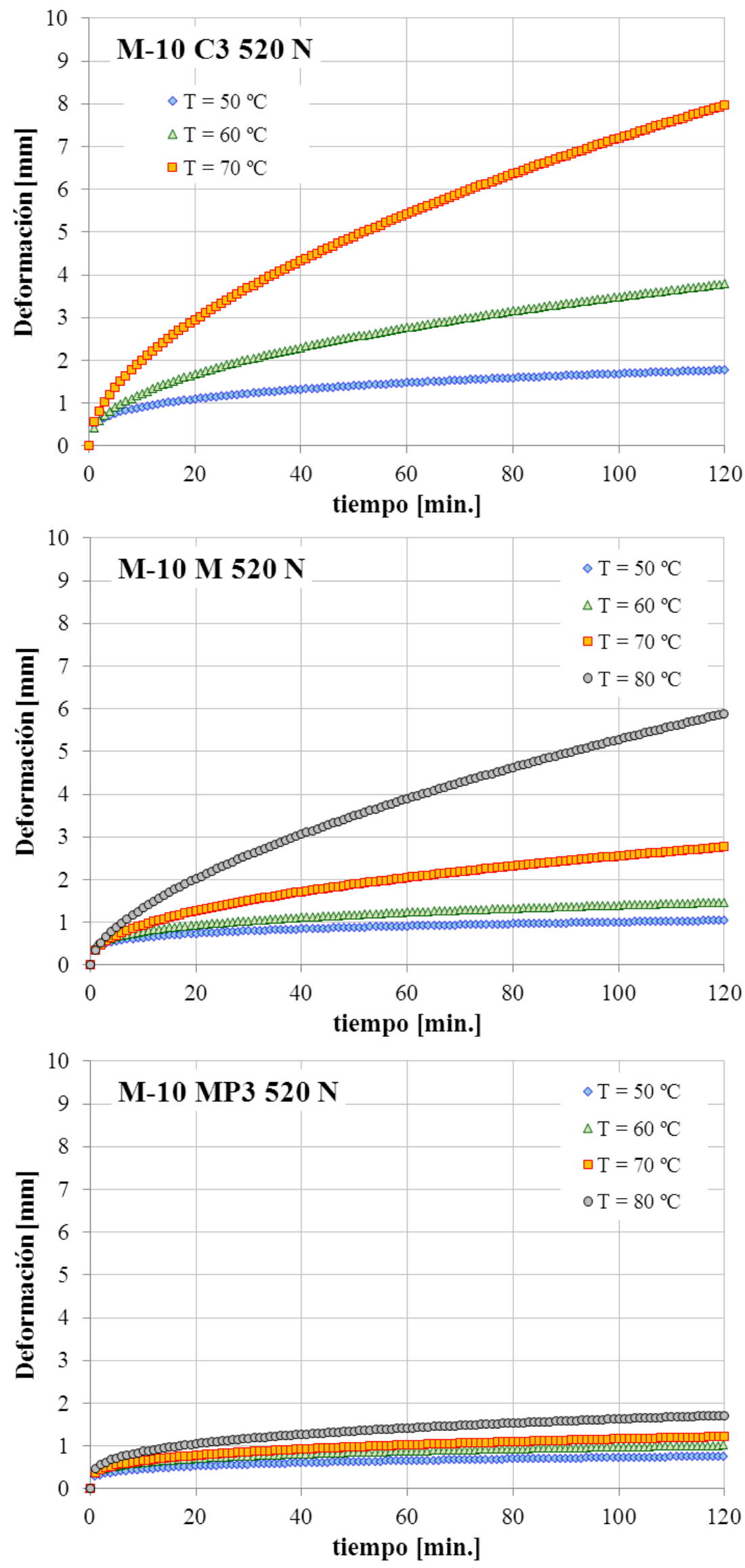



\section{Microaglomerado (M-10) \\ Ensayos a diferentes niveles de carga}





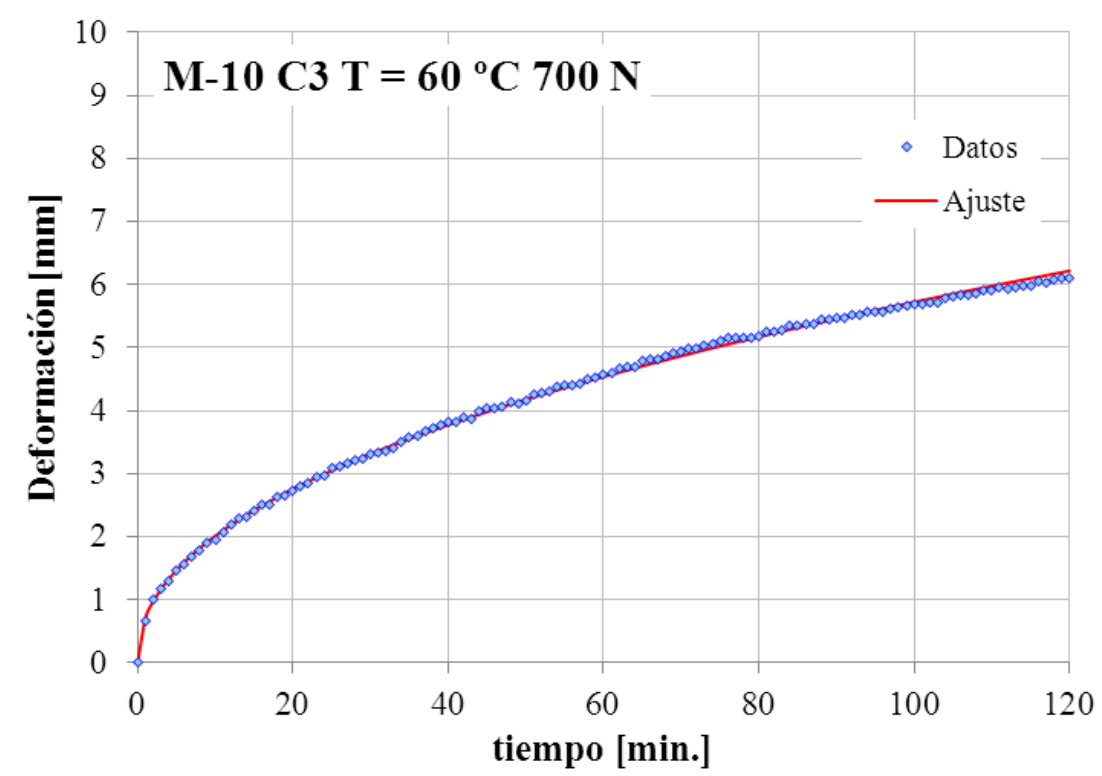

Mezcla (M-10)

Asfalto C3

$\mathbf{T}_{\text {ensayo }}=60^{\circ} \mathrm{C}$

Carga $=700 \mathrm{~N}$

Ajuste

$\mathbf{a}=0,7074 ; \mathbf{b}=0,4540$

$\mathbf{R}^{2}=0,99$

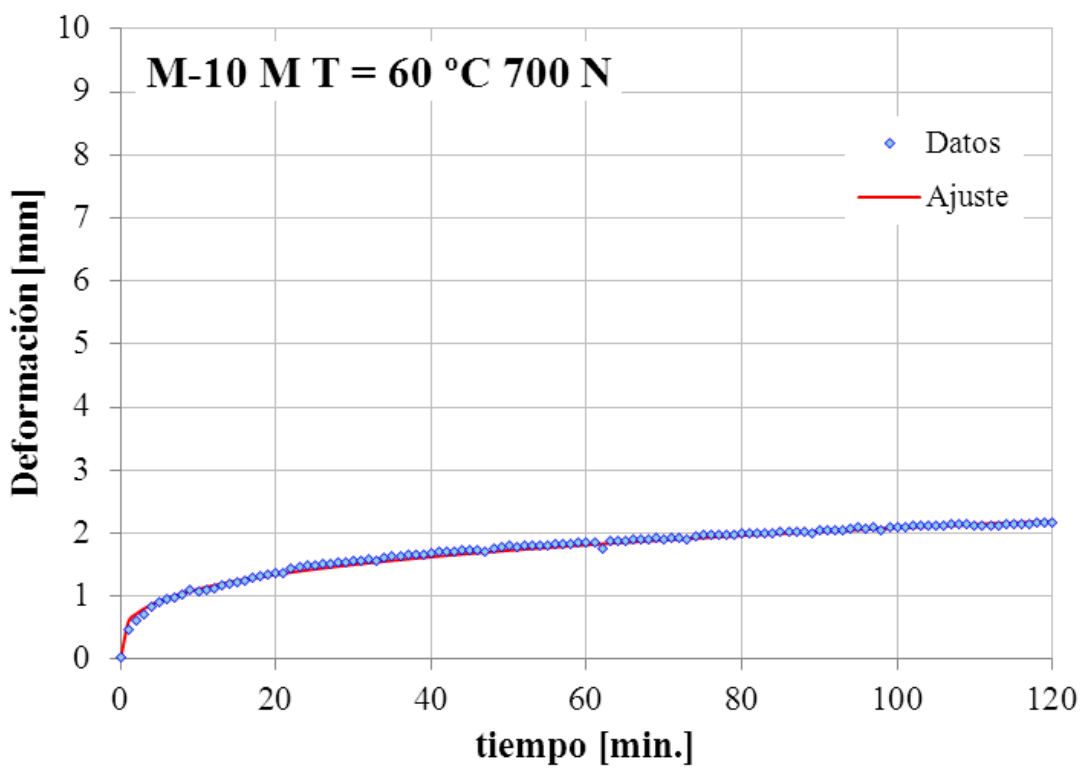

Mezcla (M-10)

Asfalto $\mathrm{M}$

$\mathbf{T}_{\text {ensayo }}=60^{\circ} \mathrm{C}$

Carga $=700 \mathrm{~N}$

\section{Ajuste}

$\mathbf{a}=0,5961 ; \mathbf{b}=0,2719$

$\mathbf{R}^{2}=0,99$

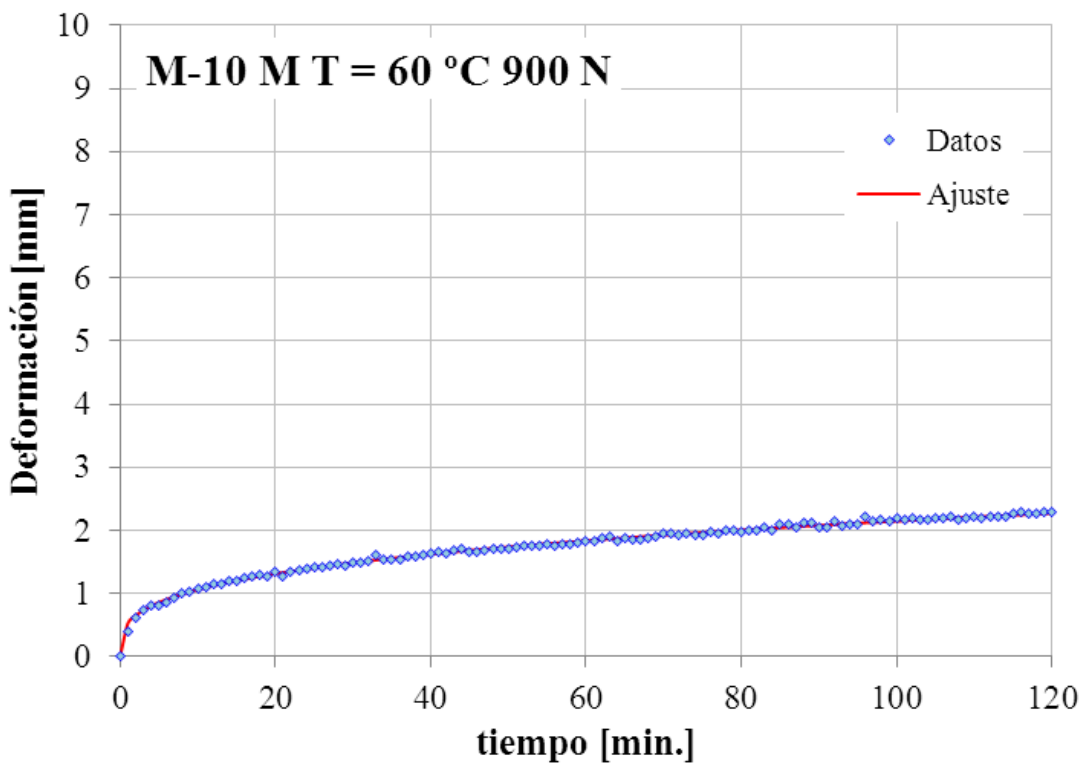

Mezcla (M-10)

Asfalto $\mathbf{M}$

$\mathbf{T}_{\text {ensayo }}=60^{\circ} \mathrm{C}$

Carga $=900 \mathrm{~N}$

\section{Ajuste}

$\mathbf{a}=0,5268 ; \mathbf{b}=0,3052$

$\mathbf{R}^{2}=0,99$ 


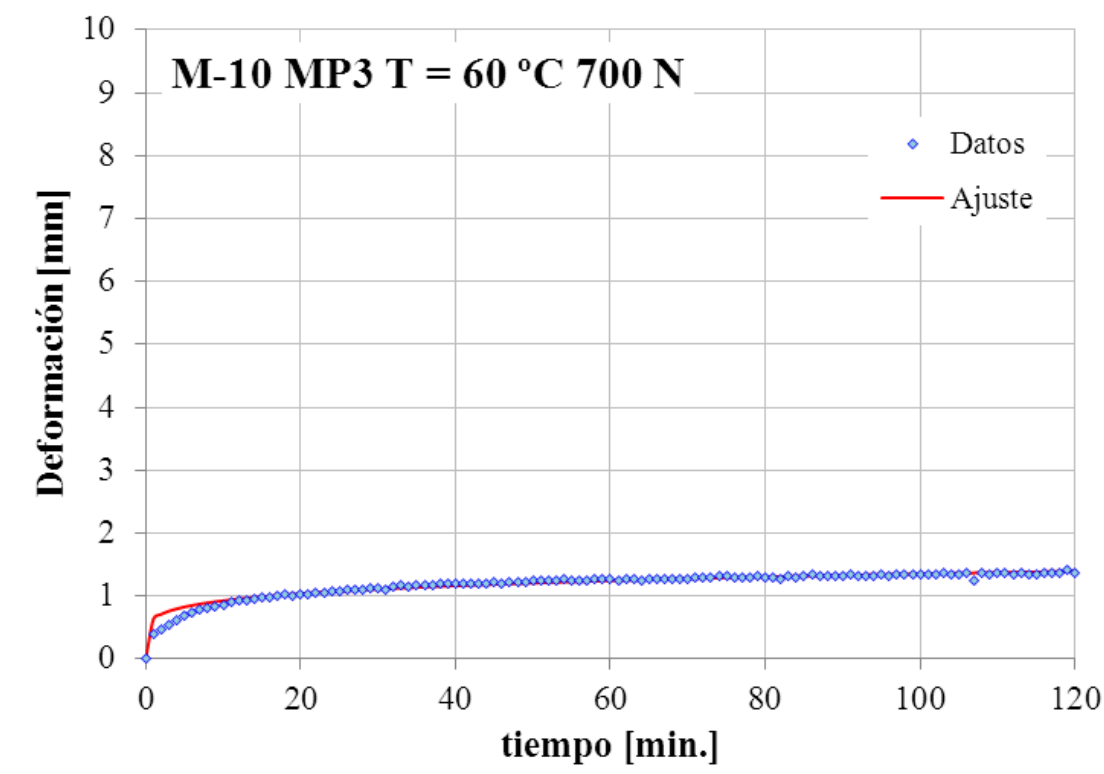

$$
\begin{aligned}
& \text { Mezcla (M-10)) } \\
& \text { Asfalto MP3 } \\
& \mathbf{T}_{\text {ensayo }}=60^{\circ} \mathrm{C} \\
& \text { Carga }=700 \mathrm{~N}
\end{aligned}
$$

\section{Ajuste}

$\mathbf{a}=0,6363 ; \mathbf{b}=0,1641$

$\mathbf{R}^{2}=0,96$

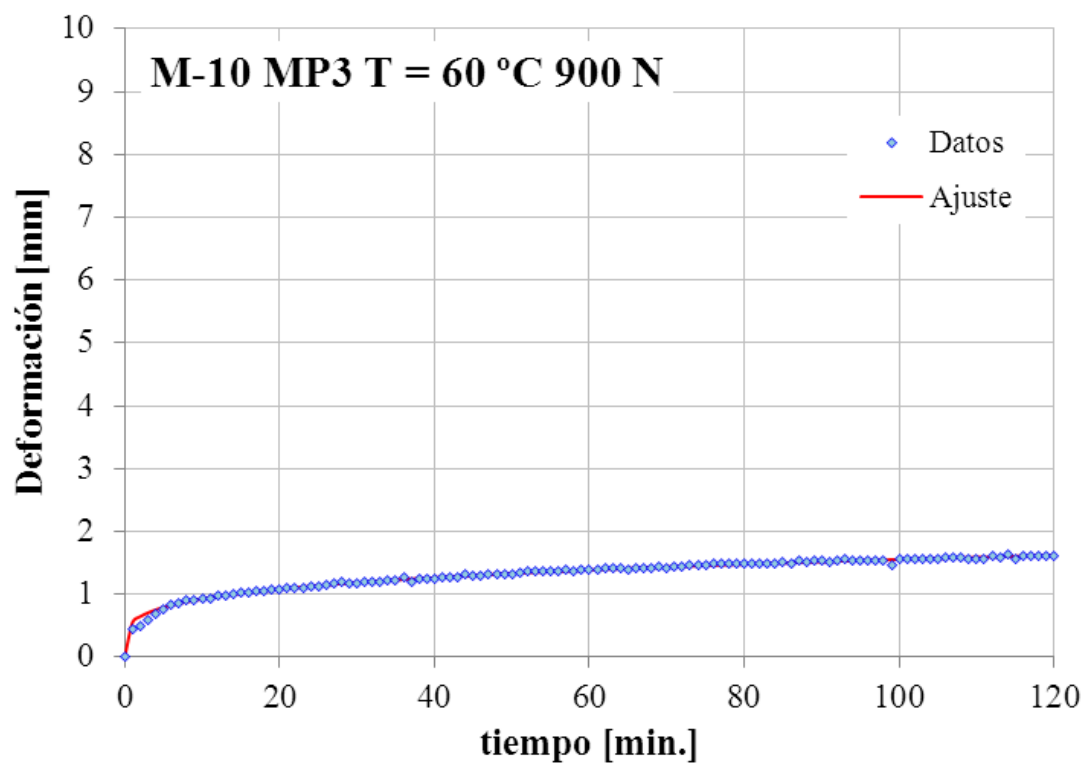

Mezcla (M-10)

Asfalto MP3

$\mathbf{T}_{\text {ensayo }}=60^{\circ} \mathrm{C}$

Carga $=900 \mathrm{~N}$

\section{Ajuste}

$\mathbf{a}=0,5538 ; \mathbf{b}=0,2243$

$\mathbf{R}^{2}=0,99$ 


\section{Curvas comparativas diferentes niveles de carga}
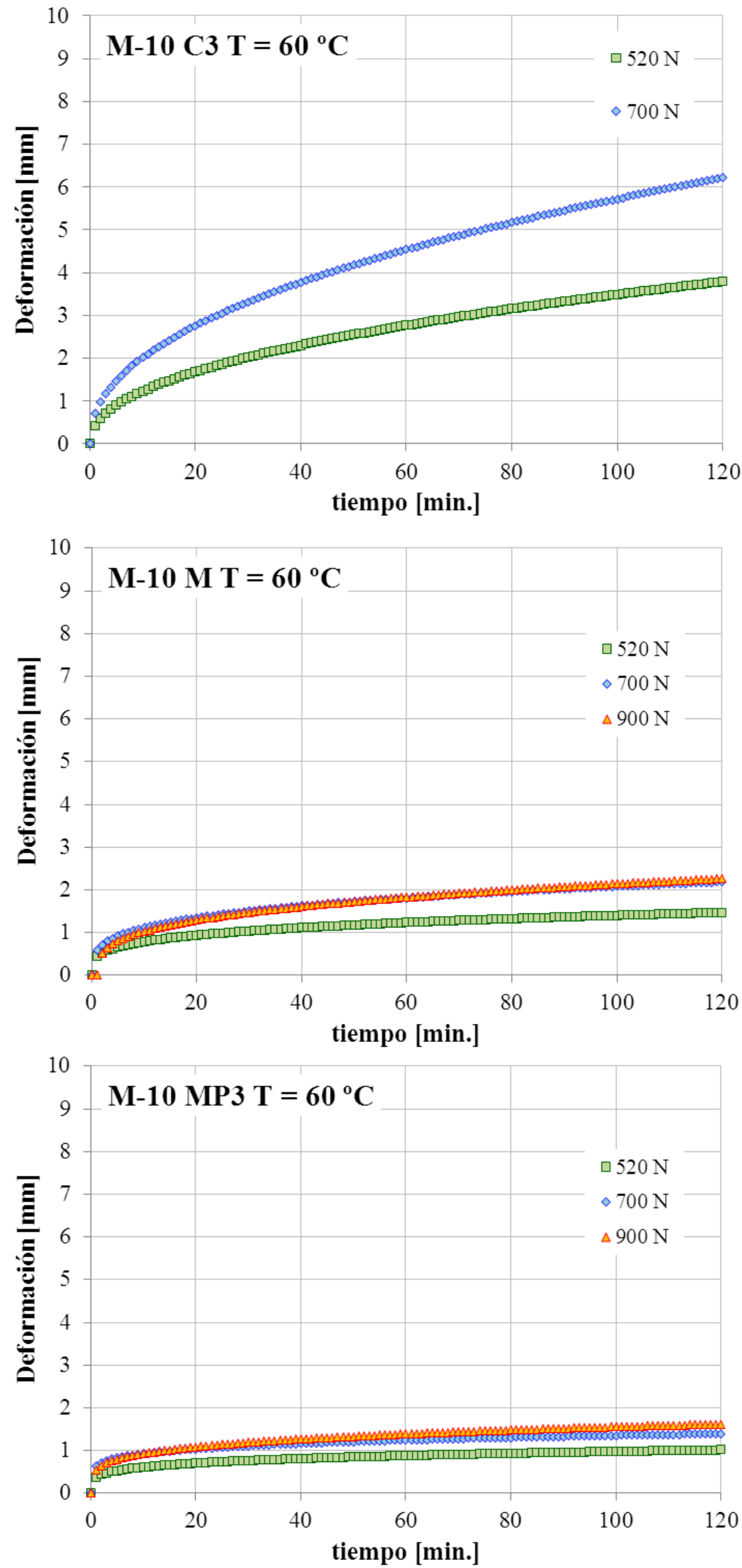

Stone Mastic Asphalt (SMA-10)

Ensayos a distintas temperaturas 



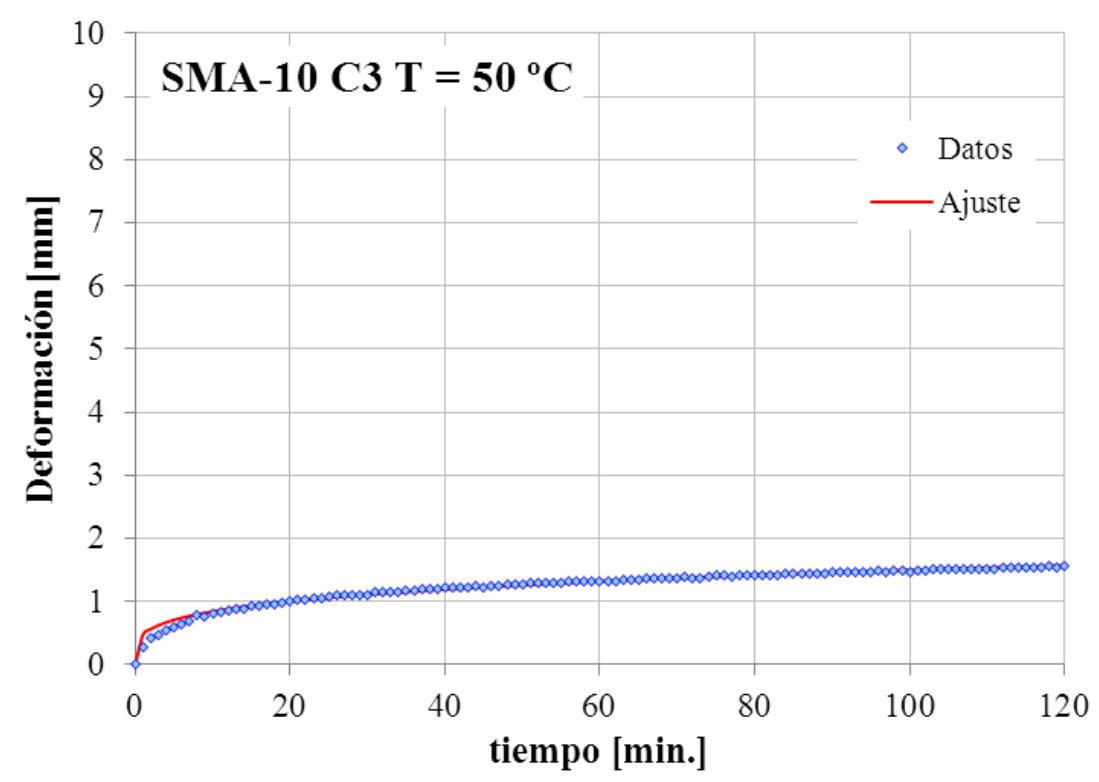

Mezcla (SMA-10)

Asfalto C3

$\mathbf{T}_{\text {ensayo }}=50^{\circ} \mathrm{C}$

Carga $=520 \mathrm{~N}$

Ajuste

$\mathbf{a}=0,4751 ; \mathbf{b}=0,2496$

$\mathbf{R}^{2}=0,99$

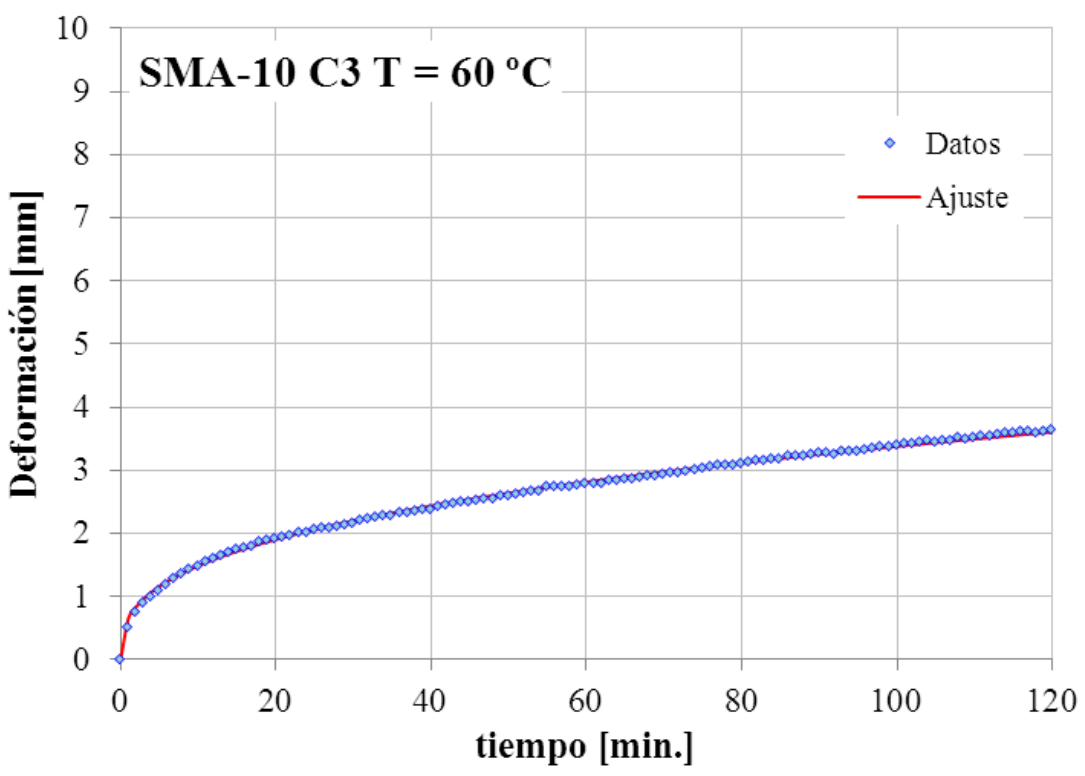

Mezcla (SMA-10)

Asfalto C3

$\mathbf{T}_{\text {ensayo }}=60^{\circ} \mathrm{C}$

Carga $=520 \mathrm{~N}$

\section{Ajuste}

$\mathbf{a}=0,6552 ; \mathbf{b}=0,3562$

$\mathbf{R}^{2}=0,99$

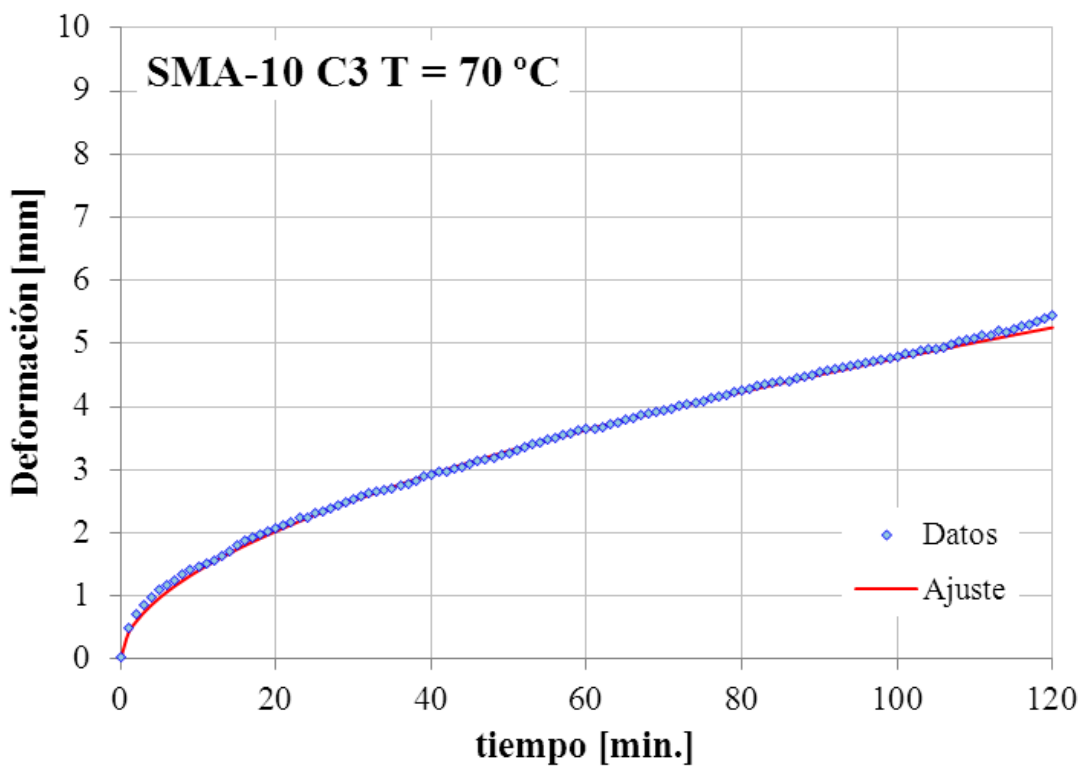

Mezcla (SMA-10)

Asfalto C3

$\mathbf{T}_{\text {ensayo }}=70^{\circ} \mathrm{C}$

Carga $=520 \mathrm{~N}$

\section{Ajuste}

$\mathbf{a}=0,4122 ; \mathbf{b}=0,5316$

$\mathbf{R}^{2}=0,99$ 


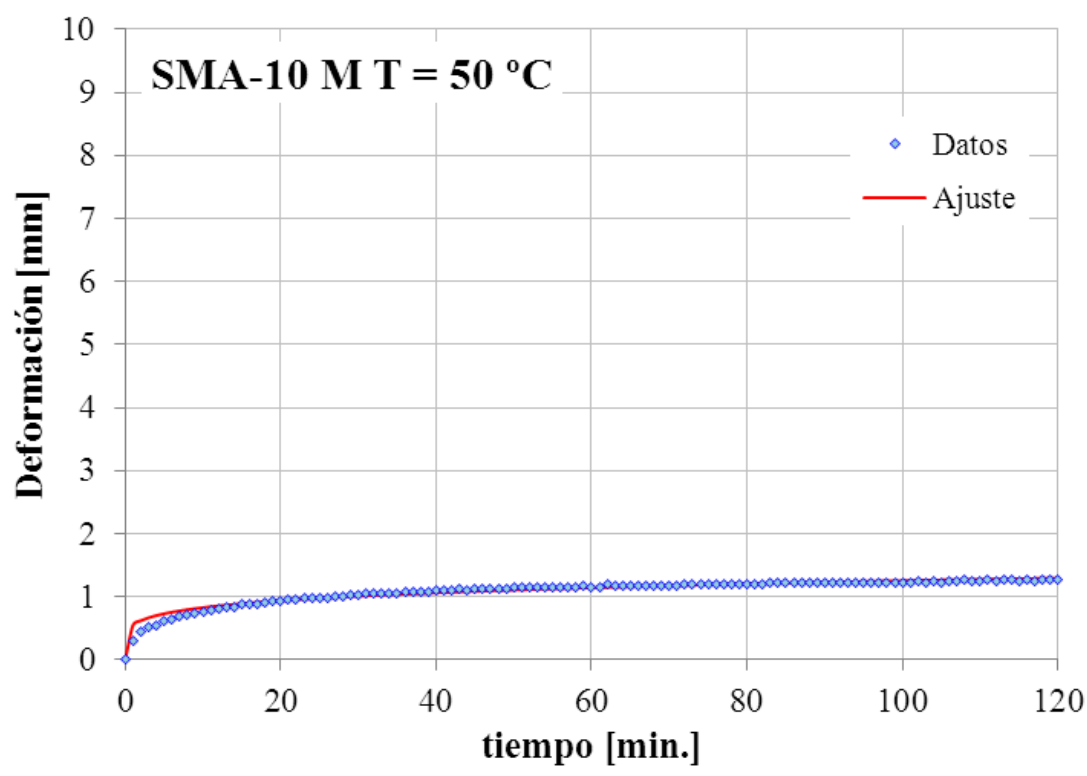

Mezcla (SMA-10)

Asfalto $\mathrm{M}$

$\mathbf{T}_{\text {ensayo }}=50^{\circ} \mathrm{C}$

Carga $=520 \mathrm{~N}$

\section{Ajuste}

$\mathbf{a}=0,5484 ; \mathbf{b}=0,1797$

$\mathbf{R}^{2}=0,96$

Mezcla (SMA-10)

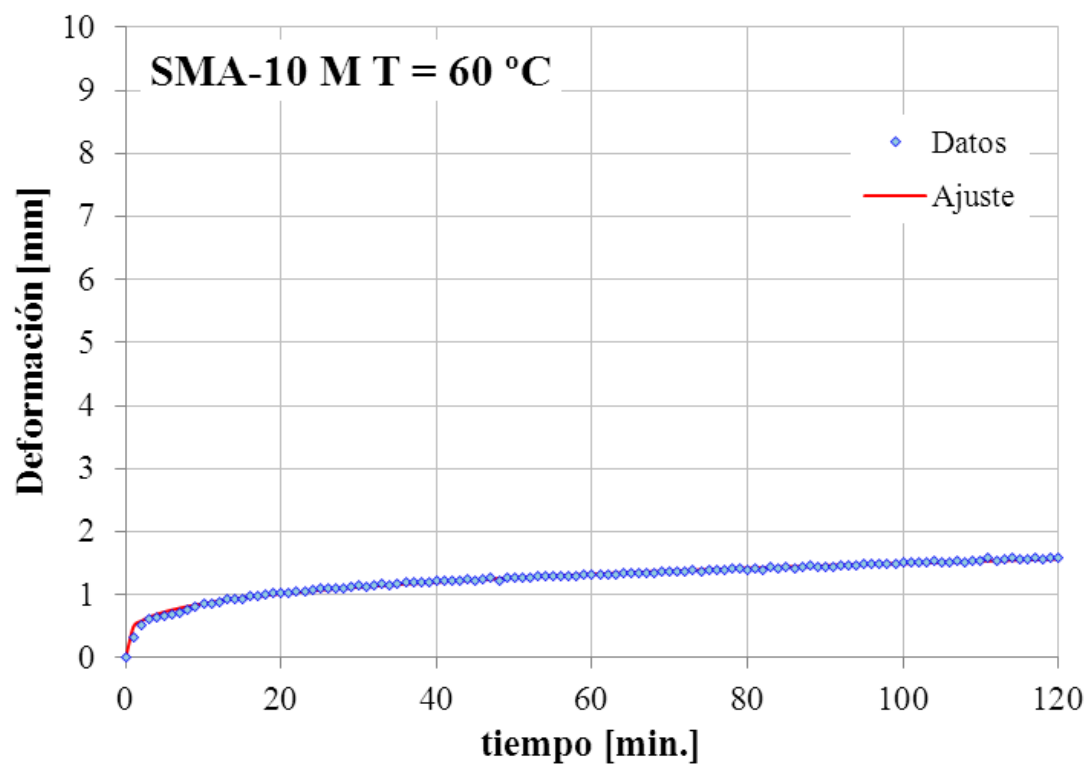

Asfalto M

$\mathbf{T}_{\text {ensayo }}=60^{\circ} \mathrm{C}$

Carga $=520 \mathrm{~N}$

\section{Ajuste}

$\mathbf{a}=0,4959 ; \mathbf{b}=0,2402$

$\mathbf{R}^{2}=0,99$

Mezcla (SMA-10)

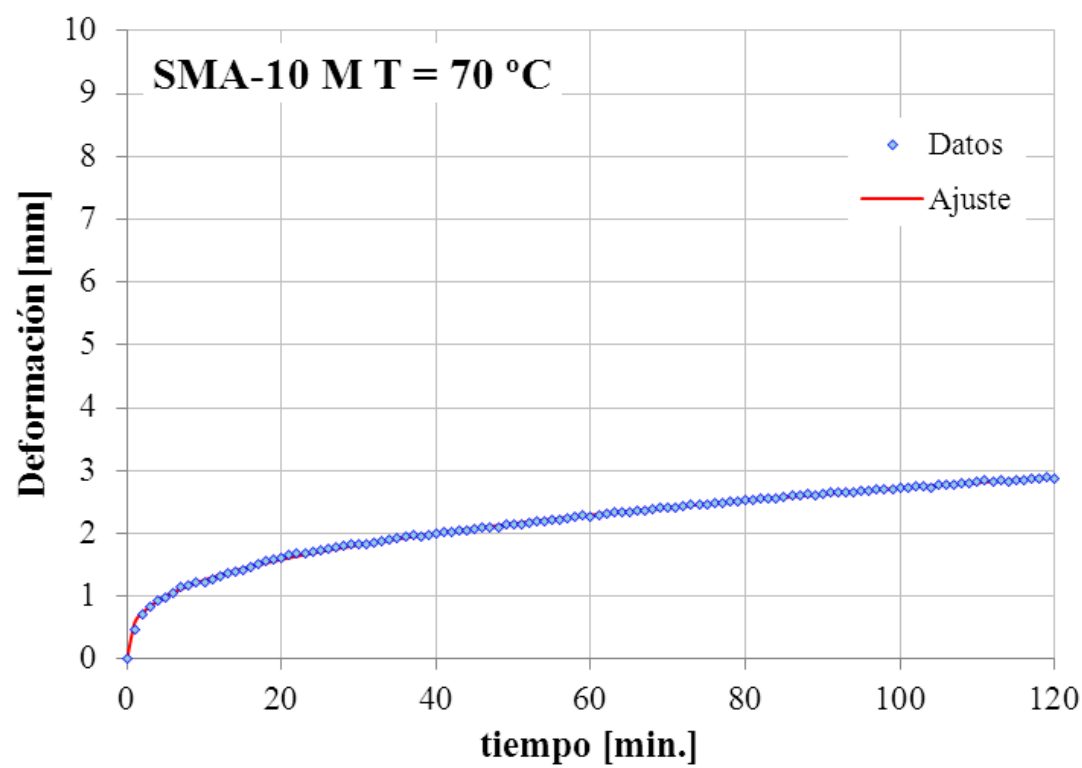

Asfalto M

$\mathbf{T}_{\text {ensayo }}=70^{\circ} \mathrm{C}$

Carga $=520 \mathrm{~N}$

\section{Ajuste}

$\mathbf{a}=0,5828 ; \mathbf{b}=0,3346$

$\mathbf{R}^{2}=0,99$ 


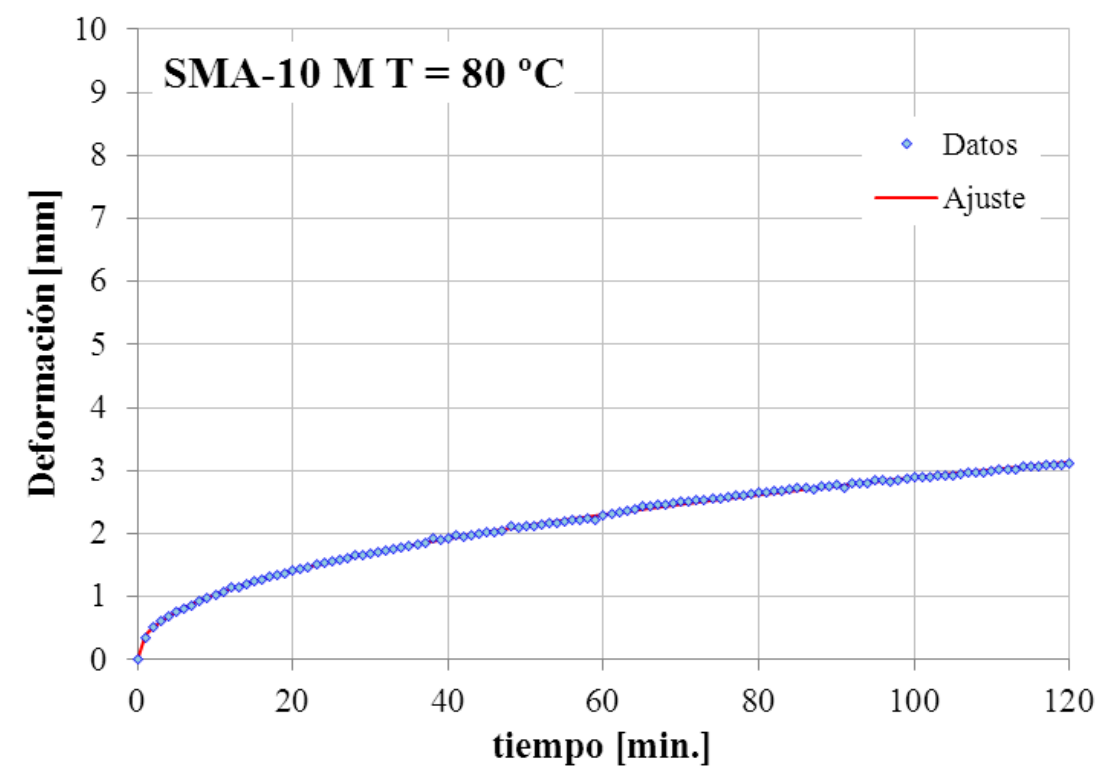

Mezcla (SMA-10)

Asfalto M

$\mathbf{T}_{\text {ensayo }}=80^{\circ} \mathrm{C}$

Carga $=520 \mathrm{~N}$

Ajuste

$\mathbf{a}=0,3722 ; \mathbf{b}=0,4452$

$\mathbf{R}^{2}=0,99$

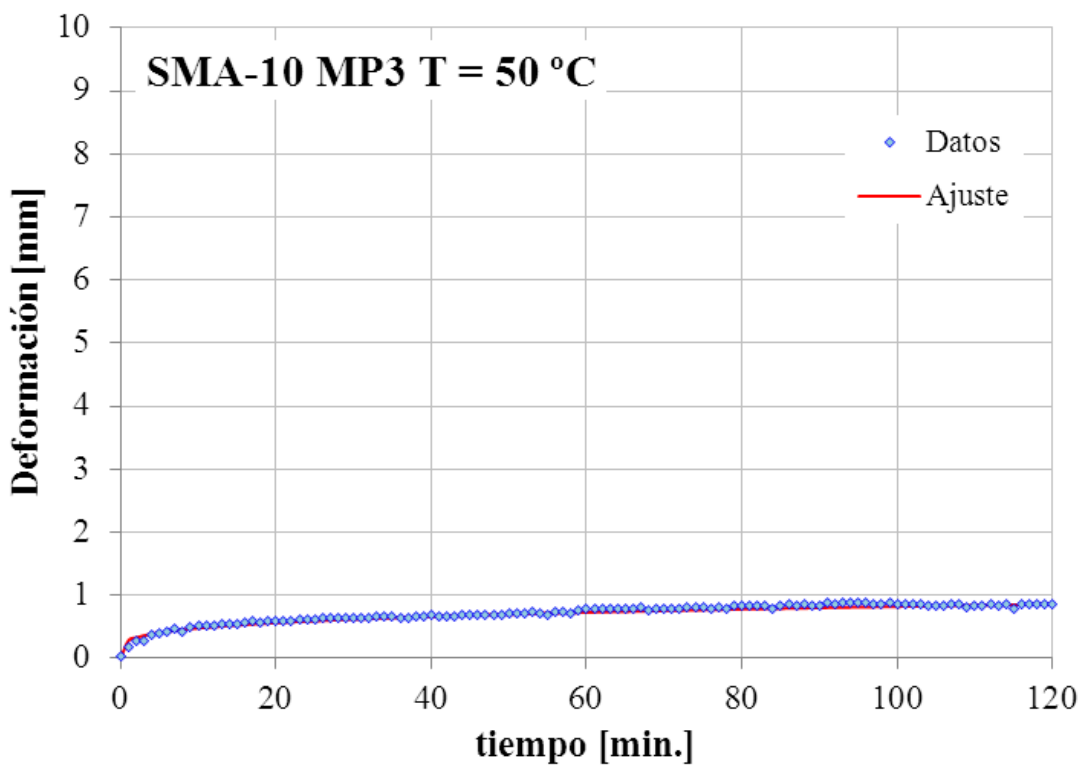

Mezcla (SMA-10)

Asfalto MP3

$\mathbf{T}_{\text {ensayo }}=50^{\circ} \mathrm{C}$

Carga $=520 \mathrm{~N}$

\section{Ajuste}

$\mathbf{a}=0,2798 ; \mathbf{b}=0,2341$

$\mathbf{R}^{2}=0,96$

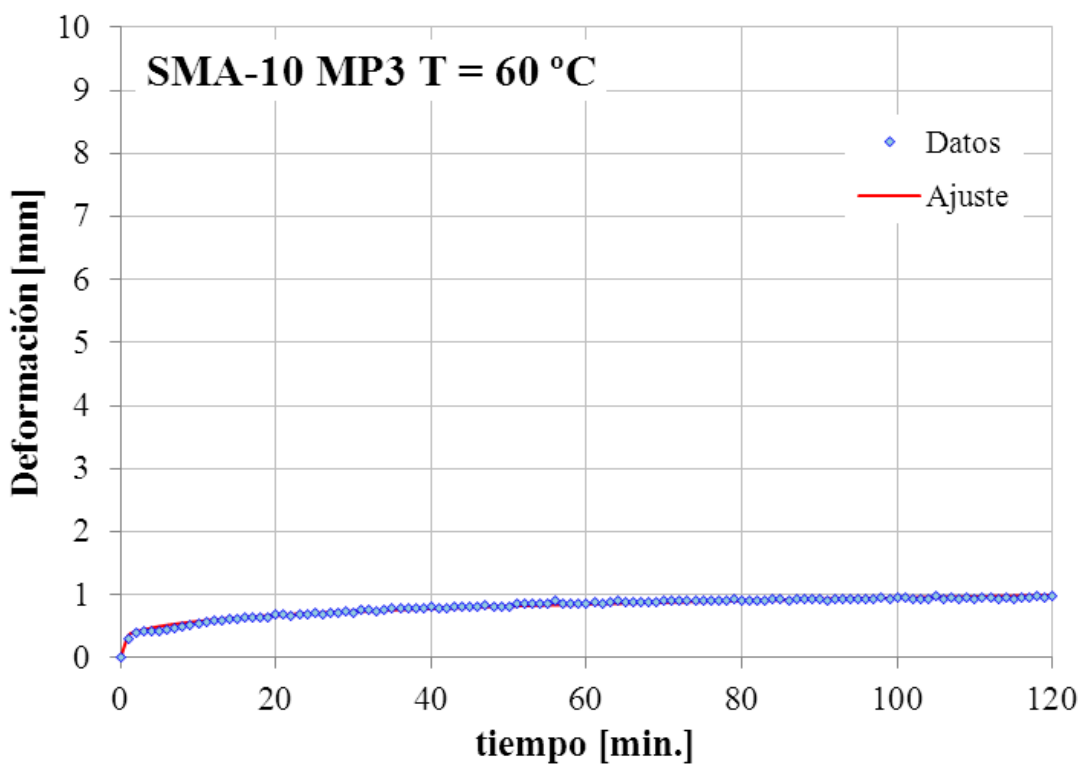

Mezcla (SMA-10)

Asfalto MP3

$\mathbf{T}_{\text {ensayo }}=60^{\circ} \mathrm{C}$

Carga $=520 \mathrm{~N}$

\section{Ajuste}

$\mathbf{a}=0,3534 ; \mathbf{b}=0,2125$

$\mathbf{R}^{2}=0,97$ 


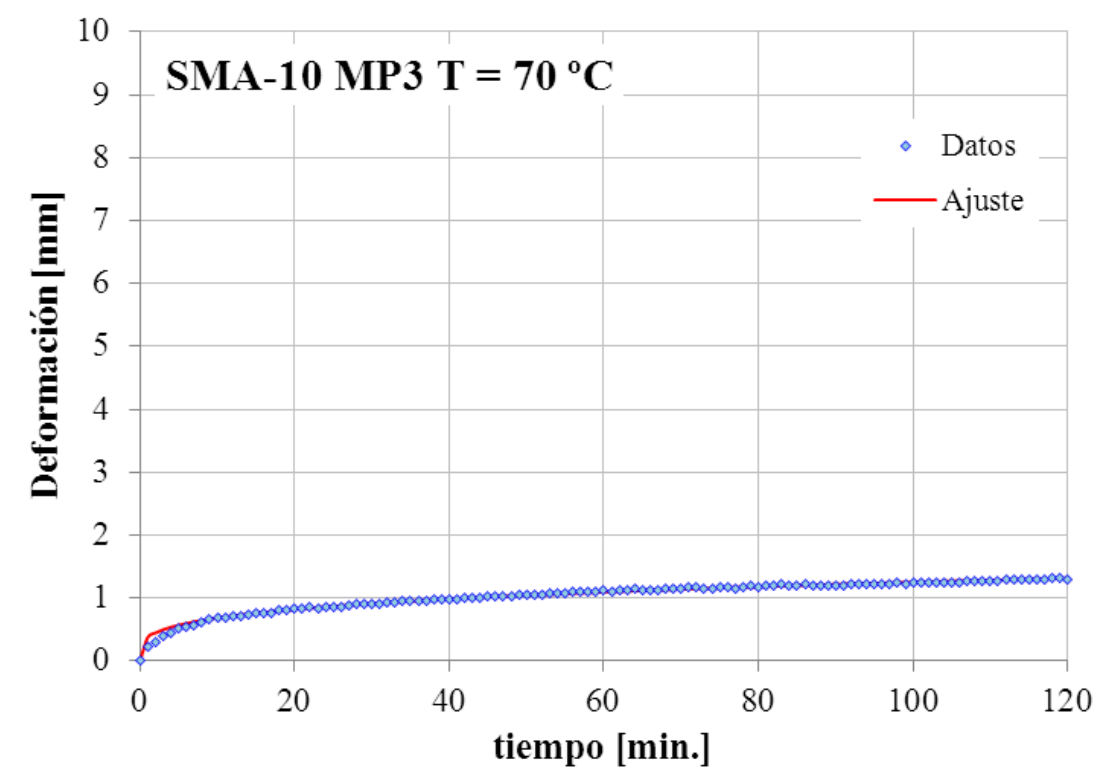

\section{Mezcla (SMA-10) \\ Asfalto MP3 \\ $\mathbf{T}_{\text {ensayo }}=70^{\circ} \mathrm{C}$ \\ Carga $=520 \mathrm{~N}$}

\section{Ajuste}

$\mathbf{a}=0,3742 ; \mathbf{b}=0,2626$

$\mathbf{R}^{2}=0,99$

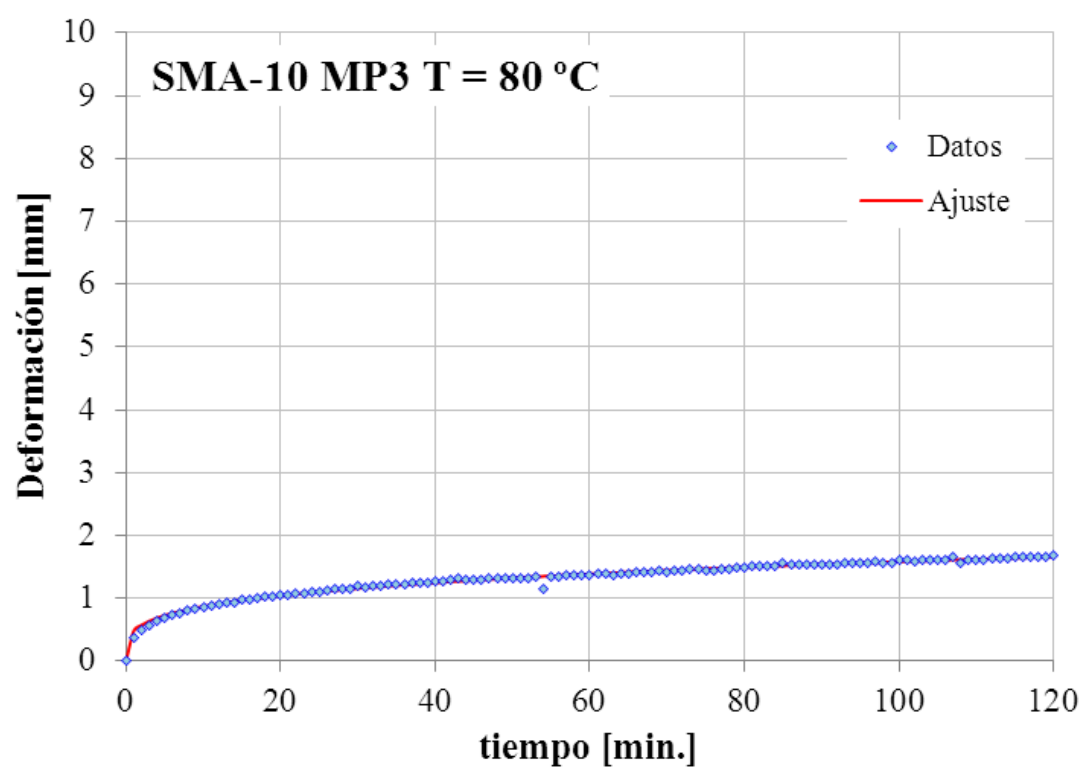

Mezcla (SMA-10)

Asfalto MP3

$\mathbf{T}_{\text {ensayo }}=80^{\circ} \mathrm{C}$

Carga $=520 \mathrm{~N}$

\section{Ajuste}

$\mathbf{a}=0,4799 ; \mathbf{b}=0,2594$

$\mathbf{R}^{2}=0,99$ 


\section{Curvas comparativas a distintas temperaturas}
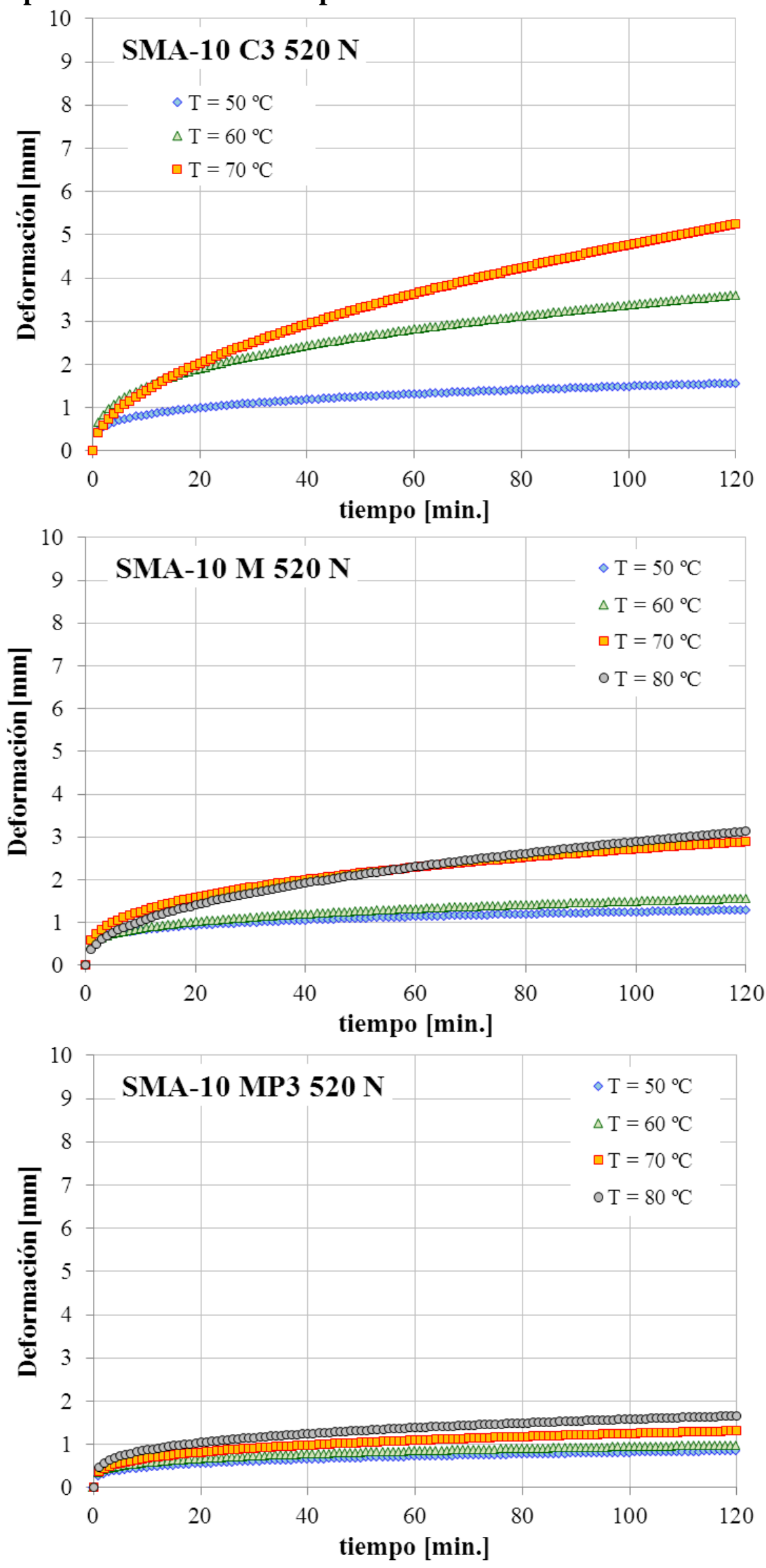

Stone Mastic Asphalt (SMA-10)

Ensayos a diferentes niveles de carga 



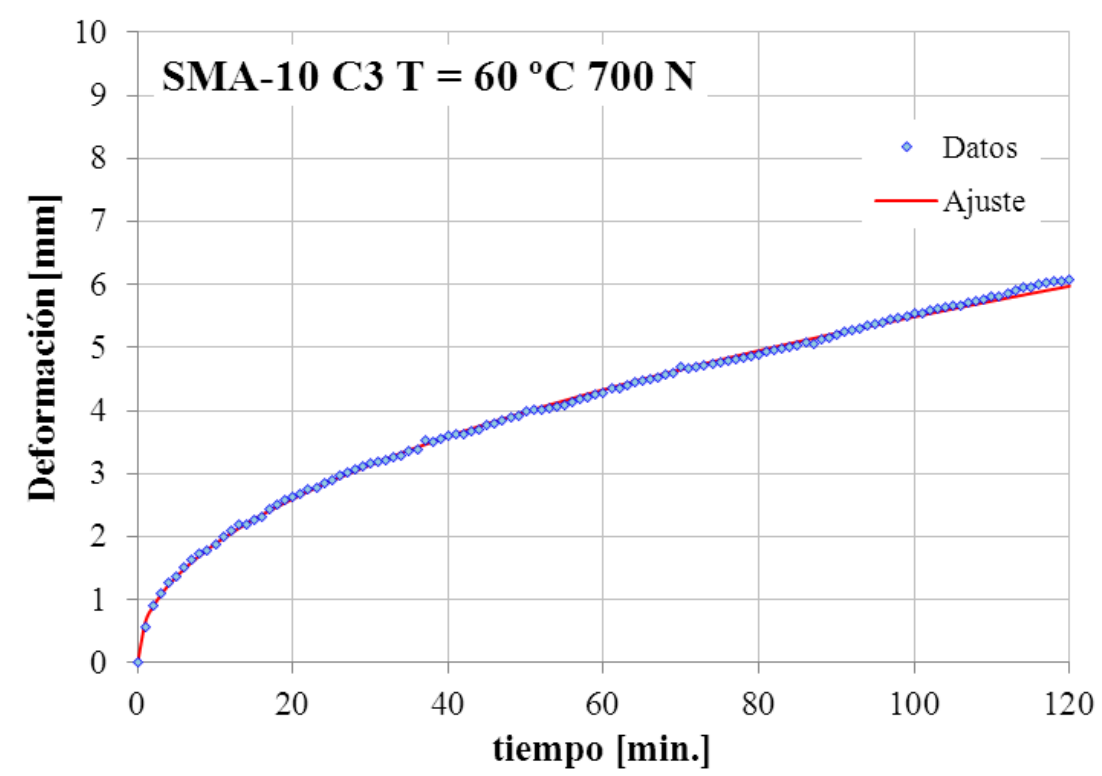

Mezcla (SMA-10)

Asfalto C3

$\mathbf{T}_{\text {ensayo }}=60^{\circ} \mathrm{C}$

Carga $=700 \mathrm{~N}$

Ajuste

$\mathbf{a}=0,6489 ; \mathbf{b}=0,4637$

$\mathbf{R}^{2}=0,99$

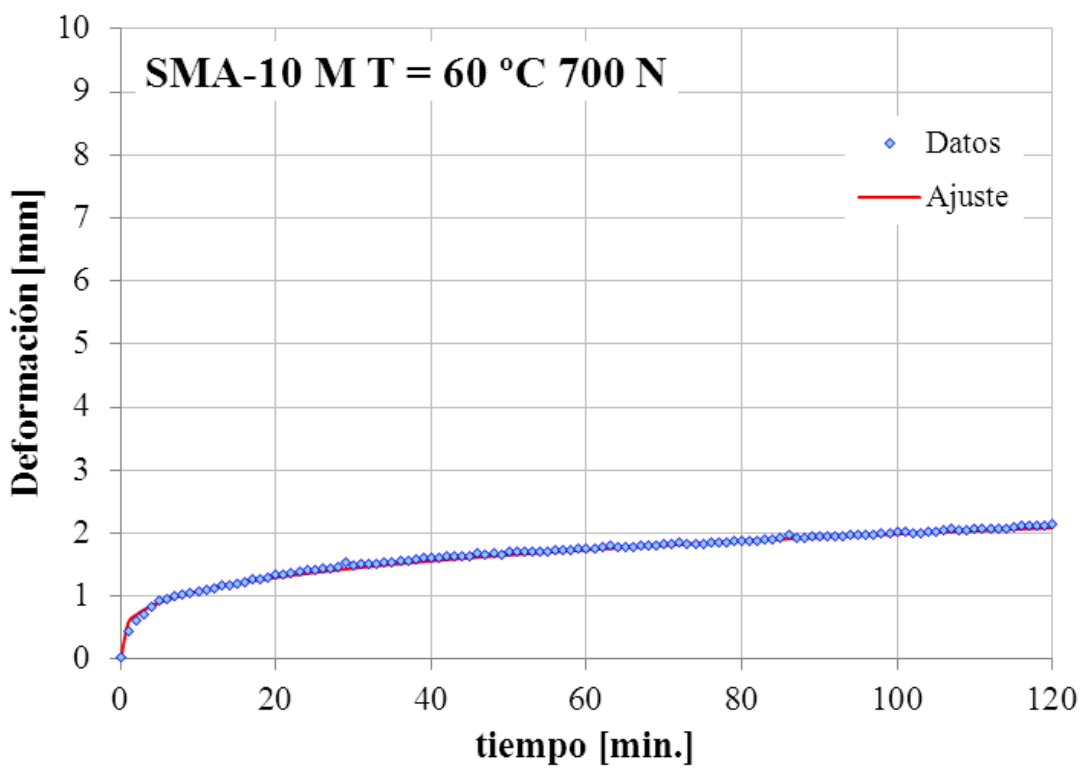

Mezcla (SMA-10)

Asfalto $\mathbf{M}$

$\mathbf{T}_{\text {ensayo }}=60^{\circ} \mathrm{C}$

Carga $=700 \mathrm{~N}$

\section{Ajuste}

$\mathbf{a}=0,5883 ; \mathbf{b}=0,2644$

$\mathbf{R}^{2}=0,99$

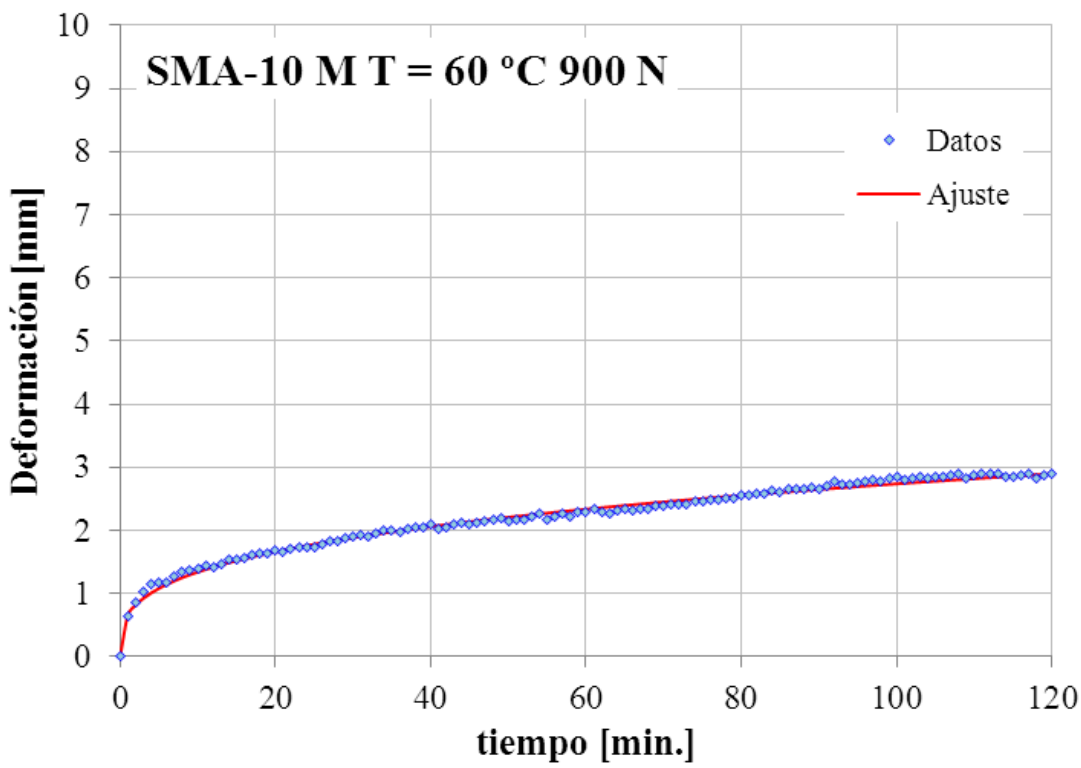

Mezcla (SMA-10)

Asfalto $\mathbf{M}$

$T_{\text {ensayo }}: 60^{\circ} \mathrm{C}$

Carga: $900 \mathrm{~N}$

\section{Ajuste}

$\mathbf{a}=0,6575 ; \mathbf{b}=0,3098$

$\mathbf{R}^{2}=0,98$ 


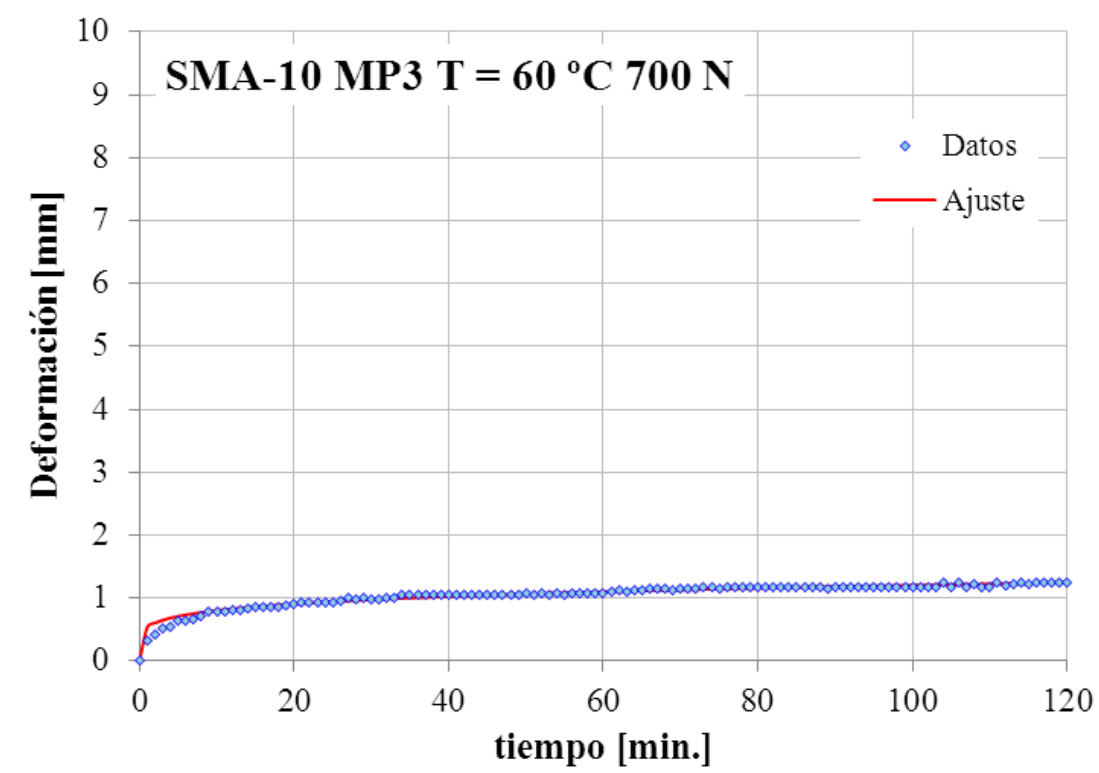

\section{Mezcla (SMA-10) \\ Asfalto MP3 \\ $\mathbf{T}_{\text {ensayo }}=60^{\circ} \mathrm{C}$ \\ Carga $=700 \mathrm{~N}$}

\section{Ajuste}

$\mathbf{a}=0,5365 ; \mathbf{b}=0,1757$

$\mathbf{R}^{2}=0,97$

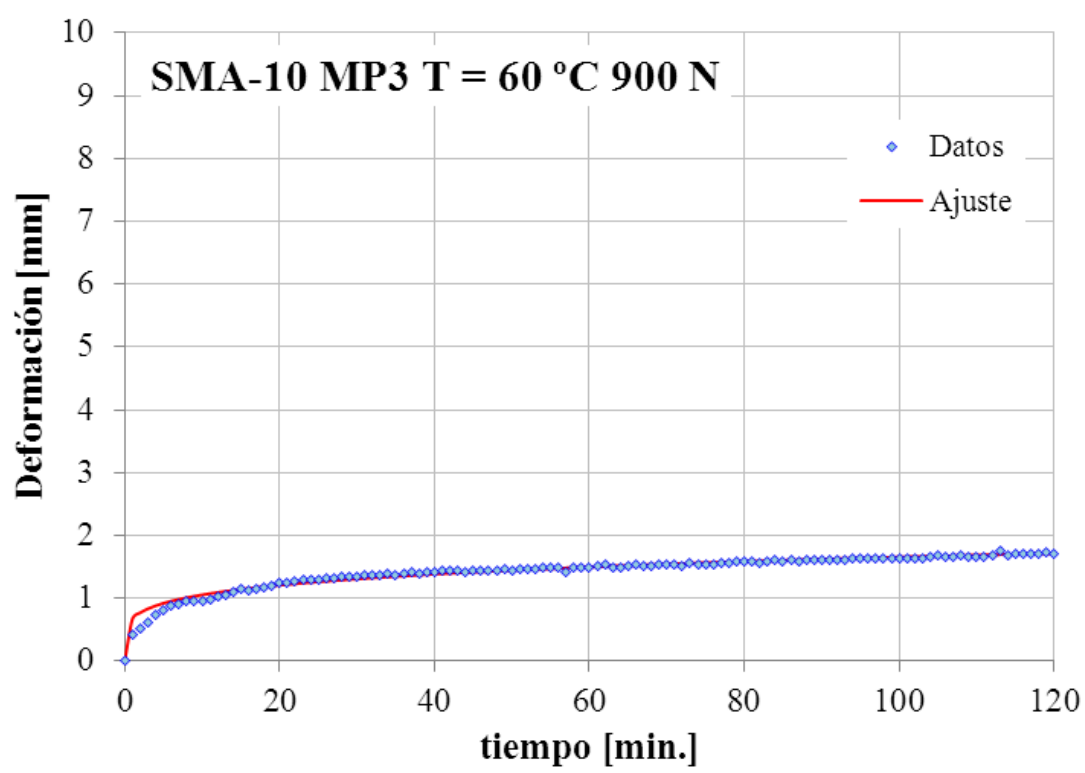

Mezcla (SMA-10)

Asfalto MP3

$\mathbf{T}_{\text {ensayo }}=60^{\circ} \mathrm{C}$

Carga $=900 \mathrm{~N}$

\section{Ajuste}

$\mathbf{a}=0,6743 ; \mathbf{b}=0,1952$

$\mathbf{R}^{2}=0,97$ 


\section{Curvas comparativas diferentes niveles de carga}
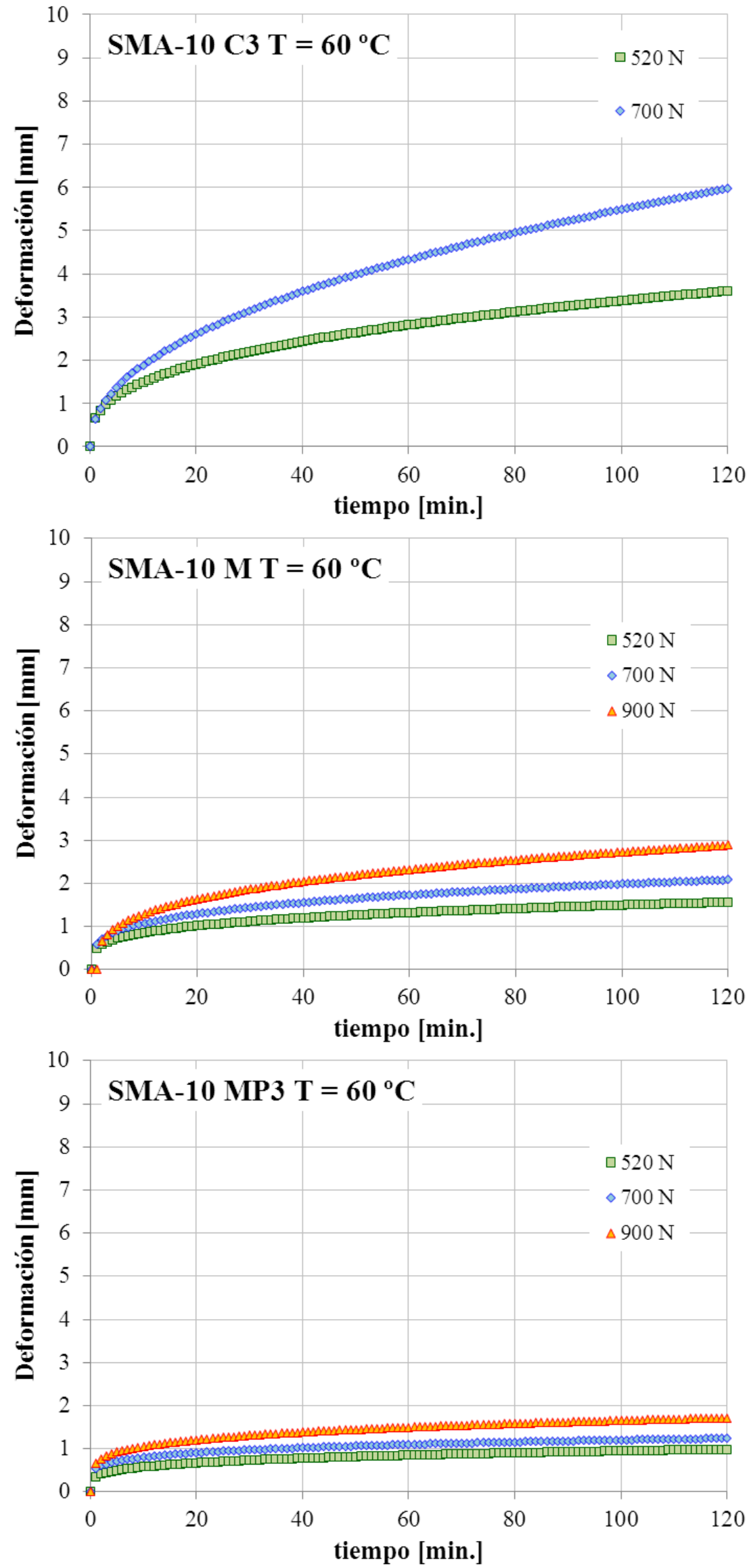